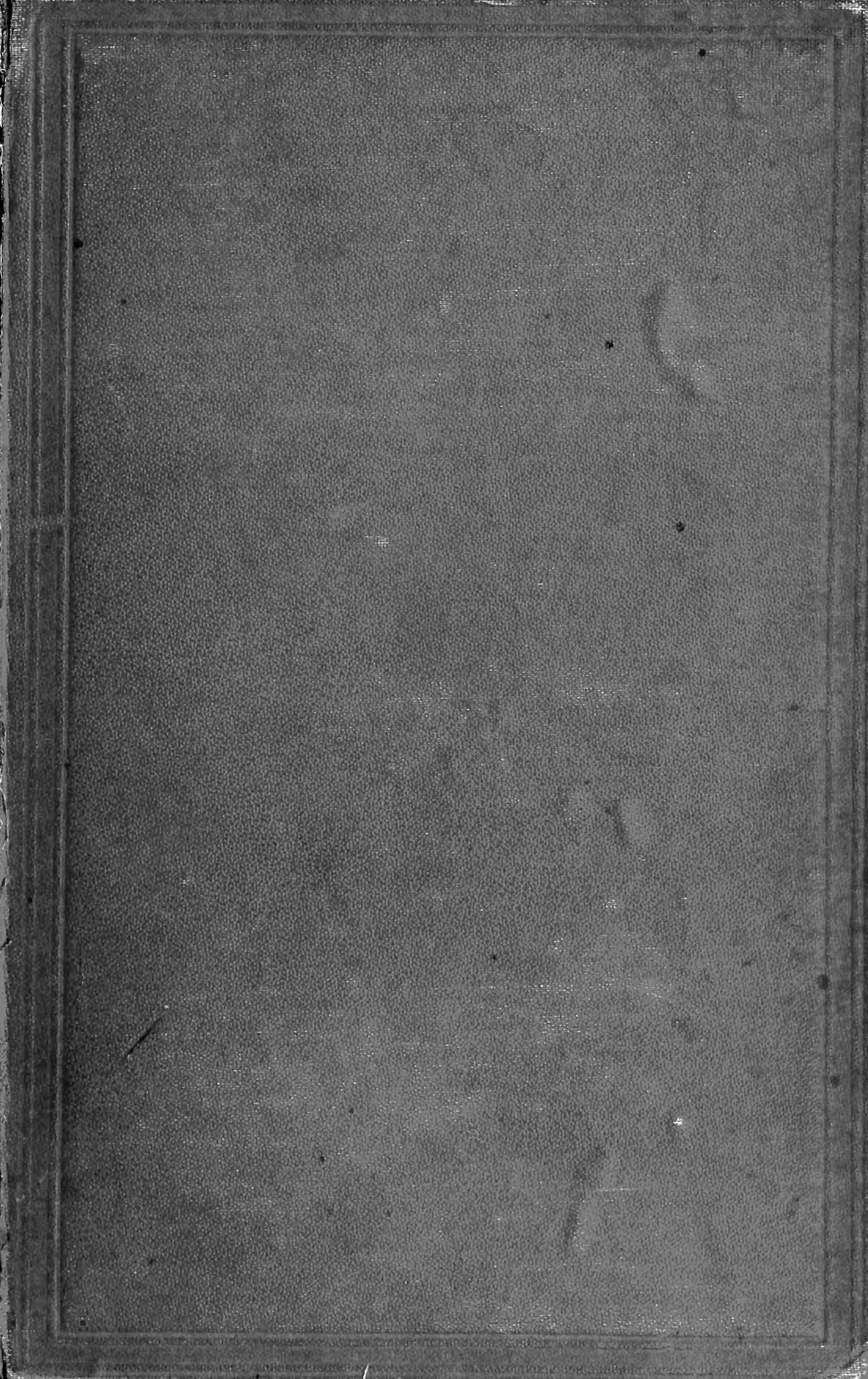




\section{mene}

\section{wey}

$x^{2} \sin ^{2} y^{2}$

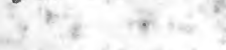

$$
\begin{aligned}
& \text { rat }-14 \\
& e^{4}+4+4-4
\end{aligned}
$$

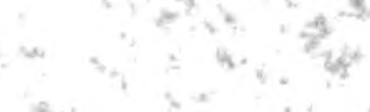

, the k.
S.

$45^{3}+$

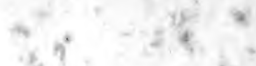

$$
\begin{aligned}
& \text { A. } x+x^{2}: 4 \\
& \text { (1) } 15.4 \frac{2}{4}+k^{2} \\
& \text { t, the } \\
& (x), 45 x+7 \\
& 3 y^{4} \text { को } \\
& \text { 사. }
\end{aligned}
$$

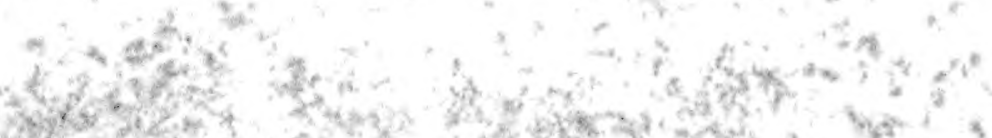

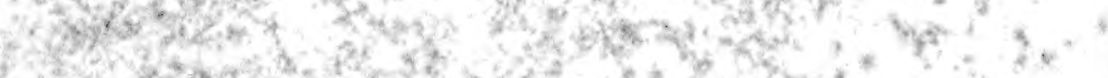

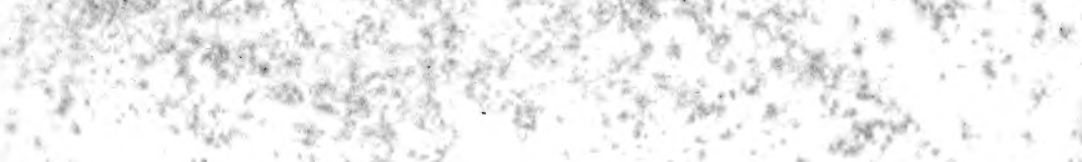

is 7 .

$$
y+2,+2,-2
$$

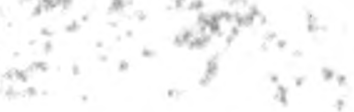

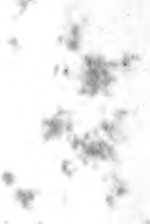

$+x+7$
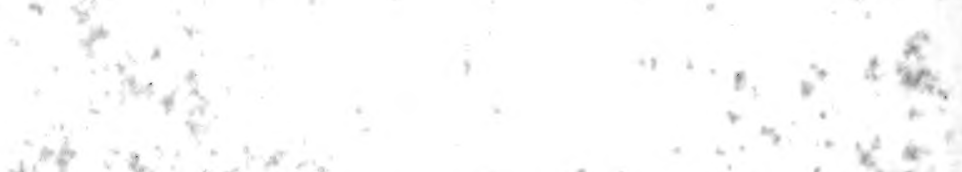

西, atis 2

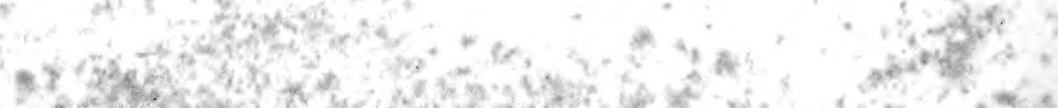

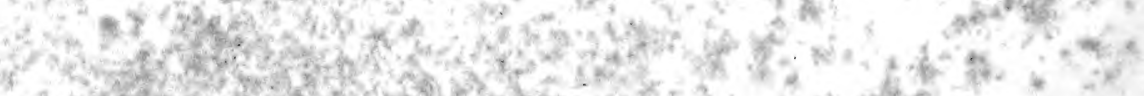

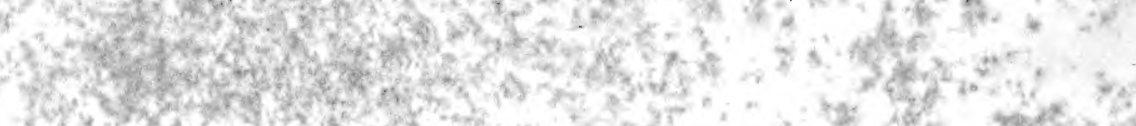

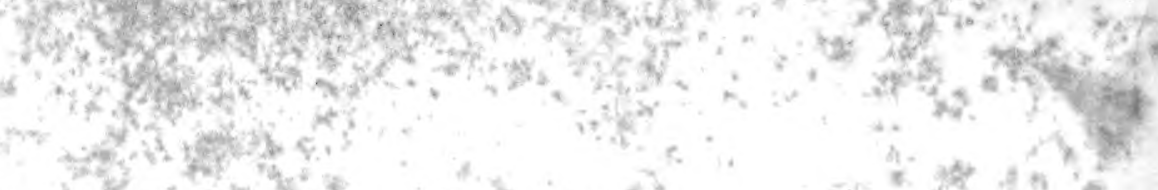

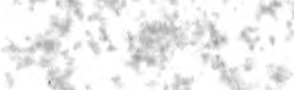

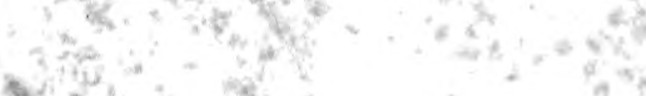

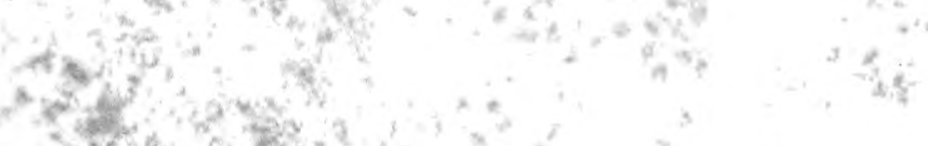

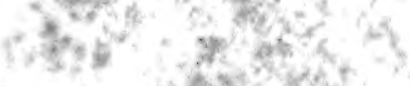

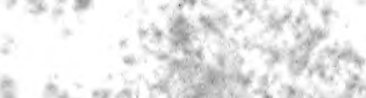

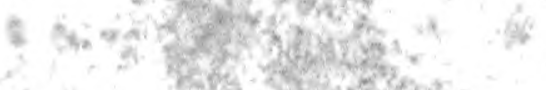

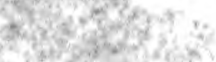

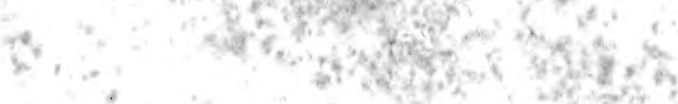

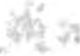

$x^{3}$

$y^{3}+4, \ldots+2, y$

74

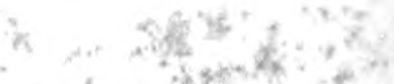

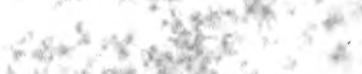

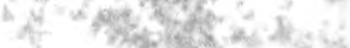


Clarendon 朋ess Series

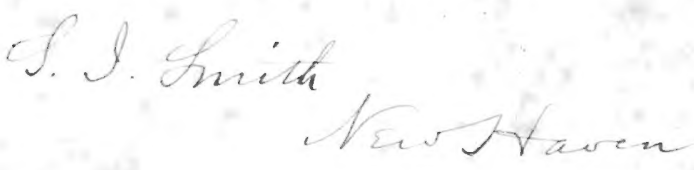

\title{
FORMS OF ANIMAL LIFE
}

\author{
ROLLESTON
}




\section{Zlomion}

\section{MACMILLAN AND CO.}

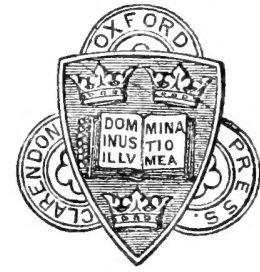

PUBLISHERS TO THE UNIVERSITY OF (1) xford. 


\section{Clareñon 羽ress Series}

\section{FORMS OF ANIMAL LIFE}

BEING

OUTLINES OF ZOOLOGICAL CLASSIFICATION BASED UPON

ANATOMICAL INVESTIGATION

AND ILLUSTRATED

BY DESCRIPTIONS OF SPECIMENS AND OF FIGURES

BY

GEORGE ROLLESTON, D.M., F.R.S.

LINACRE PROFESSOR OF ANATOMY AND PHYSIOLOGY

IN THE UNIVERSITY OF OXFORD

(1)*foxd

AT THE CLARENDON PRESS

M. DCCC. LXX 


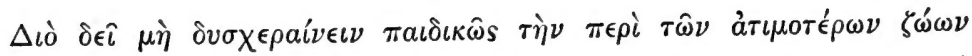

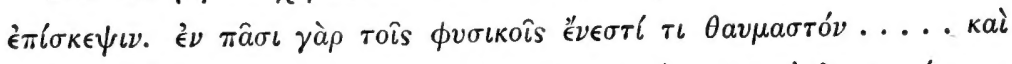

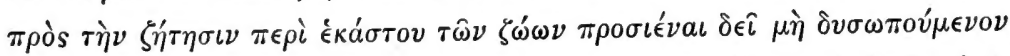

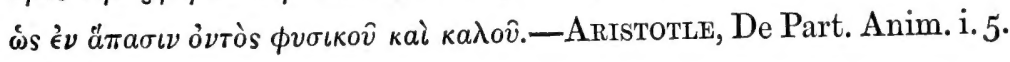

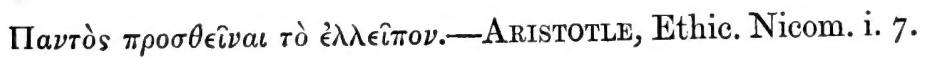

MUSEUM, OXFORD,

March 5, I870. 


\section{PREF A CE.}

THIS book is intended to meet certain requirements which, as the writer's experience has shown him, are felt by students of Comparative Anatomy. It consists of three parts; the first is an introduction, giving a Classification of the animal kingdom, with a Zootomical account of its various Sub-kingdoms and their subordinate Divisions and Classes; the second consists of descriptions of certain readily procurable specimens which illustrate in the concrete a very large number of the systematic descriptions contained in the introduction; and the third contains descriptions of figures supplementary to the descriptions of specimens, and intended to aid them in furnishing that groundwork of particular facts, without which it is impossible to obtain any real knowledge or permanent hold of general principles. The distinctive character of the book consists in its attempting so to combine the concrete facts of Zootomy with the outlines of systematic Classification as to enable the student to put them for himself into their natural relations of foundation and superstructure. The foundation may be made wider, and the superstructure may 
have its outlines not only filled up, but even considerably altered by subsequent and more extensive labours; but the mutual relations of the one as foundation and of the other as superstructure, which this book particularly aims at illustrating, must always remain the same.

It is hoped that this work, though written with a view chiefly to the needs of University students of Comparative Anatomy, and with especial reference to the application of that branch of science as an engine for education, may in some measure meet the requirements of the now not inconsiderable number of persons who are attracted to the study by seeing the important bearings which it has upon questions not only of theoretical and philosophical but also of practical interest.

The amount of knowledge which is presupposed in all persons who may use this book, may be judged of by the following account of the short preparatory course through which it is the rule that persons entering for the first time upon the study of Anatomy in the Oxford Museum should pass. The first requisite for a commencing student in this department of knowledge is that he should be taught how much there is to be observed and described in a natural object, and it has been found that such a person can have this lesson impressed upon his mind in an excellent yet easy way, by addressing himself with osteological specimens actually before him to the task of verifying the statements made relatively to them in some work specially devoted to the description of them. The vertebral column and the bones of the cranium are the specimens 
selected, and recourse is taken to human rather than to other osteologies, inasmuch as the descriptions they contain are at once more intelligible to beginners, as being couched in less technical language, and more full and precise, and therefore more valuable for the purpose in question, than most of the ordinarily accessible descriptions of the bones of the lower animals.

Whilst the student is directed not to be dissatisfied at any failure of his memory to retain, in the absence of the natural object, the multitudinous details to which a good descriptive work will have directed his attention during his examination of it, he is warned that he must not acquiesce in any failure of power to verify in such an object, when present, the structural arrangements which he is informed are to be seen in it.

When this portion of the preliminary course is completed, a similar study of the principal organs of animal and vegetable life, such as the brain, the heart, the digestive tract, the hepatic, and the renal organs, is entered upon; preparations of these structures preserved so as to be accessible to manipulation, and also microscopic specimens, being available for comparison with such descriptions as the ordinary works on Anthropotomy give in their chapters on Visceral Anatomy.

It has been found that after this comparatively small amount of previous preparation a student is competent to follow such a description as is given in this work at pp. $\mathrm{I}-4$ of a dissection of a mammal; and it is recommended that in all cases the study of the described 
preparation or specimen should precede that of the accounts in the introduction of the Class and Subkingdom to which it belongs, and that the study of the Descriptions of the Plates should be taken up only after the attainment of a considerable familiarity with actual specimens by the practice of dissection.

A short statement of the method which has been adopted in the preparation of each specimen has in most cases been prefixed to the description of it; and thus persons who have not, as well as those who have, access to the series in the University Museum, are enabled to reproduce for themselves the objects described. The specimens themselves, it will be observed, are in the great majority of instances taken from animals which may be found living in inland parts of this country; and even when they have been taken from an exclusively marine Class or Sub-kingdom, such as the Tunicata or the Echinodermata, they are, with an exception or two, readily procurable in places at a distance from the sea-coasta.

Small print has been employed in the notes and in other passages, which the student may do well to omit when first reading this book.

In some cases, even the beginner will find it necessary

a A dissecting microscope will be required for the verification of the Descriptions of many of the Preparations of the Invertebrata, and in these cases the specimens should be affixed to a loaded cork or wax tablet, and dissected under water or spirit. Some of these animals are speedily killed by being placed in a glass-stoppered bottle with a few drops of chloroform; others by immersion in water several degrees below $40^{\circ} \mathrm{F}$. 
to consult some of the many works referred to in the Descriptions of the Preparations and in the Descriptions of the Plates; but the bibliographical references have been added with a view rather to the wants indicated in the words 'Für Akademische Vorlesungen und zum Selbstudium,' so often prefixed to German works on science, than to those of the commencing student. A local reason for giving development to the bibliographical portion of this work lay in the fact, that through the well-advised liberality of the Radcliffe Trustees, one of the best of existing scientific Libraries had been transferred to the University Museum; and much of whatever value this volume may possess is to be ascribed to the happy arrangement in the way of concentration, whereby that magnificent collection of books has been placed under the same roof, with so much other scientific apparatus of a non-literary kind.

Nine of the twelve plates described in the third part of this book, were drawn from nature by Mr. George Crozier, formerly draughtsman to the Radcliffe Library.

The fifty specimens described in the second part were prepared by Charles Robertson, Esq., Demonstrator of Anatomy in the University Museum; and the greater part of them were exhibited by him as a 'Zoological Series with Dissections in Illustration,' in the Educational Department of the Exhibition of 1862. I have to thank him for other assistance rendered in the course of bringing this book to completion.

To the biological teachings of Professor Huxley I owe a larger debt than even my numerous references 
to his works would indicate. I stand in a relation of similar, though of less extensive, obligation to the systematic works of Professor Gegenbaur of Jena, of Professor V. Carus of Leipzig, of Professor Claus of Marburg, of Professor Bronn, and of Professor Keferstein of Göttingen. I have also to make acknowledgment to Professors Acland, Phillips, and Westwood of Oxford, and to Albany Hancock, Esq., of Newcastle-upon-Tyne, for suggestions requested and valued by me. In most cases in which other authorities have been consulted upon points of importance, special references have been given, except in the Introduction. 


\section{CONTENTS.}

\section{INTRODUCTION.}

PAGE

General Considerations suggested by a survey of the Subjects treated of . . . . . . . . . . . . . . . xvii-xxv

Tabular Views of the system of Classification adopted in this Work . . . . . . . . . . . . . . . $x x v i-x x x$

Characteristics of the Sub-kingdom Vertebrata . . . . . xxxi-xxxix Divisions Anallantoidea and Allantoidea . xxxix-xl Subdivisions Sauropsida and Ichthyopsida . xli xlii Class Mammalia . . . . . . . . xlii-xlvii Sub-classes Monodelphia, Didelphia, Ornithodelphia . . . . . . . xlvii-xlviii Class Aves . . . . . . . . . . xlix-lv Orders, Ratitae and Carinatae . . . . lv Class Reptilia . . . . . . . . . Iv-lxi "Amphibia . . . . . . . . Ixi-lxviii " Pisces . . . . . . . . Ixviii - lxxxv Six orders of Fishes . . . . . . . . Ixxxi-lxxxv Characteristics of the Sub-kingdom Mollusca . . . . . lxxxy-lxxxviii

,

,

9

,

9

,

9

"

Drvisions Mollusca Proper and Molluscoidea Ixxxvii-lxxxviii

Class Cephalopoda . . . . . . . Ixxxviii-xcii

, Pteropoda . . . . . . . . xcii-xcv

"Gasteropoda . . . . . . . . xcii-xciii

" Lamellibranchiata . . . . . . xev-xcviii

" Brachiopoda . . . . . . . . xcriii-c

"Tunicata . . . . . . . . c-ci

" Polyzoa . . . . . . . . . ci-ciii

Characteristics of the SUb-Kingdom Arthropoda . . . . . civ-cviii

Divisions Tracheata and Branchiata. . . cr-cvi

9

9

,

9

9)

9)

Relations of Arthropoda to Vermes . . . cvii-cviii

Class Insecta . . . . . . . . . . cviii-cxiii

Class Myriopoda . . . . . . . cxiv-cxvi

Arachnida . . . . . . . . . cxvi-cxviii

" Crustacea . . . . . . . cxviii-exxii 
PAGE

Characteristics of the Sub-KIngdom Vermes . . . . cxxii-cxxvii

Class Annulata Proper. . . . . cxxvii-cxxxi

,

,

\section{,}

,

,

\section{Gephyrea . .}

Nematelminthes

"Rotifera

" Platyelminthes

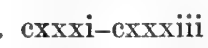

exxxiii-cxxxvii

. exxxviii-cxl

. cxl-cxliii

Characteristics of the SUb-Kingdom Echinodermata . cxliii-cxlvii

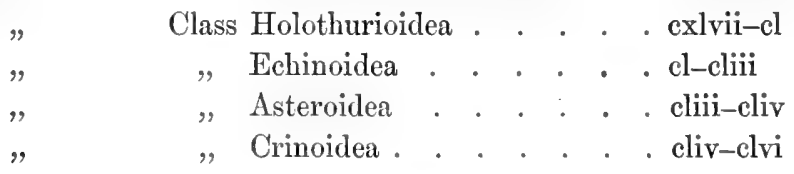

Characteristics of the Sub-Kingdom Coelenterata . . clvi-clvii

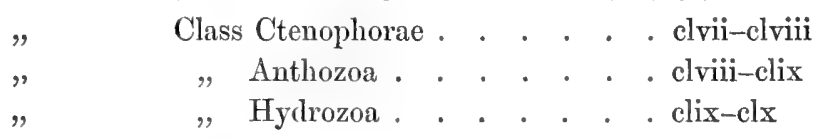

Characteristics of the Sub-ringdon Protozon. . . . elx-clxi

Relations of the various classes of this sub-kingdom, inter se. . . . . . . . . . . . . . clxi-clxii

Means for distinguishing animal from vegetable organisms clxii-clxiv Characteristics of the Class Infusoria . . . . . . . clxiv-clxv

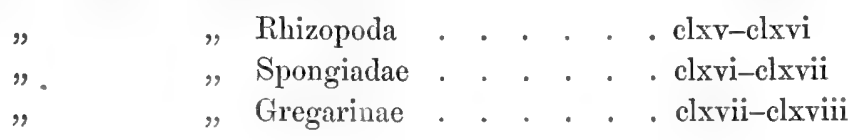

\section{DESCRIPTION OF PREPARATIONS. From the Class Mammalia.}

Prep. I. Dissection of Rat (Mrus decumanus), showing its craniospinal nervous axis, and portions of most of the organs of vegetative life . . . 1-4

Prep. 2. Skeleton of Common Rat (Mus decumanus) . . 5-9

Prep. 3. Cervical, Dorsal, and Lumbar Vertebrae of Rabbit (Lepus cuniculus) . . . . . . . 10-12

\section{From the Class Aves.}

Prep. 4. Dissection of Common Pigeon (Columba livia), showing nervous, digestive, circulatory, and part of respiratory and renal systems . . . . 12-16

Prep. 5. Skeleton of Common Pigeon (Columba livia) . . 17-25

Prep. 6. Skull and Trunk-bones of Common Fowl (Gallus gallinaceus) 


\section{From the Class Reptilia.}

PAGE

Prep. 7. Dissection of Common Ringed Snake (Tropidonotus natrix), showing the arrangement of the various organs of vegetative life . . . . .

Prep. 8. Vertebrae of Constricting Serpent (Sp. ?) . . . 33-35

\section{From the Class Amphibia.}

Prep. 9. Dissection of Common Frog (Rana temporaria), showing its nervous, circulatory, and respiratory systems, together with some of its reproductive and digestive organs . . . . . 35-37

Prep. ro. Skeleton of Common Frog (Rana temporaria) . . 38-40

\section{From the Class Pisces.}

Prep. I I. Dissection of Common Perch (Perca fluviatilis), showing its circulatory, nervous, digestive, respiratory, and reproductive systems in situ .

Prep. I 2. Skeleton of Common Perch (Perca fluviatilis) . 40-42

Prep. I3. Vertebrae of Common Cod (Gadus morrhua) . . 4 45, 46

From the Class Gasteropoda.

Prep. I 4. Shell of Edible Snail (Helix pomatia) . . . . 47,48

Prep. I5. Dissection of Edible Snail (Helix pomatia), showing its digestive and reproductive, together with parts of its circulatory and respiratory, systems . . . . . . . . . . .

Prep. 16. Dissection of Edible Snail (Helix pomatia), showing the position of the heart and of the respiratory cavity . . . . . . . .

Prep. I7. Dissection of Edible Snail (Helix pomatia), showing its nervous system . . . . . . .

\section{From the Class Lamellibranchiata.}

Prep. I8. Shell of Fresh-water Mussel (Anodonta cygnea) . Prep. I9. Dissection of Fresh-water Mussel (Anodonta cyg$54-57$ nea), showing the course of its digestive tract .

Prep. 20. Dissection of Fresh-water Mussel (Anodonta cygnea), showing its mantle . . . . . .

Prep. 2 r. Dissection of Fresh-water Mussel (Anodonta cygnea), showing its nerve system, and the route taken by the ova in passing from the ovary to the interior of the external gill . 


\section{From the Class Tunicata.}

PAGE

Prep. 22. Dissection of Ascidian (Ascidia affinis), showing the homological relations of its various systems to those of the Lamellibranchiata . . . .

$66-71$

\section{From the Class Polyzoa.}

Prep. 23. Specimens of Broad-leafed Hornwrack (Flustra foliacea) . . . . . . . . . . . .

Prep. 24. Specimen of Bugle Coralline (Salicornaria farciminoides) . . . . . . . . . . .

From the Class Insecta.

Prep. 25. Specimen of Larva of Death's-head Moth (Acherontia atropos) . . . . . . . . . 73-76

Prep. 26. Specimen of Pupa of same species . . . . . . 76-78

Prep. 27. Specimen of perfect Insect of same species . . . 78, 79

Prep. 28. Dissection of Larva of Goat Moth (Cossus ligniperda), showing the organs of vegetative life .

Prep. 29. Dissection of Larva of Privet Hawk Moth (Sphinx ligustri), showing the nervous system . . .

Prep. 30. Dissection of Common Cockroach (Periplaneta orientalis), showing its digestive, renal, nervous and reproductive organs .

\section{From the Class Crustacea.}

Prep. 31. Specimen of Common Crayfish (Astacus fluviatilis)

Prep. 32. Dissection of Common Crayfish (Astacus fuviatitis), showing the nervous, digestive, and circulatory organs in situ . . . . . . . . .

Prep. 33. Dissection of Common Crayfish (Astacus fluviatilis), showing the heart and arteries . . . . 100-102

Prep. 34. Dissection of Common Crayfish (Astacus fluviatilis), showing its digestive, respiratory, and reproductive organs in situ .. . . . . . . 102-105

Prep. 35. Dissection of Common Crayfish (Astacus fuviatilis), showing its nerve system. Tables of homologies of nerve-ganglia, and of appendages, are to be found at pp. 110,116,117 . . . 106-119

From the Class Annulata Proper.

Prep. $3^{6}$. Specimen of Common Earthworm (Lumbricus terrestris) 
Prep. 37. Dissection of Common Earthworm (Lumbricus terrestris), showing its nervous system . . .

121-123

Prep. 38 . Dissection of anterior segments of same animal, showing its reproductive organs . . . . . 124-126

Prep. 39. Specimen of Medicinal Leech (Hirudo medicinalis) 127-129

Prep. 40. Dissection of Medicinal Leech (Hirudo medicinalis), showing nervous and digestive systems in situ.

Prep. 4I. Dissection of Medicinal Leech (Hirudo medicinalis), showing nervous system .

Prep. 42. Dissection of same animal, showing the reproductive and segmental organs in situ . . . .

$133-136$

From the Class Platyelminthes.

Prep. 43. Specimen of Many-headed Bladder-worm (Caenusus cuniculi)

$136-140$

From the Class Asteroidea.

Prep. 44. Specimen of Common Crossfish (Asterias rubens) . 141-143

Prep. 45. Dissection of Common Crossfish (Asterias rubens), showing digestive and motor systems . . . 143-145

From the Class Holothurioidea.

Prep. 46. Specimen of Angular Sea-Cucumber (Cucumaria pentactes) . . . . . . . . . . 145-147

Prep. 47. Dissection of Angular Sea-Cucumber (Cucumaria pentactes), showing motor, digestive, respiratory, and reproductive systems . . . . .
(Relations of Echinodermata to Coelenterata $148-158$ and to Vermes severally at pp. 152-157 of the Description of this Preparation.)

\section{From the Class Anthozoa.}

Prep. 48. Dissection of Sea-Anemone (Actinia crassicornis), showing its various external and internal organs

From the Class Hydrozoa.

Prep. 49. Specimen of Sea-Fir (Sertularia abietina) . . . 160-163

From the Class Spongiadae.

Prep. 50. Specimen of Fresh-water Sponge (Spongilla lacustris) 


\section{DESCRIPTION OF PLATES.}

Plate I. Dissection of Mammal (Mus decumanus) . . 167-173

Plate II. Dissection of Bird (Columba livia) . . . . 175-180

Plate III. Dissection of Amphibian (Rana temporaria) · 181-185

Plate IV. Dissection of Gasteropod (Limax flavus) . . . 187-191

Plate V. Dissection of Lamellibranch (Anodonta cygnea) . 192-198

Plate VI. Dissection of Insect (Periplaneta orientalis) . . 199-204

Plate VII. Dissection of Crustacean (Astacus fluviatilis) - 205-210

Plate VIII. Dissection of Annelid (Lumbricus terrestris) 211-216

Plate IX. Dissection of Annelid (Hirudo medicinalis) . . 217-222

Plate X. Dissection of Echinoderm (Asterias rubens) . . 223-229

Plate XI. Fig. r. Diagram of Cephalopod . . . . . . 231

Fig. 2. Section of Brachiopod (Rhynchonella psittacea) . . . . . . . . . 232-234

Fig. 3. Diagram of Ascidian . . . . . . . 235, 236

Fig. 4. Diagram of Polyzoon . . . . . 237, 238

Fig. 5. Figure of Rotifer (Hydatina senta) . . 239, 240

Fig. 6. Figure of Turbellarian Worm (Dendrocoelum nausicac) . . . . . . 240-243

Fig. 7. Figure of Gregarine (Stylorhynchus oligacanthus) . . . . . . . 243, 244

Plate XII. General account of first six figures . . . . . 245, 246

Fig. I. Semi-diagrammatic figure of Strobile of

$$
\text { Taenia . . . . . . . . } 246
$$

Fig. 2. Immature segment of Strobile of Taenia 246-248

Fig. 3. Mature segment . . . . . . . . 249

Fig. 4. Segment intermediate in age . . . . 249, 250

Fig. 5. Proscolex of Taenia . . . . . . . 250,251

Fig. 6. Cystic stage of Caenurus cerebralis . . 251, 252

Fig. 7. Figure of Coelenteratum (Hydra viridis) 253-255

Fig. 8. Figure of Infusorium (Prorodon teres) . 255-257

Fig. 9. Figure of Phizopod (Amoeba radiosa) . 257-259

Errata and Addenda . . . . . . . . . . . . . . 260

Index . . . . . . . . . . . . . . . . 261-268 


\section{INTRODUCTION.}

IN several different departments of research, and from many different points of view, we are brought to see that the study of Comparative Anatomy, while raising questions of the highest theoretical importance, throws light at the same time upon problems of great practical interest. Of its twofold bearings, the controversies carried on at the present moment as to the Origin of Life and as to the Origin of Species, extending, as they do, on the one side into the provinces of Hygiene and Therapeutics, and on the other into yet higher regions than those, furnish two apposite but not isolated illustrations. It is not within the scope of this work to do more than thus glance a at such practical questions

a It may be well here to give a few instances in which light has been thrown upon complex questions of Hygiene and Pathology in the course of investigations apparently wholly dissociated from such subjects. Dr. Charlton Bastian has, in the Philosophical Transactions for I866, vol. I 56, pt. ii., pp. 583, 584, put upon record a most instructive account of the production of a spasmodic and catarrhal affection not altogether unlike hay fever, under circumstances, however, which appear to preclude the possibility of any living organisms having been, as has recently been suggested, the cause of it. This affection was invariably produced from the emanations inhaled during the dissection of a particular Nematoid worm, the Ascaris megalocephala, from the Horse, and this not only when the animal was fresh, but 'after it had been preserved in methylated spirit for two years, and even then maccrated in a solution of chloride of lime for several hours before it was submitted to examination.' It would seem certain that no morphological unit, nor even any cell-like or 'cytoid' body, can have been at work under circumstances such as these. On the other hand, we have no less an authority than Helmholtz for the coexistence of vibrios in the nasal passages with the presence of hay fever (Virchow's Archiv. xlvi., p. Ior, Feb. 1869), and indeed for the causal relation of the former to the latter condition. Chauvenu's experiments, again (Revue des Cours Scientifiques, Jan. I, 1870, p. 77), shew that in the 
as those relating to the possible modes of origination, and to the available methods for the combating of disease; neither is it advisable here to occupy space in pointing out at length or in detail the various lines along which the results of Comparative Anatomy come to bear upon the more purely speculative questions alluded to. There are, however, certain considerations of greater or less general interest, either as premises or as conclusions, which a

absence, if not of certain animal cells, still of certain animal ' cytoids' or 'leucocytes,' the vaccine poison is inoperative. For the application of such investigations to actual practice see Professor Lister's Introductory Lecture delivered in the University of Edinburgh, Nov. 8, 1869; British Medical Journal, Dec. 4, I869.-The vexed question of the method in which nerves influence nutritional processes receives considerable elucidation from the facts that not only do certain Holothurioidea (Stichopus and Colochirus) possess the power of shedding off the non-muscular elements of their integument as amorphous slimy matter upon irritation, but also that isolated fragments even of their integument, in which it would appear nerve structures are contained, possess the like power, and go through the process of self-dissolution more quickly or more slowly in correspondence with more or less stimulation. (See Semper, Reisen im Archipel der Philippinen, Theil. ii., Bd. i., pp. 72, I 71, 172, 200.) The universally acknowledged but often practically ignored influence of changes in the circumambient medium are well illustrated by such observations as those of $\mathbf{M}$. Claparède on the growth of Annelida (see Ann. and Mag. Nat. Hist. Ser. iii., vol. xx., p. 359, I867), and those of Professor Wyville Thomson on the varying rate of development of certain Echinoderm larvae (see Phil. Trans. vol. 155, pt. ii., pp. 514, 515, 532) under varying conditions of light, heat, and aeration. Dr. Charlton Bastian has drawn attention (Linn. Soc. Trans. xxv., p. 84, 1865) to the quantity of large fat globules often seen within the intestinal canal of free Nematodes as being 'remarkable, and also interesting in a physiological point of view, as an exemplification of the almost direct conversion of cellulose into fat and other products.' The facts of Comparative Anatomy and Physiology as distinct, though not dissociated, from those of Comparative Pathology and Experiment, are appealed to by both sides in the questions 'Ueber die Fettbildung im Thierkörper,' and that of the relations of various kinds of food to the various exigencies of the animal body. (See Donders, Nederl. Arch. voor Genees. en Natuurkunde, Deel. i., Utrecht, 1864; translated, Dublin Quarterly Journal of Medical Science, I866; Lawes and Gilbert, Phil. Mag., July and December, I866; Voit. Zeitschrift für Biologie, Bd. V., Hft. i., pp. I47-I55, 1869.) For the way in which the intimate relations of the fifth nerve to the optic may be illustrated by reference to Comparative Anatomy, see Mooren, Ueber Sympathische Gesichtstorungen, pp. I 17-1 I9, Berlin, I869; and for numerous illustrations of the fact that the organisms of the lower animals give answers in simple language to what are difficult problems in Anthropotomy, see Schroeder Van der Kolk, on the Spinal Cord and Medulla Oblongata ; New Sydenham Society's Translation, passim, and especially chapter vi., pp. I70-I 78,1859 . For other points of connection between Comparative Anatomy and Practical Medicine, see 'Medicine in Modern Times, pp. 79-9x, London, 1869. 
contemplation of the subjects here treated of with reference to their bearings upon Classification, is calculated to impress upon the mind; and these it may be well to state in a few words.

After some study of the details of Comparative Anatomy we begin to see that the animal kingdom is divisible into a certain number of Sub-kingdoms accordingly as the various structures or organs subserving the functions of animal and vegetable life respectively are combined with, separated from, or otherwise arranged relatively to, each other. It is, in the next place, easy to see that whilst in the Sub-kingdom Vertebrata, motor, nervous, vascular, visceral, and perivisceral systems all exist in specialized and differentiated forms, no such 'division of labour' is recognisable in the structural arrangements of the Sub-kingdom Protozoa; and that, by a further and detailed reference to the principle just mentioned, we are justified in speaking of the one as the highest and the others as the lowest of the seven animal Sub-kingdoms. It is not easy, however, to assign to the three Sub-kingdoms known as Mollusca, Arthropoda, and Echinodermata their relative rank inter se; and the Sub-kingdom Vermes would appear to underlie each and all of the three obliquely, rather than to be subordinated to any one of them in particular. The Coelenterata, finally, are approximated to the Protozoa by the low degree to which specialization has been carried out in their organization; but they form a more than ordinarily well-circumscribed group, which we are in no way justified in regarding as forming a transitional stage intermediate between the Protozoa and the other Sub-kingdoms, from which latter it lies far apart.

Within the limits of each Sub-kingdom the differentiation of organs, by the assignment of them to the more or less exclusive performance of particular functions, is very often carried out in the different classes to such a different extent as to allow us to speak without violence and without hesitation of such classes as being higher or lower in the scale of existence. Elevation in the scale of life is indirectly entailed in Sub-kingdoms which possess airbreathing representatives, as aerial respiration renders possible a greater activity of function than an organism differing in this, though similarly constituted in all other particulars, can put forth; whilst the special habit of parasitism, which often renders not merely single organs but even whole systems superfluous, and is 
then found to be correlated with the complete or nearly complete disappearance of such structures, must be regarded as entailing a true morphological degradation.

Sharply circumscribed outlines are, in the second place, as commonly wanting in the classifications we have to deal with as are precisely graduated scales of dignity. The boundaries of species, of orders, of classes, and, in more than one instance, even of sub-kingdoms, may be closely apposed not only at many single points but even along considerable lengths and depths, so that in not a few cases it is a matter of difficulty to decide whether a particular organism or set of organisms shall be placed within the one or the other of the thus complexly approximated groups.

The distances, thirdly, which intervene between the various subkingdoms at their points of widest separation from each other are exceedingly unequal. And in particular, it may be said that, in spite of recent discoveries ${ }^{b}$, it would still appear that the Vertebrate Sub-kingdom lies at a greater distance from the group made up by all the other Sub-kingdoms than that by which any one of these is separated from its nearest neighbour.

Groups, fourthly, which would be allowed on all hands to possess the same morphological or qualitative rank are found to differ very widely as to the numbers of the objects they severally include; and if, by the aid of diagrams, we represent to ourselves the quantitative relations which the corresponding divisions in almost any two of the animal sub-kingdoms hold to each other as wholes of 'extension' or of 'denotation,' we are at once struck by the great inequality of size indicated by the figures thus constituted. A similar result would ensue upon the application of a similar process to many non-biological classifications; the especial significance which these differences possess in organic classifications depends upon two singular but suggestive facts, actual observation having shown, firstly, that the poorer a species is numerically the more aberrant is it ordinarily found to be from the type of the group to which it is subordinated; and secondly, that with a paucity of individuals or of species, as the case may be, a similar paucity of the localities on the earth's surface in which they are now to be

b For a summary of these discoveries, see the Quarterly Journal of Microscopical Science, January, 1870. 
found living is ordinarily correlated. The Ganoids amongst Fishes, the Perennibranchiata amongst Amphibia, the Crinoids amongst Echinodermata, and the Monotremata amongst Mammals, furnish us with illustrations of these laws for the enunciation of which we are indebted to Von Baer ${ }^{\mathrm{C}}$.

A remark of the late Mr. W. S. Macleay, to the effect that no character is natural until it has been proved to be so d, has the merit of at once expressing tersely the necessity of constant recourse to verification when we make deductions from general principles, and of drawing attention to the striking morphological fact of the varying value of class characters. In the face of statements as to the eligibility of particular systems ${ }^{e}$ as bases of classification, which are only less sweeping and general than they are mutually contradictory, it is a satisfaction to be able to quote the following words from the writings of another English naturalist, the late Professor Edward Forbes,-' no character, whether of structure or form, preserves an equal value in every tribe, but varies in its importance, in one group characterizing a class, in another scarcely determining a species ;' whilst the words of Macleay should be

c See Nova Acta, xiii., 2, p.742, 1826, or Professor Huxley's Translation in 'Scientific Memoirs,' pp. 180, I81, 1853.

d See Linnaean Society's Transactions, xxiii, p. 75, 1860.

e For the applicability of the nervous system as a basis of classification, see Cuvier, The Animal Kingdom, English Translation, 1854, p. 3I ; Lacaze Duthiers, Comptes Rendus, r865, tom. ii., p. 800; Blanchard, Ann. Sci. Nat., Ser. iii., tom. v., pp. 276 , 376, 1846 ; Dana, Crustacea, pp. 46, 59 ; Waterbouse, Ann. and Mag. Nat. Hist., vol. xii., p. 399, 1843; Professor Owen, Linnaean Society's Proceedings, 1857. For the applicability of the Reproductive, see Dana, l.c., p. 62; Professor Owen, cit. Darwin, Origin of Species, chap. xiii., p. 490, 4th ed. ז866; Fischer, Orthoptera, p. 62 ; Stein, Vergleichende Anatomie und Physiologie des Insekten; erste Monographie; Die weiblichen Geschlechts-Organe der Käfer, I847, passim. For the applicability of the Respiratory, see Dana, l.c., p. 62. For the value of the changes gone through in development, see Professor Wyville Thomson, Phil. Trans., vol. I55, pt. ii., pp. 514, 532, where attention is drawn to the power which circumstances of light, warmth, aeration and nourishment have in modifying and hurrying over certain stages of larval growth; Oskar Schmidt, Sitzungsbericht, Nat. Wiss. Class. Kais. Akad. Wien. xix., p. 193, 1856; Darwin, Animals and Plants under Domestication, vol. ii., pp. 366-368; Origin of Species, p. 494, ibique citata. For the value of the motor system as a basis for classification, in the sub-kingdom Echinodermata, sce Brandt, Prodromus, 1835. For that of the Placental system in the class Mammalia, see Zool. Soc. Trans., vol. v., pt. 4, p. 285, 1865; H. Milne Edwards et Alphonse Milne Edwards, Recherches pour servir à l'Histoire Naturello des Mammifères, Livraison i., p. 18, seqq., ibique citata, 1868. 
borne in mind with reference to certain other statements ${ }^{f}$ of even greater generality as to the applicability or inapplicability of physiological differences as bases of zoological arrangements. Nothing is easier than to say that by the nervous, or by the reproductive, or by the respiratory systems, or by the history of the changes gone through in development, 'characters of the widest bearing in classification are furnished;' but nothing is more certain, as a verification of statements referred to below will demonstrate, than that what is true of one of these bases of classification within the limits of one Sub-kingdom, or within the limits of one Class, or even within the limits of yet smaller groups, will not be by any means invariably found to be true within the limits of another similar division. Our knowledge, again, of the power which organisms have of adjusting themselves to their environment, may incline us to think the motor and tegumentary systems to be bad bases for classification, as it is through them that the animal comes mainly and mostly into relation with external influences. Yet, if Seals and Whales exhibit marks of their affinities to the Carnivora and the Artiodactyla respectively, even in such matters as the character of their placentae, the number of the bronchi in their lungs, and, in spite of the modifications which their motor and tegumentary systems have undergone, it is nevertheless true that the specialization of the same systems in Aves and Echinodermata appears to have entailed corresponding variations throughout the entirety of their respective organisms, and in organs of vegetable as well as in organs of animal life.

The facts of the varying morphological value of zoological differentiae; of the unequal quantitative extent of divisions of equal morphological rank; and of the unequal distances separating such divisions, go some way towards accounting for the arbitrary way in which the same division has had very different morphological rank assigned to it by different classificatory writers. A provisional character however must always attach itself to a greater or smaller part of all our classifications; if they succeed in pre-

f See Erichson, Entomographien, p. 1, 1840, 'Dies ist ein physiologischer, kein 'zoologischer Character,' Semper, Reisen in Archipel der Philippinen, Theil. ii., Bd. i., p. 52; Carpenter, Foraminifera, Ray Society, p. I4, 1862; Herbert Spencer, Principles of Biology, vol. i., pp. 306, 307, r864; Darwin, Origin of Species, $4^{\text {th }}$ ed., p. 490. 
senting to our minds the knowledge we possess at the passing moment in a form which gives it compactness as to the past and availability for use in the future, that is all which in the nature of the case they should be regarded as doing, or expected to do, for us. An increase in our knowledge may confirm, but it may, on the other hand, overthrow the most perfectly symmetrical of systems $^{\mathrm{g}}$.

g It is not a little instructive to note that Macleay, to whom Zoology is indebted for the 'grand principle' referred to above, should yet have been the inventor of the 'quinary system,' with its independent but numerically identical groups arranged in circular series. For the history and for illustrations of the working of this idolon theatri, see Macleay, Horae Entomologicae, vol. i., pt. ii., p. 322, I82I ; Swainson, Geography and Classification of Animals, p. 202, et passim, 1835; Edward Forbes, Starfishes, p. xvi. I84I ; Milne Edwards, Ann. Sci. Nat., Ser. iii., tom. i., p. 79, 1844; Agassiz, Essay on Classification, p. 344, 1859. Bacon's words are singularly appropriate in relation to these arbitrary assumptions:- ' Intellectus humanus ex proprietate sua facile supponit majorem ordinem et equalitatem in rebus quam invenit; et quum multa sint in naturâ monodica, et plena imparitatis, tamen affingit parallela et correspondentia et relativa quae non sunt. Hinc commenta illa in coelestibus omnia moveri per circulos perfectos.' Nov. Organ. xlv. Neither are the words of the modern poet quoted by Sir John Richardson (Introduction, Fishes, Museum Natural History), in relation to a recent attempt to unite Fishes, Amphibia, and Reptiles into one division, the Haematocrya, unworthy of being quoted here :-

' Our little systems have their day, They have their day and cease to be, They are but broken lights of Thee, And Thou, O Lord, art more than they.'

Tennyson, In Memoriam, vi.

Striking evidence is borne to the scientific fact of the great difference which exists between the works which are and those which are not of man's creating, by the singular circumstance that of all the many metaphors which have been used to express the general or picturesque effect produced on the mind by the study of a system of biological classification, those only retain a strong hold upon the imagination which are borrowed from natural objects; whilst those which are borrowed from works of art, or from productions of the arts, are at once felt to be inadequate even when not untrue. In illustration of this, it is sufficient to lay specimens of the two kinds of metaphor mentally alongside of each other. In the latter we have the divisions of the organic world compared to the steps in upward-sloping stairs; or to a series of columns placed upon a flight of such stairs; or to the meshes of a net; or to the artificial boundary-lines of neighbouring kingdoms; the nore modern and truer comparisons we refer to are drawn from such objects as single stars, each surrounded with its own proper atmosphere; as aggregations of such stars in constellations; as trees with stems, branches, twigs and leaves; as hills clothed with woods, and separated by valleys dipping to various depths, and themselves bestudded with clumps 
The above-quoted saying of Mr. Macleay's, by suggesting the question, "When is a character to be considered as proved to be natural ?' brings us face to face with the most distinctive peculiarity of zoological classification. A character is a good basis for classification in zoology, as in every other subject, when its presence enables us to predict the presence of many, or at least of some other characters besides those which its name implies etymologically; but when we are concerned with species in zoology, these other characters must relate not only to the entirety of the organism as such, but also to the main facts of its life history. When we class two living organisms together in the same species, we include always among the other facts which their common specific name must connote, the particular fact that it is possible for them both to have descended from one ancestor or ancestors, which, either directly, or after certain stages in cyclical metamorphosis, they could reproduce. For cyclical self-repetition in the way of parentage, being eminently the characteristic of living organisms, as opposed to non-living objects, no classification of such organisms would be either natural or valuable which did not lay that particular part of their history in a compact and manageable form before the mind, whensoever evidence as to it was obtainable. It is true that such evidence is by no means invariably accessible; and when it is not, we have only likeness to guide us as to saying that it is more or less probable that between any two organisms such prospective and retrospective community in parentage might or did exist. On the other hand, where this evidence is forthcoming, the question of identity of species is instinctively and at once settled in the affirmative; even when the unlikeness between the individuals compared may be as extreme as that which exists between the well-known larvae of Batrachia and their adult forms, or between the less familiar but even more strikingly differing larvae and adults of Cirripedia, of other Crustacea, of the Platyelminthes, and of many Hydrozoa (see infra, pp. I62, 245, 252). The theory of evolution with which Mr. Darwin's name is connected, asks us to deal with species in their relation

of trees; as systems of mountain-ranges, more or less connected by outliers; or, happiest metaphor of all-as the islands of an archipelago, sometimes all but continuous through the intermediation of connecting reefs, sometimes sharply separated by unfathomable seas. 
to genera and still higher divisions, as we deal with individuals in referring them to particular species, and to believe that the 'secret bond' which colligates species under larger groups, is of the same genealogical character as that which we look for always, and often find in the case of individuals. Many of the peculiarities which attach to biological classifications would thus receive a reasonable explanation; but where verification is, ex hypothesi, impossible, such a theory cannot be held to be advanced out of the region of probability. The acceptance or rejection of the general theory will depend, as does the acceptance or rejection of other views supported merely by probable evidence, upon the particular constitution of each individual mind to which it is presented. But whether the general theory be accepted as a whole or not, it must be allowed that in the face, on the one hand, of our knowledge of the greatness of the unlikeness, which may be compatible with specific identity; and, on the other, of our ignorance of the entirety of the geological record, the value of the special 'Phylogenies,' or hypothetical genealogical pedigrees, reaching far out of modern periods, are likely to remain in the very highest degree arbitrary and problematical. 
Tabular View of the System of Classification adopted in this work, shewing the various Sub-kingdoms in some of the relations of mutual affinity and of rank which they have been supposed to hold to each other. In the cases of several names an oblique position would have been truer to nature than the horizontal one which they occupy in the Table. The lines abut upon the names of the Classes or Orders by which the several Sub-kingdoms have been regarded as connected with each other. (Arrangement of Sub-kingdoms after Gegenbaur.)

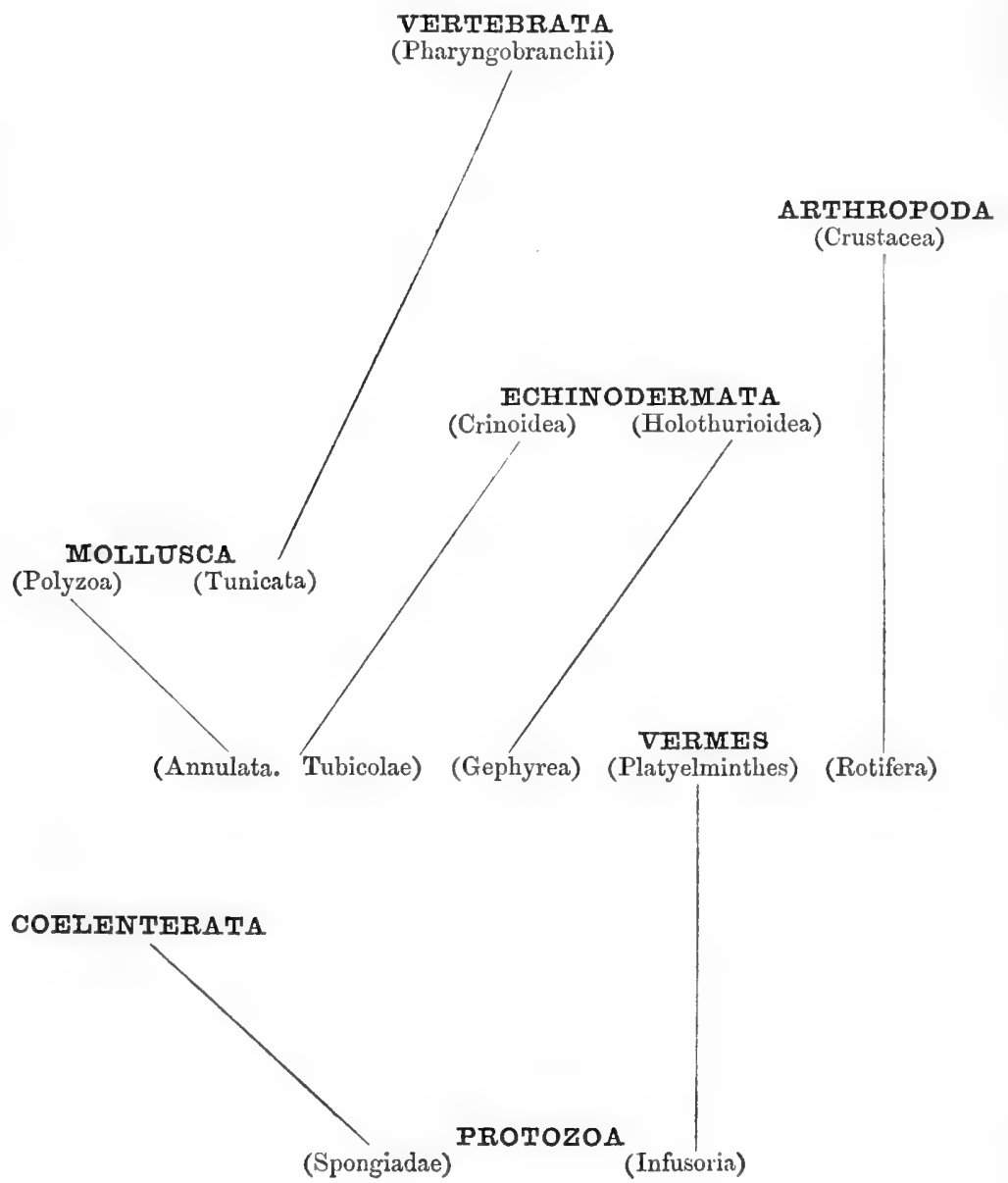


Tabular View of the System of Classification adopted in this work, giving the pages at which the characteristics of the various Sub-kingdoms and of the Provinces and Classes subordinated to them; those at which the Descriptions of the Specimens; and those at which the Descriptions of the Figures in illustration, are to be found.

I. SUB-KINGDOM, VERTEBRATA, pp. xxxi-lxxxv:

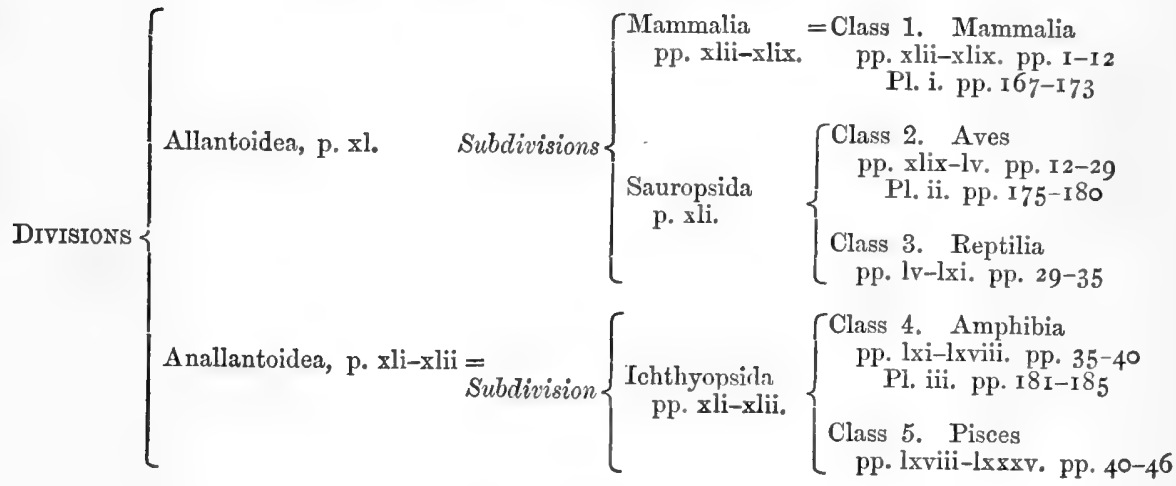

II. SUB-KINGDOM. MOLLUSCA, pp. 1xxxv-ciii.

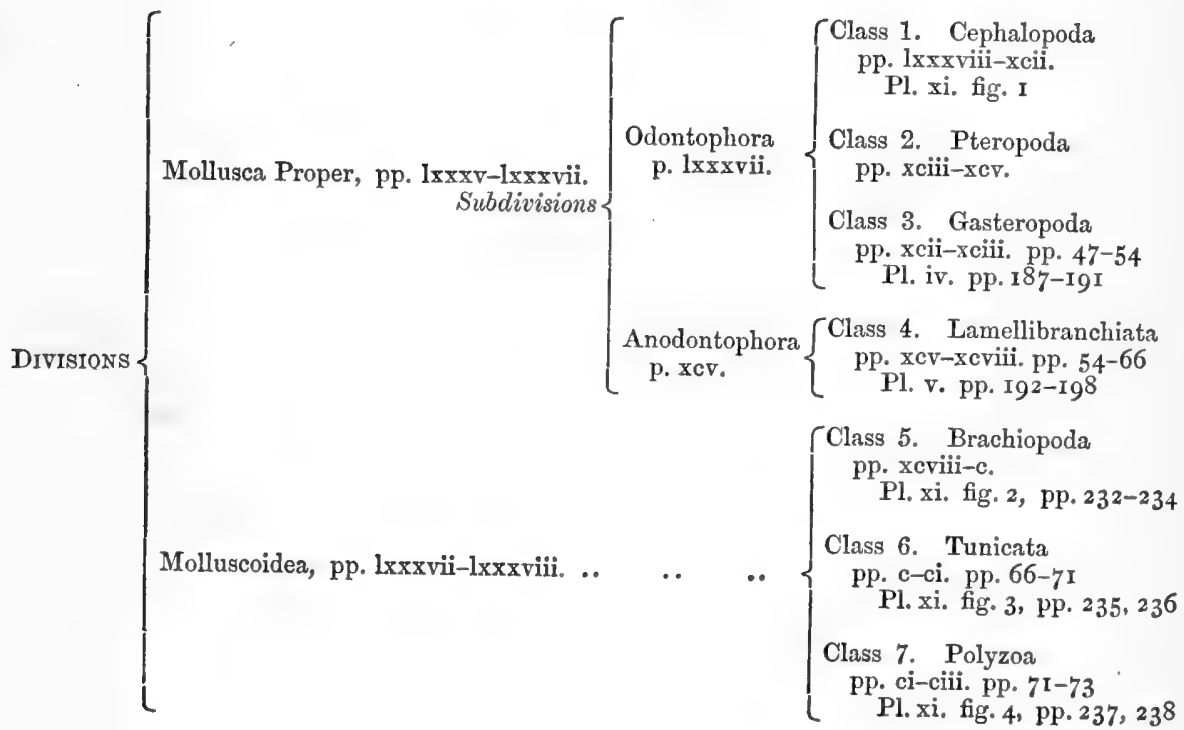


(Tabular View with Pages.)

III. SUB-KINGDOM. ARTHROPODA, pp. civ-cxxii.

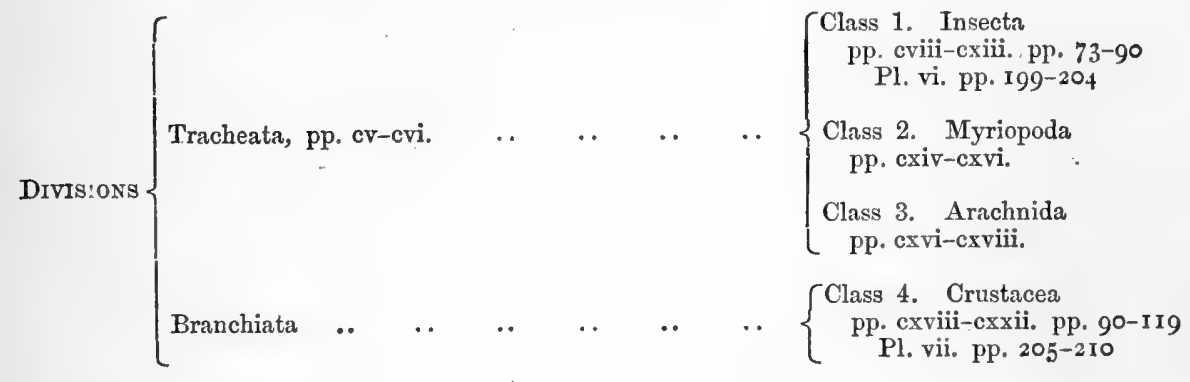

IV. SUB-KINGDOM. VERMES, pp. cxxii-cxliii.

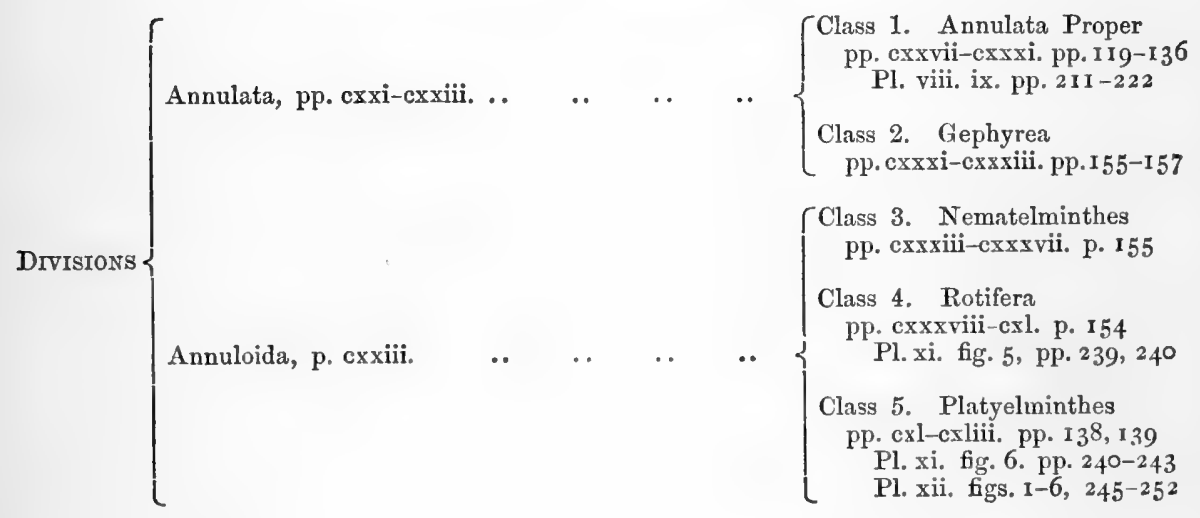

V. SUB-KINGDOM, ECHINODERMATA,

pp. exliii-clvi.

Class 1. Holothurioidea pp. exlvii-cl. pp. $145^{-1} 5^{8}$

Class 2. Echinoidea pp. cl-cliii.

Class 3. Asteroiden pp. cliii-cliv. pp. 14t-145 Pl. x. pp. 223-229

Class 4. Crinoidea pp. cliv-clvi. P. $16_{5}$ 


\section{(Tabular View with Pages.)}

VI. SUB-KINGDOM. COELENTERATA, pp. clvi-cls.

VII. SUB-KINGDOM. PROTOZOA, p.clx.
Class 1. Ctenophorae pp. clvii-clviii.

Class 2. Anthozoa pp. clviii-clix. pp. $15^{8-160}$

Class 3. Hydrozoa pp. clix-cls. pp. I6o-I63 Pl. xii. fig. 7 , pp. 253-255

Class 1. Infusoria pp. clxiv-clxv.

Pl. xii. fig. 8 , pp. 255-257

Class 2. Rhizopoda pp. clxv-clxvi. Pl. xii. fig. 9, pp. 257,258

Class 3. Spongiadae pp. clxvi-clxvii. pp. 163-166

Class 4. Gregarinæ

pp. clxvii-clxviii. pp. $243,244$. 


\section{CHARACTERISTICS OF THE SUB-KINGDOM VERTEBRATA.}

\section{Sub-KIngDom, Vertebrata .}

Animals with bilaterally symmetrical bodies, divided internally into two perfectly distinct cavities, one of which is placed dorsally and contains the principal nerve-centres, whilst the other contains the organs of vegetative life. The ventrally-placed cavity of the Vertebrata must be considered to correspond to the entire interior of the body of the Invertebrata, and their dorsally-placed cavity, the cerebro-spinal canal, to be without any homologue in the inferior Sub-kingdoms. The motor organs of Vertebrata are directed towards their heart, and point away from their nervous systems, both cerebro-spinal and sympathetic; whilst in Invertebrata the motor organs are developed upon the neural aspect of their bodies. Thus the arrangement by which the heart of the Invertebrate animal is dorsal and the nerve-system ventral in posi-

a In the account here given of the characteristics of each Sub-kingdom and Class, a few general remarks are prefixed to a more detailed zootomical account of each Division. In that account the various organs and systems are treated of very nearly in the same order as that of the 'Physiological Series of Comparative Anatomy contained in the Museum of the Royal College of Surgeons in London,' which was followed by Professor Acland in the arrangement of a large part of the Christ Church Collection now contained in the University Museum. The integumentary and motor organs are first treated of ; then the digestive, circulatory, respiratory and renal; a sketch of the nervous system is then interposed before the account of the reproductive organs. Oljection may be taken to this method of arrangement on the ground of the separation it effects between the motor and the other organs of animal life; but this theoretical drawback is more than compensated for by many practical advantages. A short notice of any peculiarities in the history of Development, which it may have seemed expedient to add, comes next in order; and in some cases an account of its subordinate divisions is prefixed or appended to the description of a larger group. 
tion, is exactly reversed in the Vertebrate; and the former may consequently be spoken as 'neuropodous,' and the latter as 'haemapodous.' In both cases the digestive tube interposes itself for greater or smaller distances between the haemal and neural systems, but the perforation of the nerve-system, by the anterior segments of the digestive tube, which constitutes the nerve-collar of Invertebrata, finds no representation in the relations subsisting between the principal or cerebro-spinal nerve-centres of Vertebrata and their digestive tube, the anterior or oral opening of which is always directed towards the ventral, and away from the neural surface of their bodies. The perivisceral cavity of Vertebrata never communicates with the blood-vascular, though it has recently been shown to communicate with the lymphatic system; nor is it ever prolonged into their limbs, which possess always an internal and segmented skeleton either of cartilage or of bone. The limbs of Vertebrata differ further from the limbs of Arthropoda in never exceeding the number of two pairs. Externally, the Vertebrata show no appearance of segmentation, and the segmentation which they do exhibit internally does not affect the organs of vegetative life, but is exemplified only in their skeleton, nerves, and muscles. The axial portion of the internal skeleton, which separates the body of the Vertebrate animal into a neural and haemal cavity, is not always divided by segmentation into the structures whence the Sub-kingdom takes its name. In the Amphioxus, the endo-skeleton is represented simply by the rod-like aggregation of cells known as the chorda dorsalis; by the sheath surrounding this structure; and by fibrous arches, which are developed above and below in connection with these axial structures, and give attachment laterally to the inter-muscular septa; but it shows no other signs of segmentation except by the possession of series of mesially-arranged cartilaginous nodules, which correspond in position to the inter-spinous bones and fin-rays of more highly organized fish. In all other Vertebrata, the endo-skeleton becomes definitely segmented posteriorly to the head, either by the development of cartilaginous neural arches alone, as in Petromyzon, or by the development of axial, in addition to neural indurations. By the more or less perfect fusion, and, ordinarily, by the calcification of these elements, the structures known as 'vertebrae' are formed.

In all Vertebrata, with the exception of Amplioxus, which is 
hence called 'Acranial,' the neural canal widens considerably in the anterior region of the body, in correspondence with the increased size of the neural axis it encloses, and with the organs of special sense to which its walls give support. The superior and the central elements of this portion of the axial skeleton make up the skull, and are differentiated from those of the vertebral series, not only by the greater size of the canal they form, but also by the fact that they undergo no segmentation until the stage of ossification is attained to. In the anterior portion, on the other hand, of the lower of the two cavities of the body, segmentation of a characteristic kind is established at an early period of the development of all Vertebrata, by the formation of the vertical 'branchial fissures,' which, in the absence of any anterior prolongations of the perivisceral cavity, lead directly from the exterior into the digestive tract. The first, and in part the second of these fissures are represented permanently by the Eustachian tube, and the tympanic cavity in all air-breathing Vertebrata possessed of these structures ; the other fissures which are retained in relation with the gill-bearing arches of Fish and Perennibranchiate Amphibia, are, in the higher representatives of the Sub-kingdom, obliterated in the course of their development.

The integumentary system of Vertebrata may develope either a dermal or an epidermal skeleton, or both; and muscular fibres are ordinarily interwoven in considerable abundance with its substance. But these structures are never, as in Invertebrata, of primary locomotor importance, the more deeply-placed skeletal and muscular systems being little less characteristic physiologically than morphologically of this sub-kingdom. The jaws of Vertebrata are always modifications of the cephalic parietes, and never, as in Invertebrata, modifications of limbs. No vertebrate animal is aproctous; the digestive tract has the shape of a distinct and independent tube, except in the region of the cephalic parietes, to which, as also to the branchial arches when present, its walls are adherent. In the abdominal region, the digestive tube is suspended by membranous lamellae, which are never fenestrated except as a consequence of absorption in adult fish, but which do occasionally resemble the membranes with similar functions in Invertebrata by possessing muscular fibres. The digestive tract rarely takes a direct anteroposterior course. Its absorbing and secreting surface is often 
increased by the addition to it of coecal diverticula, which may be very numerous, and arranged in whorls in Fishes, but are never so numerous, nor so arranged in higher Vertebrata. Oral salivary glands are often wanting in aquatic Vertebrata, the pancreatic are less frequently, and the hepatic is never absent. Microscopic absorptive, as well as secreting glands, exist in great abundance in the walls of the digestive tube.

With the exception of Amphioxus, all Vertebrata possess a lymphatic as well as a blood-vascular system; and the ultimate ramifications of the former of these systems have been recently shown to be continuous with the perivisceral or pleuro-peritoneal cavities. The blood-vascular system, on the other hand, never communicates either with the perivisceral or with the intermuscular spaces, and the efferent arteries are all but invariably connected with the efferent veins by means of capillaries, with walls distinct from the tissues they pass through. With the exception of Amphioxus, in which animal we find all the main vascular trunks endowed with contractility, all Vertebrata possess a heart of saccular shape, consisting even when most simple of two chambers, one of which receives the blood returned by the veins from the system at large, whilst the other propels that blood into the aerating organs. Thus the heart of the Vertebrata is a respiratory, whilst that of the Invertebrate animal is a systemic heart. The formation of retia mirabitia, by the breaking up of arteries into plexuses, in the interstices of which no great amount of interstitial matter is deposited, appears to be a peculiarly vertebrate arrangement; as is also the so-called 'portal system,' which appears to be formed by the development of retia miratilia, in the course of the veins returning from the chylopoictic viscera, and the intercalation of the elements of the hepatic glands in the interstices of the plexuses thus formed.

The blood of all Vertebrata, except Amphioxus, is red; the colouring matter being contained in corpuscles, which appear to be developed from the white corpuscles which are always found in company with them. The spleen and thymus glands are connected like the lymphatic glands, and many other but smaller bodies of somewhat similar histological character, found in the substance both of mucous and serous membranes, with the process of haematopoiesis; and appear to be structures peculiar to Vertebrata. 
Whether the respiration of Vertebrata be aquatic or aerial, the apparatus by which it is effected is always connected with the commencement, and never, as in some Invertebrata, with the outlet of the digestive tract. The efferent ducts, on the other hand, of the renal organs, are usually confluent and always in near relation with the anal, and also with the generative outlets. In Plagiostomous Fishes, and in all Vertebrata above the Amphibia, a primordial as well as a secondary kidney is developed; and in all cases, except those of the Cyclostomi and Amplioxus, the renal are closely connected either in their development, or throughout life, with the generative glands. When a primordial kidney, the so-called 'Wolffian body,' is replaced by a secondary and persistent kidney, the provisional gland and its efferent ducts are in the male sex partly converted into spermatic ducts, the so-called epididymis and vasa deferentia, and partly remain as the rudimentary 'cyst of Morgagni,' and 'organ of Giraldés' of the class Mammalia ; whilst in the female sex the primordial kidney and a certain part of its efferent apparatus become atrophied, and are known in Mammals as the 'organ of Rosenmüller' or 'parovarium,' and the 'canals of Gaertner' respectively ; and the remaining part of the efferent apparatus, the so-called 'duct of Müller,' becomes the functional oviduct. In the males of Amphibia, where no secondary kidney is developed, the efferent testicular ducts pass through the anterior part of the substance of their functional kidney, which in higher animals becomes limited to the functions of an epididymis; and these ducts are, on the distal side of the urinary gland, known as 'vasa uro-spermatica.' The posterior part of their functional kidney is exclusively urinary in function, and its ducts may coalesce more or less completely before joining the (Müllerian) duct, into which the uro-spermatic vessels from the anterior part of the gland open; foreshadowing thus the more perfect differentiation of these structures which we meet with in the airbreathing Vertebrata. According to some authorities, however, the duct of Müler, the parovarium, and the epididymis are developed independently of the Wolffian bodies and their ducts. This appears to be certainly the case in Mammals

In the Amplioxus, the brain can scarcely be said to exist at all, being represented merely by the nervous tissue surrounding the open ventricle, which is formed by a slight expansion of 
the central canal of their spinal cord, and has an aggregation of pigment granules, the rudimentary eye, placed anteriorly to it. The cerebro-spinal system of other Vertebrata resembles this axial nervous cord of the Amplioxus, in being developed from the uppermost part of the three layers into which the germinal membrane divides itself in the embryo, but differs from it in the great size and complete differentiation which its anterior segments attain to in the brain and organs of special sense. The brain consists of three primary vesicles, the anterior one of which is subsequently differentiated into a 'prosencephalon' and 'diencephalon,' the latter division corresponding to the parts surrounding the 'third ventricle' of anthropotomy; the middle one of which, or ' mesencephalon,' remains undivided; whilst the posterior, like the anterior, is ultimately distinguishable into two portions, an anterior corresponding to the cerebellum, and a posterior corresponding to the parts bounding the posterior parts of the 'fourth ventricle' of anthropotomy, or to the single ventricle of the Amphioxus already mentioned. As in the higher Mollusea, the organs of smell, taste, sight, and hearing are always limited to the head; and with the exceptions of the Amplioxus and Cyclostomi, in which there is but a single nasal opening, and of the asymmetrical Plewronectidae, these organs always consist of single bilaterally symmetrical pairs. The essential elements of the peripherally-placed portions of the organs of special sense, are mainly, though not exclusively, developed from the epidermic portion of the same uppermost layer of the trifid germinal membrane, whence the cerebro-spinal nerve-centres are themselves developed. The so-called olfactory and optic ' nerves' are direct outgrowths of the anterior cerebral vesicle; but in all other cases the central and peripheral factors of the sensory organs are brought into connection through the intermediation of nerves, strictly so called, and developed in the middle one of the three layers of the germinal membrane. In the peripheral apparatus also, certain enveloping and protecting structures, such as the sclerotic coat of the eye, and the skeletal elements in the auditory and olfactory organs are also productions of this intermediate layer; and in the eye the cornea, and in part the lens, are also formed from it. The peripheral apparatus retains its typical character as an involution of the integument in the olfactory, but loses it in the optic 
and, with the exception of the Elasmobranchii, in the auditory organs.

Tactile sensibility is possessed in a greater or less degree by the entire cutaneous system. Special tactile organs are developed in many Vertebrata around the region of the mouth, and in some upon the extremities; and we find in Fishes and in the larvae of Amphibia, an additional set of tactile organs in the structures which constitute the system of the lateral line, and are distributed over the walls of the head as well as along the sides of the trunk. Taste may be localized either in the tongue, or in the throat, or in both; or is probably absent altogether, where the epithelium covering this region becomes indurated or spinous. The nerves, as opposed to the nerve-centres of Vertebrata, are developed in the middle, and not in the uppermost layer of the embryo; they are divisible into dorsal, latero-motor, and splanchnic sets, accordingly as they are distributed to the structures formed by the dorsal laminae, by the ventral laminae, and by the visceral factor into which that middle layer divides itself. The sympathetic nervous system is not contained within the cranio-spinal canal, and its branches are mainly, though not exclusively, distributed to the viscera of organic life. It consists, firstly, of bilaterally symmetrical chains of ganglia arranged on either side of the thoracicoabdominal, of the cervical, and occasionally, as in osseous Fishes, also of the caudal vertebrae : and, secondly, of certain great praevertebral plexuses, partly lodged in the substance, but for the most part placed upon the exterior of the viscera they supply. With the first of these divisions are to be ranked four pairs of ganglia developed in connection with branches of the fifth cranial nerve, and in relation with the cephalic parietes. The entire sympathetic system is developed out of the middle layer of the embryo, and the greater part, if indeed not the whole of its first division, is a dependency of the similarly developed cerebro-spinal nerves with which it is connected functionally and anatomically in adult life, and which must be taken into account when the nervous systems of Vertebrata and Invertebrata are compared with each other. Certain ganglia developed upon the posterior roots of these spinal nerves in the intervertebral foramina, and upon the roots of certain cranial nerves, in or close to certain cranial canals, resemble the sympathetic ganglia in structure; but from their very obvious and 
permanent condition of dependency upon the cerebro-spinal nerves, and also from their position, they are often ranked with these latter nerves rather than with the sympathetic system.

Though the generative glands of all Vertebrata appear to be hermaphrodite at certain periods of foetal life, they are, with the exceptions of a fer Fishes and Amphibians, differentiated as either male or female organs, before the attainment of adult life. In many Fishes, in Amphibia, and in all higher Vertebrata, the ova are impregnated by sexual congress; parthenogenesis and metagenesis are entirely unknown in this Sub-kingdom, and metamorphosis has only been observed amongst Amphibia and in a few lower Fishes. In all Vertebrata, except certain osseous Fishes, the ova are set free by dehiscence into the perivisceral cavity, whence they are ordinarily taken up by the infundibuliform orifices of bilateral oviducts, or as in a few Fishes left to find their way into the circumambient water, through an azygos orifice in the abdominal walls known as the 'porus genitalis.' On the other hand, vasa deferentia, directly continuous with the capsular envelope of the testes, are found in all Vertebrata except the Amphioxus, the Cyclostomi, the Ganoidei, and the Eel.

The yolk of the impregnated ovum sometimes undergoes entire, sometimes only partial segmentation. The germinal membrane very early divides itself into three layers, from the uppermost of which the cerebro-spinal nervous centres and the cuticular systems are evolved ; from the lowermost the epithelial structures of the digestive tube, and its glands with the exception of the parotid; and from the intermediate layer all the other structures of the body, the cutis vera, the nerves, muscles, bones, and the various vegetative organs with the exceptions given. The first indication of the formation of the embryo is seen in the appearance of the 'primitive groove;' by the upgrowth of the walls of which, the cranio-spinal canal and the cerebro-spinal nervous axis are both formed as demi-canals at first, and as closed tubes ultimately, by the intermediate, and by the upper layers of the germinal membrane severally. The chorda dorsalis is developed along the infero-median line of these structures; and at a point corresponding to the level thus marked out, lamellar prolongations are sent off downwards, which form the walls of the inferior cavity of the vertebrate body, and are known as the laminae ventrales. The intestine in all Vertebrata except Amphioxus (and 
Cyclostomi and Amphibia?) is formed by the junction to the third layer, which has the shape of a groove open towards the yolk cavity, of an outer fibrous covering, due to the splitting into two portions of the ventral part of the middle layer; and by the subsequent conversion of the demi-canal, thus formed, into a tube at its two ends. The space contained between the two layers into which the downward prolongation of the middle layer divides itself, corresponds with the future pleuro-peritoneal cavity of the adult Vertebrate; and the orifice and canal of communication betwen the yolk cavity and the tube which the demi-canal is thus converted into, correspond with the more or less transitory omphalo-mesenteric duct, which connects the vertebrate intestine with the umbilicus. In no Invertebrate animals are the walls of the perivisceral cavity thus constituted; and in none does the intestine ever possess any umbilicus. In the Amplioxus, however, (as also in Cyclostomi and Amphibia?) the intestinal tract is said to be formed, as it is in many Invertebrata, by a process of invagination commencing at the future anus; and the larvae of certain Ascidians have been stated to have their nerve-centre developed similarly to the tubular cerebro-spinal centres of Vertebrata, and to possess within the locomotor caudal appendage, with which they are furnished in their larval condition, a structure closely similar to the chorda dorsalis of Vertebrata.

In all Vertebrata, with the exceptions just mentioned, a larger or smaller ' umbilical vesicle' is formed by the separation of a distal or extra-abdominal portion of the yolk-sac from an intra-abdominal moiety, at the point where the ventral laminae close upon it in the medio-ventral line, and form the 'umbilicus.' The ' umbilical vesicle' is usually cast off when the embryo is set free from the egrg; the part of the yolk sac which is intercepted within the abdominal cavity, frequently persists for a considerable period after birth as the 'omphalo-mesenteric duct.'

\section{Divisions, Allantoidea and Anallantoidea.}

Vertebrata are divided into Amniota and Anamniota, accordingly as the dermal and cuticular elements of the ventral laminae are in 
development reflected upwards from the medio-ventral line, so as to meet along the medio-dorsal line, and form thus the foetal envelope known as the Amnion; or as no such envelope is superadded to the more or less complex ones, furnished by the maternal organism. In the Vertebrata Amniota, a second foetal envelope, the Allantois, is always developed, originating from the anterior aspect of the posterior extremity of the trunk as a body, which is at first bilobed and solid, but which subsequently becomes hollow internally, and covered externally with vascular ramifications, whereby in Reptiles and Birds the respiration, and in Mammals both the respiration and the nutrition of the developing embryo are provided for. From their possession of this structure, the Amniota are also known as 'Allantoidea ;' and as gills are never developed upon their branchial arches, they are also called 'Abranchiata,' whilst the Anamniota have in their turn the two additional names 'Anallantoidea' and 'Branchiata,' as never developing an Allantois, at least beyond the stage of a urinary bladder, into which its proximal portion is converted in the higher Vertebrata, and as always developing either deciduous or permanent gills.

\section{Division, Allantoidea.}

The Allantoidea comprise the three Classes, Mammalia, Aves, and Reptilia, and possess the following characteristics distinguishing them from the Anallantoidea, in addition to those which their several names given above connote. The axis of their basi-cranial bones always forms a considerable angle with the axis of their vertebral column; the parasphenoid, which is large in the Anallantoidea, is in them rudimentary, whilst the basi-occipital and basi-sphenoid are always well ossified; and the former is never anchylosed with any of the anterior vertebrae, of which more or fewer are always distinguishable as cervical, from a thoracic or thoracico-abdominal series. Inferiorly-placed 'sternal' bones ordinarily complete the costal arches. They never have a permanent muscular bulbus arteriosus; but they always have a trachea, and a secondary kidney. They never have more than five branchial arches; and it is only in 
the three most anteriorly placed of these that cartilaginous supports have been observed to be developed.

\section{Sub-Diviston, Sauropsida.}

The two Classes Aves and Reptilia are united into a single province, that of the 'Sauropsida,' by the possession of the following characteristics which distinguish them both from the other subdivision of Allantoidea, the class Mammalia. Their integumentary system always developes either feathers or scales; their skull is articulated by a single occipital condyle to the cervical vertebrae; they have their ankle-joint interposed between the proximal and distal bones of the tarsus, and not between the distal extremity of the lower leg and the proximal tarsal bones; they have also a single auditory ossicle, the stapes; the malleus of Mammals being represented by their os quadratum, and the incus by their suprastapedial process. Their blood corpuscles are oval and nueleated. They never have the single aorta turning over the left bronchus, nor a perfect diaphragm, nor a corpus callosum, nor mammae, all of which structural arrangements are found in all Mammals.

\section{Division, Anallantoidea.}

The Anallantoidea comprise the two Classes, Amphibia and Pisces, and the province thus constituted is known as that of the "Ichthyopsida,' as well as by the names of 'Branchiata' and 'Anamniota,' given above. They differ from the Abranchiate province in the follorving particulars in addition to those which their various names imply. Their integument never developes any epidermic skeleton, except in a few Amphibia (see p. 35, infra), and in some Fishes the bony structures of the cutis may cause the total or almost total disappearance of the cuticle. The axis of the head and vertebral column form one continuous line; the basicranial bones are, except in some fishes which have not an osseous skeleton, underlaid by a large parasphenoid. The basi-occipital may be rudimentary or 
cartilaginous, and may be connected by suture, and not by movable articulation, with the first vertebra of the trunk. The apex of the scapular arch, so far as it is constituted by true endo-skeletal elements, corresponds at its first appearance to the interspace between the second and third vertebrae, marking off thus two cervical vertebrae; but a cervical region is not by any means invariably recognisable in the adult condition of these animals; when there are two occipital condyles, they are constituted by the ex-occipitals alone. They never possess a series of costal arches completed inferiorly by sternal bones; and it is only rarely that (in Amphibia) there is any sternum present at all. They always possess two aortic arches at least, and nearly invariably an aortic bulb. They are in many cases competent to the maturation of sexual products, before they attain their full size; and in the case of the Amphibian Axolotl, before the gills characteristic of the larval or tadpole-stage are discarded.

No Vertebrata are social, nor are any fixed to one spot. The power of repairing injuries and mutilations is, with possibly a few exceptions, confined to the cold-blooded Amphibia and Reptilia. As in the two higher Sub-kingdoms of the Invertebrata, the Mollusca and the Arthropoda, there are both air-breathing and water-breathing representatives of this Sub-kingdom.

As in the Sub-kingdom Mollusca, so in that of Vertebrata, there are very few animals of parasitic habit. All parasitic Vertebrata belong to the class Pisces, and amongst these we may mention the Myxinoids, which are not only ecto-parasitic, but penetrate even into the abdominal cavity of other Fishes, such as the Sturgeon. A Siluroid fish has been found to inhabit the branchial cavity of another fish (Platystomus) of the same family; and the invertebrate Asterias discoidea is infested by Oxybeles lumbricoides, and certain Holothurians by a Fierasfer. These latter cases, however, are considered by Van Beneden to be instances of 'commensalism' rather than of parasitism strictly so called. See Bulletins de l'Académie Royale de Belgique, $2^{\text {mø }}$ série, tom. xxviii., no. I 2 , pp. 624-626, 642, 643, ibique citata.

\section{Class, Mammalia.}

Air-breathing, warm-blooded Vertebrata, in which the epidermis developes hairs over a greater or lesser extent of the surface of the 
body, either persistently or during foetal life only, as in most of the true Cetacea; which are always viviparous, and always nourish their young for longer or shorter periods after birth with the secretion of lacteal glands. The anterior pair of limbs is never wanting; a perfect diaphragm always exists between the thoracic and abdominal cavities; the aorta is single, and bends over the left bronchus; the red-blood corpuscles are 'apyrenaematous,' or ' nonnucleated.' In all Mammalia, with the exception of the Cetacea and Sirenia, the abdominal vertebrae are separated into a lumbar and a sacral division, by the abutment of the iliac bones upon the vertebrae immediately anterior to the caudal series. In the Marsupial Perameles, however, there may be but one 'sacral' vertebra, whilst in the Edentata, where the ischium as well as the ilium abuts upon the vertebral column, there may be as many as nine. The cervical vertebrae are, with a few exceptions, neither more nor less than seven in number. Of these, the two first articulate with each other and with the two occipital condyles by synovial joints, whilst all the other vertebrae have their centra articulated together by fibro-cartilaginous dises, in the axis of which remnants of the chorda dorsalis are to be found. The number of dorsal vertebrae is very frequently thirteen, but it may vary from ten to twenty-four; that of the lumbar is very frequently six or seven, but may vary from two to nine; that of the sacral, as already said, varies from one to nine; whilst that of the caudal varies from four, as in certain Simiadae, up to forty-six, as in Manis Macrura. As in Sauropsida, the centres of the vertebrae are always well ossified, but they differ from those of the coldblooded representatives of that division of the Vertebrate Subkingdom, in being always anchylosed with the neural arch in adult life; and from those of both Birds and Reptiles in being during the period of growth provided with epiphyses. There are always two occipital condyles, each of which is constituted by factors from both basi- and ex-oceipital. The lower jaw articulates directly with the squamosal element of the cranial walls, the homologue of the os quadratum of Sauropsida having been withdrawn into the cavity of the middle ear, where it is known as the malleus. The lower jaw itself consists always in adult life of a single bone on each side, which in some Mammals does, and in others does not, anchylose with its fellow of the opposite side at the mental 
symphysis. It does not however appear to be always developed, as usually stated, from a single centre of ossification in the membrane covering the distal portion of the cartilage (Meckel's) of the first branchial arch. In the human subject it has been observed to be developed from as many as four centres of ossification, of which one probably corresponds to the dentary bone of the Crocodile, and the other to the splenial. In the terminal segment of the limbs, the digits never consist of more than three phalanges each, except in the true Cetacea, which order also forms an exception to the rule that the terminal digital phalanges are always in Mammals protected by a nail, a claw, or a hoof.

In addition to, and together with the hairs so characteristic of this class, and found even in some adult Cetacea upon the lips, we find the integument developing structures as various as the vibrissae on the snout of Camivora; the scales on the body and limbs of the Pangolins, and on the tail of certain Rodents, and of Ptilocercus amongst Insectivora; the spines on many members of the two last-mentioned orders; the horns as opposed to the horn-cores of the hollow-horned Ruminants; and the horns of the Rhinoceros. The scutes of the Armadillo are exclusively dermal productions. Glands of various kinds are found on very various parts of the body. Some of them are known as sebaceous, sudoriparous, lacteal and lacrymal, according to the character of their secretion; whilst others, which are usually moditications of the sebaceous type, are, according to the locality in which they are situated, known as anal, inguinal, interungular, and preputial. In all Mammalia, with the exception of the Hare, Lepus timidus, a layer of adipose tissue, the panniculus adiposus, sometimes of great thickness, is interposed between the cutis verc and the subjacent muscles or bones. The teeth, which are developments of the mucous membrane continuous with the external integument, are normally limited to the lower jaw below, and to the pre-maxillary and maxillary bones above. They may be absent altogether or replaced by horny plates, as in the Ornithorlynnchus. Only a certain number of the teeth, the so-called 'milk teeth,' are ever replaced in Mammalia after being shed; and in many Mammals no such replacement has ever been observed. In the Marsupials, none of which are ever edentulous, there is only a single 'dent de remplacement ;' the one, namely, which corresponds to the second human premolar. In 
some Mammals, such as the true Cetacea, which have only a single set of teeth, the pulp atrophies or undergoes calcification; and a term is thus necessarily put to the duration of the teeth, and of the life of the animal. In others, which are similarly 'Monophydont,' as the Sloths (Bradypoda), amongst the Bruta, the pulp is persistent; as it is also in the 'Diphyodont' Armadillos belonging to the same order, and in the incisors of all, in the molars of some Rodents, and in the permanent incisors, or 'tusks' of the Elephant. It is only in the Mammalian class that teeth have been observed to be implanted by more than a single fang, and the dentinal tissue is ordinarily free from anchylosis with the alveolus in which the tooth is lodged. The digestive tract is always rich in interstitially-placed glands, and of the larger glands appended to it by ducts, none are ever wanting except the oral salivary glands in the true Cetacea, and one pair of these glands, the parotid, in the Monotrematous Echidna. There is much variety from order to order, as to the simplicity and complexity of the stomach, and as to the presence or absence of intestinal coeca. It is only in the Ominthodelphia, thence called 'Monotremata,' that the generative and renal ducts are confluent for any great distance with the terminal segment of the intestine, so as to form a true 'cloaca;' though in Marsupialia, as also in certain Rodentia, in Centetes amongst the Insectivora, and in certain Bruta, a common sphincter muscle may surround the distal orifices both of urogenital and of the rectal tubes.

The red-blood corpuscles of Mammalia differ from those of all other Vertebrata not only in being 'apyrenaematous,' but also in being, with the exception of those of the Camelidae, circular. Their heart is always quadrilocular; their aorta always single, and bent over the left bronchus. The valves, which in other Vertebrata guard the entrance of the great veins into the right auricle, are either absent as usual, or rudimentary as in Bradypus, Elephas, Simiadae. Correlated with this structural arrangement is the fact that in Mammals the ventricles are the first, the auricles the second in point of time to contract in each systole. In many Rodentia and Insectivore, and in all Marsupialia and Montremata, there are two superior venae cavae. The lymphatic and lacteal glands are always largely developed, as are also the tonsillar and Peyerian aggregations of adenoid substance in the walls of the digestive tube. The entrance to the larynx is always protected 
by an epiglottis, and with the exception of Bradypus tridactylus, the trachea always takes a direct antero-posterior course from the larynx to its bifurcation. The lungs are always freely suspended in pleural cavities, and they are never prolonged into abdominal or other air-sacs. A perfect diaphragm is always present. Portions of this and of other muscles are always interposed between the kidneys and the lower dorsal and upper lumbar vertebrae in the region of which they lie; and their external surfaces are, consequently, not conformed, as in other Vertebrata, so as to fit into the sinuosities of the osseous structures in their neighbourhood. The kidneys are provided with a fibrous envelope, surrounded by a panniculus adiposus, the venous system of which is in anastomotic connection with that of the gland; but this connection never attains to the functional importance of a 'renal-portal' system. Similar anastomoses, possessed similarly of merely morphological importance, exist between the renal arteries, which bring to the gland the blood upon which its secretion as well as its nutrition is entirely dependent, and certain branches of the lumbar arteries. The substance of the gland is always differentiated into an external cortical secretory, and an internal medullary excretory stratum. A urogenital canal, which is only occasionally found or rudimentarily represented in other Vertebrata, is always found in Mammals, except in the females of some Rodentia or Insectivora, where the clitoris forms a,closed tube for the urethra.

The cerebral hemispheres, as distinct from the corpora striata and optic thalami which they overlie, attain a greater development than in any other class of Vertebrata. Their external surfaces are in many small, and in most large representatives of the Class, convoluted, so as to allow of the ready access of blood to the substance of the hemispheres, at the same time that the amount of the grey matter is greatly increased. The cerebral hemispheres are always connected by a more or less extensive 'corpus callosum,' and the mesencephalon is always represented by more or less sharply separated 'corpora quadrigemina.' In a few of the true Cetacea the olfactory bulbs are absent, and in certain burrowing Rodentia and Insectivora, the eyes may be absent or rudimentary, but in all other Mammals the organs of special sense are all present. Special organs of tactile sensibility are very ordinarily developed upon the snout, as in the Carnivora and Solidungula. 
The malleus of Mammalia, though limited to auditory functions, and placed within the cavity of the middle ear, corresponds to the os quadratum, which carries the lower jaw of Sauropsida, being developed out of the proximal elements of the first visceral arch, whilst the stapes and incus hold a similar relation to the second, and represent the columella of those animals and its supra-stapedial appendage.

All Mammalia have a urogenital canal independent for a greater or less length, or altogether, of the termination of the intestine; all male Mammalia have an intromittent organ; in all female Mammalia during the period of gestation, the blood-vessels of the uterus come into intimate relation with those of the foetus, and provide thus for its nutrition aud respiration during a longer or a shorter portion of its developmental life.

The reproductive system has furnished a basis for the division of the Class Mammalia into the three Sub-classes, Ornithodelphia, Didelphia, and Monodelphia.

\section{Sub-class, Ornithodelphia.}

The Sub-class, Ornithodelphia, is represented by the single order Monotremata, and the two genera, Ornithorhynchus and Echidna. In these animals, as the names Monotremata and Ornithodelphia imply, the urogenital and the rectal eanals both open by a common cloacal outlet, and the oviduco-uterine ducts remain distinct up to their points of entry into the urogenital canal. In the males, however, there is a perforated penis, which, though not continuous at its base with the urogenital canal, ean be brought into apposition temporarily with the orifices of the vasa deferentia, so as to form a functionally distinct sexual canal. The mammary glands have no nipples; in Echidna, the lacteal ducts open into a pouch-like involution of the integument; in the Ornithorhynclus they open upon a plane surface; in both, the embryoes are extruded from the uterine cavities whilst in an exceedingly immature state. In the Monotremata, as in Sauropsida, the coracoid reaches the sternum; they possess an interclavicle; and the so-called 'marsupial' bones, which are ossifications of cartilages segmented off from the pubic elements of the pelvis, and which give insertion to a portion of the tendon of the external oblique muscle. The Echicha is edentulous; the Ornithorlynchus has horny plates in the place of teeth. 


\section{Sub-Class, Didelphia.}

The Didelphia are represented by the single order Marsupialia, which resembles the Monotremata in the possession of 'marsupial' bones, though in few other points besides those common to all Mammalia. The urogenital canal is much more distinct from the rectum than in the Monotremata, but, as is the case also in certain Monodelphia, the external orifices of both canals are embraced by a common sphincter muscle. The testes are never retained in the abdomen, as in the Omithodelphia and in some Monodelphia, but are suspended in a scrotum placed anteriorly to the penis. The young are extruded from the uteri in an imperfect condition of development, and whilst going through the further stages necessary for enabling them to provide for themselves, they are attached to a long mammary nipple, which is ordinarily contained within a marsupial pouch. The coracoid never reaches the sternum; true teeth are never absent; the angle of the lower jaw is almost always inflected.

\section{SUB-CLASS, IMonodelphiq.}

The Monodelphia, which are also known as 'Placentalia,' differ from the two other sub-classes in the following points: with a few exceptions, such as the Hare amongst the Rodents, and Orycteropus, amongst the Bruta, their female generative canals form an azygos corpus uteri of greater or less length, which opens into an azygos vagina; which, again, with the exception of Bradypus, opens always by a single orifice into a urogenital canal. In all Monodelphia the vessels of the allantois come into relation with the vessels of the uterus, and the two sets of vessels form a placenta, which has not been observed in the other two sub-classes. Accordingly as portions of the maternal structures come away with the foetal elements of the placenta at birth or not, the Monodelphia are divided into Deciduata and Non-deciduata, the former of these groups corresponding to the Unguiculata, with the exclusion of Manis and probably also of Rhinoceros; and the latter to the Ungulata and Mutica of Linnaeus. The scrotum is never prepenial as in Marsupials; the testes are, however, sometimes retained within the abdomen as in Monotremata: and in Centetes, in which this is the case, a tendency to develope an inflection at the angle 
of the lorver jaw is observable, so that in the organism of a single Monodelphous animal are combined peculiarities of both the other Sub-classes. Marsupial bones are never present in Monodelplice.

\section{Class, Aves.}

Air-breathing warm-blooded Vertebrata, which have epidermal appendages of the structure of feathers, and which are always oviparous. Their anterior pair of limbs have the shape of wings, which are formed thus : the two digits of the ulnar side are aborted together with their metacarpals; the remaining three metacarpals, and the os magnum of the carpus, are fused into a single bone, upon which three digits are carried, and which abuts proximally upon two free carpal bones. Of these digits the middle one, corresponding to the index finger, and the carpo-metacarpal bone, carry the 'primary' quill feathers, whilst the ulna carries the 'secondaries,' and the humerus the 'scapularies' $s$. 'parapterum' of pterylography. Most of the peculiarities which distinguish the Avian from the Reptilian organism, are to be correlated more or less directly with their power of flight. The necessity for the possession of the power of exerting great muscular force entails the possession of warm blood; and the immobility of the dorsal, the pliability of the cervical, and the great extent of the sacral vertebral regions, are nearly as directly connected with the function of flight as the great development of the sternum, whence the muscles of flight take origin, or the conformation of the limbs upon which they act. The warm-bloodedness or 'homoeothermal' character of Birds, might appear to connect them more closely with Mammals than with Reptiles; but it will be found to be correlated with but few distinctively Mammalian characters, beyond those which may be expressed by saying that in both these homoeothermal classes, the venous and arterial systems are prevented from directly intermingling their blood by the existence of a quadrilocular heart, and of a single systemic aorta; whilst the brain holds a more favourable relation quantitatively to the body and to the spinal cord; and the spinal cord again is, with perhaps a few exceptions, larger relatively to the body than is observed to be the case in coldblooded Vertebrata of any Class. On the other hand, the totality of the Avian organization, with the exception of the epidermal 
system, as observed in existing Birds, and the fossil remains of such transitional forms as are preserved in Archaeopteryx on the one side, and the Dinosauric on the other, show that their more essential morphological affinities are distinctly Reptilian. The aberrant integument of Birds, being, as it is, by virtue of its polished surface, an imperfect radiator, and, by virtue of the layers of air it entangles, an exceedingly bad conductor of heat, is a powerful auxiliary in the economization of the heat generated by the rapid rate at which their various functions are carried on. Both Reptiles and Birds are favourably conditioned for the conservation of heat, by the semi-solid character of their excreta; and at particular seasons, as has been observed in the case of the incubation of the Python, Reptiles do appear to obtain the power of raising their temperature considerably above that of the medium in which they live. The skeleton of Birds contrasts with those of Reptiles and Mammals generally, by its greater hardness and lightness, and its greater readiness to form anchyloses. The cervical and dorsal vertebrae have their centra articulated by synovial joints, in which cartilaginous menisci are to be found. The anterior surfaces of these centra have the procoelous appearance when looked at in situ and from in front; but when one of these vertebrae is removed from apposition with the one next in front of it, the anterior surface of its centrum is seen to be saddle-shaped or cylindroidal transversely, whilst the posterior surface, being conformed so as to articulate with an anterior surface of that shape, is, in its turn, convex transversely, but concave from before backwards. On the other hand, the occipital condyle, at least of the more typical Birds, is more perfectly spheroidal as retaining less trace of its trifid composition out of the basi-occipital and the two ex-occipitals than in most Reptiles. The neck vertebrae may vary in number from nine to twenty-four, the dorsal from six to ten, of which the four or five most anteriorly placed are ordinarily anchylosed with each other, except where, as in the Ratitae and some of the Carinatae, as the Penguin, the power of flight is lost. The sacral vertebrae vary in number from nine to twenty, the enormously elongated ilia abutting directly upon them without the interposition of any sacral ribs as in Reptiles, or the separate centres of ossification which represent those ribs in Mammals. There are from eight to ten candal vertebrae, the last of which forms an 'os en 
charrue' for the support of the 'rectrices' feathers. The tro anterior ribs having often no sternal element, the character of 'dorsal' or 'cervical' comes to depend upon the relation these movably articulated appendages hold to the subjacent lung. In the Ratitae, the osseous system of which order shows many Reptilian affinities, the cervical ribs often remain unanchylosed for considerable periods of their adult life. 'Processus Uncinati' are attached by ligament or anchylosed to the dorsal ribs, with the exception of the first and last. The largely developed sternum gives support to the strong coracoids anteriorly, and to the ossified sternal elements of the costal arches laterally, but it is never prolonged outrrards at its posterior angles into costal processes as in Reptiles. The clavicles are occasionally absent, but ordinarily form a furculum by fusion at their anterior extremities, with which, as also with their upper ends, elements segmented off from the coracoids are found to anchylose. The iliac bones extend so far forrwards as to overlap some of the ribs, so that no distinct lumbar region exists. The ischiac and pubic bones are prolonged backwards, so as to be approximately parallel with each other and with the long axis of the body; except in Rhea, the ischia never form any symphysis; nor do the pubic bones, except in Struthio Camelus. The femur moves in the acetabulum in a direction parallel with that of the long axis of the body. The fibula never reaches the ankle joint, which is situated as in Reptiles between the proximal and distal row of the tarsus. In adult Birds, the tibio-tarsus and the tarso-metatarsus are each perfectly anchylosed into a single bone. This is not the case in Reptiles. The external toe is never present in Birds. The ballux is sometimes absent; when present, it is carried upon a metatarsal articulated to the tarso-metatarsus near its distal extremity, and consists of two phalanges. In the Ostrich, both hallux and index are absent, as well as the fifth toe, and the foot is reduced to the didactylous condition, though the tarsometatarsus retains a rudiment of the third distal articular trochlea.

Dental papillae, with eaps of dentine, have been observed in the embryoes of Psittacidae; in adult Birds, the digestive tract is characterized by the absence of teeth, of lips, and of a velum pendulum palati; and by the presence of a horny beak, and of a muscular gizzard placed posteriorly to a glandular proventriculus. With the alssence of comminuting organs anteriorly to the gizzard,

$$
d 2
$$


is correlated the width of the oesophagus, which often expands into a crop. The liver ordinarily consists of two lobes, into the fissure between which the apex of the heart is received. There are always two, and sometimes three bile-ducts in Birds: they open separately into the intestine; and on one of them a gall-bladder is usually developed. A large and compact pancreas, with two or three ducts, is always to be found in a fold of the duodenum. With few exceptions, two coeca are appended to the intestine at the junction of the ileum to the colon; and a third, representing the omphalo-mesenteric duct of embryonic, and of early life subsequently to hatching, is occasionally present at a point higher up in the small intestine. The urinary and genital ducts ordinarily open separately into the cloaca, but there may be a short urogenital cavity distinct from the lower segment of the digestive tube, but opening directly into it. The characters of the beak, tongue, crop, gizzard, and cireum-oral salivary glands, vary much, in correspondence with the nature of the food.

The heart is quadrilocular, and the right auriculo-ventricular valve muscular in all Birds. The fourth aortic arch of the right side, instead of that of the left, as in Mammals, forms the single systemic aorta; the fourth aortic arch of the left side is converted into the subclavian artery instead of forming a second, or left, systemic aorta as in Reptiles, though its homology with this latter vessel is spoken to in many Birds, especially Accipitres, by its retention of a fibrous prolongation onwards to the functional aorta. The aorta and pulmonary artery have each three semilunar valves. The aorta divides after a very short course into three great trunks, by giving off two subequal innominate arteries. In Birds of powerful flight, these trunks are often of larger calibre than the continuation of the aortic trunk itself. There are always two superior venae cavae, which open separately from each other, and from the vena cava inferior, the sinus venosus having disappeared by absorption into the right auricle. The vena cava inferior is formed by the confluence of the efferent renal veins, with which the veins from the lower extremities are, as in Mammals, directly continuous; though, as in Reptiles, the blood which these latter vessels carry can find its way also into the kidney, forming thus a 'renal portal' system, as well as into the liver by anastomosis with factors of the true portal system. 'The trachea in Birds is always of considerable length; it is often 
tortuous, and dilated at intervals. Its cartilaginous supports form usually perfect rings, and are not rarely ossified. In most Birds with the exception of the Ratitae, a lower larynx is developed upon the junction of the trachea with the two bronchi. The bronchi lose their cartilaginous rings when they enter the lungs, where they dilate into membranous canals which subsequently become smaller by giving off branches, and finally end by opening into air saes. The lungs are deeply indented in correspondence with the ribs, but are not otherwise lobed. There are nine air sacs, of which one is placed asymmetrically between the furculum and the trachea, two in the abdomen and pelvis, four in the posterior and lateral parts of the thorax, and one on either side of the azygos interelavicular sac. Processes are prolonged from the anterior and posterior of these sacs into the bones. The bones of the skull are sometimes, as in Mammals, the only pneumatic bones; the vertebrae, humerus and sternum come next in order as to the possession of air cavities; whilst in some Birds all the bones of the body are said to have been observed to be pneumatic. The bones of the fore-arm, on the other hand, of the lower leg, of the manus and of the foot, are often found to retain their medulla, and to be devoid of pneumatic cavities.

The kidneys are divided into three lobes, and have their outlines conformed to the sinuosities of the pelvic bones. There is never any urinary bladder; the ureters open internally to the generative ducts, either directly into a cloaca, or into a urogenital pouch of small antero-posterior extent.

The brain is much larger relatively both to the entire body and to the spinal cord than it is in Reptiles, and the spinal cord again holds a more favourable relation to the entire body than in those cold-blooded creatures. It occupies however a greater relative length in the spinal canal than it does in Mammals, and in this resembles the cord of the other Sauropsida. The cerebellum has only rudimentary lateral lobes; its grey matter however is considerable in quantity, owing to its transverse lamination. It projects forwards so as to come into relation with the prosencephalon, and, as it were, to displace the bigeminal hollow optic or mesencephalic lobes on to either side of its forward prolongation. The cerebral hemispheres are represented by a thin shell of nervous matter, which covers the large corpora striata, and incloses the lateral ventricles. The corpus callosum is alsent; and the fornix 
can only be considered to be rudimentarily represented by a portion of the inner wall of either lateral ventricle. The anterior commissure is not, the posterior is largely developed. The optic thalami are smaller than the optic lobes. Tactile sensibility is limited to the beak. Smell and taste are lowly developed. The cochlea of the ear is a much simpler, the tympanum a much more extensive cavity relatively than in Mammalia. The eyes are never absent, and, though small in the Apteryx, are never rudimentary. The globe of the eye consists of two segments, the anterior one of which is more or less obtusely conical, whilst the posterior is spheroidal; bony plates inlaid in the anterior part of the sclerotica preserve the relative conformation of the two portions. As in many lower Vertebrata, a vascular process is prolonged from the choroid into the interior of the bulb. This structure is known in Birds as the 'pecten,' or, from its shape in Ratitae, as the 'marsupium ;' and in many grallatorial and aquatic Birds it reaches to the lens. It is absent in Apteryx. The vitreous humour is relatively smaller than in Mammals. Except in Orls and aquatic Birds, the lens is flat. The ciliary muscle upon which the bird's power of accommodating the eye so as to obtain clear vision at very rapidly varying distances depends, is, in correspondence with this need, composed of transversely striped muscular fibres. The muscular fibres of the iris are of similar character. A special muscular apparatus and a special (Harderian) gland are developed, in relation with the third eyelid or membrana nictitans.

As in the Sub-kingdom Arthropoda, the sexes differ much externally; and in the case of the Accipitres, the females, as is so commonly observable in that Sub-kingdom, are larger than the males.

The testes are always retained within the abdomen anteriorly to the kidneys; the left is occasionally the larger of the two. The vasa deferentia are often dilated towards their terminations, but in neither sex are there ever any accessory glands, distinct from and appended to the generative canals by ducts, as are the Cowperian, the prostatic glands and the vesiculae seminales of many Mammals. The right ovary is usually atrophied, and when it is persistent, as in some Accipitres, its ova do not come to maturity. In the upper part of the oviduct the albumen, in the lower the calcareous shell of the egg is formed. Many young Birds are, as are also the young 
of Chelonia and Ophitia, provided with a hard knob on their upper mandible, for breaking through their shell when ready for hatching. In some Birds the food-yolk is large, and the young are ordinarily more or less entirely competent to provide for themselves when hatched. Where the yolk is relatively small, the young are incompetent to locomotion when hatched, and require to be brooded upon whilst going through further stages of development. Birds which are possessed, immediately after hatching, of the faculty of self-help have been called 'Autophagi,' in opposition to those which require further maternal care, and are called 'Insessores.'

Existing Birds are divided into two orders, the Ratitae, in which the sternum has no crest and the wings are rudimentary, and the Carinatae, in which the sternum has a crest or keel, ossified from an independent median azygos centre, and which have powerful anterior limbs ordinarily organized for flight, though sometimes not, as in the Penguins. The former order includes only the genera Struthio, Dronaens, Cusuarius, Apteryx, and is distinguished not only by many modifications curtailed by the stunting of their anterior limbs, but also by many morphological points of affinity to the cold-blooded Sauropsida, amongst which the characters of the osseous system are peculiarly striking. The Ratitae have the barbs of their feathers disconnected, have no inferior larynx, and no angle at the junction of coracoid and scapula. A more perfect diaphragm exists in them than in the Carinatae. This latter order comprises all other existing Birds. The fossil Archaeopteryx appears to have differed from existing Birds by possessing a series of caudal vertebrae equalling the body in length, and in having well-developed non-anchylosed metacarpals. A separate order, that of Saururae, has been established for the reception of this transitional form.

\section{Class, Reptilia.}

Air-breathing cold-blooded Vertebrata, with epidermal structures of the character of scales, into which processes of the cutis vera are prolonged, but which are not developed like feathers within saccular involutions of the integument. Accordingly as bony scutes are combined with these scales, and constitute an osseous dermal skeleton or not, existing Reptiles are divided into the 
two groups of Loricata and Squamata, the former containing the two orders, Chelonia and Crocoditina; and the latter the Sauria and the Oplitia. The anterior limbs are sometimes entirely absent, together with the scapular arch; they are never modified so as to form wings like those of Birds; the caudal vertebrae very frequently form a series equal in length to the length of the rest of the body; the jaws are usually armed with teeth, which are constantly reproduced during the life of the animal. There are two systemic aortae, which either fuse (Squamata) or anastomose (Loricata) with each other in front of the dorsal vertebrae; and in no Reptiles, except Crocodilina, is there a complete separation of the ventricular part of the heart into two cavities. And in Crocorlitina, the two systemic aortae arising from the two distinct ventricles, communicate with each other at the base of the heart by the foramen Panizale; so that in all Reptiles the venous and the arterial blood come to be more or less freely intermingled without the interposition of capillaries, at, at least, two points of the vascular system. Copulatory organs are always present, except in Hatteria; for the peculiarities of which see Dr. Günther, Phil. Trans. 1 867, p. 595.

The skull is less vaulted and less capacious than in Aves. Traces of the entrance of the two exoceipitals into the formation of the occipital condyle are usually persistent. The os quadratum is sometimes movably, sometimes immovably (Loricata and Hatteria) articulated to the cranial walls, a considerable part of the anterolateral elements of which remain in the condition of fibro-cartilage, except in Ophidic.

Amphicoelian vertebrae are found in the existing Geckotidae and Hatteria, where they are connected, as in Mammals, by intercentral eartilages, in the axis of which are persistent masses of substance representing the chorda dorsalis. Vertebrae of similar shape are found in the fossil Enatiosauria and Teleosauria. The Vertebrae are ordinarily procoelian; and, with the exception of Crocodilina, in which a considerable quantity of intervertebral substance remains between the centra of the vertebrae, they are connected with each other simply by synovial joints. In the Chelonia, the vertebral centra vary very much in shape, especially in the neck and tail, where they may either be amphicoelous, biconvex, or procoelous. The neuro-central sutures disappear 
in Squamata, but are persistent in Loricata. The number of the vertebrae may amount to several hundreds in the Oplitilia, and in the Saurian Amplisbaenoidea may be as many as one hundred and thirty. Though ordinarily the number is much smaller in Reptiles provided with limbs, even in the non-serpentiform Monitor it may be no less than one hundred and forty. There are two cervical vertebrae in Oplitia; in Sawria their number may amount to ten; in the Loricata it is usually eight. The dorsal vertebrae are movably articulated with each other, except in Chelonia; the sacral vertebrae are seldom more than two in existing Reptiles, though this number was often much exceeded in extinct forms of the Class. Lumbar vertebrae do not exist in Oplictia; they are present in Chelonia, and in number from four to five, whilst in Sauria they are reduced to two, or even one.

The shoulder girdle is entirely absent only in Ophictia, but present in a rudimentary condition in the serpentiform Sawria. The clavicle is wanting in Loricata, Chamaeleonoidea, and Sanropterygia. The sternum is wanting in Oplictia, Chelonia, and in. some of the serpentiform Sauria. The ribs in the Chelonia form by fusion with exoskeletal ossifications the expanded lateral or 'costal' plates of the carapace. The sternum is absent, and the ventral plates, constituting the 'plastron,' are exclusively dermal ossifications. In the Crocodilina, the ribs of the anterior thoracie vertebrae, and, with the exception of those belonging to the atlas, of the cervical also, articulate with their respective vertebrae by two separate processes, the 'tuberculum,' and the 'capitulum.' The ribs of the Sauria have only a single articular facet, which, however, may show a tendency to bifurcate. The ribs carry processus uncinati in the Crocodiles and in Hatteria. Many Reptiles have free abdominal ribs, which may be either true endoskeletal elements, or 'parostotic' ossifications of intermuscular fibrous septa, or, as in Hatteria, of the subcutaneous fibrous mesh. In Ophitilia, the posterior pair of limbs is sometimes represented by a pair of small bones placed anteriorly to the anus; and in the serpentiform Sauria the pelvic girdle and its appendages are represented merely by a single iliac bone, attached on either side to a single 'sacral' vertebra. But in all other Reptiles the three pelvic bones are present, forming pubic and ischiac arches by abutment upon the ossa ilii, which do not extend forwards anteriorly to the acetabulum. 
The number of the phalanges increases in the digits of both extremities from the innermost digit outwards, and reaches its maximum in the fourth digit. In the foot of the Crocodilina this digit has no claw on its terminal phalanx, and the fifth digit is altogether lost.

Teeth are always present; except in Chelonic, where a horny sheath covers the jaws, as in the bills of Birds. The teeth are limited in Crocodilina to the homologues of the bones which carry teeth in Mammalia; but in many Sauria they are carried upon the pterygoid also; and in Ophiclia upon both palatine and pterygoid bones, in addition to the mandibular, maxillary, and premaxillary bones. Teeth are provided with sockets in Crocoditina, but in no other existing Reptiles; they are reproduced, as shed, during the whole period of the life of these animals. The tongue may be either spatula-shaped and immobile, as in Chelonia and Crocoditina, and some Sauria, or bifid, elongated, and protrusible, as in other Reptiles. The wide oesophagus, and the muscular stomach, are ordinarily not unlike those of Birds; and this resemblance is made more striking in the Crocoditina, which, in addition to the muscular gizzard, have a special portio pylorica, such as is developed in many grallatorial and natatorial Birds. But the digestive tract of Reptiles, which are with few exceptions of carnivorous habits, exhibits, in correlation with this uniformity of diet, fewer variations of arrangement than that of Birds. Labial and lingual salivary glands are occasionally present. Of the former of these, the poison-gland of Ophiclia is a modification. The liver and pancreas have, as in Birds, two or more excretory ducts; the latter of the two glands is ordinarily perforated by the hepato-enteric ducts; a gall-bladder is always present, but is sometimes developed upon the biliary duct at a distance from the liver. This gland is unilobed in Squamata, bilobed in Loricata.

In the Squamate Reptiles and Chelonia, in which the heart has not four distinct and separate cavities, the venous blood returned from the system to the larger right auricle, is kept more or less completely apart from the arterial, returned from the lungs or lung to the left by the non-isochronism of the action of the anterior and posterior parts of the ventricular cavity. The anterior or inferior portion of the ventricular cavity is filled from the right auricle, and empties itself into the pulmonary artery, and partly into the 
left aorta, before the posterior part of the ventricular cavity, into which the blood from the left auricle is discharged, commences to contract. When this part of the ventricular mass begins to contract upon its arterialized contents, access to the pulmonary artery has been cut off by the closing up of the muscular demi-canal leading to that outlet; and the arterialized blood is consequently thrown into the two systemic aortae. Of these, the one which bends over the left bronchus, or, in Oplidia, to the left side of the body, and which is consequently known ordinarily as the left aorta, never gives any branches to the anterior parts of the body; but either as in Sauria and Oplidia, simply joins the right aorta without giving off any branches; or, as in Loricata, distributes itself to the chylo-poietic viscera, and communicates with the right aorta simply by a branch of anastomosis. In the Crocodilina this vessel arises from the right auricle, together with the pulmonary artery, and consequently never carries any arterialized blood. Its communication, by the foramen Panizzae, with the right aorta, which supplies the anterior parts of the body, may be held to foreshadow the conversion which the fourth left aortic arch undergoes into a left subclavian artery in Aves. The close proximity of the commencement of the left aorta to that of the pulmonary artery, enables it in all Reptiles alike to relieve the pulmonary circulation, when respiration may be put into temporary abeyance. The arterial outlets of Reptiles have only two semilunar-valves. In all Reptiles, as in all Birds, there are two superior as well as one inferior vena cava; but in Reptiles these three vessels open into a pulsatile venous sinus, and have their contents poured through it by an orifice guarded with eyelid-like valves into the ventricular cavity. In all Reptiles there is a 'renal portal' circulation, by which the venous blood returning from parts placed posteriorly to the kidneys finds its way into these organs, at the same time that by means of anastomoses with factors of the true portal system, it may be returned to the heart by way of the hepatic system. The suprarenal bodies are; like the renal, possessed of a system of venous inferent vessels. The lymphatic vessels, which often take the shape of loose sheaths surrounding the large arteries, communicate with the veins both anteriorly in the brachiocephalic, and posteriorly in the eaudal regions. Upon their junction with the veins of this latter region, contractile saes, the so-called 'lymphatic hearts,' are 
developed. Glands which in Birds are only scantily developed upon the cervical lymphatics, are not represented as distinct from lymphatic plexuses, except by a mesenteric gland in the Crocortilina.

The trachea of the Loricata has a more perfect larynx than that of the Squamata, and in some cases it describes a couple of convolutions before entering the lungs. These organs differ in the Loricata from those of other Reptiles in having, in correlation with their non-transpirable integument, a much greater development of internal parenchyma; and in not projecting freely into the general cavity of the body, dissepimental processes of peritoneal membrane separating them from it and foreshadowing thus, as also by their possession of intrinsic muscular fibres, the diaphragm of warmblooded animals. In the Squamata the lungs may be prolonged in air-sacs, with little or no reticulation of vessels developed upon them, and these prolongations may be numerous as in Chanceleonoidea, or simple as in Ophictia. In some of the lower Lizards, again, as Hatteria, the lungs may be nearly as simple as those of the Amphibia. The kidneys are situated posteriorly in the trunk, and, except in the Ophidia, within the pelvic cavity, and close to the cloaca. In the Crocodilina, indications of a separation of the substance of the kidney into a cortical and medullary stratum are not wanting. A urinary bladder is usually present in Sauria and Chelonia, but is absent in Ophidia and Crocodilina. In the Chelonia, a sinus urogenitalis is present. The kidneys are not conformed to the sinuosities of the bony structures as in Birds. The cerebral hemispheres are smaller relatively to the rest of the encephalon, and to the spinal chord, than in Aves. The cerebral hemispheres, corpora bigemina, and cerebellum, are larger in the Loricata than in the Squamata. A tympanic cavity is present except in Ophidia, Amphistaenoidea, and Hatteria. This latter animal has the commencement of a spiral turn indicated in its cochlea, which in other Reptiles is, as in Birds, merely a flaskshaped cavity; but it differs both from Birds and from other Reptiles in the absence of any intra-ocular structure corresponding' with the avian 'pecten,' or the 'processus falciformis' of other Reptiles.

Copulatory organs of two distinct types exist in the Loricata and Squamata respectively; those of the former division being 
developments of the anterior wall of the cloaca, whilst those of the latter consist of two protrusible hollow conical bodies, which open into that cavity from behind. In the Chelonia, two peritoneal canals are prolonged into the penis, in the distal extremity of which they terminate blindly; two canals, probably homologous with them, and also with the similarly situated pores of the Selachian and Ganoid Fishes, exist in the Crocodilina, but open at the base of the intromittent organ. The testes and ovaries are bilaterally symmetrical, except in the Oplidia, where the right gland is placed anteriorly to the left, and in the females is the larger of the two. The ova often undergo development whilst in the oviducal canals, but the young are not set free from the foetal envelopes before extrusion from the maternal organism. For liberating themselves from these envelopes, the young of the really ovo-viviparous Viper, as also of many other Reptiles, are provided with a temporary premaxillary tooth. All Loricata are oviparous in the strict sense; and amongst the Squamata, nearly allied forms may vary as to being ovo-viviparous or oviparous.

Some lowly organized Lizards, such as Hatteria, possess the power of reproducing lost portions of the tail.

The sub-division Loricata, under which are comprised the two orders of Crocodilina and Chelonia, differs from the sub-division Squamata, comprehending the two orders Sauria and Ophlictia, in the following particulars besides those already enumerated. Their' anal cleft is longitudinal, there is usually some calcareous deposit in the shells of their eggs, their ribs are double-headed in the anterior regions of the body. Setting aside a few points which may be correlated with their aquatic and less active habits, the Loricata may be considered as more highly specialized, and possessed of nearer affinities to the higher Vertebrata than the other subdivision of this class.

\section{Class, Amphibia.}

Cold-blooded Vertebrata, which for longer or shorter periods, or throughout the whole of their lives, are provided with gills for aquatic, in addition to lungs for aerial respiration, and which even when the gills are permanently retained go through some stages of metamorphosis after being set free from the eggr. Amongst these 
stages of metamorphosis, the development of limbs never exceeding a pentadactyle division in their terminal segment, and possessing the same segmentation as that seen in the higher Vertebrata, is to be reckoned as an obvious external characteristic, which, together with the absence of scales, differentiates them, with very few exceptions, from Pisces. They never have median fin-rays supported by dermal spines; and, in the absence of an ossified basi-occipital, they always have two condyles formed by the exoccipitals, for articulation with the atlas. The heart has always two auricles, perfectly separated ordinarily, and communicating with a single ventricular cavity.

Their integumentary system differs from that of Fishes in not having either dermal ossifications or dermal scales developed in the region of the trunk; Ceratophrys, however, and Brachycephalus amongst existing Amphibia, form exceptions to this rule, having dermal ossifications developed in their dorsal region; and the Caeciliae develope dermal scales. In the Salamandra unguiculata again, and in the Dactylethra capensis, a development of nails has been observed, contrary to the rule that in the branchiate Vertebrata there is no epidermal skeleton. The cutaneous system of Amphibia (Triton) has been observed to possess, during their larval life, rudimentary structures, resembling the sensory organs developed in Fish, in connection with the 'lateral line.' In adult Amphibia, the cutaneous glandular system often attains a great development as in the 'parotoids' and other glands of many Anura.

The suspensorium is immovably articulated to the skull, and is continuous with the pterygo-palatine elements of the maxillary apparatus anteriorly, whilst externally it has applied to it a membrane bone, homologous probably with the praeoperculum of Teleostean Fishes. No Amphibian, however, ever possesses in the eutaneous opercular flap which it developes, any representatives of the opereulum, sub-operculum, inter-operculum, or branchiostegal bones of Fish. The maxillary and praemaxillary bones are never alsent, and are ordinarily dentigerons. The vertebrae are very numerous, and amphicoelian in the lower Amphibia; they are few, and show, ordinarily, the procoelian, though, sometimes, the opisthococlian arrangement of the articular ends of their centra in the higher orders. The neurocentral suture is usually absent. Except in the serpentiform apodal Caecilice, the ribs are rudi- 


\section{Characteristics of the Vertebrata.}

mentary in this class. Though there is never any prolongation of costal structures to the medio-ventral line, there is a true sternum developed in relation with the coracoids in most Amphibia except Caeciliae and Protens. The ilium never abuts upon more than a single vertebra, but the ilium of one side has been observed to abut upon one, whilst the ilium of the other abutted upon another vertebra. No 'parostotic' bones are ever developed in relation with either limb-girdle.

In the highest order of Amphibia, the Amura, the tongue is attached to the front of the mouth and is protrusible; with the exception of Pipa and Daclylethra, where the organ is altogether absent. It is not protrusible in other Amphibia. Amphibia are sometimes edentulous; but usually more or fewer of the bones forming the walls of the mouth, and amongst these, the vomerine, pterygoid, and sphenoid as well as the lower jaw, the maxillary and the praemaxillary bones, are dentigerous. In Proteus, the digestive canal takes a direct antero-posterior course, without any specialization of the stomach as a segment of larger calibre than the intestine; in other Amplibia a small and a large intestine are ordinarily differentiated as well as a stomach. The small intestine of the larvae of the Amura, which, during that period, feed on vegetable food, is of great length and disposed in numerous coils. At the conclusion of their metamorphoses, the digestive tract has assumed a comparatively simple character, though the calibre, direction, mucous and muscular coats of the stomach, small intestine, and colon, severally, are most characteristically developed. A bilobed liver and a compact pancreas are always present, but oral salivary glands are represented only by small glandules impacted in the mucous membrane of the mouth.

The heart consists of a sinus venosus, a right and left auricle, a single ventricle, and an arterial bulb. Within this latter portion of the organ, a longitudinal lamellar ridge is developed, which is attached along the dorsal line of the bulb and projects freely into its interior; being connected at either end with a semilunar valve, and describing a curve like that of an italie $s$, in the interval between those points. This imperfect dissepiment may be held to foreshadow the differentiation of the pulmonary and systemic arterial trunks which we find in Reptiles; whilst physiologically, by its relation to the orifices of the branches passing to the anterior 
and to the posterior parts of the body respectively and to the lungs, it provides for the more or less perfect separation of the streams of arterial and venous blood received from the two auricles. All Amphibia possess a renal-portal system, the factors of which anastomose freely with those of the true portal system. This latter system always receives, by the intermediation of the epigastric veins, an important factor from the allantoid bladder; by which connection the connection of the umbilical and placental veins, as seen in Mammals, is very obviously foreshadowed. The transpirable and glandular character of the skin would appear to confer an aerating function upon the vascular ramifications which it contains in great abundance. The lymphatic vessels are greatly developed in the subcutaneous spaces; and lymphatic hearts are present in the Anura, both upon the anterior and upon the posterior junctions of this system to the blood-vascular. In the Urodela, as in Reptiles, the posterior hearts only exist. In the higher Amphibia, two sets of gills are developed. One of these is the external set which corresponds to the permanent gills of the Perennibranchiate Amphibia, and to the deciduous external gill filaments of the Plagiostomous Fishes, which latter it resembles in being shed early. The other is the internal set which are developed subsequently to, and retained in the Urodela and Anura longer than the ciliated external set. In certain Amphibia (Menopoma, Amphiuma, CryptoUranchus, thence called Derotremata), a fissure remains in the pharyngeal walls after the shedding of the branchiae. This event does not always take place at the same date in the life of the larva.

Cartilages representing a larynx are developed round the inlet from the pharynx into the air passages. There is a trachea of considerable length in Menopoma, Amphinma, and the Caeciliae; and there are bronchi of considerable length in Pipa and Dactylethra; but ordinarily, these tubes are only rudimentarily represented in Amphibia.

The Amphibia appear to have no secondary kidney developed; and the products of the urinary and sexual glands are always discharged into a cloaca by a single orifice, that of the duct of the Wolffian body, on either side. In Proteus, the transversely running ducts of the primary kidney remain distinct from each other, up to their junctions with the antero-posteriorly running duct of the primary kidney, the so-called 'Müller's duct.' In other Amphibia, 
the ducts of the Wolffian body form by fusion with each other a secondary duct, which opens into the primitive duct of Müller at its lower end, leaving the upper portion of that duct to serve exclusively as a generative canal.

The cerebral hemispheres always contain a lateral ventricle, which is prolonged into the interior of the sessile olfactory lobes. The optic lobes are smaller relatively than in Fish, in correlation with the smaller eyes; the optic thalami are always differentiated from them, and from the corpora striata in front. The membranes of the brain and spinal cord have an abundance of pigment cells in their visceral laminae, and upon the exterior of these membranes, and especially upon their prolongations upon the spinal nerves, deposits of crystalline carbonate of calcium are commonly observable. As in many Fishes, the portio dura often fails to be entirely differentiated from the fifth pair of nerves; as in Lepidosiren, the glossopharyngeal is represented by branches of the vagus, and the hypoglossus by the first spinal nerve. The eye is small in comparison with that of Fish, but as in that Class the lens is spheroidal, and the cornea, except in the Land Salamander, flat. There is no tympanic cavity except in the Amura, and no cochlea except in a rudimentary condition in the same order. In the aglossal Anura (Pipa, Dactylet/lia), there is a single median pharyngeal orifice to the two Eustachian tubes. The two nasal cavities open into the mouth by a canal passing between the bones of the roof of the mouth in Anura, but between those bones and the lips in Perennibranchiata.

Rudiments of an ovary have been observed to coexist with the testes in the male Bufo variabilis and cinerens. The sexes are very frequently distinguishable by external differences of colour, size, and conformation, but there are no external copulatory organs in this Class. The ova and spermatozoa come into relation with each other externally to the maternal organism, but by means of congress between the two sexes in the Anura; they come into relation with each either externally to, or within the maternal organism in the Urodela, and probably also in the Perennibranclicata, but without, at least in the aquatic species, any sexual congress. The Land Salamanders appear to be, under certain eircumstances, such as those of the Alpine species living at points of great elevation in the mountains, ovo-viviparous or viviparous, 
the larvae having in some cases shed their external branchiae previously to birth. The ova are small, the yolk undergoes nearly complete segmentation. With a few exceptions, the Amphibia are oviparous. In every case, except possibly that of the Caecilia compressicanda, the embryos very shortly after hatehing develope branchiae, or, as in the case of Notodelphys, structures equivalent to them.

Existing Amphibia are divisible into three orders. In the most highly organized of these, the swimming tail is discarded in the course of metamorphosis as well as the gills, and they are thence called Anura; in the second order, thence called 'Urodela' the tail is retained, whilst the gills are, in the sub-orders, Salamandrina and Derotremata, deciduous; and in the Perennibranchiata, retained permanently. In these two orders limbs are developed, at least on the pectoral arch; but a third order, that of the Gymnopliona, represented by the single family, Caeciliae, is constituted by Amphibia in which, though the gills are deciduous, no limbs are developed, and the body remains serpentiform.

In development, the body cavity is not formed apart from and around the yolk sac, but the intestine is formed, as in Amphioxus and the Cyclostomi, by a process of invagination, beginning from without at a spot corresponding with the situation of the future anus. The oral opening is not formed when the embryos are first set free from the egg. The Anura and the Caducibranchiate Urodela have two sets of gills, an external set of three pairs, which is soon lost, and in the land Salamanders partly or wholly before the end of intra-uterine life; and an internal set. After the disappearance of the external set an opercular fold, in which however in no Amphibia are bones ever developed, forms over the internal gills, and within the branchial cavity thus produced the anterior extremities first bud forth. When in the course of metamorphosis the gills disappear, the continuity of the circulation is maintained, or, in other words, the primitive continuity of the proximal or cardiac with the distal or dorsal elements of the aortic arches is re-established, by the expansion in calibre of a branch of anastomosis, which, whilst the branchiae were functionally active, connected the efferent directly with the afferent branchial trunks, but was itself at that time functionally insignificant. The opercular structures close up the visceral fissures, except in the Dero- 
tremata, and more or fewer of the cartilaginous branchial arches disappear after the disappearance of the branchiae they carried.

The Alpine Triton, one of the Caducibranchiate Amphibia, has been observed to attain sexual maturity as indicated not only by external characteristics, but by the maturation of ova and spermatozoa, at a time when the branchiae were still in functional activity, and when the characters of the bones in the roof of the mouth, and the presence of a continuous non-constricted cylindriform chorda dorsalis, showed the animal to be really in a larval state. The Axolotl (Siredon pisciformis) has long been known to be competent to sexual functions, whilst organs, regarded as provisional in other Amphibia, were still persistent; and it has consequently been classed with the Perennibranchiata until recently, when it was discovered that its gills are really deciduous, though at varying periods in the life of the animal. Similar instances of larval Ichthyoids maturing sexual products are furnished to us by the immature Lamprey, and the young male Salmon, known as the 'parr.' Some Amphibia possess a great power of repairing injuries, and of reproducing destroyed or amputated organs. It has been stated, however, that it is necessary for such reproduction that the basal or some other portion of the mutilated organ or limb should be left in situ; and it is not certain that the Urodela with welldeveloped lungs, such as Salamandra terrestris, and the Anura generally, possess this power in their adult state, at least to the same extent as they do when larvae, or to the same extent as other Amphibia in which the organs for aerial respiration are less highly evolved.

The Amphibia are placed together with the class Pisces in a single group, the Ichthyopsida, s. Anamniota. It is with the more generalized forms of that class, viz., the Ganoidei and the Dipnoi, rather than with those which, as the Teleostei, combine in this organization the largest number of specially piscine characteristics, that the Amphibia are allied. The Dipnoi indeed have been ranked as a separate order of Amphibia, under the title 'Ichthyobatrachia,' though, if we have regard to the entirety of their organism, we are compelled to regard them as true Fish. The Elasmobranchii resemble certain of the Amphibia in developing external gills in embryonic life, and they were spoken of by Linnacus as Amphitia nantia. The absence, however, in them of any save an occasional 
and rudimentary homologue of the pulmonary organs of the Amphibia, appears to put this order of Fishes into a position much farther removed from the higher Vertebrata with which they were thus classed, than that which the Dipnoi, and even the Ganoidei occupy.

\section{Cliss, Pisces.}

Branchiate Vertebratae, with motor organs in the shape of fins, supported by numerous internal rays, and placed along the mediodorsal and medio-ventral lines, or along these lines and bilaterally also. The endo-skeleton of Fishes takes far more various forms than that of any other vertebrate Class; and their exoskeleton is similarly distinguished with reference to all other classes except the Mammalia.

The dermal exoskeleton may take the form of scales, as in the great majority of Fishes; of placoid or spiny dentinal formations, as in Elasmobranchii; of enamelled scales or of bony plates, as in Ganoidei; and in Dipnoi, Ganoidei, and Teleostei, it extends into the sub-cutaneous fibrous mesh, and along intermuscular aponeuroses forming 'splint bones.' There are no scales in Marsipobranchii, and the Spatularidae, a genus of Ganoidei, have an almost entirely naked skin. There are no splint bones in the Elasmolranchii. The cutaneons system is further distinguished by the possession of the system of the 'lateral line,' which has not been detected elsewhere, except in certain Amphibian larvae, and which is supposed to be sensory in function. The epidermis is ordinarily prolonged as a continuous, even if thin layer, superficially to the various dermal formations, except in the cases of some of the outgrowths developed in the Elasmobranchii, and sometimes of the enamelled scales of the Ganoidei.

However various the endoskeletal structures of Fish may be, they all agree in the non-possession of a sternum, the absence of which is connected with the peculiarities of their reproductive processes;

e The low grade of organization to which the Pharyngobranchii, as represented by the Lancelet, have attainer, makes it convenient to omit this Order from consideration, whilst detailing the charncteristics more or less universally found in the other five Piscine Orders, viz. Marsipobranchii, Teleostei, Ganoidei, Elasmobranchii, and Dipnoi. 
and in the presence of a largely developed hranchial apparatus, which is similarly correlated with their aquatic life. In the Marsipobranchii, vertebrae are indicated rather than differentiated by the development of a few cartilaginous neural and haemal arches, the sheath of the chorda dorsalis remaining unsegmented throughout. Indications of the formation of vertebral centra are presented to us in the calcified annuli developed in the sheath of the chorda in Chimuerae. The characters of the axial elements of the endoskeleton vary much in Plagiostomi, attaining in some representatives of this sub-order to perfect differentiation and partial calcification. Greater variety is observable in the same structures in the now numerically much smaller order of Ganoidei, where the centra may be represented by a cylindrical fibro-cartilaginous sheath surrounding the cylindrical notochord, as in the Sturgeons; or by perfectly ossified opisthocoelian masses connected by anchylosis with perfectly ossified neural arches, as in the Bony Pikes (Lepi(losteidae). In Teleostei, as the name implies, the vertebrae are differentiated, and, in various degrees, calcified, the amount of lime deposited rarely or never attaining the proportions it assumes in other classes of Vertebrata. The neural arches are in Teleostei ordinarily, but not always, anclyylosed to the centra, without the interposition of any neuro-central suture. The number of the vertebrae may be as many as 365 in some Sharks; in some Ganoids, and in some of the Physostomi amongst Teleostei, it may amount to 200 ; in most Physoslomi it is about 80 ; it falls much lower in Acanthopteri, and may be as low as I $_{5}$ in the Plectognathi. The trunk is divisible into two main regions, the dorsal and the caudal; from the former of which a cervical region may be said to be marked off, at least morphologically, inasmuch as the seapular arch makes its first appearance opposite the interval between the seeond and third vertebrae. The Elusmobranchii and most of the Ganoidei, have their greater geological antiquity spoken to by their retention of the more typical heterocercal form of the tail. This peculiar shape is produced by a disproportionate development of the haemal caudal arches, whereby the tail, which was in the early embryo equilobed, and, as in MUursipobranchii and Dipmoi, a direct continuation of the axis of the dorsal region, is bent upwards. An additional factor in the production of the heterocereal tail, is brought into play in the case of the Holostean Ganoidei, and the Physostomous Teleostei, 
which are nearly allied to them, by the stunting of the neural in correspondence with the greater development of the haemal arches. This form of tail may to a superficial examination appear quite equilobed, and it is ordinarily spoken of as 'homocercal.' It is, however, morphologically 'heterocercal,' as the haemal and neural arches enter into its composition in very unequal proportions, the chorda dorsalis being really prolonged to the upper angle of the tail fin, and the 'hypural ' plates being all modified haemal arches, and not half of them haemal, and half of them neural ossifications. A true 'diphycercal' tail is finally produced in the Acanthopteri, by a reduction of the disproportionate size of the haemal, and by a simultaneous stunting of the central elements of the terminal vertebrae.

The differences in the structural arrangements of the skulls of Fishes are very much greater than those observable in the skulls of members of any other Vertebrate class, relating as they do to points of no less morphological and indeed physiological importance than the absence or presence of cranial bones; of freely movable gillcovers, and suspensoria; of maxillary and premaxillary, and of mandibular bones. In the Elasmobranchii and Marsipobranchii, there are no cranial bones; and with regard to the praemaxillary and maxillary bones, it can only be said, that the sites which those membrane-bones occupy in other fishes may, perhaps, be considered as marked out in these orders by the presence of certain labial cartilages. The Chimaerae differ from the other Elasmobranchii, the Sharks and-Rays, in having a movable operculum and an immovable suspensorium, and in this latter particular the nonmandibulate Marsipobranchii more or less closely resemble them. The Teleostei and Ganoidei differ from these Fishes by possessing cranial, maxillary, praemaxillary and opercular bones. Their opercula and suspensoria are always movable.

In the Elasmobranchii the skull is distinctly articulated to the first trunk vertebra. In the Chondrosteal Ganoidei, the largely developed parasphenoid reaches for a considerable distance backwards underneath the anterior vertebrae; whilst in the Holostean Ganoidei and many Physostomous Teleostei, the first and some of the following vertebrae may be suturally connected with the basioccipital. In other osseous Fish the basi-oceipital presents a concave conical cavity for apposition with the similar one upon the anterior 
surface of the first vertebra; and the biconical cavity thus formed is filled with a structure formed by the development of the chorda dorsalis, and of semi-gelatiniform consistence.

Fish are very rarely edentulous. Teeth are ordinarily present, and are very variable in number, shape, and situation. Most of the bones of the oral and pharyngeal cavities may be dentigerous; but in Cyprinoids, there may be only a single tooth superiorly, carried by the basi-occipital. The teeth are replaced as often as they are shed, and in the family just mentioned, the inferior pharyngeal are so shed and replaced periodically. It is only in Fish that the dental series is continued in an unbroken row across the middle line, without forming a diastema corresponding to either upper or lower median raphe. Fish have no oral salivary glands, and the tongue is only movable as a part of the hyoid apparatus upon which it is carried. In the Marsipobranchii, the branchial sacs open both internally and externally by the means of larger or smaller ducts, which again may form a common duct before their inner or outer termination respectively. In all other Fishes the branchial inlets and outlets both have alike the form of fissures, the inlets leading directly from the interior of the pharynx, and the outlets opening either directly on to the external surface of the body, as in the Sharks and Rays, or into a branchial cavity covered by the opercular apparatus as in Chimaerae, Dipnoi, Ganoidei, and Teleostei. The oesophagus is ordinarily short; and it is also, as the food is usually swallowed with little or no comminution, of considerable width. In the Marsipolranchii, the digestive tract takes an antero-posterior course, without any external differentiation into stomach and intestine. In other Fishes the intestine is readily distinguishable from the siphonal or coecal stomach; and describes one or two convolutions before terminating at the anus through the intermediation of a short rectum, from which a colon can scarcely be said to be differentiated. The length of the entire tract is shorter relatively to that of the entire body than in the air-breathing Vertebrata generally; it is however not inconsiderable in the species which support themselves upon vegetable diet; and the absorbing surface of the canal is greatly increased in Dipnoi, Canoidei, and Elasmobranchii, by the development of internal folds of the mucous membrane into a spiral valve, which appears to be rudimentarily represented in the Marsipobranchii by a longitudinal ridge running along the internal 
surface of the intestine. In the three more highly organized of the four orders just mentioned, a duodenal segment is distinguishable in the small intestine anteriorly to its valvular portion. 'This segment is known as the 'Bursa Entiana' in Elasmolranchii, where it is of considerable size, and marked externally by the entrance of the functional biliary and pancreatic, and the rudimentary omphalomesenteric ducts. The rectum always opens anteriorly to the urinary and genital ducts; except when these tubes open upon its dorsal surface near its termination, so as to constitute a cloaca. The suspensory mesenteric laminae often become largely fenestrated, or may disappear altogether in consequence of absorption, in adult Fish. A liver is always present; it is ordinarily unilobar; in some Fish it is multilobar; in the Cyprinoids it is trilobed, and interdigitates with the convolutions of their intestine, much as the lobes of the liver do in many of the Gasteropoda. There may be several gall ducts, and a gall bladder is very rarely wanting. Secretory coeca, the so-called 'pyloric appendages,' are developed in many Fish upon the commencement of the intestine. They are very variable in number, and ordinarily simple and distinct, though sometimes ramified and bound together more or less closely. A glandular pancreas of smaller size but more compact structure, coexists sometimes with these pyloric appendages. The heart consists of a branchial auricle and ventricle, to the former of which a sinus venosus is superadded, and to the latter, except in Marsipobranchii, an arterial bulb, which breaks up into branches corresponding in number to the gill arches. In the Ganoilei and Elasmobranchii, the arterial bulb has a layer of transversely striped muscular tissue in its walls, and several rows of valves in its interior; whereby it is enabled, as in Amphibia, to act as an accessory ventricle. The muscular fibre of the arterial bulb of Teleostei is not of the striped variety, and the bulb has only two valves internally. In the Dipnoi a second auricle exists, which receives blood brought back to the heart from the pulmonary air sacs. The systemic aorta is formed, in the embryo, by the confluence of the aortic arches into which the bulb divides; and, after the development of the gill fringes, for the supply of which these arches resolve themselves into efferent branches, by the confluence of the efferent branchial veins with which those afferent vessels are continuous through the intermediation of the aerating capillary plexuses. In the Dipnoi, 
as also in certain Muraenoid Teleostei, more or fewer of the branchial arches fail to develope gills, and the direct connections between the sub-branchially placed bulb and the sub-vertebrally placed aorta, which in other Fishes exist only in the foetal state, persist here throughout life. From each of the posterior aortic arches (Lepidosiren paradoxa), or from each of the compound factors of the dorsal aorta made up on each side (Rhinocryptis annectens), a branch is given off to the cellular air sac; and during the period in which these animals live out of the water, the aeration of their blood is dependent upon the ramifications thus formed there. The vein which brings the blood from the pulmonary air sacs back to the heart, instead of opening into the portal or hepatic vein, as the veins from the air-bladders of ordinary Fishes do, or into a vena cava inferior, as does the vein from the air-bladder of the Ganoid Polypterus bichiv, opens independently into the ventricular cavity after dilating within the pericardium; and thus, though diverging but a very little from the arrangements common in (uni-auriculate) Fishes, it constitutes a system analogous to and homologous with the pulmonary veins and auricles of higher Vertebrata. Ordinarily in Fish, the blood from the parts of the body posterior to the heirt exclusively of the chylopoietic viscera, is collected into the two subvertebral venae cardinales, which meet the two venae jugulares from the anterior parts of the body, and form with them the transverse ductus Cuvieri which open into the sinus venosus. The hepatic veins, which bring the blood of the chylopoietic viscera back to the heart, very ordinarily end by opening into the sinus venosus, without receiving any factors from any other than those organs. A true vena cava inferior is constituted in some Fishes, as in the Perch amongst Teleostei, and in the Polypterus amongst Ganoirtei, by the fusion either of veins from the air-bladder with veins from the genital glands as in the former of the two Fishes named, or of a vena cava sub-vertebralis impar with veins from the bifid air-bladder as in the latter. A renal-portal system is present, except in the Marsipobranchii; it is constituted either by caudal and dorsal reins both or by the latter only; and anastomoses, though not always, with the hepatic portal system.

The Teleostei, Ganoidei, Dipnoi, and Chimaerae have free opercular valves covering a more or less extensive branchial cavity. The gills of Teleostei are ordinarily four, and are never more than 
four in number. They are usually found to form double comb-like rows upon each branchial arch; but the last of the branchial arches very commonly fails to develope more than a single row of gillprocesses; and not rarely is wholly gill-less.

This reduction may be accompanied by a similar reduction in the gil arch immediately in front, and we find the third arch carrying a uniserial gill in Matthea, whilst it is gill-less in the Cuchia (Amphipnous). The fifth branchial arch, which is dentigerous in most, and branchiferous in no Teleostei, has a uniserial gill developed upon it in the Dipnoi and in Hexanchus. All the Elasmobranchii, the Dipnoi, and the Ganoidei, with the exception of Polypterus and Planirostra, have a uniserial gill developed upon the opercular arch anteriorly to the most anterior of the gill-laminae developed in Teleostei. In the Sharks and Rays this anterior gill forms the anterior fixed gill lamina of their anterior gill-pouch; in the Chimaerae and Ganoidei, it forms the so-called 'opercular' gill. In the Dipnoi, the development of the opercular gill appears to have prevented that of the two biserial gills placed next posteriorly in typical fish; in the American species the gills of the third branchial arch appear to have been lost also, whilst they persist in the African, as do those of the fourth and fifth branchial arches in both species. Except in Hexanchus and Heptanchus, there are only five gill-sacs in the Sharks and Rays, the last of which contains only a single gill-lamina disposed upon its anterior wall. This half-gill is homologous with the posterior row of the biserial gill developed upon the fourth branchial arch of Teleostei, but it is not represented in the Chimaerce. The pseudobranchia of osseous Fish is homologous with the spiracular pseudol)ranchia of Genoidei and Elasmobranchii, and not with their anterior functional half-gill, nor with the thyroid vaso-ganglion, which in many Fish underlies the anterior basibranchials. In osseous Fish, the pseudobranchia receives arterialized blood from the first branchial efferent vein; and it serves as a diverticular rete mirabile for the eye within which the vessels proceeding from it develope the so-called 'choroid gland.' In the Elasmobranchii, Ganoidei, and Dipnoi, it serves as a rete mirabile for the brain as well as for the eye, but it has no 'choroid gland' developed in comnection with it. Accessory aerating organs which enable the fishes possessing them to support respiration when out of the water, are developed in several genera of Teleostei (Anabas, Saccobranchus, Amphipnous), in relation with the interior of their branchial cavity.

The morphological identity of the functionally pulmonary air-saes of the Dipnoi with the air-bladder of an ordinary Teleostean Fish, which 
is functionally all but exclusively hydrostatic, may be considered to be established by a comparison of those lung-like air-sacs with the airbladder of the Ganoid Polypterus, which is somewhat similarly bifid, and opens similarly into the pharynx by an air-duct entering it on its ventral surface. From the air-bladder of the Polypterus to that of the Lepidosteus, which however opens into the pharynx from its dorsal side, and which, though divided internally into two longitudinal compartments, is yet externally a single sac, the transition is not abrupt; nor that from such air-bladders as those of the Lepidosteus and the Physostomatous Teleostei, to the ductless air-bladders of the Acanthopteri and other bony Fish.

The swimming bladder is developed as an outgrowth from the oesophageal portion of the digestive tube, and its ductus pneumaticus, when persistent, ordinarily communicates with this portion of the tract. Both bladder and duct are absent in the Marsipobranchii, and, except as rudimentary structures in certain Sharks, in all Elasmobranchii also. The duct is aborted in the majority of Teleostei (the Acanthopteri, Pharyngognathi, Lophobranchii, Plectognathi), but is present in the remainder of this order, nearly corresponding to the Malacopterygii of Cuvier, and hence called Physostomi, as also in all Ganoidei and Dipnoi. With the presence or absence of an air-duct to the air-bladder, the presence or absence of bone corpuscles appears to be nearly universally correlated. The shapes which the air-bladder assumes are very various, especially when it is ductless. In many Acanthopteri it sends two prolongations into relation with the caudal muscles, whilst in many Physostomi (Cyprinoideae, Siluroideae, Clupeidae), its anterior prolongation is brought into relation with the auditory apparatus.

It is only in the Elasmobranchii that a secondary kidney takes the place of the primordial Wolffian body, which remains as the functional renal organ in other orders of Fishes. This difference is illustrated not only by the difference of form and of compractness of the renal organs in the Elasmobranchii, but also by the facts that in the females of this order the oviducts open separately from the ureters into the cloaca; that in the males the vasa deferentia are in some species (Mustelus laeris) bestudded with what is probably the remnants of Wolffian bodies for nearly their entire length; and that the ureters are developed mainly along the internal, and not 
as in Amphibia along the outer edge, or as in many Teleostei, along the anterior or inferior surface of the renal gl inds. Urogenital canals are formed in Ganoidei of both sexes, and in the males of Elasmobranchii. In the Teleostei, the ureters often fuse into an azygos duct, which opens above, or behind, or together with the generative duct, but always posteriorly to the anus. The urinary bladder may take the shape of a bilateral dilatation, as in the Sharks and Rays; or that of a vesica bicornis, as in some Ganoidei; or of that an azygos sac, as in many Teleostei.

The encephalon fills the brain-case in the embryonic Fish, but subsequently, by the disproportionate growth of the cranial walls, it comes to occupy a very small space in the cavity which they inclose, the intervening space between it and the perichondrium or periosteum, as the case may be, of the cranial vault being filled with a mass of loosely compacted tissue, richly laden with fat. The membranes, in relation with the external and internal surfaces of the cerebro-spinal centres, develope pigment cells as in Amphibia. The nerve-centres are smaller in relation to the body in this than in any other vertebrate class; the relation of the encephalon to the body is stated as being on an average as low as 1 to 3000 ; and the spinal cord of a Sturgeon which weighed I2olbs., has been stated to have been no thicker than that of a Frog. The spinal cord is ordinarily, but not always, devoid of any enlargements, and of uniform diameter throughout its length, which is usually commensurate with that of the spinal canal. The cerebellum is very variable in size, but it sometimes, as in Sharks and in the Tunny, attains a greater size relatively to the rest of the brain in this than in any other vertebrate class. It is never bilaterally bilobed, as the divisions of the brain placed anteriorly to it are. The optic lobes are frequently in osseous Fish larger than any other division of the brain, a proportion which they never attain to in any other elass. The diencephalon, the homologue of the optic thalami, fails in some Teleostei, as also in the Dipnoi, to be differentiated from the mesencephalon or optic lobes behind, and the prosencephalon in front of it; but in many other Teleostei, in the Ganoidei, and Elasmobranchii, this division of the brain is considerably elongated antero-posteriorly, and bounds a 'third ventricle' by its two halves. In the Sharks and Rays, the prosencephalon attains the preponder- 
ance relatively to the other divisions of the brain, which it maintains in the higher Vertebrata, and developes lateral ventricles in its tro halves, which communicate with similar cavities in the rhinencephalon. These two divisions of the brain are solid in most Fishes, the rhinencephalic lobes appear to be attached laterally and by peduncles to the prosencephalic in the Elasmobranchii; they are pedunculate in many Teleostei, but sessile in the Ganoidei. Besides developing in Siturus and Cyprinoids a supero-median 'lobus impar,' or 'nodulus,' the medulla oblongata presents in various families certain lateral ganglionic enlargements, which, from their connection with peripheral nerves, are known in Cyprinoids as 'vagal,' as 'lobi nevvi trigemini' in the Sharks, and as 'electric lobes' in the Torpedo.

In Dipnoi, and to some extent in Marsipobranchii, the muscles of the eye are supplied by the fifth nerve; and in most Fishes the nervous supply of the superficial structures in the maxillary, hyomandibular, and palatine regions supplied in higher Vertebrata, with the exception of the Anurous Amphibia, by the portio dura of the seventh pair, is dependent partly upon fuctors from the fifth nerve, as well as upon an independent stem. The nervus lateralıs which supplies the sensory organs of the lateral line, as well as the mediodorsal region of the trunk, anastomosing in its course with the spinal nerves externally, much as the sympathetic chain anastomoses with them within the thoracico-abdominal cavity, is in Elasmobranchii, Ganoidei, and many Physostomous Teleostei, constituted by the vagus. In some osseous Fish (Gadus), it is formed chiefly by the fifth nerve. The glossopharyngeal is not always differentiated from the vagus, and in some Rays it interchanges fibres with the auditory nerves. The spinal accessory nerve does not exist in Fish, and the place of the hypoglossus is taken by the first spinal nerve. The existence of the sympathetic has not been demonstrated in Marsipobranchii; in Teleostei the bilateral gangliated chain does, in Elasmobranchii it does not, extend into the caudal region.

Organs of tactile sensibility are constituted in some Fishes by the development of flexible rays upon their fins; in some others, and more commionly, by that of similar structures, in the shape of barbules upon the snout; but in most cases by the mueo-nervous organs developed upon the head, where they are supplied by the 
trigeminus, and upon the trunk along the lateral line. The olfactory organ is an azygos sac in the Marsipobranchii, hence called 'Monorrhina;' it ends blindly in the sub-order Petromyzontidae, which are hence called 'Hyperoartii,' but opens into the pharynx in the Myxinoids, hence called 'Hyperotreti.' All higher Vertebrata have paired nasal sacs, and have consequently been styled 'Amphirrhina.' In the Dipnoi, the nasal sacs have valvular posterior openings, externally to the pterygo-palatine teeth; in all other amphirrhine Fishes they end blindly. The eyes are relatively large in Fish, the cornea is flat, the lens spheroidal. The Elasmobranchii possess eyelids, and sometimes a membrana nictitans. A peculiarly piscine rete mirabile, the 'choroid gland,' exists in most Fishes, except the Elasmobranchii and Ganoidei, between the layers of the choroid, where it surrounds the entrance of the optic nerve. A structure homologous with the 'pecten' of Birds exists in many Teleostei, where it is known as the 'processus falciformis.' Certain structures, consisting of pigment specks with lens-like bodies inlaid in their substance, have been found regularly arranged between the branchio-stegal rays, upon the head, and in two pairs of longitudinal rows on the ventral surface of Chauliodes and Stomias, and have been regarded as accessory eyes.

The auditory apparatus of the Marsipobranchii consists of a vestibule, with, in Myxinoids one, and in Petromyzontidae two semicircular canals, contained in cartilaginous capsules attached to the skull laterally. In all higher Fishes there are three semicircular canals. In the Sharks and Rays, and in the Dipnoi, the membranous labyrinth is entirely surrounded by the cranial walls, but in the Chimaerae, the Ganoidei, and the Teleostei, a median portion is always to be found lying free in the cranial cavity. The airbladder of some Acanthopteri, and of many Physostomous '́eleostei, comes into relation with the membranous labyrinth, either directly or through the intermediation of ossicula. In Elasmobranchii canals exist, marking the line along which the integument was invaginated, to form the 'internal ear.' The electric organs of Fishes are not represented in higher Vertebrata. They are most largely developed in the Torpedo and Gymnotus, and in a lower degree in Malapterurus and Mormyrus. They are found in various parts of the body, but consist essentially of prismatic columns, made up by the superposition of flat plates, to which nerves from 
the fifth and eighth pairs, and from the spinal series, are distributed. The nerves fuse with one surface of these plates, which is electro-negative, whilst the other is electro-positive.

In several species of the genus Serranus, a testis has been observed overlying the ovary, and a similar hermaphroditism has been observed occasionally in Cyprinoids, and in some other Fishes. On the other hand, asymmetry is often, as in the Perch, seen to be produced by the stunting of one or other of the (typically symmetrical) ovaries. The reproductive glands in the two sexes are often so much alike externally, that an examination of their substance is necessary for deciding the sex to which they belong. Sometimes, however, and especially at the breeding season, the sexes may be distinguished by external differences. Fishes are mostly oviparous, but are sometimes viviparous. Rudimentary intromittent organs exist in the male Elusmobranchii, as the so-called 'claspers.' Sexual congress or contact takes place in many oviparous as well as in the viviparous Teleostei.

The products of the generative glands sometimes find their way into the water by extrusion, by an abdominal pore or pores, as in Marsipobranchii, Anguilla, and the females of Salmonidae, from the abdominal cavity into which they have been set free by dehiscence. But in most Teleostei, the walls of both the generative glands are directly continuous with their ducts, so that neither ova nor spermatozoa are ever set free into the peritoneal cavity. This is the case also in Lepidlostens amongst the Ganoidei; but in the other members of that order, the sexual products of both kinds are taken up after dehiscence by the open mouths of 'Fallopian tubes.' In the Elasmobranchii, where the ovary is single, and the mouths of the oviducts approximated, the lower parts of the oviduct are specially modified to secrete the shell in the oviparous Scyllium and in the Rays, and to serve as a uterus in the viviparous species of Squalidae. In the males of Elasmobranchii, as of all higher Vertebrata, the testis is continuous on each side, with an epididymis and a vas deferens. The lower segment of the vas deferens is expanded into a vesicula seminalis. The Elasmobranchii have large yolked ova with partial segmentation, and in MLustelus laevis, the vessels on the yolk sae come into such relation with the maternal vessels on the walls of the uterus, as to form a sort of placenta. In osseous Fishes, where the ova are very much 
smaller, the segmentation of the yolk is more extensive than in Elasmobranchii, but less so than in Mammals or Amphibia.

In Marsipolranchii, as in Amphibia and Amphioms, the intestinal canal is formed within the yolk sac, as the result of an invagination commencing at the future anus, proceeding from without inwards, and forming thus a tube without any umbilicus, within a cavity which is at once yolk cavity and peritoneal sac.

Fishes, lilse Amphibia, are competent not rarely to sexual functions before they are mature in other particulars. Their power of repairing injuries, and reproducing lost parts, is confined to the fins. The capacity for growing as long as life lasts, which some Fishes are said to possess, may be explained by the facts that their bodies are, firstly, of very nearly the same specific gravity as the water in which they live; and, secondly, of a temperature which is but a very little higher than that which they are there exposed to. Thus the force which in other animals is expended in the way of opposition to that of gravity, and in the way of producing heat, is available for sustaining continuous growth.

The Class Pisces is divided into six orders-the Dipnoi, the Elasmobranchii, the Ganoidei, the Teleostei, the Marsipobranchii, and the Pharyngobranchii. Of these the Dipnoi are to be considered the highest, as presenting in their organization many points of affinity to the Amphibia; the Elasmobranclii and the Ganoidei have the oldest known geological history of any members of the class; they possess many characters in common with each other and with the Dipnoi, such as the abdominal position of the posterior pair of limbs; the retention ordinarily of more or less of the axial endoskeleton in a cartilaginous condition; the possession of an anterior functional uniserial gill, which is lost as such in osseous Fishes; and the possession of a spiral intestinal valve. Though coeval in geological time with the Ganoidei, the Elasmobranchii are a distinctly specialized, whilst the Ganoidei are a generalized type of Vertebrata. The Teleostei, and amongst them the Physostomi especially, are linked by many affinities to the Ganoidei. The Marsipobranchii may be looked upon as representing a very low grade of development of the type upon which the Elasmobranchii are constructed; the superaddition of specializations has however proceeded so far as to leave fer points of positive similarity beyond those which an endoskeleton in great part or wholly cartilaginous; a branchial 
apparatus differing in its pouched arrangement and posterior position from those of Ganoidei and Teleostei; the absence of maxillary and intermaxillary cartilages; and the presence of a raised ridge along the intestine constitute. The sixth order, that of the Pharyngobranchii, are the lowest of Vertebrata; their claim to that title resting indeed not upon the possession by them of a vertebral column, but merely upon that of a chorda dorsalis, underlying a membranous neural canal, and overlying a cavity containing the organs of vegetative life. Its digestive tract appears to be formed as in many Invertebrata by an invagination commencing on the exterior of the germinal membrane, and it is to certain of the stages of its metamorphosis that certain similarly transitory phases in the life-history of certain sessile Ascidians have been stated to present a strong resemblance unknown in other Invertebrata.

The Dipnoi are represented by the Mud-fishes, Lepidosiren and Rhinocryptis, of the South American and West African rivers. They possess, in addition to small external gills, seen elsewhere amongst Fishes only in developing Elasmobranchii, and to functional internal gills covered by an operculum, a pulmonary auricle into which blood is returned from two pulmonary sacs. These sacs communicate with the digestive tract by a ventrally-placed opening guarded by cartilage; they receive blood in a venous, and return it in an arterialized state. The Dipnoi differ further from the $G a$ noidei, the piscine order with which they are most nearly allied, and resemble the Amphibia in the communication of their paired nasal sacs with the mouth, in the possession of three external branchiae, in the internal structure of their arterial bulb, and in the microscopic characters of their chorda dorsalis. The totality of their organism however shows them to belong to the Sub-kingdom Pisces; the persistence of the structure last mentioned; the absence of vertebral centra; the development of cycloid scales; and, more distinctively, of the system of the lateral line; the presence of clavicular, of branchiostegal, of opercular bones, of dermal spines, and of a spiral intestinal valve; constituting a sum of characters which justify us in referring them to that class. The order Dipnoi differs from the orders Elasmobranchii and Ganoidei, to which in so many points it appears to be more or less closely allied in the nonheterocercal character of the tail. In this particular it resembles on the one hand the lowest of the Fishes; and on the other, 
the Urodelous and the larvae of the Anurous Amphibia; illustrating well what is meant by the phrase ' a generalized type.' The Dipnoi resemble the Elasmobranchii and Ganoidei in having the posterior pair of limbs placed near the anus, as in all Vertebrata above the Teleostean Fishes in which a posterior pair of limbs is developed.

The second order of Fishes, that of the Elasmobrancilii, is represented by the Sharks, Rays, and Chimaerae. They differ from the Dipnoi and Ganoidei in the following points besides those which their name connotes. They never have an air-bladder, except occasionally as a rudimentary structure; they have no cranial, nor clavicular bones; their exoskeleton has the form of 'placoid' granules, not of scales; and in the males, accessory copulatory organs are developed. They resemble the Ganoidei in the heterocereal character of their tail; in the formation of their caudal haemal arches by costal elements; and in the possession of several rows of valves within their arterial bulb; of a coating of transversely striped muscular fibre on the exterior of this structure; and of an optic chiasma.

The order Ganoidei is divisible into two sub-orders-the Chondrostei represented by the Sturgeons; and the Holostei represented by the Bony Pike, the Polypterus, and the Amia. They always possess a freely moving operculum, supported by one, as in Sturgeons, or by several bony plates, and an air-bladder provided with an air duct. With a few exceptions, (Polypterus, Amia, Scaphirhynchus, they possess an opercular gill as well as a pseudobranchia; and a blowing cavity, the remains of the first visceral cleft, may exist together with, or independently of one, or other, or both of these structures. The angular or round enamelled scales, whence their name is taken, are ordinarily but not always present, the skin being sometimes naked and sometimes developing bony plates as in the Sturgeons. The extent to which ossification proceeds in their axial skeleton is, as the two subordinal names above given indicate, very various. The Holostei and especially the genus Amia, make a considerable approximation towards the Physostomous division of the Teleostean Fishes, by the distinct specialization of maxillary and intermaxillary bones, and by failing to develope either the enamel on the scales, the fulcra on the fins, or the gill on the operculum, so characteristic of Ganoidei generally. 
The Teleostei comprise an immense majority of existing Fishes. They may be subdivided into two great sub-orders: the Physostomi, which possess an air-bladder and an air-duct, and, with the exception of the Pike, bone corpuscles in their skeleton; and the Physoklisti (Haeckel) in which the air-duct is always absent, the air-bladder sometimes, and in which, with the exception of the Tunny, bone-corpuscles are wanting. The vertebrae vary much in number, and in the extent to which calcificatory deposit takes place in them; but they are always individualized, though the most anteriorly placed of them may be suturally united with each other and with the basi-occipital bone. The gill-fringes may vary in number accordingly, as upon each of four branchial arches a biserial or uniserial gill is developed; but they never exceed the number of four biserial gills, an opercular gill being never developed. They have always more than a single bone in the opercular valve. The cartilaginous cranium may either persist or disappear, but cranial bones are always developed in addition to it. The scapular arch has a clavicular element; the anterior fins are rarely absent; the position of the posterior, which are much more commonly absent than the anterior, varies from the 'abdominal' to the 'thoracic,' and from the 'thoracie' to the 'jugular' region. The aortic bulb is not provided with more than two valves, nor has it a covering of transversely striated muscular fibre. The optic nerves decussate, but do not form a chiasma.

The fifth order of Fishes, the Marsipobranchii, consists of the tro families of Myxinoidei and Petromyzontidae. Their sac-like gills are supported on a cartilaginous framework, which is more superficially placed than the analogous visceral skeleton of higher Fish. They have a single nasal opening, and have been hence called 'Monorrhina,' in contradistinction to all higher Vertebrata. They have no mandible, and higher Vertebrata have, in contradistinction to them, been on this account spoken of as 'Gnathostoma.' They have no traces of air-bladder, of limbs, of limbgirdles, of cranial bones, of scales, of spleen, or of pancreas. Their tail retains the homocercal form characteristic of the early embryo in other Fishes. They have no vertebral centra. The sympathetic system is wanting, and the commencement of their aortic trunk has neither striped nor smooth muscular fibres developed upon it. The Myxinoids are less highly organized, being of parasitic habits, than 
the Lampreys; their single nasal sac communicates with the pharynx, whence they are called 'Hyperotreti;' whilst in the Petromyzontidae, hence called 'Hyperoartii', it ends blindly as in other Fish. The embryos of Petromyzontidae go through a metamorphosis, being blind and edentulous when set free from the egg. These larvae were formerly supposed to be a distinct species, and were known under the name of Ammocoetes branchialis. Like the larvae of some other Fish and of some Amphibia, they may attain sexual maturity whilst still in one of the stages preparatory to the perfect adult condition. The evolution of the sexual organs appears however to exhaust the powers of such larvae as attain to it, and to be incompatible with the completion of the entire curriculum of metamorphosis.

The sixth order of Fishes, the Pharyngobranclii, are represented by a single species, the Lancelet, Amplioxus lanceolatus. These animals are somewhat vermiform in outline, semi-transparent, of small size, being only two inches in length even when adult, without either cranium or brain strictly so called, or any differentiation of the axial notochordal, or the primitive membranous neural canal.

In this order we have pulsating vessels in the place of a saccular heart, whence the name 'Leptocardia' has been given to it in contradistinction to that of 'Pachycardia,' which expresses the condition of the central organ of the circulating system of all other Vertebrata. Another name, 'Acrania,' indicates the fact that in correspondence with the absence of any other encephalic nervous centre beyond a dilatation in which the myelon ends, and which may be considered as homologous with the medulla oblongata, no cranial cavity is developed upon the anterior prolongation of the notochort. The mouth is surrounded by a cartilaginous ring, carrying anteriorly tentacular outgrowths, whence the name 'Cirrhostomi' has been given to this order. The digestive tract immediately posteriorly to the mouth is constituted by a multiperforate branchial skeleton, along the bars of which blood is propelled by contractile branchial arteries, and through the fissures of which the inhaled water finds an exit into a eavity homologous with a branchial cavity, and opening by a single orifice on the medio-ventral line, posteriorly to the middle point of the animal's length. The bloodvessels, which pass from a sub-branchial vessel upwards along the 
branchial bars, are collected into a dorsal aorta, which distributes blood to the various organs of the body. A portal system is rudimentarily represented by a vessel, which is formed by the veins of the intestine, and sends ramifications to a coecal outgrowth of that tube representing the liver. There is no lymphatic system, nor have any renal organs been discovered in this small Fish. The eye appears to be represented by an azygos pigment speck, sessile upon the anterior prolongation of the nervous axis. No auditory organ has been observed. The generative glands discharge their products by simple dehiscence into the cavity surrounding the branchial sac, whence they escape by the abdominal pore together with the respired water. The ova undergo complete segmentation; the ciliated embryo is set free before the primitive streak and chorda dorsalis are differentiated, and goes through a peculiar metamorphosis.

\section{Sub-kingdon, Mollusca.}

Invertebrata, in which the body is bilaterally symmetrical, but often not obviously so; in which it never is segmented nor provided with articulated appendages; and in which the length is usually less in relation to the bulk than in either Vertebrata, Arthropoda, or Vermes. The organs of animal life often attain but an insignificant degree of evolution in this sub-kingdom; whilst those of vegetative, which are ordinarily massed together in a sacciform envelope, may attain a great predominance in point of size, with which their precedence in order of development is to be correlated. The tegumentary envelope of these latter organs is almost always prolonged so as to form a mantle, which may itself entirely surround the body, and which usually furnishes it with an external shell, or shells, or test. A well-developed digestive tract, consisting of oesophagus, stomach, and intestinal segments, and never opening into the periviseeral cavity, though it is occasionally aproctous, is always present in Mollusea. It very rarely takes a direct antero-posterior course, but has almost always its terminal segment bent round so as to be approximated to the mouth, and when it is 
proctuchous, the anal outlet is very usually in close relation to the respiratory inlet. The hepatic organ is very various in shape, but is usually, as in most water-breathing animals, largely developed. A heart is usually but not always present; it is, when present, always systemic, receiving blood, when afferent veins are present, from the aerating and renal organs, or from the general lacunar system when no such vessels exist, and propelling it by an aorta to the main organs of animal and vegetable life respectively. In many aquatic Mollusca, the external water can find its way by variously situated apertures, so as to become directly intermingled with the blood; in others, a multi-ramified water-vascular system appears to spread itself throughout the body, without becoming directly continuous with the blood-vessels. In some cases no specialized respiratory organs are present; in a few Mollusca aerial respiration is attained to, in most it is aquatic. The renal organ may be represented by a simple non-glandular sac, which communicates internally with the lacunar blood-vascular system, and externally with the circumambient medium. When its walls are clothed with glandular cells, it receives an abundant supply of venous blood, some of which is passed onwards to the aerating organs, and some sent directly to the heart.

The nervous system may be reduced to a single ganglion, as in Polyzoa and Tunicata, and in the former class organs of special sense are wanting, except occasionally as rudiments.

Reproduction may be either sexual or asexual; and in the Polyzoa polymorphic zooids are produced by gemmation. The ova undergo entire segmentation, except in the Cephalopoda; and with the exception of that class, and a fer Gasteropoda, of the pulmonate order mostly, the embryos go through metamorphosis subsequently to being set free from the egg.

The great majority of Mollusca are water-breathers, and marine in habitat; some however are fluviatile, or lacustrine; and a fer are terrestrial and pulmonate. A fer Mollusca are parasitic. Entoconcha mirabilis inhabits the perivisceral cavity of a Synapta; in the genus Eulima, which preys upon Holothurioidea, some species are ento-, others ecto-parasitic. Stylifer lives ecto- or pseudoparasitically attached to the soft tissues clothing the exterior of Asteriae and Echinoidea and Holothurioidea, as also within their digestive tract. Crenella infests Tunicata; and Vulsella, Gastro- 
chaena, and Magilus infest certain Coelenterata; but, like certain Polyzoa, such as Loxosoma and Pedicellina, which attach themselves to Vermes as to other marine objects, are not parasitic in a strict sense.

The Sub-kingdom Mollusea contains two great divisions or provinces-the Mollusea proper, under which are comprehended as classes the Cephalopoda, the Gasteropoda, the Pteropoda, and the Lamellibranchiata; and the Molluscoidea, under which are comprehended the Brachiopoda, the Tunicata, and the Polyzoa. The Mollusca proper are distinguished firstly by the great development of their organs of animal life. Their motor organs consist of a 'foot,' which may be of very various shapes, and is divisible morphologically, and sometimes actually, into a 'propodium,' ' mesopodium,' and 'metapodium;' and of an 'epipodium,' developed by the foot proper along its line of junction with the visceral mass. The names of the three classes, Cephalopoda, Gasteropoda, and Pteropoda, relate to the differences observable in these motor organs. The nervous system in all four Classes of Mollusca consists of three pairs of ganglia at least, which are sensory, parieto-splanchnic, and motor respectively; and which, being mutually connected by commissures, form a collar round the commencement of the digestive tract. The organs of vegetative life in the Mollusca contrast with those of the Molluscoidea in two chief points : firstly, their heart is all but invariably provided with one or two auricles, in correlation with their more perfectly developed and specialized respiratory apparatus, whence they have been called 'Otocardia;' and secondly, their digestive system is, also all but invariably, proctuchous. The three classes, Cephalopoda, Gasteropoda, Pteropoda, are placed together in one sub-division as 'odontophorous' Mollusea, in contradistinction to the ' bivalve' Lamellibranchiata, by virtue of their uniformly possessing the peculiar dentigerous rasping organ known as the tongue, and of their never possessing a bivalved shell. With these differences others are correlated, as will be detailed in the description of the class Lamellibranchiata.

The Molluscoidea, as a sub-division, are distinguished from the Mollusca proper by the following characteristics. They are not only, like the Lamellibranchiata, destitute of any prehensile or masticatory apparatus, and dependent therefore upon eiliary action for the ingestion of alimentary matters, but they are, with the 
exception of the Nectascidiae and a few Polyzoa, also devoid of organs for motion from place to place, at least in their adult state. The entire sub-division is aquatic, and, with the exception of a part of the Polyzon, is marine. Most of its members are monoecious, and many are social, which the Mollusca proper never are. They always have a more or less indurated external envelope, which in two of the classes, the Tunicata and the Polyzoa, into which the Molluscoidea are divided, is sacciform; and in the third, the Brachiopoda, takes the form of a bivalve shell. In this latter case the nerve-system attains a higher development in certain species than it ever does in either of the other two classes of Molluscoidea; but as no Molluscoid has a 'foot,' pedal ganglia are never developed, nor the three pairs of ganglia characteristic of the higher subdivision of the sub-kingdom attained to.

\section{Class, Cephalopoda.}

Mollusea, in which the foot proper has its margins split up into tentacles, or into acetabuliferous arms, which are arranged so as to form a corona round the mouth. The epipodia, which in Pteropoda are the principal, remain, in Cephalopoda, important locomotor organs, forming as they do, by their partial or perfect coalescence, the 'funnel,' which is lodged in their capacious neurally-situated mantle cavity, and which by the contraction of the muscular walls of that cavity has water so projected into it as to effect the peculiar backward swimming movement characteristic of the class. Movement from place to place in the way of crawling is effected by the multifid foot proper. By virtue of the high evolution of their organs generally, and especially of those of animal life, such as the eyes, the Cephalopoda are by common consent placed at the head of the Molluscan Sub-kingdom; by the retention, however, of a bilateral arrangement relatively to a median antero-posterior plane in many organs, and especially in those of regetable life, they show indications of affinity to lower Mollusca, which are lost in the intermediate classes of Gasteropoda and Pteropoda. The Cephalopoda are divided into two orders, according to the number of their gills; the Tetrabranchiata being the less, and the Dibranchiata the more highly organized of the two. All Cephalopoda possess an internal cartilaginous framework which supports and protects their nerve- 
collar and their organs of special sense; the Tetrabranchiata, in which the internal skeleton attains much less importance than it does in the Dibranchiata, have an external shell; and the Dibranchiata ordinarily possess an internal calcareous shell, as in Sepia, Belemnitidae, and Spimla, or a rigid support of conchiolin, as in Loliginidae. The Octopodidae, however, in which locomotion ordinarily is of the crawling kind, are devoid, with the exception of Cirrlotenthis, of any internal shell distinct from their various internal cartilaginous supports. The external shell of the female Argonantidae is secreted by the external surface of the expanded ends of their two mesially-placed dorsal arms; the body of the animal is not attached to it by the insertion of any muscles, and it is not homologous with the external shell of the Nautilus, nor indeed with that of any other Molluse. The tegumentary system is distinguished, except in the Tetrabranchiata, by the absence of cilia, and by the presence of chromatophores, and of certain more deeply-placed lamellar cells upon which their well-known power of changing colour depends. The organs of animal life being all highly developed, those of digestion, circulation, and respiration are so also in subservience to them. The entrance to the digestive tract, besides being armed with a rasping tongue, is further furnished with a powerful externally-placed beak resembling that of a parrot, but having its posterior segment the larger of the two.

Though the animals are exclusively carnivorous and marine, they have always, with the exception of the Tetrabranchiata, a very largely developed salivary system. A crop, and also a spiral stomachal coecum, are usually present; as also glandular appendages, which, as being distinct, at least to the naked eye, from the great mass of the liver, have been regarded as pancreatic. The intestine proper does not describe any complex convolutions in its course to the anus, which opens always in the middle line of the mantle cavity, and contributes thus, with other arrangements, to give these animals their very obvious appearance of bilateral symmetry.

The systemic heart consists of a single ventricle, the walls of which, in the higher Cephalopoda at least, are composed of transversely-striated muscular tissue. The branchial veins which return the aerated blood to the heart have, in some species of those orders, dilatations developed upon them representing auricles: and in addition to the systemic heart, we find in all the Dibranchiata accessory 
branchial hearts, developed upon the great afferent branchial veins. In the Dibranchiata the peripheral circulatory system appears to be closed, consisting of arteries connected by capillaries, in many organs at least, with the veins or great venous sinuses into which the veins expand. In the Tetrabranchiata the blood appears to be more widely distributed throughout the various perivisceral chambers than it is, according to Mr. Hancoek, in the Dibranchicata; and as the external water finds in the former free access to the various perivisceral cavities, it would appear that it may thus come, as it does, according to some authorities, in the latter order also, to mix directly with the blood. The gills are in the Dibranchiate order attached in their entire length to the interior of the mantle cavity, upon the contraction of the muscular walls of which they are, in the absence of any cilia upon their external surface, dependent for fresh supplies of water and aeration. The gills of the Nautili differ from those of the Dibranchiata not only in their number, but also in being attached only at their bases. The renal organs take the shape of bilaterally symmetrical spongy appendages to the stems into which the vena cava divides, and which carry its blood to the similarly bilateral gills. Certain orifices in the branchial chamber exist, by means of which the secretion of these organs can more or less directly find its way into the external water.

The three typical pairs of excitomotor ganglia are readily recognizable in the Cephalopoda as in all other Mollusca proper, the anterior position of the pedal ganglia and of their cerebro-pedal commissure to the visceral or parieto-splanchnic ganglia, and their cerebro-visceral commissure, being as readily demonstrable in these, the highest, as in the Lamellibranchiata, the lowest of the Mollusca proper. The accessory nerve-systems, however, which this latter class does not possess, attain a high development in the paired stomatogastric, parietal, and branchial ganglia, as also in the unpaired stomachal and other visceral ganglia of Cephalopoda. An olfactory organ appears to exist in Cephalopoda in addition to the highly-developed eyes and the auditory organs.

The Cephalopoda are always dioecious. The reproductive glands differ from most of their other organs in not being bilaterally symmetrical, and they differ from those of all other Invertebrata, except certain of the Vermes, in setting free their respective 
products into the cavity of a compartment of the perivisceral space, whence they are taken up by the open mouth of the efferent generative duct, as the ova in most Vertebrata are taken up by the Fallopian tubes. The oviducts are bilaterally symmetrical in the sub-order Octopoda, and in the genus Ommastrephes; but both male and female efferent ducts are in all other Cephalopoda unpaired like the glands with which they are in relation. The male and female Cephalopoda are distinguishable from each other by external differences, and most markedly by the modification of one of the arms or tentacles of the males to serve as an intromittent organ, the so-called 'Hectocotylus,' which in some species, Argonauta argo, Octopus carena, Tremoctopus violaceus, and Tremoctopus Quoyanus, is set free from the male animal, and, probably, reproduced after each act of sexual congress. The Cephalopoda differ from other Invertebrata in the very large proportion of the yolk which escapes segmentation; and with the large size of the nutritive yolk we may correlate the fact that the embryos do not undergo any metamorphosis after leaving the egg.

The Tetrabranchiate differ from the Dibranchiate Cephalopoda in the following particulars besides those which their name connotes. They have an external shell, to which the body is attached by strong muscles, but no ink-bag; their tentacles are much more numerous, but are not armed with the suckers which gave the Dibranchiata their name of 'Acetabulifera;' their internal cartilaginous skeleton is limited to the head, and does not there form a perfect ring; the two halves of their 'funnel' are not anchylosed, but project by two free edges into the mantle cavity, where they form a tube by mutual apposition; their blood-vascular system appears to be less sharply differentiated from their water-vascular or perivisceral, and their eyes are pedunculate. The families Nautilidae and Ammonitidae make up the entire order Tetrabranchiata, and are represented in the Silurian formations by numerous genera, species, and individuals, whilst at the present time the order is represented only by the rare Nautili, the living species of which are variously stated to be two, four, or six. The more highlyorganized Dibranchiata have attained their greatest development as an order in the modern Period, but make their first appearance in the Triassic formation. They are divided into three sub-ordersthe Decapoda calciploora, to which the existing Spimtidae and 
Sepiadae, and the extinct Belemnitidae are referred; the Decapoda chondrophora, which do not possess a calcified shell, but a horny 'pen' or 'gladius;' and the Octopoda, which, with the exception of Cirroteuthis, have no internal shell.

\section{Class, Gasteropoda.}

Mollusca, distinguished as a class from the Pteropoda and Cephalopoda most obviously by the characters of their ' foot,' which is ordinarily flat and sole-shaped, and adapted for crawling. Usually the foot is not divisible into a propodium, mesopodium, and metapodium, though the posterior part of the organ is nearly always well developed, and even when no division exists to denote its typically trifid character, the presence of an operculum frequently enables us to differentiate its metapodial portion. In the Heteropoda however, and in the Strombidae, the three divisions of the foot are very clearly distinguishable; and the epipodium is occasionally recognizable, as in Aplysia and Turbo. The foot proper may be longitudinally divided for crawling, as in Phasianella, or expanded into lateral lobes for swimming, as in Gasteropteron and Bullidae; or it may be adapted for the purpose of swimming by being converted anteriorly into a vertical fin, whilst it retains its ordinary caudate shape posteriorly, as in the Heteropocta. Finally, the foot may be merely rudimentary, as in Glaucus, Ianthina, and Termetus.

'The Gasteropoda count among their number the only representatives of the Sub-kingdom which have attained to aerial respiration, and they form by far the most numerous of all Molluscan, and, with the exception of the Insecta, of all animal Classes.

Their digestive tract is almost invariably more or less convoluted, and with the exception of the parasitic Entoconcha mirabitis, and possibly a few Apneusta (see Baur, Nova Acta, I 864, p. 7I), it is always proctuchous. The mouth and anus are ordinarily near to each other, but are never in the same median plane. In certain Apneusta and Nudibranchiata, the intestinal tract takes a straight antero-posterior course, but is provided with lateral gastro-hepatic diverticula, which give it much the appearance of the digestive tract of one of the Dendrocoelous Planarian or Trematode Vermes. The heart, which has been supposed to be absent in the Gasteropoda just mentioned, does not seem to be so in any member of the class 
except the Entoconcha and Rhodope; it is sometimes, as in Chiton, Neritina, Haliotis, perforated by the rectum, as is the case in the Lamellibranchiata, to which some of these Gasteropoda furnish an additioual point of resemblance in possessing two auricles. In many, though probably not in all Gasteropoda, the perivisceral cavity is in direct communication with the blood-vascular system. There may be no specialized organ of respiration; gills, however, are ordinarily present, except in the Pulmonata, where atmospheric air is inhaled into a cavity formed by the mantle. The renal organ is single.

The Gasteropoda may be either dioecious or hermaphrodite. In a fer dioecious species which are, as Termetus and Siliquaria, fixed to one spot, there is no sexual congress, but the ova are fertilized by the spermatozoa finding their way to them after being set free into the water; and in a ferv of the hermaphrodite species, such as Tergipes Edwarlsi and Limnaea anricularis, heautandrous impregnation has been observed to take place. But with these exceptions, sexual congress always precedes impregnation, and indeed all reproduction, in Gasteropoda. The accessory reproductive apparatus is greatly developed and complex in the hermaphrodite orders, $P u l$ monata and Nudibranchiata, whilst in some of the dioecious orders, Cyclobranchiata and Aspidobranchiata, even the intromittent organ may be wanting, and mieroscopic examination may be necessary for the distinguishing of the sexes. Gasteropoda are all but universally oviparous, the yolk undergoing segmentation, and manifesting the phaenomenon of rotation whilst within the egg. When the embryo is set free from the egg, it ordinarily goes through a metamorphosis which is marked by the possession of a provisional organ in the shape of a bilobed ciliated locomotor velum. The embryos of the Pulmonate, in which order the ova may attain a very great size, may possess from the first the form and organization of the adult animal, but provisional organs have been observed in their development (Limax) as in that of Branchiogasteropoda.

\section{Class, Pteropoda.}

Mollusea of small size varying from $I^{\prime \prime \prime}$ to $3^{\prime \prime}$ in length, of pelagie habitat, of nocturnal habits, with the head and eyes rudimentary, and with the epipodia largely developed and constituting swimming organs. The foot proper is ordinarily much reduced in size and 
importance, but its various divisions, propodium, mesopodium, and metapodium, may sometimes be all recognizable in the interspace between the epipodial alae. The processes corresponding to the propodium may be, like the arms of the Cephalopoda, armed with suckers; and these latter structures may be, as in Clione Borealis, set in great numbers upon certain circumoral retractile upgrowths, which may correspond both to the acetabuliferous arms, and to the buccal membrane, (itself also sometimes, as in Loligo, acetabuliferous in members) of that highest class of Mollusca. The Pteropoda may further resemble the Cephalopoda by having, as in Cleodora, their ordinarily large mantle cavity opening on the ventral or neural surface. This cavity, however, may open upon the dorsal surface, as in Gasteropoda, and it may be absent altogether, as in Clione. The heart consists of a ventricle and auricle, and gives off an anterior aorta which passes forwards through the nerve-collar to supply the epipodial swimming organs. The small size of their bodies enables them to dispense in most cases with branchial organs, both in the families provided with a shell (Thecosomata), and in those destitute of it (Gymnosomata). Their renal organ has the normal internal communication with the pericardial blood-sinus, as well as an opening on to the exterior, but its walls may be either merely hyaline, or contractile, without secretory tissue; or thirdly, spongy and glandular, as in the conchiferous families Hyalea and Cleodora. The eyes and, usually, the sensory tentacles are more or less rudimentary. Auditory vesicles are always present, and in relation with the pedal ganglia.

The Pteropoda are hermaphrodite. The embryos go through a metamorphosis, being provided, when set free from the egg, with a bilobed ciliated velum, which is replaced by the epipodia. The Gymnosomatous Clionidae and Pnenmodermidae go through a second stage of metamorphosis, in which they have three zones of cilia.

Most of the points of degradation, or simplicity, observable in the structural arrangements of the Pteropoda, appear to be referrible either to their nocturnal habits, which have entailed a stunting of the cephalic organs, or to their minute size, which has rendered any complex evolution of the circulatory and respiratory organs unnecessary. They have frequently been classed as an order of Gasteropoda, but the general relations of their motor organs and their mantle cavity appear to approximate them rather to the Cephalopoda, without however justifying us in ranking them as an order of that class. 
On the other hand, the Pteropoda are closely allied to the Dentalidae, the Solenoconchae of Lacaze Duthiers, or Prosopocephala of Keferstein; and this aberrant order, though possessed of a 'tongue,' of cephalic tentacles, and of epipodial lobes, as well as a foot proper, has nevertheless been separated from the Odontophora, on account of the many points of aflinity which subsist between it and the Lamellibranchiata. The most important of these appear to be, the bilateral character of the organ of Bojanus, and of the generative gland; the absence of any accessory reproductive organs, either glandular or intromittent; the absence of sexual congress and the consequent extra-corporeal fertilization of the ova; and the singleness of the larval velum. Each one of these points, however, is reproduced either amongst the Cephalopoda or the Gasteropoda, and the sum total of them therefore proves, not that the Dentalidae ought to be dissociated from, but merely that the Lamellibranchiata are rightly associated with the Odontophora, as Mollusca proper, notwithstanding these points of degradation. The organization of the Dentalidae is modified for their special habit of living immersed, during the daylight at least, in the sand; and as many of the points of difference between them and the natatorial Pteropoda may be explained by a reference to this peculiarity, whilst such points of resemblance as the likeness of their larvae to those of Pnumodermon and Clione are of purely morphological value, the two sets of animals may, as suggested by Mr. Huxley, be placed together in a class which would have very generalized affinities on the one hand to the Cephalopoda, and on the other to the non-odontophorous Mollusea s. Lamellibranchiata.

\section{Class, Lamellibranchiata.}

Mollusca, which, while agreeing with the other three classes of the Suls-division of Mollusea proper in the properties distinguishing it from the Sub-division of Molluscoidea, differ from them in having* a bivalve shell secreted by a medio-dorsally attached and bilaterally symmetrical mantle, in the absence of odontophore, of salivary glands, of stomato-gastric and sympathetic nerve-ganglia, in the great size of the collars formed by the cerebro-pedal and cerebrovisceral nerve-commissures, in the bilaterality of their reproductive glands, and in the absence of any aecessory reproductive organs. 
In having their organs bilaterally symmetrical in relation to a vertical antero-posterior plane, the Lamellibranchiata differ from the Gasteropoda and Pteropoda, but not from the Cephalopoda. Their bivalve shells differ from those of the Brachiopoda in being placed one on either side right and left of the antero-posterior axis of the body; in being scarcely ever equilateral; in being very frequently equivalve, except as regards the hinge; and in having the hinge opened by the action of an elastic ligament, and closed by that of one or two transversely-running adductor muscles. Their foot is ordinarily compressed from side to side, so as to be hatchetor ploughshare-shaped. It may be rudimentary, and not rarely secretes a 'byssus,' whereby the animal attaches itself to one spot. It never developes an epipodium, nor presents the trifid division into propodium, mesopodium, and metapodium. Movement is effected ordinarily by means of the foot; but in some instances, as Pecten, by the alternate opening and shutting of the valves. Two or more pairs of retractor, and one pair of protractor muscles, may be present to act upon the foot and visceral mass from bilateral points of attachment to the valves of the shell. In the absence of any prehensile or manducatory organs, the Lamellibranchiata are dependent for the ingestion of food upon the currents set up by the cilia covering not only all their external organs, except the outer surfaces of their mantle, but also lining their alimentary canal. The mouth is provided with labial tentacles, which are homologous with the arms of the Brachiopoda.

The digestive tract has its anterior segments closely and inseparably connected with the visceral mass made up by the hepatic, and in some cases by the reproductive coeca, after disengaging itself from which it, with some exceptions (Ostrea, Anomia, and Teredo), passes through the ventricle of the heart, before passing over the main adductor muscle of the two valves to end in a cloacal atrium. The ventricle of the heart is, with the exception of Arca, single, whilst the auricles are, with the exception of Anomia, bilaterally symmetrical relatively to a median vertical plane, like the gills and the organs of Bojanus. Gills are universally present, and are in most cases two in number on each side. They take ordinarily the shape of laterally-compressed multi-fenestrated pouches, attached along the upper line of the mantle cavity, much as the leaves of a book are attached to the interior of its 
covers; but in some cases, as Pecten, Spondylus, Trigonia, owing to the absence of the antero-posterior elements of the lattice-work, the gills may be reduced to rows of comb-like processes, as in a Pectinibranchiate Gasteropod, or in an osseous Fish. Ordinarily, there are two gills on each side; there may, however, be only one, as in Lucina and Corbis; and in these cases it is always the external pair which is absent. It is later to be developed, and very often smaller, when present, than the inner gill; and in some cases it serves as a marsupial pouch, in which the ova are impregnated by the spermatozoa brought to them by the inhaled water, and go through certain stages of embryonic development (see p. 65, infia). The renal organ is always bilaterally symmetrical; it consists ordinarily of an excretory sac, which opens into the mantle cavity, and of a secretory lamellar and glandular sac, which opens internally into the pericardial blood-sinus; but it may consist only of a single sac on either side, which communicates with its fellow, but probably not with the pericardial cavity. The external orifice of the organ of Bojanus may receive the duct of the generative gland of its own side of the body, or that duct may open within the organ, or independently of it, but at a short distance from its external orifice.

The Lamellibranchiata never possess any stomato-gastric nor sympathetic ganglia; but they may have accessory ganglia developed for the innervation of certain of their organs of animal life when these are largely developed, as in the cases of the siphons of some of the siphonate families, and of the sensory organs developed along the free edge of the mantle lobes.

The Lamellibranchiata are, with a few exceptions, such as Ostrea and Cyclas, dioecious. The generative glands are always bilaterally symmetrical, and never possess any accessory glandular or intromittent organs. There is no sexual congress in this class; the spermatozoa find their way to the ova either in the circumambient water, or in the cavity of the mantle ${ }^{a}$; or in that of the outer gill; or in the cloacal space; or in the fer viviparous species, Kellia, Galeomma, Montacuta, within the ovary itself'. 'The embryos always go through a more or less complex metamorphosis,

a See Description of Preparations, pp. 54-66, infra; and Description of Plate V. pp. 193-198, ibique citata. 
in which they are provided with a unilobar ciliated velum. The fresh-water species, as is often the case, go through less complex changes than the marine; and in one instance, that of Cyclas Corwea, the foot, and not, as usual, the mantle with its shell, has been stated to have been the first organ which differentiated itself in the germinal membrane. The unilobar velum may be armed with a flagellum, and in the marine species come to resemble the homologous organ of the Dentalium.

The Lamellibranchiata are mostly marine. They may be either fixed or free. They are never social in the sense of being organically connected, but the peculiarities of their reproductive functions render it necessary in their case, as in those of many similarly conditioned creatures, that they should be massed in considerable numbers upon the same spot.

\section{Class, Brachiopoda.}

Molluscoidea with bivalve shells, which admit of being opened, though usually not widely, either by means of a hinge acted upon by muscles, or by muscles alone, but which are not provided with an elastic ligament as are those of the Lamellibranchiata, to which the term 'bivalve' is sometimes exclusively applied. The shell of the Brachiopoda differs from that of the Lamellibranchiata further in being almost always equilateral, but not equivalve, and in having its valves articulated across and not along the dorsal ridge. They are in the adult state always fixed; either, as ordinarily, by a peduncle which is attached to the internal surface of a 'ventral' shell, placed in the living' animal superiorly to a shell called, from its relation to the heart, 'dorsal,' or by the attachment of the ventral shell, then placed inferiorly, to some marine object. Larval Brachiopoda have been observed to move from place to place in two ways; viz. either by means of the ciliated epithelium covering their arms, which are then protruded as is the lophophore of a Polyzoon, or by means of spines implanted in the ventral lobe of the mantle. The Brachiopoda are ordinarily said to be dioecious, and in Thecidium the sex can be predicated from an inspection of the shell; but observations exist to show that hermaphroditism also exists in this class, as in some representatives of every molluscan Class, except the Cephalopoda. They are never social, though, as is 
ordinarily the case with animals which are destitute of the porver of moving from place to place, and thus accomplishing sexual congress, they are found frequently placed closely together. They are always marine. They fall into two great Sub-classes, accordingly as they possess, or as they are destitute of an anus. The proctuchous Sub-class is represented byLingulidae, Discinidae, and Craniadae; the aproctous by Rhynchonellidae and Terebratulidae. The proctuchous Brachiopoda differ from the aproctous in having no hinge to their shell, in having a vasiform instead of a globular heart; in having a convoluted intestine instead of one describing but a simple curve; in the much smaller evolution of their nervous system, the existence of which has not, as yet, been fully demonstrated; and in the limitation of their generative glands to their perivisceral chamber. In the existing species of Brachiopoda provided with a hinge, a calcareous process of greater or less length and of various shapes is given off from it for the support of the arms. Some fossil articulate Brachiopoda were destitute of these calcified supports, and they are absent in all the hingeless Sub-class. The mouth opens as a simple unarmed transverse slit between the two arms; and it is by the action of the cilia covering their cirri that the ingestion of food, as also the aeration of the blood, is effected. The mantle cavity, a very large part of which is occupied in all Brachiopods, and especially in the aproctous Sub-class, by the arms, is continuous through the oviducts or 'psendo-hearts,' with a multiramified system of interviscerally-placed cavities and canals, which make up the perivisceral system, and in Terebratulidae are prolonged into the arms. 'The 'pseudo-hearts,' or oviducts, consist each of them of two segments-the one which opens externally being tubular, and the one which brings the exterior communication with the perivisceral cavities being of wider calibre. They appear to correspond with the organs of Bojanus in the Lamellibranchiata. They give passage outwards to the products of the generative glands.

A nerve-system has been rlemonstrated in the hinged Brachiopoda, and consists of five ganglia, connected so as to form a collar around the commencement of the ocsophagus. Three of these ganglia are placed below the oesophagus, and the other two at the base of the arms. 
For a monograph upon the organization of the Brachiopoda, see Hancock, Phil. Trans., $185^{8}$; see also Lacaze Duthiers, Comptes Rendus, 1865 , ii., p. 800.

For a monograph of the species Thecidium Mediterraneum, see Lacaze

Duthiers, Ann. Sci. Nat, Ser. iv., tom. xv., I86I.

For the microscopic structure of the shell, see Carpenter, Palaeontographical Society's Memoirs, I 853, pp. 23-40.

For an account of a larval Brachiopod with figures, see Fritz Müller,

Reichert und Du-Bois Reymond's Archiv., 1860, p. 72, Taf.i., figs. I and 2.

See also pl. xi, fig. 2, and Description, pp. 232-234, infra.

\section{Class, Tunicata.}

Molluscoidea, which may be either solitary or social, either fixed or free, but which are exclusively marine and are never aproctous. The animals communicate with the exterior by two orifices, pierced in a sacciform envelope, and here regarded as homologous with the inhalant and exhalant siphons of the siphonate Lamellibranchiata. As in those animals, the inhalant orifice brings into the organism not only food and oxygen, but also spermatozoa, which find their way to the ova by a route homologous to that described as taken from the neural to the haemal surface of the gill, by the male element in the Anodon (see pp. 64, 65, infia); and consequently over and along a structure which is regarded as the homologue not of a dilated pharynx, but of the gills of the bivalves. The external envelope of the Tunicata, from the external form of which the name 'Ascidiae' was given to the class by Savigny, is of very various consistency, and of very various histological appearance; but it always secretes cellulose within its substance, and is made in the way of conversion, and not in that of excretion as is the case in other members of the sub-kingdom. In Tunicata as in Lamellibranchiata, the anus and generative ducts open into a space lined by the internal tunic, more or less separable from the muscular mantle; but in the cloacal space of the Tunicata there is no posterior adductor nor any specialized organ of Bojanus, though there is contained in it their single nerve ganglion, which supplies parts homologous with those supplied by the parieto-splanchnic of the Lamellibranchiata. The heart of the Tunicata is ordinarily elon- 
gated and vasiform, with one end directly connected with that side of the branchial organ which is opposite to that nearest the rectum. Its action is periodically reversed during life; but this end of the heart may be regarded as the homologue of the vessels which bring blood to the heart, whilst the other end may be considered to represent the systemic aorta of bivalves. The Tunicata are hermaphrodite, but may multiply by gemmation as well as sexually. With the exception of Salpa, they all go through a metamorphosis, the larval form being caudate and active.

The larvae of certain sessile Ascidians, Phallusia mammillata, Phallusia intestinalis, and Phallusia canina, have been recently described by Kowalewsky and Kupffer as possessing in their caudal appendage a structure closely similar to the chorda dorsalis previously held to be a distinctive characteristic of Vertebrata ; as having their nerve-centres formed by the fusion of lamellar upgrowths into tubes, in the manner which had been similarly supposed to be peculiar to the higher Sub-kingdom, thence spoken of as 'bicavitary ;' and finally as having the caudal axiscylinder resembling the vertebrate chorda dorsalis either actually interposed between one part of their nerve-centres, or, at least, so placed, that if prolonged, it would come to be so interposed. . . . It may be added that Professor Gegenbaur, in the recently published second edition of his 'Grundzüge der Vergleichenden Anatomie,' p. I 58, 1870 , has placed the Tunicata in the Sub-kingdom Vermes, assigning in justification of this step the fact that the peculiar specialization of the anterior segment of their digestive tract as a respiratory organ finds a parallel in the organization of a rare order (or Class) of worms, the Enteropneusti, represented by two species, the Balanoglossus clavigerus, and the Balanoglossus minutus found on the Neapolitan coast. See Kowalewsky, Mem. Acad. Imp. St. Petersburgh, Ser. vii., Tom. x. 3, I866. Against this is to be set the close correspondence in the way of homologies which may be shewn (see infra, pp. 66-69, 235, 236) to exist between at least the adult Tunicate and the Lamellibranchiate organism.

\section{Class, Polyzoa.}

Molluscoidea which are always social; and, with the exception of Cristatella and, perhaps, also Lophopus and Selenariadae, always fixed in their adult state, in a 'polyzoary' or 'coenoecium.' This structure, which is either erect or adnate, and, under 
either of these conditions, may be either dendritic or foliaceous, is more or less flexible or rigid, accordingly as the ectocyst of each polypide is more or less hardened by calcareous or siliceous deposit. The animals are never aproctous, but there is only a single orifice in each cell for both month and anus, though, when the polypide is protruded, a considerable interval intervenes between these two terminal apertures. The digestive tract is freely suspended in a perivisceral cavity; which, as these animals possess neither heart nor generative ducts, serves as a receptacle for the blood at all times, and for the products of the generative glands at the periods at which they come to maturity. The mouth opens always between the two lips of a lophophore; both lips being also always, with the exception of Pedicellina, beset with tentacles. The lophophore itself may be circular, as in all marine species, with the exception of the family just named, and of Rhabdopleura; or it may be prolonged into two arms, extending from the mouth towards the neural or rectal aspect of the animal, as in all freshwater' species, hence called 'hippocrepian,' except Paludicella and Umatella. In the freshwater species the tentacles are connected at their bases by an infundibuliform membrane, known as the 'calyx;' and the mouth is guarded by a valvular organ, the ' epistome,' by virtue of their possession of which they have been classified as 'Phylactolaematous,' in contradistinction to the 'Gymnolaematous' marine sub-orders. The lophophore, being attached round the mouth, either by its entire circumference, as in the marine Polyzoa, or by the base of its two arms, as in the hippocrepian representatives of the class, forms a roof to the perivisceral space, with which cavity, the cavities of the lophophore, of the entire series of tentacula which it carries, and of the epistome when present, are freely continuous. The tentacles are not flexible in the Polyzoa, with the exception of the Pedicellineae, and probably some allied forms. Both the external and the internal surfaces of the lophophore and its tentacles are clothed with cilia, the action of which subserves the functions of ingestion of food, and of aeration of the blood. The interior of the periviseeral space is also similarly clothed with cilia; and the movements of the blood between the mutually intercommunicating cavities of the lophophore with its appendages and the general perivisceral system, are further carried out by the contractions of the muscular fibres of the endocyst, and 
of the retractor and protractor muscles of the entire polypide. The nerve mass situated between reetum and oesophagus, has been figured and described as sending filaments to the lophophore, tentacles, epistome, digestive tract, evaginable endocyst, and retractor muscles, and as also throwing a collar round the oesophagns ; and it may consequently be considered as representing both the parietosplanchnic and the cerebroid ganglia of higher Molluses. Reproduction in the Polyzoa is both sexual and asexual. The asexual takes place in the way of gemmation; and in the case of the Fresh-water Polyzoa by means of 'statoblasts' or gemmae, in which the developmental activity remains latent for a period. The Polyzoa are hermaphrodite; the testes being situated near the bottom, the ovary being attached to the parietes of the upper part of the cell. It is by gemmation that the polymorphic organisms. known in Polyzoa as 'ovicells,' 'avicularia,' and 'vibracula' are produced; and in Serialaria, where the entire colony may have its individual polypide brought into connection by a common nerve-system, we find some cells modified for the discharge of purely passive functions, as 'stem-' cells and 'root-' cells.

The Polyzoa have, like the Tunicata, been removed from the Subkingdom Mollusea by Gegenbaur and Haeckel, and classed with the Vermes. The inosculant form Loxosoma described by Kowalewsky (Mem. Acad. Imp. St. Petersburgh, Ser. vii., Tom. x. 2) has been supposed to connect them with this latter Sub-kingdom. Against this view we must set not merely the many structural homologies which can be pointed out as existing between adult individuals of the undoubtedly Molluscoid Classes Brachiopoda and the Polyzoa; (for which see p. 72, infica, ibique citata), but also the striking similarity which the larval form of a Brachiopod has been observed by Fritz Müller to present to the Polyzoa with orbicular lophophores such as all the marine suborders with the exception of Pedicellinea. See Reichert und Du-Bois Reymond's Archiv. für Anatomie und Physiologie, p. 79, 1860.

For an account of the nervous system in Serialaria, see Fritz Müller, Archiv. für Naturgeschichte 1860, p. 3 I I , Taf. xiï. 


\section{Sub-kingdom, Arthropoda.}

Animals consisting of a series of more or less heteronomous segments, the 'Metameren' or 'Folgestücke' of Haeckel, to which jointed appendages are articulated ventrally in pairs, and, ordinarily, in very different proportions and grades of development in the different regions of the body. These appendages are, in contradistinction to those of Vermes, hollow, and have muscles prolonged into their interior. This external integument is rendered more or less rigid by chitinous deposit, which may be made still more resistent by calcification. Chitinization extends itself from the exterior into the interior, and in many cases an endophragmal skeleton is thus formed, which arches over the ventrally-placed portion of the nervous system. Tubular prolongations of the cuticular chitine extend inwards along the various ducts and canals opening on to the exterior, and are shed together with the integument in the moultings which these animals, so long as they continue to grow, must necessarily go through.

The chitinous deposit at the commencement of the digestive canal may take the shape of 'lips,' or even of non-segmented processes, like the 'jaws' of certain Vermes, but the true functional jaws of Arthropoda are always produced by the modification of the hollow segmented appendages of more or fewer of the anterior segments of the body. The organs of special sense are ordinarily confined to the prae-oral segments, and, like the rest of the appendicular skeleton with which they are, either actually or morphologically, connected, contribute at least as much to the heteronomy of the external appearance as the segments upon which they are carried.

The antennae, eyes, and auditory organs are all but invariably limited to the prae-oral cephalic segments, and the muscles of the chitinous elements of the segments are never found to form continuous antero-posterior layers, as in Vermes, corresponding with the length and often with the circumference of the body. On the other hand, the chief internally-placed system of animal life, the gangliated nerve-cord, presents a striking resemblance to the homologous system in Vermes; and the respiratory system of certain Myriopoda appears to attain in its stigmata an approximation to 
correspondence with the number of the segments of the body, which resembles that manifested by the multiple respiratory organs of many Annulata. But the circulatory, depuratory, and reproductive organs are never found to be thus multiplied, such segmentation as they may exhibit being ordinarily limited to one, and that the abdominal region of the body. The digestive tract takes ordinarily a very direct antero-posterior course, rarely presenting any lateral diverticula except in Arachnida, or any convolutions, except in adult Insecta, and some Cladocera. This latter Crustacean family has the anus placed dorsally, and some way anteriorly to the termination of the body segments, and furnishes an exception to the general rule, that the intestine in Arthropoda ends in the last segment of the body. Except in the larvae of Hymenoptera and of Myrmeleon, the intestine is always proctuchous. But in the suctorial Cirripedia, and in the 'complementary males' of the other families of that order, as also in a suctorial Entomostracan, Monstrilla Danae, the digestive tract is wanting altogether, and the mouth when, as in the last case, present, leads directly into the general cavity of the body. A heart is very usually present, underlying the dorsal elements of the abdominal segments, and ending in an aorta in the thoracic region. It is usually vasiform and segmented, lateral apertures at the anterior end of each segment serving as venous inlets for the blood filling the pericardial sinus in which the heart is suspended by means of the elastic alae cordis. The circulation is always more or less extensively lacunar; even arteries may be wanting.

Accordingly, as the respiration is aquatic or aerial, the Arthropoda are divisible into two great groups, one of which is constituted by the Crustacea, in which respiration is branchial, or in the absence of branchiae, carried on in water by the general surface of the body; and the other by the other three classes, Arachnida, Myriopoda, and Insecta, in which respiration is effected by the admission of air into the interior of the body by tracheae, or some modification of those organs. The air-breathing Arthropoda agree with each other, and differ from the Crustacea in the following points:-they never have two pairs of antennae; and, with the exception of certain Ephemeridae, Strepsiptera, and Diptera amongst Insecta, and certain Epeirae amongst Arachnida, their eyes are never pedunculate; their mandibles are not palpate; one 
or both pairs of maxillae are more or less completely fused mesially so as to form a functional lower lip; and, with the exception of the lower Myriopoda, their post-abdominal segments, when present, rarely or never carry appendages with locomotor functions in the adult state. The portion of the supra-oesophageal ganglionic mass which corresponds with the eyes, is much larger relatively to that which corresponds with the antennary organs than it is in Crustacea; and in exact opposition to what we observe in this latter class, we find the salivary and renal organs largely developed, and the hepatic only represented rudimentarily. The digestive tract is never aborted in air-breathing Arthropoda, nor aproctous in adult individuals. Except in certain lower Crustacea and Arachnida, where the supra-oesophageal nerve-mass is represented simply by a fibrous commissure, the nerve-system consists of supra-oesophageal and of ventrally-placed ganglia, connected with each other so as to form a collar round the oesophagus, and connected with a sympathetic system ordinarily consisting of a 'stomatogastric' division and of 'nervi transversi.'

All Arthropoda, with the exception of the Cirripedia and Tardigrada, are dioecious, and, with the exception of the Tetradecapodous or Hedriophthalmatous Crustacea, and cornuted Insecta, the males are ordinarily smaller in size than the females. Reproduction is ordinarily sexual, but both parthenogenesis and asexual genesis by means of pseudovaria, if not also by internal metagenesis without the intermediation of such structures, are known to occur in this Sub-kingdom. The Arthropoda are ordinarily oviparous, but are sometimes viviparous, and even pupiparous. Except in the cases of certain of the lower Crustacea and Arachnida, the segmentation of the yolk is always partial, and the first appearance of the embryo takes the shape of a 'primitive streak.' Though the embryos of Arthropoda very ordinarily go through more or less numerous stages of metamorphosis, neither larvae nor adults ever possess cilia. In the more usually observable forms of metamorphosis, the embryo leaves the egg not only with its reproductive system, but also with its motor and sensory organs in a less perfect condition than those of the adult; in the less ordinary, or retrogressive metamorphosis, observable in parasitic families, the animal organs of the larva are more perfect than those of the adult. In both cases, change of tegument accompanies metamorphosis. 
The most essential difference between the various Classes of the Subkingdom Arthropoda, is that which tracheal and branchial breathing respectively correspond to, and with this principle of classification in view, we place the Crustacea, the earliest representatives of the Arthropodal type in geological times, apart from the other three Classes.

Within the limits of any one of these four Classes, the greater or lesser heteronomy of the several regions of the body, the greater or lesser extent, that is, to which the specialization of segments, and, even more, of appendages, has been carried out, constitutes the most important difference between one order and another, next to that which the actual abortion of segments or appendages entails.

The two Classes, Crustacea and Arachnida, differ from the Myriopoda and Insecta in comprehending much more varied forms; the Myriopoda contrast with the other three Classes by their low degree, whilst the Insecta are distinguished by their high degree of heteronomy.

The Crustacea and Arachnida are very closely approximated by such forms as the Cyamidae and the Pycnogonidae. This latter family is referred to the Class Arachnida mainly on account of the lateral diverticula which the digestive tract is furnished with, but there is reason to believe that some of its species possess free and functional antennae, and it should be considered therefore as Crustacean. If the parasitic Hedriophthalmatc, such as the Cyamidae, connect the Crustacea with the Arachnida on the one side, they connect them also with the Insecta through Pediculus on the other. A more striking, though perhaps not more real, link between the Crustacea and the Insecta and Myriopoda, is presented by the air-breathing Isopoda, such as Oniscus, on the one side, and the apterous Orthoptera and Glomeris on the other. The Arachnida approximate to the Insecta very obviously by such forms as Galeodes; and though their marked heteronomy and the definite number of their body segments cause them to differ very widely in external appearance from the Myriopoda, the peculiarities of their reproductive and respiratory systems appear to speak to the existence of a real affinity between them and the Chilognathous division of that class.

The Arthropoda have frequently been classed together with more or fewer of the Vermes in one Sub-kingdom, that of the 'Annulosa;' and whilst by such highly-organized forms as the Marine Polychata an approximation appears to be made to certain of the less specialized of the Crustacea; or even of the Myriopoda, or the larvae of Insects, amongst the air-breathing Arthropoda : the microscopic Rotifera connect the Vermes, to which Sub-kingdom they are to be referred, very closely to the Crustacea. The possession at one period, or, as usual throughout life, of 
hollow articulated and segmented motor organs, into the interior of which transversely striated muscles are prolonged, and the absence at all periods of cilia, are points which distinguish all Arthropoda from all Vermes; and a third point of nearly equal generality is furnished by the early appearance of a 'primitive streak' and the partial segmentation of the yolk in development. Fourthly, whilst in Vermes it is only rarely possible to differentiate the postcephalic segments into several regions, this is always possible in Arthropoda; the history of the development and that of the relation of the internal organs to the external skeleton rendering this possible even in the externally nearly perfectly homonomous Myriopoda, and in the most degraded representatives of the Crustacean Class as well as in such homonomous forms as certain of the Isopoda. Fifthly, true metagenesis is unknown in Arthropoda. The various organs and systems of the Crustacean, as being a water-breathing Class, appear to attain a lower degree of evolution than those of the other Arthropoda, and the Vermes may be supposed to approximate to them more closely than to any of the air-breathing classes ; but the points just specified will always serve to differentiate the members of the two Subkingdoms, howsoever closely they may at first sight resemble each other. Still it must be said, that the two Sub-kingdoms have their boundaries approximated at many points, if not along great lengths, in space ; and for a concrete illustration of this principle, the student is referred to the description of Echinoderes Dujardinii, an animal which, though classed as a Crustacean, combines with many of the characters of Arthropoda many also of those of such Vermes as the Nematelminthes and the Oligochaetu, and has been pointed out by Claparède, (Anatomie und Entwickclungsgeschichte Wirbelloser Thiere, I86, p. 92,) as constituting a link between these two Sub-kingdoms.

\section{Cisass, Insecta.}

Air-breathing Arthropoda with well-marked heteronomous division of the adult body into three distinct regions, the head, thorax, and abdomen. The middle region, or thorax, is composed of three segments, the prothorax, mesothorax, and metathorax, each of which has a pair of jointed appendages, the legs, articulated to it ventrally, whilst each of the two posteriorly-placed segments has also, ordinarily, a pair of unsegmented appendages, the wings, or the wingcovers, articulated to it dorsally.

A post-abdomen is never very obviously marked off from the 
abdomen, but there are not wanting more or less obscure indications of the presence of three segments between the generative outlet and the terminally-placed anus, which may be considered as representing the post-abdomen. The abdomen proper never carries any articulated appendages in adult insects, with the single exception of the Coleopterous Spirachtha Eurymedusa, in which the third, fourth, and fifth abdominal segments each carry a pair of biarticulated appendages. The post-abdominal segments however may carry segmented appendages both in the adult and in the larval condition, but these organs, though they may attain a considerable development, especially in Orthoptera (Chloeon dimidiatum), do not appear to possess locomotor functions in adult insects. The motor organs are mainly localized in the thoracic, the vegetative in the post-thoracic regions. None of the thoracic segments are ever, except in certain Coccina, fused with the cephalic, nor are any thoracic appendages ever modified so as to serve as manducatory organs. The greater relative size of the eyes gives as distinctive a character to the head in this Class of Arthropoda as its freedom from fusion with the thorax. The mandible has never even a rudiment of a palp; and the second pair of maxillae are always more or less completely soldered together so as to form a functional lower lip, the 'labium' of entomologists. The digestive canal is never aproctous except in the larvae of most Hymenoptera, of the parasitic Diptera, and of Myrmeleo. In these larvae the renal organs open into what is subsequently by moulting brought into communication with the blind end of the digestive tube, and so converted into a ' rectum;' the entire apparatus previously to this change bearing a striking resemblance to the so-called 'water-vascular' or excretory system of certain Vermes. The digestive tract presents more numerous and more distinctly distinguishable divisions than in other Arthropoda ; and it is often, at least in adult insects, arranged in convolutions, and is thus longer relatively to the body than in other members of the Sub-kingdom. The salivary glands may be large and racemose as in Orthoptera, or very small and tubular as in the adult Lepidoptera. The liver appears to be represented by certain coeea which are set round the commencement of the digestive tract in varying numbers in the Orthopterce and Hemiptera, the great development of the respiratory tracheal system appearing to compensate for this rudimentary or aborted condition of the hepatic 
organ, as in the reverse way the great development of the liver in Arachnida may be supposed to compensate for their less developed aerating organs. The other set of depuratory organs, those, namely, which are charged with the direct elimination of effete nitrogenous substances, are always, with the exception of Aphis, Coccus, and Chermes, present in insects as the 'Malpighian vessels.' The tracheae of insects inosculate or anastomose in various parts of their course, but the capillary tracheae in which the spiral thickening of the inner lining membrane may fail to be developed, end blindly in the tissues to which they are distributed. The aquatic larva of one insect, Chloeon dimidiatum, has no tracheae developed in the first three stages of its larval life, but subsequently, like the larvae of many other Orthoptera, Neuroptera, and Diptera, has tracheae developed which are exposed to the action of the oxygen dissolved in outgrowths known as 'tracheal gills.' These organs do not ordinarily possess any 'spiracle' whereby to come directly into communication with the air of the atmosphere, and must therefore obtain the oxygen they contain as gas from that which is dissolved in the water they live in. They may be said therefore to present us with an instance of an arrangement transitional in character between aquatic and aerial respiration. In a single insect, Pteronarcys regalis, one of the Orthoptera Amphibiotica, which is of lucifugous habits, and inhabits damp localities, tracheal branchiae are retained during adult life, but in other cases, when the insect leaves the water, the external lappets into which the internal tracheae send ramifications fall off, and the ordinary laterallyplaced spiracles are formed at the points of their separation.

The heart is a vasiform organ, consisting ordinarily of eight segments, with as many pairs of venous inlets. It underlies the dorsal elements of the abdominal segments, is ordinarily closed posteriorly, but ends anteriorly at the thorax in an aorta which may be prolonged forwards as far as the cephalic ganglia.

In Insects there is never wanting a ventrally-placed ganglionic mass in addition to the first sub-oesophageal centre, which by its commissural junction to the cerebroid mass forms the nerve collar. The first sub-oesophageal ganglia supplies the jaws, and though not so closely apposed to the supra-oesophageal centres as is the case in Arachnida, it is yet so close as often, but inconveniently, to have been spoken of as part of the 'brain.' The ganglionic centres 
placed posteriorly to it may be represented by a single continuous mass giving off nerves laterally and posteriorly; or they may take the shape of a chain of ganglia, which are never more than eleven, three being thoracic and eight abdominal, though by fusion or abortion they ordinarily fall below this number. The sympathetic system, both in its stomato-gastric division, and in that part of it which is in connection with the ventral ganglia and supplies the tracheae, attains in insects a large development. The eyes are always confined to the head; in a few instances, of which the Chloeon dimidiatum, one of the Orthoptera Amphibiotica, already mentioned, is one, as also in certain Dipterous, Strepsipterous, and Hemipterous genera, the eyes are elevated upon peduncles or pillars, which however are never movably articulated to the head. In most orders of insects, but most frequently amongst Hymenoptera, Diptera, and Orthoptera, the so-called ' simple eyes,' s. 'stemmata,' s. 'ocelli,' coexist with the larger multifacetted eyes.

The males and females are ordinarily very different in insects; the males, except in the cornuted species, being slighter in make, swifter, furnished with larger eyes and antennae, and more brightly coloured. The difference may be so great, especially when the females are apterous and the males winged, as to amount to a kind of Dimorphism.

The generative organs of Insects are very varied in the details of their arrangement. The reproductive glands are always double and symmetrical, but the efferent ducts always fuse into a common duct before opening. This they do posteriorly to the eighth abdominal segment; which is homologous with the third caudal segments of Scorpionidae and Crustacea, and therefore posterior by eight segments to the genital segment of the Arachnida just named, and to that of Limulus; and by three to the hinder of the two genital segments of the Decapodous Crustacea. The female generative organs of insects have often a large number of accessory appendages; the most constant of these is the 'receptaculum seminis;' but there may be present also an 'accessory gland' appended to the 'receptaculum seminis;' secondly, a 'bursa copulatrix;' and thirdly, a number of 'colleterial' glands which secrete a glutinous material for fixing the ova to various external objects. The male accessory organs are of two kinds, one of which is considered as analogous to the prostatic organ, and the other to the vesiculae seminales of Mammals. 
The segments of the body posterior to the eighth abdominal may be modified so as to serve in either sex as 'ovipositors' or as intromittent organs. There are no hermaphrodite insects, and sexual reproduction is the rule in the class.

Several forms of agamogenesis have been observed amongst Insects. In one of these, females with a reproductive apparatus provided with a receptaculum seminis produce (without any congress with males), either embryos, as Lecanium hesperidum, Chermes abietis, amongst the Coccina; or ova, as, amongst Lepidoptera, Psyche helix, Solenobia liclenella, and Solenolia triquetrella, and as, amongst Hymenoptera, Cynips, apterous Queen bees, and normal winged Queen bees before they leave the hive. In this class of cases sexual may alternate with asexual genesis, and it is to be noted that the male offspring of the Queen bees are only and exclusively due to the agamogenetic process. In a second class of eases, females with a more or less imperfect reproductive apparatus produce either ova, as is the case with the 'workers' amongst the social Hymenoptera, Apis mellifica, Tespa, Bombus, in which the vagina as well as the receptaculum seminis is rudimentary, and which, with, possibly, the exception of the Vespidae, always produce males; or embryos, as is the case with Aphis, in which certain generations without spermathecae or colleterial glands are viviparous agamogenetically, whilst others with a perfect sexual apparatus are oviparous gamogenetically. This form of asexual genesis is called 'pseudoparthenogenesis,' and the reproductive gland a 'pseudovarium.' Asexual genesis was supposed to take place metagenetically, that is to say, by a process of internal gemmation in a non-differentiated part of the body, in the larvae of certain Diptera of the family of Cecidomyidae; but the diseovery, by Leuckart, of specialized germproducing organs in these animals appears to show that the only differences between this process and that observable in Aphis consist in its taking place in forms of a holometabolous order, which, as being larvae, are very different in external appearance from the perfect sexual insect, and in the 'pseudovaria' being destitute of any 'pseudoviduct.'

In the development of the ovum the yolk is surrounded by a germinal membrane, in which the first traces of the head and the ventral half of the embryo make their appearance as the so-called 'primitive streak.' Insects are ordinarily oviparous, but they may 
be viviparous, and the larva in one sub-order (the so-called Pupiparae), is so far developed, by means of the nutriment furnished to it by a gland opening within the maternal oviducal canal, as to be nearly ready to enter upon the stage of chrysalis or pupa when set free from the mother's body. The form which an insect has on leaving the egg always differs more or less from that which it possesses when adult, and capable, as only full-grown insects are, of reproducing its kind by sexual genesis. The larvae of apterous insects, such as certain of the Orthoptera and Hemiptera, differ from the adult, irrespectively of the undeveloped state of the generative organs, only in such points as size, the number of joints in the antennae, and the number of facets in the corneae. It is only in the quantitative increase accruing to these two sets of organs of special sense that the adult after the entire number of its moults comes to differ from the larva in the way of heteronomy. A greater degree of heteronomy is attained to in the families of the two orders specified which are endowed with wings, by the superaddition of those organs, and by the concomitant greater differentiation of the thoracic from the abdominal region of the body. Insects which go through either of these two series of metamorphosis are called 'ametabolous.' A third kind of metamorphosis is that in which the adult insect, whilst gaining certain organs which the larva does not possess, such as wings, loses certain others, which the larva does possess, such as the provisional structures making up the 'mask' of the Libellulidae. Such insects are called 'Hemimetabolous,' and in them the heteronomy of the various regions of the body is always well pronounced. Insects, finally, which when adult do not only differ very markedly from their larval forms both by general heteronomy and by the conformation of their particular organs, but also attain to this condition after going through a period of quiescence known as the 'pupa' or ' chrysalis' stage, preparatory to their final moult and the assumption of the adult condition, are called 'Holometabolous.' A period of quiescence as 'pupae,' in addition to the period of quiescence as ova, gives the Holometabolous orders of Insects an advantage as regards their distribution over the colder regions of the earth, relatively to the orders the pupae of which are active; and, therefore though certain small Poduridce resist cold well, it is amongst the Holometabola that we find a nearer approach made to cosmopolitanism than is usual elsewhere amongst Insects. 


\section{Class, Myriopoda.}

Air-breathing Arthropoda in which the segments and their appendages make a nearer approach to homonomy than in either Insecta or Arachnida, and in which the post-cephalic locomotor appendages, even when least numerous, and amounting to nine pairs only as in Pauropus, are still more numerous than the similar organs in either of the two other classes mentioned, except in the larvae of certain IIymenoptera, Cimbex and Tenthredo, which possess eight and seven pairs, respectively, of prolegs, besides the three pairs of true legs. In the homonomy and number of their segments and appendages, the Myriopoda resemble certain of the Crustacea, with which Class they have often been ranked, as also in having the first, or the first tro pairs of post-cephalic appendages, subordinated more or less completely to the manducatory organs, so as in one order, Chiloporla, to form 'foot-jaws,' and in another, Chilognatha, to form 'labia' by the partial fusion and other modifications of their coxae, whilst in Pauropus the anterior pair of legs is rudimentary. There is however no fusion of segments in the Myriopoda of the kind which produces a cephalo-thorax in Crustacea. It may be added here that an additional point of similarity to the Crustacea is manifested by the Myriopoda in their mode of growth; as their larvae instead of leaving the egg, as insect larvae do, with at least as many segments and legs as they ever afterwards possess, leave the egg with a much smaller number of segments and legs than by the periodical addition of segments at successive moultings, they attain in the adult state. The Myriopoda however must be classed with the air-breathing Arthropoda, not only on account of their respiration being tracheal, except in the case of the diminutive Pauropus, but also on account of the singleness of their antennae; the sessile position of their eyes; their non-palpigerous mandibles; the fusion of their maxillae into a labium; the large development of their salivary and renal, and the rudimentary condition of their hepatic glands.

The Myriopoda appear to stand midway between the two other classes of air-breathing Arthropoda, as to the mutually correlated and mutual supplementing complexity and simplicity of the circulatory and respiratory apparatus. Their digestive and nervous. systems are closely similar to those of the larvae of Insects. 
The Class Myriopoda is ordinarily divided into two orders-the Chitopoda and the Chilognatha or Diplopoda, from which the Siphonizantia and the genus Pauropus ought, it is probable, to be separated.

The Chilopoda are the most highly organized of the Myriopoda. They are distinguishable externally by the flatness of their bodies; the large size of their antennae, which always possess fourteen joints at least; by the modification of the two anterior pairs of post-cephalic appendages into foot-jaws, the hinder pair of which is armed with a sickle-shaped unguis and poison-gland; and by their locomotor legrs being attached in single pairs. With these external characters, the following points of internal structure are correlated; the stigmata for the admission of air to the tracheae do not correspond with the number of segments, and are situated on the sides of the body between the bases of the feet and the dorsal shields; the generative ducts open at the posterior extremity of the body; and there is no intromittent organ. It is amongst the Chilopoda only (in Scutigera) that we meet with compound facetted eyes. In another Chilopodous family (Scolopendridae) we find the generative ducts single, and the tracheae anastomosing as in Insects. The larval Chilopoda may have as many as six or eight pairs of locomotor appendages when they leave the egg; and the addition of fresh segments takes place in the way of intercalation at each moult, in the intervals between each pair of older segments.

In the Chilognatha the body is sub-cylindriform, the antennae are inconspicuous and do not possess more than seven joints; the two anterior pairs of post-cephalic appendages, or at least the first of them, may be spoken of as 'foot-jaws,' or as forming 'labia,' inasmuch as they are directed forwards like the operculiform 'foot-jaws' of Crustacea, and have their basal joints or coxae more or less enlarged, apposed mesially, and anchylosed, though they are much less altered in function and structure than their homologues in the Chilopoda; and their legs are, after the first six, or, in the males, seren post-cephalic segments, arranged in double pairs. Differing thus externally from the Chilopoda, they differ from them also in the following points of structure and developmental history, and approximate more closely than they do to the Arachnida and Crustacen, and less closely to the Insecta. The stigmata leading into their tracheae correspond in number with their segments, and are situated on the anterior border of the ventral plates, under cover of the coxae of the legs, which are articulated to the posterior border of these plates; the tracheae do not auastomose; the generative ducts are bilaterally symmetrical, having double openings in or upon the borders of the third thoracic segment, which never carries legs, 
and corresponds precisely with the genital segment of the Scorpion (see p. I 6 , infra), and with that of the Poecilopodous Crustacea. The seventh post-cephalic segment ordinarily carries a double penis, which may however, as in Glomeris, be removed to the posterior extremity of the body, indicating hereby an approximation to the Chilopoda. The larvae of Chilognatha, when they leave the egg, have ordinarily only three pairs of appendages, which are carried upon three of the four first post-cephalic segments; and they contrast still further with the Chilopoda, by attaining their additional segments at each moult by intercalation only in that portion of germinal membrane which is interposed between the penultimate and ante-penultimate segments.

Pauropus appears to resemble the Chilognatha in having the generative orifices situated anteriorly instead of posteriorly in the body, and its larvae are hexapodal; but it differs from them in many points of its external anatomy. The shape of its body as a whole, its dorsal plates, and elongated posterior legs, give it a resemblance to some Chilopoda. As tracheae may be absent in the early developmental stages even of an Insect, Chloeon Dimidiatum, too much weight must not be laid upon their absence in Pauropus; and it may be safely said that for our present purpose, that, namely, of showing the relationships which subsist between the various classes of Arthropoda, the most important morphological point in this genus (or order ?) is its possession of bifid antennae, carrying multi-articulate flagella, by which peculiarity, as also by the others specified above, a very distinct affinity is shown to exist between Myriopoda and Crustacea.

For the structure and affinities of the Myriopoda, see Sir John Lubbock, on Pauropus, a new type of Centipede, Linn. Soc. Trans., xxvi., I867, ibique citata; and also Mr. Newport's Papers on the Myriopoda, in the Transactions of the Royal and Linnaean Societies.

\section{Class, Arachnida.}

Air-breathing Arthropoda, with well-marked heteronomy between the several divisions of the body, which are usually only two, a cephalo-thorax to which the limbs are limited, and an abdomen, usually marked off from it by a constriction, a postabdomen being developed only in the Scorpions. Their antennae are modified so as to serve in the prehension of food; and they 
have four pairs of limbs, which correspond to the maxillary, and to the labial palps, and to the two anterior pairs of legs in Insects. The fusion of head and thorax approximates the Arachnida to the Crustacea, and puts them into a position of contrast to the other Arthropoda; the Myriopoda furnishing here, as frequently elsewhere, an example of a transitional arrangement, by having the two anterior pairs of thoracic appendages subordinated functionally to the oral appendages, though the segments carrying them are not in them actually fused with the head. As the history of the development of the nervous system in the Scorpion appears to show that the first post-oral, which is the cheliferous appendage, corresponds to the mandible, and not, as is ordinarily stated, to the first maxilla of other Arthropoda; we may add that the Arachnida resemble the Crustacea in a second point of external anatomy, that of possessing a palp on the mandible, a structure never seen in the air-breathing Arthropoda except as a rudiment in some Chilopodous Myriopoda. The lesser development of the respiratory apparatus is a point of internal anatomy which distinguishes the Arachnida from the other Arthropoda; and the large development of the hepatic organ, which may be considered to compensate for this comparative deficiency, is another point of resemblance to Crustacea. As peculiarities which may possibly be correlated with these, and which certainly point in the same direction, we may mention the power of repeatedly moulting ; of reproducing at those periods limbs which have been detached or mutilated; and of producing offspring repeatedly in the adult state, which the Arachnida possess in common with Crustacea. The higher Arachnida resemble the Chilognatha and the Crustacen, in the bilateral termination of their generative ducts on anteriorly-placed segments of their body; and they resemble the Chilognathe in the non-anastomosis of their tracheae. The digestive tract of the Arachnida differs from that of all other Arthropoda in having in many cases lateral coeca appended to it, and prolonged into the interior of the limbs and mandibular palps. Their respiratory system consists either of tracheae alone; or of the so-called 'lungs,' which are sacciform modifications of tracheae, alone; or of both combined; and in some cases, such as those of certain parasitic families and orders, and of the Tardigrada, a specialized air-breathing apparatus is wholly wanting. The tracheae when present have very ordinarily a fasciculate 
rather than an aborescent arrangement, and they not rarely differ also from those seen in Insecta and Myriopoda, by not possessing the internal spiral thickening, so characteristic of the respiratory tubes in those two classes.

The limits within which the variations of the circulatory and nervous systems may range, are very wide; the arteries and veins may attain, as in Scorpions, a very high grade of evolution and distinctness, or both sets of vessels and the heart also may be absent, as in such lower forms as the Acarina and Linguatulina, in which the nerve-system is reduced to a single ganglionic mass perforated by the oesophagus. The supra-oesophageal and the sub-oesophageal ganglia are always closely approximated in Arachnida, in correspondence with the assignment of the antennary to act in aid of the manducatory organs, and with the more or less suctorial modification of their carnivorous habits, with which a small pharynx and oesophagus are correlated.

The Arachnida, with the exception of the Tardigrada, are dioecious; and with the exception of the order just named, and the Linguatulina, the segmentation of the yolk is partial in the class. With the exceptions of Scorpionidae and some Acarina, the Arachnida are oviparous. Most Arachnida, when hatched, resemble the adult animal; amongst the Acarina, however, we meet with hexapod larvae, which attain their fourth pair of legs subsequently by moulting, whilst the Linguatulina reverse this history in their development, and undergo a retrograde metamorphosis from a larval form provided with two pairs of biarticulate and unguiculate appendages to a vermiform adult destitute of limbs.

\section{Class, Crustacea.}

Water-breathing Arthropoda, which may, in accordance with the grade of specialization attained to by their segments and appendages, be as markedly heteronomous as the Insecta, or as homonomous externally as the Myriopoda. Normally, every segment in the Crustacean body carries a pair of articulated appendages; and two pairs of antennae are all but invariably present, indicating the presence of two cephalic segments between the jaws and the eyes. The appendages of one or more of the three segments immediately posterior to the jaws, are always converted into auxiliary jaws, or ' maxillipedes ;' 
and the subordination of these thoracic segments to the cephalic, may be still further manifested by a fusion of the segments themselves into a cephalo-thoracic carapace. The post-thoracic segments in Crustacea are more obviously divisible into an abdominal and post-abdominal series, than they are in such other Arthropoda as do possess a post-abdomen. The normal number of the abdominal segments is five, and the appendages they carry are in the adult state very ordinarily either alone, or in association with the postabdominal segments and appendages, the locomotor organs. Accordingly as only one of the three pairs of thoracic appendages, or as all three lose their primordial and typical locomotor functions and become associated with the oral appendages, the higher Crustacea are classified as 'Tetradecapoda' (Dana) (the five abdominal segments furnishing ten, and the tro posterior thoracic four limbs), or as 'Decapoda.' The normal number of the caudal or postabdominal segments is six, the appendages of the first four of which may be modified so as to earry ova, or branchiae, but do not attain the importance as locomotor limbs, which those of the five abdominal segments do.

The appendages of the sixth segment, however, very ordinarily attain considerable importance as locomotor organs, and they constitute, together with a median azygos element, developed posteriorly to the sixth segment, the powerful 'swimmeret' of the Macrurous Decaporda. Their morphological importance is equally great, as they correspond with the caudal feet of naupliiform larvae, and together with the two pairs of antennae which they may resemble by carrying, as in $M$ Iysis, organs of special sense, and the mandibles, make up the entire sum of the appendages of the 'primitive body' of Crustacea, as represented by those forms. The bilateral appendages which certain lowrer Crustacea carry at the posterior extremity of their bodies, are not articulated ventrally as these eaudal feet are, and on this account, as also upon others, they cannot be considered as homologous with them. There is much difference of opinion as to whether the mesially-placed azygos element of the swimmeret ought to be counted as a seventh post-abdominal segment. (See p. II 3 , infia.)

The mandible is ordinarily provided with a palp, which in a Class with but ferv exceptions aquatic in habit, serves to direct floating food towards the mouth. There are no salivary glands in 
Crustacea, the so-called antennary glands of Decapoda, the 'cement glands' of Cirripedia, and the poison-glands of Argulus, though homologous probably with each other, not being homologous with salivary organs. The stomach consists very commonly of two portions, the anterior one of which corresponds in function and position to the gizzard of Insecta, whilst the posterior receives the ducts of what when multi-ramified is spoken of as a 'liver ;' what when simply coecal is spoken of as 'hepatic coeca;' and, what is sometimes considered, as in Argulus, to be simply ' lateral diverticula,' such as those often observable in Arachnida. The intestine, except in certain Cladocera, takes a straight course to the anus. This orifice is usually situated on the ventral aspect of the terminal segment, or the median appendage of the terminal segment of the post-abdomen, except in the Cladocera and Copepoda. An azygos coecal sac may open into the digestive tract dorsally on the line of demarcation between the pyloric portion of the stomach and the duodenum; and three other coeca may similarly open on the dorsal surface of the duodenum at one or other part of its course. These latter coeca have been spoken of as urinary organs; they are, however, as being by no means constantly present, probably homologous rather with the multiple hepatic organs of the Scorpion than with its renal organs, or with those of the other air-breathing classes. The heart is ordinarily present, and is either elongated and vasiform, as in the sessile-eyed and many of the lower Crustacea, or short and polygonal in the Decapoda, where it gives origin to several arterial trunks; or short and semiglobular, as in Copepoda, where no arteries exist. In every case blood finds its way into the interior of the organ through venous inlets, which are dilated as in other Arthropoda, by the recoil of the elastic alae cordis.

Respiration is sometimes effected by the general surface of the body, specialized branchial organs are however usually present, and take the shape either of tree-like or of leaf-like hollow outgrowths attached either to segments or to appendages, or to both. As there are no cilia in Arthropoda, the aerating surfaces have fresh supplies of water brought into relation with them either by the movements of appendages specially modified for the purpose, or by the movements of ordinary locomotion, or by both combined. The gill-covers of certain air-breathing Isopoda contain multi-ramified cavities, which have been supposed to constitute a rudimentary 
tracheal system, but which with more probability have been considered to have a glandular function, and to keep the gill-plates lubricated and transpirable by their secretion.

The nerve-system resembles that of other Arthropoda in its general arrangement, but differs in the two following points:-The commissural cords connecting their prae-oral and post-oral ganglia are of so much greater length, that their 'brain' is never described as that of other Arthropoda sometimes is, as consisting of an infraoesophageal as well as of a supra-oesophageal mass, the ganglia of the jaw-bearing segments having receded so as to become apposed to the first of the thoracic series, with one or all of which they are always fused, whilst the ganglia of the two antennary segments maintain their usual continuity with those of the eye-bearing segment. And, secondly, the paired, and the azygos systems of stomatogastric nerves, except in the terrestrial Isopoda, take origin from the commissural cords of the nerve collar, and from the prae-oral ganglionic mass instead of from any distinct ganglia, such as the lateral and frontal ganglia of other Arthropoda. The nervi transversi, however, appear to be represented in Crustacea by a nervous stem, passing off from each interganglionic segment of the cord, as is the case in other Arthropoda, and indeed also in those Vermes which possess a chain of ventral ganglia. The eyes may vary from the very simplest up to the most complex form observed in the Sub-kingdom; two kinds may co-exist in the same individual, and in two genera, Euphausia and Thysanopoda, eyes may be, contrary to the otherwise invariable rule in Arthropoda, found elsewhere than upon the head. An auditory organ has been observed in Decapoda in the basal joint of the superior antennary organs; and in Mysis, in the lateral appendages of the last post-abdominal segment, which, together with the two pairs of antennary organs, were the only appendages developed in the earliest period of its larval life.

With the exception of the Cirripedia, all the Crustacea are dioecious. 'Complementary males' are found in the order Cirripedia, and also amongst the parasitic Entomostraca, and in the former order these 'pygmy' males are devoid of any digestive tract, and even of any oral opening. The sessile-eyed Crustacea furnish an exception to the rule, that in Arthropoda the females are larger in size than the males. The generative organs have bilaterally symmetrical ducts, opening a considerable distance anteriorly to the 
anus, except in Daphnidae; but not always on numerically corresponding teguments in the two sexes. Crustacea attain the power of sexual reproduction before they attain their full size, and they retain it, and repeatedly exercise it, in many eases at least, for an indefinite period.

In development the yolk may undergo complete segmentation, and a larva of the form known as Nauplius may be produced without the formation of any primitive streak, as is the case with the Cirripedia, Entomostraca, Penaens amongst Decapoda, and most Branchiopoda; or, as in all the higher Crustacea, the yolk undergoes a partial segmentation, and the embryo, when ready to be set free from the egg, may either be of the larval form known as Zoea, as in most Decapoda; or may differ from the adult form only by the possession of certain structures, which are subsequently aborted, as is the ease with the outer division of the abdominal limbs of the common lobster, Homarus vulgaris; or, finally, may, as is the case with Astacus flutiatilis, from the time it is set free from the egg, possess the same number and proportions of appendages as the adult. Instances of retrograde metamorphosis are common in this class, several of the orders of which possess parasitic families. Parthenogenesis occurs in the Cladocera, the 'summer eggs' of Daplnia being developed without sexual congress, and one genus, Cythere, of the allied family, Ostracodea, is viviparous.

\section{Sub-kingdom, Vermes.}

Bilaterally symmetrical animals, very various in shape and other external characters, but agreeing in the absence of heteronomy from their post-cephalic regions, in not possessing hollow segmented limbs, and in having their locomotor muscles closely connected with their integumentary system, not only on the ventral, but also on the dorsal and lateral aspects of their body walls.

The Sub-kingdom Vermes consists of two Divisions, the Annulata and the Annuloida. The first of these contains the multisegmental Vermes, which, in Mr. Herbert Spencer's language, would be spoken of as 'aggregates of the third order.' Their bodies are more or less 
distinctly divided externally by annulation, and internally by the development of dissepiments forming compartments. The nerveganglia, the organs of motion, and, sometimes, even those of special sense, exhibit a more or less closely corresponding multiplicity as do also the organs of vegetative life. The Annulata are divisible into two Classes, the Annulata proper s. Annelides and the Gephyrea. The Annuloida are unisegmental Vermes or 'aggregates of the second order.' Their nervous system consists (with, possibly, an exception in the case of certain Turbellarians, see P. I55, infra) at most of a simple oesophageal collar to which a few accessory nervecentres, but now a chain of ganglia may be appended; and their water-vascular or depuratory system is (with an exception again in the case of certain Turbellaria, the Nemertinea, see description of the class Platyelminthes given below, p. cxli.) the only vascular system which they possess. The Division Annuloida contains three Classes, the Nematelminthes, the Rotifera, and the Platyelminthes.

The integument may possess a perfectly smooth chitinous exterior; or it may be covered with cilia; or it may develope numerous chitinous outgrowths in the shape of spines, hooks, bristles or hairs. These appendages often attain a very considerable degree of hardness; but the chitinized cuticular secretions of the body-wall as opposed to these specialized developments which often pass right through the thickness of the visceral envelope, are usually much less resistent both to physical and to chemical agencies than the similarly placed structures of the Arthropoda; they never become indurated by calcificatory deposit, and have only rarely (in Nematoidea and Hirudineae) been observed to be changed by moulting as in that sub-kingdom. In some of the ento-parasitic Vermes (Cestodes), which lie immersed in an atmosphere of more or less perfectly digested and diffusible albumen, and which by virtue of their readily permeable integument can imbibe nutriment at all points of their external surface, there is absolntely no digestive system present. In the parasitic Nematoids, on the other hand, in which the integument developes a much more considerable chitinous cuticular deposit, a proctuchous digestive tract is always present. The non-parasitic Vermes, with the exception of the male Rotifera, always possess a digestive tract, which is usually proctuchous, except in the case of the Dendrocoelous Turbellaria, which in this as in other points resemble the parasitic order Trematodes. 
The digestive canal in Vermes when present resembles their external tegumentary system in being homonomous except in its anterior portion. In this part of the tract we often find a muscular protrusible and dentigerous oesophagus; the stomach is by no means always differentiated from the intestine, and the segments which intervene between the oesophagus and the short often upward turning rectum, may be conveniently called 'gastro-ileal.' It may take a simple antero-posterior course, or it may have lateral diverticula of very various degrees of complexity developed upon it. It is seldom convoluted. The salivary glands are usually, and the hepatic are always represented merely by layers of cells impacted in the walls of the digestive tube.

Many Vermes possess an extensive vascular system, which, however, as containing usually a coloured, but not a corpusculated fluid, is called a 'pseudhaemal' system, and is to be considered respiratory in function. The corpusculated nutritive true blood is contained usually in the perivisceral cavity alone; in a few instances it has been found to penetrate into the so-called pseudhaemal vessels. Specialized respiratory organs are rarely found in Vermes; the possession of a peculiar depuratory apparatus is characteristic of the entire Sub-kingdom. This system appears to stand in a complementary relation to the branchial; being largely developed where, as in the Oligochaeta and parasitic worms, that system fails to be developed, on account of the medium in which those animals live; and being reduced to comparative insignificance in the marine Polychaeta, where the branchiae are so prominent a feature in their organization as to have gained for them the name of 'Branchiata.' In the non-segmented worms these organs are known as the 'water-vascular' system; and they take the shape of two bilaterally symmetrical tubes, opening by one or tro orifices on the external surface of the body, and ramifying abundantly in its interior. In the segmented Vermes or Annulata, these organs are known as 'segmental organs;' and may be repeated in nearly every segment of the body. In most Vermes the internal terminal segments of these tubes appear to be clothed with cilia; the segments in more immediate connection with the exterior outlet are very ordinarily possessed of much thicker, glandular, and contractile walls. In the Annulata, with a few exceptions, the inward prolongations open by infundibuliform orifices into the perivisceral 
cavity; and in certain segments these organs are modified, so as to serve as efferent ducts for the generative products.

The existence of a nerve-system appears to be doubtful in certain of the Platyelminthes (Cestodes). In the parasitic Acanthocephali it is reduced to a single anteriorly-placed ganglion. In certain both of the free and of the parasitic Platyelminthes, it consists of two ganglia placed one on either side of the pharynx (Trematodes), or one on either side of the anterior extremity of the body (Turbellaria), and connected with each other by a transverse commissure. The ordinary Nematoidea possess a complete circumoesophageal collar, which again is represented in the microscopic Rotifera by a single bilobed supra-oesophageal ganglion. The Gephyrea have in addition to the nerve-collar of lower Vermes a simple elongated band of nervous tissue, extending from the anterior to the posterior pole of the body along its medio-ventral line. In the Annulata proper the ventral chain is distinctly bilaterally symmetrical, and its two halves are sometimes widely divaricated. In many Vermes the organs of special sense (optic and auditory) are very well developed; in many, they are entirely absent.

In the Annulata proper, with the exception of the Discophora, the ova and spermatozoa are set from the secretory glands, by dehiscence into the abdominal cavity, and are conveyed thence to the exterior by modified 'segmental organs.' In the other Vermes, with the exception of the female Acanthocephali, the generative glands have their walls prolonged into ducts; and their products are thus conveyed out of the body without falling into the perivisceral cavity. Structures corresponding to the intromittent organs of higher animals are found in representatives of every class of Vermes, not even exclusively of the Rotifera; the Platyelminthes almost invariably possess a complicated reproductive apparatus, in which, besides other accessory organs, vitelligenous exist independently of germigenous glands. The marine Annulata, on the other hand, are distinguished by a great simplicity in their reproductive apparatus, contrasting herein at once with the lowest Vermes, and with the Discophorous and Oligochaetous members of their own class.

Vermes may be either hermaphrodite or dioccious; either viviparous or ovjparous; they may reproduce their kind either scxually or asexually, and their embryos may or may not go through a metamorphosis. When reproduction takes place asexually, it may 
take place either in the way of parthenogenesis, as in Rotifera and Ascaris nigrovenosa in its ento-parasitic stage; or in that of metagenesis from a part of a protozooid, which is not differentiated as a sexual gland. Metagenesis is observable both in the highest and in the lowest of the Vermes.

In some instances, at the time of the setting free of the deuterozooid produced by gemmation, both protozooid and deuterozooid may be in the asexual condition, as is ordinarily the case with Nais and Chaetogaster amongst Annulata, and with Microstomeae amongst Turbellaria. In the cases of certain other Turbellaria (Strongylostoma and Catenula), no other than this simple metagenetic form of reproduction has been, as yet, observed. When this form of reproduction alternates as in the other Turbellaria, and in the Annulata just mentioned, with sexual reproduction, we have a series of phaenomena before us which has been spoken of as 'Digenesis with Heterogony.' In some cases, as occasionally in Nicrostomeae, and in the Annelidan Syllidea and Protula, a sexual protozooid has been observed to give origin by gemmation to a sexual deuterozooid, furnishing thus an example of digenesis with contemporaneous heterogony. In some rare cases, the sexual organs of the protozooid have been observed to be of one, and those of the deuterozooid of the other sex. In other cases, the protozooid is always asexual, when it is known as a 'nurse;' whilst the deuterozooids it gives origin to attain the sexual condition, either whilst still attached to the parent organism, as in the Taeniadae amongst Platyelminthes, and Autolytus amongst Annulata; or subsequently to detachment from it, as in Trematodes. These forms of reproduction may be spoken of as cases of 'digenesis with alternation of generations,' inasmuch as the asexual forms or stages of metamorphosis interposed between the products of sexual congress and another set of sexually perfect individuals may be regarded as sufficiently distinct and independent to merit the title of 'generations.'

The relations held to the adult forms by the provisional organs of the larvae of certain Turbellarian worms (Pilidium), and also of certain Gephyrea (Actinotrocha), bear a considerable resemblance to those observable in the larvae of Echinoderms. The Oligochaetons and the Discophorous Annulata do not go through any metamorphosis. In worms of parasitic habits, even where, as in Nematoids, 
no alternation of generations is observable, the history of the evolution of the embryo is much complicated by the fact that two 'hosts' are necessarily required for its harbouring and sustentation at different periods; in one only of which, usually a vertebrate animal, the sexual condition can be attained to. The enormous quantities of ova which parasitic Vermes produce, stand in direct relation to the very great difficulties which their peculiar mode of life opposes to the continuation of the species.

Vermes of the same species in the higher orders of the subkingdom appear to be competent to the maturation of sexual products at very different ages. In thus assuming sexual functions before attaining their full size, these Vermes resemble the Fishes in the Vertebrate Sub-kingdom, but differ not only from the airbreathing classes of Arthropoda, but also from the lower members of their own Sub-kingdom.

It is sometimes said that the power of repairing injuries and mutilations which distinguishes this sub-kingdom as a whole in an eminent degree, is connected with the possession of the faculty of metagenesis. The power of repair however is very great in the terrestrial Oligochaeta s. Lumbricidae, in which metagenesis has not been observed; and though the two faculties are both alike absent in the Nematoidea and in the Discophora, it is better to explain this fact by a reference to the special habits of these animals, which, as testified to by the universal presence in the one, and the very common presence in the other of caudal suckers, would appear to be more or less incompatible with reproduction by gemmation.

\section{Class, Annulata proper.}

Vermes of elongated and almost always cylindrical shapes, made up of a series of segments, which are homonomous except at either extremity of the body. They are annulated externally, and internally their perivisceral eavity is divided by dissepiments into more or less perfectly separated compartments and chambers. They all possess a chain of ventral in addition to, and in commissural junction by a circum-oesophageal collar with a prae-oral cerebroid mass; the digestive tract is in all of them proctuchous, and, with the exception of the Hirudineae, suspended in a large perivisceral space. With a few exceptions they possess a closed system of 
'pseudhaemal vessels,' and a series of depuratory organs, opening internally into the perivisceral cavity, as well as externally on the surface of the body. They are divided into two sub-classes, the Chaetophora s. Chaetopodes, and the Discophora, accordingly as their external locomotor organs are chitinous spines, or terminal suckers. The Chaetophora again are divided into Polychacta s. Branchiata and Oligochacta, according to the number of their locomotor and the presence of branchial appendages. The Discophor $\alpha$, with the exception of Branchellion, have no external appendages locomotor, branchial, or tactile; in the absence of appendicular organs of the two latter kinds, as also in being hermaphrodite, the Oligochaeta resemble the Discopliora, and differ from the Polychaeta.

The Annulata may form tubes for the lodgment of their bodies by the secretion either of calcareous matter (Serpula), or of organic (chitinous?) substance (Onuphis), or by the agglutination of arenaceous particles (Terebella), and their integument, which is always chitinogenous, even in the Hirudineae, where it developes no external appendages, may develope chitinous appendages of the most varied forms. But these chitinized outgrowths are with the single exception of the operculum of Serpula, never indurated by any deposit of calcareous salts, as is the case in Echinodermata and Crustacea. The integument is frequently, even in adult Annulata, found to be beset with cilia, especially in the anterior regions of the body. This is the case with many Naidina, with Polyophthatmus, with Siphonostomum gelatinosum, and with Spio and Tomopteris; and in these two latter, as in many other genera, the integument has been observed to contain tricho-cysts, or 'bacillar corpuscles,' which have been compared with the acicular or urticating organs of the Coelenterata, of certain Infusoria, of the Apneustic Mollusca, of the Turbellarian Vermes, and, according to M. A. de Quatrefages, of Synapta amongst the Echinoderms.

All Annulata possess two layers of muscles in their body-wallsan external consisting of circular, and an internal of longitudinal fibres. To these an alditional layer may be superadded internally, and enter into the formation of the dissepiments which divide the perivisceral cavity into its transverse and longitudinal compartments. The digestive tract takes, with the exception of Chloraema, a direct antero-posterior course, without describing any convolu- 
tions, but its absorbing surface is very ordinarily largely increased by the development of lateral sacculations. It is very often armed with a protrusible, muscular and dentigerous, proboscis. The mouth opens ventrally, and the anus dorsally or terminally. A perivisceral cavity is present in all Annulata except certain Discophora, in which it becomes obliterated in the course of the evolution of the internal organs. In this cavity, when present, the true corpusculated blood is ordinarily contained. In some Annulata which are called 'anangian,' there is no 'pseudhaemal' vascular system developed, and in them the internal surface of the perivisceral cavity is richly ciliated, and the circulation and aeration of the corpusculated fluid it contains thus secured. But in most members of the class we find a closed system of contractile vessels, which, as they contain a fluid which, though ordinarily coloured, is not corpuseulated, are called 'pseudhaemal,' and appear to be respiratory in function; and in these worms the perivisceral cavity shows no other ciliation than that of the mouths of the segmental organs which open into it. In a few Annelids again (Syllidea armata, the Opheliae, the Cirratulida, and the Stauroceplari and Branchiobdella), the socalled 'pseudhaemal' system contains corpusculated blood, and communicates with the perivisceral cavity so as to form a lacunar circulation. Arborescent branchiae are not rarely developed in the Polychaeta on the dorsal aspect of the parapodia; and the tactile cirri ordinarily present on the same, as also on the ventral aspect of the locomotor outgrowth, must possess an aerating as well as a sensory function. The branchiae are often ciliated, and contain afferent and efferent branches of the pseudhaemal system, which run parallel and are connected with each other by a double series of vascular loops within the aerating lamina. Nearly all Annulata possess certain organs, known as the 'segmental organs,' which open externally on the surface of the body, and internally into the perivisceral cavity. The internal orifice is wanting in some Polychaeta (Capitellae) as also in some Discophora; a part of the often complexly convoluted canal which they consist of is glandular, and as the movement set up by the cilia with which they are lined, ordinarily sets outwards, they may be supposed to be depuratory in function, excer, in those segments in which they are specialized, as they are in all Amnulata except the Discophora, to act as efferent ducts for the generative products. In some cases, however, as in 
Tomopteris, the ciliary movement within these organs has been observed to set inwards and to carry spermatozoa with it; and this must be the case whenever the ova are impregnated within the maternal body. The nervous system consists of a ganglionic praeoral mass, and a ventral ganglionic chain, which by their commissural junction form the oesophageal collar. In the Polychaeta accessory ganglia are developed upon their muscular proboscis; in Oligochaeta upon the pharynx; and in Discophora in relation with the jars (in the Grathobdellecee), and also with the ventral surface of the digestive tract. In some Annulata the cirri are supplied with nerves, and would appear to be tactile organs. The eyes are usually but not exclusively carried upon the praestomium; they may be repeated in each segment (Myxicola and Polyophthalmus), or carried upon the branchiae (some Subellae and Terebellae), or carried upon the caudal extremity (Amphicora). Bilaterally symmetrical otolithic capsules have been found in a few Annulata (Arenicola, Fabricia, Sabella), in the neighbourhood of the oesophageal nerve-collar. In the Polychacta, which with the exceptions of Protula, Spirorbis, and Erogone pusilla, are dioecious, the sexual glands develope themselves round branches of the pseudhaemal vessels, and discharge their products, as in Oligochaeta but not in Discophora, by dehiscence into the perivisceral cavity, whence they are taken up by specially modified segmental organs. In the Oligochaeta and Discophora, which are hermaphrodite, certain accessory generative organs are present, which are not found, except, possibly, as rudiments, in the Polychaeta; and the Discophora differ from all other Annulata, in that their generative products do not find their way into the perivisceral cavity by dehiscence, but are conveyed along closed ducts to azygos efferent canals, the terminal segment of the male division of which is modified so as to serve as an intromittent organ as in the Platyelminthes. In development a 'primitive streak,' out of which the various organs both of vegetable and of animal life, with the exception of the digestive tract, are evolved, has been observed to make its appearance; it appears, however, subsequently, and not, as in Arthropoda, anteriorly to the formation of the primitive embryo. The embryos of the Oligochaeta and Discophora undergo no metamorphoses after being set free from the egg. Those of the Polychaeta are, with a few exceptions (Amphicora), when set free from the egr, furnished with 
provisional organs, in the shape of terminal or biterminal (telotrochal) or mesially-placed (mesotrochal) zones of cilia ; and sometimes in that of long setae. In every case the cephalic and caudal segments alone are present when the Polychaetous embryo leaves the egg; and their full complement of segments is attained to in the way of intercalation anteriorly to the terminal segment. A few Polychaeta belonging to the genera Eunice, Nereis, Syllis, have been observed to be viviparous. The Discophora differ from the other Annulata, in never multiplying asexually; and in possessing but little power of repairing injuries, and none of reproducing lost organs. In these points the Discophora differ very widely from the Platyclminthes, with which they have sometimes been classed (see p. I3 8 , infr $($ ), and resemble the Nematelminthes, a Class to which also they are approximated by the possession of a terminal sucker, though by few other properties beyond those common to all members of the Sub-kingdom Vermes.

\section{Class, Gephyrea.}

Marine worms, which have been supposed, as their name denotes, to furnish an example of a transitional form connecting two distinct types, and which not only in habits of life and in external appearance, but also in a few points of internal structure, do appear to be allied to the apodal Holothurioidea, though the totality of their organism causes us to class them amongst the Vermes, and to consider them as most nearly related to the Annulata proper. They are usually cylindriform in outline, their integumentary system is indurated by chitinous, but never by calcareous deposit; in two families (Sternaspidea and Echiuridec), it carries locomotor setae; and in one species at least (Anoplosomatum antillense) of another family (Priapulaceae), it developes trichocysts. It ordinarily possesses numerous follicular glands. The Gephyrea never have their bodies definitely segmented, but the integument is not rarely so corrugated as to form more or less distinct zonular folds; and in one case (Phascolosoma Cumanenseb), rudimentary dissepiments have been observed in the large perivisceral cavity. The month is surrounded in the Sipunculidae with a coronet of ciliated tentacles,

b Keferstein, Zeitschrift für Wiss. Zoologie, xvii., I867, p. 53. 
into which a circular vessel surrounding the oesophagus, and furnished with contractile ampullae, sends prolongations. Thongh this vascular system has no locomotor feet, like those of the normal Echinodermata, in connection with it, yet, as it is clothed with cilia internally, and as it sends branches to the integument as well as to the tentacles, it would be considered homologous as well as analogous to the ambulacral system of the apodal Holothurioidea, were it not observed to contain a corpusculated fluid of the same characters as the blood in the perivisceral cavity. Another point of resemblance to the Echinodermata is furnished to us by the respiratory cloacal trees of the Echiuridea, which in Bonellia have been very clearly shown to open by numerous infundibuliform orifices into the perivisceral cavity. The cloacal respiratory trees or 'lungs' are said by Semper to open similarly in the Holothurioidea ; and the resemblance between the two classes is made stronger by the fact that where these respiratory trees are absent, or, as in Sipunculus, only rudimentary, in both classes alike we find the intestinal mesentery beset with certain ciliated infundibuliform organs, which are, probably, connected with a water-vascular system. The muscular system consists, as in Holothurioidea and Chaetophorous Annulata, of an external circular and an internal longitudinal stratum, to which in the Sipunculidae special retractor muscles may be superadded, as in the Dendrochirotae amongst the Holothurians. The chitinous armature of the proboscis, upon which these muscles act in the Sipunculidae, and the peculiar prolongation of the organ seen in the Ecliuridea, are points which do not find any parallel in the Echinodermata. The digestive tract is usually complexly convoluted; the anus opens always on the dorsal surface, often at a point in the anterior third of the body's length, as in Sipunculidae. It is clothed with cilia internally, and richly glandular in its middle segments, from which an oesophagus and rectum are distinguishable. The Echiuridea and Stcrnaspidea appear to possess a pseudhaemal system, which may be distinct from the vascular system already spoken of in the Sipunculidae. The nervous system consists of a ventral cord, and of a circum-oesophageal collar, in which, however, a supra-oesophageal ganglionic mass is not always present. The ventral cord, it would appear, does not ever develope ganglia, as it has been stated to do; and it resembles, in this absence of aggregations of nerve-cells, the band-like radial 
nerve-cords of the Echinodermata. There are no organs of special sense in this Class, with the exceptions of the tentacles of the Sipunculidae; and of the eye-specks retained by some members of that family from their free larval into their adult life, which they spend immersed in mud or sand.

The Gephyrea are not hermaphrodite ; the organs formerly considered to be testes having been shown to be ducts for the generative products, and homologous with the segmental organs so characteristic of the Annulata. The embryos go through more or less complicated metamorphoses; the provisional organs of the larval form known as Actinotrocha, attaining proportions and relations to the future Sipunculus, which are similar to those of the most characteristically developed Echinodermata; whilst in other cases the larval may differ from the adult form only by its possession of locomotor ciliated zones, and of a relatively more prominent nervous system.

For the anatomy and classification of the Gephyrea, see Lacaze Duthiers, Ann. Sci. Nat., Ser. iii., tom. x., $185^{8}$; Claparède, Anatomie und Entwickelungsgeschichte Wirbelloser Thiere, I 863, pp. 61, 83; Keferstein und Ehlers, Zoologische Beiträge, I86I ; Ehlers, Zeitschrift für Wiss. Zoologie, xi. ; Keferstein, ibid. xii., p. 35, г862; Semper, ibid. xiv., p. 420 ; Keferstein, ibid. xv. and xvii., 1867 .

\section{Class, Nematelminthes.}

Cylindriform non-segmented Vermes, in which the external layers of the integument ordinarily attain considerable rigidity by chitinization, and occasionally develope hooks and bristles, but in which true locomotor more deeply implanted setae, and cilia are absent. Three orders, the Chaetognatha, Nematoidea, and Acanthocephali, are contained in this class, of which the first consists of a very few species which are always free; the second comprises a very large number of species which may be either free or parasitic; and the third is exclusively entoparasitic, and devoid of any digestive tract.

Lateral and caudal fins, and suckers, as well as setiform spicula, are often present in this Class; and in the two orders, Chactognatha 
and Nematoidea, the muscular system does not possess the external circular layer so universal in other Vermes, its presence being rendered superfluous by the chitinization of the cuticular layer of the body walls. This chitinous deposit is secreted by a subcuticular 'granular layer,' and as in Arthropoda it is frequently changed by moulting during growth and metamorphosis. In many cases the muscular envelope is divided into four bands by the median and lateral lines. In the Nematoids, bladder-like processes are sometimes given off from the muscle-cells, in such abundance and proportions as to fill up a large part of what in the entire class is ordinarily a large perivisceral cavity; and a second set of processes given off from them make up the internal 'transverse muscles' of authors. In the Chaetognatha the muscular fibres are very definitely marked with transverse striae. The digestive tract is entirely absent in the Acanthocephali, and the short oesophagus is said to open into the general cavity of the body in Gordius, and into a simple coecal sac in Mermis. In the Nematoidea, whether parasitic or free, a digestive tract is always present and always proctuchous; the anus being situated some distance anteriorly to the caudal extremity in the free species, but terminally or subterminally in the parasitic. The oral opening is always placed terminally at the front of the body, a point of some consequence in differentiating certain forms, such as Ichthydium and Chatonotus, which have sometimes been referred to the Turbellaria, and sometimes to the Rotifera, as well as to the Nematoidea. The pharynx may be armed with horny plates or teeth, and the oesophagus is often highly muscular, and the remainder of the digestive tract simple, and of a uniform calibre. There is no blood-vascular system as distin trom the perivisceral cavity, nor any respiratory organs. The water-vascular depuratory system has, in compensation for the absence of special respiratory structures, and, in the parasitic Nematelminthes, in correlation also with their habits, a very considerable development. In the Nematoidea it opens externally by an azygos vential pore, and in some cases by two symmetrically placed lateral pores, both of which orifices are situated in the anterior portion of the body; in the Acanthocephali, the homologous system appears to have no external orifice, though its cutancous ramifications are very extensive; and it is possible, therefore, that this system may be in this order circulatory and nutri- 
tional rather than depuratory, as the water-vascular system of the Infusoria is supposed to be by some authors.

The nervous system in the Chaetognatha consists of a single ventral and a single prae-oral ganglion, connected by commissures, so as to form a collar round the oesophagus; in the Nematoidea we have a fibrous ring, with ganglion cells interspersed in its substance, surrounding the oesophagus, and connected posteriorly with three main aggregations of ganglionic cells. Of these three aggregations the first is placed medioventrally, and consists of two symmetrical masses, one of which is on either side the middle line; the other two are placed on either side in the substance of the two lateral bands; and the three ganglionic centres correspond thus with the triradiate cephalic lobes of some families, and the triquetrous division of the oesophagus of most Nematoids. In the Acanthocephali there is only a single ganglion, placed at the base of their proboscis, and resembling thus the structure which has been stated to exist in the anterior extremity, the so-called 'head' of the Taeniadae. In the free Nematoids, certain aggregations of pigment granules, situated on the dorsal surface of the oesophagus, are spoken of as ocelli, but no nerve filaments have been traced into continuity with them, as there have been in the case of the similar organs in the Clactognatha. The cephalic lobes when present, as also certain papillae developed on the ventral surface in many Nematoids, are considered to be tactile organs.

With the exceptions furnished by the order Chaetognatha, and the Nematoid genus Pelodytes (Schneider), all Nematelminthes are dioecious. Their generative organs resemble those of the Platyelminthes and Discoploora, in possessing an intromittent apparatus; and, with the exception of the female Acanthocephali, where the ova escape by dehiscence into, and are taken up by an infundibuliform oviduct from the perivisceral cavity, the Nematelminthes resemble the Rotifera, Discophora, and Platyelminthes, and differ from the Annulata in having the walls of their generative ducts continuous with the envelopes of their generative glands. The ovaria are greatly developed, and the ova very small and numerous in the parasitic Nematoids, the reverse being the case with the free species. The spermatozon of the parasitic Nematoids are spherical or ovoidal cells, and move only by the protrusion of pseudopodial protoplasmic processes; in the free genera they are 
cylindriform, and possessed of the power of oscillatorial movement.

The impregnated ova of the Chactognatha are developed without going through any metamorphosis, and without the formation of any ciliated coat. The first stage of the embryonic life of the Acanthocephali is constituted by a form armed anteriorly with deciduous spiny hooks, and containing internally a mass of germinal matter, out of which the internal organs are developed after the animal has found its way into the appropriate portion of the body of its first host, and discarded its provisional organs. The sexual condition is only attained in the body of a second host, which is a Vertebrate, whilst the first is ordinarily (or always?) an Invertebrate animal. In the free Nematoids the development appears to be direct; but in the parasitic species it is complicated by the fact that the embryo is not developed in the same medium as that in which its mother lived, but migrates either into some other organ of the same animal, or into the exterior water or damp earth, whence it may find its way back into the body of the animal whence it was extruded, either directly or after a migration into some second host. A parasitic Nematoid may be undistinguishable in its free stage from a true free Nematoid, being of the same shape, and feeding, growing and moulting in the same way. Ascaris nigrovenosa, when set free from the body of the frog where it is produced parthenogenetically, attains to sexual perfection in the free state which they spend in moist earth. The development of the Guinea-worm, Filaria Medinensis, within the subcutaneous tissues of the human subject, would appear to be similarly parthenogenetic, and probably alternative with a free stage, which, though it has not been observed, may be supposed to be similar to that of the Ascaris nigrorenosa. Parthenogenesis has also been observed in a Nematoid worm infesting Limax cinerens; and Spladerularia bombi, if Schneider's explanation of Sir John Lubbock's account of this animal be correct, must be considered as furnishing a fourth instance of asexual reproduction in this class. No instances of reproduction by gemmation or metagenesis have been observed in the adult Nematelminthes; the power of repairing injuries has, in the free Nematoids, been found to be low, or absolutely none; and the breaking of the body of the Guinea-worm, Filaria Medinensis, appears to entail its death even under the condition of its 
entoparasitic life in the human subject, which is so favourable in this creature to the reproduction of the species. The tenacity of life, as against desiccation, which has been supposed to characterize many members of the class, is possessed in reality by only a few land and fresh-water genera, Tylenchus, Cephalobus, Aphelenchus, and Plectus; and in them is to be considered as partly, but, as it would appear, not wholly, dependent upon the power which they have of maintaining their tissues in a moist condition, and which they owe to the absence from their integument of the pores so characteristic of other free Nematoids.

The Chaetognatha, an order of marine worms of small size, represented by the single genus Sagitta, have been here ranked with the Nematoidea and Acanthocephati as Nematelminthes, instead of being placed in a separate Class. The differences which separate them from the free Nematoids appear to be in no respect of more than ordinal importance, consisting mainly in the facts of their hermaphroditism, and of their possession of transversely-striped muscles. The peculiar armature of the mouth, with two laterally and two dorsally-placed series of setae in the Sagittae, is obviously homologous with the intra-oral armature so common in Nematoidea; and the production of the external layers of the integument into fins, supposed to be characteristic of the Sagittae, is often observable both in the free and in the parasitic representatives of the order with which we are comparing them. The same remarks apply to the cuticular setiform spicula, and to the muscular structures of the Sagittae. The interior of the digestive tract in Sagitta is lined with ciliated epithelium, and Claparède has described a species, Sagitta Cephaloptera, which has a semilunar area in its nuchal region surrounded with a band of cilia. Thus the Sagittae, and through them the entire class of Nematelminthes, come to coincide with the rest of the Sub-kingdom Vermes in the possession of ciliated epithelium.

The animal described by Claparède, Anatomie und Entwickelungsgeschichte Wirbelloser Thiere, p. 88, Taf. xviii., Figs. 2 and 3 , under the name of Chactosoma ophiocephahum, would appear to stand as a transitional form midway between Nematoidea and Chaetognatha; whilst Gordius, and possibly also Echinoderes, described by Claparède, I.c., p. 92, and by Greef, Archiv. für Naturgeschichte, I869, connect the former of these tro orders with the somewhat aberrant Acanthocephali. 


\section{Class, Rotifera.}

Vermes with a retractile ciliated disk at the anterior extremity of their bodies, which are ordinarily microscopic in size, though they may attain as large a size as $\frac{1}{36}$ th of an inch in length. They are usually more or less plainly annulated externally, but they never are divided internally into compartments by any transverse septa. In most Rotifera the entire body is divisible into a 'body' proper, and a tail or foot, anteriorly to which the digestive and reproductive viscera with their ducts and outlets are situated. The 'body' can often be seen, when chitinization has not advanced so far as to form a carapace, not only to be distinctly annulated, but to possess both circular and longitudinal muscles in its walls. Cilia are never found on the external surface of the body, except upon the cephalic organ, whence they take their name; the chitinous surface of the integument may develope setiform outgrowths of various shapes, or the animals may secrete or agglutinate a tube for the lodgment of their body, or may clothe themselves, as Notommata centrura, with a mucous envelope. The 'tail' is usually anmulated when its integument is soft, or segmented when it is indurated; it often carries paired claw-like processes, or a suctorial disk terminally, and it may be ciliated externally. Internally it contains museles and a peculiar glandular body. It has been considered to represent a fused pair of arthropodal appendages, by those naturalists who would class the Rotifera with Arthropoda; it is more correct to compare it with that portion of the body of a free Nematoid, anteriorly to which the anus and generative ducts open; and though the anal outlet is upon the ventral surface in the Nematoids, and upon the dorsal surface anteriorly to the foot in the Rotifers, it must be recollected the anus is placed dorsally in a very great number of Vermes, as well as in a few of the lower Crustacea with which the Rotifera have been supposed to be allied. The opening, however, of the genital organ on the dorsal surface, is a point in which the Rotifera stand alone among Vermes, but in which they resemble not only the Arthropoda in question, but also many Echinodermata.

The muscles of the Rotifera appear to be, in some cases at least, transversely striated; but their ciliated 'rotary' disk is in most the 
main organ of locomotion. The ingestion of food is dependent upon the agency of the same organ, on the ventral aspect of which it almost always hies; though the anterior portion of the digestive tract is protrusible in the Rotifera, as in the most typical Annulata. In the male Rotifera the digestive tract is entirely absent, or represented only by a rudiment of an oesophagus. In the females of certain orders, the digestive system consists merely of an oesophagus and a coecal stomach, as in Ascomorpha, Notommata, Asplanchna; whilst in others it possesses a proctuchous intestine which ends in a cloaca, together with the outlets of the water-vascular and oviducal apparatus. A gizzard armed with chitinous, often complex, characteristic jaws is interposed in all female Rotifera between the mouth and the stomach; two or more coecal appendages are affixed to the commencement of this latter organ, which, as also the intestine, is clothed internally with cilia.

The Rotifera have no heart; the perivisceral cavity contains a corpusculated fluid. There are no specialized respiratory organs. The water-vaseular depuratory system has a great development, taking the shape of symmetrical tubes, which open inferiorly into the cloaca, and ordinarily, after entering an azygos contractile vesicle; and which have appended to them, peripherally at least, as many as five ciliated infundibula opening into the perivisceral cavity.

The nervous system consists of a bilobed ganglionic mass, which is placed above the oesophagus, but does not throw a collar round it. One or two eye-specks are sessile upon this ganglionic mass; and certain spots beset with non-mobile bristles, as well as a tubular process, the so-called 'respiratory tube,' are, inasmuch as they receive nerves carrying ganglioniform intumescences, to be regarded as being probably sensory organs.

The Rotifera are dioceious. The males, besides possessing no digestive tract, and living therefore but a short time, differ from the females in their external appearance; in their much smaller size; and in their much smaller numbers. The testis and ovary are azygos glands, and have their external walls continuous with those of the efferent ducts, opening at the posterior boundary of the body proper, anteriorly to the 'foot' or 'tail' when present, and on the dorsal surface. Reproduction takes place by means of two kinds of ova, the 'summer' and the 'winter ova.' Of these, the former are agamogenetic, like the summer ova of the Daphnidae and Cladocerce 
amongst the Crustacea; whilst the winter ova are gamogenetic. The embryos are developed from the entire yolk, without the formation of any primitive streak; and they do not ordinarily go through any metamorphosis.

They may be either solitary or social. They are mostly inhabitants of fresh water, but some are marine; a few are found living as parasites upon animal and vegetable organisms. They possess great powers of recovery after desiccation.

\section{Crass, Platyelminthes.}

Vermes, with more or less completely flat, leaf-shaped, or tongueshaped bodies, devoid both of external annulation and of internal perivisceral cavity. They are ordinarily aproctous, and, though possessed of complex reproductive organs, hermaphrodite. Metagenesis, with 'alternation of generations,' is very common in this class. They are divisible into three orders-the Turbellaria, the Trematodes, and the Cestodes. Of these the two latter are parasitic in habit, as is indicated by their possession of organs of adhesion in the shape of suckers or of hooks, or of both, and by their non-possession of cilia in their adult parasitic life; whilst the Turbellaria have a ciliated integument, whence their name is taken, and never possess either suckers or hooks. Even in the richly ciliated Turbellaria, the muscular layers of their body-walls are their active locomotor organs. There are three of these muscular layers in most Platyelminthes, the innermost, however, is said to be wanting in certain Turbellarians; like the outer layer it takes, when present, a direction more or less completely at right angles to the long axis of the body. Layers of granular glandular substance are observable in the more deeply-lying of the cortical layers of the integumentary system of all members of this class; and crystals of carbonate, and of phosphate of calcium are very commonly found in the cortical, and more sparingly in the more centrally placed portions of the body, especially of the Trematodes and Cestodes, and occasionally also of Turbellaria. Chitinous hooks and spines are very commonly present, but there is never any extensive induration of the integument in this Class, either by chitinous or calcificatory deposit.

The Cestodes, which are always entoparasitic in their sexual 
state, never possess any digestive tract; Ampliptyches urna, which appears to be the connecting link between the Trematodes, to which order it belongs, and the Cestodes, is also devoid of this system, and dependent upon imbibition through the external integument for nutriment. In the Trematodes, and Turbellaria, with the exception of the Nemertinea in which there is a perivisceral cavity, the walls of the digestive tract are not separable ordinarily as distinct layers from the rest of the parenchyma, except so far as the contents of the hepatic cells, which clothe the interior of the system, may enable us to distinguish them. In the Trematodes, the digestive tract consists either of a simple stomachal coecum, or of two similar structures, appended to a short muscular pharynx; and the two coeca may either each end blindly, or may anastomose, or may give off great numbers of lateral ramifications. The Trematodes are never proctuchous; and in this those Turbellaria which, from their possession of a multi-ramified digestive apparatus, are called 'Dendrocoelous,' resemble them. The 'Rhabdocoelous' Turbellaria may be either proctuchous or aproctous. The Nemertine Turbellaria, which are called 'Rhynchocoelous,' from possessing a proboseis armed with a calcareous style, and lodged in a tube distinct from the digestive canal, are always proctuchous. Their digestive tract takes a straight antero-posterior course, but is provided with lateral sacculations. The Nemertinea differ further from the other Platyelminthes in possessing a pseud-haemal vascular system, which consists of a dorsal and two lateral vessels connected with each other in the neighbourhood of their nerveganglia. All Platyelminthes possess a water-vaseular depuratory system, which opens externally either by a single posteriorly placed pulsatile vesicle, or by two symmetrical orifices more anteriorly placed. Its walls are often of different characters in various parts, being contractile towards their outlets, and possessed of vibratile cilia in their peripheral ramifications, in which again the calcareous concretions already spoken of are often observed to be contained. The flatness of their bodies, which enables aeration to be so readily and thoroughly effected in the most of the free and in the entoparasitic representatives of this class; and the multi-ramified character of the digestive and depuratory systems, enable the Platyelminthes to dispense with specialized respiratory and circulatory organs, the more or less cylindriform Nemertinea alone 
possessing any pseudhaemal respiratory vessels, and in this as in so many other points approximating to the Annulata.

The nerve-system consists, in the Trematodes and many Turbellaria, of a single pair of ganglia, placed in the anterior part of the body, and connected with each other by a transverse commissure. (See, however, p. I 55 infra.) In the Nemertinea it consists of a double pair of ganglia,connected by two commissures, one passing above and the other below the proboscis. From these ganglia two main nervestems pass off down either side of the body. Certain Trematodes, in the free locomotor stages of their larval life, may possess eyes, but with this exception, it has only been amongst Turbellaria that either these organs or auditory capsules have been observed to be present. In the Nemertine Turbellaria, two ciliated depressions on the anterior part of the body, underlaid by certain solid organs, are supposed to be sensory in function. It appear's to be doubtful whether the Cestodes really possess any nerve-system at all; a structure similar and similarly placed to the single ganglion of the Nematelminthous Acanthocephali has been described as such.

With the exception of the Nemertine Turbellaria and the proctuchous Rhabdocoela, which are sometimes placed in the same sub-order with them, all the Platyelminthes are hermaphrodite, and provided with accessory intromittent male organs, and accessory vitelligenous, uterine, and receptacular organs. The walls of the efferent ducts are always continuous with the envelopes of the sexual glands themselves, except in the Nemertinea, where the generative glands are sessile upon the body-walls, and no ducts exist as distinct from temporary, or permanent orifices in those walls. All Platyelminthes are oviparous, except a few Nomertinea and a few of the proctuchous Rhabdocoela amongst the Turbellaria. In a few fresh-water Trematodes, and Turbellaria with large ova, the embryos undergo no metamorphoses after leaving the egg; but in all other cases the embryos of the Platyelminthes go through more or less numerous stages of metamorphosis, which furnish typical instances of what is known as 'digenesis with heterogony,' and 'alternations of generations.' The histories of these metamorphoses are complicated in the parasitic orders by the fact that the different 'generations,' or, in other words, the sexual and the asexual stages in the metamorphosis, require different animals as 'hosts' for their sustentation and lodgment; and that 
in the Trematodes more than one asexual stage may interpose itself between the stage of embryo and that of the perfect sexual form. In the Cestodes, the sexual zooids are retained for considerable lengths of time attached to the asexual zooid, in the successive antero-posterior series in which they have been budded off from its posterior extremity. Compound colonies are thus formed, in which the setting free of the sexually perfect deuterozooid does not entail the death of the 'nurse.' In the Trematodes the deuterozooids are contained within the body of the 'nurse,' and are only set free by its disruption and death. Several of the forms of reproduction observable in the Turbellaria, have been mentioned above in the history of the Sub-kingdom Vermes.

The Turbellaria possess a great power of repairing injuries and mutilations, and differ herein very markedly from the Discophorous Annulata, which have sometimes been classed with them.

\section{Sub-Kingdon, Echinodermata.}

Animals which may be spheroidal or vermiform, star- or discshaped, but which, whatever their external form, combine with a radial and, ordinarily, pentamerous arrangement, traces of a bilateral symmetry always detectible in developmental, and usually also in adult life. The Sub-kingdom is divided into four Classes, the Holothurioidea, the Echinoidea, the Asteroidea, and the Crinoidea. The Class Asteroidea is divisible into two Sub-classes, the Asteriae and the Ophiuridae.

They possess a water-vascular system which surrounds the commencement of their digestive tract, and, from the central ring thus formed, sends out prolongations into the radii. Tubular processes are developed upon these radial water-vascular stems in all Echinodermata except the apodal Holothurioidea, and, except in the Crinoidea, are used for the purpose of locomotion. The water with which this system is distended finds its way into it through the usually calcareous 'madreporie' canal and 'tubercle,' which are in all Echinodermata, except the Crinoids, appended to 
the water-vascular ring, and admit fluid to filter into it, through their pores, either from the exterior sea-water when they are part of the external skeleton (Asteroidea, Echinoidea), or from the perivisceral cavity when they are contained in it (Holothurioidea). Other appendages, either of the nature of accessory reservoirs, the 'Polian vesicles,' or of a glandular character, the 'racemose appendages,' are very ordinarily found in connection with the watervascular ring. The madreporic system may consist of a single, or of multiple canals and tubercles. Trichocysts have been said to exist in the integument of Synaptidae, but some doubt appears to attach to this statement. (See Semper, Reisen nach Philippinen Hft. iv. I64.) Their integument never developes any chitinous structures, but is always more or less indurated by calcareous deposits, and more or less roughened by spinous out-growths. The calcareous deposits may be almost, or quite microscopic; or they may form a continuously and immovably articulated skeleton for the entire animal, or for its central dise; the spinous outgrowths are similarly various in size, as also in shape, and they may be movably, or immovably articulated to the subjacent integumentary system. In any case they are normally covered with an epidermal layer of sarcode, which is often richly ciliated. Where the calcareous skeleton forms a continuous capsule for the animal's body, the muscular system is correspondingly reduced, and in Echinoidea there are no specialized muscles except for the movable spines, and for the pedicellariae homologous with them, and for the manducatory organs. Where the calcareous skeleton, though greatly developed, is yet made up of movably articulated pieces the muscular system may be moderately developed, as in Asteroidea, where the water-vascular system is locomotor in function; or greatly developed, as in Crinoidea, where it is not. Where, as ordinarily in Holothurioidea, the calcareous deposits, both external and internal, are reduced to a minimum, the muscular system attains a very high grade of evolution. There if always a large perivisceral cavity in the Echinodermata, into which the sea-water finds its way. The digestive tract never communicates with the perivisceral eavity directly, and is only rarely aproctous. Though it never possesses any specialized, salivary, or hepatic glands, by its possession of extensive radial diverticula (Asteriae) or of lengthy convolutions (Echinoidea and Holothurioidea), the digestive system 
comes to possess an absorbing surface which is by no means inconsiderable in relation to the other organs of the body. Coeca are appended to the anal segment of the digestive tract in Asteriae and Holothurioidea. In the Holothurioidea these coeca take a great development, and are known as the 'lungs' or ' respiratory trees,' and their terminal ramifications are supposed to be perforated, and to admit the sea-water into the perivisceral space. Respiration is further provided for by the existence of perforations in the integument, through which tubular processes of the perivisceral spaces which contain true blood as well as sea-water, project into the aerating medium. The very numerous but non-locomotor tubular processes of the water-vascular system of the Crinoidea must be supposed to exercise an aerating function, as must also the processes of the same system known in certain Echinoidea as 'ambulacral gills.' A system of 'pseudhaemal' vessels exists, in all Echinodermata, in connection with a ring-shaped vessel or plexus which surrounds the oesophagus between the nerve- and the waterrings; and in Asteroidea and Echinoidea it is further connected with a second and circum-anal ring. The branches of this system are distributed to the viscera and pass into the radial divisions of the body; when there are two rings present, they are connected by a pulsatile sac, the so-called heart. The pseudhaemal system has been often supposed to communicate with the water-vascular and the perivisceral systems; it differs from them both in not possessing cilia on its internal surface; but this difference would not disprove the possibility of the several systems being continuous.

The nerve-system consists in all Echinodermata, so far as is at present known, with perhaps an exception in the case of the Crinoidea, of nerve-cords containing nerve-cells which run along the axis of each ray exterually to the pseudhaemal and water-vascular radial stems, and have their proximal ends connected by eommissures of less complex structure than themselves, so as to form a more or less pentagonal collar in the peristomial region.

The Echinodermata are, with the exception of the Synaptidae, dioecious; there is no external difference between the sexes, nor between the generative glands. The generative glands very ordinarily have a radiate arrangement; the ova are usually very small, and impregnated externally to the body of the female; but in some cases they are large, and several species of Ophiuridae (Ophiolepis) 
are viviparous. In probably every case, except perhaps the lastmentioned, the impregnated ovum takes the shape of a bilaterally symmetrical and ciliated larva, provided with more or fewer provisional organs. Where the ova are few and large, and during development, as in Pteraster, Echinaster, and some other Asteroidea, protected by a dorsally or ventrally formed maternal marsupium, the provisional organs may be reduced to a minimum, and the development becomes almost direct. But in most cases the Echinodermata go through a very well-marked metamorphosis, which often has more than one larval stage. The distinctive character of the metamorphosis appears to be the possession by the larvae of at least a mouth and pharynx, which, whether absorbed or cast off, is never converted into the corresponding organs of the perfect Echinoderm developed inside of the provisional organism. The mass of more or less differentiated sarcode, of which the larva or pseudembryo as opposed to the Echinoderm within it, is made up, always carries upon its exterior certain bilaterally-arranged ciliated bands, by the action of which the whole organism is moved from place to place; and it may be strengthened by the superaddition to it of a framework of calcareous rods. In the larval Astericie known as Bipinnariae, the provisional organism, when discarded, as it is, by the young Echinoderm, has been observed to retain an independent vitality for some days; but it has not been observed to give rise to any second zooid; and when we consider the greater tenacity of life which isolated portions of these animals (Asteriae and Holothurioidea) have often been observed to possess, the history of a Bipinnaria might appear to be analogous rather to the ecdysis of a Crustacean, or the metamorphosis of a Dipterous Insect, than to true metagenesis.

The history, however, given by Professor Grube (Monatsbericht. Konigl Akad. Wiss. zu Berlin, I 2 Marz, I 868) of the discovery of an Echinoid, Anochanus sinensis, which, while possessing the external organs, such as spines, pedicellariae, and ambulacra, characteristic of adult Echinodermata, had neither genital glands nor orifices; but in place of them an apically situated sac containing severit young Echinoidea in very various stages of development; will, if confirmed, cause us to demur to the view adopted below (pp. 147, r53), to the effect that in Echinodermata metagenesis with alternation of generations, as distinct from metamorphosis, is not to be found. At present, as but a solitary specimen has been observed, it 
may be allowable to suggest that we have in reality a case of intra-marsupial development, such as that known to occur in Ptercester militaris.

The radial character of the future Echinoderm is first shown in the formation of the ambulacral elements of the water-vascular system, which first shows itself as a simple tubular depression, the future 'madreporic' system, on the dorsal surface of the larva. The Echinodermata are exclusively marine; some of the Holothurioidea, however, can live in brackish water, or, rather, in the sand and mud of estuaries. They are never social; and, with the exception of Pentacrinus, all the living representatives of this subkingdom are free.

\section{Class, Holothurioidea.}

Echinodermata, varying in shape from being subcylindrical and vermiform to being plano-convex like an ordinary snail, with an integument different from that of other members of the sub-kingdom, with the exception of a single Echinus, in being, through default of development of the calcareous skeleton, left supple and pliable. Their mouth is surrounded by a circlet of tentacles which are modifications of the ambulacral feet; are frequently used as locomotor organs; and in certain Synaptidae, as also in the developing stages of other Holothurioidea, are provided with suckers. With a few exceptions (Synaptidae and Molpadidae), the Holothurioidea have a well-developed radial ambulacral system, in addition to their peristomial ambulacral tentacles. If the ambulacra are arranged in five functionally similar rows, the body of the animal obtains a somewhat pentagonal outline; if they are scattered over the entire surface so as to leave no distinct inter-ambulacral areae, the body is vermiform in general outline; if the five rows are divided into a ventral locomotor trivium; and a dorsal bivium, the ambulacral feet in which may have no suckers, or be wholly absent; the body comes to resemble that of a Gasteropodous Molluse. In the Molpadidae the radial stems of the water-vascular system are present, as also certain tubular prolongations of them which pierce the skin, but they have no feet developed upon them; in the Synaptidae the water-vascular system has no radial stems, and consists simply of the circum-oral ring, with its Polian and madreporic appendages, and its ampullae and branches for the tentacles. In some cases the Polian, glandular, and madreporic appendages of the water-vascular ring are very $k 2$ 
numerous, and the madreporic canals may be branched as well as multiple; but in all Holothurioidea the madreporic tubercle or tubercles are contained within the perivisceral cavity, and it is from thence consequently that the fluid for the ambulacral system is drawn. The madreporic canal, when single, is always to be found marking out the inter-radial space of the dorsal bivium by its suspensory lamellar mesentery. The ambulacral feet of the pedate Holothurioidea are very frequently strengthened, as in Echinoidea, by the addition to them of ealcareous dises; they may, however, and especially along the two rays of the dorsal bivium, as also when scattered over the inter-ambulacral areae, be tuberculate and conical, when they are called 'ambulacral papillae.' All Holothurioidea possess an internal skeleton in the shape of a calcareous ring in relation with the pharynx, and thus with the water-vascular ring, the nerve-collar, and the annular pseudhaemal plexus. It consists of five radial ossicles, which are either notched, or, as in Synaptidae, pierced for the passage of the water-vessels and nerves, and of a corresponding number of inter-radial pieces. The five radial ossicles are the fixed points to which the five radial muscular bands which give the body of all Holothurioidea a pentamerous character, are attached. As the calcareous skeleton, except in a very few cases (Psolus and Ocnus), is merely represented by spiculae scattered in the substance of the corium, the muscular system is more largely developed than in the other classes of this sub-kingdom, the externally-placed circular layer being especially and distinctively prominent. By means of this highly-developed muscular system the Holothurioidea not only obtain the power of moving in the same way as the Vermes, but, so long as its connection with the nerve-system, and that of the several radial factors of their nerve-system with each other are uninjured, they possess also the singular faculty of ejecting their viscera, and in the case of Synapta digitata of dividing their bodies at various points when injured or alarmed.

The digestive tract is, with the exception of a few Synaptidae, where it takes a straight antero-posterior course, arranged in convolutions, as in the Echinoidea. It consists of a pharynx and an intestine, between which a small and short muscular stomach is distinguishable as interposed. When these animals discharge their viscera upon irritation, the intestinal tract is always separated about the line of junction of the pharynx and stomach, and immediately posteriorly 
to the water-vascular ring. The first segment of the digestive tract is suspended by a muscular mesentery along the middle line of the dorsal bivium, which is thus made actually as well as morphologically a line for the bilateral division of the body. The terminal segment has, as in so many Invertebrata, a respiratory function, and, in the great majority of Holothurioidea, has certain multiramified coeca, the.so-called 'lungs,' or 'respiratory trees' of the 'Pneumonophorous' order, appended to it. Where these 'trees' are absent, as in Symaptidae, certain ciliated funnel-shaped organs are to be found bestudding the mesentery; and as these organs are in the Gephyrean Worms similarly absent, or present, accordingly as in them cloacal respiratory trees are present (Echiuridae), or absent (Sipunculidae), the two sets of organs may be supposed to stand to each other in a supplementary relation. The apical terminations of the respiratory trees are supposed to be perforated, and thus to furnish a route whereby the sea-water can find its way into the perivisceral cavity. As the ciliated infundibula are, according to the figures of them given by Sars, Norges Echinodermer, Tafs. xv. xvi.; and Leydig, Lehrbuch der Histologie, p. 39 I, fig. 203; Müller's Arch., I 852, p. 514; connected with a system of vessels in the mesenteric membrane, it would appear that they may discharge the same function.

To the respiratory trees or to the cloaca whence they arise, the so-called 'Cuvierian organs' are appended, which may have a glandular function, but which are probably organs of defence, as they are observed to be very readily discharged upon irritation.

The pseudhaemal system consists of two main stems, connected the one with the dorsal, and the other with the ventral line of the digestive tube; and of a circular plexus representing the circular pseudhaemal vessel surrounding the pharynx. These two vessels are connected with each other by reticulations in the walls of the intestine, and the 'rete mirabile' developed by the dorsal vessel is brought in many cases (Aspidochirotac) into intimate counection with the left respiratory tree.

The nervous system is said to differ from the nerve-systems of other Echinodermata by having its circular commissural collar thicker than the radial 'Ambulacral-gehirne.' It appears, however, to be of less complex structure, and it must be recollected that in some other Echinodermata the radial stems taper towards their proximal 
as also towards their distal ends. Organs of special sense, in the shape of otolithic vesicles, have been observed in Synaptidae appended to the radial nerve-cords just where they pass through the foramina in the radial ossicles of the internal calcareous ring.

With the exception of the Synaptidae, the Holothurians are always dioecious, resembling in this all other Echinodermata, but differing from them in never having the radiate arrangement retained in their generative glands. These organs take the shape of longer or shorter, simple or branched coeca, which are attached to one or both sides of the inter-radial dorsal mesentery, and discharge their products by a single duct running in the same medio-dorsal line to open either posteriorly to, or within the circle of oral tentacles. In one case, Ilolothuria tremula, the development has been observed to be nearly direct, the provisional organs being represented merely by a rapidly-disappearing layer of ciliated sarcode; but in most cases there are two larval or psendembryonic forms, the earlier of which, Auricularia, possesses a mouth and alimentary canal, and special bilaterally symmetrical natatory lobes, whilst the second, the so-called 'pupa,' is barrel-shaped, devoid of mouth and of lateral outgrowths, and girded with five zonular ciliated bands, which disappear as the ambulacral system is developed.

\section{Class, Echinoidea.}

Echinodermata varying in shape from that of a sphere to that of a disc, with, in all living species but one, in which the skeleton has been reported to be flexible, an immovably articulated external shell, the so-called 'corona,' which, with its ambulacral and interambulacral spaces, occupies the entire exterior of the body, with the exception of a small circum-oral and a small anti-ambulacral circum-anal area. When the mouth and anus are at opposite poles, the Echinoidea are called 'regular,' or 'endocyclica ;' when the anus is placed excentrically, they are called 'irregular,' or 'exocyclica.' The two types are mutually connected by transitional forms; the irregular shows bilateral symmetry very obviously; the bivium, however, and the trivium do not hold the same relations to the dorsal and ventral surfaces as in Holothurioidea. The locomotor feet are in many of the regular forms uniformly sucker-shaped, and provided with a distal calcareous support; but the dorsal feet, even in some regular forms, may lose their sucker-shape; and in the 
irregular forms Spatangidae and Clypeastridae, they take very various shapes, and amongst them that of the so-called ambulacral gills, which form a rosette of petaloid ambulacra limited to the apical half of the shell.

The madreporic plate is always to be found at or near the apical pole of the body, and is usually fused with one or more of the genital plates. Five eye-bearing plates alternate radially with the inter-radially placed genital plates. The ambulacral plates lie externally to the free radial water-vascular trunks, but there are certain internal calcified processes, the so-called 'Auriculae,' which may, as in the genus Clypeaster (Lam.), Echinantlus (Müller), attain a great development, homologous with the internally-placed ambulacral ossicles of the Asteroidea. Both the ambulacral and the interambulacral plates are beset with very numerous movably-articulated spines of the most varied forms, between which pedicellariac are, as in Asteriae, interspersed. In Spatangidae certain areae, the 'semitae,' are occupied by bristle-like appendages, which have clubshaped ends, are strengthened internally by calcareous deposit, and are covered externally with cilia.

The tentacular corona of the Holothurioidea is represented in Echinoidea by certain largely-developed ambulacral feet placed radially on the innermost circle of the peristomial area, and immediately therefore on the edge of the mouth. But in Echinidae and Clypeastridae, a complex prehensile masticatory apparatus exists as the so-called 'Lantern of Aristotle,' at the entrance of the digestive tract. The teeth of this apparatus are lodged in inter-radially placed alveoli, composed of two main and two accessory pieces, and alternating with radially-placed structures, each consisting in Clypeastridae of one, and in Echinidae of three, ossicles. The elements in the radially-placed portion which both families alike possess, are known as the 'rotulae' or 'falces,' and as they, like the radial elements of the calcareous ring of the Holothurioidea, cover in the junctions of the radial water-vascular trunks to the central water-vascular ring, and as they resemble them still further in not belonging to the perisoma, but being true internal calcifications, they would appear to be, as Müller taught, homologous with them.

An oesophagus, and sometimes, as in Ectimus saxatilis and Spatangus, a coecum, is distinguishable at the commencement of the 
digestive tract; which, in the rest of its course, is intestiniform and attached by a fenestrated mesentery in festoons round the interior of the shell. They are never aproctous.

The pseudhaemal system has a circular vessel developed both at the oral and apical poles, the ring at the oral pole lying inferiorly to the water-vascular ring at the base of the dental apparatus. The two rings are connected by a pulsatile sac, the so-called ' heart,' and vessels are given off to the viscera, and especially to the intestine.

Special respiratory organs are developed in many Echinidae in the shape of arborescent outgrowths communicating with the perivisceral, but, according to most authorities, not with the watervascular system, and arranged in the peristomial area. They are absent in the Echinoidea with petaloid ambulacra, the widely expanded lamellar gills carried by which exercise an aerating function.

The nerve-pentagon lies immediately below the oral peristoma, at a much lower level than the pseudhaemal and water-vascular rings. The nerve-stems, which are given off from it radially, are much wider in the middle part of their course than at either distal or proximal end.

It is of importance to note, that, though growth ordinarily takes place in Echinoidea in the way of interpolating fresh plates at the apical pole of the corona, similar additions may be made in Cidaris at the oral pole to the movable plates which, in that genus, are prolonged on to the peristomial area from the immovably articulated corona.

The generative glands in the regular forms are five in number, opening by five separate ducts in the five genital plates. In the irregular forms, Spatangidae and Clypeastridae, there are only four genital glands, ducts, and plates.

The larva is pluteiform, and strengthened by a calcareous framework. The embryo appropriates no part of the larva except the stomach and some formative blastema which is aggregated round it.

Professor Grube is reported by Dr. Semper, Reisen im Archipel der Philippinen, p. $1 \sigma_{3}$, to have met with an Echinid with a perfectly soft integumentary system. The structural differences between such an animal and a Holothurian would be comparatively small-the resemblances very numerous. Amongst them may be mentioned, as probably existing, the possession of calcareous dises by the feet; the presence of specially mo- 
dified fect homologons with the Holothurian tentacles on the peristomial area, and the peculiarities of the digestive tract. The ordinary representatives of these two classes resemble each other in the small size of their anti-ambulacral area, and in the tendency they have to assume bilaterally symmetrical forms. Their developmental history, however, is very different.

\section{Class, Asteroidea.}

Echinodermata, with flat, star-shaped, or simply pentagonal, bodies, with a well-developed and functionally locomotor water-vascular system, the ambulacral surface in relation with which is developed commensurately with the anti-ambulacral, centrally or sub-centrally in which the anus, when present, opens.

The Asteroidea differ from the other Echinodermata in having a well-developed 'internal skeleton,' externally to which their nervecords and radial ambulacral vessels lie. This system is represented rudimentarily by the auriculae of Echinidae, and the similar but more developed internal structures of Clypeaster; but it is wholly wanting in the Crinoidea.

The Asteroidea are divided into two sub-classes, the Asteriae and the Ophiuridae; in the former of which the arms, firstly, are prolongations of the central dise; and, secondly, contain within them prolongations of the digestive tract, and portions, or the whole of the reproductive organs; and thirdly, are furrowed on their medioventral surface for the reception and protrusion of the ambulacral feet; whilst in the latter, the arms are differentiated from the central dise, not only by their mode of taking origin from it, but also by not containing any portions of the viscera of organic life, and by not having any medio-ventral ambulacral furrows, but in place of them, ordinarily, a row of dermal scales, on either side of which the feet are protruded. The vertebral ossicles of the Optiuridae resemble those of the Asteriae in being composed of two symmetrieal halves; but these two halves are articulated together immovably, except in the pair next the mouth, whilst the entire series of mesial ambulacral ossicles is in Asteriae composed of mesially and movably articulated bilateral halves, for the adduction and divarication of which special muscles are developed. The Ophiuridae have not the internal prolongations of the branches of the radial vessel to the feet, which are known in Asteriae and the other higher Echinodermata as ampullae; but 
these branches are lodged in a separate canal, leading from the central demi-canal, in which the nerve-cord and the radial watervessel are both lodged, outwards. The madreporic tubercle, instead of being a prominent object on the dorsal surface as in Asteriae, is situated on the ventral surface, where it is either distinct but very small as in Astrophyton, or partially fused with, and concealed by one of the oral plates, so as to communicate only by a very small pore with the exterior. There are no pedicellariae in the Ophiuridae. The Ophiuridae have a digestive system consisting of a simple sac without diverticula or anus; whilst, except in the three genera Astropecten, Ctenodiscus, and Luidia, the digestive tract of the Asteriae is always proctuchous, and is without any exception even in the case of the genus Brisinga, which is described as being intermediate in character between the two Sub-classes, is prolonged for a greater or less distance into the arms.

The feet of the Ophiuridae differ from those of the Asteriae, with the exception of the three genera just mentioned, in not possessing terminal suckers. In some further points in which the Opliuridae differ from the Asteriae they appear to resemble the Echinoidea. Their feet sometimes show a tendency to effloresce into lateral ampullae, and thus to approximate in character to the ambulacral gills and tactile feet of certain Echinoidea; they possess a calcified peristomial apparatus which finds its homologue in parts of the peculiar manducatory apparatus found in that class, but which is not represented in Asteriae; and their larvae, finally, are pluteiform, whilst those of the Asteriae are vermiform, and never possess a pseud-embryonic calcareous skeleton. It is mainly upon the descriptions of such transitional or inter-connecting living forms as Brisinga endecaencmos; and of such fossil forms as Protaster and Paleodiscus, that a justification of the placing the Asteriae and Oplizuridae together in one Class must rest.

\section{Class, Crinoidea.}

Echinodermata with arms radially appended to a central dise or ' calyx,' which dise at one period of their lives, or permanently, is attached by a segmented peduncle to marine objects. They possess a well-developed dermal skeleton, which is movably articulated in the arms, but immovably in the region of the dise. The water-vascular system gives off a great number of tentacular tubules 
along the furrorws, which radiating from the mouth pass down the medio-ventral surface of the arms, and of their laterally articulated pinnulae. But the water-vascular system appears to be in the Crinoidea wholly, as it is in other Echinodermata partly, respiratory in function. The segmented arms can execute exceedingly active movements by means of the muscles with which they are provided; but these movements are mainly confined to the action of closing the arms upon the oral surface of the dise, and so protecting it from the contact of irritating matters. The act of swimming from place to place however by the alternate action of the arms, is by no means so habitual to the Crinoidea as has been supposed. The Crinoidea are dependent mainly upon the action of cilia lining their digestive tract, and partly upon that of the similar structures upon the integument of their arms, for the ingestion of alimentary matters. Their oral surface is, in the natural condition, always turned upwards; the digestive tract, in the living genera, Antedon and Pentacrinus, possesses an anus opening in one of the spaces between two of the water-vascular furrows radiating from the mouth. The digestive system is confined to the central disc ; but the perivisceral space has tubular prolongations along the arms and their pinnules, whereby the nutritive fluid is on the one hand itself aerated, and on the other brought into relation with the powerful muscles whereby the movements of the arms are executed. Their generative organs differ from those of all other Echinodermata in being lodged externally in the membranous lamellae developed from the ventral surface of the pinnulae, and in setting free their products simply by dehiscence. The larva or pseud-embryo gives rise within itself to a second form, which, without taking up any part of the short digestive tract of the first, developes a peduncle which is discarded in Antedon, but is permanently retained in Pentacrinus.

Jointed cirri project at interrals from this peduncle in Pentacrinus, and in the non-pedunculate $A$ ntedon are attached to the aboral surface of the calyx. The existence of these cirri would appear to show that the true homologue of the 'arms' of the Crinoidea is to be found in the ambulacral tentacles of the Holothurioilea, whilst they themselves are homologous with the radial ambulacra of other Echinodermata. It shows further that the Echinodermata are in Mr. Herbert Spencer's language 'tertiary' rather than 'secondary aggregates,' a view to which 
elsewhere in the sub-kingdom, evidence is only obscurely borne in the mode of growth of the Echinoidea, and possibly also in the spontaneous self-mutilation and division observable amongst the Holothurioidea.

See, for the development of Anterton Rosacens, (Comatula Rosacea,) Professor Wyville Thomson, Phil. Trans., 1865; Dr. Carpenter, ibid., I866.

\section{Sub-kingdon, Coelenterata.}

Radially-arranged or bilaterally-symmetrical animals, in which the general cavity of the body and that of the digestive sac are always continuous. They may be fixed or free, solitary or social; they are exclusively aquatic, and almost exclusively marine. The walls of the body consist always of two layers, an ectoderm and an endoderm; both, but especially the outer layer may become indurated by interstitial deposit; and the outer layer may secrete a more or less hard exterior cell. Both layers, but especially the exterior, are provided with 'thread-cells,' and both layers, but especially the interior, are, at one period or other, ciliated. The mouth is the only outward opening of the digestive tract; it is ordinarily surrounded by a corona of tentacles, the hollow interior of which is continuous with the general body cavity. This cavity may be a simple and direct prolongation of the digestive sac; or this sac may, whilst suspended by its sides in the perigastric space, open at its bottom into it. The interior of the stomach and of the general body cavity being ordinarily ciliated, circulation is maintained in the alimentary fluids; but there is no tubular vascular system of any kind, nor any specialized respiratory apparatus in these animals.

The Sub-kingdom is divisible into three Classes, the Ctenophorae of which the Cestum Veneris, the Cydippe, and the Beroe may be taken as examples; the Anthozoa; and the Hydrozoa.

A nerve-system has been supposed to exist centrally in the Ctenophorae; and peripherally, as special sense organs in the Medusae in their marginal cysticles, but much doubt has been justifiably raised as to the really nervous character of the structures in question. (See Claus, Zeitschrift Wiss. Zool., xiv., 1864, pp. 385 , 388). The Ctenophorae are hermaphrodite; the Anthozoa and Hy- 
drozoa are ordinarily dioecious. The generative products are always developed between the two layers of the body walls; and are discharged by dehiscence, either into the external medium in which the animal lives, as in Hydrozoa; or into the perigastric cavity, to be thence discharged by the digestive tract, as in the two other Classes. Reproduction may take place asexually by gemmation or by fission; and the power of repair and regeneration is very great. The sexual method is very ordinarily accompanied by metamorphosis and metagenesis; and the variety of forms found in any one of the compound species, is often increased by the specialization of certain zooids to particular functions, so as to be purely agamic and digestive, purely motor as in Siphonophorae, or purely reproductive.

\section{Class, Ctenophorae.}

Bilateral Coelenterata, ordinarily oval, rarely cestoid in form; the place of the corona of tentacles seen in the two other Classes of Hydrozoa and Anthozoa, is taken ordinarily by a pair of long highly contractile cord-like prehensile organs, the interior of which communicates with that of the system of canals, representing the body cavity, and the exterior of which is armed with thread-cells. Their most distinctive characteristic, and the one whence they take their name, is the possession of four pairs of motor organs, consisting of parallel comb-like rows of plates, which work like paddlewheels in propelling the ereatures. They are all marine, and never microscopic in size, nor social, nor indurated by deposit of any kind. They differ from the Anthozoa in having the intermesenterie spaces of the body cavity reduced to a system of bilateral canals by the increase of the gelatinous parenchyma; and from the Hydrozoa, in having the stomach surrounded by, and suspended, though not freely, in a perigastric cavity ; and from both, not only in their well-marked bilateral symmetry, but also in having a communication between the external medium and the body eavity, not only through the digestive tract and the mouth, but also by means of a funnel-shaped, and ordinarily bifid canal at the opposite pole of the body. A central nerve-system, consisting of a single or double ganglionic mass, has been supposed to be demonstrable in these creatures at the point where the funnel-shaped canal just mentioned comes into communication with the system of perigastric camals, and to send branches in correspondence with the rows of swimming 
plates. An otolithic cysticle, sometimes called the 'ctenocyst,' is situated at the point of junction indicated. (See, for the doubtful character of the nerve-system, Claus, Zeitschrift für Wiss. Zoologie, I864, p. 386.) The Ctenophora are hermaphrodite, the testes and ovaries being placed on either side of each of the eight canals, corresponding with the rows of swimming plates. The development of the embryos, which are as in Anthozoa set free through the mouth, is ordinarily simple; but they are in some instances furnished with provisional ciliated and other organs.

\section{Class, Anthozoa.}

Coelenterata, of sub-columnar form, with their mouth surrounded by a corona of tentacles, the number of which is either four or six, or some multiple of four or six, contrasting herein, as in so many other points, with the pentamerous Echinodermata. Their opposite imperforate extremity is ordinarily fixed; and they are ordinarily social. They are all marine, and may be no more than a line in length and breadth. With the exception of Actinidae and Cerianthidae, all have the external integumentary system more or less indurated by inorganic deposits, which form 'the coral structures.' These structures are ordinarily divided into two classes, accordingly as they have been supposed to be cuticular formations or 'foot secretions,' when they have been called 'sclerobasic;' or to be due to deposition within the tissues, when they have been called 'sclerodermic;' but doubt has been thrown on the soundness of this distinction by Kölliker (see Icones Histiologicae, ii., pp. I I 7-I 70). The body cavity is not only directly continuous with the cavity of the stomach by means of an orifice at the bottom of this latter cavity, but it is also continued upwards round the outside of the stomach, which is freely suspended in it by means of lamellar mesenteries. These lamellae divide the body cavity into a series of radially-arranged chambers, which again are prolonged upwards so as to be continuous with the interior of the tentacles. The interior of the tentacles may communicate directly with the exterior by perforations placed at their lips, as may also the general cavity of the body by peripherally-placed apertures called 'cinclides.' In Cerianthus and Peaclia, the axis of the foot may be perforate.

The Anthozoa are, with the exception of Cerianthus, dioecious. The generative organs are developed in the mesenterial lamellae. 
The embryos are discharged by the mouth of the parent as free ciliated larvae of smaller size and with fewer tentacula, or without any, but in other points they are like their parents. Reproduction may take place also in the asexual ways of gemmation and of fission, and the entire animal may be regenerated from a separated fragment; but there are no 'Medusae' in this Class.

\section{Class, Hydrozoa.}

Coelenterata, which may be fixed or free, social or solitary, but which are often of much smaller size, and invariably of a simpler construction than either of the other two Classes in this Subkingdom. The wall of the digestive cavity is continued directly into that of the body cavity, or, in other words, the stomach is never suspended freely in a perigastric cavity. The general body cavity is prolonged, under the form of 'gastro-vascular canals,' through the parenchyma of the body, and into the interior of the tentacles. The body wall is made up of two layers, an ectoderm, which in early stages is ciliated, and in later is very richly provided with thread-cells; and an endoderm, which is ordinarily ciliated, and keeps up a circulation in the gastro-vascular fluids, and contains also some, but ferver thread-cells than the ectoderm. The outer layer of the ectoderm secretes a chitinous tubular polypary in the fixed orders, with the exception of the IIydridae; the deeper layers of the body may attain in the free forms a greater or less amount of induration, either in a disc-shaped (MIedusae), or tube-shaped (Siphonophorae) mass; but it is only rarely that in the fixed orders any calcareous deposit takes place, as in the Lithydrodea. (See, however, Kölliker, Icones Histiologicae, ii., p. 1I7). No central nerve-system has been demonstrated in these ereatures; the marginally-placed cysticles of the Mledusae may represent special sense organs. The Hydrozoa are rarely hermaphrodite; the generative organs are developed in them as in all Coelenterata between the two layers of the body walls, but owing to the absence of any perigastric cavity, such as that of the Anthozoa and Ctenophora, they come to be placed externally, and to be diseharged into the water not throngh the mouth, but simply by dehiscence of the exterior layer. Reproduction may be asexual in the way of gemmation frequently, and of fission rarely; development may be nearly direct, as in Tubularia and Coryne Van Benedonii, where the stage 
of a ciliated embryo, s. 'planula,' is wanting; or it may be accomplished by metamorphosis, complicated with 'alternation of generations.' In this latter case the specialized generative zooid may be either fixed to the asexual coenoecium, or set free as a medusiform zooid. The power of repair and of regeneration after injuries, and from isolated portions of body substance, is very great.

\section{Sub-kingdom, Protozoa.}

Organisms, which, being ordinarily microscopic and unicellular, rarely have their exterior outlines fixed in definite forms, or their interior parenchyma distinguished by much histological differentiation. By the absence of a rigid external envelope the unicellular Protozoon is distinguished from most forms of vegetable life, except the Mycetozoa and the locomotor gonidia of certain Cryptogamia; and by the absence of histological differentiation in correspondence with the different vital functions, it is distinguished from most or all higher animal organisms. The greater part, or even the whole of the body of a Protozoon, may consist simply of Protoplasm, s. Cytoplasm, s. Sarcode, which may vary from being purely hyaline to being markedly granular, and from being semifluid to being exceedingly viscid and strongly coherent, but which, chemically, is nitrogenous, and physiologically, contractile. The exterior or cortical layer's of the body ordinarily differ more or less in consistence from the interior; they may secrete a calcareous, or agglutinate an arenaceous shell; and the internal layers may, in their turn, furnish themselves with a solid support in the shape of an internal skeleton composed of inorganic, siliceous, or calcareous particles, or of organic horny substance. In some cases an external shell is secreted, of an organic substance resembling chitine. Movement may be accomplished by the contraction of the general mass of the parenchyma, as in Gregarinae; or the protoplasm may develope cilia, as in Infusoria; or pseudopodia, as in other Protozoa. Nutriment is absorbed in some cases by the general parenchyma of the body which envelopes the alimentary matter within its own substance, as in Amoebina and Actinophryna; or the entire animal may live immersed in an atmosphere of assimilable albumen, 
as is the case with the parasitic Gregarinae, and absorb soluble pabulum at all points of its exterior. In other cases the pseudopodia, in which a constant cyclosis of the granular cytoplasma may be observed to be carried on between the central part of the animal's body and its radial processes, act as suctorial and absorbing organs. In one class only, the Infusoria, do we find both mouth and anus; but these two orifices are not connected with each other by any continuous tubular canal, the ingested aliment passing from the mouth and oesophagus into the general parenchyma of the body, and the refuse matter finding its way into the neighbourhood of the anus, whence it is extruded by the contractile sarcodic substance surrounding it. In many Protozoa the vacuolation of the contractile protoplasm produces the structures known as 'contractile' or. 'pulsatile vesicles,' which have sometimes been regarded as a rudimentary circulatory apparatus, but which, as they have sometimes been observed to open externally, may with more probability be considered to be depuratory in function, and to correspond with the rvater-vascular system of higher animals. No specialized respiratory nor nervous system exists in this sub-kingdom, unless the red pigmentspecks of certain Infusoria may be considered to correspond to eyes.

Reproduction is ordinarily asexual, taking place in the ways of fission and gemmation, but in the Spongiadae and Infusoria we find true sexual reproduction by means of ova and spermatozoa. Encystation very frequently accompanies the agamogenetic, and conjugation the sexual process.

The Protozoa may be either solitary or social, and are found either in sea or fresh water, or as Entozoa, but their respiration is never aerial.

The Gregarinae would by most writers be considered, as they are here, to be the lowest of the Protozoa. Their ento-parasitic habits, however, which will account for much of the simplicity or degradation of their organism, must not cause us to overlook their close affinity to certain forms of Rhizopoda, especially the Amoebina; and it has been rather from considerations of convenience, which, in the absence of any actual demonstration of genetic affinity, have weight in classification, that they have been here separated from that elass. The Rhizopoda are by some writers placed higher, by others lower, in the scale of life than the Infu- 
soria ; but the 'polymorphismus' of their more complex forms, amongst which the Radiolaria are usually included, may be considered in some sense to counterbalance the higher grade of specialization to which the Infusoria in virtue of their digestive, reproductive, and motor organs, must be allowed to have attained. The Spongiadae should, for the same reason and in the same sense as the Rhizopoda, be placed in co-ordinate rank with the Infusoria.

It is not rarely difficult to differentiate a unicellular organism as animal or vegetable, umless we happen to be acquainted with its past or future history. The gonidia of many Algae are locomotor, ciliated, possessed of contractile vesicles, and devoid, whilst yet active, of that eminently vegetable structure, an encapsulating envelope of cellulose. Whilst these organisms imitate the movements, structure, and chemical composition of the Infusorial Protozoa, the mycelium of certain Fungi, the Myxogastres, s. Myxomycetes, which have hence been called 'Mycetozoa,' is similarly devoid of any cellulose envelope, and exhibits the pseudopodial movement so characteristic of Rhizopoda; while such forms of life as Euglena Viridis and the Volvocineae must be held to belong to the vegetable kingdom, not so much on account of the abundance of chlorophyll in their parenchyma, as because of the history of their development, in which a period of quiescence and encapsulation in cellulose is readily observable.

There are not a few organisms for the identification of which, as belonging to the animal or vegetable kingdom, we have no other guide than a consideration of their gradational affinities to other organisms, as to the position of which in one or other of the two kingdoms there can be no question. By the application of this test, it would seem that the MLonera of Professor Hreckel should be ranked as animals, as they are so closely similar to certain of the Rhizopoda, as to the right of which Class to be considered as animal few other naturalists would raise a doubt. And as either from the point of view furnished by the facts of gradational affinity, or from that into which we are put by the knowledge of the history of development, probably all the other forms of life out of which the naturalist just mentioned has formed a third Kingdom of life, the Regnum Protisticum, can, without violence, be regarded as either animal or vegetable, the necessity for accepting such a third Kingdom would appear to be doubtful.

In dealing with the microscopic organisms, about the position of which it is possible to raise a doubt, the most unambiguous criterion is that which the formation of an external envelope of cellulose, when present, furnishes. When this means of deciding is absent, the exhalation of 
oxygen, and the power of supporting life upon inorganic matters, are, perhaps, the two points to which we should next look, though both of them would fail us in the case of the Fungi. The presence of chlorophyll in very great abundance in the parenchyma of an organism points, though less certainly, than any of the three characters already specified, to the vegetable character of an organism. Stentor, however, among Infusoria, Hydra among Coelenterata, Vortex amongst the Turbellarian, and Bonellia amongst Gephyrean Worms, are said, though not in all cases upon the evidence of the spectroscope, to possess this chemical substance as an essential ingredient of their parenchyma irrespective of any which may be ingested with their aliment. An organism which should be seen to envelope alimentary substances within its own parenchyma would be, in almost any case, rightly considered an animal; but this test would fail with the ento-parasitic forms of either kingdom which live by the absorption of the soluble nutriment in which they live immersed at all points of their exterior; and would further be held by most naturalists to prejudge unfairly the allocation of organisms feeding by means of suctorial pseudopodia, in the face of the preponderating evidence in favour of their animality which the totality of their history offers. It would fail also, in the cases of the spermatozoa, which may be called the male 'gonidia' of most animals, and the male zooids, the 'complemental males,' of a few animals, such as the Cirripedia.

Irritability, contractility, locomotion and the 'cyclosis,' or circulation of absorbed and assimilated nutritive matters, are phaenomena universal in the animal, and occasionally observable in the vegetable kingdom; whilst the secretion of chlorophyll, and of cellulose, and the power of regenerating an entire compound organism from a more or less fragmentary portion, are properties nearly though not quite universal in vegetables, and only occasionally noticeable among animals. It may be anticipated that in the few cases in which it may at present be difficult to decide with perfect certainty as to the animal or vegetable character of an organism, an increase in our knowledge, if not of its very simple structure, yet of its development, and if not of either its development or its structure, yet of the development and structure of forms which by gradual transitions comnect it with undoubted animal or undoubted vegetable forms, is likely at some time to enable us to place it in one or other of these two kingdoms of life. But it must be said that there are organisms which at one period of their life exhibit an aggregate of phaenomena such as to justify us in speaking of them as animals, whilst at another they appear to be as distinctly vegetable. $A$ monad may at one period be possessed not only of a nucleus and contractile vacuole, lut of a cilium, 
by the aid of which it swims about; at another it may have lost its cilium, and effect locomotion by the protrusion of pseudopodia, like an Amoeba; whilst in a third it may surround itself with an envelope of cellulose. If it should prove to be true that organisms as high in the scale as the Amoebina and Actinophryna, can have their development traced back to the specialization of protoplasm within vegetable cells, it would appear to be necessary to adopt a phraseology which should speak of such creatures as being at one time plants, and at another animals.

\section{Class, Infusoria.}

Protozoa, which have the external layers of their bodies so far indurated as to give them more definitely-fixed external outlines than the other classes of the Sub-kingdom, and are provided, except in the case of the adult Acinetina, with cilia as motor organs. They may secrete a cuticular shell or carapace, distinct from their more or less indurated external cortical cuticular envelope, but they never form any shell or skeleton of inorganic substances. They always possess a nucleus and nucleolus, which are in function ovary and testis respectively, and a contractile vesicle; and with the exception of the order Acinetind, which is provided with suctorial tentacula, and the parasitic genus Opalina, they have always a mouth and anus. From the mouth a short oesophagus lined with a prolongation of the cuticle leads ordinarily, and opens by an oblique or transverse aperture, into the central parenchyma of the body, which is more loosely compacted than the cortical layers. In the intertrabecular or vacuolated spaces of this central parenchyma, the ingested alimentary particles are circulated together with the water, along with which they are drawn in by the eiliary currents; and from it the refuse particles are finally extruded by the anus, into which there is only rarely a tubular process of the cuticle prolonged. The cortical layers of the parenchyma are less diffluent than the central, and in them we find the contractile vesicle, the generative nucleus with its adherent or closely approximated nucleolus, the trichocysts, and a certain amount of very fine pale granular matter. By the use of reagents, it is easy to see that the cilia are in reality processes not of the cuticular membrane, but of the outer layers of the enclosed parenchyma; and they must therefore when protruded find their way through very fine orifices in the external envelope. 
This membrane is not always demonstrable, and appears to be occasionally wanting, as in Oxytrichina. The contractile vesicles may be very numerous, as in Trachelins ovum, but ordinarily they are not more than two in number. They are in some eases seen to give off vessels into the body; and they are said to communicate with the exterior, and thus to become analogous to the water-vascular rather than, as is often said, to the circulatory system of higher animals. The so-called 'nucleus' or ovary may vary in shape from that of a spheroid to that of a horse-shoe. The 'nucleolus' or testis is also very variable in shape, but is usually closely apposed to or immersed in the substance of the ovary, which is much larger in size.

In sexual reproduction the 'nucleus' breaks up into a number of ova, which it is probable are directly transformed into embryos. It is often seen to be preceded by conjugation, in which the spermatic elements of the two individuals have been supposed to be interchangèd.

Asexual reproduction takes place in the ways of gemmation, when compound colonies may be formed, as in Epistylis and Carchesium; and of fission, which is ordinarily preceded by encystation.

\section{Class, Rhizopoda.}

Protozoa possessed of psendopodia, by which, in the absence of cilia, the functions of locomotion and of ingestion of aliment are performed. Their bodies may consist of sareode alone without any morphological element except fine granules, and without any cell wall; and in these cases a calcareous shell may be secreted, as in the majority of the Foraminifera, or a test of organic chitin-like substance, as in Gromida; or an external casing may be formed by the agglutination of arenaceous particles, as in Lituolida; or the sarcode may show considerable differences between its central and peripheral layers, and may contain a nucleus and a contractile vesicle, but be devoid of any external inorganic deposit of the nature of a shell, as in Amoebina and Actinophryna; or, finally, the sarcode may be divided into two portions by a central eapsule, and be further supported by a siliceous skeleton, in which case both the extra-capsular and the intra-capsular sarcode contains many and various morphological elements, as in the multi-cellular 
Radiolaria. In all Rhizopoda, except the Amoebina, the pseudopodia are very numerous, ramify minutely, inosculate by their ramifications, and show in their interior a cyclosis or circulation of granular sarcode; and it is by their suctional agency that nutritive matters are absorbed. In the Amoebina, which on this account have been sometimes, as by Kölliker and V. Carus, separated from the Rhizopoda and classed with the Infusoria, the pseudopodia are few and large, and neither anastomose nor show any cyclosis of granular sarcode in their interior. The exterior layer of the bodies is better defined than that of other Rhizopoda, and they extract nutriment from their food by enveloping it, as indeed the Actinophryna do also, in the substance of their parenchyma.

The differentiation of the outer layers or 'ectosare' of the Amoebina, from the inner or 'endosare,' is carried so far in the direction of increase of tenacity and consistence as to render it probable that a definite spot must exist in their external periphery, which acts as an oral inlet. No other Rhizopoda possess either a mouth or anus.

Reproduction appears to be effected in the simpler Rhizopoda by fission of the protoplasmic mass, of which their bodies are exclusively made up; but in the higher forms of the class, the Amocbina and Actinophryna, it would appear that true sexual products may be formed.

The Rhizopoda may be either solitary or social. They are mostly marine, but some Amoebina, Actinophryna, and Gromida are found in fresh water.

\section{Class, Spongiadae.}

Social Protozoa, which form one or many aggregated colonies, each one of which possesses on its exterior a single exhalant 'osculum,' and a great number of smaller inhalant 'pores;' whence the Class has taken its name of 'Porifera.' The cells which make up each colony, are supported upon an internal skeleton, which may be siliceous or calcareous, horny or leathery in consistence; Halisarcina, which has been described as devoid of any skeleton, and as being merely a colony of naked amoebiform bodies, having been shown by Dr. Borverbank to possess more or less of a siliceous skeleton. The cells are of very various forms in each colony; some being ciliated, some amoebiform, whilst others may have their sarcodic substance so fused together as to form continuous masses, 
which however do not lose the power of reappearing as separate organisms. The ciliated cells line the interior of certain spheroidal chambers in the substance of the Sponge ; and by their action water is drawn in through the smaller 'pores,' and with it the alimentary particles which the amoebiform cells appropriate. The larger orifices or 'oscula' are exhalant in function. Both sets of orifices are opened or closed at the will of the animal; but the larger are permanent, whilst the smaller are intermittently formed and intermittently obliterated. A wide interspace intersected by irregular trabeculae may be interposed between the exterior layer of the Sponge in which these orifices are situated, and the deeper layers which make up the great mass of the organism. The spicula have a cavity in their interior, which is occupied by sarcode, and are thus to be considered as produced like ' external skeletons' or 'tests' by an outward excretion-process.

Reproduction may be sexual, ova and spermatozoa being produced by the specialization of cells in the general parenchyma ; or asexual, in the way of fission, or in that of the production of gemmules. The gemmules of the fresh-water Sponge are formed towards the close of the warmer period of the year by means of the 'encystation' of portions of the parenchyma, whilst the sexual process takes place during the summer months; so that the history of the 'winter' and 'summer' ova of the Daphnidae and Rotifera is here exactly reversed.

\section{Class, Gregarinae.}

Protozoa, with an external envelope only obseurely limited off from the contained parenchyma, without either mouth or anus, of parasitic habits, moving in some cases with considerable energy, not, however, by the protrusion of pseudopodia, but by the contraction of their ordinarily vermiform bodies in a direction from behind forwards. They are very ordinarily visible to the unassisted eye, presenting, when circular in shape, the appearance of small white specks, which may be as much as a millimetre in diameter, but which attain sometimes a length of as much as half an irch, when, as more usually, they are elongated and vermiform.

They may have the appearance of being divided (Dicystidea) into two unicellular organisms : the septum, however, is stated by Kölliker to be produced, not by an involution of their external cell-wall, 
but by the thickening of a part of the contained protoplasm, so that they are truly unicellular organisms. This cell-wall is readily permeable by water, which first separates it from the contained parenchyma, and ultimately, as in the case of many other Entozoa, bursts it. The integument may be longitudinally striated or costate, and may carry delicate or strong bristles, or even vibratile cilia, and more or fewer spines. The contents of the cell-wall are of three kinds: the nuclens, the hyaline protoplasm, and the fatty granules, which give the adult animals their milky appearance, but which may be wanting in young specimens. The nucleus is placed centrally in the IIonocystidea, and in the anterior half of the posterior half of the body in the Dicystidea. It contains a nucleolus, or several small granules. The reproduction of the Gregarinae, so far as it is known, appears to be accompanied by the successive processes of encystation : of resolution of the nucleus and the parenchyma, firstly, into small round corpuscles a little larger than a human red blood-cell; and, secondly, into the organisms known as 'pseudo navicellae:' and, lastly, of the change of the amoebiform contents of those bodies into Gregarinae by direct growth. The resolving up, and the rearrangement of the contents of these unicellular organisms, resemble the process known in the higher animals as the segmentation of the yolk; and it is preceded, though not always, by 'conjugation,' which might, had it been an invariable antecedent, been compared to sexual congress.

The Gregarinae have been regarded as merely Amoebae, which are possessed of a better defined external envelope than other Rhizopoda in adjustment to their parasitic habits. They have again been supposed to have, by virtue of the peculiarities of their reproductive process, and of their first stages of development, to show much affinity to certain fungi. And, finally, whilst the pseudo-navicular cysts bear some resemblance to the 'psorospermiae' of Fishes, the adult Gregarinae, as ordinarily, though not exclusively, found in the digestive or perivisceral cavities of Invertebrata, are by no means unlike the wormlike organisms found in the heart and the voluntary muscles of many Mammals, and known as 'pseudentozoa.' 


\section{DESCRIPTIONS OF PREPARATIONS.}

\section{Common Rat (Mus Decumanus),}

Dissected so as to show its craniospinal nervous axis in its entire length as well as portions of most of the organs of vegetative life.

A RED injection has been thrown into the veins, and the left halves of the walls of the craniospinal, thoracic, abdominal, and pelvic cavities, as well as the greater part of the integument in the facial region and the greater part of the left lung, have been removed so as to show in situ the organs previously concealed by these structures.

Of the encephalic nerve-centres we see most anteriorly the olfactory lobes: next to them the cerebral, separated from each other by the longitudinal fissure in which is lodged the longitudinal sinus: next the cerebellum bounded off anteriorly from the posterior border of the cerebral ovoids by the diverging lateral sinuses, into which the longitudinal sinus divides. The presence of the lateral sinuses prevents us from seeing the corpora quadrigemina which would otherwise be visible a in the middle line, owing to the divergence there from each other of the cerebral lobes. The medulla oblongata, which is, like the cerebellum, of considerable width, comes into view between the two occipital condyles, from which point down to the second dorsal vertebra, recognizable by its long spine carrying an ossicle articulated to its apex, the medulla spinalis is of much greater thickness than it attains posteriorly. It is seen in the lumbar region to break up into the cauda equina.

In the dorsal region, a black bristle has been passed under the aorta where it underlies the bodies of the vertebrae, and this position

a For the relations held by the cerebrum and cerebellum to each other and to the tentorim, see 'Turner, 'Proceedings Royal Society of Edinburgh,' March 3, 1862. 
relatively to the craniospinal canal superiorly, as also to the digestive tract next inferiorly, and the heart most inferiorly, is held by the aorta in all vertebrata. The singleness of the aortic trunk in the adult state is characteristic of all warm-blooded animals; but mammals, as is seen here, differ from birds in having the single trunk arching from the heart over the left and not over the right lung's root. Behind and to the right of this black bristle from before backwards are to be seen, firstly, the fourth lobe of the right lung in its pleural cavity resting on the diaphragm below, and in relation above with the heart, and on the left with the phrenic nerve; secondly, the oesophagus, a lowly vascular tube the small calibre of which is correlated with the working of the dental apparatus in these creatures; thirdly, the third lobe of the right lung placed far back and to the right, and, like the lungs of all mammals, freely suspended in its pleural cavity and bearing no impressions on its exterior from the different bony constituents of the thoracic cavity; fourthly, the vena azygos ${ }^{b}$ of the left side between the aorta and the vertebral column, passing up to arch over the root of the left lung, and join the vena cava descendens of that side; and fifthly, the spinal cord. The complete diaphragm, forming a dome-shaped floor, with the heart and lungs in relation with its convex, and the liver, stomach, spleen, and kidney in relation with its concave surface, and receiving a large nerve, the phrenic, from the cervical region, is eminently characteristic of Mammalia. The upper part of the pericardial sac has been removed, and the two ventricles (less distinctly separated from each other than in many mammals) and the left auricle are brought into view. The anterior surface of the heart is more equally shared in by the two ventricles than is the case in many mammals, in which the right ventricle forms nearly the entire anterior aspect of the organ. The left vena cava descendens, a trunk which is found in most Rodents, except the Guinea Pig and Agouti, is seen to pass in front of the root of the left lung in company with the phrenic nerve round to the back of the heart to end in the right auricle. The vena azygos of the left side is seen to join it just above the root of the left lung, and at a point some way above this, the vein from the fore-leg, which is in connection with the nerves going to

b For the various arrangements observable in the system of the vena azygos, see Milne-Edwards, 'Leçons sur la Physiologie,' vol, iii. p. 598, ibique citata. 
that limb, is seen passing up to join another vein, which, from its being placed superficially to the sterno mastoid muscle, we know to be the homologue of the external jugular of anthropotomy. The external jugular is the main trunk by which the blood from the interior of the skull returns to the heart in the Rodents and many of the lower Mammalia, and by its confluence with the vein from the anterior limb the vena cava descendens is constituted. Internally to the external jugular, just above its confluence with the subclavian vein, is seen a part of the hibernating ${ }^{c}$ gland; externally to it lies the submaxillary; above this again we see the parotid with its duct; and above the parotid, the facial portion of the lacrymal gland sending up a duct, under which a piece of blue paper is placed, to enter the orbit and join there with the duct of a second portion of the lacrymal gland, which is placed within the orbit, and anteriorly to the duct of the extraorlitally-placed portion. Within the orbit we see the Harderian gland. For a fuller description of these glands, see Deseription of Plate I, which represents a dissection somerwhat different from that which we have of these organs in this preparation.

In the middle line of the body inferiorly to the heart we see the cut surfaces of the six sternal bones, and in the angle intercepted between the lowermost of these and the diaphragm, we see some lobules of fatty tissue set in the process of serous membrane which connects the apex of the pericardium with the sternal bones and with the diaphragm. From these structures a vein passes back along the pericardium to end in the vena cava descendens of the left side.

In the angle between the inferior surface of the diaphragm and the lumbar muscles, the tro psoas muscles and the quadratus lumborum of the left side, we see the smooth-surfaced kidney, which by this external character, as also by the internal one, of the separation of its cortical or secretory from its medullary or excretory parts, characterizes the class Nammalia. The spleen is in relation with it on the right; to the right of the spleen we have the left end of the stomach, which is less vascular and glandular than the pyloric half, which is here concealed and overlapped by the

- For the histology and literature of the Hibernating Gland, see Hirzel and Frey in Siebold's and Kölliker's 'Zeitsehrift fuir Wissenschaftliche Zoologie,' Bd. xii. Hft. ii. 1862. 
left lobe of the liver. From the inferior or convex margin of the stomach the curtain-like omentum or epiploon, a process of peritoneum found only in mammals, hangs down over the left cornu of the uterus, which is distended with embryoes, and over portions of the intestines. Immediately below the kidney and the spleen, the left ovary and Fallopian tube and the upper end of the left cornu uteri are situated. A fibrous band, under which a black bristle is placed, and which is the remnant of the ligamentd by which the Wolffian body in the foetus was kept in relation with the diaphragm, attaches the ovary and tube to the peritoneal covering of that muscle. Below the upper end of the left cornu uteri is seen the caecum, which is of less size and complexity than in Rodents with rootless molars and less varied and nutritious food than these omnivorous representatives of the order, or than those, such as the Squirrels, which live on seeds and have, like the Murini, rooted molars. It tapers off superiorly into the large intestine, which however in many Rodents is not, when compared with the small intestine, as much inferior in length and larger in calibre and thicker in its walls as its name and the homology of anthropotomy might lead us to expect. Below the caecum we see the cut ends of the veins from the hind-limb, and lower still we see a bristle passed underneath the ureter as it passes forwards to enter the base of the conically contracted bladder. The vagina, rectum, and bladder have, each of them, separate and independent outlets ${ }^{\mathrm{e}}$; into those from the two latter organs black bristles have been passed. The flat nail on the rudimentary thumb, the presence of tactile vibrissae above the eyes as well as upon the snout, and of hairs of great coarseness along the mesial dorsal region, the absence of hair from a small area, in which are the orifices of the nostril, and which is called the 'muffle f,' and its presence between the annulate scales on the tail, are points worthy of notice.

d For a figure and account of this ligament in the foetal state, see Kölliker's 'Entwickelungsgeschichte,' p. 438, fig. 215.

c For an account of a similar arrangement in another Rodent, see 'Hunterian Catalogue of the Physiological Series contained in the Royal College of Surgeons,' vol. iv. p. 2745 ; for a similar arrangement in an Insectivore and the Simiadae, see loc. cit. $2810,2811,2812$.

f For the various senses in which the word 'muffle' is used, see Waterhouse's 'Natural History of the Mammalia,' vol. i. p. 50 ; vol. ii. pp. 7,8 . 


\section{Skeleton of Common Rat (Mus Decumanus).}

THE skeletons of many of the lower Mammalia bear a general resemblance to those of certain quadrupeds lower in the scale of life in such points as the nearness of the level at which their trunk is carried by their limbs to that of the ground on which they move; and in the maintenance by the long axis of their head, of much the same direction as that of the long axis of their entire trunk. But they invariably present the following distinctive characters, which are as peculiar to the Mammalian class as any of the points furnished by the soft parts, such as the blood-cells, the hairy integument, or the mammary glands. In every Mammalian skeleton the lower jaw will be found to be made up of a single mandibular bone on each side, which articulates by a convex facet with the squamosal element of the cranial wall; and the vertebrae in the trunk always differ from those of the different lower vertebrata in one or more or all of the following points: either in the anchylosis of their several elements, or in the size of their neural eanal, or in the shape of the articular ends of their centra, or in the means whereby in the recent state these articular ends are brought into relation with each other. In the vertebra of a young mammal the neural arch may not have anchylosed with its centrum; but in all such cases two discoid epiphyses belonging to the articular ends of the centrum would also remain unanchylosed, as they fuse with it at a later period than the neural arch, and they furnish a mark as distinctive of the Mammalian class as any other connected with the vertebrae. Some mammals have an opisthocoelian ball and socket articulation between the centre of their vertebrae; and the crocodiles resemble the mammals in having interarticular fibrocartilaginous dises to connect their ball and socket centre-joints instead of synovial joints; but in such cases the greater size of the neural canal or the absence of neurocentral sutures, or the absence of sutures between the body and the lateral processes, would enable us, without having recourse to a microscopic examination of the bony tissue, to identify a vertebra as having belonged to a mammal. In all mammals, except the Cetacea, the maximum number of phalanges in any one digit is limited to three; in nearly all the number of cervical vertebrae is 
neither more nor less than seven; and the number of the lumbar vertebrae is never less than two. There are very rarely any vertebrae with unanchylosed ribs anteriorly to the first dorsal vertebrae. The jars are ordinarily dentigerous, but teeth are never found elsewhere than upon the mandibular, maxillary, and intermaxillary bones; the grinding teeth very frequently have more than a single root or fang, a method of implantation never observed in any other class.

The most distinctive character of the Rodent order is the possession of the pairs of scalpriform incisors in the upper and lower jaws, from the functions of which their class-name is taken. There is a single pair of incisors in the upper jaw in all Rodents, except those of the family Leporidae, in which there are two pairs placed one behind the other, the hinder pair being the smaller. In the lower jaw there is a single pair only in all Rodents, without exception. The upper incisors form a larger segment of a smaller circle, the lower a smaller segment of a larger circle. The peculiarities of their growth, which goes on uninterruptedly during the life of the creature from a persistent pulp, and of their functions, entail changes of great importance in the general conformation of the skull and of particular bones. The intermaxillaries, in relation with which the upper incisors are first developed, and which form a large part of the sockets in which they are permanently lodged, are larger in relation to the rest of the skull and of the animal than in perhaps any other mammals; - they form the whole, or nearly the whole, of the sides and under surface of the bony snout, and in all Rodents they shut off the nasals from contact with the maxillaries. The maxillary bone, besides forming part of the socket for the lodgment of the teeth, furnishes in its malar process a point of origin for a deeply-placed part of the masseter, which co-operates very strongly with the temporal muscle in moving the lower jaw in a vertical direction, and bringing its incisors into play upon those of the upper jaw; whence probably the inverse ratio which has been observed to obtain between the temporal and the antorbital fossae is to be accounted for. The masseter muscle arises from nearly the whole length of the malar arch, which is made up ordinarily of the malar process of the maxillary, of the malar bone, and of the malar process of the squamosal, and sometimes of the lacrymal also. It is by the contraction of those of its fibres which pass 
backwards on to the posterior edge of the lower jaw, aided by that of the pterygoids, that the anteroposterior movement of the lower jaw with its molar series upon that of the upper jaw is effected. The glenoid cavity has, to allow of this movement, an anteroposterior direction throughout the order, with the exception of the Leporidae, and the unbroken molar series and the absence of canines is characteristic of the order withont even that exception. Though the malar arch has a downward, rather than, as in Carnivora, an outward curve, still the interzygomatic diameter is in all Rodents the widest transverse cranial diameter. The temporal is never separated from the orbital fossa; the cranial cavity is always much compressed from side to side on a level with the optic foramina, so as frequently to leave an interorbital fenestra by the fusion of the two foramina into one, at a point a little behind that at which the olfactory chamber succeeds the cerebral internally.

The length of the tail and the number of the caudal vertebrae vary much within the limits of this order, just as the external concha of the ear and the characters of the integumentary system do. But, in spite of the very various special habits of the animals belonging to this order, the two pairs of limbs almost invariably present the same ratio of development inter se, the hind limbs being the stronger and longer pair. The tibia and fibula are anchylosed, as they are here, more frequently than the ulna and radius. There is, however, little tendency to anchylosis in the skeleton of the Rodents; in this specimen the posterior pair of sacral vertebrae are not anchylosed with the anterior, with which the ilia articulate, and the mandibular bones never throughout the order become anchylosed with each other at the symphysis of the lower jaw, in spite of the great afflux of blood which their permanently growing incisors bring into them. In the trunk we observe that the spines of the dorsal vertebrae, from the largely developed spine of the second dorsal to that of the tenth inclusively, point backwards, whilst those of the six lumbar vertebrae and of the two last, the thirteenth and the twelfth dorsal, point forward towards the vertical spine of the eleventh dorsal, which has been called in eonsequence the ' antichinal" vertebra. 'The anterior dorsal vertebrae diminish progressively in size as they are placed nearer to this vertebra, whilst the vertebrae placed posteriorly to it, and markedly the transverse processes of the lumbar vertebrae, increase in size as we pass 
backwards from it towards the sacrum. Well-marked and distinct anapophyses and metapophyses are developed on the anticlinal vertebra, and are to be seen on the succeeding vertebrae nearly or quite up to the sacrum. The direction of its spine relatively to those of the other vertebrae in front of and behind it causes it to be the point of greatest mobility in the trunk. Points of less striking proportions, but more or less distinctive of, and universal in, the order are presented in the skull by the presence of an interparietal bone; by a vacuity in the skull walls for the blood to pass out from the lateral sinus, either as here by a conjugate foramen between the squamosal and the periotic, or by a foramen in the squamosal itself, the so-called ' canalis temporalis;' by the development of the post-auditory process of the squamosal into a lamina of bone, which may reach as far back as the occipital, but serves always to keep the tympano-periotic, with which it never anchyloses, in place; and, finally, by the smallness of the angle formed by a line drawn from the posterior edge of the supraoccipital on to the basicranial line. The depth of the symphysis pubis, and the oblique forward direction of the transverse processes in the lumbar region, are points probably correlated functionally with the strength of the hind limbs. The large size of the abdominal relatively to the thoracic cavity may be connected with the multiparous character of the order generally. The spine of the second dorsal vertebrae has a small ossicle articulated to its apex, and pointing forward, much as in the long-necked grazing mammals the ligamentum nuchae is placed along the dorsal and cervical regions. The two first cervical vertebrae are, as is usual in mammals, much the largest in the series, and they contrast with the other cervical vertebrae, as also with all the rest of the moveable vertebrae, in having, when adult, the centre of the first fused with that of the second, and in being connected with each other and the skull by cartilages and synovial membranes without fibro-cartilaginous discs. The first rib has its head articulated to the bodies, and its tubercle to the transverse processes of both the last cervical and the first dorsal vertebra. There are two lateral episternal bones between the first of the six sternal bones, the so-called 'manubrium' and the clavicle, one on each side, but there is no central episternum.

In the carpus there are the same number of bones as in that of man, for though the scaphoid and lunar are fused into one bone, the 
scapho-lunar, as they are also in Carnivora and Chiroptera, a bone, the os centrale, exists between it and the os trapezium, or trapezoides, and os magnum in the second row of carpals, which is not represented by a distinct bone in the human carpus, nor in those of Ungulata, Cetacea, Chiroptera, Edentata, Marsupialia, and Monotremata, but only in those of Rodentia, Insectivora, and Simiadae, exclusively of the Chimpanzees. As in all mammals, though in no reptile nor amphibian, a single bone, the os unciforme, supports the two outer metacarpals. In this enumeration the ulnar sesamoid bone, or ' os pisiforme,' is not reckoned as a carpal bone, nor any bone of similar function in connection with the tendons on the volar side of the hand.

In Rodentia we find two more bones in the tarsus than we do in the human subject, owing to the division of the os scaphoides, and to the presence of an accessory bone on the inner side of the inner os cuneiforme.

For the general characteristics of Mammalian vertebrae, see Professor Owen, Descriptive Catalogue of the Osteological Series of the Royal College of Surgeons, vol. i. pp. 7, 8 .

For the nomenclature of the several elements of a vertebra, ibid.p.xliv. For the Osteology of the Rodentia, see Cuvier's Ossemens Fossiles, 2nd ed., I823, vol.v. pt. i. pp. 4, I4, 44; and Giebel's Beiträge zur Osteologie der Nagethiere, 1859.

For the Carpus and Tarsus and Shoulder-girdle, see Gegenbaur's Untersuchungen zur Vergleichenden Anatomie, Hft. i. ii. 1864, 1865. Carpus and Tarsus, Hft. i. pp. 42 seqq., 53, 109-II I, et passim. Schultelgürtel, Hft. ii. p. 2 I.

For the 'Canalis Temporalis,' see Otto, Nova Acta, xiii. pt.i. p. 27, and Kölliker's Entwickelungsgeschichte, p. 422.

For the means whereby the vertebral centra are articulated in the different classes of vertebrata, see Rathke, Entwickelungsgeschichte der Wirbelthiere, mit einem Vorwort von A. Kölliker, $186 \mathrm{I}, \mathrm{p} .130$.

For the characters of the order Rodentia, see Waterhouse, Natural History of the Mammalia, vol. ii. pp. I-9.

For the Osteology of the Muridae, see Osteological Catalogue, Royal College of Surgeons, vol. ii. Preparations 2223-2245. 


\section{Cervical, Dorsal, and Lumbar Vertebrae of Rabbit (Lepus Cuniculus).}

Great mobility is secured by the particular arrangements observable in the region where the two upper cervical vertebrae articulate with each other and with the skull, and in the region of the lower dorsal and upper lumbar vertebrae. On the other hand, the transverse processes of the lower cervical vertebrae and the imbricated neural spines of the upper dorsal vertebrae prevent the possibility of any great range of movement between any two of the constituent segments of those portions of the spinal column.

The cervical vertebrae are seven in number, as almost invariably in the Mammalian class; the numbers of the dorsal and lumbar series are variable, but twelve and seven, the numbers of the dorsal and lumbar vertebrae respectively in the Rabbit, are very common numbers for those series throughout the class. The number of the caudal vertebrae is the most variable, that of the lumbar next, that of the dorsal less than that of the lumbar, that of the cervical the least variable of these four sets of vertebrac. As the number of the cervical vertebrae is all but invariable, the variability of the length of the cervical region depends upon variations in the length of the bodies of the seven vertebrae. The first cervical vertebra or 'atlas' is the widest from side to side of all the neck vertebrae; it has a low but broad neural arch, and superadded to it in front a smaller areh which is in the perfect condition of the parts made into a ring for the reception of the 'odontoid process' of the next vertebra by a transverse ligament. Its neural arch is overhung by the spine of that vertebra, and it does not give any point of attachment to the ligamentum nuchae. It contains two more or less separated canals for segments of the vertebral artery; one of them pierces the base of its broad 'transverse process' from behind forwards, the other turns more or less horizontally from without, inwards, behind and below the articular processes. This latter canal may be represented merely by a groove in the Rat, and ordinarily has this imperfect character in the human subject. The former has generally a short horizontal canal leading forward from it and opening on the anterior surface of the transverse process ; it is 
however absent in the Leporidae, though present in the Rat and many or most other Rodents. The second cervical or 'axis' vertebra has its spine greatly developed, both anteroposteriorly and vertically, giving attachment by it both to the muscles which move, and the elastic ligamentum nuchae which supports the head. It has no anterior articulating processes upon its neural arch in mammals, but it comes into articular relation with the atlas by means of two oblique zygapophysial surfaces developed on either side of the base and a third on the front of its odontoid process, which is the backwardly displaced and anchylosed centrum of that vertebra. It is the deepest from above downwards, and the longest from before backwards, but also the narrowest from side to side of the cervical series. The first two cervical vertebrae articulate with each other and with the occiput by means of synovial joints as the neurapophysial processes are articulated to each other throughout the rest of the trunk, where however the centra are connected by interarticular fibrocartilaginous dises containing in their central pulp remnants of the primitive chorda dorsalis. The neural spines of the third and fourth cervical vertebrae are low but long, corresponding with the long neural roof which these two vertebrae possess; the spines of the shorter neural arches of the fifth, sixth, and seventh vertebrae have more of the shape which their name implies. The lateral processes or 'cervical ribs' of these vertebrae are greatly developed; those of the atlas more or less obliquely outwards, those of the axis backwards; those of the third, fourth, fifth, and sixth, both anteriorly and posteriorly, and those of the seventh outwardly. The fourth, fifth, sixth, and seventh have prominent upgrowths developed on .this process or rib which are homologous apparently with the prominent tubercles of the ribs of these creatures, or, possibly, with the metapophyses of the dorsal ribs. This process makes up by itself almost the whole of the transverse process of the seventh cervical vertebra, the inferior, anteroposteriorly-produced, proecss, which is much larger in the preceding vertebrae and largest of all in the one immediately preceding, l,eing lost in this, the last of the series. These inferior elements of the transverse processes, by bending inwards form with the vertebral bodies furrows, in which the long anterior neck museles are lodged, a central slightly-raised line marking the line of separation of these muscles and repre- 
senting the homologously-placed hypapophyses of lower vertebrata. The segment of bone which completes the ring of the atlas anteriorly is homologous with these hypapophysial downgrowths. The last cervical vertebra in the Rabbit has not, as it has in the Rat, any connection with the tubercle of the first dorsal rib.

Eight of the dorsal vertebrae, from the second to the ninth inclusively, have, each, two half facets on their centra, the first has one whole facet anteriorly and a half facet posteriorly, and the tenth, eleventh, and twelfth have, each of them, single whole facets placed on the anterior superior angle of the lateral aspect of their centra, for articulation with the heads of the ribs. The neural spines of the dorsal vertebrae are largely developed, their apices from the second to the ninth showing a tendency to become bifid anteroposteriorly. The tenth is the anticlinal vertebra, and upon it and upon each succeeding vertebra down to the sacrum a large metapophysis is developed. A small anapophysis is also seen to take origin from the base of its neural arch, and to be possessed by each succeeding vertebra up to the antepenultimate lumbar. Several of the anterior, as also of the posterior dorsal vertebrae, have low hypapophysial ridges developed subcentrally; and longer ones possessing the character of spines are developed on the three anterior lumbar vertebrae. The lumbar vertebrae, their metapophyses, and their distally bifid transverse processes increase in size from before backwards as far as the penultimate one; the transverse processes point obliquely forward, but form a more open angle with the long axis of the column than they do in the Rat.

\section{Common Pigeon (Columba Livia),}

Showing nervous, digestive, circulatory, and parts of respiratory and renal systems.

True brain has been exposed in situ by the removal of the roof of the cranium; the integument has been removed from the right side of the front of the cervical region, as have also most of the feathers from the entire body; an opening has been made into the right side of the crop, which has been distended; the larger part of the right half of the body walls has been removed, together with the muscles and the limbs which it supported, and a red injection has been thrown into and filled the venous system. 
The surface of the cerebral ovoids is smooth $\mathrm{g}$; the proportion of the encephalic nervous mass to the intraspinal is much greater than in the cold-blooded vertebrata. The backward projection of the cerebellum is very considerable. The eyes are large. The vertical third eyelid is drawn forward. The nostrils open externally as long slits overhung by a tumid membrane; the external auditory meatus, which has no concha, has the feathers arranged round it like a circlet of tentacles. The great pectoral $\mathrm{h}$ muscle, the main depressor of the humerus and the wing, is seen in section along its origin from the lower portion of the keel of the sternum, and from the furculum, the outer and lateral portions of the sternum, from which it also took origin, having been removed. Placed dorsally with reference to this muscle we see the second pectoral, the main elevator of the humerus and the wing, arising from a larger portion both of the keel and of the lateral parts of the sternum than the pectoralis major, and passing internally to the coracoid to enter its pulley-like canal, formed by the clavicle or furculum, the coracoid, and the scapula.

From this canal, its tendon, which is cut short, is seen issuing on the further side of the glenoid socket for the head of the humerus. The cut-short triangular end of the pectoralis major is seen to become partially bifid towards its apex; in the perfect condition of the parts the smaller inferiorly-placed division of the muscle gave off two tendons, one to the long and the other to the short extensor plicae alaris anterioris; the larger division passed over a smooth facet on the humerus and over the coracoid head of the biceps to be inserted into the great triangular tuberosity of the humerus. Dorsally to the apex of the great pectoral we see a thin stratum of muscle in relation internally with the crop and homologous with the deltoid of anthropotomy. This muscle was divided into three portions, of which the first and most internallyplaced joined the long extensor of the anterior fold of alar membrane; the second and mesially-placed portion joined the short extensor, whilst the third was inserted into the outer aspect of the humerus from its

G For the nervous system of birds, see C. G. Carus, 'Tabulac Anat. Comp. Illus.' pars vii. tab. $v$. fig. 7 .

h For the muscular system generally, see Cuvier, 'Leçons d'Anatomie Comparée,' vol. i. For the muscles of the wing and shoulder, see Schoepss's Monograph in 'Meckel's Archiv,' 1829, and plate ii. with description in this work. For those of the lower extremity, see Professor Haughton, 'Proceedings Royal Irish Aeademy, May 23, 1864 ; Professor Owen, 'Comp. Anat.' vol. ii. p. 10\%. 
middle down to a nodule marking the commencement of its lower fourth and of the origin of the long radial extensor of the metacarpus. Underneath the alar extensor portions of the deltoid are seen two thicker muscles cut short. They seem to correspond to the shorter coracobrachiales sometimes seen in the human suljecti. The long tendon of the biceps may be seen passing internally to those two muscles to be inserted into the anterior and internal process of the coracoid. Immediately below the origin of the humeral portion of the deltoid, from the anterior internal process of the scapula, is seen the origin of the long head of the triceps from the upper surface of the anterior external process which supports its glenoid facet.

On the lower portion of the coracoid are seen the remnants of the origins of the longer coracobrachiales, the so-called coracobrachiales 'superior' and 'inferior.' In the posterior tibiofibular region the peroneus medius muscle has been exposed, together with parts of the flexors of the toes, with the exception of the deeply-placed flexor perforans, and of the gastrocnemius. A black bristle has been placed under the tendon of the peroneus mediusk, which a little below is seen to hifurcate and send one of its divisions inwards to lose itself in the fibrous tissues at the back of the tibiometatarsal joint, and the other onwards to pass under the sole and become a flexor of the middle toe. Superiorly between the under part of the origin of the peroneus medius from the fibula, and that of the outer head of the gastrocnemius from the femur, a muscle is interposed which bifurcates about opposite the junction of the upper with the second fourth of the tibia. One of its divisions runs in close relation with the tendon of the external gastrocnemius, and is finally distributed to the index digit, whilst the other passes to the medius. This bifid muscle is known as the flexor perforatus et perforans. In the interval formed by its bifurcation we see parts of the flexor communis s. perforatus, which by one of its divisions is connected with the tendon of the peroneus medius, and by another with that of a muscle which, arising from the spine of the pubis, passes along the inner side of the thigh and crosses in front of the kneejoint round to the flexor aspect of the lower leg. Most posteriorly we see the external gastrocnemius, in the muscular belly of which an artificial division has been made.

The crop forms a bilateral pouch with glandular walls, at the lower end of the distended oesophagus. It rests on either side

i See Henle's 'Anatomie des Menschen. Muskellehre,' pp. I 72 , I80.

k See Cuvier, 'Leçons,' pp. 5+2, 558 . 
upon the furculum and the muscles arising from it. In the cavity of the thorax a black bristle has been passed between the proventriculus and the aorta as this vessel arches over from the left to the right. The gizzard is concealed from view by the right lobe of the liver and the posterior or xiphisternal end of the sternum which supports and protects both these viscera. The distal segment of the duodenal loop of intestine is held in relation with the under surface of the right lobe of the liver, which is excavated conformably to it. In the concavity of the duodenal fold is seen the longitudinally-fissured, compact, elongated, largely-developed pancreas. Anteriorly to this duodenal fold are seen the two other main folds of smaller calibre which the lengthy small intestine of these birds describes. The right side of the heart rests upon the right lobe of the liver ${ }^{1}$, from which the vena cava inferior is seen to pass up into the right auricle, entering it at a point a little superiorly as well as posteriorly placed to that at which the vena cava superior of the right side opens into it. The veins from the upper extremity and shoulder are cut short at their point of junction with the jugular to form the vena cava superior. The pneumogastric nerve is seen in relation superiorly with the jugular vein ; superiorly again, and internally to the nerve, we see the proventriculus; and superiorly again to it, the longi colli muscles arising from the vertebral hypapophyses. Tracing the aorta backwards towards the heart from the point where it arched over the right bronchus, which, together with the pulmonary artery placed before it and the pulmonary vein placed behind it, has been removed in this dissection, we see it pass behind the vena cava superior dextra, and give off the two arteriae innominatae, one for either side of the body, very close to the base of the heart. The right arteria innominata is seen to divide into its common carotid and subclavian trunks. This latter vessel, after giving off a small branch homologous with the internal mammary artery of anthropotomy, divides into an axillary trunk, which passes into the wing together with the brachial nerves, and into the much larger artcria thoracica externa which supplies the great pectoral museles. The lung, which oceupies a much smaller space in the dorso-sternal plane than in mammals,

1 For the peculiarities of the circulatory system, see Cuvier and Duvernoy, 1. c. tom. vi. p. 192; Barkow, 'Meckel's Archiv,' 1829, p. 493; and for a figure of the circulatory system, 'Hunterian Catalogue,' Phys. Series, vol. ii. pl. xxv. 
reaches backwards so far as to interpose itself for some distance between the anterior lobe of the kidney and the os ilii. It differs from the Mammalian lung also in being lodged conformably to the intercostal spaces, and being indented by the six unanchylosed ribs, instead of being freely suspended, as is invariably the case in mammals, and divided into lobes, as is very ordinarily the case in those animals. Another and most important point of difference is furnished by the prolongation of the lung, by means of its bronchial stem and branches, into air-cells ${ }^{m}$ permeating a very large part of the entire body. The largest of these receptacles are the infrarenally-placed 'abdominal air sacs,' the right one of which, presenting an appearance like that of the Mammalian omentum, is seen extending from the posterior border of the lung above and behind the liver, so as, firstly, to interpose itself between the inferior surface of the kidney and the intestines, and, secondly, to stretch beyond the region of the kidney into that of the rectum. The kidney, like the lung, is indented by the bones it is in relation with; and it is divisible here into three lobes, increasing in size from before backwards conformably with the iliac and pelvic fossa. There are no specialized renal arteries in birds as there are in mammals, but we see some branches passing to the organ from the ischiadic artery in the interval between the middle and posterior lobe, whilst one of the chief factors of their short vena cava inferior is seen in the interval between the middle and the anterior lobes.

In all birds, and in no other class of animals, will the same description as that given here apply to the nerve-system, and the relations of the muscles of the anterior limb, and to the relations of the aorta to the right bronchus. The peculiarities of the pancreas and duodenum are probably nearly equally distinctive. The crop and the uropygial gland are peculiar to, though not universally found in Birds.

m For an account of the air sacs, see Milne-Edwards, 'Leçons,' ii. 35I, and for the relations of the air sacs shown in this preparation, see Natalis Guillot, 'Ann. Sci. Nat.' 1846, series iii. tom. v. p. 60; and for figure, C. G. Carus, 1. c. pars. vi. tab. vii. 


\section{Skeleton of Common Pigeon (Columba Livia).}

THe relations held by the hind limbs and the pelvic bones to the rest of the body serve at once to distinguish the Bird from all other classes of animals. The peculiarly distinctive character of its skeleton as compared with that of the living and extinct animals which it most essentially resembles, viz. Reptiles, depends in the second place upon the relative proportions and the different degrees of mobility of the cervical, dorsal, sacral, and caudal vertebrae respectively; upon the great development of the sternum relatively to the entire body, of the ilium anteroposteriorly relatively to the vertebral column, and of the tibia relatively to the bones of the whole hind limb; and, thirdly, upon the greater proportion of inorganic elements, the greater tendency to anchylose with their fellows, and the greater pneumaticity which the individual bones ordinarily possess. Peculiarities less striking, but not less distinctively and universally avian, are furnished us in the hand and foot. Parts of the carpus and tarsus are in either extremity fused with three of the bones of the segment, placed distally to them into a single bone, which directly supports all, or, in the foot, all but one, of the terminal digits. In the foot the fifth or outer digit is never present; in the hand neither fourth nor fifth, and in it the outer, the homologue of the middle finger, is never armed with a claw. In very nearly all Birds, and in very few and in some eases in no other animals, may the following peculiarities be noted :The articulations of the vertebrae when looked at from in front present the procoelian appearance, the anterior articular surface being concave from side to side, though convex, and therefore saddleshaped, from before backivards. The basitemporals form a secondary floor to the cranium, concealing the junction of the basisphennid to the basioccipital.

The caudal vertebrae vary little in number, are not numerous, are mobile, and are terminated by a single bone compounded of several fused segments and of a ploughshare shape. The ossa ilii and ischii coalesce posteriorly to the acetabulum to form a foramen more or less homologous with the sacroischiatic notch of anthropotomy. Finally, in most birds most or all of the vertebrae, with the exception of the atlas, and also sometimes of the caudal vertebrae, 
are pneumatic (i.e. have air cells in the place of the fatty medulla of other bones). In all birds, though not exclusively in them, at least as regards some of the points to be herewith specified, the following structural arrangements may be noted:-The lower jaw, which is compounded originally of twelve distinct bones, swings upon a moveably articulated os quadratum, which has ordinarily two crura for articulation with the skull, and a largely-developed orbital process. The upper jaw is mainly made up of the premaxillary bone, the maxilla being lost or rudimentary, and its place being taken by the prevomerine bones, which by their outer surface articulate at once with the premaxillary bone and with the quadratojugal rod, and bring thus the upper jaw into connection with the os quadratum. A second chain, also consisting of two bones, viz. the palatine and the pterygoid, serves the same purpose as the quadratojugal in connecting the os quadratum with the upper jaw. The squamous never reaches the jugal bone. The occipital always articulates by a single head, which however may, like the occipital condyle in Reptiles, show traces of its primitive composition out of three bones, by being bifid superiorly, with a more or less perfect cup on the atlas. The sclerotic is strengthened by bony plates. The scapular arch is completed inferiorly by the junction of the coracoids to the sternum. The number of the carpals existing in the adult bird as separate bones is, as a rule, tro. The tarsals always coalesce, the proximal ones with the tibia above, and the distally-placed with the metatarsus below. The fibula never articulates with the tarso-metatarsus. There are no lumbar vertebrae; and respiration is mainly effected by the movement of the sternum from above downwards, the vertebral and sternal ribs moving on each other, and on the sternum, all but exclusively in that direction. The length of the cervical region is never less than the height from the ground at which the body is carried by the legs, nor than the length from the root of the neck to the terminal ploughshare-shaped vertebrae which supports the uropygial gland. It depends not, as in mammals, exclusively upon the greater or less length of the bodies of its vertebrae, but also upon the increased or diminished number of these vertebrae, which may vary from eleven to twenty-four, being thus in birds the most, as it is in mammals the least, variable number of any of the numbers of the several vertebra series. The dorsal vertebrae, or vertebrae 
carrying unanchylosed ribs, are much fewer and less variable in number than the cervical, their number varying from six to ten; they contrast even more strongly with the cervical in their possession of scarcely any mobility, some of them being ordinarily fused with each other, and one or more with the ilium and sacrum. The sacral vertebrae vary in number from nine to twenty, the caudal from five to nine; they resemble the cervical in being mobile, but differ from it, as also from the series homologous to themselves in mammals, in being the least variable in number of any of the segments of the vertebral column.

The neck vertebrae of this, as of other birds, differ from those of mammals in their greater number, in the conformation of the articular surfaces of their centres, and in the soft tissues, cartilages, and synovial capsules, with which those articular surfaces were clothed in the fresh state; in the attachment of the ligamentum nuchae to the bases and not to the apices of the neural spines, a condition by which, as by those previously specified, greater mobility was secured for this part of the column in the bird; and, finally, by the development of hypapophyses in the anterior and posterior, and of a demi-canal in the middle portion of the region along and beneath the bodies of the vertebrae. The second cervical vertebra has articular processes developed upon its neural arch as well as upon the odontoid process, a point in which the Bird and Reptile coincide as in many others, and differ from the mammal, and which throws light upon the homological nature of the odontoid. The neural arches of the cervical vertebrae posterior to the second are considerably emarginated in the middle line, both before and behind, so that a lozenge-shaped space crossed in the natural condition of the part from before backwards by the ligamentum nuchae is left uncovered by any bony roof in the middle line of the roof of the neural canal. The neural spines, or rather the central depressions at the base of the most elevated portions of each neural arch, to which each segment of the ligamentum nuchae is attached, being situated at about the central point from before backwards in each neural arch, greater length and greater range of extensibility and recoil is secured for the elastic ligament. In the Pigeon the four anteriorly and the two posteriorly-placed cervical vertebrae are provided with hypapophyses. The six centrally-placed, which make the entire complement of twelve cervical vertebrae which this 
bird possesses, have the place of the hypapophysis taken by the carotid demi-canal. The ten posteriorly-placed cervical vertebrae have by the anchylosis of the lateral process or cervical rib to the body of the vertebrae a lateral and complete canal formed for the deep portion of the sympathetic and the vertebral vessels. Between the cervical vertebrae and a projection which is the homologue of the 'promontory' of the sacrum in anthropotomy seven dorsal vertebrae, or vertebrae carrying unanchylosed ribs, intervene. Each rib is, as all but invariably in Birds, articulated to the anterior portion of the body, and also by its tubercle to the transverse process of its own vertebra. The two first ribs have no sternal element superadded to them, and fail consequently to reach the sternum; the first, however, is in relation with the lung, and the second forms an indentation on its surface. The four ribs which succeed them have ossified sternal ribs connected directly with the sternum, and the fifth has its sternal rib connected indirectly to it by means of that belonging to the vertebra next in front of it. Each rib, with the exception of the first and last, has an epipleural process, the so-called processus uncinatus, developed from its posterior edge and overlapping the rib next behind it; the third, fourth, and fifth vertebrae have their spines, neural arches, transverse processes, and hypapophyses anchylosed, as well as their centra, which are laterally compressed so as to pass into the greatly-developed hypapophyses quite gradually. The flexor muscles of the neck, seen in the preceding Preparation, take their origin from these hypapophyses. The sixth dorsal vertebra is not anchylosed either anteriorly or posteriorly; the seventh is anchylosed to the sacral vertebrae posteriorly, but its rib remains unanchylosed, and in the fresh state has the lower portion of the lung in relation with, and indented by, itself. The sacral vertebrae are thirteen in number; their spines form a long, low, continuous ridge, which is not in this, as it is in some Columbidae and in the Rasores, fused anteriorly with the ossa ilii; the foramina on either side are much encroached upon but not as yet closed up by ossificatory ingrowth, the longest transverse process is on a level with the anterior edge of the acetabulum, and divides the cavity of the true pelvis internally and posteriorly into two fossae, in which the middle and posterior lobes of the kidney are lodged conformably to the irregularities in the surfaces of the bones. A 
much shorter but also stouter transverse process limits the iliae fossae, into relation with which the superior lobe of the kidney and the lower end of the lung come, from the 'true pelvis.' The iliac bones have their internal margins in apposition or anchylosed with the outer ends of transverse processes of the sacral vertebrae; they anchylose with ossa pubis and ischii to form the acetabular annulus, and with the ossa ischii, as usual in Birds, to form the sacroischiatic foramen which is homologous with the sacroischiatic notch of anthropotomy. In the Pigeons the ossa pubis do not ordinarily coalesce with the ossa ischii, so as to convert the notch for the tendon of the obtusator intermus, which lies immediately below the sacroischiatic foramen, into a foramen also. Neither do they coalesce with them, as they do in some birds, posteriorly to this point, so as to form a "foramen ovale.' The iliopectineal spine, which is well developed in the Rasores, is absent in the Columbidae. The caudal vertebrae, which are not pneumatic, are seven in number, counting the compound os en charrue which supports the uropygial gland and certain of the tail feathers, the rectrices, as one. These vertebrae possess considerable mobility, having no zygapophyses developed on their neural arches, and being articulated simply by ball and shallow socket joints on their centra and intercentral fibrocartilaginous dises. The pelvis and coracoids are pneumatic, but the furculum and scapulae are not, and it is only in adult birds, either of the Fowl or the Pigeon tribes, that the coracoids become so. The humerus is the only bone in either limb which is pneumatic. The coracoid is exceedingly strong, and the keel of the sternum very deep, as if to compensate for the feebly-developed furculum. The muscular ridges for the origin of the second pectoral muscle, the chicf elevator of the humerus, are well marked both upon the keel and upon the body of the sternum. The sternum has a wide lateral emargination homologous with the exterior emargination in the Rasorial sternum, but it presents only a small fontanelle to correspond with the deeper and more internally-placed emargination of those birds. 'The grooves for the reception of the articular ends of the coracoids meet anteriorly, and there is no downward prolongation of the episternum between those bones as in the Rasores. On either side of the middle line of the episternum, a large pneumatic foramen is seen entering the bone; other 
similar foramina are seen on the upper or visceral surface of the bone, as also in the interspaces of the bifid articular surfaces for the sternal ribs. Short hyposternal processes project upwards from the anterior end of the line on which these ribs abut, but they do not attain the proportions nor take the direction of the homologous processes in the common fowl. Neither has the furculum the downward projecting lamina developed at its symphysis, which is characteristic of that bone in the Rasores. The scapula, a broadsword-shaped bone, has a small bony outgrowth developed on its lower edge, about one third of an inch from its articular surface. The process is very well marked in the Dodo, and serves in the Pigeon to give insertion to the tendon of the serratus anticus minor. The processes of membrane which pass from the episternum to the coracoids and furculum have been taken to represent the episternum and epicoracoids of Lacertilia and Monotremata. From the upper end of the coracoid two strong ligaments pass outwards to be attached, one in front of, the other behind, the articular head of the humerus. Immediately posteriorly to the insertion of the anterior ligament, a broad smooth facet is seen, which, in the perfect condition of the parts, was played upon by the tendon of the great pectoral muscle inferiorly and superiorly by the coracoid head of the biceps, to the shorter or humeral head of which latter muscle it gave origin by its posterior concave border. Superiorly to this smooth facet we have the great tuberosity of the humerus rising into a triangular process for the reception of the insertion of the great pectoral tendon, and nearer to the middle dorsal line we have a low ridge for the insertion of the tendon of the second pectoral, the great elevator muscle of the humerus. An irregularly-shaped bony process, placed internally to and between the articular head and the smooth facet of the humerus, and separated externally from this latter surface by the furrow in which the anterior coracohumeral ligament is inserted, forms with this smooth facetted process a cup-shaped cavity perforated at its bottom by pneumatic foramina. From the inner and outer lips of this cup, and from a considerable portion of its internal surface, the triceps took an extensive and bifid humeral origin; whilst into the segment of its rim, which is placed immediately inferiorly and posteriorly to the insertion of the coracohumeral ligament, the large teres major s. infra- 
spinatus muscle was inserted. Into the anterior surface of the irregularly-shaped process were inserted the coracobrachialis inferior and the conjoined tendons of the coracobrachialis superior and subscapularis muscles, for which see Plate II. $u, v$, and $l$, with description. Into its upper surface the posterior coracohumeral ligament and also scapulohumeral ligament are inserted. A nodule on the outer or radial side of the humerus towards the lower fourth of its length, marks the limit to which the insertion of the deltoid reaches downwards, and itself gives origin to the upper head of the extensor metacarpi radialis longior, which upper head seems to represent the supinator radii longus of anthropotomy. The humerus is shorter than the antibrachium, and the antibrachium than the hand-segment of the fore-limb. The three metacarpals have fused with each other and with the os magnum of the carpus into a single bone with a wide lacuna between its elements, corresponding to the metacarpals of the index and middle finger. Between the latter of these elements and the distal end of the ulnar is wedged the ulnar carpal bone; and between the former and the distal end of the radius is wedged the radial carpal bone. On the proximal areh and radial side of the compound metacarpal is carried the pollex, consisting in the Pigeon of one phalanx; on the distal end and ulnar side of the same bone is carried the single phalanx which, in this and all birds, makes up the whole of the homologue of the middle digit. This single phalanx is in close apposition with the lamellar portion of the strigil-shaped first phalanx of the index digit, which is succeeded in the Pigeon by one more which is somervhat similarly shaped; some birds, however, possess three phalanges in this digit and two in the pollex.

The same proportion prevails between the three segments of which the lower limb is made up, as prevails between the humerus antibrachium and manus in the fore-limb; the great length of the middle toe compensating for the great length of the tibia on the one side, and the comparative shortness of the tarsometatarsus on the other. The posterior extremity resembles the anterior also in having a compound bone made out of elements taken from parts homologous with the carpus and metacarpus, and supporting, like that bone, three digits. But it differs from it in having no unanchylosed representatives of the earpal series, 
whilst it has an unanchylosed metatarsal which is unrepresented in the fore-limb, and which carries a hallux consisting of two phalanges, and in having a medius digit with four phalanges, and a fourth or 'annularis' digit with five, which latter is not represented at all in the bird's fore-limb, but corresponds to the similarly constituted 'annularis' of the Lacertilia. In the tarsometatarsus two foramina are seen to pass through from before backwards a little below its proximal double articular head, showing its essentially triple composition. At the same end and on the posterior aspect of the bone, a bony canal passes along the outside of the base of the entocalcaneal process for the lodgment of the tendon of the flexor perforans digitorum; and at the distal end of the bone, a little above the external intertrochlear notch, we see another bony canal for the tendon of the adductor annularis. The posterior unanchylosed metatarsal bone has, in Pigeons as ordinarily in perching birds, its distal articular facet at such a level as to put the inferior or plantar surface of the inner or hind toe on to a level with that of the other three.

For the points in which the skull of the Pigeon contrasts with that of the gallinaceous birds, see Description of next Preparation; and for many other points in the comparative anatomy of the Columbidae, the Rasores, and the extinct Dodo, see Strickland and Melville, The Dodo and its Kindred, 1848, pp. 44, 7I, et passim. See also Alphonse Milne-Edwards, Sur l'Ostéologie du Dronte, Ann. Sci. Nat. Ser. v. tom. v. I 866, p. 355; Professor Owen, Transactions of the Zoological Society, vol. vi. pt. 2, 1867. A description of the tarso-metatarsus and the posterior or inner metatarsus, with a specification of the very slight differences which exist between them and those of Columba Livia, is given by Professor Melville in the work on the Dodo just referred to, pp، I00-rog.

For the Osteology of the Gallinaceous and Pigeon Tribes generally, see the very valuable paper by W. K. Parker, Zoological Transactions, v. pt. 3,1864 ; the views put forth in which have been adopted to a considerable extent in this description.

For the Osteology of the skull, see the paper by the same author, Phil. Trans., I 866, and Professor Huxley's Lectures, pp. 69-129. 
For the Tarsus and Carpus and Scapular Arch, see Professor Gegenbaur's Monographs, Untersuchungen zur Vergleichenden Anatomie der Wirbel thiere, 1864, I865, Hft. i. pp. 38, 40, 51, 93; Hft. ii. p. 27, et passim.

For the Homologies of the digits of the fore-limb see Gegenbaur, l. c. Hft. i. p. 41 .

\section{Skull and Bones of the Trunk of Common Fowl (Gallus Gallinaceus).}

THE skull of the Common Forvl differs from that of the Common Pigeon in being less pneumatic and polished; and in being less evenly globose in its fronto parietal and fronto nasal regions; in the shape of its nostrils; in the much smaller obliquity of its quadratojugal arch; in its much smaller occipital angle, superethmoidal and interorbital vacuities; in its possession of a rudimentary vomer, of a larger external angular process to the lower jaw ; in the abortion of the posterior erus of its os quadratum or incus, the anterior head retaining two facets, one for the prootic and the other for the squamosal; in its differently-shaped palatines, pterygoids, squamosals, and lacrymals, and in the absence of an azygos supra occipital fontanelle, or venous canal. The basioccipital articular condyles, however, of the Fowl and Pigeon, resemble each other in being emarginated in the middle line superiorly, as though to indicate, as the single occipital condyle does more plainly in the Reptiles, its prinitive composition out of three elements. The cup of the atlas is alike in both families, imperfect and not typically avian, and the two families resemble each other yet further in the absence in both alike of the lateral vertebral canal in the axis and atlas.

There are in the Common Fowl seven. vertebrae which earry unanchylosed ribs. One of these vertebrae, however, is itself anchylosed to the sacrum, and is sometimes reckoned as a sacral vertebra; but it may be better, perhaps, reckoned in the dorsal series, as its rib is, besides being unamehylosed and artieulated just as the ribs placed anteriorly to it, in such relation in the fresh state with the lower end of the lung as to form an indentation upon it. 
The first and the second of the unanchylosed ribs have no sternal rib articulated to them, and the first, besides failing thus to reach the sternum, has less relation also than the six placed posteriorly to it to the lung and the respiratory process; and these two ribs consequently are often reckoned as cervical ribs. But on account of the absence of anchylosis, and the presence of a processus uncinatus on the second, which differs very little in size from the first, though the lung is indented by it, it may be better to speak of them as dorsal, even though they do not become connected with any sternal element inferiorly. Adopting then this nomenclature, we may say that the Fowl has the same number of dorsal vertebrae as the Pigeon, namely, seven; but fourteen cervical as against twelve in the latter bird; fourteen sacral as against thirteen; and six caudal as against seven. The congeneric subfamilies, under either great family of the Rasores and Columbidae respectively, are found to maintain pretty regularly these numerical relations between their several sets of vertebrae. The differences given may be accounted for as follows:-The terminal bone of the column, the os en charrue, appears in the Fowl to have coalesced with a vertebra which remains ordinarily free in the Pigeon; and a simple inspection of the sacral vertebrae from in front shows us that it is in the more elongated anterior iliac fossa, or 'false pelvis,' that the Fowl possesses one more sacral vertebra than the Pigeon. In the neck of the Fowl, the five anteriorly-placed vertebrae have hypapophyses, the five in the middle have the carotid demi-canal, and the four posterior have hypapophyses again, on the under surfaces of their centra, and it may be seen that it is from one of each of the series provided with hypapophyses that the Pigeon has lost the two vertebrae which place its cervical series in a numerical inferiority to that of the Fowl. For the two vertebrae which come in the Fowl after the axis and atlas are remarkable, as they are also in many other Birds, and (as remarked in Deseription of Preparation III.) also in the Rabbit, for the width and depth of the roof of their neural arch, which is less emarginated both before and behind in the middle line than those of the vertebrae placed posteriorly to them, and is prolonged out laterally into alar processes connecting the anterior and posterior zygapophyses, and pierced by foramina only faintly indieated in the mammal specified. Now, as the Pigeon possesses only one vertebra in this region which answers this description, one of 
its missing cervical vertebrae may be said to correspond to one of the two which come third and fourth in order in the neck of the Fowl. The other seems to correspond to one of the four vertebrae bearing hypapophyses which interpose themselves in the Fowl between the first dorsal vertebra and the last cervical with a demicanal on its under surface, as well because this portion of the neck which corresponds to the lower portion of the italic $S$ shaped curve which this region describes in Birds is markedly shorter in the Pigeon than in the Forvl, as for other reasons relating to number and shape.

The neural spines are not greatly developed anywhere in the cervical region, and least in its central portion, where the hypapophyses are also wanting, and their place taken by the carotid demicanal. In the dorsal region in the Forwl, the second, third, fourth, and fifth vertebrae are anchylosed to each other by their bodies, arches, and outgrowths, making thus a rigid central bar with one free vertebra interposed, both anteriorly between itself and the cervical series, and posteriorly between itself and the last dorsal vertebra which is anchylosed to the sacral series. In the Pigeon and many of its allies it is only the third, fourth, and fifth vertebrae which have thus coalesced, the second remaining free. In the Forl the second, third, fourth, and fifth rilss carry each an epipleural appendage, the processus uncinatus, as they do also in the Pigeon, in which bird, however, the sixth also is similarly armed, which is not the case in the Common Fowl. In both birds alike, four only of the seven ribs articulate by means of the sternal ribs with the sternum. Each of these sternal ribs has its upper or costal articular surface elongated anteroposteriorly, and its lower or sternal elongated transversely, and more or less distinctly bifacetted, to correspond to the more or less distinctly bifacetted articular surface of the costal border in the sternum. The last sternal rib articulates not with the sternum but with the sternal rib next in front of it, and both of these haemapophysial elements, and especially the more posteriorly-placed one, are at their upper end much broader than any of the other ribs. The similarly-expanded, or 'pedate' extremity of the external hyposternal process overlaps the posterior sternal ribs, and shows, as does also the shape of the articulations of the ribs, that little, if any, transverse dilation of the thorax is possible in these creatures, and that the act of respiration 
depends mainly upon the opening and closing of the angles formed by the sternal ribs with the vertebral ribs and with the sternum. In the Fowl the fontanelle in the posterior part of the Pigeon's breastbone is represented by a deep emargination, reaching from the level of the xiphisternal portion of the sternum up nearly, or quite in some specimens, to that of the last or fourth articular facet for the fourth sternal rib. The hyposternal element of the sternum is thus divided into two long distally pedate processes, which, it may be remarked, are developed on each side from a single centre of ossification, distinct and apart from the three others from which the sternum is made up in Rasores. The hyosternal processes are continued forward in the direction of the articular costal border, instead of taking a direction at right angles to it as in the Pigeon. The coracoid grooves are continued into each other by means of a canal which pierces the base of a vertical lamella prolonged downwards from the episternum into the entosternal raphe. The episternum differs also from that of the Pigeon in having no pneumatic foramina anteriorly at its base, though it is sometimes perforated here by a canal opening on the upper or visceral surface of the bone. Pneumatic foramina, it may be added, are in the sternum of the Forvl, as in many or most other parts of its osseous system, much more sparingly distributed than in the Pigeon, as may be noted in the intervals of the costal articular facets, and superiorly, along the middle line, and internally to the costal processes on either side. The entosternal crista, which, owing possibly to unequal pressure during incubation, is rarely straight from before backwards, slopes up to its maximum height at a point posterior to the level of the last costal facet, instead of rising to it almost immediately from the episternal level as in the Pigeon. It is much less deep relatively, and the space marked out upon it for the great pectoral muscle is very little deeper absolutely than the corresponding parts in the Pigeon. The xiphisternal portion of the sternum is a little wider and more concave upwards than the entosternum, and by virtue of its shape furnishes some protection to the gizzard and other viscera it is in relation with during incubation.

The Fowl's pelvis differs from that of the Pigeon in general shape and texture much as its cranium does from that of the same bird, being, as it is, more elongate and angular and less polished. As minor points of difference, which are nevertheless with certain ex- 
ceptions to be observed in the congeners of the subjects of comparison, are to be noted,-the anchylosis of the iliac bones with the neural spines of the anterior sacral vertebrae, the vertical rather than horizontal direction of the external iliac fossae, and the presence of praeacetabular spurs, of closed obturator tendinal foramina, and of a more elongated sacro-ischiatic foramen. Internally, the iliac fossae which are in relation with the upper lobe of the kidney and the lower portion of the lung have one more vertebra entering into their composition than the Pigeons; and the middle are less sharply limited off from the posterior renal fossae.

The caudal vertebrae contrast with the rest of the column, with the exception of the atlas, in being non-pneumatic; and with all the rest in the absence of well-developed articular facets on their neural arches, and the connection of their centra, as in Mammalia and crocodiles, by interarticular fibrocartilages.

\section{Common Ringed Snake (Tropidonotus Natrix),}

Injected and dissected so as to show the way in which its various organs are arranged within its cylindriform body, and especially how by their subordination to the functions of prehension and deglutition of a living prey, the digestive system becomes the dominant system in the organization of these creatures. The different viscera have been exposed in situ by an incision carried along the middle line of the ventral surface, and by the fastening out of the reflected integuments.

Tire following peculiarities, most of which are explicable by a reference to the special habits and needs of the creature, may be first noted in a description of this preparation. Both the liver and the pulmonary organs are unilobar, the left lung being merely represented by a rudimentary structure seen immediately to the left of the apex of the heart; the generative and the renal organs are not arranged severally side by side, but each one of the right side is placed more or less completely in front of its fellow of the left. The oesophagus and stomach form together a highly distensible tube rumning nearly directly from before backwards, whilst the small intestine furnishes an example of a transversely folded digestive tube arranged in short coils intimately connected with each other. There is, however, no such approximation of the large 
intestine to the stomach and commencement of the small intestine as is usually found in vertebrate animals. The position of the tongue in a sheath beneath the trachea which thus interposes itself between that tactile organ and the oesophagus, and also the removal of the gall-bladder from immediate connection with the liver down to a level where it is less liable to be injured by sudden pressure, are probably to be regarded as modifications specially subserving the special habits of Ophidia.

In this specimen, which is thirty inches long, the liver measures about seven and the lung about twelve inches in length. But the walls of the lung are but very lowly vascular after the first three inches of its length. Its blind posterior non-vascular end is seen just anteriorly to the right ovary; the anterior end of the lung, represented by the development of a spongy layer on one side of the trachea, is seen a little anteriorly to the base of the heart. Just where the trachea begins to lose its distinctive character on the surface of the lung, it gives off the rudimentary left lung, which occupies the angle intercepted between the apex of the heart and the vena cava inferior, as it passes up from the apex of the liver to enter the heart. Midway between the apex of the heart and the apex of the liver a black bristle has been passed between the dorsal aorta which has been raised a little from its natural position some distance below the vertebral column, and the oesophagus, with which it is in close relation below this point. The dorsal aorta is seen to be constituted by the confluence of two trunks, a larger one which gives off no branches, and which as it passes to the left on leaving the heart is called the 'left aorta,' and a smaller one which owes its diminished calibre to the fact of its having given off the arteries of the anterior parts of the body, and which, from the course it takes, is known as the 'right aorta.' The walls of the oesophagus are seen to be thin and lowly, or not at all, muscular. The absence of contractile power in this tube is compensated for by the working of certain muscles homologous with the transversales abdominis of anthropotomy. A slip of blue paper has been passed under a fascicle of one of these muscles immediately opposite the apex of the liver on the left side, whilst on the right the muscle of that side is seen to take origin from the internal aspect of the thoracicoabdominal cavity along a line passing about midway between the ventral apex and the vertebral abutment of each rib. Each muscle 
consists of two layers, and meeting, as they do, by means of a median aponeurosis, they must, in these animals which possess ribs of great mobility, and no sternum, act to great advantage in propelling the food which they swallow. Branches of the intercostal nerves are seen passing over the homologue of the rectus abdominis along the outer surface of the costal cartilages. Immediately above the line occupied by this muscle are seen a series of muscular fasciculi which arise from the tips of the ribs, and from the cartilages at their junction with the ribs, and pass from behind and above, forwards and downwards, to attach themselves to the lateral and ventral rows of scales. More superiorly again we see a similar row of muscles passing from an insertion on the ribs to an attachment on the scales in such a direction as to decussate with that of the first series.

By the removal of the front wall of the right auricle a view is obtained of the eyelid-like valve which guards the entrance of the great veins into the auricle. The left auricle is very much smaller than the right. The left superior cava is seen winding over it. Between the two superior cavae we see the thyroid gland. Anteriorly again we see the hyoid apparatus which is not connected with the larynx, and consists of two long delicate bars of cartilage which are free posteriorly, but anteriorly are connected with each other by a fibrous commissure about on the level of the angle of the lower jaw. 'The hyoglossi muscles, which make up a considerable part of the general mass of the tongue, are seen to take origin from the posterior portion and inner aspect of each hyoid bar, and to enter the dark-coloured sheath in which the tongue is lodged in front of the trachea. A large salivary gland is seen to lie along the outer surface of both upper and lower jaw; each gland discharges its secretion by numerous ducts, which open externally to the rows of teeth in each jaw. In the angle between the eye and the superior maxillary gland we see the lacrymal gland, which, like the other two just mentioned, is large in nonvenomous Snakes.

Posteriorly to the liver a slip of blue paper has been placed under the cystic duct just where it leaves the gallbladder and passes down to join the hepatic duct. The ductus choledochus communis thus formed comes into relation with the pancreas, and receives its ducts as it passes to empty itself into the dnodenum. 
The pancreas is in relation, and, by means of bloodvessels and fibrocellular tissue, in connection with the spleen anteriorly. The small intestine describes two more or less open convolutions at its commencement, but after this, is arranged, differently from the intestinal tract of the other reptiles, in several closely-apposed festoonlike coils which lie between the right ovary and the left side of the body-cavity, and are enveloped in a sac of the peritoneum which is continuous posteriorly with a mesentery, and, anteriorly, takes the shape of a membrane laden with deposits of fat. By the fastening of this membrane out to the right of the animal, we are enabled to see the upper end of the right oviduct, which is prolonged much farther forward than the left one; secondly, the upper end of the right ovarian sac; and, thirdly, the lower end of the lung; in the interval between the duodenum and the right side of the body. In that portion of the peritoneal membrane which supports the lobules of fat, a large vessel is seen, the homologue of the vena abdominalis anterior, which is usually more closely united with the anterior muscular wall of the abdomen, just as the dorsal aorta is usually more closely connected with its posterior or vertebral wall, than is seen to be the case in Snakes. It passes forward and joins the portal vein which is seen passing from the right side of the gall-bladder to gain the inner aspect of the liver, along which it distributes itself.

The lower half of the left ovary lies side by side with the upper half of the right kidney. Below the lower end of this ovary, the two oviducts are seen passing side by side down towards their common termination in the cloaca, into which a black bristle has been introduced. Posteriorly to the transversely directed opening of the anus we see, the integument and muscles having been removed, the two conically-shaped sacs which correspond to the intromittent organ of the male.

For the muscular system of Ophidia, see D'Alton, Müller's Archiv. I 834 .

For the digestive system, see Duvernoy, Ann. Sci. Nat. tom, xxx. I 833 ; Pl. xi. fig. 3 , ibique citata.

For the circulatory, see Jacquart, Ann. Sci. Nat. tom. iv. ser. iv. I 855. Jourdain, ibid. tom. xii. ser. iv. 1859 ; where the Portal and Renal-Portal systems of the Common Ringed 
Snake are described at p. I78. Brücke, Denkschrift. Kais. Akad. Wiss. Wien. iii. p. 342, 1852 .

For the reproductive, see Martin St. Ange, Étude de l'Appareil Reproducteur, 1854, pl. x. fig. 4 .

\section{Vertebrae of Constricting Serpent (Python Sp?).}

THE vertebrae of Ophidia may be divided into three classes: the first of which consists of the two anterior vertebrae corresponding to the atlas and axis of anthropotomy; the second of the trunk vertebrae, which in these animals possessed of no functional limbs nor limb-girdles nor sternum, all support moveable ribs, and correspond with the posterior cervical, dorsal, lumbar, and sacral of other Reptiles; and the third of the caudal series which is placed posteriorly to their anal outlet, and has the ribs anchylosed with the other vertebral elements. The number of the first series is, probably, constant in the Ophidia; that of the trunk vertebrae may vary from one hundred to three hundred; that of the caudal is the most variable, being in some snakes as few as five, and in others as many as three hundred. The neural arches of all the vertebrae, except the atlas, are anchylosed with their centra in the squamate Reptiles, whereas in the loricate a neurocentral suture is permanent. The Ophidia differ from all other Reptiles in having the anchylosed costal elements of the anterior caudal vertebrae bifid on each side for the protection of their lymphatic hearts; and in the nondevelopment in the same region of detached chevron bones for the protection of their caudal bloodvessels, for which however the bifid exogenous hypapophyses form a channel at least in part of their course.

The special needs of these limbless animals are met by the 'ball and socket' articulation or 'enarthrosis' of the procoelian bodies of their vertebrae; and by the presence of a 'zygosphene' on the anterior, and of a 'zygantrum' on the posterior aspect of the opisthocoelian roof of their neural canal, internally and superiorly to the ordinary zygapophyses. The 'ball' in the enarthroses of the trunk and tail vertebrae of the Ophidia forms a larger portion of a sphere, and that sphere a more perfect one than in ordinary Reptiles. The socket for its reception is proportionately deeper, 
especially at the sides and above; and the enarthrosis thus formed between each pair of vertebrae being supplemented by the arthrodial joints developed above, mesially by the neurapophyses, and laterally by the zygapophyses, great flexibility is conferred upon the trunk as a whole, whilst great security against the dislocation of individual vertebrae from their fellows is obtained at the same time.

In venomous snakes the hypapophyses are greatly developed and present in all the trunk vertebrae; in non-venomous snakes they may be, as in the Python, aborted for the posterior two-thirds or three-fourths of the length of the trunk. They are always present, and mostly bifid in the caudal region.

There are no very important differences between the two cervical vertebrae of Ophidians and the atlas and axis of any other Reptiles. The first of the two cervical vertebrae has no neural spine, contrasting herein with that of the Crocodilidae, but coinciding with that of the rest of the class. Its neurapophyses neither anchylose with each other above, nor with any other autogenous vertebral element; together with the anterior hypapophysis of the vertebra and its centrum which is more or less confluent with that of the 'axis,' the neurapophyses form the transversely elongated and shallow articular cavity for the trefoil or heart-shaped occipital condyle which is usual in Reptiles, and still retained in the less highly specialized Birds ${ }^{n}$. The centrum of the 'atlas,' the so-called 'odontoid,' comes into apposition and partial coalescence in the way of amphiarthrosis with the concavity of a crescent-shaped surface on the body of the second cervical vertebra. Its homology with the centra of the succeeding vertebrae, which is proved by other considerations, is illustrated by the presence on its upper surface of a foramen on either side of the middle line just as in these vertebrae. A second hypapophysis is articulated to its inferior surface and to that of the 'axis' where they come into amphiarthrosis. The axis resembles the vertebrae placed posteriorly to it in having its hypapophysis anchylosed with its centrum, and in having a welldeveloped ball differentiated by a slight constriction both from the hypapophysis and from the posterior end of the centrum for articulation with the socket in the anterior end of the vertebral centrum next behind it.

n See Parker, Osteology of Gallinaceous Birds and Tinamous, Zool. Soc. Trans. I862, p. I83. 
For a full description of the Ophidian Skeleton, see Professor Owen, Monograph on the Fossil Reptilia, pt. iii. p. 53, 1850 . Hunterian Osteological Catalogue, Prep. 602 et seqq., I 853 . Orr's Circle of the Sciences, Organic Nature, vol. i. p. 196, 1834 . For an account of the development of the two first cervical vertebrae in Vertebrata Allantoidea, as discovered by Rathke, see Kölliker, Entwickelungsgeschichte, p. I87, and H. Müller, cit. in loc. See also, Rathke, Entwickelungsgeschichte und Körperban der Krokodile, p. 46, 1866.

\section{Common Frog (Rana Temporaria),}

Injected and dissected so as to show its nervous, circulatory, and respiratory systems, together with some of its reproductive and digestive organs.

THE roof of the cranium, and the body-walls in front and on the left side, have been removed with the integument and muscles in connection with them. The reproductive appears to be the dominant system in the economy of this and of the other Amphibians, the sudden evolution of the generative glands, especially in the females at the breeding season, necessitating certain special coordinations and correlations in all, or nearly all, the other organs of the body. The absence of complete costal arches may be explained by the fact that great room must of necessity be available for the lodgment of the ova previous to extrusion, and the transpirability of the skin compensates in some measure for the suspension of the function of the lungs which the great distension of the thoracico-abdominal cavity entails at those periods. The transpirability of the skin again exercises an important influence on the special habits of these animals as it is incompatible with the sustentation of life except in media containing a certain proportion of watery vapour. The physiological importance of the skin as an aerating and depurating organ, in correlation at once with the kidneys and liver as well as with the lungs, is well shown by the distribution of vessels to it as illustrated in Plate III. The skin of the true Reptiles is far inferior in this point of view to that of the Amphibia, which again is inferior to that of the more highly organized classes in the all but universal absence of scutes, seales and claws, and the universal absence of any of those 
' parosteal' bones which are developed from the skin and the subcutaneous and aponeurotic tracts underlying it, and form the important bones known as 'clavicle' and 'interclavicle.' This preparation shows eminently well the loose connection and wide interspaces which exist between the skin and the muscles of the body-walls. In this interspace the bloodvessels and lymphressels take a considerable development, but, as in cold-blooded animals usually, we observe an entire, or an almost entire, absence of adipose tissue.

The heart is seen in the middle line in the notch between the main lobes of the liver. In the main median fissure of this latter organ the gall-bladder is lodged, but, like the posteriorly-placed commissural bridge of hepatic tissue connecting the two lobes, is concealed from view by their apposition. The epigastric, or anterior abdominal vein, here, as in all cold-blooded air-breathing animals, one of the main factors of the portal vein, passes into this fissure to join the visceral factors of that vessel. The left division of the liver, which is much the larger of the two, and is itself deeply incised as though to indicate its morphological correspondence with much more of the substance of the gland than is called by the same name in Anthropotomy, overlies, superiorly, the lower three-fourths of the distended left lung, and, inferiorly, the stomach and duodenum. In the angle between the pylorus and the lower end of the lung is seen the testis of that side in a state of turgescence, with which the condition of the basal joint of the pollex is to be noted as correlated. The epigastric vein is seen in the region of the symphysis of the pelvic arch to receive factors from the bifid allantoid bladder. On the dorsal surface of this organ is seen the rectum round and behind which the first segment of the intestine has passed, so as to abut upon the epigastric vein by the convex aspect of a loop open towards the right. This first portion of the intestine, it may be remarked, has its internal surface greatly increased by the development upon it of mucous folds the larger of which have the direction of the 'valvulae conniventes,' and the smaller of which have a longitudinal direction, so that the internal surface of the bowel has a beautifully reticulated appearance. The portion of intestine which follows upon the coil just described, lies on the right side of the median line, and having formed one or two more or less well-marked loops, ends in the large intestine 
at a point between the liver and the duodenum. The terminal and proximal segments of the digestive tracts are thus brought, as is usual in vertebrata, into close apposition ${ }^{\circ}$. On the dorsal surface, and immediately behind the tip of the coccygeal style, is seen the anus. From the tip of the coccyx a slender muscle, the pyriformis, passes outwards to be inserted into the femur, and in the angle between it and the coccyx anteriorly and internally, we see the posterior lymphatic heart.

The cerebral ganglia form elongated ovoidal masses separated, from each other by a median fissure, and by a slight constriction from the olfactory lobes which are fused mesially with each other. The cerebral ovoids have their anterior extremities converging and their posterior extremities diverging, whilst the anterior extremities of the somewhat similarly shaped but much smaller corpora bigemina, or 'optic lobes,' homologous with the corpora quadrigemina of mammals, diverge, and the posterior are in mutual apposition. An irregularly diamond-shaped space is thus marked out between these two divisions of the encephalon; and in it we see the vascular pineal gland and the homologues of the 'optic thalami.' Posteriorly to the optic lobes, and interposed between them and the triangular 'fourth ventricle' formed by the divergence of the strands of the spinal cord, we see a thin transverse lamina of nerve-substance, the homologue of the cerebellum.

Good figures and detailed descriptions of various organs and systems in this creature will be found in Professor Ecker's Icones Physiologicae. See, for the circulatory system, Taf. iv., for the lymphatic system, Taf. v., for a history of the development, Taf. xxiii., and for the nervous system, Taf. xxiv. For a detailed account of the venous system generally, see Gruby, Ann. Sciences Naturelles, Ser. ii., tom. xvii., 1842; and for one of the renal portal system, see M. Jourdain, Ann. Sci. Nat. Ser. iv., tom. xii. 1859 , whose very valuable paper appeared subsequently to the third volume of M. Milne-Edwards' Leçons sur la Physiologie, but has had its conclusions endorsed by that authority in his vol. vii. p. 349, 1862.

For the tegumentary system with its muco-nervous organs, see Leydig, Nova Acta, I868, p. 62.

- See Duvernoy in Cuvier's Leçons d'Anatomie Comparée, tom. iv. pt. ii. p. 657 . 


\section{Skeleton of Common Frog (Rana Temporaria).}

The following points relating to the skeleton are common to the entire sub-kingdom Amphibia. Their vertebrae have no neurocentral suture. They have no sternal ribs, nor any representatives of the clavicle and interclavicle of higher and lower vertebrata. Their cervical vertebrae do not exceed two, or at most three, in number, the supra-scapula making its appearance first opposite the second vertebral intercentrum. Their first cervical vertebra differs from that of all higher vertebrata, except a ferv Chelonia, in retaining as its centre what is known in them as the odontoid process of the second vertebra; and it differs from that of all vertebrata, except Mammalia and a few Selachian fishes, in having two lateral articular facets for articulation with the occipital bone, which latter bone rarely possesses even a rudimentary centrum, and never any spine. There is a common suspensorium, as in nearly all fishes but in no higher vertebrata, for both the hyoidean and the mandibular apparatus; and there is no natural division between the suspensorial and the palato-quadrate cartilages. The long bones and some others may have epiphyses; the terminal limb-segments are never more than pentadactylous.

The following points in the skeleton of Rana are common, probably, to the entire order Anura. The number of their free vertebrae is small, being nine in the Raninae, and most members of the order, but falling occasionally as low as seven; the coccygeal style, however, which is not reckoned in this numeration, represents at least more than two fused primordial vertebrae. The vertebrae are procoelian; with the exception of the first, they all have long diapophyses which carry cartilaginous rib-rudiments; the diapophysis of the third vertebra expands distally and carries a hammershaped cartilage behind which the anterior lymphatic heart lies on the inner surface of the thoracico-abdominal cavity. In Anura alone is the supra-scapula ossified both by ectostosis and endostosis. The os pubis is of a triangular shape and enters into the formation of the acetabulum together with the ischium and ilium; it may be indurated by the deposition of calcareous salts, but it is never converted into true bone. By apposition of each pubis and ischium with its fellow of the opposite side, and with each other, a vertical 
symphysis is constituted instead of the more or less horizontal one seen in other Amphibia. Anteriorly to the symphysis thus formed the ilia form a second continuous with it by the apposition of two processes homologous with the praeacetabular spurs of the Gallinae, mentioned at p. 28 .

A similar advantage in point of strength is conferred upon the shoulder girdle of the Anura by the prolongation of the more perfectly developed praecoracoids towards, or to the middle line, and by the somewhat similarly more perfected structure of the sternum posteriorly to the coracoid or epicoracoid symphysis.

The greater development of the limbs, together with the greater strength of the arches supporting them, compensates for the absence of a swimming tail such as the Urodela possess. The bones of both forearm and lower leg are anchylosed to each other. In the lower limb the tarsal segment is greatly elongated. It consists of two bones, the astragalus and calcaneum, which are connected to each other at either end by epiphyses, but have a wide interval between them for the greater part of their length.

The following points serve to distinguish the Frog's skeleton from the Toad's. Its ossa ilii are relatively longer, as also the segments of its lower limb; it is not edentulous; it has an azygos osseous ' omosternum' segmented off from its praecoracoids anteriorly in the middle line; the ossification of the coracoid proper has encroached upon the area occupied by the epicoracoid in the Toad, so that scarcely any of this merely endosteally ossified bone appears in the Frog in the line it occupies so prominently in the Toad from the interspace between the mesial end of the coracoids and the mesial end of the praecoracoids.

The male Frog differs from the female in having a large ridge developed along the posterior aspect of the humerus from the inner condyle upwards for tro-thirds of the length of the bone, and in the appearance at the breeding season of a supernumerary ossicle near the thumb. The scapular arch is stronger in correspondence with these structures than we find it in the female.

For an account of the skull of Amphibia, see Professor Huxley, Elements of Comparative Anatomy, pp. 2I 3-218.

For an account of the shoulder girdle, see Mr. Parker's work On the Shoulder Girdle and Sternum, published by the Ray Society, pp. 58-89. 
For an account of the development of the vertebral column, see Gegenbaur, Untersuchungen zur Vergleichenden Anatomie der Wirbelsaüle bei Amphibien und Reptilien, I862, pp. $3^{\circ}$ and 40.

For the sexual peculiarities, see F. Pouchet, Comptes Rendus, r 847, pt. ii. p. 761 .

\section{Common Perch (Perca Fluviatilis),}

Injected and dissected so as to show its circulatory, nervous, digestive, respiratory, and reproductive systems in situ.

THE part of the body posterior to the middle of the second dorsal fin above and the anal fin below having been removed, an injection was thrown into the dorsal aorta; the walls of the body-cavity and the opercular and branchiostegal apparatus were removed upon the right side; and the roof of the cranial cavity superiorly.

In the triangular space bounded by the four bipectinate gills of the right side anteriorly, by the liver posteriorly, and by the middle line of the body in front; we see the heart with its auricle above, its ventricle below, and the bulbus arteriosus anteriorly. Posteriorly to the liver we see the large single ovary, the upper three-fourths of the right half of which have been removed, but, owing to its extreme distention, without showing the transversely lamellar arrangement of its more or less annular ovigerous involutions. The upper end of the turgescent gland has interposed itself between the under surface of the liver to the right and the stomach, and the commencement of the small intestine and the pyloric appendages to the left. A loop of intestine, which is a little less in length than the half-length of the abdominal cavity, and which, passing downwards from the commencement of the duodenum, contains the spleen in its concavity, is similarly concealed from view by the distended ovary.

Owing to the same cause only one of the three pyloric caeca is visible in this preparation, the two which arise from the posterior or concave aspect of the commencement of the duodenum having been displaced to the left. The gall-bladder has been displaced upwards and to the right; and may be seen occupying the apex of an oval emargination in the free edge of the liver, which is 
homologous with the fossa cystis felleae of anthropotomy, but with which the gall-bladder of this fish does not come into relation when the ovary is not in a state of turgescence.

The rectum, on the other hand, is seen commencing, as in so many vertebrate animals, in close proximity to the commencement of the small intestine, and passing with a straight course down the middle line of the body to terminate, as in fishes only, in an anus placed anteriorly to the openings of the urinary and generative ducts. In the peritoneal lamellae which connect the rectum with the ovary, and also along the outer side of the air-bladder, are seen bands of yellowcoloured pellets of fat in a condition of atrophy correlated with the hypertrophy of the ovary. In the glistening walls of the airbladder may be seen its vaso-ganglia. Between the upper end of this organ and the hindermost gill is seen a gland placed homologously to the thymus of the Frog, and resembling the spleen both in its naked eye, and in its microscopic appearances. The upper end of the kidney is separated from this gland by a fibrous partition, and its entire length, corresponding with that of the abdominal cavity, is concealed by the air-bladder below it. Immediately in front of the dorsal end of the first true gill is placed the uniserial pseudobranchia.

The four divisions of the encephalon are in apposition with, but do not overlap, each other in any case from before backivards; they fall far short of filling the cranial cavity, whence much cellular tissue, richly laden with oleaginous matter, has been removed. The optic lobes are the largest of the four ganglionic centres; they are, like the prosencephalon and rhinencephalon, paired, whilst the sub-globular cerebellum is unpaired.

The large size of the eyes, and the bilateral pairing of the nasal orifices, which do not communicate with the digestive tract, are characteristically piscine peculiarities, though not universally found in members of the class.

The membranous valve projecting backwards into the mouth from the under surface of the upper jaw deserves notice.

A series of scales, perforated by mucous ducts supplied with nerves, forms a 'lateral line' along the trunk, the contour of which corresponds with that of the upper line of the back, beginning with the bone called by Cuvier 'surseapulaire' (Hist. Nat. des Poissons, i. 274), but recognized by him (1. c. p. 273.), as also by 
Parker (Shoulder Girdle, p. I6.), as being merely a 'scale bone.' Similar muco-nervous organs are to be seen upon several of the dermal bones of the head, especially upon the scaleless praeopercular and dentary bones.

As is the rule in Acanthopterygii with two dorsal fins, all the rays of the anterior one are rigid and spinous. The first of the thirteen fin-rays of the second dorsal is similarly rigid, as are two of the anal, and one of the ventral. All the pectoral fin-rays are soft and jointed.

For the general anatomy of fishes, with remarks as to its bearing upon their zoological position, see Müller, Vergleichende Anatomie der Myxinoiden, I $83^{8-1845}$; Rathke, Darmkanal und Geschlechtstheils der Fische, 1824, especially p. 7 and p. $12 \mathrm{I}$; Cuvier et Valenciennes Hist. Nat. des Poissons, vol. j. I 828, p. $20 \mathrm{I}$ and p. $4 \mathrm{I} 9$.

For a detailed account of the anatomy of the perch, see Cuvier and Valenciennes, vol. ii. pp. 28-30, pl. i.-viii., with plates.

For an account of the brain, see Gottsche, Müller's Archiv., 1835 .

For the Thymus, see Stannius, Handbuch der Zootomie, i. 256 ; Leydig, Handbuch der Histologie, p. 431 .

For the lateral line, see Macdonnell, Transact. Royal Irish Academy, vol. xxiv. 1862, p. I69, and F. Leydig, Nova Acta, I 868.

For the terms employed in zoological description, see British Museum Catalogue of Acanthopterygian Fishes, by Dr. Günther, I 859, vol. i. p. vi. and p. 58, and Yarrell's British Fishes, vol. i.

\section{Skeleton of Common Perch (Perca Fluviatilis).}

The perch, and indeed the entire Acanthopterous order to which it belongs, may be taken as illustrations of highly specialized, as opposed to high types of organization; as they accumulate in their economy a large number of the peculiarities of their own class rather than show any affinity, as do the ganoids, to forms of life higher in the scale than themselves.

One half of the moveable vertebrae are caudal, and by the absence of ribs and transverse processes, and by the presence of three vertical fins in this moiety of the animal's body, great power 
is given to the organ of motion thus constituted. The imbrication of the spinous first dorsal fin shows that the movements of the vertebral columu must be but limited in the vertical plane, and whilst for rising and sinking leisurely, the expansion and contraction of the air-bladder may suffice, the animal is seen to be, as experiments have shown it is, dependent upon its pectoral and. ventral fins for giving to the movement generated by the lateral strokes of its tail an upward or downward direction. Besides thus directing movement, the ventral fins serve by extension to maintain the fish at any desired level in the water; and the pectorals, by moving horizontally, are competent to move the animal, though but feebly, in a forward or backward direction. The anterior dorsal fin has a great vertical as well as anteroposterior development which, besides subserving the purpose of defence for a fish with a dentition 'en fin velours,' serves to maintain the fish in a position of stable equilibrium with which the large size at once of the muscles along the upper dorsal region and of the air-bladder at a lower level below them, would otherwise have been incompatible. The tail-fin, having its upper and lower lobes equally developed, does not retain any indication of the more generalized heterocercal form of tail which many Malacopteri, such as the herring and salmon, and some Acanthopteri show. The plane of greatest transverse sectional area lies at a point about one-fourth the entire length of the animal's body from the tip of its snout; the narrowing from this plane forwards to the tip of the snout is, in a well-fed fish, sudden and abrupt. The absence of both neck and sacrum, which is otherwise expressed by saying that fish possess only trunk and tail vertebrae, is as obviously correlated with the peculiarities of these animals' locomotive, as the absence of a sternum is with the peculiarities of their generative functions.

The suspensorium is articulated moveably to the outer and back part of the cranium by a glenoid cavity which is formed for its head by the squamosal, opisthotic, and prootic bones. Into the composition of the suspensorium there enter four bones, viz. the hyomandibular which forms the articular head just mentioned, the symplectic, the quadrate, and the praeoperculum. The lower end of the quadrate is received into the articular cavity formed by the os articulare of the lower jaw. On the inner surface of the suspensorium the stylohyal comes into relation with the synchon- 
drosis between the hyomandibular and the symplectic. The rectangular praeoperculum by opposing itself to the posterior and outer edges of the hyomandibular, symplectic, and quadrate, at once clamps them together into a coherent suspensorial pedicle, and brings the entire apparatus into as direct a functional relation with the true opercular bones posteriorly as that into which it is brought anteriorly with the upper jaw through the meta- ento- and ectopterygoids.

Riblike ossifications of the intermuscular aponeuroses are attached to the neural arches of the two first trunk vertebrae and to the true ribs of the succeeding twelve. The majority of these latter structures are appended to the extremities of the parapophyses, which again in the caudal region bend down and fuse at their apices, to form a haemal canal.

The pectoral fin with the four brachials, scapula, and coracoid, is supported on an arch consisting of three parostotic bones. The uppermost of these, a forked bone, suspends the arch to the squamosal and epiotic bones by its two branches; it has been called the 'supra-scapula,' but is not homologous with the structure properly so named in placoids and sturgeons, being in reality the first ' lateral line' scale bone, and perforated, as the insertion of a bristle shows, for one of the muco-nervous tubes of that system. It overlaps the clavicle from the outside, and this latter bone, after giving support to the true scapula and coracoid, comes into relation with the apex of its fellow of the opposite side, in the middle line, with the bones supporting the ventral fins, posteriorly, and with the urohyal in front. The scapula has a sub-circular fenestra; it gives support directly to some of the upper rays of the pectoral fin, and mediately by the two upper and smaller of the four brachials to a larger number of these rays; the lowest of the four brachials is carried by the coracoid; and a fourth finds a glenoid facet for itself on the lower edge of the scapula, the upper edge of the coracoid, and the line of suture between them. The clavicle overlaps a postclavicular bar consisting of two bones, one squamiform and placed superficially, the other styliform and placed beneath the integuments in the fresh state.

A number of muco-dermal bones lie on the exterior of the cranium and are connected with the system of the lateral line. Six such, of which the most anteriorly-placed is the largest, form 
the inverted suborbital arch, and three or four others, the ossa supratemporalia, occupy the space beneath the bifurcation of the post-temporal scale, the so-called 'supra-scapula.' A black bristle introduced into a canal passing down the vertical $\operatorname{limb}$ of the rectangular praeoperculum shows that it holds the same functional relation to the muco-nervous ducts as the bones just mentioned.

For accounts of experimental investigations into the functions of the vertical and of the paired fins of fish, see Sir Anthony Carlisle, Phil. Trans., I 806, p. 4 ; J. Müller, Vergleich. Anatomie der Myxinoiden, I845, p. 53 ; Monoyer, Ann. Sci. Nat. Ser. v. tom. vi., I 866.

For the homologies and nomenclature of the shoulder girdle in Fish, see W. K. Parker, on the Shoulder Girdle and Sternum of the Vertebrata, pp. 4, I2, 50, 52, and fig. 6, D. p. 46.

For the microscopic characters of the skeleton of osseous fishes, see

Kölliker, Royal Society's Proceedings, I859, ix. p. 656.

For those of the cartilaginous skeletons of this class, see Quekett,

Histological Catalogue, Coll. of Surgeons, ii. pp. 5-37.

For those of the Chorda dorsalis, see Quekett l. c. pp. 108, I09.

\section{Vertebrae of Common Cod (Gadus Morrha).}

THE anterior and posterior surfaces of the bodies of the vertebrae are, as in the great majority of fishes, concave, and intercommunicate with each other by a fine canal. These surfaces are marked by concentric rings of striation, which are wider as we pass from the centre of each terminal surface towards its periphery, and indicate thus the rate at which the animal's growth progressed. Deep wedge-shaped cavities are observable around the periphery of each vertebral centrum, two of especial depth and significance lying in many vertebrae at the base of the parapophysial outgrowths on their under surface, and bounding a single similarly shaped, but sometimes shallower cavity in the middle line of that aspect of each bone. The cod's vertebra resembles those of the majority of osseous fish, but differs from those of the common fluviatile representatives of the elass such as the Cyprinidae, Salmonidae, and Esocidae, in having its various processes and arches anchylosed 
with its centrum. About twelve of the trunk vertebrae have two parapophyses, developed one in front of the other, from the lateral surfaces of their centra, the more forwardly placed being the larger of the two. These two outgrowths, besides serving as zygapophyses, as may be seen in the dried bone, gave in the living animal protection to the air-bladder, which, though devoid of the air-duct possessed by the three fresh-water orders just specified, is yet largely developed in the Gadidae. There are two articular facets, a larger looking outwards and a smaller one looking inwards, developed upon the anterior aspect of the base of each neural arch, as it rises from the anterior edge, or close upon the anterior edge of each centrum. An imperfect socket is thus formed in some of the vertebrae for the posterior zygapophyses of the vertebrae next in front, which zygapophyses are upgrowths developed upon the centra, independently of the neural arch, and have their single articular facets looking inwards. The parapophyses of the trunk vertebrae after the fifth, carry ribs, or rib-like intermuscular ossifications, or both, and in the caudal region they form perfect haemal arches.

The bones of fishes are the poorest in inorganic constituents of all the five classes of vertebrata, and the bone cells, the microscopic morphological essential of true bone, are wanting in both Plagiostomi and Cyclostomi, in Acanthopteri, and most other fishes, with the exception of the Physostomi and Ganoids. In the small proportion of inorganic matter in their bony or 'osteoid' tissue fish resemble the Amphibia; but as the lowest of this latter class possess true bone-tissue, it may seem that the absence of bone cells is correlated more or less exactly with the absence of the air-duct which is possessed by the two orders, Physostomi and Ganoidei, which possess true bone. The low proportion of inorganic salts in the bones both of Amphibia and of Pisces, may be correlated in both alike with their aquatic habits.

For the absence or presence of bone cells in the skeleton of fish, see Kölliker, Royal Society's Proceedings, ix. p. 656, 1859; Quekett, Histological Catalogue, ii. B. a. I32, p. 40. 


\section{Shell of Edible Snail (Helix Pomatia).}

WHEN the shell has its apex directed upwards, and its aperture downwards, and towards the describer, its spire will be seen to ascend obliquely towards the right, and this is the case in the great majority of spiral Gasteropodous shells, which are in consequence ordinarily called 'dextral.' In such molluses the heart is placed on the left, and the generative, respiratory, and anal orifices on the right of the animal's body. The columella is seen in the angle formed by the left border of the peristome, and the first whorl of the shell; its umbilicus is partly, but not wholly, as in the common garden snail, Helix Aspersa, concealed by the reflection over it of the peristome, corresponding to which structure in this situation, there was developed in the mantle of the living animal, a process of the collar known as the 'columellar lobule.' The smooth rounding off of the peristome shows the animal to have been adult. The shell is coarsely striated in a longitudinal direction, that is to say, in a direction corresponding with the lines of growth; and more delicately in a spiral direction, that is to say, in a direction at right angles to these lines, and parallel to the five coloured bands with which it is marked. 'The 'apex' or 'nucleus' of the shell, which was the earliest developed or' embryonal shell-whorl, differs, as is so often the case, from the rest of the shell, and in this instance, by possessing a smooth and semi-porcellanous appearance. The way in which the injuries which the shell had received during the life of the animal, have been repaired, without any attempt at a restoration of the damaged exterior layer, shows that it is only along the peristomal margin that such repair can be effected. Injuries received posteriorly to the free rim of the shell, which is in relation with the collar of the mantle, call forth the secretion of protecting layers, by the thin and transparent portion of the mantle; and these layers by successive super-imposition from the mantle outwards, produce the thickenings visible on the interior, in correspondence to the injuries on the exterior of the shell which is left unrepaired.

The thickness of the Gasteropodous shell diminishes from its free rim upwards, and it is probable, consequently, that, except under the stimulus of injury, little accession of growth takes place 
in it posteriorly to the peristome. In this point, as also in that of possessing a much smaller amount of organic matter, the Gasteropodous contrasts with the Lamellibranchiate shell.

For the structure and mode of development of the shell, see Huxley, Cyclopaedia of Anatomy and Physiology, Article 'Tegumentary Organs,' pp. 489-492. For views somewhat different from those put forth there, see Bronn und Keferstein, Klassen und Ordnungen des Thierreichs, iii. 2, pp. 901, 902, 9I3, 920, I I 77, I 1 81, and Rose, Abhandlung, Berlin, Akad. 1858, pp. 94, 95 .

For the terminology employed in describing shells, see English Cyclopaedia, Article 'Gasteropoda,' p. 925.

\section{Edible Snail (Helix Pomatia).}

Dissected so as to show its digestive and reproductive, together with portions of its circulatory and respiratory, organs.

The shell has been detached from the body to which it adhered mainly by means of the columellar muscles, and that part of the general muscular envelope of the viscera, which was continuous with their insertion. The greater part of this muscular envelope and of the mantle has also been removed. The coils of the liver, which were lodged in the uppermost whorls of the shell, and which contain the hermaphrodite gland impacted in their substance, have, together with the rest of the reproductive apparatus, been arranged on the animal's right side; the larger part of the liver with the intestine, heart, and respiratory sac, occupies the left of the preparation; the nerve collar and digestive apparatus down to the pylorus, are seen in the middle line; and between them and the parts to the left, lies at a lower level the sole-shaped locomotor disc known as the 'foot.' A black bristle has been passed between the cephalic ganglia, or supra-oesophageal portion of the nerve-collar and the buccal mass, which, together with the horny crescent-shaped jaw, has been retracted somewhat from its natural position. From the lower part of the buccal mass, a small conical body, in which the back part of the so-called 'tongue' is lodged, projects posteriorly. Along the upper and 


\section{Edible Snail.}

posterior border of the buccal mass, we see mesially the entrance into it of the oesophagus; and on either side that of the duct of either salivary gland, just above the stomatogastric ganglion. Posteriorly to this, the oesophagus expands gradually into the stomach, which is embraced by the salivary glands, and has a pyloric caecum developed upon it, just where it comes into relation with the liver. The bile-duct, which is single at its termination, opens at the pylorus, as directly into the intestine as into the stomach. The first segment of the intestine runs up towards the heart, and, together with the oesophagus and stomach, makes up a curve with its concavity towards the pedal ganglion; as is the case also in Cephalopoda, Pteropoda, and Lamellibranchiatap. Just below the heart, and above the aorta, which is seen to be cut across, the intestine passes on to the external surface of the liver, to reappear again on the left of the preparation, whence it runs with a straight course to the anus, into which a white bristle has been introduced. To the right of the terminal segment of the intestine we see the pulmonary sac, its vessels, and the heart; and between these structures and the buccal mass, the left parietal nerve passes off to distribute itself in two divisions to the body walls. At a little lower level, and a little posteriorly, a more delicate nerve distributes itself to the muscular fibres, which retract the posterior part of the foot, joining them just as they rise above the level of the mass of the foot, to pass up to their insertion on the columella. This portion of the columellar muscles lies, in this preparation, immediately to the left of the buccal mass. It is much feebler than the anterior retractor columellar muscles, as may be seen from the fact that much of the posterior part of the animal's foot is still left unprotected, when during life it has retracted itself as far as usual into the shell. The posterior retractor fibres are continuous on either side with the general muscular envelope of the viscera, and a deep furrow separates them, as in life, from a portion of the mantle which is here left in situ. Immediately above these structures we see three nerves, which have been cut away from their peripheral distribution, but remain attached to the centre whence they arise, viz. the upper

F Sce Huxley, Royal Society's Transactions, 1853, pp. 46, 57 : Englisł Cyclopaedia, Article 'Mollusca,' p. 858 ; but see also page 68 , infra. 
or parieto-splanchnic portion of the sub-oesophageal mass. Two of these are the parietal nerves of the right side; and the third, which is seen to be double at its termination, is the visceral nerve in connection with the aorta. The hermaphrodite gland is lodged in the concavity of the penultimate and ante-penultimate coils of the liver, which occupy the lowest part of the preparation on the right hand. From the gland a convoluted hermaphrodite duct passes up to a spleen-shaped body, the albuminiparous gland; and after this junction, the duct passes upwards again as a much thicker tube consisting of two parts, one of which is much plicated, whilst the other is a riband made up of granulations. These two elements of the tube are not differentiated from each other till just opposite the convex end of a cylindrical hollow muscular organ, the dart-sac, where they separate and form, the one the oviduct, and the other the vas deferens. The vas deferens loops round the right tentacle, and joins the basis of the penis-cylinder at the point where the flagellum, or organ for secreting the spermatophore, also joins it. This latter organ is of great length, ending blindly at the lowest part of the preparation, and to the right of it is placed the pedunculate receptaculum seminis of commensurate, as obviously of correlated, length. The retractor muscle of the penis is attached to it a little below the point of junction to it of the vas deferens and flagellum. Below the penis are seen the multifid vesicles, forming ultimately two main trunks. These vesicles, the dart-sac and the flagellum, are peculiar to, though not uniformly found in, European Helicidae. The flagellum is never found in American species, and the dart-sac and the multifid vesicles are much rarer in these representatives of the family than in the European species. Some, however, of the American Limacidae possess them, which is not the case with the Old World slugs. Much variability, both as to size and as to constancy, is, as is usually the case with structures specially developed in particular families, and not generally possessed by the entire order to which they belong, observable in these structures, as investigated in one species after another in the families possessing them.

For the anatomy of the Pulmonate Gasteropoda, see Leidy, vol. i. p. 198, in Binney's Terrestrial Air-breathing Molluses of the 
United States; see also Semper, in Siebold and Kölliker's Zeitschrift fur Wiss. Zool., viii. 1857, p. 340; and for the points of difference between the reproductive apparatus of the Old and New World Pulmonata, see Leidy, l. c. p. 229.

For a monograph of Helix Pomatia, see Cuvier, Mémoires pour servir à l'Histoire et à l'Anatomie des Mollusques, i 8 i 7 , or Annales du Muséum, tom. vii., 1806.

For the reproductive apparatus, see Owen, Comp. Anat. Invertebrata, p. 562 ; Baudelot, Ann. Sci. Nat. Ser. iv., tom. xix., p. 170, pl. ii. fig. 17, 1862. The identifications of the various organs adopted by the two latter authors, differ from those adopted by Cuvier and Leidy, but are doubtless more correct.

\section{Edible Snatl (Helix Pomatia),}

Dissected so as to show the position of the heart, and the respiratory cavity.

THE greater part of the shell has been removed, but a part of the spire has been left in situ. An incision has been made transversely through the roof of the pulmonary sac, and its cavity has been exposed by turning forward the anterior flap. The vessels have been injected with a red-coloured fluid from the auricle. The bilocular heart is seen, as in dextral molluses, on the left side, and posteriorly, and, in this preparation, inferiorly to it is seen the triangular pale-coloured kidney. Along the front border of the posterior section of the roof of the pulmonary sac, the pulmonary vein is seen passing towards the apex of the pyramidal auricle. Just before entering it is joined, as not rarely in mollusca, by the efferent renal veins. The right half of the roof of the respiratory cavity is covered by vascular ramifications; the anterior part of the left half is destitute of them, the posterior corresponds to the kidney, or is constituted by the 'pericardium.' The nonvascular floor of the respiratory cavity is seen to be formed by muscular fibres, arranged somewhat after the fashion, and doubtless, during life, performing some of the functions of a diaphragm. A more delicate muscular layer enters into the formation of the roof of the sac, taking origin from a thickened band which runs 
along the concavity of the visceral spire, and joins the free thickened rim or 'collar' of the mantle, a little posteriorly and superiorly to the respiratory orifice. One of the afferent pulmonary veins is figured by Milne Edwards, Mémoires de l'Institut, tom. xx., 1849 , pl. v. d., as taking a similar course. The muscular floor of the respiratory sac discharges a secondary function, in propelling the animal downwards when it has been retracted into its shell, as well as a more obvious and primary function in the act of breathing. In the completion of the act of forcing the animal's body out of the shell, the 'collar' takes a share. And it is to this thickened muscular and glandular border of the mantle that the secretion of the epidermis of the shell and its increase of capacity is due in all shelled Gasteropoda, whilst the formation of the epiphragm is also to be ascribed to it in the air-breathing representatives of the class.

For the formation of the epiphragm, as observed in the Helix hortensis, see Binney, Terrestrial Air-breathing Molluses of the United States, vol. ii. p. 114; Keferstein, Klassen und Ordnungen des Thierreichs, iii. ii. p. I 86.

For figures of the pulmonary vessels in Helix Pomatia, see Milne Edwards' Mémoires de l'Institut, tom. xx. I 849, pl. iv., pl.v.; C. G. Carus, Tabulae Comp. Anat. iv. vii., 2, 5 .

\section{Edible Snail (Helix Pomatia),}

Dissected so as to show its nervous system.

TuE mantle has been separated from its attachment around the base of the visceral mass, except for a short distance, corresponding to the middle line of the foot posteriorly, and along from that attachment, a short distance round on the animal's left side, where a triangular lappet, the so-called 'columellar lobule,' is developed upon it. It has been turned over to the left side, together with the organs in connection with the roof of the cavity it developes, viz. the heart and the pulmonary vessels, the rectum, and the kidney with its duct. The integument covering the head and neck has been divided in the middle line, and fastened out on 
either side; the muscular envelope which was continuons with this part of the integument, and formed the floor of the mantle cavity on the one hand, and a roof over many of the viscera not already specified on the other, has been removed, as have also all the viscera unconnected with the mantle, except the nerve system and the buccal mass. A black bristle has been passed through the nerve collar, between the supra-oesophageal cerebroid ganglia and the commencement of the digestive tube; and another has been inserted between the stomato-gastric ganglion of the right side, and the back part of the buccal mass. A stout nerve passes from either side of the supra-oesophageal mass to the superior or eye-bearing tentacle, indicating thus by its distribution the sensory character of the nerve centre whence it arises. The inferior tentacles are supplied from the same source, as are also the rudimentary 'organs of Semper,' and the upper lip. A long and delicate commissural cord is seen to connect the cerebroid mass with the stomato-gastrie ganglion, which is placed in the re-entering angle between the oesophagus and the retracted buccal mass. A much stouter and double commissural cord is seen passing downwards, from the supra-oesophageal mass on the right side. By one of its strands, the shorter and the more posteriorly placed of the two, it connects the upper or parieto-splanchnic portion of the sub-oesophageal mass with the supra-oesophageal of its own side; and by its longer and more anteriorly placed, it comes into a similar relation with the lower or pedal portion of that part of the nerve collar. From the upper part of the sub-oesophageal mass, three nerves pass off to the parietes, as opposed to the foot, two on the right side, and one on the left. Certain other nerves which supply the columellar retractor muscles, as also the great visceral nerve, which has been removed together with the aorta, which it accompanied, had a similar origin. Immediately below the origin of these nerves, the small otic vesicles may be seen situated at the upper and posterior aspect of the pedal mass, which is so closely connected with the parieto-splanchnic portion of the sub-oesophageal mass in the Helieidae, as to be differentiated from it mainly by the position of these vesicles externally, by the orifice through which the cephalic aorta passes mesially, and by the origin of the nerves passing off to the locomotor-dise or 'foot' inferiorly. 
For the nervous system of the Cephalous Mollusca, see Hancock and Embleton, Phil. Trans. 1852, p. 238; Huxley, Phil. Trans. 1853 , p. 53 .

For figures of the nerve system of this and other Pulmonate Gasteropods, see Keferstein, Die Klassen und Ordnungen des Thierreichs, iii. 2, Taf. xcvi., and Walter, Microscopische Studien, 1863, cit. in loc.

For a figure of the nerve collar with the otic vesicles and aorta in situ, see Leidy in Binney's Terrestrial Molluscs of the United States, vol. i. pl. xvii. fig. iv., and vignette, p. 248.

For the distribution of the nerves, see Cuvier Ann. du Muséum, tom. vii. p. I72, 1806; or Mémoires pour servir à l'Histoire et à l'Anatomie des Mollusques.

\section{Shell of Fresh-water Mussel (Anodonta Cygnea).}

WHEN the bivalve shell of the fresh-water mussel, or of any of the British fresh-water species of Lamellibranchiata, is held with its hinge-line upwards, its line of aperture downwards, and its ligament and its umbones, the most convex portions of the valves, placed, the one proximally, and the other distally to the observer, he will then have the animal's right valve at his right hand, its left valve at his left hand, the anterior portion of its body placed distally, and the posterior proximally to himself. Such Lamellibranchiata as have the power of moving from place to place, by the protrusion of their distensible 'foot,' do so in the direction which the words 'anterior' and 'posterior,' as used here, imply. The shell of the Anodon is, as in the immense majority of Lamellibranchiata, nearly or quite equivalve, whilst, as in all, it is inequilateral. By its size, which is in an inverse ratio to the extent of junction of the lobes of the mantle which secretes it, it surpasses all European fluviatile bivalves, and sections, or indeed fragments of it, are consequently exceedingly instructive, as to the structure of the various layers of which the shell is composed. Nearly the whole of the inner surface of the shell possesses an iridescent appearance, due, probably, mainly to the light being diffracted by the layers of delicate lamellae with irregularly overlapping edges, which make up the nacre or inner layer of the shell, and are 
themselves made up of polygonal masses of small size secreted by the mantle exclusively of its margin. Very frequently, even in the dry shell, it is possible to separate a thin white layer consisting of a structureless membrane, laden with granular calcareous deposit from the nacreous or 'mother of pearl' internal layer of the shell, which was formed by the successive super-impositions of such membranes from within outwards. The free rim of the shell is constituted by the coloured opaque epidermal layer, which forms a flexible border of several lamellae, immediately internally to which, in this, and in all still growing shells, on the inner surface of the shell, a similarly dark-coloured but non-flexible strip intervenes between the epidermal free border and the nacreous surface of the shell. This portion of the shell which bounds the nacreous portion like a fringing reef, is seen, when looked at with a simple lens, to possess an appearance like that of shagreen, and this appearance on examination under a higher porver, is found to be due to its being divided into minute polygonal spaces, over which the nacreous layer has not yet extended. The inner of the two layers of which this portion of the shell is made up, is known as the 'prismatic' layer, and is formed by the deposition of calcareous matter in the interior of vertical prismatic cavities, which are themselves formed by the successive super-addition and coadaptation of fenestrated laminae secreted by the margin of the mantle. There is less difference between the thicknesses of the two inner layers of the shell in the Anodon than in most other Lamellibranchiata; the middle or prismatic layer is, as the fact of its being secreted by the margin of the mantle would have led us to anticipate, thickest, both absolutely and relatively, in those parts of the shell in which peripheral growth is carried on at the most rapid rate; and consequently it is thicker at the free edges than along the dorsal region, and in the posterior than in the anterior parts of the shell. The relation held by the 'prismatic' layer of the shell to the parts where growth is going on most rapidly; its existence there inclependently of the 'nacreous' layer; and, thirdly, the fact that the calcareous particles in its substance do not possess a crystalline character, appear conclusive against the view ${ }^{q}$ which has been

' See H. Müller quoted by Hessling, 'Die Perlmuscheln und ihre Perlen,' p. 261, Bronn and Keferstein, iii. 2, 913, and Rose, Berlin Akad. Abhand, 1858, p. $9^{8}$. 
proposed, to the effect that the prismatic layer has been formed by some such rearrangement of the particles deposited in the inner nacreous layer, as takes place in certain calculi, after the primary deposit of the solid substance of which they are made up in an amorphous condition, or in the alteration of an amorphous glass into the so-called ' Reaumur's porcelain.' The 'ligament' which connects the two valves along the dorsal line, posteriorly to the beaks of the umbones, consists of two layers-an outer corresponding to the epidermal layer of the shell; and an inner, the so-called 'cartilage,' which combines by its two sets of striae, one running vertically and the other horizontally, the laminate appearance characteristic of 'nacre,' with the 'columnar' characteristic of the prismatic layer of shell, and illustrates thus the fundamental morphological and developmental identity of these structures. The ligament in the Anorion is said to be 'external ;' it is, however, a little overlapped on either side for a short way by the superficial layers of the valves which it connects, and divaricates when not antagonized by the adductor muscles. Corresponding to the ligament, there is on the inner surface of the shell a long low ridge, indented at its posterior end; a similar structure exists in the pearl mussel, Unio Margaritifer; and seems to be a rudimentary representative of the elongated posterior lateral tooth, developed in the two other British Naiades, Unio Pictorum and Unio Tumidus. The cardinal teeth are absent also in the Anodon, and the anterior laterals are wanting in all the British Naiades. There are three principal muscular depressions on the inner surface of each valve, two towards the upper edge of the blunted anterior end, and one at about the same distance from the dorsal or haemal edge of the valve, and about midway between the posterior limit of the ligament and that of the valve. Of the two anterior depressions, the larger marks the place of attachment of the anterior adductor of the valves, and also of the anterior retractor of the foot; the smaller, which is close to the posterior inferior aspect of the larger in the angle between it and the pallial line, marks the place of attachment of the protractor of the foot. The larger part of the posterior muscular depression corresponds to the insertion of the posterior adductor, the irregular process into which its anterior and upper angle is prolonged into, corresponds to the point of origin of the posterior and larger retractor of the foot. An irregularly denticulated line, which is 
known as the 'pallial line,' and which corresponded in the living animal to the line along which the muscular border of the mantle was more or less loosely attached, just where it became confluent with the central lobes of the organ, describes a curve, similar to those of the concentrically arranged ribs on the outside of the shell, between the two principal muscular depressions. Certain smaller muscular depressions are visible just anteriorly to the apices of the umbones, marking the points of origin of certain retractor fibres. The thinner, lighter coloured, and less eroded of these two shells came from shallow water; the thicker, darker, and more eroded is an ordinary deep water form. That the amount of inorganic salts which these as also other organisms take up, is by no means dependent upon the amount present in the medium in which they live, but upon the selective working of their tissues, which may be intensified or diminished by other chemical and also by non-chemical conditions, is seen from instances such as these, as also from a comparison of the dense shell of the Pearl Mussel from mountain streams, such as those of Westmoreland, with the thin light shells of the Anodons from the Oxford waters so much richer in salts of lime.

For an excellent disquisition upon the last-mentioned point, as well as upon many others relating to the physiology of the Pearl Mussel, Unio Margaritifer, a species allied to the Anodon, see Voit in Siebold and Kolliker's Zeitschrift fur Wissenschaftliche Zoologie, x., I 859 , p. 470.

For a monograph of the former species, see T. von Hessling, Dic Perlmuscheln und ihre Perlen, Leipzig, 1859.

For accounts of the formation and structure of the shell, see Bronn, Klassen und Ordnungen des Thierreichs, iii. i. p. 420; Voit, 1. c. p. 487; Huxley, Cyclopaedia of Anatomy and Physiology, Article 'Tegumentary Organs;' Carpenter, British Assoc. Reports, I847, pl. iii., figs. 8, 9, 10.

For a description of the animal's muscles, the impressions of which on the interior of the shell are mentioned above, see Poli Testacea Utriusque Siciliae, tom. i. p. $3^{6}$, tab. ix., fig. 2.

For the amorphous non-crystalline character of the calcareous deposit in the shell of Unio, see Hessling, 1. c. pp. 25 I, 26. See also Rose, Berlin Abhandlungen for $185^{8}$, p. 98 . 


\section{Fresh-water Mussel (Anodonta Cygnea),}

Dissected so as to show its digestive tract, with a neural flexure formed by it at its commencement.

THe mantle and the lamellae of the gills have been removed from the animal's right side, together with so much of the body-walls as it was necessary to remove so as to expose the coils of intestine, and the stomach, in situ, and in connection with the liver and reproductive gland. The passage from the mouth to the stomach is similarly laid open, and is seen to be lined with a smooth membrane, lying upon the anterior adductor and the anterior retractor muscles, and thrown by their contraction into corrugations. The ingestion of alimentary matters depends, as no prehensile apparatus exists in the Lamellibranchiata, upon the currents of water which find entrance into the digestive tract, and have their passage along it greatly promoted by the readiness with which the circumjacent tissues become charged with, and also set free from the transuding fluid; by the alternate opening and closing of the valves; and, finally, by the ciliary movement of the microscopic epithelium which clothes the interior of the digestive tube as well as the neural surfaces of the mantle, gills, and labial tentacles. The bilamellate oral tentacle of the left side is seen to become continuous with the lining membrane of the mouth, to which, by its junction with its fellow of the opposite side, removed in this preparation, it furnished lips. Further down, the liver is seen supporting the lining membrane of the stomach and sending ducts to open into its cavity. The diverticulum for the 'crystalline style,' an organ somewhat variable, but found in greatest size and constancy after the winter, opens on the right side of the stomach; whilst the pylorus leads into the intestine from the left in the preparation. A black bristle is passed along the first segment of the intestine which is seen to form, when viewed in connection with the stomach, a curve with its concavity towards the pedal ganglion. This, the primary flexure of the intestine, is thus a 'neural' flexure; the concavities, however, of the other loops which the intestine alone describes, look towards the dorsal or 'haemal' surface. Considering the intestine exclusively of the stomach, we may speak of it roughly, as describing three concentric curves in intimate connection with the viscera, and 


\section{Fresh-water Mussel.}

before it disengages itself from the mass they make up. Of these, the one directly continuous with the stomach, is placed between the other two, and two raised ridges are visible upon its inner surface-one, the larger of the two, upon its neural, the other, the more delicate, upon its haemal aspect. With this first loop, the one placed most externally is continuous, and is seen bending sharply back from, and closely round upon it along the posterior free margin of the foot. Upon its surface there is no longitudinal ridge developed, but a raphe with plice running from it at right angles to the long axis of the intestine. It is in close relation with the muscular strata of the 'foot.' In ends in the third loop, which at its beginning passes over the first so as to become quite superficial in the middle of the right side of the visceral mass; and then takes a horizontal course, as seen in this preparation, to the haemal border of the animal's body, at a deeper level parallel to and immediately posteriorly to the portion of intestine immediately continuous with the pyloric end of the stomach. Where it reaches this deeper level, a raised ridge is developed upon it, which commences with a club-shaped end, and is prolonged on the neural wall of the intestine as far as the anus. After thus completing its third coil, by reaching the haemal edge of the visceral mass, the intestine emerges from it, and turns at a right angle to its previous direction to pass, as in the great majority of Lamellibranchiata, through the heart, the cut edge of the ventricle of which is seen to the left of the intestine. The pericardial space appears, in section, as a triangular cavity, bounded by the heart and intestine to the left, the retractor pedis posterior below, and the organ of Bojanus to the right. The two cavities or sacs of which this organ is made up, are well seen in section; though the walls of the superiorly placed and non-glandular sac are more nearly in apposition than in nature. The lamellate glandular sae is seen prolonging itself around the tendon of the posterior retractor, and along the anterior and inferior surface of the posterior adductor. Posteriorly again to the posterior adductor, we see the attachment of the gill of the left side to the mantle at a point corresponding to the junction of the fimbriate with the non-fimbriate portion of the mantle. The preparation is suspended by the apex of the muscular 'foot;' by the protrusion and implantation of which into the soft bottoms of the ponds and streams in which these creatures live, they can move 
themselves slowly along the furrow they thus form. The shape of the 'foot' varies much within the limits of the class, from being exceedingly small or rudimentary, up to the proportions we see here, where the name 'pelecypoda' has been coined to express its shape and proportions.

For a description of the digestive system of the Anodon, see Langer, Denkschrift. Akad. Wiss. Wien. viii., I 854 , p. I9, and Taff. i. and ii. figs. I, 2, and 9, or V. Hessling, Die Perlmuscheln, p. 266.

For that of Lamellibranchiata generally, see Huxley, English Cyclopaedia, Article 'Mollusca,' p. 86 .

For a description of the organ of Bojanus, see Lacaze Duthiers, Ann. Sci. Nat. Ser. iv. tom. iv. 1855 , with semi-diagrammatic figure, pl. v. fig. 2, which is reproduced by V. Hessling, l. c. pl. v. fig. 6. Langer, Denkschrift. Akad. Wiss. Wien. B. xii., p. 39,1856 , tab. i., figs 3 and 4 .

\section{Fresh-water Mussel (Anodonta Cygnea),}

Prepared so as to show some of the functional as well as the anatomical relations of the mantle.

A RED injection having been thrown into the auricles, has passed not only into the gills, but also over the central portion of each mantle lobe, from the line of attachment to it of the external gill, down to the border where the central portion becomes continuous with the free muscular rim of the mantle, and where it was attached to the 'pallial line' in the shell. From the central portion of the mantle, the injection has spread by anastomosis into the vessels of the free muscular and tentaculate rim of the organ, and, more freely, into the labial tentacles. Thus the functions of the principal aerating organ, the gills, are seen to be more or less supplemented by the subsidiary working of the structures specified.

The mantle lobes are not united below the plane of the inferior or neural surface of the two adductor muscles, except indirectly by the commissural junction of the branchiae posteriorly to the foot. By this junction of the gill plates the mantle cavity is divided into two chambers, an inferior or branchial chamber, the entrance 
to which is guarded by the tentaculate postero-inferior portion of the mantle, representing the inhalant siphon of the siphonate orders; and a superior, or anal chamber, into which a white bristle is introduced in this preparation, and which corresponds to the exhalant siphon of the other orders just named. The large mantle lobes have been turned upwards, and fastened on to the haemal surface of the animal on either side of the raphe, along the middle line of that aspect of the animal's body. Their thickened muscular border, corresponding to the collar of the Gasteropoda, is well seen, the radiating striae on its lateral surface marking its extent, which corresponded in the living animal to the space between the free edge of the shell and the 'pallial line.' Two main lips run along its free edge, inclosing however between them two somewhat smaller ridges. To segments of this furrowed and ridged surface, portions of the epidermal shell-layer which they secreted are still left adhering. The prismatic layer appears to be deposited by the most peripherally-placed strip of the external surface of the organ, just where it becomes continuous with the downward-looking surface just mentioned. The two halves of the dorsal raphe diverge from each other in the genus Unionidae, and then re-unite immediately anteriorly to the posterior adductor. The cirrhi, which guard the entrance to the branchial compartment of the mantle eavity in the natural condition of the animal, are developed from the inner of the two lips of the mantle edge, beginning at a point corresponding with the line of attachment to it of the outer gill lamina. The inner gill lamina of each side fuses, as already said, with its fellow of the opposite side so as to form a continuous floor, perforated only by microscopic apertures, between the anal and branchial chambers. But as the gills fail to become attached to the body for about the posterior three-fifths of its length from before backwards, free intercommunication exists between these two chambers for this space. In this interval between the free gill-edge, along which a large branchial vein is seen to run, and the visceral mass, the glandular portion of the organ of Bojanus comes into view from above. It is from the retia mirabilia of this organ that the branchial inferent vessels take their origin, and pass upwards to distribute themselves on the inner surface of the gill-laminae, whilst the efferent branchial veins have their distribution, as seen by the injection, on the outer or inferior surface of these organs. As shown 
by Dr. Sharpey, ${ }^{\mathbf{r}}$ it is in the direction from without inwards that the currents of water pass through the gills under the influence of ciliary action; and it will be seen therefore that the water which comes into relation with the vessels returning blood to the heart, has lost as little as possible of its aerating value, by contact with other tissues of the animal's body. It is well to add that the surface of the mantle which looks towards the gills is like them clothed with ciliated epithelium; whilst its surface which looks towards and secretes the two inner layers of the shell, is covered with non-ciliated cylindrical cells.

For the structure of the gills, and the relations subsisting between the vascular systems of the body generally, of the gills, and of the organ of Bojanus in the Naiades, see Langer, Denkschriften Akad. Wiss. Wien. viii., x854, and xii. 1856, pp. 36, 37, 61 ; V. Hessling, Die Perlmuscheln, pp. 216, 230, 245, 247; and the figures in V. Carus' Icones Zootomicae, xix., 1, 6, 8, 9 and 10, which are taken from the former of these two authorities. See also Robin, Rapport à la Société de Biologie, 1852, p. 120.

\section{Fresh-water Mussel (Anodonta Cygnea),}

Dissected so as to show its nerve system, and the route along which the ova pass from the generative gland into the interspaces of the external gills, where, as in the pouch of a marsupial mammal, they are lodged, and go through certain stages of their development.

PART of the muscular foot has been removed on the left side to show the pedal ganglion in situ; part also of the organ of Bojanus has been cut away on the same side, and the commissure which connected the two inner lamellae of the two inner gills posteriorly to the posterior limit of the foot has been divided, so as to show the nerve cord connecting the labial with the parieto-splanchnic ganglia in its entire length. The labial ganglion, which is homologous with the supra-oesophageal of the Odontophorous molluses, is seen lying upon the tendon of the retractor pedis anterior, and just

r Cyclopaedia of Anatomy and Physiology, Article 'Cilia,' p. 62 I. 
anteriorly to that of the protractor pedis. Three commissural cords, under each of which a slip of blue paper has been placed, pass off from it. The one which passes vertically downwards in the preparation, and passes vertically, or nearly so, upwards in the position ordinarily maintained by the animal during life, brings the labial ganglion into commissural junction with the parieto-splanchnic or branchial ganglion, which is seen lying upon the posterior adductor. A second cord passes obliquely forwards towards the foot, to join the pedal ganglion, which is situated a little way within the inferior periphery of the ' visceral mass,' a division of the body which in these molluses is less sharply differentiated from the 'foot' proper than in many other members of the class. The third cord, which looks like a production of the second, from the ventral to the haemal side of the plane of the labial ganglion, is in reality the cord of commissure between this ganglion and its fellow of the opposite side. This cord holds the same relation to the commencement of the digestive tract as the commissure of the cephalic ganglion holds in the Odontophora; and the cord of commissure to the pedal ganglion is, as in them, placed anteriorly to the cord of commissure to the parieto-splanchnic. There are, however, no stomato-gastric, nor any separate sympathetic ganglia in the Lamellibranchiata. The absence of the former of these structures is obviously correlated with the absence of any prehensile apparatus, or any triturating 'buccal mass,' whilst the absence of the second is ordinarily to be noted in structures and in organisms, which are as richly provided with cilia as are those of this class. Special siphonal ganglia are however sometimes superadded to the three pairs of ganglia here specified in the siphonate species; and small ganglia may be developed in this class along the free edge of the mantle, in connection with the sensory plexuses which the anterior and posterior pallial nerves, from the labial and parieto-splanchnic ganglia respectively, make up by their ramifications along it. The cord of commissure from the labial to the parieto-splanchnic ganglia passes from before backwards; firstly, between the fibres of the anterior retractor and those of the protractor pedis; and, secondly, after skirting the orifice of the reproductive gland, on its inferior or inner edge, through the glandular portion of the organ of Bojanus, externally to the tendon of the posterior retractor. Immediately posteriorly to this tendon, and anteriorly to the large 
parieto-splanchnic ganglion, the nerve of the right side, as well as that of the left, has been brought into view, and a slip of blue paper has been passed under the two nerves just before they enter the ganglion. This nerve-centre is well seen giving off sensory branches to the mantle, and motor to the adductor muscle, and visceral branches to the gills. Its finer visceral branches given to the organ of Bojanus, and to the anus, are not seen in this preparation. Four or five delicate nerves may be seen to pass off from the pedal ganglion into the muscular strata of the foot; to the most posteriorly placed but one of these, the auditory vesicle may be found appended, at a point corresponding pretty nearly with the junction of the anterior two-thirds with the posterior third of the foot, close to the line beyond which the viscera do not extend downwards within their muscular envelope. The branches which the labial ganglion gives to the anterior portion of the mantle, are not seen in this preparation.

By the division of the transverse commissural floor which united the inner lamellae of the two inner gills across and below the structures already described as being placed posteriorly to the posterior edge of the foot, and by the turning outwards of the flaps thus formed, a view is obtained of the spaces bounded by the two lamellae of each gill, and also of the line of junction of the outer lamella of the inner gill and the inner lamella of the outer gill, on each side to the organ of Bojanus, which sends blood into the lamellae of the gills along their internal surfaces.

Each gill is seen to be a hollow pouch or sac with its cavity divided into innumerable partitions by strips of tissue which run across from one lamella to another. But for some distance downwards from the attached or upper border of each gill, these transverse bands fail to be developed, and passages are thus left along this border of the gills along which the ova pass in their circuitous course from the reproductive gland to the marsupial pouch which the external gill is formed into for them. The portion of this canal which the inner gill forms is divisible into three segments-an anterior, a middle, and a posterior. The anterior segment is formed permanently by the attachment of the inner gill's inner lamella to the visceral mass; and it is just within the posterior portion of this segment that in the Anodon the orifice of the generative gland opens. The middle segment is formed temporarily into a 
closed canal, by the apposition of the inner gill-lamella to the visceral mass, when the ova are being extruded, and the foot and visceral mass retracted and compressed by the contraction of the animal's various muscles. The third portion of this canal is constituted, below, by the commissural floor passing between the two inner gills, and, above, as in the two anterior segments, by the posterior part of the organ of Bojanus. It is easy to see in this preparation, how, by the contraction of the retractor pedis muscles, the ova would be extruded, and the upper portion of the visceral mass brought into close temporary apposition with that portion of each inner gill, which, ordinarily, is separated from it by a slight interspace. We can see also how under these circumstances a closed canal for the transmission of the ova is formed from the orifice of the generative gland up to the point at which the large branchial nerves enter the gills, and beyond which the internal gill passage and also the outer, open into a space which, as the anus opens into it also, we may call the 'cloaca.' This space being but small in the Naiades relatively to their ovaries, is rapidly filled by the large quantities of ova which are poured into it under pressure; and, the shell being closed, there is no other path left for the ova to take but the one which leads into the cavity of the external gill. As these animals are dioecious, and as spermatozoa are sometimes found free in the interior of the gills, to which it is plain they would find access more readily when inhaled with the water for " respiration than to the interior of the ovaries of the female, it is probable that it is not till after they reach the external branchial marsupium that the ova are fertilized. The ova may be found in great abundance in the external gill cavity of the Anodon during the autumn and winter months; and whilst lodged there, they go through several stages of their development.

For an account of the way in which the ova reach the external gill cavity, see V. Baer, Meckel's Archiv. 1830, p. 313, Taf. vii., figs. $I, 2$, and 4.

For observations which V. Hessling thinks make it probable that the ova of one mussel may find their way into the external gill-cavity of another, see Zeitschrift fur Wissenschaflitche Zoologie, 1860, p. $35^{8}$.

For a detailed account of the nervous system in the Lamelli- 
branchiata, and in the Anodon particularly, see Duvernoy, Mémoires de l'Institut, tom. xxiv., 1854, and pl. 7, fig. 2, pl. 8 and 9, figs. I and 2, and pp. 87-96 for that of the Naiades.

For a more general account, see English Cyclopaedia, Article 'Mollusca,' p. 869; Siebold's Comparative Anatomy, American Translation, p. I98; Gegenbaur's Vergleichende Anatomie, p. $3^{\text {IO }}$, with excellent figures 77 , A. B. C., pp. 315, $3^{16}$; Hancock and Embleton, Phil. Trans. I 852 , p. 239.

\section{Ascidian (Ascidia Affinis).}

Dissected and prepared similarly to Preparation 19 , and showing thus the homological relations of the several structures of the Tunicata to those of the Lamellibranchiata.

THe animal has been suspended by what was, in its erect position during life, its base of attachment; and its inhalant and exhalant orifices point, consequently, downwards instead of upwards. Parts of the test, of the two internal tunics, and of the upper part of the branchial sac, have been removed on the animal's right side, which corresponds with the front of the preparation; and so much also of the walls of the stomach, and intestine, and of the vesicular substance,

- and of the liver in connection with them, has been similarly taken away, as was necessary for exposing the interior of the digestive tract from the mouth to the anus. A black bristle has been introduced through the inhalant orifice along the interior of the branchial sac into the mouth and stomach, and a white one has been similarly passed through the exhalant orifice into the rectum. In this species the inhalant orifice is terminal, and the anal is lateral; just as in many Lamellibranchiata the inhalant siphon, or the tentaculate portion of the mantle which corresponds to it in the non-siphonate orders, reaches farther backwards than the anal siphon, or the anal portion of the mantle. The mantle, which is recognisable by its muscular fibrillation, has since the death of the animal shrunk away from the external test, the homologue of the bivalve shell. The rectum and the generative ducts are seen to open, as in life, a little way within the periphery of the mantle, and into a space which is homologous with that described, Preparation 2 I, 
p. 65 , as the 'cloaca' in the Anodon, but which differs from it by being much larger, by not possessing an organ of Bojanus, except in a rudimentary condition, and by not being traversed by any muscle such as the posterior adductor. A wide interspace thus exists here between the branchial sac and the envelopes or tunics placed exteriorly to it, to which, however, it is attached continuously along the white band seen along the median ventral line, and known as the 'endostyle;' along an encircling zone, placed immediately superiorly in this preparation to the circlet of tentacles just within the inbalant orifice; along a line passing from the other end of the endostyle to the neighbourhood of the mouth; and lastly at intervals in all parts of its circumference except in the cloacal region, by hollow tubular suspenders, which convey blood between its vessels and the visceral and pallial sinuses. The line of the 'endostyle' is constituted by four folds, the two external being membranous, and the two internal of a rigid yellowish substance; and in this, as also in the relation it holds to a large vessel, the so-called 'thoracic sinus' of Milne-Edwards, passing along it from the heart, and in the more general relations which it holds to the other organs of the animal, it resembles the line of the symphysis of the mantle of the Lamellibranchiata which have the mantle lobes united inferiorly, or the free margin of the mantle lobes of such bivalves as the Anodon (see Preparation 20, p. 6I). Along the opposite side of the branchial sac there runs the 'oral lamina,' which in other species, such as Ascidia Intestinalis, may be represented by a row of ' languettes.' It is connected with the line of the 'endostyle' by the encircling zone already spoken of as lying superiorly to the circlet of tentacles. In the interval between this encircling zone and the coronet of tentacles, at the point where the oral lamina becomes continuous with the former of these structures, is seen the 'ciliated sac' or ' anterior tubercle.' Posteriorly to the encircling zone, or ' anterior collar' of Hancock, in the immediate neighbourhood of the anterior tuberele, is seen the single ganglion of the Tunicata, supplying the mantle. This ganglion therefore would seem to be homologous with the branchial or parietosplanchnic ganglion of the Lamellibranchiata; and the circlet of tentacles will, by consequence, be seen to be homologous with the tentaculate inhalant portion of the mantle in those animals.

The 'oral lamina' is seen to be underlaid by a large vessel, the 
'branchial' or 'dorsal sinus' of Milne-Edwards, the 'branchial vein' of Savigny. It is connected with the one already spoken of as holding a similar relation to the endostyle on the opposite side of the branchial sac, firstly, by means of the numerous transverse vessels encircling the branchial sac; secondly, by a vessel taking a similar course to these vessels around a zone in relation with the 'anterior collar;' and thirdly, by a vessel holding a similar relation to a chord uniting the upper end of the endostyle to that of the oral lamina, and known as the 'posterior collar.' The 'dorsal sinus' receives factors from the pallial plexuses by means of tubular ties similar to those which pass from these and the visceral plexuses on the left side of the animal's body to the other portions of the branchial network. Finally, it is seen to receive a large vessel from the neighbourhood of the anus, and by this vessel, which passes to it through the visceral mass from the heart, it is brought into direct communication with the dorsal end of that vasiform organ as the 'thoracic sinus' in relation with the line of the endostyle is, even more directly, with its ventral end. On either side blood-vessels are seen crossing the interval between the test and the mantle to join one or other of the two vascular trunks in connection with the dorsal and ventral end of the heart respectively.

The mouth, in all Ascidians, occupies a point in the branchial sac which is on the opposite side to the line of the 'endostyle,' and to that of the 'thoracic sinus' of Milne-Edwards, the so-called 'branchial arteries' of Savigny, which are here regarded as more closely homologous with 'branchio-cardiac veins.' In this species the mouth is much nearer the upper or anterior extremity of the sac than it is in Ascidia Mentula. The digestive tract is seen to describe two curves; the first of these is made up by the stomach, and the first segment of intestine which bends sharply back upon it; whilst the second is made up by this first segment of intestine and the rectum. The concavity of the first of these curves looks anteriorly, or towards the base of attachment of this erect species, and away from the nerve ganglion; the concavity of the second looks posteriorly, or towards its inhalant aperture. But if, as in this deseription, the single ganglion of the Tunicata be regarded as the homologue, not of the pedal but of the parieto-splanchnic ganglia, if their branchial sac be also regarded as homologous not 
with a dilated pharynx, but with the branchial cavity, and if their inhalant aperture be taken to represent, not the mouth, but the inhalant siphon of the Lamellibranchiata, it will be seen that the essential character of the curves described by the digestive tract beginning with the orifice into which the upper end of the black bristle is introduced, is the same as that of those described in the Anodon, Preparation 19, p. 58, and that the two classes cannot be contra-distinguished as 'haemal' and 'neural' respectively. The digestive tract of the Ascidian is seen to differ from that of the Anodon mainly in not possessing the two posterior of the three concentric coils, described in that animal, whilst its first and most important curve, and also that portion of it which is seen in the cloaca, and in relation with the large blood-vessel passing from the heart through the visceral mass to the 'branchial' or 'dorsal sinus' of Milne-Edwards, corresponds very closely in all essential particulars with the initial and the terminal segments respectively of the digestive tract of the bivalve. The floor of the stomach is occupied by a longitudinally folded eminence, which again is prolonged into and along the intestine, where it forms an elevated ridge, dividing the tube into two demi-canals, and much increasing its absorbing surface. The liver, which Mr. Hancock (Proc. Linn. Soc., June 1867, p. $3^{1} 3$ ), has, in opposition to Savigny, shown to exist in the genus Ascidia, opens into the cavity of the stomach by two ducts. The reproductive organs are seen in the concavity of the second or intestinal curve of the digestive tract; and their excretory ducts open into the cloaca, together with the anus.

The view which has been taken in this description of the relationship subsisting between the Lamellibranchiata and the Tunicata, was suggested by Cuvier in his memoir on the Ascidians (Mémoires du Muséum, 18 15, tom. ii., p. 34), and was adopted by V. Baer, in his paper on the route taken by the ova of Unionidae in passing from the ovary into the branchial marsupium, already referred to, and published in Meckel's Archiv. for 1830, p. 341. This view has been revived by Mr. Hancock (see Proceedings of Linnaean Society, June 1867, p. 343), and illustrated by many new arguments.

Professor Huxley's view, according to which the branchial sac of the $\Lambda$ scidian is to be regarded as a dilated pharynx, will be found expounded by him in the British Association Report for 18.52, 
p. 77, as also in his article on 'Mollusca' in the English Cyclopaedia. See also Professor Allman, Fresh-water Polyzoa, 1856, p. 44, seqq., and Mr. J. D. Macdonald, Transactions of the Royal Society of Edinburgh, vol. xxiii. I862, I863, for general remarks on the morphology of the Tunicata.

Much information as to the anatomy of the various orders of this class will be found in the memoirs of Cuvier and Hancock, already quoted; in the second volume of Savigny's Mémoires sur les Animaux sans Vertèbres; in Milne-Edwards' 'Observations sur les Ascidies Composées,' published in the Mémoires de l'Institut for 1 839, and in Professor Huxley's Papers in the Royal Society's Transactions for I 85 I.

For figures of Pyrosoma giganteum, a free social Ascidian, which lend much probability to the view which has been here adopted, as to the homological identity of the branchial sac of the Ascidian with the gills of the Lamellibranchiata, see Le Sueur, in the Bulletin des Sciences par la Société Philomathique, I815, pl. i. fig. 2, or Journal de Physique, June I 8I5; and Keferstein und Ehlers, Zoologische Beiträge, I86I, Taf. xii., figs. iv. and v.

For the essential character and structure of the branchial sac, see Milne-Edwards, 1. c. pp. 271-274; Hancock, 1. c. pp. 327-334.

For a description of the three tunics of the Ascidians, see MilneEdwards, 1. c. p. 270.

For an account of the circulation in this class, see Bronn, Klassen und Ordnungen des Thierreichs, iii. i. pp. I72-176; MilneEdwards, 1. c. pp. 224-228; Hancock, l. c. pp. 32I-325.

Cuvier's and Savigny's figures of the various systems and organs of Ascidians, as well as those given in V. Carus' Icones Zootomicae, tab. xviii., from the most recent authorities, are well worthy of being studied.

For an account of a new genus of Ascidian which possesses a bivalve shell, see Lacaze Duthiers, Ann. Sci. Nat., Ser. v. tom. iv., 1865, p. 293. Sur un genre nouveau d'Ascidien, Le Chrevreulius Callensis, Lac. Duth., where, at p. 307, the differences between the type of organization which the animal named presents and that of the Lamellibranchiata are pointed out. 
The internal anatomy of the species here described resembles in many points that of the Ascidian, Ascidia Phusca, figured by Cuvier, Mémoires du Muséum, tom. ii., 1815, pl. i., fig. 9, and described by him, l. c. pp. 29, 30 ; or Mémoires pour servir à l'Histoire et à l'Anatomie des Mollusques, Mémoire sur les Ascidies, pp. 20, 21. The mouth is similarly situated at the bottom of the branchial sac in Ascidia Scabra, which differs from this species, Ascidia Affinis, in being smaller and rougher externally.

\section{Broad-Leafed Hornwrack (Flustra Foliacea).}

A SEAWEed-LiKe Polyzoon, very common and universal in European seas. The Polyzoary is flexible, of silk-like texture and appearance, ordinarily forming erect fronds but occasionally loosely adnate to marine objects. The cells, which by their mutual apposition in these social animals form the Polyzoary or Coenoecium, are arranged multiserially in parallel longitudinal rows on both sides of the frond they make up. The individual cells are ovoidal in shape, and have from four to eight spines set round their larger end, in which their mouth, which is crescentic and protected by a lip, is placed subterminally. The avicularium and mandible are semicircular and immersed. There are no vibracula. The polypide itself is, when contained in its cell, bent several times upon itself. Its tentacles are very long. It resembles the great majority of fresh-water Polyzoa in the absence of a gizzard. The ovicell, a sort of marsupial pouch, analogous, in respect of function, if not homologous, with the cloaca of the Ascidians, and continuous with the perivisceral space through a passage at the upper and back part of each cell, is inconspicuous in this species, being deeply immersed. The ova themselves are of a striking colour, and, as in other Polyzoa, are set free by the death and disruption of the parent polypide.

For excellent figures of the external and internal anatomy of this animal, see Van Beneden, Recherches sur l'Anatomic, la Physiologie, et le Développement des Bryozoaires qui habitent la côte d'Ostende, Mem. Acad. Royale de Bruxelles, tom. xviii., 
1844, pp. 32-34, pl. iv., figs. I I-17. For similar figures of another marine Polyzoon, Acamarchis Avicularia Lmx. Bugula Avicularia, Busk. Brit. Mus. Cat. p. 45; see Bronn's Klassen und Ordnungen des Thierreichs, iii. 1, Taf. v., fig. 3, A.B.C.D. For figures of the Hippocrepian fresh-water species, see Allman, Fresh-water Polyzoa, pl. ii. et passim.

For an account of the zoological characteristics of the class, and especially of the marine subdivision of it, see Busk, 'Fossil Polyzoa of the Crag,' Palaeontographical Society's Memoirs, I859, part 12; and British Museum Catalogue of Marine Polyzoa, 1852 , where, at pp. 103-108, an account of the structures above mentioned under the names of 'vibracula' and 'avicularia,' will be found.

For the microscopic anatomy of the fresh-water Polyzoa, see Nitsche, Reichert und Dubois Reymond's Archiv., I868, p. 465; and for that of the nerve-system especially, see Taf. xiii. fig. 23. For similar observations, see Alpheus Hyatt, Proceedings of Essex Institute, Salem, Mass., U. S. A., vol. iv. No. v., 1864-1 868.

For remarks as to the homologies and affinities of the class to the Brachiopoda, and also to other Molluscan classes, see Lister, Phil. Trans. I834, p. 385 ; Farre, Phil. Trans. r837, p. 417 ; Hancock, Phil. Trans. 1857, p. 849; Allman, I. c. pp. 43-55; and Quarterly Journal of Microscopical Science, January, I869, p. 62; Hyatt, l. c. vol. v. No. v., pp. I 50-157; Fritz Müller, Reichert und Dubois Reymond's Archiv. 1860, p. 79, where at Taf. i. fig. 2, a larval Brachiopod is represented with four arms borne upon a retractile proboscis ending in an oval protuberance closely similar to the epistome of the Hippocrepian Polyzoa.

For the identification of the Polyzoa, as belonging to the subkingdom Mollusca, see Audouin and Milne-Edwards, Ann. Sci. Nat. tom. xv. I828; Milne-Edwards, ibid. tom. vi., p. I6, 1836; Recherches Anatomiques, Physiologiques et Zoologiques sur les Polypiers de France, I 841-1 844, 8vo.

For the literary history of the nomenclature of the class, see Busk, Ann. Nat. Hist. x., 1852 . 


\section{Bugle Coralline (Salicornaria Farciminoides).}

THE Polyzoary is plant-like, erect, calcareous, dividing dichotomously, the internodes articulating by flexible chitinous bands instead of being continuous as in the preceding specimen. It is ordinarily about three inches high, and is attached by a fibrous branching root-like base. The cells are arranged quincuncially round an imaginary stem, and divide the surface of the internodes which they make up, into more or less regularly rhomboidal or hexagonal spaces bounded by the raised borders of the cells. The mouth has a tooth on each side at its orifice within its lowest border. The avicularia are distinct from and placed above the cells, but not regularly. Their rostrum is immersed, and their mandible semicircular. No vibracula are present in this species. The ovicells, which are immersed as in the preceding specimen, have here their position frequently identifiable by the presence of a perforation above the mouth.

For specific characters, see Busk, British Museum Catalogue of Marine Polyzoa, pp. 16-18, pl. lxiv., fig. 3; Fossil Polyzoa of the Crag, p. 23 ; Johnston's British Zoophytes, p. 355, 2nd ed.; English Cyclopaedia, article 'Polyzoa,' p. 420, fig. 4; Cam. Heller. Verhand. Zool. Bot. Gesellschaft im Wien, bd. xvii,, I 867, p. 85 .

\section{Larva of Death's-head Moth}

\section{(Acherontia Atropos).}

THIs and the following five preparations are intended to illustrate the various points of external and internal anatomy, such as the presence of prolegs, the absence of wings, the rudimentary condition of the reproductive system, the shortness, large calibre and straightness of the digestive tract, the great development of the salivary glands and of the fat body, in which the larva or pupa, or both differ from the perfect insect. The caterpillar of the Death's-head Moth is the largest of all European species. The greater or less homonomy of its segments from head to tail, and the fact that the segmentation of its legs and antennae is not very 
obvious to the unassisted eye, give the larva somewhat of a vermiform appearance; and together with the absence of wings and of the dense scaly covering clothing both wings and body in the adult Lepidopterous insect, put it into sharp contrast with the imago. Each of the three segments immediately posterior to the head carries with them a pair of quinquearticulate legs. The fourth and fifth post-cephalic segments have no appendages, but, like the first and unlike the second and third, are pierced on each side by a respiratory foramen known as a 'spiracle' or 'stigma.' 'The sixth, seventh, eighth, and ninth segments possess spiracles, and carry sucker-shaped motor organs, armed with spines, which are known as 'pedes spurii' or 'prolegs.' The tenth and eleventh segments are furnished with spiracles but have no prolegs; the eleventh carries on its dorsal surface a tuberculate horn characteristic of the family Splingidae, with the exception of a few species, one of which is North American; and representing the funis of the embryo. Posteriorly to this horn and between it and the triangular supra-anal valve are two half-ring-shaped ridges, reaching from the level of the spiracle of one side over the dorsum to the level of the spiracle of the other. They appear to be distinct from the ventrally-placed half-ring which carries the posterior or fifth pair of prolegs, and it is possible therefore that the presence of three segments may thus be indicated posteriorly to the eleventh, whereby fourteen, the typical number of post-cephalic segments in Arthropoda, would be made up. The greater part of the covering of the head is made up by two large scales, the 'parietal scales' of Lyonet, the 'procephalic lobes' of Huxley;' the 'Scheitelplatten' of the German authors referred to below, corresponding to the 'epicranium' of the imago. Anteriorly a triangular plate, the 'frontal scale' of Lyonet, the representative of the 'labrum' and 'clypeus' of the perfect insect, is interposed between the procephalic lobes. These lobes or scales are each divided into two nearly equal halves by a dark stripe, on the inferior termination of which are to be found the six ocelli. Mesially to the lower part of the area occupied by the ocelli, the parietal scales give articular origin to the antennae, and more mesially again we have on either side the articulation of the mandible. From the position thus held by the antemnae of the larva relatively to that of the organs of the mouth on the one hand, and to that of the antennae of the imago 
on the other, they have been supposed by Zaddach to correspond to the inferior or posterior pair of antennary organs of the Crustaceans, the so-called 'antennae,' whilst the antennae of the imago correspond with the superior or' anterior antennary organs or ' antennules' of the Crustaceans. The structures corresponding to the maxillae and labium of such insects as the Coleoptera and Orthoptera, and to the two pairs of maxillae in Crustaceans, are here more or less fused into a horizontal plate which forms a sort of operculum to the mouth, and carries three segmented organs on its free edge. Of these three organs, the one which is placed mesially is the labium, modified so as to give exit to the common duct of the two silk glands; and the organs placed one on either side of this 'spinneret' are the maxillae, modified so as to serve not only in the prehension of food, but also, in many larvae, in the construction of the cocoon. The two pairs of appendages which this compound organ thus represents in the larva, retain more of their typical distinctness in the imago, where they take the shape of a spiral proboscis, and a largely developed and palpigerous labium. On the other hand, the largely developed mandibles of the larva are represented by merely rudimentary organs in the imago, reversing thus the history of the posterior oral appendages. If the eyes be taken as indicating the presence of one segment, the antennae of the larva a second, and those of the imago a third segment, to which three other segments would have to be added for the mandibles, maxillae and labium, the head of the insect will be seen to consist, like that of the typical Arthropod, of six segments indicated by as many pairs of appendages ; and the six cephalic segments, together with the three thoracic and eleven abdominal, will make up the entire number of all the segments of the body to twenty. In their possession of prolegs and of bright colours upon the integument, the larvae of Lepidoptera differ from those of Coleoptera and Hymenoptera Geunina, which they resemble, as they do also those of the Diptera and Neuroptera, in passing into a state of perfect quiescence as pupae.

For the typical number of segments in the Arthropoda, see Huxley, 'On the Agamic Reproduction and Morphology of Aphis,' Limn. Soc. Trans., vol. xxii., 1858, p. 225.

For the indication of a distinct cephalic segment which the presence of the eyes furnishes, see Zaddach, Die Entwickelung 
und Bau der Gliederthiere, pp. 78, 87, 88; Rathke, Morphologie, pp. 126-I 27.

For the antennae of the larvae in relation to those of the imago, and the antennae and antennules of Crustacea, see Zaddach, 1. c. pp. I $3,86,89$.

For a history of the metamorphoses of Lepidoptera, see Westwood, Introduction to the Modern Classification of Insects, vol. ii., pp. 310-32I.

For figures of the oral organs of the Larvae of Lepidoptera, see Lyonet, Traité Anatomique de la Chenille qui ronge le bois de Saule, pl. i. ii., and p. 59 for functions.

For those of the imago, Savigny, Mémoires sur les Animaux sans Vertèbres, vol. i., pl. i. ii. iii.

\section{Pupa of Death's-head Мoth}

\section{(Acherontia Atropos),}

Showing the form of chrysalis known as 'obtected,' or better, as ' larvate' or 'signate.'

IN this form the external organs of the future perfect insect are more or less obscurely distinguishable beneath the hard elastic membrane in which they are inclosed instead of being free as in the so-called 'exarate' or. 'liberae' pupae of Coleoptera and Hymenoptera, and which is a product of the hardening of a secretion instead of being merely the dried integument of the maggot, as in the 'coarctate' pupa of many Diptera. The conical form of the pupa case is characteristic of the Heterocerous Lepidoptera, in contradistinction to the angular form of the Rhopalocerous. The apical portion of the cone, the 'cremaster' of Kirby and Spence, is made use of by the pupa when it works its way up from the chamber, six inches or so deep in the ground, before entering upon the imago-stage of its existence. In possessing thus a power of motion in the last stages of their pupa-life, the Lepidoptera resemble the Phryganeodeae or ' caddis flies,' as they do also in many other particulars, though the chrysalis of the family just mentioned differs from that of the Lepidoptera in being 'free' or 'exarate' like that of the beetles and bees. Seven spiracles are seen on either side upon the abdominal segments; 
an eighth, which belongs to the most anteriorly placed of the abdominal segments, is concealed by the wing-case on either side. The ninth abdominal ring is marked by a depression on either side of the middle ventral line, the lines limiting which extend into the interspace between it and the eighth segment, and indicate thus the normal position of the outlet of the generative glands. Posteriorly to this symmetrical depression, and separated from it by the entire breadth of the tenth segment, is seen an azygros depression with an antero-posterior direction indicative of the true position of the anus, which is in relation with the eleventh abdominal segment and its appendages, one of which the apical horn may be taken to represent. The dorsal part of the mesothorax or 'mesonotum' is largely developed; and the wing-cases are seen to take origin along either side of it, as well as from the much smaller ' metanotum,' which is represented by a dumb-bell-shaped mass, constricted mesially and rugose on the surface. The 'pronotum' is much larger both relatively and absolutely than in the perfect insect, and forms a transversely elongate oval mesially carinate shield. The head-cover is divided by faintly marked transverse lines into three portions; the most posterior of which gives origin to the 'ceratothecae,' and appears to correspond to the 'parietal scales' of the larva and the 'epicranium' of the imago, whilst the two anterior portions correspond to the 'frontal scale' of the larva, and the posterior and anterior 'clypeus' of the imago. The middle division of the head cover is the largest, the anterior is minute and the smallest of the three. In the middle line inferiorly between the 'ophthalmothecae' is seen the 'glossotheca' in which the 'spirignatha' or 'antlia' of the future imago is lodged; and externally to it on either side upwards, the 'podothecae,' ' ceratothecae,' and 'pterothecae,' lodging respectively the future feet, antennae, and wings.

For the relations of the posterior segments of the abdomen to the generative and anal outlets, see Lacaze Duthiers, Annales des Sciences Nat., I853, tom. xix., Ser. iii., p. 220; Huxley, Linn. Soc. Trans., r 858 , vol. xxii., p. 230.

For the nomenclature adopted by various writers for the various parts of the external skeleton, see Newport, Cyclopaedia of Anatomy and Physiology, Article 'Insecta,' pp. 885, 913; and 
for a fuller vocabulary, Burmeister's Manual of Entomology, translated by W. E. Shuckard, chaps. ii. and iii.

\section{Imago of Death's-head Moth \\ (Acherontia Atropos).}

The development of wings and the differentiation of the body into three great heteronomous divisions, the head, the thorax, and the abdomen, are the most prominent external points in which the perfect insect differs from the imago. The scaly covering of the body and wings, the great development of the eyes, the somewhat smaller but still not inconsiderable relative increase of the size of the antennae and of the legs, the replacement of the fused maxillae and labium of the larva by a spiral sucking proboscis, and a labium provided with large palpi, and the reduction of the actively functional mandibles to purely rudimentary structures, are almost equally obvious points of difference between the larva and the imago of a Lepidopterous insect. The maxillary palps are, as in many Hymenoptera, and unlike what we observe in Diptera, very small as compared with the labial. The prothorax is much reduced in size. When viewed from above, the dense covering of scales having been removed, it has the appearance of a narrow ring, whence its technical name of ' collar,' interposed between the head in front and the largely developed mesothorax behind. The pronotum carries laterally a pair of vesicular scales covered with hairs, and known as 'patagia.' They are characteristic of the order, and distinct from the 'tegulae' or wing-covers, with which they have been sometimes confounded, and which are carried by the mesonotal praescutum, and though very largely developed in the Lepidoptera, are not peculiar to them.

As points of more or less classificatory importance, mostly with reference to the differences observable as existing between the diurnal and nocturnal Lepidoptera, may be noted, firstly, the termination of the multi-articulate antennae in a filament, not in a club; secondly, the existence of a ' retinacular' apparatus, whereby a spinous outgrowth on the under surface of the base of the hinder wing connects it with an annular ligament similarly developed on the under side of the anterior wings; and thirdly, the two pairs of spurs on the inner side of the posterior tibiae. The family 
Sphingidae have no ocelli, and the genus Acherontia has the spiral proboscis much shorter than other genera belonging to the family.

In their possession, when larvae, of provisional organs, of which no traces are left in the perfect insect, the Lepidoptera resemble the Neuroptera and Hymenoptera Phytophaga, amongst the orders distinguished by quiescence in the pupa-stage, and said consequently to have a 'perfect metamorphosis,' as also the Orthoptera Amphibiotica amongst Ametobolous insects. The true Hymenoptera, on the other hand, and the Coleoptera, with a ferv exceptions, possess no provisional organs in this larval state, though they pass into perfect quiescence as pmpae. This latter condition therefore should be taken as the essential characteristic of a 'perfect metamorphosis.'

For the characteristics of perfect and imperfect metamorphosis, see Gerstaecker, Klassen und Ordnungen des Thierreichs, bd. v., p. 189 .

\section{Larva of Goat Moth (Cossus Ligniperda),}

Dissected so as to show the various internal organs of vegetable life, and the points in which they differ from those observable in the perfect insect.

THE dorsal integuments have been divided down the middle line, and turned outwards on either side, together with the muscles which were in connection with them. The greater part of the bodycavity is occupied by lobulated masses of adipose tissue, known as the 'fat body,' or 'rete,' which disappear almost completely in the adult insect of the orders with a perfect metamorphosis. In the middle line we see the digestive tract, which passes, without forming any convolutions at right angles to the long axis of the body, from the mouth to the anus. Its most anterior segment, seen in this Preparation, is the transparent-walled oesophagus upon which is seen the highly developed nervus recurrens. This nerve is connected, anteriorly, with a series of three ganglia which are placed one behind the other, and correspond with the single ganglion frontale of some insects; and, posteriorly, at the junction of the oesophagus and stomach, with a plexus into which the two lateral stomato-gastric nerves enter. The stomato-gastric nerves undergo less change in metamorphosis than perhaps any other system of 
the larva. The stomach succeeds to the oesophagus, from which it is readily distinguished by the opacity of its walls and the tracheae which are distributed to it in great abundance. Bands of oblique muscles are observable decussating superficially, and longitudinal muscles lying at a deeper level in its walls. The tubular renal organs, the so-called 'Malpighian vessels,' are seen upon the posterior half of the stomach, forming two loops on either side, the mesially placed being shorter than the more externally placed loops, and having its limb which passes towards the anal end of the body bifurcated, whilst the returning limb of each outer loop remains undivided. The two loops on each side thus form three trunks which form an intricate interlacement in the posterior part of the body-cavity, on either side of the intestine. The two stems themselves fuse on either side into a single trunk, which opens into the intestine a short way below the pylorus; and as the product of these tubules is uric acid, the portion of intestine below their opening may be regarded as excretory, and that intercepted between their opening and the pylorus, as corresponding functionally with the small intestine. The point however at which these vessels open into the digestive tract may vary, in different orders, from the immediate vicinity of the pylorus to the immediate vicinity of the anus. The looped portions of these organs are of larger calibre than the more complexly convoluted posterior portions; from which they differ also in being smooth exteriorly, and cylindriform, instead of having a moniliform appearance, from being beaded over with sacculi. The rectum, which is considerably longer than the small intestine, has its external surface divided into six longitudinal strips by as many muscular bands; and the spaces thus marked out are again subdivided by a very much larger number of very much smaller transversely running muscular bars. The long convoluted white tubes, the coils of which are seen to commence with a blind end on either side, about opposite the junction of the stomach and intestine, are the silk glands, and they pass to the under surface of the digestive tract, anteriorly, to end in a common duct opening in the modified labium or ' spinneret.' Underneath the coils of the silk gland of the left side, a large transparent walled bladder is seen, from the posterior end of which a tubular gland passes off to form the mass of convolutions called the 'quene du vaisseau dissolvant' by Lyonet in his elaborate mona- 
graph of the anatomy of this larva, and bent round so as to lie in apposition with the bladder into which it opens, and in the interval between it and the stomach. The bladder, with the posterior extremity of which this tubular gland is thus connected, opens anteriorly by means of a wide duct into the mouth; and the organ thus made up of a duct, a bladder-like receptacle, and a tubular gland, may be seen to correspond with the much smaller salivary glands of the perfect insect. Neither upon the fasciculi of tracheae which are seen passing inwards from the spiracles to distribute themselves to the viscera, nor upon the longitudinal canals connecting the stem whence these fasciculi spring, which may be seen here and there in the intervals left between the lobes of the ' fat body,' are there any vesicular dilatations developed in the larval state. This relatively inferior evolution of the respiratory system may be explained upon purely mechanical grounds, when we consider the comparatively sluggish movements of the larva, whilst the physiological necessity which exists during periods of growth and development for an active performance of the renal functions, will account for the large development of the Malpighian vessels here observable. And the all but complete absorption and disappearance of the 'fat body' at the end of the metamorphoses of metabolous insects, is to be explained by the need they have, especially during their period of existence, as pupae, for a large supply of force and matter, for the carrying out of the complex changes in, and the superadditions to, the larval organism which the arrangements of the muscles and the evolution of the reproductive organs in the imago may be taken as illustrating. Such differences in the digestive apparatus of the larva as those already spoken of (Prep. 25, p. 75) in the appendages of the oral segments, as the larger calibre and the lesser length of the digestive canal, as the absence of convolutions, and of a crop, and as the much larger size of the salivary glands, are obviously correlated with the differences existing between its mode of sustenance and that of the butterfly. The presence of a rectal coecum in the perfect insect, is to be noted as an additional point of contrast. The disappearance of the silk-glands during the pupa-stage is readily explicable by the fact, that all need for such organs ceases after the formation of the cocoon; and the condition of semi-fluidity to which the various organs of the pupa are reduced in the early stages of the 
period of quiescence, makes the method of their disappearance easily intelligible.

A monograph of great merit and detail has been written upon the anatomy of the larva of the Goat Moth, by P. Lyonet, Traite Anatomique de la Chenille qui ronge le bois de Saule, I762, in which excellent figures will be found of the digestive system in pl. v. xiii. xviii., of the respiratory in pl. x. xi., of the muscular in pl. vi. vii. viii., of the ganglia frontalia of the azygos stomato-gastric system, pl. xviii., for which see also Brandt, Ann. Sci. Nat., Ser. ii., tom. vo, 1836 , p. 99.

For the sources for the production of fat within the animal's body, see Voit, Zeitschrift für Biologie, Bd. v., Hft. i., p. 79, I869.

For the development of the 'fat body' in Lepidoptera, see Hermann Meyer, Zeitschrift für Wissenschaftliche Zoologie, i. I75.

For the absorption of it in the processes of growth and development, especially of the reproductive organs, see Peters, Carus, and Gerstaecker, Handbuch der Zoologie, p. I20, and Weismann, Die Entwickelung der Dipteren, p. 178 .

For the changes of consistence observable in the tissues and organs of the Lepidopterous pupa, see Newport, Phil. Trans., I832, p. 390 ; and for the much more extensive changes in the way of histolysis which appear to furnish an instance of ' free cellformation' on the one hand, and on the other to approximate the character of the metamorphosis of the coarctate dipterous pupae to that of 'alternation of generations,' see Weismann, l. c., pp. I35, I64, I76, 23I, 232, 239.

For the respiration and temperature of insects, see Newport, Phil. Trans., 1836,1837 .

\section{Larva of Privet Hawk Moth (Sphinx Ligustri),}

Dissected so as to show its nervous system.

THE dorsal integuments and the various organs of vegetative life have been removed; a black bristle has been passed through the nerve collar, and slips of blue paper placed under various parts of the chain of ventral ganglia. In the nerve system as thus ex- 
posed and prepared, twelve main ganglionic masses are readily detectible with the naked eye. The first of these is placed above the oesophagus, is divisible into two lobes by a shallow anteroposterior depression, and from its relation to the eyes and antennae, may be called the 'cerebroid' ganglion. The first sub-oesophageal ganglion, by the commissural junction of which to the cerebroid, the nerve collar is formed, is in closer proximity to the second than this is to the third, or the third to the fourth, or the fourth to the fifth. These five ganglia resemble each other in being more or less heart-shaped, the nerves they give off being directed forwards; the first of them supplies the organs of the mouth, and the other four those of the thorax. The first of these ganglia is represented in the developing Crustacean Astacus fluviatilis by three pairs of ganglia corresponding severally to the mandibles, the anterior, and the posterior maxillae, but, so far as is known, it is connate in the developing insect from the earliest periods. The second, third, fourth and fifth pairs of ganglia are distinct in development in both these animals; they are fused into a single ganglionic mass in the adult forms of both; the single mass thus formed may retain more or less distinct indications of its originally composite character, but in the insect it does not, as in the Crustacean specified (see Prep. 34), fuse with the similarly fused mass supplying the three true jaws. Thus the distinctness of the head of the insect from its thorax is preserved and reproduced in its nervous system, whilst the fusion of head and thorax in the Crustacean is similarly reproduced also. The fact so far as relates to the class Insecta is sometimes expressed by speaking of their brain as consisting of a sub-oesophageal as well as of a supra-oesophageal portion, or of a 'cerebellum' as well as a 'cerebrum,' the former of which is in connexion with a chain of ventral ganglia. As however the serial homology of the various ventrally-placed appendages of the articulate Neuropods is universally recognised, this nomenclature is less to be recommended than one which by numbering the segments of the nerve cord as is done here, enables us at once to see where correspondence has or has not existed, or been retained between the external and the internal organs. Though the line of division between the head and thorax of the insect, both in its larval and its perfect state, has thus a diastema in the ganglionic chain corresponding to it internally, which is not preserved in the 
rephalo-thoracic ganglion of the Crustacea; it is by no means invariably the case in other parts of the insect's organism, that a fusion or distinctness of external segments is reproduced internally by a fusion or segmentation of the chain of nerve ganglia. The sixth, seventh, eighth, ninth and tenth ganglia are more or less spheroidal in form, the two first disappear, the three last are retained in the adult insect. The eleverth ganglion is distinctly divisible into two lobes by a bilaterally symmetrical construction, representing thus, as also by the distribution of its nerves, the two ganglia, by the fusion of which it is composed. In the larvae of some insects, as, for example, Phalaena neustria, Dorcus parallelepipedus, and Corettra plumicomis, these ganglia retain as much or more of their typical distinctness, and even in the larvae of Muscidae, where the ventral cord is not itself segmented, eleven pairs of nerves are given off from it exclusively of those in connection with the jaws, indicating thus that the number of post-oral ganglia is twelve. The tenth, and the bilobed eleventh ganglia, appear to correspond to the six post-abdominal ganglia of Astacus fluviatilis; and the five ganglia from the fifth to the ninth, with the five ganglia in relation with the five pair of ambulatory limbs in the Crustacean. A slip of blue paper has been passed underneath the two diverging cords of commissure of the third and fourth post-oral ganglia, and we see in the intercepted space one of the systems of ' respiratory,' 'accessory,' or ' transverse' nerves, connecting itself with the larger ganglia of the ventral in much the same way as the 'ganglion frontale' and the 'lateral nerve ganglia' are connected with the cerebroid ganglia. The 'transverse nerves' of each inter-ganglionic space are not only connected with these larger ganglia, but also with each other, so as to form a continuous chain overlying the ventral cord. From this chain, nerves pass to the tracheae and spiracles, and also to the muscles which act upon these organs and upon the wings. One of the large longitudinal tracheae is seen on the right side of the future thorax, in which part of the body the respiratory system attains ultimately its greatest size and importance, and has the system of transverse nerves similarly evolved in correlation with it. One of the diagonal muscles is seen passing through the interval between the cords connecting the second and third ventral ganglia. This and the succeeding interspace are represented in the perfect insect 
by a single oval foramen, the third post-oral ganglion having disappeared, and the mass made up by the fusion of the fourth and fifth, having closely approximated to that representing the second.

For a detailed account of the metamorphoses of the nervous system in the Sphinx Ligustri, resulting in the replacement of the eleven ventral ganglia of the larva by one sub-oesophageal, two thoracic and four abdominal in the imago, see Newport, Phil. Trans., I 832 and 1834; or, Cyclopaedia of Anatomy and Physiology, Article ‘ Insecta,' p. 962; Herold, ‘ Entwickelungsgeschichte der Schmetterlinge,' pp. 58, 59; and description of Tab. ii., where he speaks of the ventral ganglia of the larva of Papilio Brassicae as being twelve in number; the commissural cords between the eleventh and twelfth being absent. For accounts of the first appearance of the nerve system, in the developing embryo of various orders of insects, see Weismann, 'Entrvickelung der Dipteren,' I864, pp. 38, 82, I90, I92; Rathke, 'Zur Morphologie, Reisebemerkungen aus Taurien,' I837, pp. I23-127; Léon Dufour, Ann. Sci. Nat., Ser. ii. tom. $18, \mathrm{pl}$. iv. and v. See also, for the relatively late period at which the nerve system is developed and differentiated from the structures which underlie it, Rathke, 'Bildung und Entwickelung des Flusskrebses,' p. 85 ; Zaddach, 'Die Entwickelung und den Bau der Gliederthiere.'

For development of the first sub-oesophageal ganglion, see Metschnikow, 'Embryologische Studien an Insecten,' p. 79, Taf. xxx., fig. 33; Zeitschrift für Wissenschaftliche Zoologie, Bd. xvi.

For the 'nervi transversi,' see Newport, 1. c. 1834, p. 401 ; Leydig, Vergleich Anat. p. 205, Taf. vii. fig. I, Taf. ix. fig. 2.

For descriptions and figures of the systems of tracheae and of muscles, see Lyonet, Traité Anatomique de la Chenille qui ronge le bois de Saule, 1762; and Newport, Phil. Trans. 1836 ; and for descriptions of the variations in the muscles of the larva of Pygaera Bucephala, see Lubbock, Linn. Soc. Trans., vol. xxii. pt. iii., I 857 .

For the relations existing between the external and internal structures, see Burmeister's ' Manual of Entomology,' translated by W. E. Shuckard, p. 28r ; Blanchard, Ann. Sci. Nat., Ser. iii., tom. v., 1846, p. 281 . 


\section{Common Cockroach (Periplaneta Orientalis), \\ Female,}

Dissected so as to show its digestive, renal, nervous, and reproductive systems.

THE greater part of the dorsal integumental system has been removed by incisions carried along either side; the short elytron, the only representative of the wings in the females of this species, has been left in situ on the right side, where it is seen reaching just far enough back to overlap a part of the metanotum; the greater part of the fat body which abounds in the interspaces between the viscera, especially in the abdominal region of these insects even in their adult state, has been removed, and the digestive tract fastened out upon the left side of the body. The upper segment of the digestive canal, seen in this preparation, is the crop, which is about three-fourths of the entire length of the body, and is distended with food. The entire length of the digestive tract would be little more than trvice that of the body, and this comparative shortness may be considered as compensated for partly by the character of the food of this species, and partly by the large quantities which, as seen in this preparation, they devour. A muscular subconical gizzard, an organ which is not developed in the larvae of insects with a perfect metamorphosis such as the Coleoptera, even in species which have it when adult, but is developed in the larvae of Orthoptera, including Libellulidae, follows after the crop. Eight coeca are arranged in a whorl round the commencement of the 'chylific stomach,' and a very much larger number of very much longer and more slender tubes are similarly arranged around its lower end. The gizzard does not open directly into the chylific stomach, a narrow neck of about the same length as the gizzard itself intervening between the apex of the gizzard and the zone marked out by the eight coeca just mentioned. These coeca appear, from the facts that they often contain a yellowish fluid, and that they never afford lodgment for particles of food even when the digestive tract is distended, to be analogous to the liver of higher animals, whilst the existence of uric acid in the other set of tubules already mentioned, the so-called 'Malpighian vessels,' would appear to justify 
us in speaking of them as 'renal' organs. The colon, which is bent upon itself, and has its external surface beaded over with granulation-like pouches by the action of its muscular coats, is connected with the lower end of the chylific stomach by a short segment of small calibre, and of similar length to that which connects the upper end of the chylific stomach with the larger end of the gizzard. The colon ends in a rectum, which is divided into six longitudinal areae by as many longitudinal muscular bands, alternating with internally-placed lamelliform projections of the inner coats of the intestine. A somervhat similar arrangement has already been noted in the larva of the Goat-moth (p. 80); and in the larvae of certain Libellulidae the supply of tracheae to the ridged surface thus constituted, is so abundant as to convert it into a respiratory organ. On either side of the junction of the crop to the oesophagus is seen the bilobed salivary gland.

On the right side in this preparation is seen the salivary receptacle, a pellucid bladder, reaching a little farther back than the gland. The duct from this receptacle fuses with that of its fellow of the opposite side, and into the common duct thus formed a second duct, formed by the junction of the ducts of the two glands, is received, so that all the four ducts find an outlet into the mouth by a short common canal.

An azygos nerve, the nervus recurrens, from the 'ganglion impar' or 'ganglion frontale' of the stomato-gastrie system, is seen passing from before backwards to join a triangular ganglion placed a little way in front of the middle point of the dorsal median line of the crop. From this ganglion a nerve passes off on either side to the posterior extremity of the crop, and may be seen to have an elongated thickening developed upon it at the lower third of its length. A third nerve, not seen in this preparation, has been described as passing off from the centrally-placed triangular ganglion to the salivary glands. The ganglion impar, from which the nervus recurrens takes origin, is not seen in this preparation, being situated anteriorly to the cerebral ganglia, with which it is connected by delicate filaments joining it just internally to the large antennary nerves. The paired ganglia of the stomato-gastric system are situated some way posteriorly to the cerebral ganglia; and the short nerve seen on either side of the nervus recurrens, just where the salivary gland abuts upon the crop, is given off by the posterior 
of the two pairs of ganglia, of which the symmetrical portion of the stomatogastric system consists, in this as in most other insects. The paired ganglia are connected with each other, with the cerebral ganglia, and finally with the nervus recurrens, which structure, horvever, together with the ganglia in connection with it, constitutes in these and most other insects by far the most important part of the stomato-gastric system.

In the abdominal region are seen six ganglia corresponding to the six posterior ganglia of the Lepidopterous larva. The two first of the six, which correspond to the two which become obsolete in the butterfly, are more closely apposed to each other than are any of the succeeding four. The last ganglion is more or less cordiform, and larger than those which precede it, and gives off nerves to the lower portions of the generative and digestive tubes. The ovaries are of the kind called 'verticillate' by Müller; and consist of eight moniliform tubes on either side, which are connected anteriorly with the dorsal element of the prothorax by means of a suspensory ligament, made up of the fusion of filaments given off from their apices; and which inferiorly open upon the convex end of a pear-shaped oviducal infundibulum, as ordinarily figured. The infundibula of the two sides which may be seen, when undistended, to have the egg-tubes inserted laterally as in other Orthoptera, pass beneath the terminal nerve structures and the 'oviscapt' to form a common vagina, which opens in the interval between the eighth and ninth abdominal segments. Immediately posteriorly to the last nerve ganglion, in the angle limited by its branches, we may see with a lens the receptacula seminis, which take the shape of two short contorted coeca, one of which is rather larger in calibre than the other, and which open by means of a single short duct in the sternum of the ninth segment. The 'colleterial' or 'sebaceous' glands, which consist of numerous delicate tubules of much greater length than the receptacula seminis, open by two ducts in an orifice upon the sternum of the tenth segment. The sternum of this segment developes the smaller and inner processes of the 'oviscapt,' whilst that of the ninth developes the elongated exterior pieces of that apparatus; and as the lateral anal valves represent an eleventh segment, we have thus the typical number of the segments of the Arthropodous abdomen made up. The receptaculum seminis is ordinarily in insects an azygos vesicle, and it is 
possible that the aberrant arrangement observable in the Blattinae may foreshadow the more usual one in which a single receptaculum seminis has a gland of a secretory character superadded to it. And, as the number of the 'colleterial' tubules is very considerable, they may be taken, perhaps, to correspond not only to the colleterial glands of other insects, but also to their so-called 'scent glands.' The food, and to a considerable extent the habits, of the larvae and of the adult insect being identical in this family, we find little difference existing between their internal structural arrangements beyond that which a greater prominence in the evolution of the reproductive apparatus constitutes. The retention of the 'fat body' is obviously correlated with the absence of any period of quiescence and abstinence from food, such as that of the pupa stage of Metabolous insects, and of the need for a supply of force which the changes gone through by those classes entail. Externally the imperfect insect in the class Orthoptera does not, with the exception of the Orthoptera Amphibiotica, such as the Libellulidae and Ephemeridae, differ from the adult by the possession of any provisional organs of which the perfect insect is destitute, but contrasts with it almost exclusively by inferiority of size, by the smaller number of facets in its corneae, by the absence of wings, and in this family by a greater lightness of colour. Great differences, however, exist as to this latter particular between adult individuals of this species.

For a monograph of the order Orthoptera, see the Latin work, 'Orthoptera Europaea,' Auctore Leop. Henrico Fischer, Lipsiae, 1853 , where a general account of the external and internal anatomy of the entire order will be found, pp. 5-32, and an account of the anatomy of the family Blattinae will be found, pp. 84-88. See also Léon Dufour, Recherches Anatomiques et Physiologiques sur les Orthoptères, 1834, Mem. Acad. Sci., tom. vii., des Savans Étrangers; also in 4 to, Paris, 1841. At pl. v., figs. 44-47, good figures of the digestive and reproductive systems are given. See also Pl. vi. infra, with description.

For a monograph on the digestive and renal systems of this insect, see S. Basch, Sitzungsberichte, Kaiser Akad. Wiss. Wien, vol. 33,1858, p. 234, Math. Nat. Classe.

An account of the natural history, as well as of the anatomy of the common Cockroach, may be found in a short monograph, 
entitled 'Beiträge zur nähern Kenntniss von Periplaneta (Blatta) Orientalis,' von C. Cornelius, Elberfeld, I853.

For an account of the various glands superadded to the essential organs of the female reproductive apparatus, see Siebold, in Müller's Archiv. for 1837 , p. 393 seqq., and for their arrangement in Blatta (Periplaneta) Orientalis, p. 408. For figures of a female reproductive apparatus essentially similar to that here described, see Lespés' account of the Termes Lucifugum, Ann. Sci. Nat. Ser. iv., Tom. v., Pl. 6, fig. 24-27. For the orifices of the various ducts in the reproductive apparatus, see Huxley, Linn. Soc. Trans., vol. xxii. p. 231. For the 'suspensory ligament' of the ovary, see Stein, 'Vergleichende Anatomie und Physiologie der Insecten,' pp. 36, 4I-43; Müller, Nova Acta, xii., pt. ii., p. 578. For the composition of the 'oviscapt' and the number of the abdominal somites, see Lacaze Duthiers, Ann. Sci. Nat., Ser. iii., tom. xvii., I 852, p. 227 ; tom. xix., pp. 229-233, and Huxley, Linn. Soc. Trans., vol. xxii., I 858, p. 23 I.

For the development of the fat body independently of the yolk, see Elias Metschnikow, 'Embryologische Studien an Insecten,' p. 73, and for its connection with the production of phosphorescence in such insects as the Lampyris splendidula, see Leydig, 'Lehrbuch der Histologie,' p. 342.

For a description, with figures, of the stomatogastric nervous system, see Brandt, Ann. Sci. Nat., Ser. ii., tom. v., $183_{6}^{6}$, p. 103 , pl. iv., figs. 4,5 .

For Bibliographical references, see Scudder, Smithsonian Institution's Catalogue of Orthoptera, Washington, 1868, pp. I7-63.

\section{Common Crayfish (Astacus Fluviatilis), Female.}

This Crustacean's body consists of two great divisions, the so-called 'cephalo-thorax,' covered dorsally and at the sides by a carapace, and carrying fourteen pairs of articulated appendages, and the post-abdomen consisting essentially of six definitely annulate and calcified segments, to the posterior one of which a powerful natatorial organ, the 'swimmeret,' is articulated. The 
cephalo-thoracic carapace again is divisible into two regions, an anterior and a posterior, by the well-marked curved line with its concavity looking forwards, which is known as the 'cervical suture.' The anterior portion of the carapace is called the 'cephalostegite;' and the posterior the 'omo-stegite;' inasmuch as an examination of the relation of the inner aspect of the cervical suture to the hindmost of the three pairs of jaws, that is to say, to the most posterior of the cephalic appendages, sherws that the anterior portion of the carapace corresponds with the head, and the posterior with the post-cephalic segments. The crayfish furnishes an excellent example of the general law that every segment carries an appendage in the Crustacean, the first post-abdominal segment in this (female) specimen being the only segment in which a distinct pair of appendages is not readily recognizable. The pedunculate position of the eyes in the Decapodous Crustaceans makes it easy to understand, even without a reference to the history of development, or to instances of abnormal replacement of the eyes by articulated appendages ${ }^{\circ}$, how the eyes may be regarded as homologous with articulated appendages; and that the eyes and antennae do not really belong to the tergal aspect of the anterior cephalic segment, may be shewn not merely from the history of the reflection upwards and backwards of the developing cephalic blastoderm, but also from the direction and relations of these three pairs of sensory appendages in such Crustaceans as the Squillina. With the history of the relations of these organs in the developing Astacus, or with that of their disposition in the family just mentioned, before the mind, it is easy to see how the ophthalmic peduncle may be spoken of as the most anterior of the appendages, and as marking out the most anterior of the segments of the body. Next in order to the ophthalmic peduncles come the ' antennules,' consisting, as usual in Crustacea, of three basal joints, succeeded by a multi-articulate flagelliform element, which is here double. The 'antennules' are said to correspond to the antennae

- See A. Milne-Edwards, Comptes Rendus, vol. lix., p. ү10, f, 1864. It may be added that the pedunculate position of the two centrally-placed eyes in certain Ephemeridae, for which see Westwood, Modern Classification of Insects, pp. 25, 3r, De Geer, Histoire des Insectes, viii., pl. 18, tom. 2, fig. 10; Kirby and Spence, pl. xxvi, fig. 39, is, when we consider the many Crustacen affinities of the order Orthop. tera, not without significance. 
of perfect insects; in some Isopoda, however, which in many points approximate to insects, they are rudimentary. The inner of the two antennulary flagella is the smaller, and correspond to the structure described in other Crustacea as a 'secondary appendage.' Posteriorly, and a little externally to the antennules, come the antennae, each of which consists of a single multiarticulate flagellum carried by a series of five basal joints, the second one of which, if we count the sternal or proximal joint as the first, carries the representative of the appendages which are developed early upon this joint, but are subsequently aborted in Carcinus maenas, in the shape of two scales, one much the larger, somewhat of the shape of a short wide knife-blade, the other minute, prolonged into a spinous point externally, and articulating internally with the fourth basal segment. A comparison of the five basal joints of the antenna with the five basal joints of such a typical seven-jointed appendage as any one of the four posterior ambulatory legs in the Astacus, will leave no doubt as to their correspondence; and the multi-articulate flagellum will thus come to be the homologue of the two terminal joints of those appendages which are known as the 'propodite' and 'dactylopodite,' and are sometimes supposed to correspond to the 'tarsus' of insects. The proximal joint of the antenna has a conical process developed on its inferior surface, internally to the apex of which there exists an orifice leading into the antennary gland. On the triangular space between these two conical processes which is known as the 'epistoma,' and is constituted by the sternum of the antennary segment, are seen lying the anterior extremities of the palpiform exopodites of the two anterior maxillipeds, which correspond to the two anterior thoracic legs of insects. The posterior pair of maxillipeds have been displaced a little backwards, so as to give a better view of the two other pairs of foot-jaws, and of the three pairs of jaws which they partly conceal; though they never form for them, either in Macrurous or Anomurous Decapods, such a perfect operculum as they do in the Brachyurous. Posteriorly to the 'epistoma,' we see the upper lip or 'labium,' and between it and the first pair of thoracic appendages, or 'maxillipeds,' we have the three cephalic appendages essentially concerned with the prehension of food, and assisted in that function in the Hedriophthalmatous or fourteen-footed Crustaceans by two, and here in 
the Decapods by all three pairs of thoracic limbs. Of the three true jaws the most anteriorly placed, the so-called 'mandible,' carries a tri-articulate palp with an expanded terminal joint, and corresponds as a whole to an ambulatory leg, or to the endopodite of a foot-jaw. The palp, as being of great use in directing floating food towards the mouth, is rarely absent in Crustacea, except in the terrestrial Isopods and Amphipods. The basal portion of the mandibular appendage $t$ appears to correspond to the four basal joints of the ambulatory legs; and it may be remarked that the denticulation and anchylosis of the second and third segments of the third pair of foot-jaws afford an instructive example of transition towards the modification of the basal segments seen in the mandible. The tro pairs of foliaceous maxillae, the posterior one of which remains mesially divided, probably in relation to the ingestion of floating food, and does not form a 'labium' as in air-breathing Arthropoda, are not seen in this preparation, being closely appressed by the foot-jaws in apposition with them. Of the five pairs of ' ambulatory' or ' abdominal' legs, whence the order Decapoda take their name, the first has its two terminal joints or tarsus modified, so as to form a large pair of pincers, by having the posterior distal angle of the penultimate joint, or propodite, prolonged so as to be parallel with and commensurate with the dactylopodite. Similar but smaller pincers are developed similarly upon the second and third pairs of feet; the fourth and fifth are not so armed, the penultimate joint not being prolonged beyond its distal articular surface. It may be noted that the chela of the Scorpion, which bears a considerable resemblance to the largest of the three chelae of the Astacus, has its pincer-like portion somewhat differently constituted, the anterior or interior angle of the propodite being produced instead of the posterior or exterior; and the smaller of the two blades of the prehensile organs lying exteriorly, instead of interiorly as in the Crustacean. The large pincers of the scorpion are homotypical, as representing the two terminal joints of an appendage with the large pincers of the crayfish, but they are not

t See figure of edentulous mandible of Matuta Victor in 'Règme Animal,' Crustacés, pl. vii. fig. i. c., where the palp has six joints, the three proximal ones of which are very small, whilst the three distal have the proportions of those which make up the ordinary tri-articulate palp. 
its exact homologues, inasmuch as they correspond in strictness with the two terminal joints of its mandibular palp. The four posterior of the five abdominal legs of either side consist each of seven joints, seven being considered by Mr. Spence Bate to be the typical number of the joints in the normally developed appendage of every kind in Crustaceans. The second and third joints are anchylosed in the anterior of these five appendages, as they are in all the five of the Brachyura, so as to reduce the number of separate joints to six. The proximal joint is known as the 'coxopodite;' a black bristle is in this (female) specimen introduced into the oviduct, which opens in Macrurous and Anomurous Decapods, as also in Hedriophthalmata, in the coxopodite of the third abdominal appendage. The second joint is known as the 'basipodite,' or 'basis.' It is in the interval between the 'basi-' and 'coxopodite' that the separation of the limb takes place when a Crustacean throws it off in consequence of fright or injury. The third, or ' ischiopodite,' is marked by an annular constriction a little way distally to its articulation with, when it is distinct from, the basipodite. This constriction may perhaps represent the aborted exopodite, which in the three posterior abdominal legs of Squilla is articulated to the third segment of the appendage; by observing its presence we are enabled to identify the various segments in the appendages of the abdomen in Brachyura. The fourth, the longest of all the segments in all the five appendages except the first, is known as the 'meropodite,' and has been compared with the 'femur' of insects; the fifth is known as the 'carpopodite,' and the two terminal are known as 'propodite' and 'dactylopodite,' and have been compared to the 'tibia' and 'tarsus' of insects. The appendages on the first post-abdominal segment are rudimentary; to the hairs upon the appendages of the succeeding segments, some of the large ova of this fresh-water Decapod may be observed to be attached. The appendages of the second, third, fourth and fifth post-abdominal segments consist of a biarticulate 'protopodite,' the proximal segment of which is small and annular, and the distal cylindriform; and of two multiarticulate filaments representing an 'exopodite' and an 'endopodite,' the basal segment of the latter of which is much the largest in either series. The appendages of the sixth abdominal segment form the powerful 'swimmeret' of the crayfish. The lateral elements of this organ 
correspond to the appendages already described in the five anterior post-abdominal segments, and consist each of an uniarticulate 'protopodite,' which carries on its apex a biarticulate ' exopodite' and a uniarticulate 'endopodite.' The mesial element of the 'swimmeret' is constituted by the so-called 'telson,' an azygos plate divided in the crayfish into an anterior and posterior portion by a transverse suture, immediately anteriorly to which the anus opens on the ventral surface of the body. The telson has sometimes been reckoned as a seventh post-abdominal segment, but as it, with scarcely an exception, is without appendages; as it is generally aborted, or rudimentary, or fused with the sixth segment in Hedriophthalmata; and as, finally, it is developed after the other segments and from the dorsal surface of the body, it is better to regard it as being simply an outgrowth from the sixth segment of the post-abdomen, in the same way as the rostrum may be considered to be an outgrowth from the carapace. The proximal segment of the 'telson' is not calcified continuously across its ventral surface, whereas the true post-abdominal segments have each of them a horizontal calcified chitinous chord, connecting, without the interposition of any suture, the opposed internal surfaces of the are represented by their dorsal wall. At the junction of the chord and are are the articular surfaces for the post-abdominal appendages already described. The portion of the dorsal wall which is prolonged downwards beyond the level of the junction of the ventral and dorsal portions of the external skeleton of each segment is known as the 'pleuron.' There is no such element in the telson. The pleura of the sixth, fifth, fourth and third segments, and the convex tergal surfaces whence the pleurae arise in all the segments, have facets developed upon them anteriorly, which are overlapped by processes of the segments next in front. The pleura, horvever, of the second and first post-abdominal segments, develope processes which are not overlapped by, but themselves overlap, the one the pleuron of the first post-abdominal segment, and the other the posterior pleural edge of the carapace.

A quadrangular area, corresponding pretty accurately with the position of the subjacent heart, is marked off in the posterior portion of the carapace, or 'omo-stegite,' by two linear depressions on either side the middle line, and by an anterior faintly marked line, curving concentrically with the convexity of the cervical suture, 
and uniting the anterior extremities of the two laterally placed lines. The area on the omo-stegite intercepted between the curved line and the cervical suture represents the terga of the three thoracic segments; the area posteriorly to this line represents the terga of the five abdominal segments. The portions of the omo. stegite which lie laterally to these mesial areae are the connate pleura of all the eight segments just mentioned; from their function they are called 'branchio-stegites.' Their free border consists of a smooth rim, thickly fringed with hairs, arising along its inner edge; between which and the coxopodites of the thoracicoabdominal segments, water can find free access to the branchial chamber. The branchial portions of the carapace may be considered as representing the fused pleura of the eight thoracico-abdominal segments. The cervical suture which separates the omo-stegite from the cephalo-stegite begins anteriorly opposite the middle line of the antennary sternum. From this point it passes at first horizontally backwards; then it turns almost vertically upwards, bounding a surface of the omo-stegite, which is slightly convex forwards, and beset with from four to five spines; finally, it bends boldly backwards, describing a curve the mesial portion of which bounds the cardiac area anteriorly. The cephalo-stegite is prolonged anteriorly into a triangular mesial rostrum, terminating anteriorly in a sharp point, about on a level with the commencement of the antennary flagellum. The cephalo-stegite carries a sharp spine on either side, just externally to the basis of the rostrum. Immediately posteriorly to this spine is seen a convex surface, which is conspicuous even in early stages of development, and marks the origin of the porverful adductor mandibulae muscle. Inferiorly the cephalo-stegite is connected, though it is not anchylosed, with the antennary sternum, as it is in the Brachyura, and indeed in the much more nearly allied species Homarus Vulgaris.

For a full description of the external and internal anatomy of Astacus Fluviatilis, see Huxley, Medical Times and Gazette, Feb. 7, 1857 seqq.; and for the tegumentary skeleton and morphology of Decapodous Crustacea generally, see MilneEdwards, Ann. Sci. Nat., Ser. iii., tom. xvi., p. 22 I, I8 5 I.

For the development, see Rathke's Monograph, 'Ueber die Bildung und Entwickelung des Flusskrebses,' 1829; and for the de- 


\section{Common Crayfish.}

velopment of the 'telson' in particular, p. 27, and 'Zur Morphologie, Reisebemerkungen aus Taurien,' 1837, pp. II $3^{-11} 5$. In this latter work about fifty pages are devoted to general remarks on the development of Crustacea.

For the development of other Crustacea, see Spence Bate, Phil. Trans., 1858; Fritz Müller, Archiv. für Naturgeschichte, 1862, 1863; Van Beneden, Recherches sur la Faune Littorale de Belgique, Crustacés, 186I; Claparède, Beolachtungen über Anatomie und Entwickelungsgeschichte wirbelloser Thiere, г 863, ibique citata.

For the morphology of the appendages, see Savigny, Mémoires sur les Animaux sans Vertèbres, 1816, vol. i., p. 4\%, Mem. ii., pl. iii. and iv.; Erichson, Entomographien, I 840, where, at p. 28 , attention is drawn to the fact of the relative prominence of the thoracic appendages in the larval (Zoea) stages of Crustacea which undergo metamorphosis, and to the illustration which this peculiarity in the development of Crustacea affords of their essential affinity to other Arthropoda which possess the same hexapod arrangement permanently as adults in the class Insecta, or, it may be added, pass through a hexapod larval stage, as Iulus among Myriapoda, and Hydrachna among Arachnida. That the prolegs of Insect larvae are rightly considered as homologous with the abdominal and post-abdominal limbs of Crustacea, though the proleg, even when greatly elongated as in the anal appendages of the Puss Moth (Cerura Schrank), is still an annulated rather than a segmented and articulated outgrowth, may be seen from the fact that prolegs and true legs may replace each other. In the Coleopterous Insect Spirachtha Eurymedtusa, deseribed by Schiödte in the Ann. Sci. Nat., Ser. iv., tom. v., $185^{6}$, p. $1 ; 8$, pl. i., fig. 19 , we have the first, second, and third prolegs of the Lepidopterous larva replaced by biarticulate appendages; whilst in the Coleopterous Curcutionidae we have the thoracie legs replaced by prolegs.

For excellent figures of the appendages, see Brandt and Ratzeburg, 'Medizinische Zoologie,' Bd. ii., Taf. xi., p. 58 ; or', Victor Carus, 'Icones Zootomicae,' Taf, xi.

See also Milne-Edwards, 'Suites à Buffon,' Crustacés, tom. i. ii. iii., and in 'Règue Animal,' Crustacés, Atlas, pl. iv. 
For generalizations as to the homologies of the appendages in the various orders of Crustacea, see Spence Bate, ' History of British Sessile-eyed Crustacea,' Spence Bate and Westwood, 1868 , Introduction, pp. vii-xx.

For the billiography of memoirs upon the anatomy of the Freshwater Crayfish, see Brandt and Ratzeburg, 'Medizinische Zoologie,' Bd. ii., p. 65, note I ; or, Leydig, ' Handbuch der Vergleichenden Anatomie,' p. 2.53.

For the differences between Macrurous and Brachyurous Crustacea, see Dana, 'Crustacea, U. S. Exploring Expedition,' pt. i., p. 49.

\section{Common Crayfish (Astacus Fluviatilis),}

\section{MaLe,}

Dissected so as to show the nervous, circulatory, and digestive systems in situ, and in the relations they hold to each other and to the external tegumentary skeletal system.

THE nerve system underlies the sternal elements of the various segments ; the heart, the dorsal portion of the omo-stegite, giving off both anteriorly and posteriorly an azygos artery which may represent the more elongated and vasiform heart, which is more usual in Arthropoda than the compressed irregularly polygonal organ seen here; and the digestive tract occupies a position between those of the two other systems. A white bristle has been introduced through the mouth into the oesophagus and stomach, and shows that this latter organ is prolonged as far forwards internally as the antennary sternum is externally, and to a point, therefore, much in front of the plane of entrance of the oesophagus. In order to show these points, the external skeleton and its appendages, with the exception of the eyes, antennule, and antenna, have been removed on the animal's left side, together with the muscles in connection with them, and together with the two lobes of the liver and the 'green' or 'antennary' gland of the same side. A slip of blue paper has been placed under the nerve cord in the postabdominal region, in the interval between its penultimate and antepenultimate ganglia; a second has been placed in the same region, but in its dorsal portion, under the azygos caudal artery and above 
the intestine; a third is placed underneath the sternal artery, just at its origin from the bulbus arteriosus, at the posterior extremity of the heart, from which the post-abdominal artery just mentioned is continued directly backwards; the fourth and most anteriorly placed slip of blue paper occupies an interval between the coecal process, the rudiment of the embryonic yelk-sac, which marks the commencement of the intestine, and the hepatic artery of the left side, just as it emerges from under the cover of the testis, and passes down on to the pylorus. The anterior wall of the stomach, finally, has been displaced a little backwards, and the commissural cord between the supra- and the infra-oesophageal ganglia, which was rendered visible by the removal of the antennary gland, has had its various connections made more evident.

The twelve post-oral and the supra-oesophageal ganglia are here seen in profile, and the great lengths of the commissural cords passing between the last-named ganglia and the first of the postoral series whence the three pairs of foot-jaws as well as the three pairs of true jaws are supplied, is well seen, corresponding with the elongated antennary sternum. Visceral nerves are seen passing from the commissural cords and from the supra-oesophageal mass on to the stomach. A sub-circular raised area on the anterior aspect of the stomach as displaced backwards, and about midway between its upper and lower border, marks the position of the so-called 'eye,' a circular calcareous disc periodically developed in the Crayfish. A convex protuberance marks the pylorus, immediately behind which is seen, the two hepatic lobes having been cut away, the opening of the left ductus choledochus into the commencement of the intestine. The inferior portions of the hepatic lobes of the right side come into view beneath the pyloric portion of the stomach and the duodenum, along the middle line of which they come into the apposition with the homologous portions of the left hepatic lobes. The convolutions of the vas deferens of the left side fill up the space between the two slips of blue paper which are placed under the hepatic and the sternal arteries, and which abut by their upper angles upon the anterior paired and the posterior azygos testicular lobe respectively. Superiorly to the testicular lobes, and, as in all $\Lambda$ rthropoda which possess it, immediately underneath the dorsal integument, is seen the heart. In the interior of the post-abdominal region are seen, 
besides the straight intestine, the nerve cord, and the post-abdominal artery already mentioned, the powerful and complex flexor muscles of the post-abdominal segments and the 'swimmeret;' fascicles from which are observable passing to find attachment to 'apodemata,' as far forwards as the entrance of the oesophagus. It is by these muscles that the more rapid movements of these animals are executed. For their slower crawling movements, the ambulatory legs are employed, and the muscles which act upon the limbs of the right side, may be seen passing upwards through the apodematal cells to take origin from the epimera as seen in Prep. 34. Some muscular fasciculi not ordinarily described pass backwards from the sternal regions, anteriorly to the mouth on to the anterior surface of the stomach, decussating thus with the commissural and stomato-gastric nerve cords.

As a sexual peculiarity, the modifications of the first and second post-abdominal appendages should be noted. But the testis itself does not extend further backwards than the posterior border of the carapace, and the outlet of the vas deferens, as being placed in the basal joint of the last ambulatory leg, justifies the application of the term 'post-aljdomen' to the segments placed posteriorly to it.

For figures of the Crayfish as thus dissected and described, see plate vii.

For a detailed account of the flexor muscles of the post-abdominal segments, see Milne-Edwards, 'Suites à Buffon,' Histoire Naturelle des Crustacés, tom. i. p. 157, tom. iii. pl. xiii.

For the late period at which the digestive tract is developed in Arthropoda, and the possibility of thus accounting for its comparative simplicity and the straightness of its course, see Zaddach, Untersuchungen über die Entwickelung und den Bau der Gliederthiere, p. 42.

\section{Common Crayfish (Astacus Fluviatilis),}

Dissected so as to show the heart, its six arteries, and two of its six venous inlets, in situ.

THE cardiac and part of the cephalo-stegal portion of the carapace has been removed, as well as a flattened venous sinus which was 
interposed between the shell and the heart, and the terga of the two anterior post-abdominal segments. The heart in the Decapodous, as also in some of the lower Crustacea such as Daphnia, differs in its compressed shape from the vasiform structure which is observable in the other classes of Arthropoda, and indeed in such Crustaceans as Squilla and the Hedriophthalmata. From the anterior border of the heart a single artery is given off in the middle line, and supplies the eyes and antennules. On either side of this artery is given off the trunk which supplies the antennae; and finally, from either outer angle of the front border of the heart, an artery passes downwards, between the testicular lobe of either side and the intestine, over the pylorus to the hepatic lobes. A slip of blue paper has been placed under the post-abdominal artery, which, passing immediately beneath the middle dorsal line and above the intestine, may be taken as representing the posterior segments of the forms of heart more usually seen in Arthropoda. The sternal artery, which is larger than the post-abdominal, and is given off from the same short trunk, is not seen in this Preparation. Two venous inlets are seen in the anterior fourth of the upper surface of the heart; the two laterally placed and the two inferiorly placed are not seen in this view. The cavity in which the heart is lodged has been sometimes called 'a pericardium,' and sometimes an 'auricle.' It is formed by a reflection of the membrane which lines the general visceral cavity; and it receives the blood returned from the branchiae, so as functionally at least to represent a branchial auricle. Six elastic ligaments, the 'alae corlis,' pass from the cardiae aspect of this 'pericardial' or 'auricular' memlrane, to attach themselves to the walls of the heart, their main function being probably to reopen by their recoil the six venous orifices which each systole of the ventricle eloses. These ligaments may serve also to suspend the heart in the pericardial sinus, but the arteries which pass off from it are probably in these, as in other animals, the chief means whereby the heart is maintained in silu.

The five arteries arising along the anterior edge of the heart, and the sort of bulbus arteriosus into which the posterior end of the heart tapers, give it the polygonal appearance which distinguishes the heart of the Deenpodous Crustaceans from the similarly unilocular and non-vasiform heart of the Entomostacous order which gives off no arteries. The anterior edge of the heart corre- 
sponds more or less exactly with the curved line already described at page 96 supra, as limiting off in the omo-stegite an area representing the coalesced terga of the thoracic segments anteriorly from one similarly representing the coalesced terga of the five abdominal segments posteriorly. In having thus its anterior edge or boundary not prolonged beyond the region of the abdomen, the heart of Crustacea corresponds with the heart of all other Arthropoda, and furnishes an excellent illustration of the value in morphology of identity in the relative positions of organs which may differ very widely in external shape and appearance.

For a figure of the heart of a Decapodous Crustacean, see Professor Owen, Comp. Anat. Invert., p. 318.

For a discussion as to the venous system, and as to the prolongation or non-prolongation of the branchio-cardiac vessels as distinct tubes through the pericardial sinus into the ventricle, see Straus Durekheim, Considérations générales sur l'Anatomie Comparée des Animaux Articulés, p. 346; Milne-Edwards, Histoire Naturelle des Crustacés, p. 103, I834; Leçons sur la Physiologie et l'Anatomie Comparée, tom. iii., p. 183,1857 , where the views of Straus Durckheim are adopted.

For the Alae Cordis and their functions, see Verloren, Sur la Circulation dans les Insectes Mém. Couronn et Mém. Sav. Étrang. Acad. Roy. Belgique, tom. xix., pp. 68-70, I 844, where the alae cordis are said not to be muscular even in insects.

\section{Common Crayfish (Astacus Fluviatilis), Male,}

Dissected so as to show its stomach, intestine, reproductive and respiratory systems, in situ.

The greater part of the tergal elements of all the segments of the body have been removed, together with the venous sinuses which underlaid them, as also the heart and its arteries. An arcuated plate, the 'cardiac ossicle,' is seen crossing the cardiac portion of the stomach, and receiving the insertion of the anterior gastric muscles, which arise from the ventral base of the triangular 
rostrum. Between these gastric muscles anteriorly is seen the azygos stomato-gastric nerve entering a small ganglion. From this ganglion it is continued onwards, after giving off a nerve on either side, across the cardiac ossicle, posteriorly to which it bifurcates, and joins one of the lateral stomato-gastric nerves to supply the liver lobes. A small ossicle, the 'pterocardiac,' articulates with either outer angle of the cardiac; and from the base thus constituted the supero-lateral ossicles pass backwards so as to form with it anteriorly, and with the 'pyloric ossicle' distally, a triangular framervork, into the apex of which two other muscles are inserted, which take origin posteriorly from the carapace. Immediately in apposition with the portion of the stomach thus strengthened, is seen the end of the adductor mandibulae muscle, separated from its attachment to the carapace; and exteriorly again to the muscle, are seen on either side the two lobes of the liver. In the middle line between the hepatic lobes are seen the paired lobes of the testis. Where these lobes join an azygos lobe placed posteriorly to them in the middle line, and superiorly to the intestine, the vasa deferentia are seen taking origin as slender tubes, the calibre of which rapidly widens, and the lengthy convolutions formed by which intrude some way into the post-abdominal cavity, before they turn downwards to open in the basal joint of the last abdominal limb on either side. Posteriorly, the comparatively small strata of extensor muscles having been removed, we see the intestine taking a straight course, as always in Crustacea, to the anus. Externally to the vasa deferentia and hepatic lobes are seen the branchial organs, arranged in three rows, the outermost consisting of the branchiferous epipodites, which are developed upon the coxopodites of the two posterior maxillipeds and upon the four anterior ambulatory legs; and the two innermost of simple tree-like upgrowths, developed in pairs from the third maxilliped to the fourth ambulatory leg inclusively, and singly upon the second maxilliped and the last ambulatory leg. The branchiferous epipodites are in shape like a leaf, with the two halves of the blade or lamina folded backwards, and with the mid-rib looking forwards. Both halves are longitudinally plicated, but the branchial filanents are developed only upon the half which looks outwards. The branchiae proper are sessile, internally to the epipodites, upon the epimera, and the membrane intervening between them and the basil joints 
whence the epipodites spring. The seven branchiferous segments, which, it may be remarked, correspond with the seven segments carrying ambulatory legs, in Amphipoda and Isopoda, carry ten branchiae in the pairs which all of them except the first and last support, and a single branchia upon the first and last of their number. To these twelve respiratory organs we may add six, by counting the branchiferous epipodites as such.

In the American species of the genus Astacus, with one exception, there is no branchia upon the fifth abdominal leg; and with the absence of this branchia a lesser width of the cardiac area on the carapace has been observed to be correlated. In the genus Homarus, on the other hand, the branchiae are much more numerous than in Astacus, and indeed without counting the epipodites which, as may be seen in the common lobster, are setigerous rather than branchiferous, and act mainly as the scaphognathite does, by changing the water in the neighbourhood of the true branchiae, they out-number all the branchial organs of the Astacus, whilst the cardiac area on the carapace is relatively much less clearly indicated than in the smaller Decapod. Most of the anatomical points upon which weight has been laid in these descriptions of the fresh-water Crayfish, may be illustrated in the structural arrangements of the common lobster, in places where the Astacus may not be procurable. The marine species will however be found to differ from the fluviatile in the following points. Its hepatic coeca are shorter, and the anterior portion of the entire gland is larger, whilst the vasa deferentia are shorter, the testes are very long and only joined by a commissure. The coecum at the conmencement of the intestine, which has already been spoken of as the rudiment of the yelk-sac, is smaller and bilobed in the lobster, whilst it is simple in the Astacus. The duodenum itself is smooth, and the rectum plicated internally in the lobster, and the duodenum, where it ends in the rectum, has an azygos coecum appended to it dorsally, as in Amphipoda, and most other Decapoda except Astacus. The nervous system differs mainly in having the ganglionic mass, whence the jaws and foot-jaws are innervated, more distinctly constricted at the sides, and less in size relatively to the five abdominal ganglia which succeed it, than we find the homologous structures to be in the Crayfish. Of external points of difference, perhaps the two most important are presented by the telson, which is uniarticulate in the lobster, and the second abdominal appendage in the male, which is much less modified, and differs much less in appearance from those which succeed it, than the same appendage does in the male Astacus. 
For the points of difference between Astacus and Homarus, see Milne-Edwards, Histoire des Crustacés, vol. i., pp. 329-333. For the American subgenus Cambarus, to which the species inhabiting the mammoth cave in Kentucky belongs, see Dana, Crustacea, United States Exploring Expedition, 1852, p. 522. For the nervous systems of the common lobster, see Swan, Comp. Anat. Nerv. System, pl. iii. and iv., where the endophragmal arch formed by the mandibulo-maxillary apodema, and interposed in the natural position of the parts between the stomach and the cords of the nerve collar, and the first sub-oesophageal ganglion is well seen. See also Newport, Phil. Trans. I834, pl. xvii., fig. 40 .

For an account of the development of the common lobster, Homarus Vulgaris, see Rathke, Wiegman's Archiv. für Naturgeschichte, 1840, p. 24I, translated in Annals and Magazine of Natural History for I $84 \mathrm{I}$, vol. vi., p. 263 , where the embryo on the point of hatching is shown to differ from the adult mainly by the presence on the ambulatory legs of an exopodite, such as the two posterior maxillipeds retain in the adult Decapod, and the ambulatory legs themselves in Mysis and Squilla.

For the correlation of large size of ova with the completion of development before hatching, see Bergmann and Leuckart, Vergleichende Physiologie und Anatomie, p. 647; and for an exemplification of this law, in the instance of Mysis, where the eyes are ferw (fifty) in number and large, and where the development is direct and without metamorphosis, as compared with such cases as those of the Palinuri and Carcini, where the eggs may be from one to three hundred thousand, and are of small size, and where the well-known metamorphoses with forms known as 'Zoea' and 'Megalopa' are gone throngh, see Van Beneden, Recherches sur les Crustacés, pp. $52,53,57$. The fresh-water congeners of marine species which go through metamorphoses, are very frequently ametabolous in the sub-kingdoms of Mollusea and Vermes as well as in that of Arthropoda. In the instances here under comparison, of the fresh-water Astacus and the marine Homarns, it should be borne in mind that the ova of the former animal are larger than those of the latter, though the adult Crayfish rarely attains one-third of the size of the lobster. 


\section{Common Crayfish (Astacus Fluviatilis),}

Dissected so as to show its nerve system; the greater part of all the terga of the animal, and the viscera of organic life, with the exception of the commencement and the termination of the digestive tract, having been removed.

Besides the prae-oral or so-called 'supra-oesophageal' ganglionic mass, supplying the eyes, antennules and antennae, there are twelve post-oral ganglia in the Crayfish, of which six belong to the segments anterior to the post abdomen, and six to these terminal segments. The first post-oral ganglion is the largest of the series, and supplies no less than six pairs of appendages, viz. the mandibles, the two pairs of maxillae, and the three pairs of foot-jaws. In the developing Crayfish, as shown by Rathke ${ }^{u}$, this mass which is thus fused in the adult is represented by six pairs of white specks. Posteriorly to it we see five ganglia, remaining distinct, and corresponding in the adult as they do in the embryo of the Macrurous Decapods, and also of the Hedriopthalmatous Crustacea, with the five pairs of abdominal feet. Each of these six ganglionic masses presents a perfectly fused and continuous surface, but traces of the primitive antero-posterior bifidity of the nerve chain are still faintly visible, even to the unassisted eye, in the commissural cords passing between the ganglia. The wide opening which is seen in the commissural cord connecting the third and fourth abdominal ganglia, gives passage to the sternal artery seen in Prep. 32, p. 99, and the cord which connects the fourth with the fifth, differs from the cords which connect the pairs anteriorly placed in being shorter than any one of them. There are six post-abdominal ganglia, under the third and fourth of which, as also under the cord of commissure between the fifth and last, slips of blue paper have been placed. Each of the five anterior post-abdominal ganglia gives off two pairs of nerves, the sixth, which is the largest of the series and alone of the six connected with the one preceding it by a double commissure, gives off a considerably larger number of nerves, supplying as it does both the anus and the telson, in addition to the parts homologous with those supplied by the five anterior

u Ueber die Bildung und Entwickelung des Flusskrebses, pp. 32, 33 . 
ganglia. This ganglion has been said to represent two ganglia, which were separate and distinct in the embryo. Rathke, however, informs us, l. c., that he has not been able to observe anything as to the mode of origination of the post-abdominal ganglia; and though the distribution of the nerves of the sixth ganglion may seem to make it probable that it was so developed, the comparative anatomy of the homologous series in other Crustacea would appear to militate against such a view. A system of nerves homologous with the nervi transversi or 'briles épinières' of Lyonet, described under Prep. 29, p. 84, in the insect, is represented by a nerve which arises in each segment, as seen with the naked eye in the third post-abdominal segment over the slip of blue paper placed there, from the commissural cord, and bifurcates into two lateral nerves. The bilaterally symmetrical and the azygos stomatogastric system of insects are represented in the Crayfish by a system of nerves which arises symmetrically on either side of the oesophagus from a thickening on the commissures of the nerve collar, and by an azygos nerve which arises from the supra-oesophageal mass; but which has not any separate prae-cerebroid ganglion frontale developed upon it as in insects. A slip of blue paper has been placed between the commissural cords of the nerve collar, and the antennary sternum with which they are commensurate in length; and in the interval between the commissural cords, the various trunks of the stomato-gastric system are seen. The commissural cords are connected anteriorly to the first post-oral ganglion by a transverse cord, which is in apposition with the posterior wall of the oesophagus, and represents, probably, an anterior fragment of the backwardly displaced ganglionic mass which supplies the jaws and foot-jaws. The prae-oral ganglionic mass, which in embryonic life was seen by Rathke to be made up of two ganglia on each side, of which the posterior or the one more nearly placed to the mouth was the larger, and supplied the antennae and antennules, sends nerves to these organs, to the auditory organ lodged in the antennule, to the antennary gland, and finally to the eyes. The ocular portion of the prae-oral mass has not assumed the degree of relative importance which it has in air-breathing $\mathrm{Ar}$ thropoda.

The distinctness of the fibrous chords from, and their position superiorly to the ganglionic elements of the ventral chain, can 
be recognized in Astacus as well as in other Arthropoda, when the specimen has been, as in this case, sufficiently hardened in alcohol. The summits of the branchial plumes are well seen in this Preparation, between the omo-stegite and the epimera of the abdominal segments. From the internal aspect of the epimera, the muscles which move the limbs are seen passing downwards and bifureating as they pass through the apodematal cells to their insertions in the upper segments of those appendages. In the cephalo-stegite, the adductor mandibulae is seen taking origin from the internal aspect of the protuberance already described, at page 96, as existing on its outer surface.

On the ventral surface a packet of spermatozoa, aggregated in their passage along the convolutions of the vasa deferentia into the so-called 'spermatophore,' may be observed adhering to the coxopodite of the last abdominal segment, in which the vas deferens opens. These structures, which are of comparatively small size as compared with those of some much smaller Crustacea, but which are produced in great numbers in the Crayfish, are by no means found exclusively in the neighbourhood of the generative outlet of the male, but may be seen adhering to various parts of the animal's body. In the Chilopodous Myriapoda they may be attached even to foreign bodies.

It may here be noted that though in many Hedriophthalmata, or fourteen-footed Crustacea, the number of post-oral ganglia may be the same, or nearly the same, as in such Macrurous Decapods as the Crayfish or Lobster, it is never made up of the same pre-thoracie, thoracic, abdominal, and post-abdominal factors in the same proportions as in the higher order. The ganglia supplying the ambulatory appendages, which in the Hedriophthalmata correspond with the two posterior maxillipeds or foot-jaws of Decapods, escape fusion with the first post-oral mass consisting of the coalesced ganglia belonging to their three pairs of footjaws and single pair of foot-jaws; and maintain their typical distinctness, just as the appendages which they supply maintain their primordial locomotor functions. Having thus two more ganglia in the anterior portion of their segmented bodies, the Amphipods and Isopods have fewer than the Decapods in the post-abdominal region; and by a reduction of the number of the ganglia of this region from six to five or four, the entire number of their ventral ganglia comes to be thirteen or twelve, as in Homarus or $\Lambda$ stacus. In some of the air-breathing 
Isopoda, the post-abdominal may be represented by but a single mass. Though, as already stated, we know that in the earliest periods of dcvelopment of the nerve system, at least in the Crayfish and Scorpion, the single ganglionic centre which innervates the first six post-oral segments, consists of an equal number of pairs of ganglia, it has been shown in other cases, as by Weismann in the developing Dipterous larva, and Metschinow in Aphis liosae, that the nerve centres of many typically distinct segments may from the very earliest periods be conuate. As, indeed, the nerve system is specialized in Arthropoda at a very late period as compared with that of the segmentation of the body and the development of the appendages, it may seem that when it does thus come into being, it must adjust itself to any secondary arrangement or disposition which these organs may have assumed in the course of their evolution, rather than to any typical relations of distinctness or of oneness which they may have manifested in earlier periods. In cases such as those of the larvae of Muscidae, as described by Weismann, where the nerve centres of the entire series of post-maxillary segments are, if no earlier and rapidly transitory period of distinctness has been overlooked, connate from their first appearance, the number of nerves given off from the connate mass may serve to indicate its really compound nature. But though in the larvae specified, as many as eleven pairs of nerves are given off from the single mass corresponding to eleven post-maxillary ganglia of such larvae as Corethra plumicornis or Phalaena neustria, it is well to note that in the perfect insect, even this indication of the typical plurality of nerve ganglia is wanting, and that the ventral cord of the adult fly, exclusively of its first sub-oesophageal mass which supplies the modified jaws, gives off only four pairs of nerves, and one terminal azygos abdominal cord.

As in the Myriapoda the jaws are supplied from a single ganglion, just as in the other three classes of this sub-kingdom, we may say that in all Arthropoda, the first three post-oral segments upon which the mandibles and maxillae are developed, are innervated, at least in the adult state, by a single ganglion. In Crustacea and Myriapoda, this, which may be spoken of as the manducatory ganglion, is always fused with more or fewer of the succeeding ganglia accordingly as more or ferwer of the thoracic appendages are converted into auxiliary jaws. In the fourteen-footed Hedriophthalmata therefore, where only the anterior pair of thoracic limbs is converted into an accessory oral organ, we should say that the 
first post-oral ganglionic mass consists of the manducatory ganglion fused with one thoracic ganglion; whilst in the Decapoda all three thoracic centres have coalesced with the manducatory. In insects, on the other hand, we should say that even when the nerve ganglia attain the very extreme of concentration, the manducatory ganglion is always distinct from the rest of the ventral ganglia; and that the thoracic ganglia, as might be expected from the importance of the parts they supply, have a much greater relative size and independence than the homologous ganglia in Crustacea. The first abdominal ganglion in insects very frequently coalesces with the third thoracic, which is rarely the case in the Crustacea, in which the nerve centres of what Fritz Müller has called the 'middle body,' very ordinarily are the best developed in their entire ganglionic series. The Arachnida resemble, on the one side, Crustacea, in having their manducatory fused with their thoracic ganglia, and on the other, Insecta, in having more or fewer of the abdominal ganglia coalesced with the thoracic. The Arthrogastrous Arachnida, as the scorpion, may have as many as four post-abdominal ganglia; Insecta appear never, even in the larval state, to have more than three; whilst Crustacea may have as many as six; or may, in the air-breathing Isopoda, as Oniscus Murarius, have a single ganglionic mass partially coalesced with the last abdominal to represent the entire caudal series, which, together with the post-abdominal segments, may be wholly lost in Laemodipoda.

On the other hand, though fusion and connation even may be carried out to the extreme degree witnessed in Diptera, as also in Carcinus Maenas amongst Crustacea, and the Araneae amongst Arachnida, it would be wrong to hold that the nerve system of Arthropoda is in no case a guide towards the determination of the homologies of their segments and appendages, or that the necessity existing in particular instances for the establishment of consentaneous muscular action in segments and appendages, entirely obliterates all traces of a common typical arrangement of the elements of this system. The innervation of the so-called 'mandibles' or 'cheliceres' in the Arachnida from the supraoesophageal mass, must be held to prove that these organs are essentially antennae; and a study of the appended Tables will show, that if we make allowance for the (possible) connation of the three ganglia, which should typically be developed in correspondence with the three manducatory 

Table of Post-oral Nerve Ganglia of Decapodous Crustacean, of Macrurous Arachidin, and of Lepidopterous

INSECTS, AS OBSERVABLE IN DEVELOPING AND IN ADULT INDIVIDUALS OF THE GENERA

Astacus, Scorpio, and Sphinx.

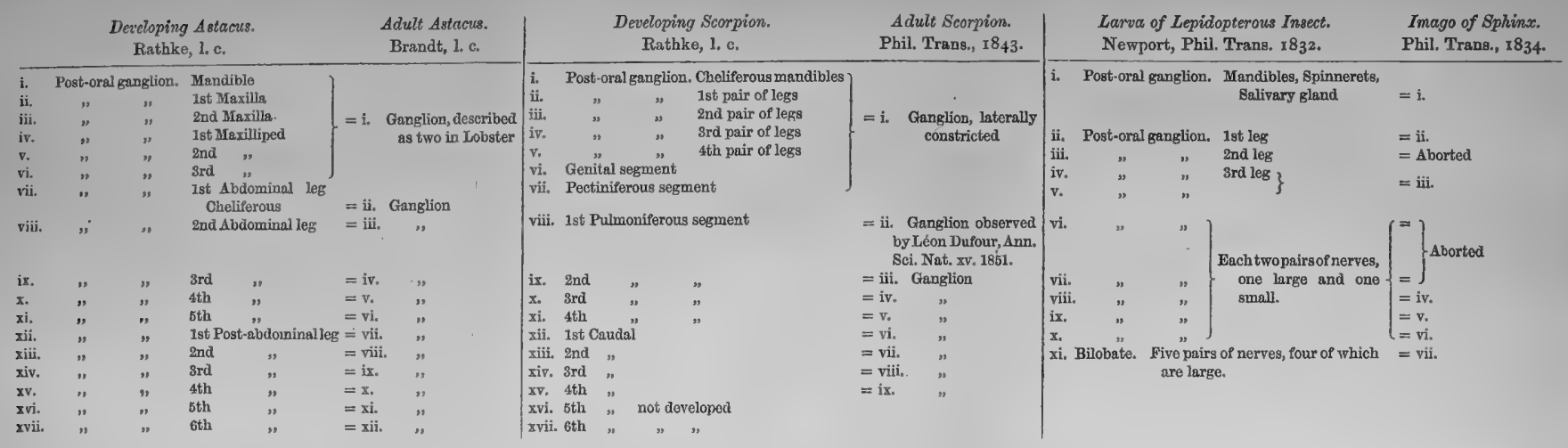

Table of Post-oral Nerve Ganglia as observable in Amphipodous and Isopodous Crustacea and in ORTHOPTEROUS INSECTS.

Amphipodous Crustacen, Talitrus, Milne-Edwards and Spence Bate, Amphithoe, Bruzelius, Hyperia, Straus Durckheim, Gammarus Putex, mihi.

i. Post-oral ganglion gives branches to jaws, is not figured by Straus Durckheim in Mem. du Miseum, 1829, tom. xviii., in Hyperia Galba. But see Bruzelius' figures, Arch, für Naturgeschichte, 1859, Taf, x., fig. 18.

ii. 1st Ambulatory foot) Fused in Hyperia with each other
iii. 2nd and with i approximating De-

ii. 2nd " " $\}$ and with $i_{\text {, approximating }}$

iv. 3rd " , Distinct ganglion

v. 4th " " " "

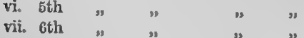

vii. oth

ix. 1st Pleopodos

x. 2nd "

xi. 3rd

xii. 4th Pleopodos. Distinct "ganglion" according to Spence Bate in Talitrus Locusta; but in Talitrus, Hyperia, and Amphithoe, as figured by Milne-Edwards, De la Valette, and Straus Durckheim, and in Gammarus Pulex where it is much elongated, supplying the sth popodos also.

i. 5th Pleopodos. Distinct ganglion in Talitrus Locusta, Spenco Bate, in British Association Report, 1855, p. 56, Pl. $x x i$
Isopodous Crustacean, Oniscus Asellus, Woodlouse, Leydig, 1. c. Taf, iv. 7.

i. Post-oral ganglion, very small and ordinarily overlooked. The nerves for the manducatory organs are said to come from the commissures of the collar. Nova Acta, ¿x., p. 35, in Idothea and 2 ga, as also in the Scolo$\mathrm{xx}, \mathrm{p} .35, \mathrm{in}$

ii. 1st Ambulatory foot

iii. 2nd " $" ~$
iv, 3rd "

$\begin{array}{lll}\text { iv. 3rd " } & \text { " } \\ \text { v. 4th } & \text { " }\end{array}$

vi. Eth

vii. 6th

viii. 7 th

ix. Supplies terminal segments, being itself distinguisl able from the eighth ganglion by a foramen placed

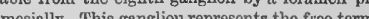
mesially. This ganglion represents the free terminal ganglia described by Rathe and Hilne-Edwards in the marine species Idothea Entomon, Ega Bicarinata and Cymothoo, and by Lereboullet in the airbrenthing and closely allied Ligidium Persoonii. See Nova Acta, xx., Pt, i. p. 34; Hist. Crustacés, Tar. xi, 2; Ann. Sci, Nat, sx. P1. v, 24.
Orthopterous Insect. Periplaneta Orientalis. See Plate vi.

Post-oral ganglion supplies mandibles and bifid labium; is closer to supra-oesophageal mass thon in Crustacea.

ii. 1st pair of feet

iii. 2nd,

v. This ganglion is probably to be considered as having become fused with No. iv.

vi. 1st abdominal ganglion

vii. 2nd "s

viii, 3rd

ix. 5th abdominal ganglion, corresponding as the tenth post-oral of the Larvw of Lepidoptera and tenth postoral of the embryo Scorpion do with the first postabdominal of the Crustaceans.

xi. 6th, bilobed terminal ganglion, corresponding to the three terminal ganglia of Gammarus Pulex. 
segments in the insect, a very close, even if not complete, correspondence exists between the arrangements of the ventral ganglionic chain in Insecta, Arachnida, and Crustacea.

In this Table the series of ganglia as observable in the developing and in the adult forms respectively of Astacus, Scorpio, and Sphinx, have been placed side by side in six columns, the maximum number of divisions in which is seventeen, the typical number, according to the view here adopted, of the post-oral segments in Arthropoda. Each actually existing ganglion is placed in the particular division of the scale of seventeen which is regarded as its homological relation to the complete series furnished by the developing Astacus. Thus a glance shows both where coalescence has taken place and where ganglia have failed to be developed.

In a second Table the ganglionic series of an Amphipodous, of an Isopodous Crustacean, and of an Orthopterous insect, have been similarly arranged in parallel columns, the Amphipodous Gammarus making the transition from the Decapodous Astacus to the Isopodous Oniscus easy, and the Oniscus in its turn approximating perhaps more closely than most or all other Crustaceans to the insects.. The anatomical points

x The order Orthoptera is believed to be the earliest representative of the class Insecta in geological times, see Gerstaecker, Klassen und Orlnungen des Thier-reichs, Bd. v., p, 292; and as an order they are distinguished by the possession of a number of characteristics which approximate them to the Crustacea, the earliest geological representatives of the sub-kingdom Arthropoda. Amongst these may be mentioned the possession of the processes figured at $c$ in pl. vi., and known as 'cerci anales,' which appear to be homologous with certain processes which Rathke has spoken of in Crustacea, e.g. Apus, Branchipus, Cyclops (Morphologie, p. I15); the retention by the second pair of maxillae of something of their typical distinctness as opposed to fusion, as in other insects, into a 'labium ;' the presence of three basal joints as a support to the multiarticulate antenna which thus resembles the antennule of Crustacea; and, lastly, the functional peculiarity of ecdysis, which attaches even to adult Ephemeridae in this order of insects, and the pedunculate position of the central eyes in certain male Ephemeridae, Chlöe diptera s. Ephemera bioculatu, Linn. The internal structural arrangements of the order Isopoda, irrespective of those of their nervous system, present some points of interesting resemblance to those of Insecta, and especially of Orthoptera. Their long non-ramified hepatic coeca are essentially similar to those seen in the Orthopterin; see above, p. 86, and pl. vi. $h$, and description; Leydig, Lehrbuch der Histologie, pp. 362, 3.33, fig. 194; whilst in their air-breathing genera, Oniscus and Tylos, a system of canals has been discovered in the opercula of their branchial plates, which has been supposed to be a rudimentary tracheal apparatus. As these peculiarities do not relate to the nervous system, it is of the more importance to note that a sympathetic 
embodied in this Table can be illustrated by dissection of the readily procurable animals, Gammarus Pulex, Oniscus Murarius, and Periplaneta Orientalis.

Much has been written as to whether twenty or twenty-one is the typical number of segments in the Arthropoda. The great number of homonomous segments which in Myriapoda are developed posteriorly to their thoracic region, enables us to eliminate them from consideration, except so far as the thoracic and cephalic segments are concerned; but in all other Arthropoda, with the exception of the Trilobites and Phyllopoda amongst Crustacea, the number of actually, if not of homologically distinct segments, appears to be very definitely limited. The typical number of segments has been considered here as being twenty, in accordance with the views of Professor Huxley, and in opposition to those of Professors Milne-Edwards and Van Beneden; inasmuch as the 'telson' or terminal so-called segment of the Crustacea does not appear to possess the characteristics of a true segment. In the Sessile-eyed Crustacea, the telson is, accorling to $\mathrm{Mr}$. Spence Bate, l. c. p. xxi., who however appears to reckon it as making a twenty-first segment, "generally an abortive, and frequently a rudimentary part;" and in the Isopoda, with the exception of two genera, it is always fused with the preceding segment. With one, or perhaps two exceptions, the telson never carries appendages, "whereas it is a law common to all Crustacea, that every segment has its appendage;" and Rathke, from whom however Van Beneden differs, describes it as being developed after the other segments, and from the dorsal aspect of the body.

Even if it should be proposed to regard it as representing in a rudimentary form the very great or all but indefinite number of homonomous segments which we meet with in Apus amongst Crustacea, and in the Myriapoda, we should still be justified in eliminating it from the number of the typical segments of Arthropoda; that is to say, from the number of segments to which some of the best marked representatives of three out of the four great classes into which the sub-kingdom is divided, can all alike be shown to conform. The history of the development, and to a considerable though lesser extent, that of the comparative

ganglion corresponding in position and connections to the azygos 'ganglion frontale' of Insecta and Myriapoda has been discovered by Leydig in Oniscus. In other Crustacea, the nervus recurrens has no ganglion frontale developed, but appears to take origin from the supra-oesophageal ganglia. Brandt has figured a lateral paired system of sympathetic ganglia in this Crustacean, see Med. Zool., Bd. ii. Taf, xv. fig. 27 ; but Leydig declares the structures thus described to be merely glands in connection with the stomach. 
anatomy of the antennae and jaws in Arthropoda, prove that they are appendages in just the same sense as any of the ventrally placed appendages attached to segments posterior to the cephalic; and with them, most authors, with the exception of Claus and Fritz Müller, would be inclined to rank the eyes. The facts of the pedunculation of these organs in the Podophthalmatous, and indeed in some other Crustacea; of the occasional replacement of their facets by a flagellum such as the antennae carry ; of their having a separate pair of lobes developed in connection with them in the supra-oesophageal ganglionic mass in ordinary Decapods, as shown by Rathkey, see p. I08, supra, in Amphipoda, and also

y Bruzelius, Archiv. für Naturgeschichte, tom. xxv., 1859, p. 306 ; Beiträg zur Kenntniss vom innern Baue der Amphipoden, has described the supra-oesophageal mass of an Amphipod, Amphithoe Podoceroides, as consisting of three pairs of ganglia, the most anterior of which is in relation with the eyes, the middle one with the antennules, and the one nearest the mouth with the antennae. Similarly Mr. Newport, Phil. Trans., 1834, p. 422, pl. xvii. fig. 40, $a, b$, c, has figured and described the supra-oesophageal nerve-mass in the common Lobster, Homarus Vulgaris, as consisting of three pairs of ganglia in relation with the three pairs of sensory organs specified. Though no air-breathing Arthropod has at any one period of its life more than a single pair of antennary organs, Rathke's figures of the cerebroid mass in the developing Scorpion, Morphologie, Reise nach Taurien, Taf. i. fig. 1o, and his description of it in contrast to the brain of the adult animal, as 'composed of several pairs of ganglia lying one behind the other,' and also Metschnikow's figures, Zeitschrift für Wiss. Zool., Bd. xvi. Taf. xxx., figs. 31, 33, though not his description of the brain in Aphis Rosae, lead us to think that the brain, even in these classes, may make its first appearance as a bilaterally trilobed mass, indicating thus the presence of three prae-mandibular segments.

Mr. Newport indeed has put on record, Phil. Trans., 1843, p. 245, an observation to the effect that in the embryo of a Chilopodous Myriapod, Geophilus Longicornis, the brain is at the moment of its bursting its shell composed of four double ganglia. But here it is probable that one of the pairs, as Metschnikow $l$. $c$. has shown to be actually the case in Aphis Rosae, corresponded to the 'lobi optici,' which are lateral outgrowths of the cerebroid ganglia, and do not therefore indicate the presence of a separate segment, though they may have been displaced inwards by lateral compression. See Leydig, Vergleich. Anat., p. 183. The brain in adult Myriapoda is very obviously quadrilobular, as has been noted. by Newport, locc. citt., of Scolopcnelia, Polydesmus, Geophilus Subterraneus when adult, and by Zaddach of Lithobius Forficatus. This point is particularly well shown in the brain of Glomeris Marginatu, a Myriapod closely resembling the Oniscus in external appenrance. It has been figured by Brandt, Müller's Archiv., 1837, Taf. xii. fig. 7, p.,324, as consisting of two irregularly quadrangular masses, prolonged at either outer angle into ocular and antennary nerves respectively, and united at either inner angle to each other by commissures passing over the oesophagus, and inclosing a wide open space between them. For the development of the prae-oral ganglia in Astacus, see liathke, Flusskrebs, p. 50. For the segnentation of the head, Rathke, Morphologic, rlp. I 26 , 
in Myriapoda, Geophilus, Lithobius and Scolopendra; and finally, that of their having an all but independent annular segment, as well as a peduncle, developed for their support in Squilla, appear to justify us in regarding the eyes as either being or, when sessile, as representing articulated appendages, and, by consequence, a distinct cephalic segmentz. The apparent paradox of speaking of the eyes, which ordinarily have a more or less completely dorsal position as homologous not with such dorsal outgrowths as the wings of insects or the shells of certain Crustacea, but with the ventrally placed articulated appendages, is to be justified by the history of the development of the pro-cephalic lobes, which at an early period are bent upwards at a right angle to the rest of the blastoderm, and even backwards, so that the roof of the skull, which is really a sternal, appears to be a tergal surface. Taking then the eyes as indicating one segment, and the two pairs of antennae and the three pairs of jaws as indicating five segments, we find that the typical number of segments in the head of the Arthropod amounts to six. The segments anterior to the maxillae, together with that part of the body which ultimately becomes the swimmeret, in the Astacus, Fritz Müller has called the 'primitive body,' as being that which makes up the 'Nauplius' form of larva, and which carries the sensorial apparatus, as, for example, the ear, which is lodged orilinarily in the scale of the second pair of antennae, but sometimes in the 'uropodos,' as in Mysis. The sections of the body which are intermediate to these extreme points, he divides into a 'fore-body,' which corresponds to what is here spoken of as 'thorax,' and which is second in order of development; into a 'hind-body', the 'post-abdomen,' deducting the sixth segment, which is third in order of development; and finally the 'middle body,' the 'abdomen' in the language here employed, which in Crustacea always puts forth limbs immediately after its segments are developed,

127. The demonstration of the points relating to the brain of Amphipoda, is made much more easy if acetic acid is added to the alcohol employed for hardening the specimens to be dissected.

${ }^{z}$ Two pairs of articulated appendages have been observed in the larval forms of Cirripedia anteriorly to the superior pair of their natatory antennae; and if the posterior of these be taken as equivalent to the 'olfactory filaments' of the superior antennae, the anterior, the 'larger' antennae' of Darwin, the so-called 'horns of the carapace' would still indicate the presence of a third pre-mandibular segment. For an account of these outgrowths, see Gerstaecker, Klassen und Ordnungen des Thierreichs, Bd v., p. 508 ; Spence Bate, Ann. and Mag. Nat. Hist., Ser. ii., vol. viii., 1851, p. 327 ; Fritz Müller, Archiv. für Naturgeschichte, 1862, p. 7, 1863, p. 25, note 2; Darwin, Lepadidae, 1851, p. 9 ; Balanidae, 1854 , p. 105. 
and which has a high degree of independence manifested by its nerve ganglia in Podophthalmata and Hedriophthalmata.

The number of the prae-oral segments being thus taken as three, and the so-called 'lips' of certain Crustacea being eliminated from the enumeration as not representing appendages, but being merely indurations of the lining membrane of the digestive tract homologous with the 'jaws' of the leech, we obtain, by omitting, for the reasons above stated, to count the telson as a segment, seventeen as the typical number of postoral, and twenty as the typical number of the entire series of segments in Arthropoda. The appended Table shows how these views may be applied to the Insecta, the Arthrogastrous Arachnida, Myriapoda, and to the two above-named orders of Crustacea, as also to the Copepoda; which, in spite of their small size, with which inferiority of organization has been supposed to be commonly correlated in Crustacea, present many important points of affinity to the highest order in the class. Amongst these may be mentioned the degree to which heteronomy or differentiation is carried out in the various regions of the body; and the external similarity which these small animals thus obtain to such Crustacea as Penëus and Mysis is made the more striking, when we recollect that they all alike leave the egg with no other appendages than those of the 'Nauplius ;' and that the adult Copepod corresponds very closely, if not exactly, as to the number of articulated appendages on its 'fore-' and 'middle-body,' with certain ' Zoea' stages in the development of Podophthalmata. See Spence Bate, Phil. Trans. $185^{8}$, pl. xl. figs. A and B; Claus Die frei Lebenden Copepoden, 1863, Taf. xxxiii. fig. 6; Dias Longiremis, Taf. xix., fig. 2, Thalestris harpactoides a. The non-segmentation of the post-abdomen in many of the parasitic Copepoda, as also in the Cladocera, Daphnis, the Ostracoda, Cypris and the Cirripedia, eliminates them as it does the non-Arthrogastrous Arachnida from consideration, except as to the anterior regions of the body. The Myriapoda together with a few Branchiopoda, Apus, and the extinct Trilobites, are similarly eliminated for the opposite reason.

The term 'Hedriophthalmata,' Schiödte, Ann. and Mag. Nat. Hist., Ser. iv., vol. i., 1868 , p. 6 , is employed in the following Table in the same restricted sense as its etymological equivalent, by Professor Westwood and Mr. Spence Bate, in their work on the Sessile-eyed Crustacea.

a The internal anatomy of the Copepoda is well illustrated in the former of these two figures; the dorsal opening of the anus being especially noteworthy, as corresponding with a condition observed by Rathke, in the early stages of the development of the Astacus, see p. 97, supra. 


\section{OF POST-ANTENNARY SEGMENTS}

\begin{tabular}{|c|c|c|c|c|}
\hline $\begin{array}{l}\text { Number } \\
\text { of } \\
\text { Segment. }\end{array}$ & Insecta. & Arachnida. & Myriapoda. ' & Crustacea. \\
\hline I. & $\begin{array}{l}\text { Mandible, never pal- } \\
\text { pate. }\end{array}$ & $\begin{array}{l}\text { 'Chelae' of Scorpion } \\
\text { are the palps of its } \\
\text { mandible. The so-call- } \\
\text { ed 'maxillae' of Spiders } \\
\text { are also palpate. }\end{array}$ & $\begin{array}{l}\text { Mandible, with rudi- } \\
\text { mentary palp in Chilo- } \\
\text { poda; not palpate in } \\
\text { Chilognatha. }\end{array}$ & $\begin{array}{l}\text { Mandible, ordinarily } \\
\text { carrying a tri-articu- } \\
\text { late palp, exept in } \\
\text { terrestrial Isopods and } \\
\text { Amphipods. }\end{array}$ \\
\hline II. & Maxilla, palpate. & $\begin{array}{l}\text { First pair of legs are } \\
\text { the palps of the 'la- } \\
\text { bium." }\end{array}$ & $\begin{array}{l}\text { Outer element of 'La- } \\
\text { bium,' in both orders, } \\
\text { as in Lepidopterous } \\
\text { larva. }\end{array}$ & $\begin{array}{l}\text { 'Mraxilla' i. or 'Siag- } \\
\text { onopodos' } i \text {. Westwood } \\
\text { and Bate in 'Sessile- } \\
\text { eyed Crustacea,' p. } 3 \text {. }\end{array}$ \\
\hline III. & ‘Labium,' palpate. & Second pair of legss. & $\begin{array}{l}\text { Mesial elements of } \\
\text { 'Labium." }\end{array}$ & $\begin{array}{l}\text { 'Maxilla' or 'Siagono- } \\
\text { podos' ii. Bifid, Cyclops. }\end{array}$ \\
\hline IV. & $\begin{array}{l}\text { First pair of legs. } \\
\text { First spiracle in Cater- } \\
\text { pillar. }\end{array}$ & Third pair of legs. & $\begin{array}{l}\text { Basal joints forming } \\
\text { a Labium by junction. }\end{array}$ & $\begin{array}{l}\text { 'Maxilliped' i. Auctt. } \\
\text { 'Siagonopodos' } \\
\text { Westwood and Bate. }\end{array}$ \\
\hline V. & Second pair of legs. & Fourth pair of legs. & $\begin{array}{l}\text { Basal joints as in vii, } \\
\text { and in Chilopoda arm- } \\
\text { ed with claw and poi- } \\
\text { son duct. }\end{array}$ & $\begin{array}{l}\text { 'Maxilliped' ii. or } \\
\text { 'Gnathopodos'i. Last } \\
\text { foot of early Zoea Lar- } \\
\text { va. }\end{array}$ \\
\hline VI. & Third pair of legs. & $\begin{array}{l}\text { Genital segment in } \\
\text { Scorpion. }\end{array}$ & $\begin{array}{l}\text { Genital opening in } \\
\text { some chilognatha. } \\
\text { Simple pair of legs in } \\
\text { Chilopoda. }\end{array}$ & $\begin{array}{l}\text { 'Maxilliped', } \\
\text { 'Gnathopodos, or } \\
\text { Third swimming foot, } \\
\text { Cyclops. }\end{array}$ \\
\hline VII. & $\begin{array}{l}\text { First abdominal seg- } \\
\text { ment. Second spiracle } \\
\text { in Caterpillar. }\end{array}$ & $\begin{array}{l}\text { Per'tiniferous seg- } \\
\text { ment in Scorpion. }\end{array}$ & $\begin{array}{l}\text { Simple pair of legs in } \\
\text { both Chilognatha and } \\
\text { Chilopoda. }\end{array}$ & $\begin{array}{l}\text { First ambulatory ap- } \\
\text { pendage of Astacus; } \\
\text { third of Amphipod. } \\
\text { 'Pereiopodos'i. West- } \\
\text { wood and Bate. }\end{array}$ \\
\hline VIII. & $\begin{array}{c}\text { Second abdominal } \\
\text { segment. }\end{array}$ & $\begin{array}{l}\text { First pulmoniferous } \\
\text { segment in Scorpion. }\end{array}$ & Ditto, ditto. & 'Pereiopodos' ii. \\
\hline IX. & $\begin{array}{l}\text { Third abdominal seg- } \\
\text { ment. Carries first pro- } \\
\text { leg of Caterpillar. }\end{array}$ & $\begin{array}{l}\text { Second pulmoniferous } \\
\text { segment in Scorpion. }\end{array}$ & Ditto, ditto. & $\begin{array}{l}\text { 'Pereiopodos' iii. In } \\
\text { basal joint of append- } \\
\text { age or in sternum of } \\
\text { segment we find the fe- } \\
\text { male generative outlet. }\end{array}$ \\
\hline $\mathrm{x}$. & $\begin{array}{l}\text { Fourth abdominal } \\
\text { segment. Second pro- } \\
\text { leg of Caterpillar. }\end{array}$ & $\begin{array}{l}\text { Third pulmoniferous } \\
\text { segment in Scorpion. }\end{array}$ & $\begin{array}{l}\text { Simple pair of legs in } \\
\text { Chilopoda and female } \\
\text { Chilognatha. Penis in } \\
\text { male Chilognatha. }\end{array}$ & $\begin{array}{l}\text { 'Pereiopodos'iv.abort- } \\
\text { ed, as also iii. and v. in } \\
\text { Copepoda. }\end{array}$ \\
\hline XI. & $\begin{array}{l}\text { Fifth abdominal seg- } \\
\text { ment. Third proleg of } \\
\text { Caterpillar. }\end{array}$ & $\begin{array}{l}\text { Fourth pulmoniferous } \\
\text { segment in Scorpion. }\end{array}$ & $\begin{array}{l}\text { Simple pair of legs in } \\
\text { Chilopoda. Double pair } \\
\text { in Chilognatha. }\end{array}$ & $\begin{array}{l}\text { 'Pereiopodos' v. In } \\
\text { basal joint of append- } \\
\text { age or in sternum of } \\
\text { segment male genera- } \\
\text { tive outlet in Podoph- } \\
\text { thalmata and Hedri- } \\
\text { ophthalmata. }\end{array}$ \\
\hline
\end{tabular}




\section{MARKED BY APPENDAGES IN ARTHROPODA.}

\begin{tabular}{|c|c|c|c|c|}
\hline $\begin{array}{l}\text { Number } \\
\text { of } \\
\text { Segment. }\end{array}$ & Insecta. & Arachnida. & Myriapoda. & Crustacea. \\
\hline XII. & $\begin{array}{l}\text { Sixth abdominal seg- } \\
\text { ment, Fourth proleg } \\
\text { of Caterpillar. }\end{array}$ & $\begin{array}{l}\text { First caudal segment } \\
\text { in Scorpion. }\end{array}$ & $\begin{array}{l}\text { Simple pair of legs in } \\
\text { Chilopoda. Double pair } \\
\text { in Chilognatha. }\end{array}$ & $\begin{array}{l}\text { First post-abdominal } \\
\text { segment. 'Pleopodos' } \\
\text { i. Generative outlets } \\
\text { in Copepoda. }\end{array}$ \\
\hline XIII. & $\begin{array}{l}\text { Seventh abdominal } \\
\text { segment. Last gang- } \\
\text { lion in larva. }\end{array}$ & $\begin{array}{l}\text { Second caudal seg- } \\
\text { ment in Scorpion. }\end{array}$ & Ditto, ditto. & 'Pleopodos' ii. \\
\hline XIV. & $\begin{array}{l}\text { Eighth abdominal } \\
\text { segment. Ninth spi- } \\
\text { racle and horn of } \\
\text { Sphinx larva. }\end{array}$ & $\begin{array}{l}\text { Third caudal seg- } \\
\text { ment in Scorpion. }\end{array}$ & Ditto, ditto. & 'Pleopodos' iii. \\
\hline XV. & $\begin{array}{l}\text { Ninthabdominal seg- } \\
\text { ment. Vulva opens in } \\
\text { front of it and outlet } \\
\text { of Spermatheca upon } \\
\text { its sternum in Cock- } \\
\text { roach. Symmetrical } \\
\text { depression on the me- } \\
\text { sial ventral line in } \\
\text { pupae of Sphingidae. }\end{array}$ & $\begin{array}{l}\text { Fourth caudal seg- } \\
\text { ment in Scorpion. }\end{array}$ & Ditto, ditto. & $\begin{array}{l}\text { 'Pleopodos' iv. or } \\
\text { 'Uropodos' } \mathrm{i} \text {. }\end{array}$ \\
\hline$X V I$. & $\begin{array}{l}\text { Tenth abdominal seg- } \\
\text { ment. Orifice of col- } \\
\text { leterial glands of Cock- } \\
\text { roach. }\end{array}$ & $\begin{array}{l}\text { Fifth caudal segment } \\
\text { in Scorpion. }\end{array}$ & $\begin{array}{l}\text { Last segment in Pau- } \\
\text { ropus, see Lubbock, } \\
\text { Limn. Soc. Trans. xxvi. } \\
\text { pp. 182, 184. }\end{array}$ & $\begin{array}{l}\text { 'Pleopodos' v. or } \\
\text { 'Uropodos' ii. }\end{array}$ \\
\hline XVII. & $\begin{array}{l}\text { Eleventh abdominal } \\
\text { segment. Anal orifice. } \\
\text { The 'cerci anales' are } \\
\text { carried by it in Panor- } \\
\text { pa, and are supposed } \\
\text { to belong to it in other } \\
\text { insects Wy Lacaze Du- } \\
\text { thiers, Ann. Sci. Nat. } \\
\text { 1852, 1853. They are } \\
\text { probably homologous } \\
\text { with the caudal ap- } \\
\text { pendages of Apus and } \\
\text { Branchipus, sec p. 111, } \\
\text { supra. }\end{array}$ & $\begin{array}{l}\text { Sixth caudal segment } \\
\text { of Scorpion carrying } \\
\text { sting on its apex. An } \\
\text { appendage homologous } \\
\text { probably with mesial } \\
\text { clement or 'telson' of } \\
\text { Astacus. }\end{array}$ & - & 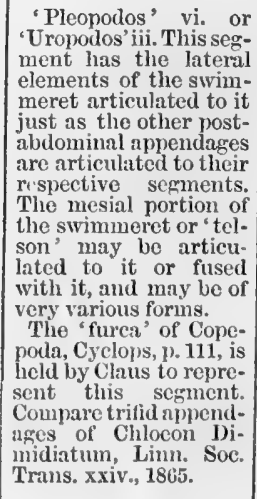 \\
\hline
\end{tabular}


A very clear account of the nerve system of the various orders of Crustacea may be found in Frey and Leuckart's Lehrbuch der Zootomie, $1847, \mathrm{pp}$. 195, 623.

For an account of the development of the nervous system of the Crayfish, see Rathke, Ueber die Bildung und Entwickelung des Flusskrebses, 1829 , pp. 32, 33, 50, 61, 64, 85. For that of the Scorpion, see Rathke, Morphologie Reise nach Taurien, p. 28, cit. Huxley, Linn. Soc. Trans., vol. xxii., pp. 227, 228.

For a figure of the nervous system in the common Lobster, Homarus Vulgaris, see Newport, Phil. Trans., 1834, pl. xvii. fig. 40; where, however, the evident constriction of the first post-oral ganglionic mass has caused the writer to count it as two, and to speak of the entire number of ventral ganglia as being thirteen. The relative superiority in size of this first post-oral ganglion is not so marked relatively to those which come posteriorly to it in the marine as it is in the fluviatile species here contrasted.

For the nervous system in the Decapodous Crustacea generally, see Leydig, Vergleichende Anatomie, Bd. i. p. 253, ibique citata.

For the stomato-gastric system, see Huxley, Medical Times and Gazette, April I I т 857 , p. 353; Brandt, Ann. Sci. Nat. Ser. ii. tom. v, 1836, p. 87, pl. 4 , figs. I, 2,3 .

For the nervous system of Myriapoda and Macrurous Arachnida, see Newport, Phil. Trans., 1843, pt. ii. pp. 243-272; and for the structure of the cord, p. 248, and Phil. Trans., 1834, p. 406, pl. xvii. fig. 42; Leydig, Vergleich. Anat., pp. 229241 ; and Helmholtz cit. in loc.; Carpenter, Comp. Physiology, p. 669 .

For various views as to the homologies of the segments, see Savigny, Mémoires sur les Animaux sans Vertèbres, 1816; Milne-Edwards, Histoire Naturelle des Crustacés, I 834, p. 50; Ann. Sci. Nat., I 851 ; Erichson, Entomographien, 1840; Lacaze Duthiers, Ann. Sci. Nat., Ser. iii. tom. xvii., 1852, pp. 227, 232, 233, tom. xix., pp. 34, 40, 229-233; Dana, Crustacea, U. S. Exploring Expedition, 1852, p. I9 seqq.; Zenker, Archiv. für Naturgeschichte, 1854, p. I I8; Van der Hoeven, Handbook of Zoology, English translation, vol. i., I856, p. 557, ibique citata; Huxley, Linn. Soc. Proc., vol. 
xxii., 1858, p. 228 ; Van Beneden, Recherches sur les Crustacés, 186I, p. 29; Claus, Copepoden, 1863, pp. I3-18; Gerstaecker, Klassen und Ordnungen des Thier-reichs, I866, Bd. v., pp. 38, 48, 3.33, 339 ; C. Spence Bate and Westwood, British Sessile Crustacea, I 868 , vol. i. pp. viii.-xxi., 3-7, vol. ii. pp. 102-105.

For the reckoning of the eyes as appendages indicating the presence of a distinct segment, see Zaddach, Untersuchungen über die Entwickelung und den Bau der Gliederthiere, pp. 78, 87; Gerstaecker, Klassen und Ordnungen des Thier-reichs, Bd. v., pp. 202, 343; Alphonse Milne-Edwards, Comptes Rendus, lix., p. 7 Io, f.

\section{Common Earthworm (Lumbricus Terrestris),}

\section{Prepared so as to show the external organs which subserve locomotion and reproduction.}

The epidermis forms an iridescent capsule for the animal's body, the tissues of which have shrunk a little away from it under the action of spirit. The integument is at various points to be hereafter specified, thickened and intumescent, but these thickened portions are all developed in relation to the function of reproduction, there being no specialized organs of respiration. A thickened white ring, the 'clitellus,' made up of the fusion of the dorsal and lateral portions of about six segments, may be seen in the middle third of the body. The thickened glandular threefourths of these segments are separated off from the ventrally placed and unthickened fourth, by a hyaline slightly elevated ridge, which is muscular and more constant in its characters from species to species than the glandular portion of the clitellus. On either side of this ridge may be seen the rows of setae, the inner one of which has its spines much lengthened. An orifice with prominent tumid lips produced similarly to the clitellus by the development of the glandular layer of the integument, is seen on the fifteenth segment of the body, and corresponds to the termination of the vas deferens on either side. A somewhat similar but smaller prominence may be observed on either side the middle line of a 
segment sixth in order anteriorly to the clitellus. In this prominence there is no foramen, but tro spines modified so as to co-operate with the clitellus as an organ of adhesion in the act of copulation may be observed to be implanted in it. These spines belong to the inner series of locomotor spines, which are prolonged from the third or fourth or fifth segment of the body anteriorly, down to the posterior segments, upon the last of which they, as well as the spines of the outer series, fail to be developed. The outer row of spines is very visible along the line where the darker coloured dorsal region shades off into the lighter coloured ventral. Each series is represented in the Lumbricidae by two spines only; the multiple or fasciculate arrangement not being found in this family, which are therefore pre-eminently 'oligochaetous.' The external series is wanting not rarely upon the anterior segments, and may be wanting even as far back as the clitellus inclusively. The spines of the inner series are modified so as to subserve the mutual adhesion of the allotriandrous Lumbricus in the act of copulation, not only in the segment already specified, but also in the entire series of segments occupied by the clitellus, and in the tenth and fifteenth segments, where they are thinner and twice as long as in other segments. The oviducts and the vasa deferentia open in the fourteenth and fifteenth segments respectively, just externally to the outer of the two setae of the inner row. In large specimens of Lumbricus communis, an orifice may often be noted in the median dorsal line, in the interspace between the rings from the tenth segment or so backwards. From this orifice, which opens into the interior of the posterior of the two segments between which it is placed, in a recently killed animal, the peri-gastric fluid may be seen to escape in small jets upon pressure. Much variety is observable in the condition of development of the clitellus, and even the number of segments composing it and interposed between it and the head are by no means uniform within the limits of the same species.

For the zoological characters of the family Lumbricidae, see British Museum Catalogue of the British Non-parasitical Worms, by George Johnston, M.D., I865, pp. 57, 318, and especially p. 323 for the variability in external anatomy just mentioned. For the anatomy of Lumbricus, see E. Ray Lankester, Esq., Quar- 
terly Journal of Microscopical Science, 1864-1865, ilique citata.

See also D’Ukedem, Mémoires de l'Academie Royale de Belgique, tom. xxxvi., I 865 .

A monograph on the natural history and anatomy of the Lumbricus Terrestris, of considerable merit, was published in Latin by C. F. A. Morren in 1829 , under the title "De Lumbrici Terrestris Historia Naturali neenon Anatomia Tractatus.'

\section{Common Earthworm (Lumbricus Terrestris),}

Dissected so as to show its gangliated nervous system consisting of a bilobed supraoesophageal mass and a ventrally placed nerve-cord, connected with each other by commissures, which give off numerous branches on either side to the large sympathetic ganglionic mass lying upon either side of the pharynx.

THE integuments having been divided down the middle dorsal line and fastened out on either side, the entire digestive tract with the exception of the commencement of the pharynx, through which a black bristle has been passed, has been removed, together with the pseud-haemal vessels in connection with it; the segmental organs, and the muscular dissepiments dividing the body into compartments. The organs of reproduction have been similarly removed, with the exception of the two receptacula seminis of the right side, two globular white sacs which are seen opening in the line of the outer rows of setae, in the intervals between the ninth and tenth, and between the tenth and eleventh segments respectively: The two lobes making up the supra-oesophageal mass are pyriform, and have their broader ends apposed to each other in the middle line. From their outer and narrower ends a thick nerve passes off, bifurcating almost immediately, to supply the proboscidiform and tactile anterior segment or upper lip. These nerves would appear to be homologous with those given off from the post-oral ganglia, and the anterior or upper surface of the ganglionic mass whence they are given off to be homologous with the under surface of the ventral ganglia. The cords of commissure to the first ventral ganglion pass downwards and form the nerve 
collar in which a part of the pharynx is still left. Upon either side of the pharynx a reticulation of ganglionic masses may be seen with a lens, one of which masses is much larger than the rest, and running parallel with the commissural cords is connected with them by six or more nerve branches. Two distinct strands may be distinguished in the anterior portion of the ventral cord, and they are underlaid by a continuous stratum of vesicular substance, which at intervals is aggregated into more or less distinct ganglia, from each of which a pair of nerves is given off on either side, whilst a single nerve is given off on each side from the portion of the cord interposed between each two pairs of ganglia. These latter nerves may probably be considered as homologous with the nervi transversi of the Arthropoda, and as serially homologous with the branches of the plexus already described as existing upon the pharynx. They are given off in each segment anteriorly to the paired nerves, and take a course outwards in relation with the posterior aspect of the anterior dissepiment of each segment. They are accompanied by a branch from the sub-neurally placed pseudhaemal vessel, whilst the paired nerves are similarly accompanied by a branch from one of the pseud-haemal vessels on either side of the nerve cord. The ventral cord takes the shape of a thick band in which the ganglionic enlargements are difficultly recognizable for a space corresponding with that occupied by pharynx oesophagus and reproductive organs; posteriorly to the fifteenth segment it becomes much slenderer, but the ganglia become much more distinguishable, though separated by wide interspaces up to a point a little way posterior to the middle of the entire length of the body. Finally, for a length nearly equal to that of the posterior half of the animal, the cord becomes much more distinctly moniliform, its ganglionic enlargements being very plainly marked though very closely apposed. The terminal ganglion of the chain is, contrary to what is seen in some other Annelids, as also in many Arthropoda, smaller than those which precede it. The ganglia do not maintain the same numerical equality with the segments in other Annelids as in Lumbricus, exceeding their number in some, as Aphrodite, and falling below it in others, as Hirudo, see Preps. 4I, 42. The two rows of paired setae are well seen on either side of the middle line; the inner setae in the two segments fifth and sixth in order anteriorly to the clitellus are seen together with the 
glandular follicle secreting them to be considerably enlarged in relation to their function as accessory generative organs.

In the anterior fifteen segments in the interval between the inner row of setae and the nerve cord, a white muscular fascicle is seen passing forwards and finally upwards alongside of the commissural cords of the nerve collar, and dorsally to the nerves given off from the first ventral ganglion, to be inserted partly in the capsule of the cephalic ganglia, and partly in the muscular and tegumentary tissues above them. No muscular fibres are developed upon the commissural cords connecting the ventral chain with the supra-oesophageal ganglia, as there are upon the ventral cord itself; and the function of retracting the supra-oesophageal ganglia, together with the structures above them, is performed by the muscle here described, which from its origin and course acts at great advantage. These two muscular bands have at first sight an appearance closely similar to that presented by the two somewhat widely separated halves of the ventral cord of the Tubicolar Annelids, and of Peripatus, or to that of the accessory nerve-chains, developed in the Amphinomidae in relation with the locomotor organs.

For an excellent account of the nerve system of the Earthworm, see Lockhart Clark, Royal Society's Proceedings, 1857, pp. $344-351$.

For figures of the general arrangement of the nerve system, see pl. viii., and Description. Quatrefages, Règne Animal Annelés, pl. i. $e$, fig. $2 a$, and Ann. Sci. Nat., Ser. iii., tom. viii., $\mathrm{r} 847, \mathrm{p} .3^{6}$, for discovery of sympathetic system in Lumbricus. See also D'Ukedem, l. c., pl. iii. fig. 4.

For the histology, see Leydig, Tafeln zur Vergleich. Anat., iv., fig. 8, and the various authors cited in the letter-press of that work at pp. 138 seqq., 168 seqq.

For figures of the nerve cord as existing in two separated halves, see Grube, in Müller's $\Lambda$ rchiv. for 1853, Taf. x., 14. Quatrefages, 'Suites à Buffon,' Annelés, pl. iii., figs. 7 and 8 ; in Peripatus Edwardsii, and Sabella and Serpula. 


\section{Anterior Segments of Earthworm}

\section{(Lumbricus Terrestris),}

In number about forty, and including three placed posteriorly to the clitellus; dissected so as to show the reproductive system, the whole of which, together with the various accessory organs, is contained in or constituted by modifications of the structures of these segments; as also the portions of the pseud-haemal and the digestive system which are contained in this part of the animal's body.

THe integument having been divided down the middle dorsal line and pinned out on either side, the digestive tract is seen to occupy the middle line of the Preparation, and to have in connection with it the vascular system, which is called 'pseud-haemal,' because though the fluid which it contains is coloured and probably respiratory in function, it is not corpusculated, and therefore not morphologically blood. The digestive tract manifests a very considerable degree of heteronomy, consisting of a pharynx which extends through the first six segments; an oesophagus which extends through the succeeding ten; a crop which occupies a large space in the sixteenth and seventeenth; a gizzard which is seen in the seventeenth and eighteenth; and finally, the intestine which is laterally sacculated for its first eight segments, and posteriorly to them more evenly cylindriform. The pharynx has a coarsely villous exterior, orving partly to the breaking arvay in the dissection of the muscular bands by which it was connected with the muscular dissepiments and with the body-walls, and partly to the salivary gland-tissue which composes part, and especially the outer part, of its walls. The oesophagus is of much smaller calibre than either of the two segments of the digestive tube, the pharynx and the crop which it connects. The so-called 'hearts' are in close connection with it in the anterior segments of its course, and the reproductive and certain oesophageal glands are seen at its sides in the middle and posterior. The crop is considerably distended with dark coloured contents, and forms a larger mass than the thicker coated lighter coloured gizzard which comes next behind it. The dorsal pseud-haemal vessel is well seen along the median dorsal line of the crop and intestine, where owing to the contraction of its muscular walls it has a moniliform appearance. 
Posteriorly to the gizzard the dorsal vessel is seen to give off tiro, or sometimes three, vessels in each segment on each side, which pass round the intestine, in close connection with its walls, and indeed invested by the glandular hepatic tissue which forms here the exterior layer of the coats of the tube, to join a sub-intestinal vessel. This vessel is not so closely attached to the digestive tube as is the dorsal vessel, but is loosely suspended between the nerve cord and the intestine. It gives off branches to the segmental organs, and is connected with a third set of longitudinal vessels which are in close relation with the several aspects of the nerve cord, one inferiorly and two laterally, and send branches outwards with the nerves. In possessing this vascular supply to the segmental organs, and this third set of longitudinal vessels, the Lumbrici differ from other Oligochaetous worms. The commissural vessels connecting the dorsal and the sub-intestinal are reduced in number to a single pair in each segment, anteriorly to the crop and posteriorly to the pharynx; but they are so much enlarged in size as to have been called 'hearts,' in about six segments posteriorly to the pharynx. In the first six segments of the body corresponding with the pharynx, both the dorsal vessel and the commissural vessels are resolved into plexuses.

Anteriorly to the crop and in the line of the outer row of setae are seen the large pendulous lobes which are the vesiculae seminales, increasing in size from the ninth segment, where the first of the three is attached, backwards. On the left side, the posterior having been displaced a little backwards from the middle vesicula seminalis, the corrugated funnel-shaped opening of the posterior of the two branches of the left vas deferens is seen in the interval between them. Immediately exteriorly to the line of attachment of the vesiculae seminales are the so-called 'capsulo-genous' glands, which appear to be due to the development in these segments of the setiparous glands of the inner row of setae; and more exteriorly again, in the intervals between the ninth and tenth and the tenth and eleventh segments, are seen the two globular receptacula seminis in the line of the external series of locomotor setae. On the walls of the oesophagus, in the segments corresponding to the two posterior vesiculae seminales, may be seen the oesophageal or 'calciferous' glands, structures said to attain a great development in the Perichactous worms. On the internal surface 
of the body-walls are seen the remnants of the muscular dissepiments which gave to the body and to the digestive tract their annulate appearance. Near the line of the inner row of setae, a little way exteriorly to which they ordinarily but not invariably have their external outlet, are to be seen the 'segmental organs,' which are muciparous glands forming complexly convoluted coils, attached by a sort of mesenteric membrane to the muscular dissepimental walls of the segments in which the greater part of their length is lodged, and prolonged through the anterior wall of this segment into the segment next in front, to end by expanded and ciliated infundibula near the middle line and the ventral surface.

For a description and figure of the reproductive organs of the Lumbricus Terrestris, see pl. viii. infra; and Hering, Zeitschrift für Wiss. Zool. viii., I 857, p. 400. See also D'Ukedem, Mémoires Couronnés Acad. Belg., I 856, tom. xxvii., p. 9 seqq.; Mém. Acad. Roy. Belg., tom. xxxv., I865, pl. ii., figs. 2 and 3 .

For the 'segmental organs,' see Gegenbaur, Zeitschrift für Wiss. Zool. iv., I853, p. 221. See also a note by Hering, $l$. $c$. p. 40I, and for the homologies of these organs with the efferent ducts of the reproductive glands, see Claparede, Recherches Anatomiques sur les Annélides, Turbellariés, \&c., 186I, p. 28 ; and Lankester, Journal Micr. Soc., 1865, p. 7.

For the oesophageal glands, see Lankester, l. c., I864, p. 265; and D’Ukedem, Mém. Acad. Roy. Belg., tom. xxxv., pl. i. fig. ıо, p. 23 .

For the Perichaetous Worms, see D'Ukedem, l. c., pp. 30, 3I ; Schmarda, Neue Wirbellose Thiere, 186 I, i. I, p. I3.

For the classification of the Annelids generally, see Grube, Die Familien der Anneliden, 1851 ; Ehlers, Die Börstenwürmer, 1864-1868, vol. i., pp. 52-57; Claparède, Annals and Magazine of Natural History, Ser. iii., vol. xx., I867, p. 337. 


\section{Medicinal Leech (Hirudo Medicinalis),}

Showing the terminal suckers, the segmentation and annulation of the body, and the distinctively coloured dorsal bands which differentiate the variety Hiruclo medicinalis from the variety Hirudo officinalis.

THE number of annuli may be taken as about one hundred; but these annuli appear to be due merely to secondary corrugation of the primary segments of the body, each of which comprises from three to five of the secondary annuli. The primary segments are not so readily distinguishable as the smaller rings; but in a freshly killed specimen, two white spots on either side the median line and in a line with the central pair of eyes are considered to mark out the anterior boundary of each segment; whilst the posterior boundary is given by the openings of the two muciparous or segmental organs on the ventral surface, from which jets of fluid can be made to issue by pressure, especially on the posterior part of the body. The black pigment specks which are seen in this variety upon the outer and middle of the three tawny stripes on either side of the dorsum seem, by attaining a great size and prominence on every fifth annulus, to point in the same direction as those more constant land-marks just specified, and to mark out in each case a segment consisting of five annuli. Fewer annuli are interposed between each pair of the dorsally placed white specks at either extremity of the body, than in the intervening space occupied by the middle regions of the body. Upon the anterior sucker a pair may be found upon almost every one of four halfcircles of which it is made up, whilst the posterior sucker appears at certain periods of its development to be made up of no less than seven segments, to which seven ganglia subsequently fused together correspond, just as in the rest of the body each pair of white specks on the dorsal surface corresponds to the nerve ganglia on the ventral. This aggregation of segments at either end of the body corresponds firstly to the externally visible concentration of the animal functions of special sense, prehension of food, and locomotion in the region of either sucker; and secondly to a concentration of nerve ganglia and an abortion of the reproductive and depuratory or muciparous organs which are vegetatively 
repeated in each of the intervening segments of the body's length. The anterior sucker is perforated centrally by the mouth, and is prolonged superiorly into an obtusely lanceolate lip consisting of four rings. It is not separated by any constriction from the rings immediately succeeding it, whilst the posterior sucker is very markedly so separated, has the anus opening in the line of this constriction, and differs consequently still further from the anterior sucker in being imperforate and having an evenly circular uninterrupted rim. Ten eyes are carried in pairs upon the three first rings of the upper lip-like portion of the anterior suckers, and also upon the fifth and eighth segments, the ten eyes as thus arranged forming an ellipse.

The male generative orifice from which the penis is sometimes in this species, and very ordinarily in the common Horse-leech, Aulostoma gulo, protruded when the animal has been killed with chloroform, is visible in the interval between the twenty-fourth and twenty-fifth segments; and at an interval of five segments posteriorly, the female generative orifice is seen in the interval between the twenty-ninth and the thirtieth segments.

A series of raised granular but minute tubercles may be observed crossing the dorsal line in many segments, and representing in miniature the warty exterior of Pontobdella.

The external colouration of the Leech is very variable, and hence the more or less strikingly regular development of black patches at intervals of five rings in the rust-coloured line on the dorsal is of the greater morphological importance. The amount of pigment specks on the ventral surface is especially variable, and there does not appear to be any regularity as to their distribution when present.

For an excellent monograph of Hirudo Medicinalis, see Brandt and Ratzeburg, Medizinische Zoologie, I 833, Bd. ii., pp. 230-297, Taf. xxviii., xxix. A, xxix. B, xxx. See also Moquin Tandon, Monographie de la Famille des Hirudinées, 1846 ; Leuckart, Die Menschlichen Parasiten, I 863, pp. 634-739; Claus, Grundzüge der Zoologie, pp. I54-16I; Gratiolet, Ann. Sci. Nat., Ser. iv., tom. xvii., 1862 , pp. $177-182$, for the general outlines of the body.

For certain organs of which as many as sixty may be found upon 
the cephalic, and some upon other segments of the body, and which, as resembling the 'becher-formige Organe' of fish, may be supposed to be sensory in function, and concerned possibly with the perception of chemical rather than of other stimuli, see Leydig, Archiv. für Anatomie und Physiologie, I861, p. 599; Tafeln zur Vergleich. Anatomie, iii. I ; F. E. Schultze, Zeitschrift Wiss. Zool. xii., I862, p. 222.

\section{Medicinal Leech (Hirudo Medicinalis),}

Prepared and dissected so as to show its laterally sacculated stomach and its intestine, in their natural relatious to the ventral chain of ganglia inferiorly, and the pharynx anteriorly.

A stiffening injection having been thrown into the digestive tube, the specimen was hardened in spirit. After this, the integument having been divided down the middle dorsal line and reflected outwards, the portions of the pseud-haemal system which were interposed between the digestive tract and the dorsal surface were removed, and the entire cavity of the 'stomach' and of its diverticula exposed by the removal of its upper wall. Anteriorly to the stomach is seen the pharynx with a villous exterior, much resembling that in the earthworm ${ }^{b}$ as seen by the naked eye, as also when its constituent elemerits, unicellular gland cells and involuntary muscular fibre, are examined under the microscope. Partly concealed by this villous exterior of the commencement of the digestive tract, may be seen the prae-oral ganglionic mass. The walls of the portion of the digestive tube which comes next after the pharynx, are much thinner than those of the pharyox itself, and consist mainly of a structureless basement membrane and an internal layer of pavement epithelium; its muscular coat being almost wholly aborted, as in the Ophidia (see p. 30), and its functions discharged by the muscular layer of the body-walls. This portion of the digrestive tube has a much larger calibre than the pharynx, and has lateral diverticula appended to it on either side, which occupy five-sixths of the entire cavity of the body. These 
lateral diverticula are eleven in number, the two anterior being smaller than the nine succeeding ones, and differing from them also in not having their outer angles prolonged backwards. The last pair of diverticula are twice the length of any other pair, and bending sharply back almost immediately at their commencement, so as to become apposed to each other along the middle line, are prolonged backwards up to a point on a level with the commencement of the rectum, and nearly up to the termination of the body. The digestive tube is of very small calibre posteriorly to the point of origin of the two last diverticula, and lies in the interval between them superiorly. The diverticulate portion of the digestive tract is called a 'stomach' by most writers, but it is considered to be homologous and analogous with a crop or dilated oesophagus by Gratiolet, on account of its resemblance to the crop of the Horse-leech (Aulostoma gulo), and on account of its functions, which appear to be merely the squeezing out the watery part of the blood which the animal swallows, and allowing it to be discharged by the segmental organs. Dissepiments run transversely across the body, and interpose themselves between the apposed walls of the several diverticula. The central emargination in each of the septa thus formed, corresponds to what was the anteroposterior part of the digestive tube in the region of the diverticula; the method of preparation has given the shape of an ellipse to what was, in the natural state of the parts, a circular foramen in a diaphragm. A rudimentary dissepiment passes off from the posterior aspect of each of the eight larger dissepiments, inwards and backwards, within the cavity of each diverticulum towards the middle line; but it is not prolonged quite up to the line of the chain of nerve-ganglia. An accessory compartment is thus added on to each of the diverticula from the third to the tenth inclusively; whilst the eleventh pair has five pairs of accessory imperfect dissepiments, introdigitating along their interior. The ganglia of the ventral chain are seen towards the posterior part of each compartment, constituted by the median portion of the digestive and its lateral appendages; and in some cases they are in immediate relation with the anterior face of the dissepimental wall. A black bristle has been introduced into the segments of the digestive tract, posteriorly to the point where the last diverticula are given off. The 'oesophageal' portion of the tract projects and 
opens as a nipple-shaped process, into the bilobed commencement of what Gratiolet calls the 'gastroileal' intestine, the mucous membrane of which is prolonged into spirally-arranged valvular folds. This 'gastroileal' intestine ends in an ovoidal colon; and this again in a short rectum of very small calibre, which terminates in a dorsally-placed anus, as in all Hirudineae except Acanthobdella.

For description of digestive tract, see Gratiolet, Ann. Sci. Nat. Ser. iv., vol. xvii., pp. 182, 188, 197; Brandt, Medizin. Zoolog., Bd. ii., p. 246.

For figures of the digestive tract of the Horse-leech, see Moquin Tandon, Monographie des Hirudinées; Atlas, pl. v. fig. I1; Gervais and Van Beneden, Zoologie Medicale, I859, p. I 86.

\section{Medicinal Leech (Hirudo Medicinalis),}

Dissected so as to show its nervous system.

A PART of the pharynx and the jars are still left $i n$ situ, and a black bristle has been passed through the remaining part of the pharynx, where it is embraced by the nerve collar. There are in the Leech twenty-two ventral ganglia, the most anteriorly placed one of which is connected by commissures with the supra-oesophageal mass. This mass is seen above the pharynx, part of the glandular and muscular walls of which have been removed to show it, in situ, and immediately posteriorly to the middle one of the three jaws. In the narrow interspace between these two structures is seen a minute mesial stomato-gastric ganglion, which is connected with the supra-oesophageal ganglia, and sends nerves to the semilunar saw-like jaw and its muscles; and a similar ganglion similarly connected with the supra-oesophageal mass, may be seen on either side, sending nerves similarly to either of the two lateral jaws. Each lobe of the supra-oesophageal mass gives off three other nerves, whence the five eyes of either side and certain other, probably sensory, organs, the 'becher-formige Organe' of' Leydig, are supplied. The first sub-oesophageal ganglion is much 
larger than any which come after it; it gives off five pairs of nerves, and is connected by very short commissural cords to the supra-oesophageal ganglia anteriorly, as also to the second ventral ganglion posteriorly. The commissures between the second and third, and the third and fourth ventral ganglia increase in length, though they are shorter than those convecting the ganglia belonging to the middle region of the body; the ganglia at the posterior extremity of the animal are again closely aggregated together. The last ganglion of the ventral chain is much larger than any of the series except the first, and gives off from seven to nine branches to the posterior sucker; the other ganglia give off each two trunks, which distribute themselves to the muscles of the body, with the exception of the penultimate ganglion, which gives off only a single nerve on either side. The paired nerves are given off very close to each other, and the one which ramifies nearer to or in connection with the anterior wall of each dissepiment, and takes a dorsal rather than a ventral direction, arises above rather than behind the other. This lattcr nerve has, just at the point of its bifurcation, a small ganglionic mass developed upon it, which may represent the accessory ganglia seen upon the pedal nerves in Nereis, and called 'gainglions de renforcement' by De Quatrefages. With a microscope, a small detached ganglion, probably homologous with the lateral ganglia of the system of the nervi transversi in insects, may be seen apposed to but not inclosed within the capsule of each ventral ganglion, in the int rval between the points of origin of these paired nerves. A second element homologous to a portion of the Arthropodous system of nervi transversi is presented to us in the Leech by an 'intermediary" nerve, which runs in the interval between the two fibrous strands connecting the several pairs of ganglia, but which does not give off any branches. The bilateral character of the chain of nerve ganglia is as plainly seen in the Leech as in the worm; but there are no nerves given off from the inter-ganglionic commissural cords in the Hirudineae. A third nerve of the sympathetic elass exists in the Leech, in the form of an azygos nerve trunk, with ganglion cells appended to it throughout its course, which corresponds to the ventral aspect of the digestive tract, and has two lateral arms prolonged in relation with the two posterior lateral coeca of the 'stomach' or 'oesophagus.' The removal of the digestive tract 
prevents us from seeing this structure in this Preparation. It is figured, however, by Brandt, its discoverer, Tab. xxix. B, 7 d.e., where it is seen not to be distinctly prolonged uprvards into connection with the stomato-gastric or supra-oesophageal ganglia. Its relation would appear to correspond to the nervus recurrens of Arthropoda, but that it is in relation with the ventral rather than with the dorsal aspect of the digestive tube.

For the 'intermediary nerve,' see the memoir of Faivre, its discoverer, in the Ann. Sci. Nat. Ser.iv., tom. vi., p. 29. In this author's previous memoir, published in the volume of the Annales des Sciences Naturelles, immediately preceding the one just referred to, will be found, at p. 361 , an account of the various chemical reagents which may be employed in the microscopic investigation of the nervous system of Annelids. For methods of preparation of entire specimens for the dissection under a lens, without which much of what is here described carnot be made out by the student for himself, see Leydig, Vergleich. Anatomie, pp. 164, 165; and Gratiolet, Ann. Sci. Nat. iv. I7, pp. I77, I78, I8I.

For the lateral ganglia in apposition with the ventral ganglia, see Leydig, Vergl. Anat., Taf. ii., fig. $3 e$.

For the lateral ganglia developed upon the inferior pair of nerves, see Leydig l.c., p. 146; Quatrefuges, Histoire Naturelle des Annalés, tom. i., p. 81, pl. iii., fig. I, $i$. $k$., Nereis regia.

\section{Medicinat Leech (Hirudo Medicinalis),}

Dissected so as to show its reproductive and segmental organs in situ, the digestive and pseud-haemal systems having been in great part removed, and the integuments fastened out on either sicle.

AT about the point of junction of the first with the second sixth of the body's length, is seen a globular body partly overhanging and partly projecting to the left of the nerve cord, communicating mesially with a siphon-shaped muscular tube, and receiving on either side two tubes of smaller calibre but similar structure. The globular organ is constituted partly by museular and partly by 
glandular tissue, and is called consequently the prostatic part of the male intromittent apparatus; the mesial siphon-shaped tube representing a penis, and the lateral ducts being ductus ejaculatorii. Tracing the vas deferens of the right side outwards, we see that it passes under the nerve cord, to join a convoluted epididymis-like mass of a yellowish colour, which from its contents appears to be analogous to a vesicula seminalis. A slightly tortuous duct enters the organ from behind forwards, after receiving on its inner side the short transverse ducts passing to it from each of the nine globular testes which are seen close to the nerve cord, arranged one in each of nine segments, beginning with the one next but one in order to that in which the convoluted vesicula seminalis is lodged. The female generative apparatus is lodged in the segment interposed between that which contains the first testis and that which contains the vesicula seminalis; and four secondary annuli are seen to be interposed externally between those in which the outlets of the two sets of generative organs are pierced. The vagina has the form of an oval sac with thick muscular walls. From its apex a single tortuous oviduct arises which has its coils enveloped in loose tissue, the microscopic elements of which furnish us with large and beautiful specimens of unicellular glands discharging their secretion by isolated ducts. The oviduct divides into branches, one of which is seen passing under the nerve cord, on the apices of which the ovaries are carried. Externally to the line of the vasa deferentia and alternating in position with the testes, we see a row of globular sacs only a very little less in size than these organs. These sacs communicate with the exterior by the orifices already spoken of, Prep. 39, p. I 27. as marking the posterior limit of each of the primary segments of the body. Exteriorly to each of these sacs we see a loop-shaped gland, the outer convex end of which is directed upwards, and in the natural condition of the parts almost vertically so, whilst internally it is connected with the globular sac by a short duct passing from the anterior limb of the loop backwards; and in the region of the testes has a coecal process prolonged on to each of those organs. The connection which subsists in the Lumbricidae between the open mouth of a modified segmental organ and the reproductive glands, may be regarded as represented in the Leech by the arrangement just described. There are eight of these segmental 
organs arranged opposite the interspaces of the testes, and two in the two anterior genital segments. Four more are to be seen in the segments anterior to those last named, and the three first of these are in closer proximity than the rest of the series. There are three segmental organs in the segments posterior to that containing the last testis; and they possess a coecal process prolonged inwards beyond the line of the globular sac, by which their excretion is discharged on the exterior of the body. The coecal process of the most anterior of the three, comes into apposition with the posterior testis, but its homologue is not developed in the six anterior segmental organs. The segmental organs are much larger in the Medicinal Leech than in the Horse-leech; and Gratiolet connects the greater power which the former animals have of living out of the water with the greater power of moistening the skin thus attained. Hirudineae, such as Branchellion, which possess only two pairs of segmental organs, and Nephelis and Clepsine, in which these organs attain but a small development, appear never to leave the water, as the other genera do, spontaneously; and in them, it should be added, the segmental organs open, which they do not in either of the Leeches mentioned, by ciliated infundibula into the general cavity of the body. The various portions of the loop-shaped constituent of the segmental organs of the Leech, communicate with each other very freely by lateral branches of anastomosis, which make the gland to be labyrinthiform rather than merely tubular. It is of importance both to the morphology and to the physiology of these animals, to observe that the failure of the organs of vegetative life here described to be developed at either end of the body, coincides with an agreregation both of segments and of animal organs in the same two regions. The azygos character of the generative ducts is noteworthy, as is also the development of an intromittent organ; a structure not found in other Annelids, though existing both in Platyelminthes and Nematelminthes.

For the segmental organs, see (iratiolet, Ann. Sci. Nat. iv. I7, p. I 92, pl. vii., fig. 4; Lenckart, Die Menschlichen Parasiten, i., p. 672 .

For the reproductive organs, see Leuckart, l. c., p. 673; and for the antagonism which subsists between the evolution of these 
organs and that of those of animal life, ibid., p. 549, and Art. 'Zeugung' in Wagner's Handworterbuch für Physiologie, Bd. iv., pp. 7 I9-1853.

\section{Many-headed Bladier-worm \\ (Caenurus Cuniculi),}

In its cystic stage, from the region of the masseter nuscle of a rabbit (Lepus Cuniculus).

THis specimen illustrates the cystic stage in the metamorphoses of the true Taeniadae. It belongs probably to the same species as the one individuals from which are, when in the cystic stage, lodged usually in the brain of the sheep, and are the cause of the disease commonly known as the 'sturdy,' 'gid,' 'staggers,' or 'turnsick.' The specimen consists of a white walled semi-transparent sac; and a large part of its walls having been removed, one end of it is seen to be beset on its interior surface with a number of closely apposed but distinct opaque white bud-like bodies, the area occupied by which is prolonged out laterally into lobes indicating the continuing proliferation of the cyst. Two smaller cysts, one of which is similarly bestudded internally, are attached by mere filaments of tissue to the lower parts of the large cyst, to the proliferation of which they may also be considered to be due. For, though it is possible to suppose that these all but perfectly isolated outgrowths may have been produced by the pinching off from the mother vesicle of small portions of its walls, the large cyst having been necessarily subjected to much pressure from time to time by the masseter muscle; cysts of this tapeworm showing a tendency to form or forming similar accessory vesicles, have been figured from parts such as the brain, or lungs and liver, where no constriction could be effected by muscular pressure; and the analogy of certain of the forms of the proliferating cysts of the Taenia Echinococcus would appear to indicate that the formation of such pedunculate outgrowths is one of the normal modes of self-multiplication in the cystic stage of the 'Taenioid mutamorphoses. The white gemmules represent the 'heads,' or 'nurses' 
of the cestode many-jointed tape-rorms which this cyst might have given rise to if it had found its way into the intestines of a $\operatorname{dog}$; and it is therefore as truly a social animal, or rather, a colony of animals in this its cystic, as it is in its cestode form. Each of these heads is called by helminthological writers a 'scolex;' and the sac upon which they have developed themselves, and upon which the remnants of the six hooks of the embryo might be detected, is the result of the growth of such microscopic embryo, or ' proscolex,' as the one figured pl. xii. fig. 6, when by the aid of its hooks it has bored its way from the intestinal canal into the blood-vessels of its 'host.' The 'scolices' possess two sets of organs for adhesion upon their proboscis; viz. four suckers placed proximally to the sac, and two rows of hooks placed near their free apical extremity. The heads themselves, as well as the parent vesicle, are endorved with considerable contractile power; a layer of muscular tissue existing in their walls by the action of which the heads with their armature can be retracted as in this Preparation, or protruded. The cystic stage of the bladderworm is passed in the organism of some herbivorous animal, and ordinarily in the brain of the sheep; and it has been shown by actual and repeated experiments with dogs, that when the cystic form of this Taenia is swallowed by them, its various heads will develope in their intestines into cestode worms, attaching themselves by their armed proboscides, and producing sexual hermaphroditic segments, the so-called 'proglottides,' in the interval between the remnants of the embryonic vesicle and the asexnal adherent head. The entire colony is called a 'strobile.' The asexual character of its 'head' may remind us of the similar exclusion of the generative organs from the anterior segments of Hirudo Lumbricus; and the successive repetition of the testes in nine segments, as described in the former of those animals, bears a distant resemblance to the successive antero-posterior development of sexual deuterozoids, as presented to us in the 'proglottides' of the 'strobile' in a Taenia. A process, however, all but identical with the budding off of sexual zooids by an asexual 'head' or 'nurse' as seen in the cestoid stage of the parasitic Taenia, takes place in dutolytus (Grube), Nereis prolifera (O. F. Müller), Myyrianida (II. Edwards), which are Vermes of the most highly organized order of the Polychaetit; and the resemblince pointed out in the preceding sentence, as 
existing between the Leech and the Tapeworm, must not be taken as justifying the views of writers who would class Hirudineae with the Platyelminthes ${ }^{\mathrm{c}}$.

c The class Platyelminthes is here taken as comprehending three orders-the Cestodes, Trematodes, and Turbellarians; and it is with the Trematodes that the Leeches have been supposed to be so closely allied as to justify the removal of them from the class Annulata, which comprehends the Polychaeta, Gephyrei, and Oligochaeta. The principal reasons for this dissociation are those furnished by the absence of external appendiculate organs such as locomotor setae or gills, and the presence of suckers in both Trematodes and Leeches; by the sacculate character of the digestive tract; by the absence of a body cavity; and by the structure of its skin. In answer it is to be said that the absence or presence of such organs as setae or gills is not to be considered as of such consequence as the similarity or dissimilarity of such systems as the reproductive or nervous; and that even if only external characters are to be compared together, the definite segmentation of the Hirudineae differentiates them very sharply from the Trematodes, which are not even annulated. With reference to the similarity which the dendritic digestive tract of certain Trematodes presents to the diverticulate tube of the Hirudineae, it must be borne in mind that amongst the Polychneta, forms with more complexly diverticulate intestinal tubes, Aphroditea, are to be found than amongst the Leeches; whilst the presence of an anal sucker in other members of the same order, Leucodore and Clymene, furnishes a similar answer to the argument for classing the Hirudinea with the Platyelminthes which is based upon their common possession of these organs of adhesion. Another answer is furnished by the fact that the construction of the suckers is, as Leuckart has pointed out, by no means identical in the two classes under comparison; and that the possession of suckers is a point of physiological rather than of morphological importance, is even more clearly shown by their existence on the cardal extremity of the free, and the ventral surface of the parasitic Nematoids, which belong to a class very distinct from both Annelids and Platyelminthes. Neither are the Hirudineae truly 'parenchymatous' or 'sterelminthous' Vermes in the same sense as the Trematodes. For Leuckart has shown that in all Hirudineae more or less of a perivisceral cavity remains, after the full development of the large digestive tract, and of the 'dorso-ventral' muscles which encroach so much upon it. In Branchiobdella there exists a large perivisceral cavity, as well as a system of vessels, which appear to be homologous with the so-called 'pseud-haemal' vessels of the common Leech and other Annelids, though at the same time they are continuous with, and must be supposed to represent a part of the perivisceral cavity. And by consequence, therefore, the pseud-haemal vessels of other Hirudineae must be taken to represent the remnant of the perivisceral cavity, when such a space appears to have become obliterated. So that the true way of expressing the facts would be to say, not that the Hirudineae resemble the Trematodes in not possessing a perivisceral cavity, but that they differ from them in possessing a system of vessels which, as being continuous with a perivisceral cavity in Branchiobdella, may be regarded as actually being in the species mentioned, and as representing in other species a part of a perivisceral cavity. To this interpretation the fact that in certain Polychaetous Annelids, Glycera and Phoronis Hippocrepic, the pseud-haemal vessels have been observed to contain true 
For a further account, with figures of the metamorphoses, of the Taeniadae, see Description of the semi-diagrammatic figures, I -6, in plate xii. infra. See also Cobbold's Entozoa, 1864, pp. I0+ seqq. et pussim; Leuckart's Menschlichen Parasiten, pp. I8I-220; and P. 25I for the formation of the proglottides by the development of annular constrictions in the vermiform

corpusculated blood, appears to lend considerable probability. On the other hand, the Hirudineae do to a certain extent resemble the Trematodes, in possessing a muscular system which is more complex, and more closely connected with the glandular and epithelial elements of the integument, than is usually the case in other Vermes. It may be suggested however that the changed relations of the contractile and other elements of the integument in the Leeches, may be correlated with the other changes which are ordinarily produced in subordination to the special habit of parasitism; and which, in this sub-kingdom, appear to entail the loss of the setae, the gills, and the cilia. And the development of an additional transversely crossing set of muscles in addition to the external circularly arranged and the internally longitudinally arranged muscles of other Vermes, seems similarly referrible to community of habits, and not to any morphological affinity subsisting between the Trematodes and Leeches. For a similar layer of muscles has been observed by Dr. Charlton Bastian to exist in the Nematoids (see Plil. Trans., I866, p. 564); and as in all three orders alike, the special need for some such arrangements, for propelling and otherwise acting upon the contents of a digestive tube, altogether or nearly devoid of muscular fibres, may be considered to account for its presence, it cannot be held to furnish a good basis for classification.

On the whole, the Hirudineae appear to be rather Annelids degraded by the special habit of parasitism, than to be intermediate forms in a series which should represent the various stages in progression upwards from the lower Platyelminthous Vermes to the highly organized Annelids. The characters which appear to approximate them to the Platyelminthes, relate mainly to such external points as the shape of the body, and the modifications of the tegumentary system; and whilst these characters are probably to be regarded as explicable by reference to a community of habit, and therefore as devoid of classificatory value, those which connect the Hirudinene with the Annelids possess a real morphological importance. Among these we may mention the segmentation of the body not merely in the way of external annulation, but in that of internal division into more or less completely separated cimpartments by the development of dissepiments; the possession of a chain of nerve ganglia, and in most cases of a similarly multiple series of segmental organs; and the presence of the so-called 'pseud-haemal' system. And it should be further noted, that whilst in all these points the organizations of the Hirudineae and the setigerous Annelids resemble each other, and differ from those of the Platyelminthes in the direction of greater complexity and perfection, they still further resemble each other but in the reverse direction, and as presenting lesser complexity and importance, when we come to compare their reproductive systems, which never possess either the high degree of morphological differentiation, or the actual bulk relatively to the rest of the body, which distinguishes the generative organs of the Platyelminthes. See pl. viii., ix., and pl. xii., figs. 2 and 4 with descriptions, infra. 
appendage of the head, and the constant intercalation of new segments formed in the same way between the head and the earlier formed segments. See also Van Beneden, Mémoire sur les Vers Intestinaux, 1858, pp. 235-25I ; and for an account of similar processes observed in the Polychaeta, see Huxley, Edinburgh New Phil. Journ., Jan. I855; Ehlers, Die Börstenwürmer, Bd. i. 207 seqq., ibique citata; and for the Oligochaeta, see Lankester, Linn. Soc. Trans. xxvi., Quart. Journ. Microsc. Science, I869.

For a special history of this Tapervorm, Caenurus Cerebralis s. Cuniculi, see Van Beneden, l.c., pp. I $46-148$; Cobbold, l.c., p. I 6 ; Gamgee, Fifth Report of the Medical Officer of the Privy Council, J.862, pp. 234-237; Thudichum, Seventh Report of the Medical Officer of the Privy Council, s 865, p. 335; Numan, Verhandelingen der eerste Klasse van het Koninklijk. Nederlandsche Instituut, I 850 . where many figures, microscopic and other, are given of this animal.

For the classificatory relations of the Platyelminthes and the Hirudineae, see Grube, Die Familien der Anneliden, I85 I, pp. 3-8 ; Schneider, Monographie der Nematoden, x866, p. 329 ; Leuckart, Die Menschlichen Parasiten, pp. I56, I 57 ; Claparède, Bibliothèque Univer'selle, tom. xxii. Bull. Sci., pp. 346-355, I 865 ; Ann. and Mag. Nat. Hist. Ser. iii. xvii., 1866, p. I00; and M. de Quatrefages, p. I08; Claparède, vol. xx., I867, p. 337 ; Van Beneden, Turbellariés, p. 48, s860.

For the structure of the integument in the Platyelminthes, see Lenckart, l. c., pp. 459, 645; Schneider, l. c., 333.

For their 'parenchymatous' or 'sterelminthous' character, see Leuckart, l. c., pp. 157, 666, 713; and for the presence in the pseud-haemal vessels of true corpusculated blood, such as is ordinarily found only in the perivisceral cavity, see Leuckart, l.c., p.670; and Dyster, Linn. Soc. Trans., xxii., p..254, I $85^{8}$. 


\section{Common Crossfish (Asterias Rubens), Linn. (Dried.)}

THE animal consists of a central disk which is prolonged into five lobes, the so-called 'arms' or 'rays.' One surface of the specimen is hollowed out into a deep central cavity corresponding with the mouth, and made pentagonal by the abutment upon its edge of the rows of spines bounding the five 'avenues,' which radiate out from it on the same surface, and, from lodging the locomotor feet, have given this aspect of the animal the name of 'ambulacral.' The other surface is more or less convex, and beset with spines; and in one of its interradial spaces it carries the concentrically striated disk known as the 'madreporic tubercle.' The tro surfaces are nearly equally developed in Asteriae and Ophiurae. Along the middle line of each radial avenue there runs a central furrow, formed by and at the junction of the 'vertebral' ambulacral ossicles. In this central furrow were lodged first and most superiorly the water-vascular canal supplying the ambulacral sucker-feet; then some transverse adductor muscles; and thirdly and most superficially, the gangliated nerve cord, the 'Ambulacral-gehirn' of the German writers. Externally on either side to this central furrow, the lateral processes of the ambulacral ossicles form, by the apposition of their emarginated edges, two alternately placed series of conjugate foramina, for the vessels bringing the sucker-like exteriorly-placed portion of the fect into communication with internally placed ampullae as seen in Preparation 45. These ampullae are wanting in the Ophiurne, as also in the ambulacral tentacles of certain Holothurioidea, for which see Preparation 47. Each of the five radial avenues tapers up to its distal extremity where the eye was lodged, and where in the fresh specimen the suckers may be observed to attain a considerable relative length. On each side of each avenue we see two sets of spines, one of which is placed internally, and consists of two rows of long and slender spines; whilst the more externally placed one is made up of three rows of stouter, shorter, and bluuter spines. Towards the apex of each ray the external set of spines attains a greater development relatively to the internal; and out of it is there evolved 
the circlet of specialized spines, which protect the eye and the contractile tactile organ in relation with it. A third set of spines marks the line of junction of the vertical and dorsal surfaces in each ray; and the middle line of the anti-ambulacral surface has more or less of a keeled appearance, from the more or less regular longitudinal arrangement there of the spines with which the dorsal surface generally is beset. Remnants of the organs known as 'pedicellariae,' which appear to be spines modified so as to be mobile and prehensile, are to be seen in the interspaces between the spines, and some, though of smaller size and not in especial abundance, may be seen also round the bases of the spines. The spines themselves are immobile in the Asteriae, and, though they may carry a coronet of numerous calcified setae on their apices when they are called 'paxillae,' when modified into 'pedicellariae,' they rarely carry more than two terminal processes, which make up a pincer-like organ. In the Echinidae, on the other hand, the spines are themselves mobile, and provided with a muscular apparatus; and the 'pedicellariae,' which are mainly distributed about the oral region, are trivalved. Opposite one of the inter-radial spaces is seen a whitish, circular, raised, concentrically striated disk, the so-called 'madreporic tubercle.' In a fresh specimen of any one of the Asteriae which is provided with sucker-like and not with conical feet, the anus may be found near the centre of the dorsal surface a little to the left of a line drawn from this madreporic tubercle, down the longitudinal axis of the ray, opposite to the inter-radial space in which it is lodged. The same line will enable us to divide the five rays into a 'bivium,' between which the madreporic tubercle lies, and a 'trivium,' the two lateral arms of which lie on either side of the arm which is opposite to that tubercle. But we cannot speak properly of an anterior or posterior radius or inter-radius in these Echinodermata, inasmuch as, like Echinidae and Ophiuridae, they move in locomotion indifferently in the direction of any one radius or inter-radius. The radius which lies to the right in the madreporic bivium in this specimen, when the central ray of the trivium is placed so as to point away from the observer, is much shorter than any one of the other four; having been reproduced after some injury, but not having attained the size of its fellows. The power of reproduction of injured parts is very great in these animals, having indeed 
scarcely any limit short of the retention of the stomach, and of at least one coecal appendage uninjured. As the Echinodermata, on the one hand, all go through more or less complex metamorphoses, and, on the other, never when adult multiply by gemmation, it is obvious that the power of repairing injuries cannot be, as it has been held to be, correlated either with the absence of metamorphosis, or with the power of reproduction by metagenesis strictly so called.

For the account of the structure of the Echinodermata generally, see Johannes Müller, Abhandlungen Kon. Akad. Wiss., Berlin, for 1853 , translated in part by Professor Huxley in the Annals and Magazine of Natural History for 1854 , Ser. ii., vol. xiii. ; Professor Sharpey, Article 'Echinodermata,' in Todd's Cyclopaedia of Anatomy and Physiology.

For a monograph of the Asteroidea, see Müller und Troschel, System der Asteriden, 1842.

For an excellent account of the nerve system of the sensory organs, and of the power of reproduction of lost parts in the common Cross-fish (Asterias rubens), as also of that of the Solaster papposa, and Cribella oculata, see Wilson, Linn. Soc. Trans., s860, vol. xxiii., pt. i., p. 107.

For an analysis of the tegumentary skeleton, see Gaudry, Ann. Sci. Nat. Ser. iii., tom. xvi., 185 I.

For reviews of Müller's researches into the anatomy and development of the Echinodermata, see Huxley, Ann. and Mag. Nat. Hist., Ser. ii., vol. viii., 1851 ; Baur, Nova Acta, 1864, pp. 17,57 .

\section{Common Crossfish (Asterias Rubens), LiNN.}

Dissected so as to show its digestive and motor systems.

One of the rays, the central one of the trivium, has been cut short, and more or less of the anti-ambulacral integument removed from each of the other four, and from the central disk. In the inter-radial space which is opposite to the ray which is cut short, 
is seen the madreporic tubercle; and a little to the left of a line producing the long axis of that ray to the centre of the madreporic tubercle, and near the centre of the disk, is seen the small piece of the apical integument in which the anus opens. From the intestiniform portion of the digestive tract immediately following upon the anus, two diverticula arise, and efflorescing into two or three coecal ampullae, reach a short way into each of the two inter-radial spaces in the disk, which lie on the left of the madreporic or anal inter-radius. In this species there are only these two inter-radial coeca; the one nearest the madreporic inter-radius is the larger of the two; both have their internal surface plicated longitudinally, and from this it may be seen that, like the 'respiratory trees' of the Holothuriae, with which they are homologous, they are highly extensible. In a starfish which has died with its stomach pouted out, as it often is during life, these coeca may be observed to be drawn down much farther than the much longer coeca, which are prolonged into the interior of the rays from a lower level in the digestive tract, but are attached to the anti-ambulacral surface by a mesenteric membrane. These latter coeca are seen to take their origin from a much wider portion of the digestive tract as single trunks; and very shortly after entering the rays they break up into two trees, which, with their foliaceous glandular ampullae, fill up, in this specimen in which the generative glands are in a state of quiescence, the greater part of the interior of the cavity of each ray. At a lower level again than the plane whence the stems of these arborescent coeca take origin, the saccular dilatations of the stomach proper are seen bulging for a short distance into each radial space to the vertebral ossicles in which they are braced by ligaments. The Asteriae are the only Echinodermata in which any radial arrangement attaches to the digestive system beyond that of the calcareous apparatus set around the mouth in all of them, and subservient to the prehension or manducation of food in most except the Crinoidea. In the interior of each ray, and between the ramifications of the digestive coeca, which are here and there slightly divaricated to show them, are to be seen the bilaterally symmetrical biserial rows of ambulacral ampullae on either side of the central stem, resembling that formed by the bodies of a true vertebral column, and made up by the apposition of the mesially articulated ossicles called 'vertebral' from this resem- 
blance. The feet with which these ampullae communicate are seen to be provided with sucker-like ends, though not with calcareous terminal supports, as in the Echinoidea and Holothurioidea. In the three genera of Asteriae, Astropecten, Ctenodiscus and Luidia, the locomotor feet end by conical and not by sucker-like terminations; and with this point of inferiority is correlated also the absence of an anus. In the Ophiuridae, the digestive tract is a simple coecal sac, bulging somewhat like the true stomach of the Cross-fish radially, but not prolonged into the interior of the arms, as in all the Asteriae including the three aproctous genera just mentioned and Brisinga; and with this increase of inferiority in the digestive apparatus, an increase of inferiority in the locomotor is found to correspond, as the feet are devoid not only of true suckers but also of ampullae. It is in the Asteroidea alone that the nervesystem lies externally to the ambulacral plates, which form thus an ' internal skeleton,' absent in the Crinoidea, and existing in the Echinoidea and, possibly, in the Holothurioidea also, only as rudiments. The nerve-cord is further protected in Ophiurae by a row of dermal ventral scutes.

For a figure of the digestive tract, see pl. x. infra.

For figures of the locomotor feet in Ophiurae, see Sar's, Norges Echinodermer, 1861, tab. i., fig. I-5.

\section{Angular Sea-Cucumber (Cucumaria Pentactes), Forbes,}

Prepared so as to show the external characters of the class Holothurioiden; and the traces of a bilateral symmetry, the co-existence of which with the more obvious appearance of a radial arrangement is very well seen in these Echinodermata.

Tue five rows of ambulacral feet and the ten arborescent circumoral tentacles, which are merely modifications of ambulacral feet, give the Sea-Cucumbers at first sight a very markedly radiate appearance. But upon looking closely at these structures, both will be seen to admit of being divided into two bilaterally symmetrical halves, each of which is composed of heteronomous elements. The five rorvs of ambulacral feet are seen to fall naturally into a ventrally placed trivium, the feet in each of the rays of which are more numerous, more perfectly developed, and more regularly 
disposed than those of the two rays of the dorsally placed bivium; and of the ten tentacles the two which are placed immediately opposite the central ray of the dorsal trivium, and one of which is placed therefore on either side of the medio-ventral line, are very much smaller than any of the other eightd. The ventral trivium gives the surface of the body which it occupies a somewhat flatter surface than is possessed by the surface corresponding to the dorsal bivium; and this, together with the diminution in number and importance of those two rows of ambulacra, appear to constitute a transitional arrangement between the more perfectly pentagonal appearance which nearly allied species may present, and the close adumbration of the form of an ordinary Gasteropod which we note in Psolus (Cuvieria), where the dorsal bivium is wholly aborted. The ten tentacles are seen to be carried upon the outer rim of a cylindriform prolongation of the body-walls, which is transparent and carries no ambulacral feet. The anti-ambulacral surface is reduced in Holothurioidea as it is in Echinoidea to the small region immediately surrounding the anus; in Cucumaria communis, indeed, the ambulacra almost abut upon that orifice; and it may be here

d Systematic zoologists differ as to whether the smaller size of the pair of ambulacral tentacles, which are placed opposite the central ray of the ventral bivium, is of generic, of specific, or even of less classificatory importance. Troschel, in the Archiv. fuir Naturgeschichte for 1846 , speaks of this difference as being of generic value, and as separating Cladodactyla (Cucumaria) doliolum, Brandt ; Cladodactyla Dicquemarii, Cuvier and Brandt, and Cladodactyla Syracusana from the species here described. Forbes, however, in his 'History of British Star-fishes,' I $8+1$, says of Cucumaria pentactes, "It is extremely variable in colour; generally of a deep purple, sometimes altogether white, sometimes purplish white. The tentacula and head of both varieties vary equally, either purple or white. It varies also in the pinnation of the tentacula, and in their relative size and number. The Holothuria Montagui of Dr. Fleming, founded on a white variety described by Montagu, has tight full-sized tenticula and two small ones, which are alternately in motion covering the mouth. The tentacula of this form are not so pinnate as in the common or purple state.' It has been said that the 'Cuvierian organs,' certain structures of various forms and doubtful function attached to the stem of the respiratory trees or inserted upon the cloaca, are wanting in all Cucumariae with unequal tentacles; but the readiness with which these organs are ejected by the Holothurians, when they are alarmed or irritated, is such as to make it unsafe to base a conclusion as to a specific difference upon their absence or presence. Semper, on the other hand, Reisen im Archipel der Philippinen, p. 47, assigns this smaller size of the two medio-ventral tentacles as a generic property to the Cucumariae; but he also specifies the presence of this peculiarity in individual cases of particular species as though it were not universally present. 
remarked that the troo classes just mentioned, though they may at first sight, owing to the great differences of their external tegumentary organse, appear to be entirely unlike each other, are in reality more closely allied by structural, if not by developmental history, than any other two classes in this sub-kingdom. The Holothurians with rows of ambulacral feet are divided into two families, according to the shape of their ambulacral tentacles; those in which the tentacles are, as in the Cucumariae, dendritic in appearance, and carried upon a cylindriform stem of different texture from that of the rest of the body, being called ' Dendrochirotae;' and those in which the tentacles are shield-, or rather shovel-shaped, and in which the integument is continued without any alteration in its texture up to the tentacles, being called 'Aspidochirotae.' With these external differences a considerable number of points of difference in their internal structures are correlated, for which see description of next Preparation. In all Holothurians, but especially in the otherwise apodal Synaptidae, the ambulacral tentacles are used as locomotor organs; and in the Aspidochirotae they are also used for bringing the sand, in which these animals very ordinarily live partly immersed, into their digestive tract. The intestinal tract, on the other hand, of the Dendrochirotae, in which the tentacles could not be used for this purpose, is ordinarily found to contain no sand or stones.

For an excellent account of the anatomy of the entire class Holothurioidea, see C. Semper's beautifully illustrated Monograph, Reisen im Archipel der Philippinen, Theil ii.; Wissenschaftliche Resultate, Bd. i., Hft. i. I867, pp. 1-6, Hft. iv. I 868, pp. IOI-I 78 ; Emil Selenka, Zeitschrift für Wissenschaftliche Zoologie, Bd. xvii., Hft. 2, 1867.

For the anatomy and development of the Synaptidae, see a memoir by Dr. Albert Baur, Nova Acta, vol. xxxi., 1 864; where, at p. 50-60, Ab. ii., some valuable remarks will be found upon the 'so-called alternations of generations in the Echinoderms ;' and at p. $17, \mathrm{Ab}$. i., certain less convincing views as to the homologies of the calcareous ring in the Holothurioidea with the auriculae of Echinoidea.

e For a note as to the existence of an Echinus with a soft integument, see Semper, $l$. c., p. $16_{3}$, citing Grube. 


\section{Angular Sea-Cucumber (Cucumaria Pentactes), Forbes,}

Dissected so as to show its motor, digestive, respiratory, and reproductive systems.

TuE integument has been divided dorn the middle line of the inter-radial space of the dorsal bivium, and fastened out on either side. Five double longitudinal muscular bands are seen to divide the body-walls into a corresponding number of antero-posteriorly running zones, upon which the external circular muscular coat is very well seen. In the interval between the two factors of each double band is lodged the longitudinal water-vascular ambulacral vessel in all the pneumonophorons Holothurioidea, whether they possess ambulacral feet, or, as the Molpadidae, are devoid of them; and, as in all Holothurioidea without exception, the longitudinal nerve-cord is to be found lying in the longitudinal plane corresponding to the interval between the two muscular bands immediately beneath the cutis; and, as in the families which possess longitudinal ambulacral vessels, between the cutis and those vessels. The longitudinal muscles are prolonged from the region of the mouth, where they are inserted into the integument near its junction with the commencement of the digestive tract, down to the anus; and in the Dendrochirotae, to which family the Cucumariae belong, each longitudinal muscle gives off a long slip, which passes to insert itself into the corresponding radial ossicle of the calcareous ring. In this specimen the slip given off is much thicker than the radial muscle itself; indeed, the slightness of the radial muscles, as well as the possession of these slips, is one of the many points in which the Dendrochirotae differ from the Aspidochirotae. On either side of the radial muscles the ampullae, which in Dendrochirotae are not usually present in their tentacular ambulacra, are seen arranged alternately. The radial water-vessels with which these ampullae and the sucker-like feet are in connection, pass forward to join the circumoral water-ring, through an emargination in the anterior end of each of the radial ossicles in the calcareous ring; and as the radial nerve-cords hold the same relation to these ossicles, they have been viewed as homo- 
logous, not, as they really are, with the masticatory apparatus, the so-called 'Aristotle's Lantern,' of the Echinoidea, but with the 'auriculae' of these Echinodermata, and with the proximal pair of 'vertebral ossicles' (see p. 144, supra) of Star-fishes. The water-vascular ring surrounds the muscular pharynx a little way posteriorly to the calcareous ring; two long air-bladder-like Polian vesicles are seen hanging down from it, and ending freely in the body cavity on the left side; whilst the madreporic plate and the pedicle upon which it is placed are seen to join it in the medio-dorsal line. The internal position of the madreporic tubercle, characteristic of the Holothurioidea, renders it necessary that the water in the locomotor water-vascular system should be obtained from the fluid in the perivisceral cavity, from which the pores of the madreporic disk are, however, said to be separated by a layer of epithelium, continuous with that lining the perivisceral cavity; so that the fluid they receive enters them not directly but by diffusion through and by the intermediation of these cells. In immediate relation with the water-vascular ring is seen an annular plexus of pseud-haemal vessels, which represents the circular pseudhaemal sinus of the other Echinodermata. From it two principal vessels pass backwards; one along the dorsal, the other along the ventral line of the digestive tract, in the substance of the walls of which they are connected with each other by plexuses. Of these two vessels, the ventrally-placed one is always comparatively simple and devoid of any ramifications of importance, though the segment of it in connection with the first descending convolution of the intestine communicates with that in connection with the first ascending, by one or more transverse commissural vessels; whilst the dorsal vessel may have a considerable rete mirabile developed in connection with it, which in Aspidochirotae comes into relation with the left ' respiratory tree' arising from the cloaca. This rete mirabile may be seen in this specimen in connection with the dorsal vessel in the first segment of the intestine; it must not, however, be confounded with the reticular muscular mesentery, the very abundant fenestration of which gives it the appearance of a plexus of blood-vessels. The muscular pharynx is succeeded by a muscular stomach, which is much smaller in calibre and a little shorter in length than the portion of the pharynx which intervenes between the commencement of the stomaeh and the 
water-vascular ring anteriorly. The commencement of the intestine proper is seen to be connected with the convex portion of the second convolution of the tube by a considerable number of vessels passing between the segments of the ventral vessel in connection with each portion of the tract. The first convolution of the intestine has its concavity looking forwards, its convex aspect being in relation with the posterior extremity of the animal's body; the second convolution or the first ascending segment of intestine reaches about as far forwards as the middle of the body, where it turns backwards to end in the 'cloaca.' This term may be applied to the terminal segment of the intestine, inasmuch as, though it does not receive the duct of the generative organs, it does receive those which lead from or into the so-called respiratory trees, the functions of which, there is good reason to think, are as much depuratory or renal as respiratory. These organs are seen to take origin on either side of the cloaca as hollow stems carrying somerwat scanty ramifications, and reaching a considerable but varying distance forwards in various specimens into the cavity of the body. They are both attached to the body-walls by mesenteries, which are, however, reduced by extreme fenestration to mere series of filaments inserted along the left and right borders respectively of the ventral trivium. In the Dendrochirotae there is not, as in the Aspidochirotae, any connection between the respiratory tree of the left side and the pseud-haemal plexus developed upon the vessel in connection with the dorsal surface of the intestinal tube; and in this sense, though not in that in which the roord has been applied to them, the Dendrochirotae may be called 'Adetopneumones.' The arborescent form of the tentacles of the Dendrochirotae may, by exposing a greater surface to aeration than the short shield-shaped tentacles of the $\Lambda$ spidochirotae, compensate for this less perfect evolution of the internal aerating apparatus; and with the greater evolution of the tentacular apparatus and its division into delicate twigs, we may connect again the evolution of the special system of retractor muscles already noticed. Accordingly as these respiratory trees are absent or present, the class Holothurioidea is divided into the two orders of Apreumona and Pneumonophora; the Apneumona, Synaptidae, having, like such of the Gephyraean Vermes, Sipuneulidae, as are similarly devoid of respiratory appendages to their cloacae, certain ciliated infundi- 
buliform organs developed upon their mesenteric membranes, the functions of which may be supposed to be identical with those of the organs they replace. With the absence of lungs the peculiarity of monoeciousness or hermaphroditism is correlated in the Holothurioiden. On the right side in this Preparation is seen the generative gland, which consists of two bilaterally symmetrical fascicles of coeci, attached on either side of a thickened portion of the dorsal inter-radially placed mesentery. A single efferent duct, under which a slip of blue paper is passed, passes along in this mesentery to open inside the circle of oral tentacles, at the anterior end of the dorsal inter-radial ossicle ; and it is seen just posteriorly to it in the interval between the madreporic canal, which is also in relation with the dorsal mesentery, and one of the retractor muscles which is passing to be attached to the radial ossicle on its right.

The structural arrangements of the Dendrochirotae, as illustrated by this Preparation, differ in the following particulars from those of the Aspiclochirotac, as illustrated in the Inuterian Catalogue, vol. i. pl. iii., vol. iv. pl. xlix. Their arborescent tentacles are carried upon a cylindriform prolongation of the body, which is differentiated from the part which carries the five rows of ambulacral feet, and thus comes to be not wholly unlike the proboseis of certain marine Annelids; special retractor muscles are developed in correlation with this apparatus; a muscular stomach is more commonly found in them than in the Aspidochirotae; their respiratory trees are less developed in length and complexity, and the pseud-haemal system does not come into relation with them; the 'Cuvierian organs,' certain structures developed upon the stem of the respiratory trees or upon the eloaca, and of various shapes, appear to be very commonly wanting in them, as are also the ampullae of the ambulacral tentacles nearly invariably, though their Polian vesicles are more prominently developed than those of the Aspidochirotae. In the peripheral part of the water-vascular system, the Dendrochirotae differ from the Aspidlochirotae, in never having suckers or calcareous disks developed upon their tentacles: these structures may be absent also in the feet of the ambulacral, and especially of the dorsal ambulacral, rows, but they may be both present there.

The generative gland is hilaterally symmetrical in the Dendrochirotae, consisting of two fascicles of short and non-bifid cocea, attached on either side of a thickened portion of the inter-radially attached dorsal mesentery, and communicating with a single efferent duct of great length, 
which opens inside of the crown of tentacles; whilst in the Aspidochirotae, the generative gland is made up of a single fascicle of long, sometimes bifurcating, coeca, which are attached on the left side of the dorsal mesentery, much nearer the oral end of the body, where they open posteriorly and exteriorly to the crown of tentacles, in the dorsal interradius opposite the medio-ventral line. The Cucumaria pentactes here described, differs from the common Sea-Cucumber (Cucumaric communis) in its smaller size, smoother inter-ambulacral areae, and in not having its rows of ambulacra prolonged so closely up to the anus. Internally the larger of the two species differs from the smaller in having a much longer intestine, more numerous generative coeca, and longer respiratory treesf.

f The two next Preparations are intended to illustrate some of the characteristics of the Coelenterata as seen in the two chief classes of that sub-kingdom, the Anthozoa s. Polypi, and the Hydrozoa; and it may be well here to give some of the reasons which have induced Naturalists to accept the separation of the Echinodermata, illustrated in the last four Preparations, from those animals with which, until the publication of Leuckart's views in 1848 , they were classed under the common name of Radiata or Zoophytes. The resemblance connoted by the name Radiata has no more than a superficial basis in the organization of the Echinodermata. Not only are their radial divisions ordinarily pentamerous, whilst those of the Coelenterata are ordinarily four or six or some multiple of these even numbers, but they always in developmental, and usually in adult life show marks of bilateral symmetry. The plant-like character of fixation to one spot which the name Zoophyta may be taken to refer to, attaches to a very large number of Coelenterata, but to only two genera of existing Echinodermata throughout life, and to a third temporarily. The deposit of calcareous spicula in greater or less abundance within the perisoma, and the absence of any but histological sexual differences, are points common to the majority of Coelenterata and to all Echinodermata, and both sub-kingdoms are exclusively aquatic and all but exclusively marine in habit; but these points are probably the only points of real resemblance between the two subjects of comparison. The integumentary system of the Echinodermata never shows any traces of the possession of the 'nettle-cells,' all but universally found in Coelenterata, as also in certain Turbellarians and Nudibranchiate Mollusks, and not always absent in the higher Vermes, with which the Ecbinodermata are probably more closely connected than is usually supposed. They possess a large perivisceral cavity, in which not only an intestinal tract, but two other well-defined tubular sysw tems, the pseud-haemal and the water-vascular, are always, and a generative system with well-differentiated outwardly opening ducts, is almost always, contained; whereas in the Coelenterata, as is shown in the next Preparation, the digestive tract is directly continuous with the body-cavity, and the generative products are set free from the generative glands directly by dehiscence, either into the perivisceral cavity or at once into the external water. The Echinodermata are multiplied exclusively by the intermediation of the congress of the two sexual elements; and in this absence of agamogenesis of all kinds, they contrast as strongly with the Arthropodir and Vermes as they do with the Coelenterata; the metamorphoses which 
For the danger which, orving to the habits of the Holothurioidea of ejecting their viscera when alarmed, may attend upon the basing of specific or other differences upon the presence or absence of the internal organs, see Forbes, History of British

they do go through differing essentially from the phenomena known as 'alternation of generations,' in that a part, and usually a large part, of the larval organism, is worked up into the composition of the sexually perfect individual. While the characters of the Coelenterata are such as to make them into a sub-kingdom with more sharply circumscribed boundaries than those of any other, except the Vertebrate sub-kingdom, it must be confessed that the characters of the Echinodermata, as presented to us not only in their life-history but also in their structure, approximate them so closely and at so many points to the sub-kingdom Vermes, as to throw some doubt upon the propriety of separating them, as has been done here, and as is all but universally done by foreign Naturalists, from the Vermes, and elevating them to the rank of a separate and co-ordinate sub-kingdom. For viewing the Echinodermata as a sub-kingdom co-ordinate with the sub-kingdoms Arthropoda or Vermes the following justification may be offered. No Echinoderm ever presents any trace of transverse, as opposed to antero-posterior segmentation of its body, unless the jointed character of the peduncle of the Crinoidea constitutes a real exception to this rule; whilst the perhaps most nearly allied order (or class?) of Vermes, the Gephyrei, do occasionally, Phascolosoma Cumanense, Keferstein (Zeitschrift für Wiss. Zoologie, xvii., 1867 , p. 53), show rudiments of the same division of the body into transverse compartments, which we have so well marked in the typical Annelids. They never multiply except through gamogenesis; gemmation, to the existence of which, actually or potentially, the presence of the transverse compartments just mentioned may be considered to speak, being as entirely unknown in them as is parthenogenesis, whilst both forms of genesis are common in Vermes. The rarity of hermaphroditism amongst the Echinodermata, and the non-existence in them of any sexual differences except those of the ultimate histological structure of the respective sexual glands, are minor points of difference between the two groups of animals under comparison. Their possession in common of the power of repairing great mutilations and injuries, as also of maturing sexual products before attaining their full size, may be connected probably with their common aquatic habit, and may be considered as constituting a point of physiological rather than of morphological affinity.

On the other hand, there can be no doubt that the Echinodermata as a whole present, both in their life-history and in their anatonical structure, many points of affinity, firstly, to the Vermes as a whole, and secondly, to each of the four great orders into which they are here divided. The passing through a larval stage, in which locomotion is effected by zones or circlets of cilia, is common to the majority of Vermes and to almost every Echinoderm ; and the clothing of the interior of the perivisceral cavity and of the digestive tract with the same microscopic element is a second point common to the majority of Vermes and to all known Echinodermata. Thirdly, all Echinodermata and almost all Vermes possess a system of vessels, which in either may be either locomotor or depuratory in function, but which are distinct from the cavities in which the true blood is lodged, though they may communicate 
Star Fishes, p. 199; and Peach, Annals and Magazine of Natural History, vol. xv. p. I7 I, I 845, for an account of one of the Aspidochirotae, belonging to the British Fauna, Holothuria nigra, which, from its constantly observed ejection of

more or less indirectly with them as also with the exterior. And fourthly, the antithesis which might be supposed to exist between Vermes and Echinodermata by virtue of the chitinogenous character of the integumentary system universally found in the one, and the calcificatory character of the same system as observed in the other of the two sub-kingdoms, vanishes when we observe that amongst the Vermes at least, the integumentary system of the same animal in both the highest and the lowest orders, is competent to secrete or excrete both these chemical substances. All the three orders of the class Platyelminthes, the Taeniadae and Trematodes (Leuckart, Die Menschlichen Parasiten, p. 475), and the Turbellarians (Schmarda, Neue Wirbellosen 'Thiere, 1859, i., pp. si. xiii. 29), have calcarenus particles deposited abundantly in, as well as chitinous armature developed upon, their integument. And the secretion of a calcareous vermidom by certain of the Tubicolar Annelids (Serpulaceae), a family, which, in their history as well as their structure, appear to combine the peculiar characteristics of the sub-kingdom Vermes in the most distinctive manner, points very clearly in the same direction.

The relationship of the Rotifera to the Echinodermata is founded upon their resemblance to the larval forms of these animals, and upon their possession of a very well developed water-vascular system. The resemblance of the adult Rotifera, which it should be borne in mind do not themselves go through any metamorphosis, beyond that of attaining in some cases a few appendages wanting in the young state, to the larvae of various Echinodermata and Vermes, is very clearly shown in a series of semi-diagrammatic figures appended to Professor Huxley's Paper on Lanicularia Socialis, in the Transactions Microscop. Society, New Series, vol. i., $1853, \mathrm{pl} .3$. But striking as this resemblance is, it may be said to approximate the Rotifera to the Vermes as much as to the Echinodermata, and may be, by persons who demur to allowing that a close parallelism exists between the two latter subjects of comparison, expressed as amounting to nothing more than a permanent retention by the Rotifera of certain of the characteristics of the larval state of higher Annelids.

The affinities again of the Echinodermata to the Platyelminthes must be held to be overstated by Semper, when $l . c .$, p. I97, he speculates in a controversy with Haeckel as to the 'Phylogenie' of the Echinodermata, whether the Dendrocaelous Planarian may not have been the parent stock of the Gephyrean Sipunculidae and of the Echinodermata. The Platyelminthes as a class do, it is true, present a singular resemblance in their developmental stages and metamorphoses to the Echinodermata; some of them possessing a pseud-embryo, as Pilidium, which may compare for complexity and importance with Bipinnaria Asterigera, whilst others have their larval stages marked merely by the possession of some external ciliated integument, which is got rid of by ecdysis or absorber, and may have as direct a development as Holothuria tremula. To this point of resemblance may be added the dislocation of the oral orifice from the anterior eye-carrying part of the body which the Turbellarians present us with, and which even in the face of the fact that in some Annelids every segment of the body may carry an eye, as in Polyophthaluus, bears no inconsiderable 


\section{the 'Cuvierian organs,' has received the trivial name 'Cotton- spinner.'}

For figures of the Cuvierian Organs, see Hunterian Catalogue, vol. i. pl. 3 ; J. Müller, Abhandlungen Konigl. Akad. Wiss., Berlin, I853, p. 208.

rescmblance to the relation subsisting between the compound eye of a Star-fish, carried at the apex of one of its rays, and its centrally-placed mouth. A double nerve-cord beset with pairs of ganglia has been figured by Schmarda, $l$. c., Taf. viii., fig. $83, c$. , in a Turbellarian, Splyyrocephalus dendrophilus, as extending from the region of the eyes and frontlet backwards to that of the pharynx, and lends an additional feature of resemblance to the two sets of structures just compared to each other. On the other hand, the Turbellarians, with the exception of the Nemertines (see Keferstein, Zeitschrift fur Wiss. Zoologie, xii. p. 68), and all the other Platyelminthes are sterelminthous, and contrast herein very strongly with the Echinodermata.

Several points of resemblance have been pointed out by Dr. Charlton Bastian, as existing between the Nematoids and the Echinodermata (see Phil. Trans., 1866, pp. 622-627), and amongst these, the arrangement of the nervous system and of the various systems of vessels and integumental pores, deserve especial notice. The Nematoids further resemble the Echinodermata in the large size of their perivisceral cavity, and the absence from it of any of the transverse compartments which are so common amongst Annelids, and which so plainly show that they are, in $\mathrm{Mr}$. Herbert Spencer's language, 'tertiary aggregates.' But they differ from them, as indeed from the Vermes also, very markedly, in not going through any metamorphosis, and in the absence of cilia from their entire organism at all times of their existence. The Acanthocephali, which have been placed together with the Nematoids and Chatognatha as forming the class Nematelminthes, differ from both these orders, and resemble the Echinodermata in having their adult forms originating with a provisional larva or pseud-embryo.

Perhaps more points of affinity exist between the Echinodermata and the highest class of Vermes, the Annelids, than between them and the lower classes just compared with them. The resemblance of the Gephyrean Vermes to the Holothurioidea is so striking as to have caused certain members of the order (or class ?), the Sipunculidae, to be ranked in former times with the Echinodermata; and this resemblance relates to matters of greater morphological importance than the resemblances of external form and of habits which are so obvious as existing between the Synaptidae and the Sipunculidae. The absence or presence of cloacal respiratory trees is similarly correlated in the Holothurioidea and the Gephyrean Vermes with the presence or absence of certain ciliated infundibula opening into the perivisceral cavity. The existence however in the Sipunculidae of a system of internally cilinted vessels, which, from throwing a ring round the oesophagus, whenco prolongations are given off into the interior of their peculiar tentacles, and to the skin, and upon which contractile Polian vesicle-like sacs are developed, must be taken to bo homologous with as well as partly analogous to tho peculiar ambulacral system of tho Echinodermata, is of the very greatest importance as showing the real affinity in question. It must here be said that the Tubicolar Annelirls, which attain a 


\section{For a discussion as to the nature of the functions of the Cuvierian organs, whether they are to be considered as weapons of defence, or as exciting organs in connection with reproduction, or as depuratory glands, see Semper, l.c., pp. I $3^{6-142}$.}

considerable external resemblance to the lower Echinodermata, and especially to the Crinoidea, by the peculiar (Capitibranchiate) arrangement of their respiratory organs, possess structures which may with probability be considered to be rudimentary representatives of the tentacular vascular system of the Gephyrei, and, by consequence, of the ambulacral system of the Echinodermata. Professor Huxley, who (Edinburgh New Philosophical Journal, Jan. 1855), has drawn attention to the resemblance of the branchial organs of a Tubicolar Annelid, described by him under the nane of Protula Dysteri, to the pinnate arms of the Crinoids, has figured from the same animal, $l$. $c$., fig. $3^{b}$, a structure exceedingly like a rudimentary circum-oral water-vascular ring, with two stunted saccular appendages. This structure is described by its discoverer in the following words: 'On the dorsal surface of the head, a longitudinal canal, which sometimes appears to be ciliated, was visible at $b$, fig. 3 ; posteriorly it divided into two branches, which dilated into granular coeca, arranged in a kind of festoon in the first segment of the thorax.' The presence of cilia is of importance as differentiating this structure from the non-ciliated pseud-haemal vessels both of Vermes and Echinodermata. It is possible that the somewhat similarly situated and similarly obscure organ in Arenicola piscatorum (see Grube in V. Carus' Icones Zootomicae, Taf. ix., fig. I $x$ ), may be, as has been suggested (Nat. Hist. Rev., Oct. I86r, p. 487), a rudimentary structure of the same import ; at any rate, it is plain that the transition from the 'calcareous ring" with a Polian vesicle appended to it, which has in the new Holothurian species, Rhabdomolgus ruber, described by Keferstein (Zeitschrift für Wiss. Zoologie, xii., I862, p. 34), taken the place of the entire water-vascular system of other Echinodermata, to the glands supposed to secrete the calcareous tubes of many Serpulaceae, and the homologous excretions of certain Terebellaceae and their allies is but very slight.

Grube has (Müller's Archiv., 1853, Taf. ix. x., pp. 340-342), described in the aberrant terrestrial Annelid, Peripatus Edvardii, a system of vessels, one of which is dorsal, and two lateral, but none of which are branched or connected with each other. The two lateral canals lie each on the outer side of the halves of the nerve cord, which are in this Annelid, as in many Tubicolar species, widely divaricated; their calibre is considerably larger anteriorly than posteriorly; the structure of their walls is grumous or glandular, and no other contents than clear fluid could be found in them. In relation with and probably in connection with these canals on their under surfaces anteriorly, was a delicate looped tube; and similarly constructed tubes were to be seen also in the posterior part of the body in relation with the feet. The lateral canals appear to be of different structure from the dorsal; at any rate, the absence of continuity between the two sets of vessels in a terrestrial Annelid goes far towards doing away with the difficulty of homologizing the, probably, similarly discontinuous pseud-haemal and ambulacral vessels of the Echinodermata with the ordinarily continuous and closed system of pseud-haemal vessels in Annelids.

The divarication of the nerve-cord into two halves observed in Peripatus Edwardii, appears to correspond with the divarication from each other on the ventral surface 
For a good figure of the pseud-haemal system, and the commissural junction between its ventral factors upon the first and second segments of the intestine, see Sars, Oversigt af Norges Echinodermer, I 86 I, Tab. xv. fig. I $m, l$.

For the homology of the 'auriculae' of the Echinoidea, of the

of the rows of feet which it supplies, and to be more or less physiologically similar to the allocation of a series of ganglions de renforcement (for which see p. 132, supra, ibique citata), to the line of insertion of the feet as seen in Nereis regia. An exactly similar separation of the nerve-cord into its two component halves, is to be seen in many Serpulaceae; see Quatrefages, Hist. Nat. Annelés, pl. iii., fig. $\%, 8$; Ann. Sci. Nat., Ser. iii., tom. x., pl. 2, tom. xiv., pl. ro; and when we couple these facts of comparative anatomy with the fact, that whenever the development of the nerve centres of Invertebrata has been observed, that is to say, in Mollusca, Arthropoda, and Vermes, these centres have been observed to be differentiated at a late stage in the series of developmental changes (see page rog supra, and Claparède, Beobachtungen über die Anatomie und Entwickelungsgeschichte wirbelloser Thiero, I863, p. 87), it will appear probable that the physiological necessity which the already radiate Echinoderm has for a radiate nerve-system, may be the regulating condition of its peculiar arrangement, and that they are therefore, protanto, and as regards their nerve system, approximated rather to the highest Annelids than to the Nematoids, as suggested by Dr. Charlton Bastian. A truer homology for the trifid nerve-system of the Nematoids, may be found in the nerve-cord of the singular Annelid, Sphaerodorum peripatus, as figured by Claparède, l. c., pp. 50-53, pl. xi., fig. 17 , where the super-addition to an organism, in other respects closely akin to that of a Nematoid, of motor organs, in the shape of numerous pairs of comparatively simple setigerous uniramous feet, has been accompanied by a corresponding addition of trifid nerve-ganglia, which are united by commissures into a continuous cord. Coming finally to the indications of affinity which the history of the various stages of development is properly held to point to, we may say that what is known of the development of the Polychaetous and especially of the Tubicolar or Capitibranchiate Polychaetous Annelids, shows that a closer relationship subsists between them and the Echinodermata than between even the Gephyrean Vermes and these latter animals. To judge of this similarity, it may be well to compare such figures as are given of the development of Antclon Rosaccus (Comatula Rosacea) by Professor Wyville Thomson, Phil. Trans., I865, pl. xxiv., xxv., and xxvi.; of Synapta digitate by Baur, Nova Acta, 1864, pl. iv.; or such figures as are given of various forms of Echinoderm larvae, from the memoirs of Müller and others, in Bromn's Klassen und Ordnungen des Thier-reichs, Taf. xxxv., xxxvi., xxxvii., and especially Tif. xlvi,, with the figures given by Claparede, l. c. ; of the development of Leucodore, Spio, Terebella and Magelona, Taf. vii., viii., ix., x., xi., and those given by Keferstein and Ehlers, in their Zoologische Beitrüge, Taf. viii. of Sipunculus. Siee especially Claparede's remarks as to the Tubicolar Annelids going in their early stages through more typical forms than those they ultimately rest in, and as presenting us thcrefore with instances of retrogressive metamorphosis, a possibility which is not rarely lost sight of in such discussions as these. 
'calcareous ring' of the Holothurioidea, and the 'vertebral ossicles' of the Asteriae, see Semper, l.c., pp. 16I-163; Baur, l. c., p. 18 ; Müller, Anatom. Studien, 1850 , p. I 54 .

For the compensatory relation which exists between the respiratory trees and the ciliated infundibula upon the mesentery, see Brandt, Prodromus, Fascic. i., 1 835, p. 59, who, in describing the genus Chiridota, says, 'Respirationis organum ramorum mullum, sed ejus loco corpuscula cylindrica, apice saepissime fissa, illae mesenterii parti, quae primam secundamque intestini curvaturam retinet affixa.' See also Semper, l.c., pp. 4, 132. For figures of these organs in the Synaptidae, see Broun, Die Klassen und Ordnungen des Thier-reichs, Bd. ii., Taf. xliv., fig. I2 ; Sars, l.c., tab. xv., xvi.

\section{Sea-Anemone (Actinia Crassicomis),}

Dissected so as to show its various external and internal organs.

A verticas section having been made through the entire length of the sub-columnar body, one of the halves thus obtained has been suspended, so as to show the direct continuity, firstly, of the cavity of the stomach with the general cavity of the body, and secondly, of the general cavity of the body with the cavities of the tentacles. These latter organs are arranged in four rows, within the circumference of the oral disc, which forms a low parapet externally to them; they are shorter than the diameter of the oral disc, even when fully extended; in this specimen they are not fully retracted, the animal having, probably, been killed by the addition of fresh water; and their natural short and conical form is well seen. Each tentacle tapers somervat abruptly to a point, apparently under the action of the muscular fibres, which act as a sphincter to the foramen in its apical extremity. The peristomial dise, internally to the inner row of tentacles, is divided into two concentric areae by a line of depression corresponding with the strong oral sphincter, which is seen in section at the entrance of 
the digestive cavity. Both the peristomial dise and the internal surface of the digestive cavity are marked by fine radiating lines, which are seen to correspond with the attachment to their under and outer surfaces respectively of the vertical muscular lamellar' ' mesenteries,' which, radiating from a point in the centre of the hydrorhiza to the outer wall of the body, as well as to the roof of the perigastric space, and to the outer surface of the tubular stomach, divide the body cavity into a number of radially-arranged, mutually inter-communicating, wedge-shaped compartments. Some of these mesenteries fail by greater or less intervals to reach the outer surfice of the stomach, and they are called 'secondary' or' 'tertiary' mesenteries, whilst those which attach themselves to that organ as well as to the outer wall are called 'primary.' 'The greater part of the external warty integument having been removed, the lines of attachment of the mesenteries to it are as plainly seen as those similarly produced on the digestive and peristomial surfaces. At the lower part of the Preparation one of the mesenteries has been reflected back, and the decussating muscular fibres which make up a large portion of its substance are well seen. At a little distance internally to this mesentery, and in connection with the free border of another similar lamella, where it projects into the general cavity of the body below the level at which the stomach opens into it, we see some of the generative glands surmounted by certain long convoluted filamentous organs, the so-called 'craspeda,' which are richly furnished with threadcells; but which are often spoken of as renal organs, as concretions in which guanin is said to exist have been found in connection with them. The lower orifice of the digestive tube is seen to be of about the same size as the oral inlet, but it is not seen in this preparation to be guarded with a muscular sphincter as the mouth is. In Actiniae there exists a demi-canal on each of the opposite sides of the mouth, which is prolonged down the inner surface of the stomach, and is continued a little way beyond the termination of the sub-cylindrical organ, so as to project as a free languet into the general cavity of the body. The external surface of the body is similarly furrowed in this specimen, and an appearance of bilateral symmetry is thus produced. The Actiniae and Cerianthidae are the only Polypi s. Anthozoa in which the external integument is not more or less indurated by inorganic deposit. 
For the anatomy of the Actiniae, see Hollard, Ann. Sci. Nat., Ser. iii., tom. xv., $185^{\text {I }}$, p. 257 ; Huxley, Med. Times, June, I 856 .

For a zoological description of Actinia Crassicornis, see Johnston, British Zoophytes, 1847, 2nd edition, p. 226.

For the anatomy and morphology of the entire sub-kingdom Coelenterata, see Greene's Mantal of the sub-kingdom Coelenterata, I86r.

For the points of distinction between the Coelenterata and the Echinodermata, see Van Beneden, Recherches sur la Faune Littorale de Belgique Polypes, 1866, pp. 55-62.

\section{Sea-Fir (Sertularia Abietina).}

A compound Hydroid Polype, plant-like in form, and differing from the preceding specimen in being fixed to one spot in adult life, and from the entire class to which the Sea-Anemones belong, by the much smaller size and simpler structure of each of its constituent zooids. The specimen consists of a number of regularly branched stems, which arise near to each other from a creeping stolon; and are beset by series of closely arranged subalternate cells, the 'hydrothecae' containing the zooids. In the upper half of the specimen, the main stems and the pinnae may be observed to carry, besides the regularly arranged hydrothecae, certain larger cells, irregularly arranged along their upper surfaces. These latter cells are the 'gonophores' of Hincks, the 'teléophores' of Van Beneden; they differ from the other cells or hydrothecae, in that their contents are the sexual products developed within processes of the 'coenosare,' which possess neither the digestive cavity nor the prehensile tentacles of the smaller hydrothecae. Appended to the apices of some gonophores, may be seen the marsupial pouch, into which the ova are transferred at a certain stage of their development. The gonozooids, or the contents of the gonophores, we may call 'medusiform buds,' but they never in the family Sertulariidae take the shape of Medusae. The embryos are at first spheroids richly covered with cilia; subsequently 
they become cylindriform; and finally they attach themselves by one extremity which widens into a 'hydrorhiza,' and develope a circlet of tentacles and a digestive sae at the other. In the family Campanularidae, which differs from the Sertularidae mainly in the pedunculation of its cells, many species have Medusae set free from their gonophores. The outer layer of the ectoderm has secreted a firm but flexible polypary, which is continued into the cups for the lodgment of the digestive and generative zooids, as 'hydrothecae' $s$. 'calycles' $s$. 'cells,' and as 'gonothecae' $s$. 'capsules,' in the language of different writers. The digestive or alimentary zooids are known as 'polypites;' their cavity, which is not a distinct sac freely suspended, but a mere hollow scooped out in the part of the coenosare which is prolonged into each cell, is continuous with that of the coenosare or 'coenenchyma' by a narrow tubular passage, the 'transition piece' of Reichert, passing inwards from the bottom of the stomach. Representations of two other sub-kingdoms may be seen to have affixed themselves semiparasitically to the main stems of this zoophyte. One of them is the Spirorbis, a small Tubicolar Annelid, with a discoidal shell, somervhat like that of the fresh-water molluse Planorbis; the other is one of the Cyclostomatous Polyzoa, Tubulipora patina, which with its aggregated calcareous cells presents an appearance not unlike that of a small tubiflorous flower belonging to a plant of the order Compositae.

Coelenterata, with an external polypary, and a uniserial circlet of tentacles such as this specimen possesses, bear a superficial resemblance to many Polyzoa, which indeed were formerly classed with them. But beyond these more or less unimportant points of resemblance, the Hydroid Polypes and the Polyzoa have searcely any points of real similarity, unless we reckon as such the absence of ducts to the generative glands, and the power of multiplying by gemmation, properties which attach to them however in common with representatives of several other classes of Invertebrata. In the absence of a digestive tube differentiated from the peri-viseeral cavity; in the absence of muscles differentiated into distinct fascicles and crossing that cavity; in the absence of any nerve-centre, and in the presence of thread-cells (all points to be made out, and, with the exception of the one relating to the nerve system, with very little trouble, under the microscope, with a fresh specimen of the 
present species)-the Hydrozoa differ widely and essentially from the Polyzoa. It may be further added that it is very usual in Polyzoa to have each cell cut off by a diaphragm or septum, into the formation of which both ectocyst and endocyst enter, from continuity with the rest of the colony; whilst it is only in the few cases such as Hydra, Corymorpha, Vorticlava, Myriothela, in which the hydrosoma consists of but a single polypite, that such independence is attained to in the Hydroid Zoophytes. In the form of 'Polymorphismus,' which the 'medusoid bud' presented to us in the 'gonophore' of the Sea-Fir exemplifies, we have the connecting link between the distinct testis and ovary of the Hydra, (for which see pl. xii., fig. 7 , and description), and the free sexual zooids known as 'Medusae,' and exemplified in genera as nearly akin to the Sea-Fir as the Campanularia gelatinosa. And, as has been well observed, a study of such histories as those of the various modes of development of this class of Coelenterata, shows how impossible it may become to draw sharp lines of distinction between individual animals or zooids and simple organs on the one hand; and on the other between asexual generation and simple growth.

For a monograph of the British Hydroidea Diplomorpha, V. Carus, see Hincks, History of the British Hydroid Zoophytes, I868, where a general account of their structure and life-history is given in the Introduction, pp. i.--lxv. For the Siphonophora, see Professor Huxley, Oceanic Hydrozoa, Ray Society, I859. For the Hydrozoa generally, see Professor Huxley, Medical Times and Gazette, June 7, I 856, p. $5^{6} 3$.

For an account of the particular species to which the specimen here described belongs, see Hincks, l.c., i., 226.

For an account of the development of the Sertularia cupressoides, see Van Beneden, Recherches sur l'Histoire Naturelle des Polypes, I866, pp. I79-I84, pl. xvi., where what is spoken of above as a 'marsupial sac,' and described and figured as such by Hincks, l.c., p. xvi., is figured at fig. 3 , but spoken of, p. I80, as a 'hernie au bout de la capsule;' and for the development of the Hydroidea generally, see Allman, British Assoc. Rep. for 1863, p. 35 I.

For a short account of the Histology of this class, see Professor 
Reichert, on the contractile substance and intimate structure of the Campanularidae, Sertularidae and Hydridae, translated in the Annals and Magazine of Natural History for Jan. 1867, from the Monatsbericht der Akademie der Wissenschaften zu Berlin, July 1 866, p. 504; and for the Histology of the entire sub-kingdom Coelenterata, see Kölliker, Icones Histiologicae ii., Abtheilung, Hft. i., I 866.

\section{Fresh-water Sponge (Spongilla Lacustris),}

From the Isis, growing on the wall of a lock.

THis specimen, like the preceding, is plant-like in appearance, consisting as it does of a root-like basis of attachment, and two upright stems arising close together from it. The stems are about five inches in height, and of the thickness of a drawing-pencil, but the Spongilla Lacustris not rarely attains a greater size than this. Owing to its having been preserved in spirit, this specimen has its surface more fenestrated than it was in the living condition; its protrusible bladder-like cloacae are no longer visible; and its emerald-green colour is nearly lost. Its exterior is hispid with fascicles of spicula, and the orifices in which the cloacal oscula were lodged are very plain; though the smaller inhalant orifices or 'pores' are not distinguishable, and indeed can only be seen in small and transparent specimens under the microscope. Towards the lower part of the stem, numbers of reddish globular seed-like bodies, the asexual reproductive gemmae, formed towards the close of the summer, are to be noted. The coriaceous capsule of these gemmae is strengthened in this species, not by the birotulate spicula known as 'amphidises' from their resemblance to a couple of toothed wheels connected lyy an axle, and existing in the other fresh-water Sponge, Syongillu flucialilis, but by simple curved acicular spicula which lie in it parallel to its surface. These spicula are abundantly spinous, as are also the spicula which are to be found in the dermal membrane of this, though not of the other fresh-water species; the spicula of the skeleton proper 
are smooth in both species. It is, of course, necessary to have recourse to the use of the microscope for the verification of these points; and for the detection of the finer spicula, the specimens must be mounted in Canada balsam. Owing to the neglect of this latter method of investigation, the existence of spicula has frequently been overlooked, as, for example, in the case of the Halisarca Dujardinit, which, on account of the supposed absence of these structures, has been elevated to the rank of a distinct genus.

Discussions have been frequently raised, firstly, as to the claim of the Sponges to be considered animal organisms at all; secondly, as to what is to be considered the unit of their organisms; and thirdly, as to the rank which the class is to take relatively to other divisions of the animal kingdom. With reference to the first of these questions, which is now all but universally answered in the affirmative, it may be said that the motile phaenomena noticeable in these creatures, and their great need for, and rapid consumption of oxygen, without which, as supplied by constant additions of fresh-water, the Spongillae may be observed to die and putrefy with very great rapidity, are, from the physiological point of view, very strong evidence for their animal character. The histological evidence however drawn from the detection in them of ciliated as well as non-ciliated epithelium, of cells for the formation of the spicula, and above all of contractile fibre-cells which, though not detected in Spongillae, do exist in the more highly organized Sponges, Cerato-spongiae and Corticatae, is, as Kölliker has remarked, quite conclusive upon the question.

It is not possible to give as distinct an answer to the second question, as to whether the Spongiadae are to be considered as colonies made up of uni-cellular but polymorphic organisms, or whether we ought not rather to regard each exhalant osculum as marking out a corresponding zooid, into the constitution of which, as of all higher animals, a multitude of polymorphic 'cells' enter. For, as has been already said, with reference to the Hydroidea, it is not easy always in the lower subkingdoms to draw a sharp line of demarcation between what in a higher and indeed sometimes also in a lower organism would be unhesitatingly spoken of as an 'organ,' and what in nearly allied genera to one which may chance to be under examination would be spoken as a specially modified 'zooid.' It is agreed upon all hands, that, in addition to the nucleated cells, ordinarily but not always, destitute of a cell wall, and 
capable of amoeboid movements, which make up the greater part of the non-skeletal elements of the Spongiadae, there are to be found in them several other kinds of cells, and even tissue, which however readily reassumes the form of the independent cells by the fusion of the sarcode of which it was composed; and it is not therefore necessary to say more than that the better mode of expression for the facts acknowledged by both parties is the one which speaks of each exhalant osculum as corresponding not to an individual Sponge, but to an individual colony.

With reference to the third question, that of the position which the Spongiadae may be considered to hold relatively to the Protozoa on the one hand, to which sub-kingdom they are ordinarily referred, and to the Coelenterata on the other, it is perhaps more correct to regard them as exemplifying the highest stage of evolution of the former, rather than as being a transition towards the latter of these two types. The distinctness indeed of their 'oscula' from their 'pores' would appear to place them in a position of superiority as regards the Coelenterata, in which there is but a single orifice both for the ingestion of aliment and for the ejection from the system of refuse matter. Kölliker has thrown doubt upon the view that certain of the sclerous elements of the organisms of the Anthozoa are due to epidermal excretion, and thus one point of distinction between them and the Spongiadae would be done away with; but the external chitinous polypary of the Hydroid Zoophyte will serve always to differentiate it from the Sponge, in which the skeletal elements are always internal. This, however, is perhaps a point of merely secondary importance, as is also the non-secretion by Coelenterata of the siliceous deposits so common in the Sponges.

For the anatomy and pliysiology of the Spongiadae, see Dr. Bowerbank, Monograph of the British Spongiadae, 1864-1866, pp. I-I 52 .

For the methods to be employed in the examination of Sponges, ibicl. i., 225 ; and for their application in the cases of Halisarcina Dujardinii and Spongilla lacustris, ibid. ir., 225, and Zool. Soc. Proc., 1863, p. 462.

For the physiology of the 'oscula' and 'pores', see Dr. Bowerbank, British Assoc. Report for 1857, p. 125, pl. i., figs. I-7.

For a diagrammatic representation of the mutual relations of the various parts of a Sponge, see Professor Huxley, Introduction to the Classification of Animals, 1869, p. I 5 , fig. 4 . 
For the histology of the Spongiadae, see Kölliker, Icones Histiologicae, r864, i., p. 46, and Dr. Bowerbank, l.c., passim.

For the various views which have been taken as to the position of the Spongiadae in the animal kingdom, see Kölliker, $l$. c., p. 73, ibique citata; Van Beneden, Polypes, 1866, p. I98; Claparède et Lachman, Études sur les Infusiores, i., p. $42 \mathrm{I}$, I858-1859; Haeckel, Generelle Morphologie, I866, ii., p. xxix.; Natürliche Schopfungsgeschichte, 1868, p. 396.

For the different views which may be taken as to the 'indivual' organism in the Spongiadae, see O. Schmidt, Handbuch der Vergleichenden Anatomie, 1865, p. 25; Lieberkühn, Archiv. für Anatomie und Physiologie, I863, p. 728 ; Claus, Grundzüge der Zoologie, 1868, p. 52 . 

PLATE I.

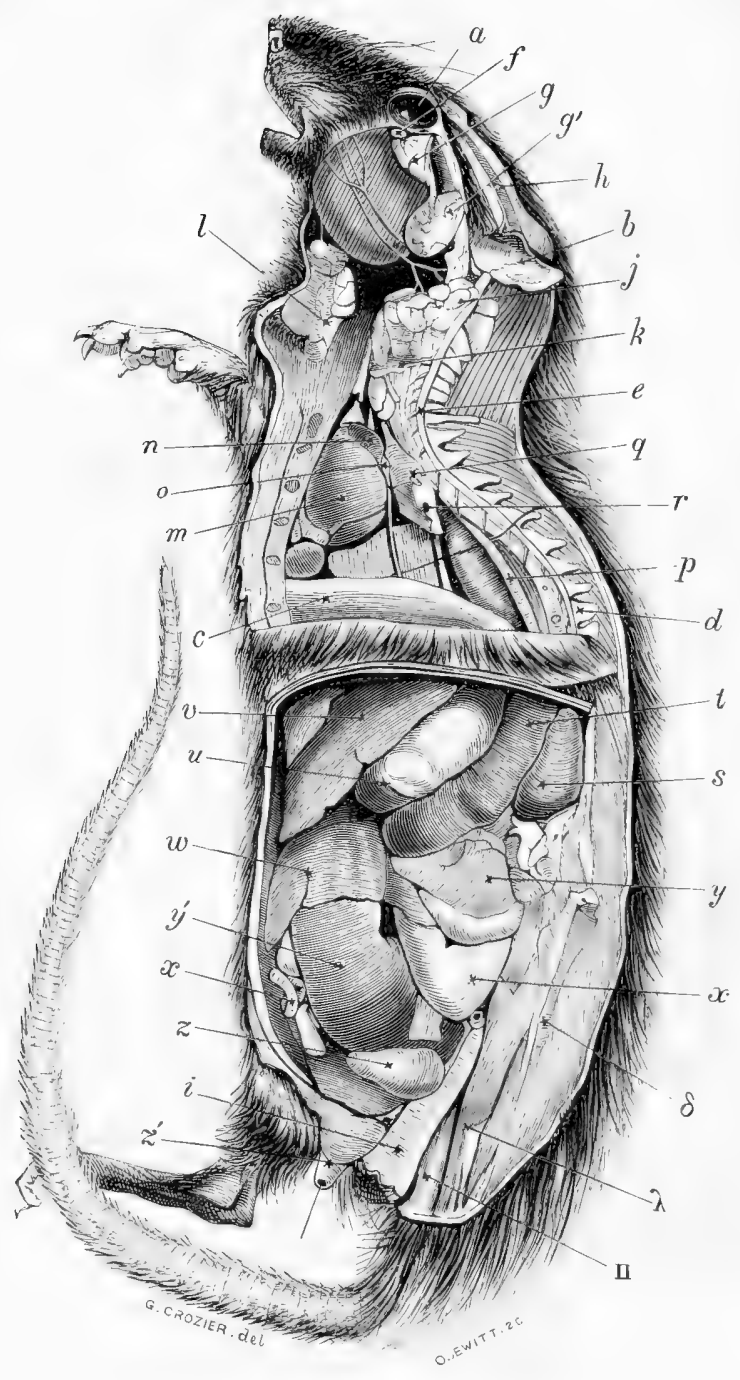

Common Rat, MIus Decumanus. 


\title{
DESCRIPTION OF THE PLATES *
}

\author{
PLATE I. \\ Common Rat (Mus Decumanus),
}

Dissected so as to show, superiorly, the cerebrospinal nervous system lodged in the craniospinal cavity, and, inferiorly, portions of most of the organs of vegetative life.

The distinctive characteristic of the Vertebrate type, the possession, namely, of an internal skeleton specially connected with the organs and functions of animal life, is clearly shown in this figure. The internal skeleton is seen forming a separate chamber for the central nervous system which presides over motion and sensation, apart from the larger cavity in which the organs of vegetative life are lodged. By virtue of this arrangement Vertebrata may be spoken of as 'Bicavitary' animals, in contradistinction to Invertebrata which are ordinarily 'Unicavitary.' Secondly, we see that it is the internal, and not as in Invertebrata an external, skeleton which gives origin and support to the active and passive organs of locomotion. Thirdly, the limbs, which are never more in number than two pairs, are directed towards that surface of the body in apposition with which the heart, the great centre of the circulatory or haemal system, is placed $(m)$. Hence Vertebrata may be spoken of as 'Hacmapods,' in contradistinction

a The Description of the figure given in this plate will be found to coincide in many particulars with the Description given at pp. x-5 supra of the first series of Preparations. The Descriptions of plates vi. and vii. stand in a somewhat similar relation to the Descriptions of the Preparations 30 and 32. But in none of these cases are the Descriptions mere repetitions, but will be found to be complementary of each other. In the present Description, for example, the upper part of the figure has been drawn from a disscetion distinct from that described at pp. 1-5 supra; and the structures lettered here $g$ and $y^{\prime}$ will be found not to have been described before. 
to Invertebrata which are 'Neuropods,' having their main nerve centre placed in the same relative position as that occupied by the heart in the former class ${ }^{b}$.

Above the heart we see the digestive canal, and above the digestive canal the craniospinal, and the nervous centres it contains. But the great vessel, known as the aorta $(p)$, which carries blood from the heart to the organs of the body generally, interposes itself in all Vertebrata between the lower surface of the craniospinal and the upper surface of the digestive tube.

A minor point distinctive of Vertebrata is the presence of a spleen.

The peculiarities of the tegumentary system are distinctively mammalian, as are also the following points in the anatomy of the internal organs shown in this figure: the suspension of the lungs freely in closed cavities, the so-called 'pleural' cavities; the presence of a perfect diaphragm (c) supplied by a phrenic nerve originating in the region of the neck; the smoothness of the external surface of the kidney; the persistence of the aortic arch of the left side $(p)$; and the presence of an omentum or epiploon $(w)$.

The scalpriform incisors characteristic of the order Rodentia are concealed in this profile view by the lips, but the figure shows well the great size of the masseter muscle, by the contraction of which the characteristic anteroposterior movement of the lower upon the upper jaw is effected. The great size of the organs of special sense relatively to the entire bulk of the animal, and of the hind relatively to the fore limbs, are characteristic, though not universally nor exclusively, of Rodents.

b These two latter names are more strictly accurate than the two former, for in some Invertebrata the main nerve-centres are separated from the viscera of organic life by more or less perfect septa, formed by separately calcified ossicles in the Asteroidea, or by the prolongation inwards of processes from the external skeleton, as in many Crustacea and Insecta. But in all such cases the neural still remains the motor surface, and the term 'Neuropod' applies to them as strictly as it does to any of the Vermes or Mollusca. For the ossicles of Asteroidea, see pl. x., infra; and for the 'endophragmal' skeleton, in Crustacea, see Huxley, Medical Times and Gazette, Feb. 21, I859, p. I8I ; Nov. 7, 1857, p. 467: in Insecta, see Burmeister, Manual of Entomology, translated by W. E. Shuckard, p. 236; and for figures of it, see Spence Bate, British Association Report for 1855, pl. xxii., figs. I and 2: Straus Durckheim, Considérations générales sur l'Anatomie Comparée des Animaux Articulés, pl. ii., fig. I. 
Points of less classificatory importance are furnished to us by the presence of a vena cava descendens on the left side, of smooth cerebral hemispheres $(h)$; of a uterus all but completely bifid ( $y$ and $\left.y^{\prime}\right)$, of a Harderian gland $(f)$, of a hibernating gland $(i)$, and of a double lacrymal gland ( $g$ and $\left.g^{\prime}\right)$.

The left halves of the parietes of the craniospinal, thoracic, abdominal, and pelvic cavities were removed to expose to view the parts shown in this figure. The integument has been removed from the greater part of the facial region, but a narrow strip has been left connecting the concha of the ear with the upper eyelid. A similar strip has been drawn as left in situ overlying the costal attachment of the diaphragm.

a. Left eye.

b. Left ear. Both eye and ear are largely developed in most Rodents, and markedly so in this family.

c. Diaphragm forming a contractile dome-shaped floor between the abdominal cavity below and the thoracic above.

d. Eleventh dorsal vertebra, counting from before backwards. The ten anterior dorsal vertebrae have their neural spines directed more or less obliquely backwards; the two vertebrae-one only of which is seen in the figure-immediately behind $d$, have their spines pointing forwards. The spine of the eleventh dorsal vertebra has a vertical direction, and it marks the point of greatest mobility between the segments of the vertebral column, as also the point whence the size of the vertebrae progressively increases both towards the cervical and towards the sacral regions. The spine of the second dorsal vertebra is of great length, and in the natural condition of the parts it had an ossicle articulated to it, homologous to the ligamentun muchae of longer-necked animals, and running forwards amongst the muscles of the nape of the neck. The dorsal vertebrae are thirteen in number, as is very commonly the case in this order, as also among the Ruminantia and Carnivora. The first two cervical vertebrae are, as is usual, though not invariable, among mammals, much larger than any of the five which succeed them in the neck.

e. Spinal cord. The part where it widens into the medulla oblongata, a part of considerable transverse dimensions in 
this and other Rodents, is concealed by the large external ear.

f. Part of Harderian gland, which discharges its secretion by a duct opening under the rudimentary third eyelid or nictitating membrane. This gland is found in most mammals, with the exception of Chiroptera and Simiadae.

g. Intra-orbital portion of lachrymal gland. Its duct joins that of a second portion of the lachrymal gland $\left(g^{\prime}\right)$, which lies without the orbit.

$g^{\prime}$. Extra-orbital portion of lachrymal gland, lying upon the masseter muscle, and sending a duct with some glandular tissue inlaid in its walls to enter the orbit at its posterior angle, and receive the duct of the intra-orbital portion $(g)$.

h. Cerebral hemisphere of right side. The external surface of the two hemispheres is not convoluted; at their posterior aspect the longitudinal venous sinus is seen to divide into the two lateral sinuses. A small triangular portion of the large cerebellum comes into view at this point; the sinuses prevent the mesencephalon or corpora quadrigemina from being seen.

$i$. Vagina.

j. Parotid gland. Its ducts are seen to converge from its constituent lobules, which are loosely aggregated from the neighbourhood of the ear to that of the acromion, and to cross, when united, the ramifications into which the motor nerve of the facial muscles is seen to break up. The buccal pouch is wanting in the true Mures, but some lymphatic glands have been removed from the space between the masseter muscle and the parotid gland.

k. Portion of 'hibernating gland;' a gland found in many Rodentia, Chiroptera, and Insectivora, and spreading in them into the axillary, the nuchal, the thoracic, and occasionally even into the abdominal regions.

l. Submaxillary gland and duct.

$m$. Heart; the line ends upon the left ventricle. The apex of the heart is not turned so much to the left as in man and in some of the lower mammals, as, for example, the mole. The fold immediately below the point where the line abuts upon the ventricle is formed by the cut edge of the 
pericardium, the upper four-fifths of which have been removed. Between the inferior surface of the heart and the diaphragm the fourth lobe of the right lung intervenes posteriorly; and between the apex of the heart and the diaphragm and sternum anteriorly, a process of serous membrane entangling lobules of fatty tissue is interposed, and connects thus the apex of the pericardium with the sternum and diaphragm.

n. Left auricle.

o. Phrenic nerve lying in relation with the left superior cava and passing down from its origin in the neck, in front of that vessel and between the root of the left lung and the pericardium, and by the side of the fourth lobe of the right lung, to distribute itself in the diaphragm.

p. Aorta. A bristle has been passed between it and the left azygos vein, and abuts on the diaphragm where the left phrenic nerve enters it. Behind this bristle are seen from behind forwards, firstly, the third lobe of the right lung; secondly, the oesophagus, which is seen to be of a small size in correlation with the scalpriform incisors of the Rodent; thirdly, the fourth lobe of the right lung within its orn pleural cavity, in relation with which is the phrenic nerve; and, lastly, the lobules of fatty tissue, already spoken of, in apposition with the fourth and fifth of the six sternal bones.

q. Left azygos vein joining the vena cava superior of the same side, and receiving some veins from the masses of fat just mentioned in connection with the pericardium.

$r$. Root of left lung: the lung of this side has been removed; it consisted of a single lobe, as is often, though not always, the case in Rodentia, Marsupialia, and Insectivora, though very rarely in Carnivora and Quadrumana; see Cuvier, Leçons d'Anatomie Comparée, tom. vii. ed. sec., I $840, \mathrm{pp} .156-\mathrm{s} 63$.

s. Kidney; lying in the angle between the diaphragm and the psoas and quadratus lumborum muscles. The smoothness of its external surface is a mammalian character.

t. Spleen.

u. Stomach. 
$v$. Liver; the line abutting upon its left lobe.

w. Omentum or epiploon, a process of the peritoneum peculiar to mammalia.

$x$. Coecum. The entrance of the small intestine into the coecum is not seen, but we may observe that the coecum becomes smaller in calibre where it is bent on itself superiorly. It passes thus into the 'large intestine,' which does not however contrast so markedly either in its relative shortness, or in the thickness of its walls, or in its calibre with the 'small intestine,' in the Rodentia, as in many other orders. These omnivorous Rodents, and also the Sciuri, have smaller coeca than the Rodents which live on less nutritious and coarser food and have rootless molars.

$x^{\prime}$. Convolutions of intestines.

$y$. Upper end of left cornu of pregnant uterus, passing into the Fallopian tube, which together with the ovary fills up the space between this convolution of the uterus and the kidney. The ovary and tube are connected by a ligament to the peritoneum covering the diaphragm, the 'ligamentum diaphragmaticum' connected with the 'Wolffian body' in the foetus.

$y^{\prime}$. Lower portion of same uterine cornu distended with foetuses.

$z$. Bladder contracted into a conical shape and receiving the ureter at its base on the left side.

$z^{\prime}$. Outlet of urinary organs through a perforated clitoris distinct from the vagina.

$\pi$. Rectum.

$\lambda$. Flexor muscles of the tail, which arise from the internal surface of the pelvic bones.

$\delta$. Anterior portion of ilium, the posterior part of which has been removed, together with the pubis and ischium. From its internal surface the caudal flexors are seen to take origin, and in front of them and in a line with the point on which the letter $\delta$ is placed, the cut end of one of the great veins returning blood from the hind limb is seen.

The following peculiarities in the tegumentary system deserve notice:-the absence of hair from a part of the anterior portion of the snout, the so-called 'muffle,' in which we see the orifices of 
the nostrils; the presence on the snout, as also over the eyes, of long tactile bristles, which, like the large eyes and ears, are correlated with the nocturnal habits of the creature; the presence of a nail on the rudimentary thumb, which is occasionally overlooked or lost in adult specimens; the coarseness of many of the hairs along the middle line of the back; and the annular arrangement of the scales on the tail, and the outgrowth of hair in the intervals of the rings thus formed.

For an account of the 'hibernating glands,' see Hirzel and Frey, Zeitschrift für Wissenschaftliche Zoologie, xii., 2, 165, 1862; Ecker, Wagner's Handworterbuch der Physiologie, iv., p. I2I, I853, ibique citata. 


PLATE II.

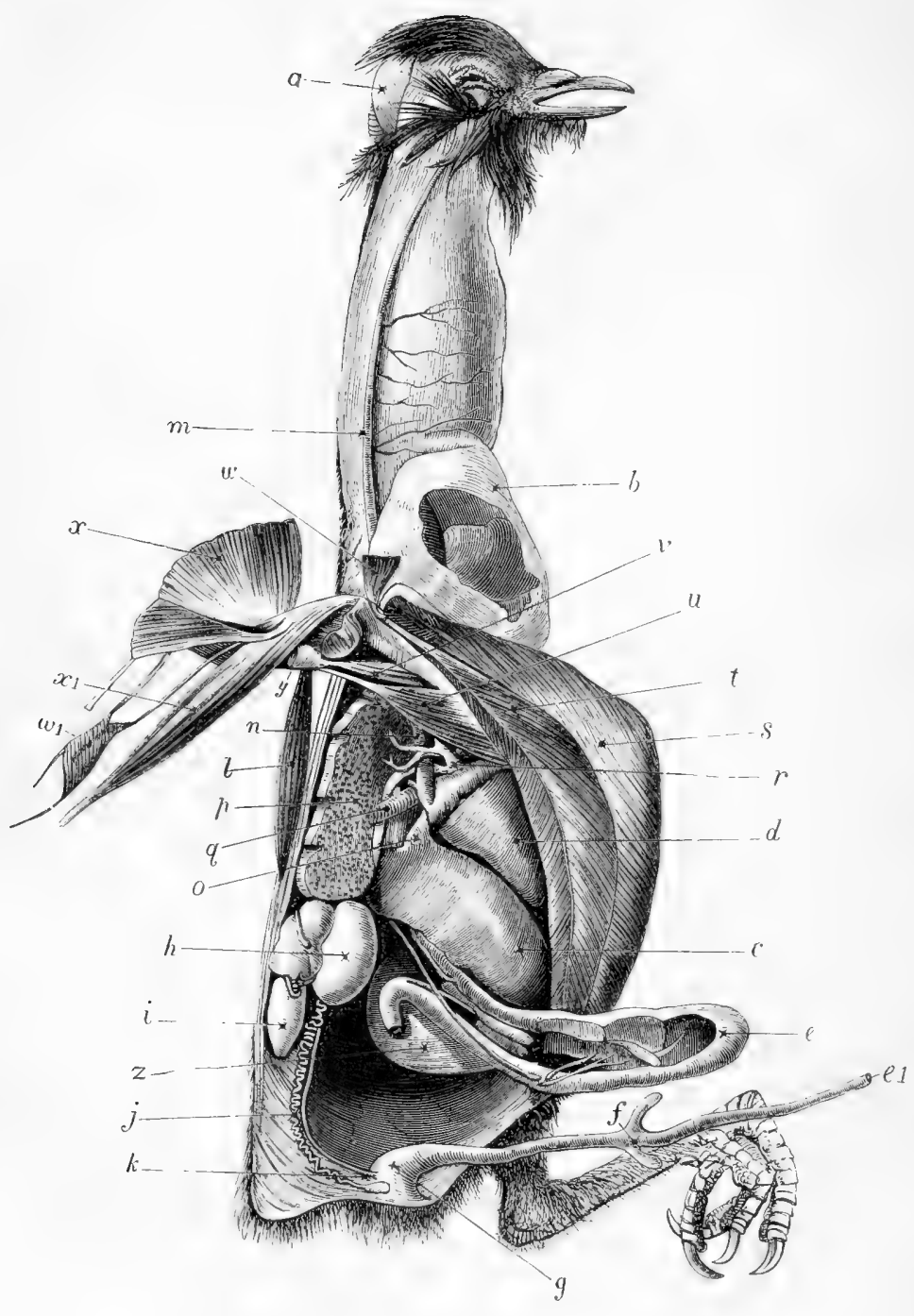

G. Crozter, del.

o. Jewitt, sc.

Pigeon, Columba Livia. 


\section{PLATE II.}

\section{Common Pigeon (Columba Livia),}

Dissected so as to show, firstly, some of the main points of agreement and difference between Aves, Reptilia, and Mammalia respectively ; and, secondly, the arrangement of the principal muscles of flight.

IN the possession of a single aortic trunk, as seen in the figure a little internally to the letter $p$, and above the letter $q$, birds resemble Mammals, as they do also in the physiological peculiarity of being warm blooded, or 'homoeothermal.' A few Mammals resemble all Birds in being testicondous, see $h$ in figure, and in the possession of two coeca, see $f$ in figure, as also in the possession of a coracoid prolonged down to the sternum, see place of origin of muscle $u$ in figure. But all Mammals differ from all Birds in that their single aorta crosses their left and not, as shown at $g$ in this figure of a Bird, the right bronchus; in the absence of any indentations of the lungs' surface to correspond with the ribs; and in the absence of any external conformation of the kidney in relation to the pelvic bones. In all Mammals there is a sinus urogenitalis, in none do the genital and urinary ducts open separately, as shown here at $k$ and $g$, into a cloaca common to genital, urinary, and faecal products. These points are as constant as the possession by Mammalia of a hairy integument and of non-nucleated coloured blood corpuscles. The relation of the pancreas to the duodenum, as seen at $e$, is a minor point, but probably equally distinctive of Birds in opposition both to Mammals and Reptiles.

In being testicondous; in the absence of differentiation of the structures of the kidney into cortical and medullary portions, and in the supply of blood-vessels to the gland; and in the absence of 
a perfect diaphragm, and also of a corpus callosum,-Birds and Reptiles resemble each other as closely as they do in the microscopic character of their blood-corpuscles. In two points of secondary importance Birds resemble the Loricate and differ from the Squamate Reptiles; in this latter class there is a rudimentary urogenital apparatus, and the genital gland is situated a certain distance anteriorly to the kidney; whilst in Birds, Crocodiles, and Chelonia, the genital and urinary glands have separate outlets, and the glands themselves are more or less completely in apposition with each other. On the other hand, all Birds possess a quadrilocular heart, and a single aorta belonging to the left ventricle, an arrangement by which they are secured against any direct admixture of venous with arterial blood, and in which they differ as widely and constantly from Reptiles as in the peculiarity of their integumentary system.

No Reptiles possess a true crop, such as is seen at $b$ in the figure, nor two coeca; but these structural arrangements are by no means constant in Birds.

a. Right cerebral hemisphere. Its surface is smooth, contrasting herein with that of the transversely laminated cerebellum seen behind in the median line.

b. The crop, which is bilocular in the Columbidae. It is continuous above with an artificially distended oesophagus, and a window has been made in its right wall to show its division into two compartments.

c. Right lobe of liver, on which the right side of the heart rests.

d. Heart. The ventricular portion is more acutely conical in most Birds than in Mammals, and the auricles are smaller in relation to it.

$e$. Loop of duodenum in which are contained the longitudinally arranged lobes of the pancreas. Into this loop of intestine three ducts open from the pancreas and two from the liver, which has no gall-bladder in this species. Two of the pancreatic ducts open near the middle of the distal segment of the duodenum close to each other and to one of the gallducts; the third pancreatic duct opens near the distal end of the loop, and the second gall-duct near its proximal end. 
e. I. Terminal segment of small intestine ending in the large intestine at $f$, which, together with it, has been turned over out of the abdominal cavity, on to the animal's left. Two long coils of small intestine have been removed between its terminal segment and the distal end of the duodenum; the first coil being a fold of great length spirally arranged, and the second a much shorter one arranged like the duodenal fold, which however it exceeds in length.

$f$. Large intestine, two small coeca marking its commencement. In the small size of the two coeca the Columbidae contrast with the great mass of the Gallinaceae.

g. Terminal dilatation of the large intestine which receives the vas deferens and ureter posteriorly and superiorly on each side. In this cloacal arrangement Birds resemble Reptiles and Amphibia; in all mammals there is a sinus urogenitalis developed, into which these ducts open. In the absence of a urinary bladder Birds resemble Snakes and Cartilaginous Fishes, as also many Lizards.

h. Testis.

i. Kidney divided into three lobes, which are conformed to the sinuosities of the pelvic bones. Between the lower and middle lobes the large ischiatic artery and some nerves pass out to the lower limb. The artery gives a supply of blood to the gland. Between the middle and upper lobe of the kidney the small femoral artery passes outwards, and a large vein passes invards. This vein, besides acting as a ' renal-portal' vein and supplying the glandular structure of the kidney, communicates directly also with the renal efferent vein. This latter branch is not possessed by coldblooded Ovipara a

$j$. Vas deferens, dilating before its termination in the cloaca.

k. Ureter.

l. Teres major muscle, the subscapularis and great part of the scapula having been removed.

$m$. Right jugular vein receiving the veins from the oesophagus, and by virtue of these vessels, as also of a branch of anasto-

a See Jourdain, Sur la Veine Porte Rénale, Ann. Sci. Natt. Ser. iv., tom. I 2, 1 S6ro, pp. I 56 and 359 , and plate 4 , fig. 2. 
mosis with the left jugular, attaining, as is usual in birds, a larger size than that vessel.

n. Right jugular vein in thorax. The junction of the subclavian with the jugular vein is not effected until some way below the point on which this line terminates; a portion of the former vein is seen in connection with the very short vena cava superior just above the right bronchus.

o. Vena cava inferior, entering the auricle to the right of and posteriorly to the entrance of the vena cava superior of the right side.

$p$. Lung, showing on its exterior surface indentations corresponding with the ribs.

q. Right bronchus entering the lung. The right pulmonary artery and the pulmonary veins which held the same relation to the bronchus on this side which in the mammal they hold on the left have been cut away, together with a considerable portion of the spongy tissue of the lung on its internal aspect. The aorta is seen arching over the bronchus, in its singleness contrasting with the aorta of Reptiles, and in its dextral flexure with that of Mammals. Between the bronchus and the vena cava inferior we see a portion of the glandular proventriculus, and immediately above the bronchus and below the arch of the aorta, which has been a little displaced upwards, the junction of the fragment of vein left to represent the subclavian trunk with the jugular.

$r$. Right innominate artery, which is seen to break up into three main divisions, the common carotid, the axillary and the pectoral arteries.

s. Great pectoral muscle, the main depressor of the humerus and wing seen in section on the right side as it arises from the lower portion of the keel of the sternum and from the clavicle. Its origin from the external lateral portion and processes of the sternum is not seen, those parts having been removed in the dissection; its main tendon is seen turned back at $x$; two other tendons which it gives, one to the long extensor, the other to the short extensor of the alar membrane, are not shown in this figure.

t. Second pectoral, the main elevator of the humerus, seen in 
section along the upper part of the keel of the sternum and much of its lateral portion. It tapers anteriorly as it passes along the internal surface of the coracoid to enter the canal formed for it by that bone together with the furculum and scapula. This muscle is homologous with the comparatively insignificant ' subclavius' of anthropotomy.

$u$. Coracobrachialis inferior, a muscle arising from the inferior and outer three-fifths of the distal part of the coracoid, and inserted into the internal and proximal lip of the cup-shaped pneumatic cavity of the humerus. The opposite lip of this cavity receives the tendon of the teres major $l$; and from the triangular space between the muscular bellies of these two muscles the subscapularis muscle, together with the upper portion of the scapula, and a small muscle, the serratus anticus, which passed between the fibres of the subscapularis to be inserted into the inferior edge of the scapula, have been removed.

v. Coracobrachialis superior, a bicipital muscle with a very extensive origin; arising, superiorly, from the inner surface of the vertebral end of the clavicle; inferiorly, from a facet on the lateral aspect of the upper surface of the sternal rostrum; and between these two points of origin from the upper and inner surface of the fascia connecting the coracoid, clavicles, and sternal rostrum. (See Deseriptions of Preparations, p. 22.) Its tendon, which is joined by that of the subscapularis, is inserted proximally and anteriorly to that of the preceding muscle $u$. The relations which these muscles hold to each other are much the same as those subsisting between the obturator externus and internus, with which these muscles are serially homologous.

w. One head of the extensor plicac alaris anterioris longus, arising from the upper end of the clavicle in continuity externally with a head of the extensor brevis. These muscular bellies appear to be divarications of the deltoid, and to be serially homologous with the outer head of the pectineus of anthropotomy.

$w^{\prime}$. Muscle in connection with the long alar extensor tendons. Its fibres have in the natural condition of the parts much the same direction as those of the muscle $v$ and of the 
deltoid; but its origin is mainly from the fascia which covers the biceps in front, and being interposed between that muscle and the tendon of the great pectoral, it is continued up into the tendinous expanse by which the posterior layer of the tendon of the great pectoral connecting itself more or less intimately with the coracoid head of the biceps obtains an insertion into that bone. The muscle $w^{\prime}$ is inserted mainly into the inner of the two tendons at its distal extremity. This tendon is prolonged down to be inserted into the radial process of the carpometacarpal bone which carries the pollex. It is more or less intimately connected with the two other long extensor tendons from the muscle $w$ and from the great pectoral, which are here drawn as one; as also with the short extensor which is not shown in this figure.

$x$. Tendon of great pectoral muscle turned back and seen to be folded upon itself so as to form a pouch with its concavity upwards. The posterior portion of this tendon receives at its lower edge the tendon of a cutaneous muscle which is figured as attached to its outer angle, and higher up it receives the main tendon of origin of muscle $w^{\prime}$, and is ultimately prolonged either separately or in connection with the tendon of the biceps up to the coracoid.

$x^{\prime}$. Biceps. Its tendon is seen running upwards to be inserted into the internal anterior process of the upper end of the coracoid; it had a small insertion into the humerus also, which is not shown here.

$y$. Portion of inner tuberosity of humerus which overhangs the pneumatic foramen of the bone.

z. Gizzard.

For the bibliography of memoirs upon the Anatomy and Physiology of Aves, see Selenka in Bronn's Klassen und Ordnungen des Thier-reichs, Bd. vi. Abtheilung iv. 1, pp. 12-13, I869.

For the homologies of the Muscles of the Shoulder Joint, see Linn. Soc. Trans., vol. xxvi., p. 609, 1869. 

PLATE III.

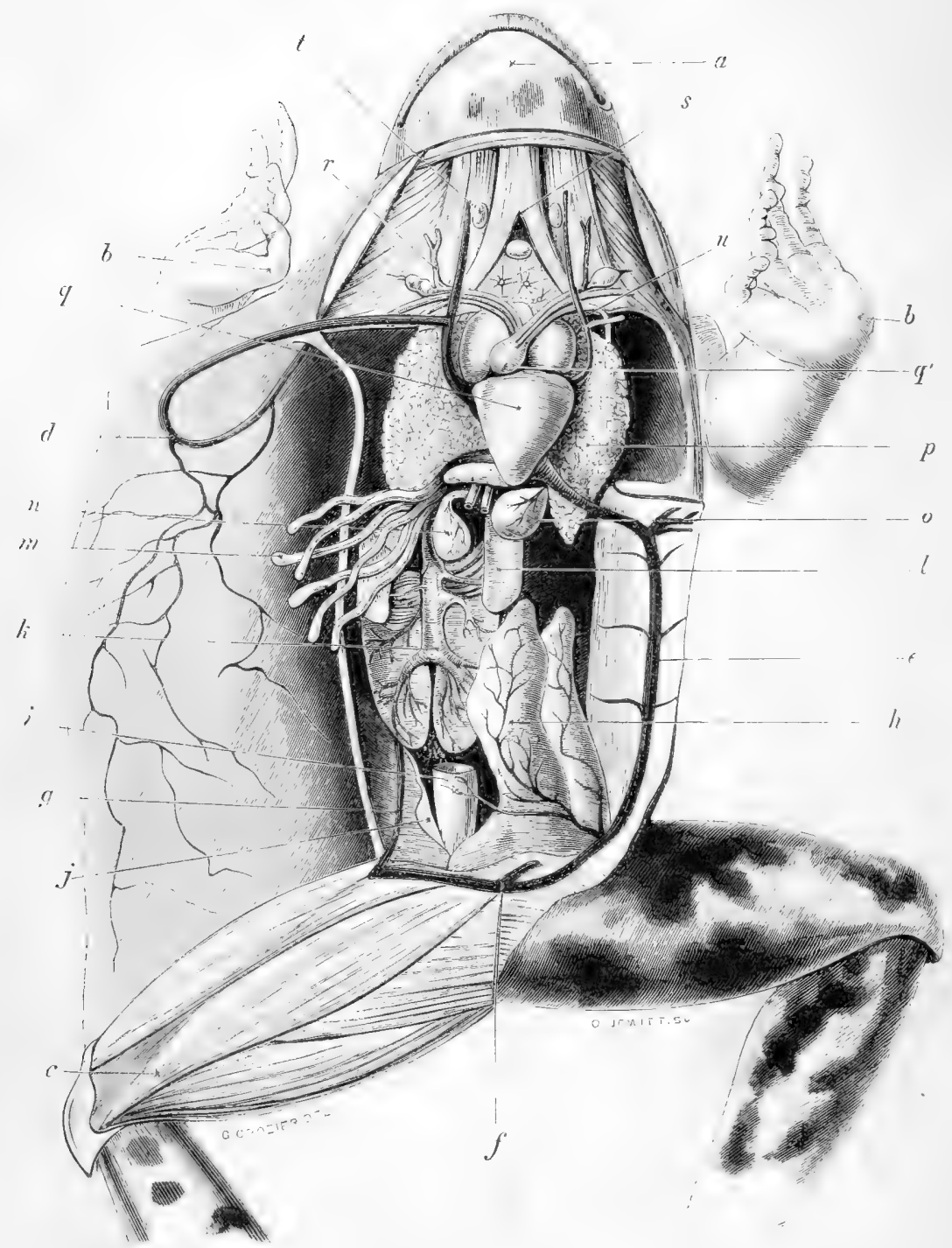

Common Frog, Rana Temporaria. 


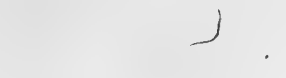

\section{PLATE III.}

\section{Common Frog (Rana Temporaria),}

Injected and dissected so as to show its circulatory organs, and especially its two systems of veins supplying the liver and the kidney, and known as the 'portal' and the 'renal portal' systems.

THE ramifications of a subcutaneous vein, which must, like the renal and hepatic systems, have a depuratory action on the blood in these animals with transpirable skin; the renal, reproductive, and parts of the muscular, lymphatic, and other glandular systems of the creature are also shown in the figure. An injection having been thrown into the ' renal portal' or renal afferent vein of the left side, in a direction the reverse of that which the blood took in it during life, that is to say, towards and not away from the lower extremities, the figure shows that by this means the greater part or the whole of the main venous system can be injected. And it shows, secondly, that a very free anastomosis exists, not only between the two renal inferent veins of the two sides of the body, but also between each renal inferent vein and the epigastric, one of the main factors of the hepatic inferent, or true portal system in all cold-blnoded air-breathing vertebrata. Hence the blood from the deeply-placed parts, muscular and other, whenee the radicles of these vessels arise, can return to the heart through the venous system of either liver or kidney, as circumstances may require; whilst the blood of the more superficiallyplaced organs, glandular, cutancous, and other, is aerated to a considerable extent in the vascular network of the musculo-cutaneous vein seen at $d$ in the figure. By these arrangements the functions of the lungs, which are lowly developed, and, in correlation with the periodically recurring vast turgescence of the generative organs, of small size in the $\Lambda$ mphibia, are efliciently supplemented. 
The integument has been turned back on the right side, together with the musculo-cutaneous vein, the superficial branches of which extend from the knee to the shoulder; part of the muscular wall of the body has been removed on that side, but part has been left in situ; and the main trunk of the musculo-cutaneous vein is seen crossing a slip which the obliquns externus muscle receives from the scapula; on the left side the muscular and cutaneous elements of the wall have been turned back whilst remaining in their natural connection with each other and with the epigastric vein; the shoulder girdle has been cut through the middle line, and fastened out on either side so as to expose the lungs, heart, and great vessels; the liver has been removed with the exception of a small part of its substance, as have also the stomach and intestines down to the lower end of the rectum.

a. Intermandibular space. The skin is left in situ anteriorly in the symphysial angle; immediately posteriorly to its cut edge is seen part of the mylohyoid or submaxillaris muscle; and posteriorly again, and at a deeper level, the converging hyoglossi in the middle line, and on either side of them the geniohyoids, with a glandular body resting upon each of them.

6. Tetradactyle hand. The thumb has its basal joint more or less tumid in this, a male, specimen.

c. Muscles of thigh. The line points to the sartorius, which is bordered externally by the vastus internus, and internally by the adductores and recti interni. See Ecker, Die Anatomie des Frosches, p. II 5 .

c. Point where the musculo-cutaneous veins, constituted by factors from the regions of the head and face, as also and mainly from those of the back and flanks, turn inwards to pass over a slip going from the scapula to the external oblique muscle and join the axillary vein. See Ecker, $l$. c., p. 81; Gruby, Ann. Sci. Nat., Ser. ii. tom. xviii., p. 224.

c. Vein, called 'epigastric' by Rathke, 'umbilical' by Bojanus and Jourdain, 'vena portae accessoria,' and 'vena abdominatis inferior s. anterior,' by other authors. This vein is mainly constituted by the convergence of the two descending branches from the femoral veins seen at $f$ in the figure, but it receives twigs also from the abdominal parietes, and 
a factor of especial significance in the shape of the hypogastric vesico-hemorrhoidal vein from the allantois and rectum. The occasional pathological distension in liver diseases of the veins of the anterior abdominal parietes in the human sulject shows that an arrangement may exist in a rudimentary condition in the higher vertebrata similar to that shown here to exist functionally between the epigastric and the parietal veins; and its connection with a vesico-hemorrhoidal vein, whilst it may be held to foreshadow the arrangement of the umbilical vein in the foetus of mammals, puts prominently forward the fact that anastomoses exist between the portal and systemic veins. For the 'renal portal' of the Frog, see Jourdain, Ann. Sci. Nat., Ser. iv., tom. xii., p. I80.

f. Point where the descending branch of the femoral vein of either side fuses with its fellow to form the trunk of the epigastric.

9. 'Renal portal,' or renal inferent vein of the right side, being. the other branch of the bifurcating femoral vein, which is thus seen to be freely and indifferently continuous with the portal systems of both liver and kidney.

h. Bifid allantoid bladder distended, with ramifications upon it of the vesico-hemorrhoidal veins which are seen to have radicles of origin upon

i. The rectum, which is cut short. Cf. Quain and Sharpey, vol. ii., pp. 478,479 , fig. 325 , ed. 7 th.

j. A vesicular dilatation developed upon the duct, by which both testicular and renal produets pass down to the cloaca. From it a vein passes directly into the kidney.

$k$. Vena cava inferior, constituted mainly by the efferent kidney veins, but receiving also those of the testes and fat bodies.

$l$. Testis of left side. It has, together with its fellow and with the kidneys, been displaced a little to the right side. The vasa efferentia of the testes are seen to pass inwards to the internal edge of the lidneys, which they enter, and some veins pass in the same transverse direction inwards to join the vena cava inferior. Between the lower ends of the kidneys we see a reticular appearance produced by a plexus of arterial blood-vessels, cach accompanied hy two lymph vessels, elosely 
apposed to and so appearing to surround it. See Langer, Lymphgefässsystem des Frosches, I866-I 867, Wien. Akad. Wiss. Sitz. Bericht.

m. Fatty bodies.

n. Spleen. To the left and a little above the spleen are seen the cut ends of two vessels, one of which receives a factor from that organ, coming itself from the intestine, and the other of which took its origin in the stomach, and, like the former, joined a branch of the epigastric, and was distributed to the liver, a small portion of which is seen as left immediately above them.

o. Gall bladder left attached to the epigastric vein by a vein which passes from it to that vessel.

$p$. Lung of left side. The cavity seen on the outer side of either lung has its outer wall constituted by the internal abdominal muscle, homologous with the internal oblique and transversalis which arches inwards in a dome shape, and is connected with oesophagus, pericardium, and the coracoid and hyposternal bones. In the natural condition of the parts these cavities are however mainly occupied by the lobes of the liver, which nearly entirely cover the lungs in an anterior view.

q. Heart. From the base of the ventricle the muscular bulb is seen to take origin, a constriction known as the fretum Hallevi marking the line of separation of the two organs. The bulb bifurcates into two great divisions, which again are each firstly subdivided by two imperfect internal partitions into three canals, and then subsequently into three perfect tubes, the carotico-lingual, the aortic, and the pulmonary trunks, of which the first is most internal and anterior, and the last the most external and posterior.

$q$. Musculus bulbus arteriosus, with the auricles one on each side. It inclines to the left, and is attached on that side to the ventricle by the frenulum bulli of Brücke. Denkschrift. Akad. Wien. Bd. iii., p. 355, I 852 .

$\gamma$. Lingual branch of the first of three trunks arising just internally to a caverno-muscular dilatation of the artery known as the 'carotid gland,' from the outer side of which the carotid artery, called sometimes the 'ascending pharyngeal,' 
passes to the back of the oesophagus in close apposition with the second main trunk or aorta, with which it is usually connected by a ductus Botalli.

s. Convergence of hyoglossi muscles, which, together with the diverging arterial trunks, enclose a diamond-shaped space, in the anterior angle of which a large glandular mass, and posteriorly in which several smaller masses of similar character, are lodged. Into the posterior angle of this space the right auricle, which is here, as in all cold-blooded vertebrata, possessed of two auricles, the larger of the two, protrudes itself from behind the arterial trunks. Underneath these structures the recurrent laryngeal nerve passes to the larynx.

$t$. Thyroid proper, of which the glandular masses just spoken of may be considered as divarications. It is placed just internally to the jugular vein. The Thymus is not seen in this figure, lying far back as it does near the angle of the jaw. See Ecker's Icones Physiologicae, tab. vi., fig. 5; Remak, Entwickelungsgeschichte der Wirbelthier, tab. viii., fig. 8. a.; Kolliker, Entwickelungsgeschichte, p. 39 I.

$u$. Left jugular vein passing down to receive the subclavian, and thereby constitute the left cava of that side.

For the continuity of the lymphatic vessels with the various serous cavities of the body, see V. Recklinghausen, Handbuch der Lehre von den Gerveben, herausgegeben von S. Stricker, ii. Lieferung, 1869, p. 222; Virchow's Archiv., 1863, Bd. 26, p. 172; Dybkowsky, Sehweigger-Seydel, Dogiel, and Ludwig in Ludwig's Arbeiten aus der Physiologischen Anstalt zu Leipzig, I867. 


PLATE IV.

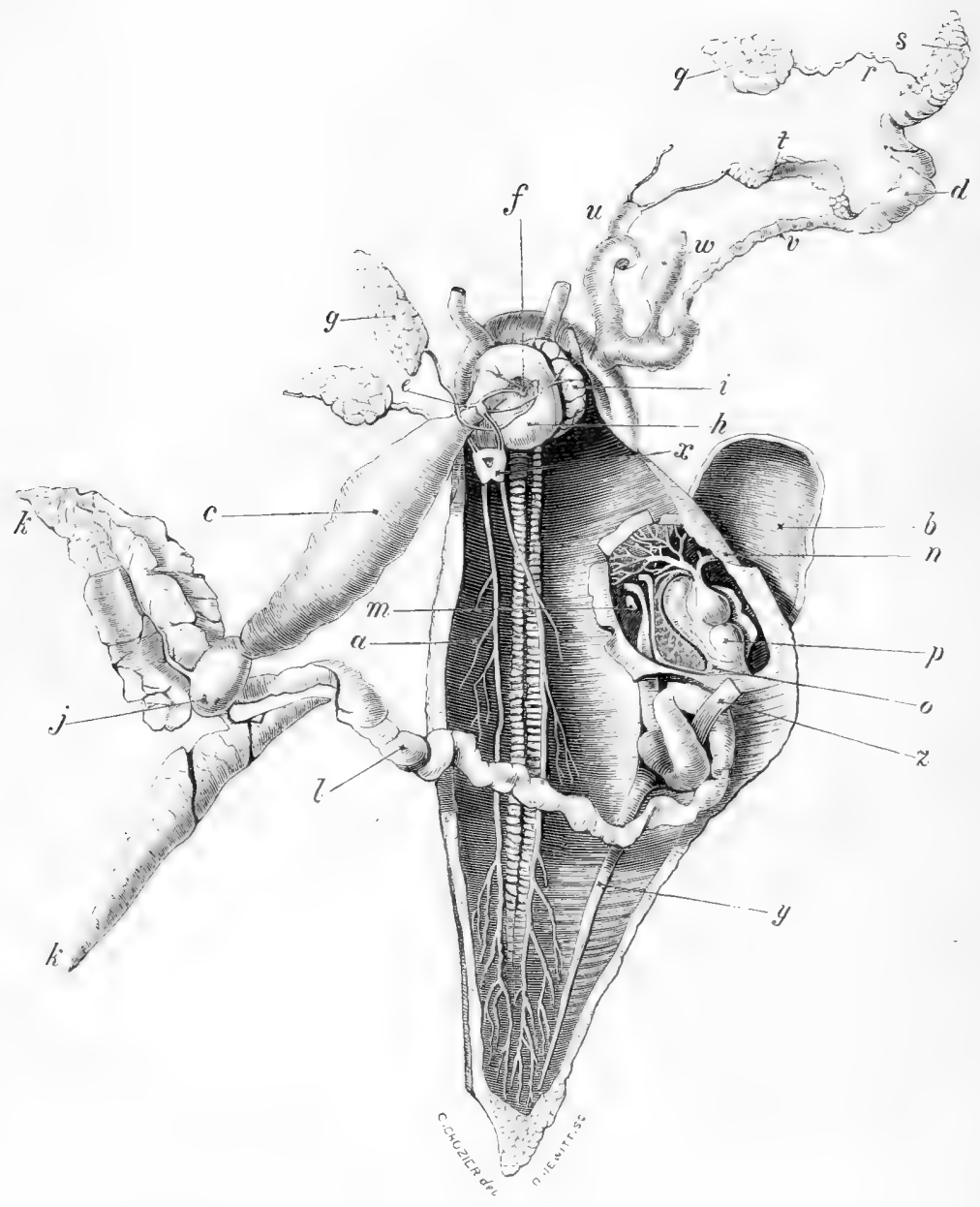

Celiar Slug, Limax Flavus. 


\section{PLATE IV.}

\section{Cellar Slug (Limax Flavus s. Variegatus),}

\section{Dissected so as to show its digestive, circulatory, respiratory, nervous, and reproductive systems.}

Trie muscular envelope has been separated from the foot proper along the left side, and turned over to the right, together with the shield-shaped mantle and the organs it overlies. The buccal mass and nerve collar, together with the salivary glands, have been displaced a little to the left, on which side of the animal's body the stomach and bilobed liver have been fastened out, as the generative apparatus has been upon the right. Some of the nerves, muscles, and arteries have been cut arvay, but most of the organs in the animal's entire system have been displayed in this vier. The oesophagus and buccal mass have been pulled a little forward through the nerve collar, and occupy much the same position relatively to it as they do when in life the buccal mass and head is thrust forward. The tro first convolutions described by the intestine have been uncoiled, and the intestine has thus been drawn as taking a much less sinuous course than it does in nature from its commencement at the pylorus to the point where it comes into relation with the dorsal integument and shield, and hooks round the stem of the muscle which retracts the buceal mass and the tentacles. The generative organs have been detached from their normal connections, and are arranged on the right side of the animal's head. Their volume, as drawn here, is but small in comparison with that which it attains in the breeding season. The upper tentacles, together with the nerves which supply and the museles which retract them have been cut throngh, and turned 
forward so as to lie between the generative apparatus on the right and one of the salivary glands on the left hand. One of the lower tentacles is seen on the right side in the interspace between the right eye-bearing tentacle and the vestibulum of the reproductive system.

a. Locomotive disk or 'foot' passing upwards at the sides into the general muscular envelope of the various organs of the animal's body, from which it is limited off by a furrow. Its internal circular coat is raised into two corrugated ridges along the middle line for the greater part of the length of the body by the underlying mucous gland. This gland has its bilaterally symmetrical halves arranged on either side of a single duct, which again is underlaid by a large venous sinus, very visible in the living animal along the middle line of the foot inferiorly.

๖. Shield and organs in connection with it projecting out beyond and above the general muscular envelope of the body.

c. Stomach arranged, together with the two lobes of the liver, upon the animal's left.

d. Generative apparatus arranged upon the animal's right.

$e$. Nerve collar, consisting of two ganglia placed above, or rather at the sides of, the oesophagus, and two pairs of ganglia placed below it, and connected with the upper pair by commissural cords. The two superiorly placed ganglia are connected with each other by a flat commissural band; and with the suboesophageal ganglia by a double commissure, the posterior cord of which joins the upper or parietosplanchnic part of the mass formed by the fusion of the two inferiorly placed pairs of ganglia into a single centrally perforated body, whilst the anterior cord joins the more inferiorly placed or pedal portion from which nerves are seen to pass off to the foot. The functions of the supra-oesophageal ganglia may be judged of by the distribution of its nerves to sensory organs. The nerves which the parietosplanchnic ganglia gave off to the retractor muscles, as well as to the parts their name denotes, have been removed in the dissection.

$f$. Stomatogastric ganglion of right side placed in the angle 
formed by the inferior surface of the oesophagus with the buceal mass just where it enters it, together with the duct of the salivary gland. The ganglion is connected by a long and delicate commissural cord with the supra-oesophageal ganglion of its own side, and it gives off nerves to the buccal mass, to the oesophagus, and to the duct of the salivary gland.

g. Salivary gland.

h. Buccal mass containing the 'tongue.'

$i$. Semper's organ; a structure consisting of cells like those of a salivary gland, but devoid of a duct, and very richly supplied with nerves from the supra-oesophageal mass, and supposed by its discoverer to be, possibly, an olfactory organ. See Semper, 'Beiträge zur Anatomie und Physiologie der Pulmonaten,' in the Zeitschrift für Wissenschaftliche Zoologie, Bd. viii., I857, p. $3^{66}$. It is large in Limaces, though small in the other air-breathing Gasteropoda.

j. Coecal projection at pyloric end of stomach.

$k$. Liver, consisting of two main lobes opening each by a single duct into the digestive tube along the line of the opening of the stomach into the intestine.

l. Intestine passing from pylorus to end close by the respiratory inlet, but a little in front and above it. Its two first convolutions have been uncoiled in separating it from the liver and reproductive apparatus, but as it approaches the dorsal integument and shield it describes a curve like that of an Italic $S$. In the first concavity of this curve we see the stem of origin for the retractor muscles of the buccal mass and labial tentacles, and at its opposite extremity we see a straight coecum $y$ pass off and extend nearly to the posterior extremity of the body.

m. Respiratory orifice, with the 'rectum' curving round it to open a little above and anteriorly to it. To the right of the rectum again is seen the duct of the renal organ.

u. Portion of dorsal integument, by making an incision immediately to the right of which the shell would be found. Internally to it we see the respiratory sac, with the rami- 
fications of the pulmonary veins. The cavity of the respiratory sac is seen to be formed simply by the divarication of the two layers of the general muscular envelope of the viscera.

o. Renal organ, placed to the right of the heart in the natural position of the parts, and giving off a duct which passes backwards and curves round, inclosing between itself and its gland a portion of the pulmonary sac, to run in company with the rectum to open near the anus. See enlarged figure by Professor Leidy in Binney's Terrestrial Molluscs of the United States, vol. i., pl. i., fig. iv.

$p$. Ventricle of bilocular heart.

q. Hermaphrodite gland.

r. Hermaphrodite duct.

s. Albuminiparous gland.

$t$. Vas deferens becoming distinct from oviduct $v$ sooner than in Helix or Arion, and richly beset with prostatic glandules.

u. Penis, with part of its retractor muscle left attached to it; the origin of the muscle having been at a spot on the under surface of the muscular envelope of the viscera, close to the arterial outlet of the heart.

v. Oviduct, like the vas deferens, glandular above, and membranous below; and opening into a dilated vagina.

w. Receptaculum seminis, opening in this species, though not in the closely allied Limax Cinereus into the vagina.

$x$. Pedal portion of the suboesophageal nerve mass, enclosing, together with the parieto-splanchnic, an orifice through which the anterior aorta passes. The line is drawn to a spot where in Helicidae the otic vesicle is readily found, but where in Limax it is not easy to convince oneself that it exists, even as a rudimentary organ, without the use of reagents, such as the oxalic acid recommended by Lacaze Duthiers.

y. Coecum passing off from intestine just before it passes into relation with the pulmonary cavity, and reaching down nearly to the termination of the body cavity.

z. Retractor muscle of the buccal mass and the tentacles. Its fascicles distributed to the parts mentioned passed with the 
oesophagus through the nerve collar, being separated from the aorta by the parieto-splanchnic portion of the suboesophageal mass. They have been cut away in this Preparation.

For the anatomy of the Pulmonate Gasteropoda generally, see Semper, in Zeitschrift für Wiss. Zoologie, Bd. viii., I857.

For figures of the anatomy of Limax, see Leidy, in vol. i. of Binney's Terrestrial Molluses of the United States, pl. i.

For the reproductive system, see Baudelot, Ann. Sci. Nat., tom. xix., pl. 3, fig. I7, I863.

For the essential connection of the acoustic nerve with the supraoesophageal ganglia, which has been overlooked on account of the close apposition to the pedal ganglia of the vesicles appended to those nerves, see Lacaze Duthiers, L'Institut, No. 182 I, translated in Monthly Microscopical Journal, Feb. I, 1869; and for instances of the otic vesicle and its nerve maintaining in actuality those morphological relations undisguised by approximation to the pedal ganglia, see Gegenbaur's and Souleyet's figures of the Heteropodous Carinaria and Pterotrachea in V. Carus' Icones Zootomicae, tab. xx., fig. I2; Gegenbaur, Untersuchungen über Pteropoden, und Heteropoden, 1855 , tab. vii., fig. I ; Vergleichende Anatomie, p. 325 , fig. 83 .

The two sets of organs of special sense, the auditory and the ophthalmic, are thus seen in Gasteropoda to be both in connection with the same nerve-centres. The attachment, however, of the otic vesicle and nerve can searcely be different in reality from what it is in appearance in the Lamellibranchiata (for which see pl. v. $j^{\prime}$ ); and the multiplicity of the 'eyes' in Pecten and Spondylus set along the border of the mantle, to the nervous supply of which both cephalic and parieto-splanchnic ganglia contribute, would lead us to expect variability rather than fixity in the connections of the organs of special sense in Mollusca. The varying allocation of the organs of special sense in the two sul-kingdoms, Arthropoda and Vernus, would appear to point in the same direction. 




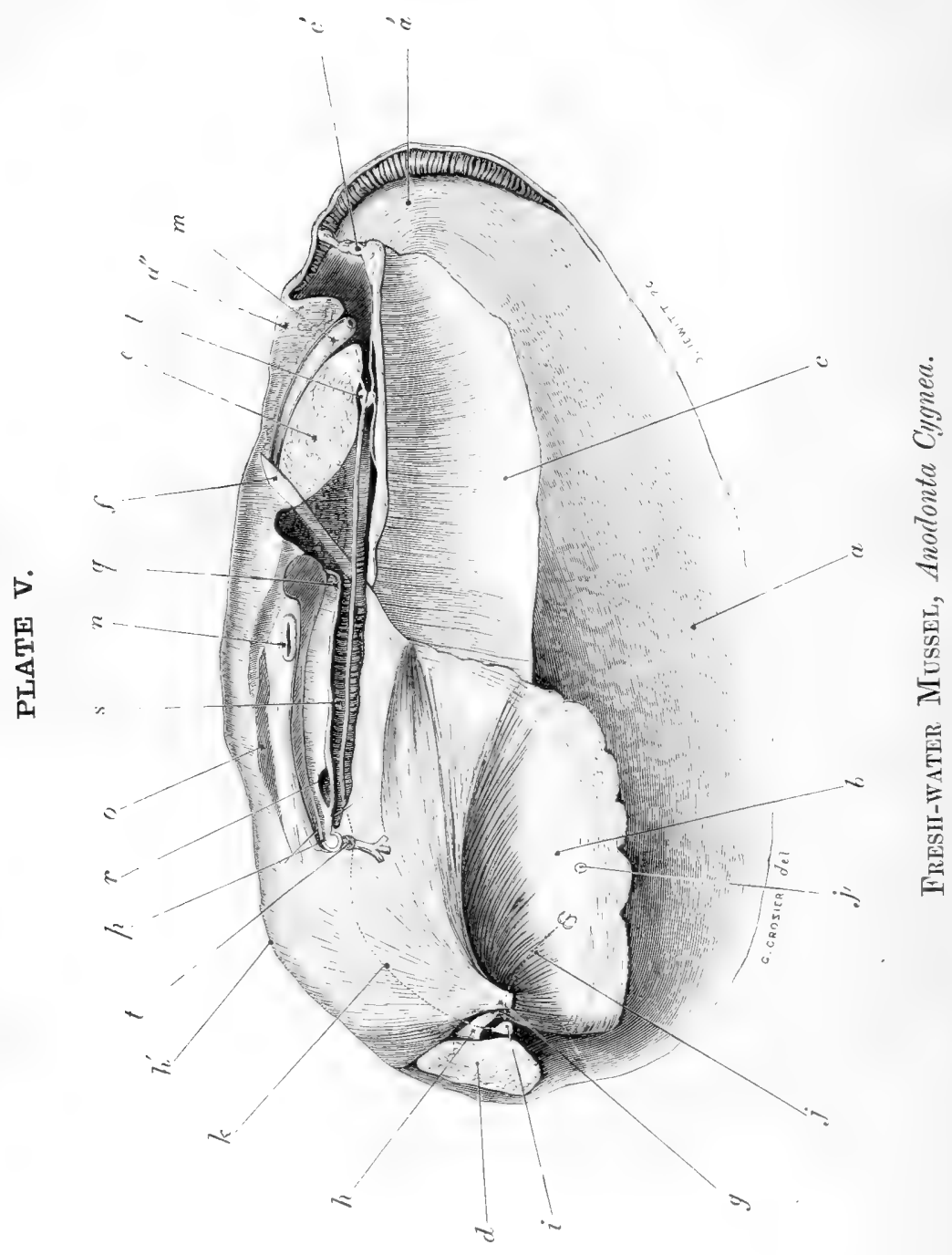




\section{PLATE V.}

\section{Fresh-water Mussel (Anodonta Cygnea),}

Dissected so as to show its muscular and nervous systems, as well as certain other organs in relation with them.

THE animal has been taken out of the shell; the gills have been removed on the left side, as also the mantle, together with the labial tentacles and parts of the pericardium, and of the organ of Bojanus of the same side.

$a$. Right mantle lobe, free along its ventral edge.

$a^{\prime}$. Fimbriated portion of mantle corresponding to the inlet by which water is drawn into the branchial eavity.

$a^{\prime \prime}$. Dorsal raphe along which the two halves of the mantle meet, and are more or less united.

b. Foot.

c. Gills of right side.

$c^{\prime}$. Process passing from external gill to join the mantle, just where its fimbriae cease and its anal region commences.

d. Anterior adductor.

$e$. Posterior adductor.

$f$. Posterior retractor of the foot, passing to be inserted into either valve, anteriorly and superiorly to the posterior adduetor, the scar or muscular impression of the two being more or less confluent. Its muscular expansion in the foot is especially well developed along the free or ventral edge of the foot, but it inter-digitates very freely with the protractor pedis, though it lies for the most part at a lower level than that muscle. 
g. Protractor of the foot. This fan-shaped muscle spreads over the external surface of the foot, from an insertion into the shell, a little superiorly to the point where the pallial line joins the impression for the anterior adductor. It must act consequently, as an antagonist to the preceding and succeeding muscles. Its impression is distinct in this animal from that of the adductor.

h. Anterior retractor of the foot. The fibres of this muscle take origin from a point in the shell, towards the dorsal aspect of the anterior adductor, though some way from its dorsal border. They spread thence into the foot especially along its anterior edge, and down as far as its anterior angle, occupying for the most part a deeper level than the preceding muscle. Some of its fibres, however, spread superficially over the liver region dorsally. Its action is that of a powerful retractor of the foot mass.

$l^{\prime}$. Smaller retractor muscles with insertions just anteriorly to the umbones, whence they radiate over the regions of the stomach, and towards the pericardium.

$i$. Labial ganglion lying upon the anterior retractor, and in the angle between that muscle, the anterior adductor, and the protractor pedis, above the entrance to the mouth.

$j$. Cord of commissure passing from labial ganglion to pedal. The pedal ganglion of each side gives off twelve nerves, six from its neural, and six, more slender, from its lateral surface. They are not figured in this plate.

$j$. Auditory vesicle appended to pedal ganglion. This vesicle is ordinarily found to be appended to a branch given off from the most backwardly-placed but one of the posterior branches given off from the pedal ganglion. It is not always to be found symmetrically developed on both sides, and, when found on one side only, it has been found to contain two otoliths. It is situated in a part of the foot narrow from side to side, at the junction of its anterior two-thirds to its posterior third, and near to the purely muscular portion of the foot, into which the viscera do not enter. Cf. Moquin Tandon, Hist. Mollus. i., p. 136; Duvernoy, Mémoires de l'Institut, tom. xxiv., p. 96.

$k$. Cord of commissure between labial and parieto-splanchnic 
ganglia. It passes between the fibres of the retractor pedis anterior and those of the protractor through the upper part of the foot, just internally or inferiorly to the generative orifice, $t$; then through the glandular portion of the organ of Bojanus, $s$; and across the tendon of the retractor pedis posterior just where it bifurcates for insertion into either shell, to end in the parieto-splanchnic ganglion.

l. Parieto-splanchnic ganglion. The two ganglia of the two sides of the body are closely apposed, so as to form a transversely oblong mass, which however still retains an indication of its morphological duality in the bilobed conformation, which is somewhat exaggerated in this figure, and is much less definite than that of the pedal centres between $j$ and $j$. Two nerves are figured in connection with it, one, a parietal nerve, going to the mantle, the other, a splanchnic nerve going to the gill.

$m$. Rectum ending in the anal compartment of the mantle, a little beyond the posterior free edge of the posterior adductor. A delicate nerve is figured by Duvernoy, l.c., as passing to it from the parieto-splanchnic ganglion.

$n$. Heart; the letter pointing to the slit left by removal of the left auricle. The rectum passes through the heart, having commenced by emerging from the foot-mass, in close connection with the aorta anterior, which lies above it and below the mantle raphe, at a point corresponding to the vertical plane of the orifices of the generative gland and of the organ of Bojanus.

$o$. Pericardial space into which open the glandular portions of the organ of Bojanus, as also certain orifices belonging to the vascular system; see V. Hessling, 'Die Perlmuscheln,' p. 239.

$p$. Opening by which the excretory portion of the organ of Bojanus communicates with the branchial eavity.

q. Opening by which the excretory portion of the organ of Bojanus communicates with the secretory.

$r$. Wide opening by which the excretory portion of the organ of Bojanus of one side communicates with that of the other. This opening does not exist in Unio margaritifer. The two secretory sacs are similarly comnected at a deep level in the same plane. 
s. Secretory or glandular portion of the organ of Bojanus, reaching from the level of the anterior end of the pericardial space to the under surface of the posterior adductor. It opens into the pericardium by a canal along which a bristle has been drawn as passing. It is seen to be covered by the excretory half of the bisacculate organ for a space corresponding with the under surface of the pericardium. With this sac it is seen to communicate by a very fine orifice at $q$. Posteriorly to this point it is prolonged into a convolutionary mass, roughly drawn here in section as sub-triangular, in relation with the posterior adductor and the tendon of the posterior retractor. These glandular lamellar sacs communicate freely with each other, as do also the excretory sacs in this species.

$t$. Orifice leading to ramifications of the duct of the generative gland. This orifice is in the Anodon, though not in the Unios, concealed by the attachment of the inner gill-lamina to the visceral mass. See V. Baer, Meckel's Archiv., I83o, p. $3^{\text {I } 8 \text {. }}$

From this semi-diagrammatic figure, the course which the ova take in passing from the generative orifice, $t$, to the external gill-cavity, where they meet with the spermatozoa inhaled with the water they breathe, and where they go through certain stages of development, may be understood. The ova are extruded from the orifice specified by the contraction of the several muscles, $g, h, h^{\prime}$, and $f$; the shell valves being appressed by the adductors, $d$ and $e$. When they pass out from this orifice, they pass along a canal, which for the first part of its course corresponds in direction with the nerve cord seen passing through the organ of Bojanus to the parieto-splanchnic ganglion, $l$. This first part of the canal is divided into three portions. The first of these is formed by the attachment of the innermost gill-lamina to the visceral mass, and into it the orifice $t$ opens. The second is under ordinary circumstances only a demi-canal, but is completed during the act of the extrusion of the ova, by the close apposition of the inner gill-lamina to the side of the visceral mass, which under these circumstances becomes more globular superiorly than when quiescent. The third 
portion begins immediately posteriorly to the tendon of the posterior retractor pedis, and extends as far back as the entrance of the branchial nerves into the gill. It is bounded below by the commissure of the two internal gills of the two opposite sides of the body, and above, like the rest of the canal, by the organ of Bojanus. Just beyond the line of entrance of the gill-nerves, the canal thus made up of three segments opens into a space, into which the external gill's cavity also opens; a canal having been left along the dorsal attached border of that gill by the failure of the dissepimental bands which connect the lower threefourths of its two lamellae together, to be developed there. And as the rectum $m$ also opens into this space, it may be called a 'cloaca.' Now it is easy to see how, under the extruding action of the foot muscles, the ova will successively be pressed through the canal described into this small cloacal space. When there, if the shell or the mantle lobes are kept appressed posteriorly, or, as in the natural position of the animal, superiorly, it is plain that they must regurgitate, as additional relays of ova find their way into the cavity, into the external gill-cavity from the point $c^{\prime}$ forwards.

In this figure the nerve system is of a somewhat smaller size than it is seen to possess, except when viewed in strict profile, in nature; and it has been owing to the necessity for maintaining this position, which the demonstration of the relations of the pericardium, and the two saes of the organ of Bojanus involved, that the distinction between the muscular free border and the main mass of the mantle has not been shown. The muscular portion of the foot is figured in a condition of extreme contraction.

For excellent figures of the nerve ganglia seen from below, with their branches and commissural cords, see Duvernoy, Mem. Acad. des Sciences, tom. xxiv., I 8.54, pl. 7, fig. 2, pl. 8 and 9, figs. 1 and 2.

For a diagrammatic figure of the organ of Bojanus, see Lacaze Duthiers, Ann. Sci. Nat., Ser. iv., tom. iv., 1855 , reproduced by $\mathrm{V}$. Hessling, $l$. c., pl. v., fig. 6 . 
For a full account of the anatomy of the organ, see Langer, Denkschriften Akad. Wiss. Wien. xii., Bd. I856, p. 39, Taf. i., figs. 3 and 4 .

For figures of the muscular system, see Poli, Testacea Utriusque Siciliae, tab. ix., fig. 2 ; and for the heart and rectum, the same plate, fig. I2; and Langer, l. c., Taf. ii., fig. 8.

For an explanation of the route taken by the ova and spermatozoa, in these dioecious animals, see V. Baer, Meckel's Archiv., I830, p. 3I3; and also V. Hessling, Zeitschrift Wissenschaft Zoologie, x., I860, p. $35^{8}$.

For the various parts of the Lamellibranchiate organism, which in different species may be modified so as to serve as marsupia for the lodgment of ova and embryos, see Bronn, Klassen und Ordnungen des Thier-reichs, Bd. iii., p. 442, ibique citata. 

PLATE VI.

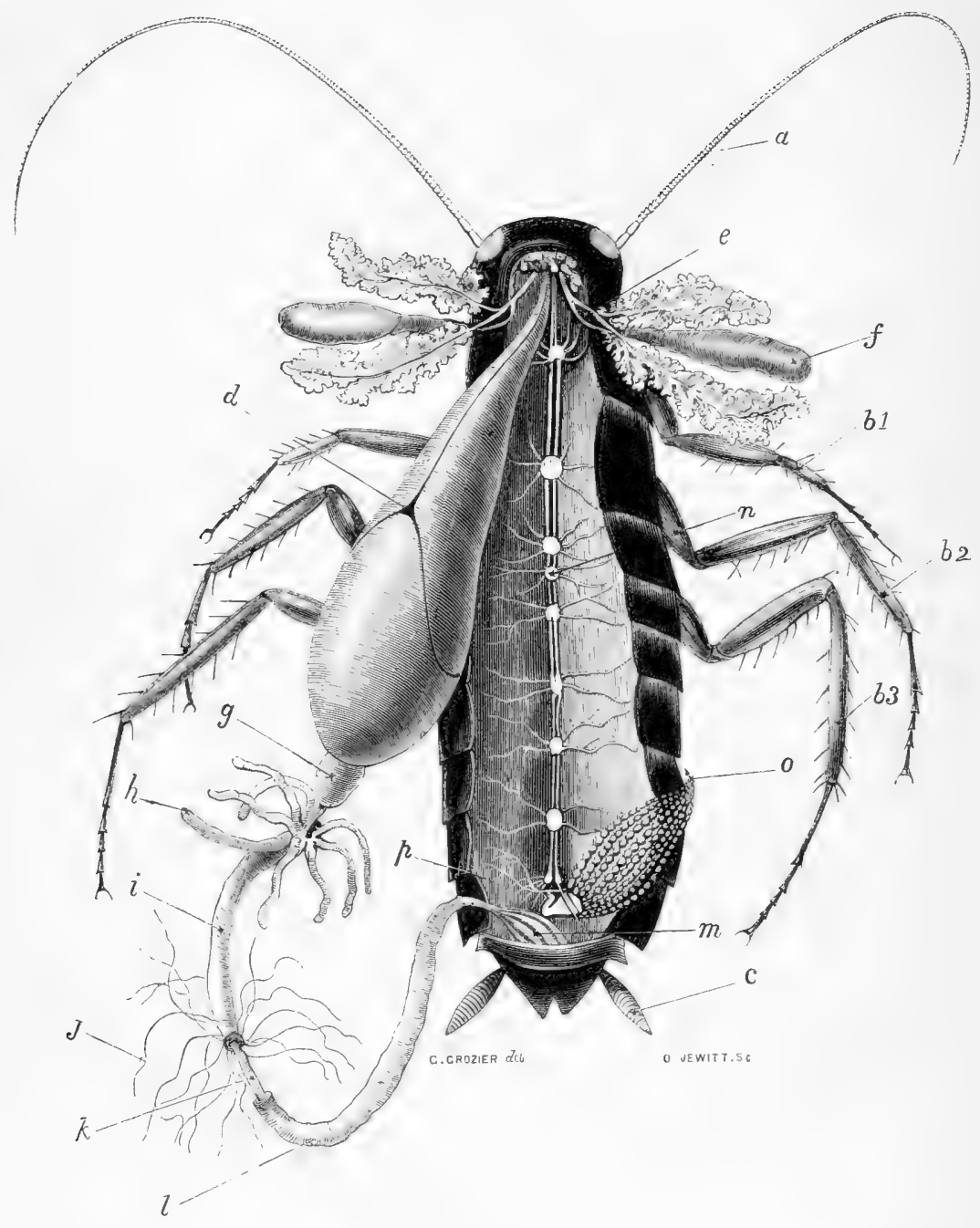

Cockroach, Periplaneta Orientalis. 


\section{PLATE VI.}

\section{Common Cockroach (Periplaneta Orientalis), Female,}

Dissected so as to show its digestive, nervous, and reproductive apparatus; the 'fat body,' and a considerable portion of the dorsal integuments having been removed.

Of the external organs are seen the multi-articulate antennae, the segmented anal appendages or ' cerci,' the compound eyes, portions of the epicranium, of the pronotal, mesonotal, and metanotal elements of the thoracic segments, and of the eight dorsal elements of the abdominal segments; and finally, the three legs articulated to the three thoracic segments on either side, and consisting each of a proximal segment known as the coxa, a second and much smaller segment, distinct in these, though not in the saltatorial Orthoptera, from the coxa, and known as the trochanter; a third, the femur, beset below with spines; a fourth, the titia, more richly armed with spines than the femur; and the fifth, the tarsus itself, which is quinque-articulate.

a. Antennae consisting of three elongated basal segments, and a multi-articulate appendage made up of as many as ninetytwo joints. The antennae of Insects correspond to the so-called 'antennules' of Crustacea, and they are here made up of large and small joints in similar proportions, see p. II I, supra.

6. I, b. 2, Z. 3. T'ibiae, sub-quadrangular in shape, and beset along their two narrower sides with spines.

c. 'Cerci anales,' consisting of twelve segments, the terminal one conical, the others thickly beset with hairs. $\Lambda$ s sexual characters may be noted the absence of the sub-anal styles 
possessed by the males, and the median emargination of the supra-anal dorsal plate with which the cerci articulate. These cerci appear to represent the processes which the last segment of the post-abdomen so frequently gives off in certain lower Crustacea, as e.g. Apus, Cyclops, Lynceus, Caligus; and, like the line of fission between the second pair of maxillae and the three basal joints supporting the antennary flagellum, to be structures by possessing which the Orthoptera resemble the Crustacea, see p. II I, supra; and Rathke, Morphologie, p. I I5.

d. Nerve ganglion developed upon the nervus recurrens, and seen to give off a nerve on either side, which passes backwards upon the crop and has itself fusiform dilatations of a ganglionic character developed upon it. From the triangular ganglion, $d$, a nerve has been figured and described as passing off to the salivary glands.

$e$. Common duct communicating with the two lobes of the dendritic salivary gland. The ducts of the two salivary glands fuse mesially with each other, in the angle formed by the convergence of the ducts of the two salivary bladders or reservoirs; and the common duct thus formed by the ducts from the two glands, fuses subsequently with the common duct from the two reservoirs, so that the two compound ducts find an outlet into the mouth by means of a short common canal. The figure does not accurately reproduce this arrangement, which cannot be demonstrated to the unassisted eye. All the four ducts and the compound ducts have their internal chitinized coat spirally thickened so as to resemble tracheae.

$f$. Salivary bladder.

g. Gizzard communicating inferiorly with the chylific stomach, $i$, through the intermediation of a short segment of small calibre.

h. Whorl of eight coeca, analogous probably to a liver, arranged round the commencement of the chylific stomach, and resembling the simple hepatic coeca of Hedriophthalmatous Crustacea.

$i$. Chylific stomach, smooth externally as is the upper half of the homologous segment in the Gryllotalpa, and limited 
inferiorly by the insertion of the Malpighian tubules in a circle around the digestive canal.

j. Malpighian tubules, in number from twenty-four to thirty; and by their insertion in a zone around the lower end of the chylific stomach, marking the commencement of the short segment which may be spoken of as the small intestine.

$k$. Small intestine.

l. Large intestine or colon; found ordinarily to be in its upper part distended with the refuse of the ingesta, and to be below of smaller calibre, and corrugated so as to present a beaded appearance.

$m$. Rectum divided into longitudinal areae by muscular bands, which alternate with internally placed lamelliform productions of the intestinal walls. The ridges thus developed upon the rectum receive in the larvae of certain of the Libellulidae a very rich supply of tracheae, and, together with a valvular apparatus developed from the caudal tegumentary skeleton, constitute their aerating organ.

n. First abdominal ganglion, closely approximated to the third thoracic, and placed at a little greater distance from the second abdominal ganglion posteriorly. The sixth abdominal ganglion should have been drawn as somewhat heartshaped, but laterally constricted so as to have the appearance of being made up, as the history of its development, of its comparative anatomy, and of the distribution of its nerves shows it to be, of two distinct ganglia. The two oviducts pass to their point of fusion from the outside of the angle bounded by the nerves, seen to pass off from this ganglion; the receptacula seminis, which are small, and not given in this figure, are situated within that angle and at its apex; distally to them, but within the angle, the two ducts of the numerous colleterial glands pass to the orifice within which they open on the sternum of the tenth segment. The first sub-oesophageal ganglion is not seen in this figure, being, as always in insects, in such close apposition to the supra-oesophageal or cerebroid ganglia, as to have been sometimes, but inconveniently, described, as together with them making up a 'brain.' Counting however this ganglion whenee the 
mandibles, maxillae and labium receive their nerve supply, we find that the entire ventral cord is made up of ten ganglia, the last of which may be taken as representing two. This number is less by one than that of the Lepidopterous larva, and, on account of the large size of the third thoracic ganglion, we may suppose that in the Cockroach, the ganglion homologous with the fifth post-oral ganglion of the Caterpillar has become fused, if it was not originally connate, with the posterior thoracic ganglion. Thus the thoracic ganglia of the Orthopterous insect, which remain always as distinct masses in this order as also in the Coleoptera, will correspond, as to the elements out of which they are composed, with the bilobular centrally perforated mass whence the three pairs of legs and the wings are innervated in Lepidoptera. The six posteriorly placed ganglia of the Orthoptera and of the Caterpillar will correspond with each other; and, allowing for the disappearance in the butterfly of the sixth and seventh post-oral ganglia of the larva, with the four posterior ganglia of the perfect Lepidopterous insect.

o. 'Verticillate' ovary of right side, consisting of eight eggtubes, connected by a suspensory ligament, which is made up by the fusion of filaments given off from their respective apices, and prolonged up to an attachment in the dorsal region of the thorax. The ovarian tubules are here figured as opening into the convex end of a pear-shaped oviducal infundibulum; and this apical insertion has been supposed by Léon Dufour and Fischer to constitute an important difference between the arrangements of the female reproductive apparatus, as existing in the Blattinae and in other Orthoptera. The pyriform shape however of the oviducal infundibula depends merely upon temporary distension; and when these receptacles are not in this condition, the egg-tubes may be seen to have the same lateral insertion as those of other Orthoptera; as, for example, the Forficula, as figured by Fischer in his work, Orthoptera Europaea, tab. i., fig. 4; or the Mantis Religiosa figured by Leon Dufour in his work, Recherches Anatomiques et Physiologiques sur les Orthoptères, les Hymenoptères et les Neurop- 
tères, pl. iv., fig. 42. The tro infundibula pass ventrally to the terminal nerve structures and oviscapt, to form a common vagina, which opens between the sterna of the eighth and ninth abdominal segments.

p. 'Colleterial' or 'sebaceous' glands of the left side. These glands consist of long delicate tubules, the contents of which are by no means always uniform in colour. The very numerous tubules of either side join a single stem, and the two ducts thus formed pass down near the middle line, and within the angle bounded by the nerves of the last abdominal ganglion, to end within a single orifice on the sternum of the tenth abdominal segment. Anteriorly to the two colleterial ducts, and occupying the apical portion of the angular space limited by the nerve structures, may be found the receptacula seminis, which consist of two short tortuous coeca, opening by a very short common duct upon the sternum of the ninth segment. Spermatozoa are said by Siebold to be found in both these coeca; otherwise, as one is of smaller calibre than the other, we might have considered one to be a receptaculum seminis and unpaired, as usual in insects, and the other to be a ' glandula appendicularis,' such as is so frequently attached to the receptaculum seminis in other insects. In thus possessing two receptacula seminis instead of one, as also in having eight ovarian tubuli instead of twelve, as is usually the case in Orthoptera, the Cockroach presents us with more or less aberrant arrangements. Figures of the various forms which the female generative organs may assume in the Orthopterous Termes Lucifugum, may be found in the plates appended to M. Lespes' memoir upon that species, in the Annales des Sciences Naturelles, Ser. iv., tom. v., pl. 6, figs. $24-27$, where the colleterial glands and receptaculum seminis will be seer to present much the same arrangement as that which has here been described in the Cockroach.

For the morphology, anatomy, and development of Insecta, the numerous memoirs by Sir John Lubbock, in the Transactions of the Royal and Limnaem Societies from 1857 onwards, should be consulted. Amongst these, see for Parthenogenesis 
in the Articulata generally, Phil. Trans., for 1857 , vol. I47, pp. 95-99; for the structure of the ova, pseud-ova, ovaria, and pseud-ovaria of Insects, ibid., I 858, vol. 148, pp. 341-36r, I86 I, vol. I5I, pp. 620-623; for the functions and structure of the tracheae, Linn. Soc. Trans., J 865, vol. xxv., p. 480; and for the subject of insect-metamorphosis generally, ibid., pp. 485-49I.

For the asexual propagation of Diptera, which takes place in larvae, and was at first supposed to do so by metagenesis independently of any ovarium or pseud-ovarium, see N. Wagner, Zeitschrift für Wiss. Zool., xiii., I863, p. 5I3; Pagenstecher, l.c., xiv., 1864, p. 410 ; Leuckart, Wiegman's Archiv., 1865, p. 286, translated in the Ann. and Mag. Nat. Hist., iii., I 7, March, 1866.

For an account of the internal and external anatomy of the order Orthoptera and of the family Blattinae, see Fischer, Orthoptera Europea, pp. 5-32, pp. 84-88, pls. i., ii., and vii.

For an account of the receptacula seminis, see Siebold in Müller's Archiv., I 837, p. 408. For the opening of these and the other ducts of the reproductive apparatus, see Huxley, Linn. Soc. Trans. ii., vol. xxii., p. 23 i, 1858 .

For number of joints in antennules of Crustaceans, see Spenc Bate, British Sessile-eyed Crustacea, Introduction, p. xi. ; and for correspondence of the antennae of Insects, with irmperfect metamorphosis both in the larval and in the adult state with the antennules of Crustacea, see Zaddach, Die Entwickelung des Phryganiden Eies, p. 86.

For the anal respiratory apparatus of the Libellulidae, which may be considered to be foreshadowed in the longitudinal folds developed upon the rectum of the Cockroach, see Dufour, Ann. Sci. Nat., Ser. iii., tom. xvii., I 852, p. 65, pls. iii., iv., v.; Leydig, Lehrbuch der Histologie, p. 337. 



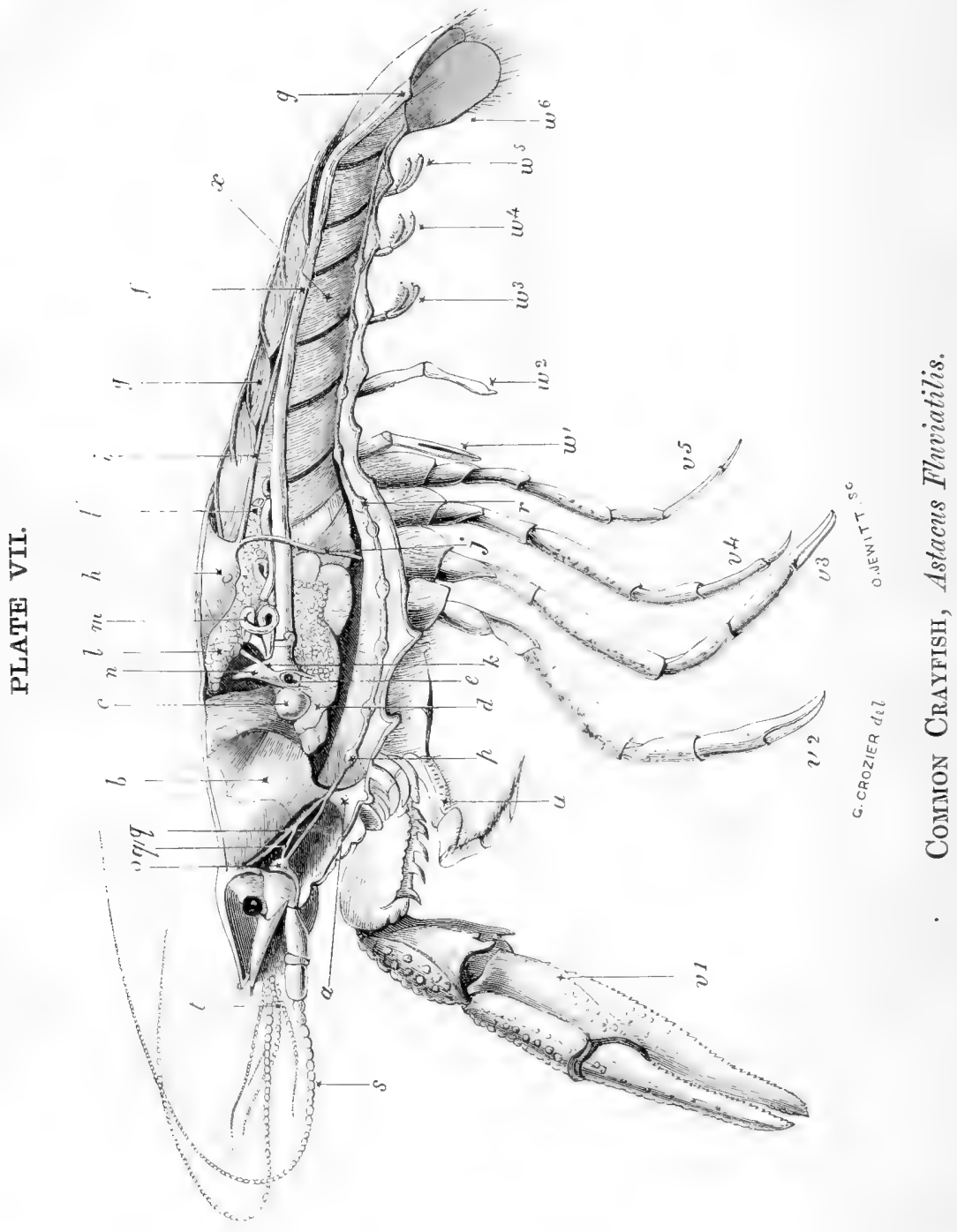




\section{PLATE VII.}

\section{Common Crayfish (Astacus Fluviatilis), \\ MALE,}

Dissected so as to show its nervous, digestive, circulatory, and reproductive systems in situ; the various organs having been exposed in an antero-posterior vertical view, by the removal of the tegumentary skeleton, the muscles, and the hepatic lobes of the left side.

a. Oesophagus leading vertically upwards from the mouth into the stomach. The labrum, the free edges of the mandibles, and of the two maxillae, are faintly indicated on the right side of the mouth anteriorly to the three foot-jaws.

b. Cardiac portion of stomach. Superiorly and anteriorly the stomach is still retained in its natural position a long way anteriorly to the line of the entrance of the oesophagus, the anterior gastric muscles which took origin superiorly to the supra-oesophageal ganglia, $o$, from the under surface of the ventral wall of the hollow rostrum, and attached themselves to the cardiac plate, having been left intact; whilst the anterior wall of the stomach has been displaced a little backwards in order to give a better view of the stomatogastric nerves.

c. Lateral valvular prominence of pyloric portion of stomach.

d. Hepatic lobes of right side where they came into apposition with those of the left side which have been now removed along the infero-median line.

$e$. Orifice by which the hepatic lobes of the left side opened into the digestive tract immediately posteriorly to the pylorus, and below the coecal process, $n$.

$f$ Intestine passing with the straight course characteristic of Crustacea, with the exception of Lynceus, to the anus. 
g. Anus, opening on the inferior surface of the 'telson' in uncalcified membrane, just anteriorly to the line of junction of its anterior and posterior halves.

h. Heart, showing one of the lateral venous orifices, and its posteriorly placed bulbus arteriosus dividing into two main branches, the larger one of which passes vertically downwards at $j$, and is known as the sternal artery; whilst the other passes along the dorsal surface of the intestine at $i$, and may be called the post-abdominal artery, and taken to represent the posterior chambers of the elongated vasiform heart seen in many lower Crustacea.

$i$. Post-abdominal artery, taking a course superiorly to the intestine, and inferiorly to the extensor muscles of the posterior segments.

$j$. Sternal artery passing down towards the orifice in the commissural cord connecting the third and the fourth abdominal ganglia.

$k$. Hepatic artery of the left side, passing down from the heart on to the pylorus towards the hepatic lobes of that side which have been removed.

1. Anterior left lobe of testis.

$l^{\prime}$. Azygos lobe of testis placed posteriorly to the paired lobes of the two sides with which it is continuous.

$m$. Convolutions of vas deferens of left side, in length equal to that of the entire body. They probably secrete the agglutinating matter of the spermatophores. There are in most, if not all, Crustacea and Myriapoda, and in the higher Arachnida, two separate outlets for the vasa deferentia, one on either side of the body, howsoever much intercommunication of the glands or ducts may take place distally to the outlets. The Insecta, on the other hand, have ordinarily a single ductus ejaculatorius, as also a single vagina, into which the generative ducts of both sides of the body open. In both Decapodous and Hedriophthalmatous Crustacea, the male generative outlet is to be found in relation with the last segments, and the female with the last but two of the ambulatory or abdominal segments.

n. Coecal sac, the rudiment of the yolk-sac of the embryo. This sac is apparently the homologue of the two coeca, which in 
Brachyura open into the upper part of the pyloric part of the stomach, just posteriorly to its valvular apparatus, and close to its opening into the duodenum. In Brachyura there is a third sac homologous with the single sac observable in some, and the two sacs observable in other Amphipoda as opening into the duodenum just before its junction with the rectum, and sometimes called a 'renal organ.' It is not found in the Fresh-water Crayfish, though it is in the Lobster.

o. Supra-oesophageal ganglionic mass, immediately posteriorly to the scaphocerite or squamiform exopodite of the inferior or externally placed pair of antennae, the 'antennae' properly so called. The likeness which this 'scale' of the antennae bears to the exopodite of the sixth abdominal segment is, as Fritz Müller has remarked, curiously illustrated by the fact that its ordinary function of lodging the auditory organ is sometimes, as in Mysis, transferred from it to that appendage. Both facts find their explanation in the vier which regards both segments and both sets of appendages as belonging to a 'primitive body' corresponding with that which the Naupliiform larvae of Cirripedia, Copepoda, and Phyllopoda bring with them out of the egg. The greater relative size of the scaphocerite is one of the external points of difference between the Crayfish and the common Lobster.

p. First post-oral ganglion, supplying the mandibles, the two pairs of maxillae, and the three pairs of foot-jaws, or thoracic appendages. In the developing $\Lambda$ stacus this mass consists of six pairs of ganglia, in correspondence with the six sets of appendages it innervates. In Insects, the first post-oral ganglion is always distinct from the thoracic ganglia, whilst in all other Arthropoda it is fused with more or fewer of them.

q. Nervus recurrens, formed by the junction to an azygos nerve, homologous to the nervus recurrens of Insects, and represented by the single trunk $q^{\prime}$, of two pairs of nerves, which arise from the nerve-collar on either side of the oesophagus. This compound nervus recurrens of the Crayfish passes up the anterior face of the oesophagus and stomach, and on the angle formed by the junction of this anterior with the dorsal wall of the organ, it has a ganglion developed upon 
it between the anterior gastric muscles, from which, as also from its posterior prolongation, nerves are given off downwards on either side of the stomach.

$q^{\prime}$. Azygos nerve, passing downwards from the middle of the posterior edge of the supra-oesophageal mass to meet two pairs of nerves given off from the thickenings developed upon the commissural cords of the nerve collar as they cross the oesophagus, and form with them the compound nervus recurrens, q. The forward position of the supra-oesophageal ganglionic mass would appear to render it impossible for the Crayfish to have any ganglion frontale developed upon such as Insects possess. Leydig, however, appears to have discovered such a ganglion in the Oniscus. This nerve, $q^{\prime}$, seems to correspond with the nerve-cord passing backwards from the ganglion frontale in Insects before it receives any branches of communication from the paired ganglia; the compound nerve, $q$, would then correspond to the similarly compounded nerve of Insects, upon which ganglia are frequently developed successively from before backwards in relation with the digestive tract, whilst the ganglion frontale must be considered to have coalesced with the supra-oesophageal mass.

$r$. Fifth abdominal, or sixth post-oral ganglion. It is more closely approximated to the ganglion next in front of it than any of the ganglia either in front of or behind it are to each other. Posteriorly to it are the six post-abdominal ganglia. From this ganglion and the two in front of it, long nerves pass off upwards to the reproductive organs and the superiorly placed muscles.

s. Multi-articulate flagellum of inferior or outer pair of antennae, the 'antennae,' strictly so called, supported by a peduncle consisting of five joints, to which the scaphocerite and a smaller calcified nodule are laterally articulated.

$t$. Paired flagella of upper pair of antennae, or antennules, carried by a triarticulate peduncle, as are the antennae of Orthoptera. On the larger of these two flagella certain delicate membranous cilia are to be found, which, though of very various forms, are yet constant in Crustacea, and are supposed to be olfactory organs by many authors. 
u. Second joint of posterior thoracic appendage, or ' maxilliped,' or 'foot-jaw.' This joint, as in the large cheliferous appendage $v \mathbf{I}$, next behind it, represents two joints, the basipodite and the ischiopodite of the normal seven-jointed endopodite, as seen in $v_{2}, v_{3}, v_{4}, v_{5}$. Its antero-internal edge is denticulate, as in the Lobster, but its serratures are concealed by a fringe of setae.

$v$ I. First abdominal appendage, modified terminally by the production of the distal outer angle of its penultimate joint or propodite so as to form a pair of pincers with the opposed last joint, or dactylopodite. Two other joints, the 'carpopodite' and 'meropodite,' are shown in this figure; the two basal joints are not seen. The two first abdominal legs are not symmetrically developed in the Crayfish, nor in the Marine Lobster, foreshadowing thus the extreme inequality seen in the Hermit-Crabs.

$v 2$ and $v_{3}$. Second and third pairs of abdominal or ambulatory legs, differing from $v \mathbf{I}$ in their smaller size, and in not having the second and third joints fused. It is at the interval between the first and second joints, the 'coxopodite' and the 'basipodite,' that the power of casting off a limb, in consequence of a fright or injury, is put in play by Crustacea.

$v 4$ and $v 5$. Fourth and fifth pairs of the ambulatory legs of the Decapod. The two terminal joints do not form pincers, otherwise they resemble $v 2$ and $v_{3}$. The vas deferens opens in the coxopodite or basal joint of $v 5$.

$w$ I and $w 2$. The appendages of the two first post-abdominal segments modified so as to form an accessory copulatory organ.

$w_{3}, w 4$, and $w_{5}$. Appendages of the third, fourth, and fifth postabdominal segments, consisting each of two basal joints, which serve as a pedicle to two multiarticulate filaments representing an exopodite and an endopodite. The inner of these two filaments has its first joint longer and larger than the other joints in either filament. This greater relative importance of the endopodite is more plainly seen in the antennae and thoracie limbs, where the exopodite is markelly smaller than the endopodite, and most plainly in the abdominal limbs where it is absent, or only represented by the constriction marking the third joint, or ' ischiopodite.' 
w 6. Appendage of sixth post-abdominal segment, forming the right lateral element of the swimmeret. It consists of a single basal joint, supporting a biarticulate squamiform exopodite and a uniarticulate endopodite, which reverse thus the positions of relative size held by these elements in the segments anterior to the swimmeret. The telson is interposed mesially between the two appendages of the sixth postabdominal segment.

$x$. Flexor muscles acting on the swimmeret and post-abdominal segments in the animal's rapid movements; its slower movements being dependent upon the ambulatory feet.

$y$. Extensor muscles, in two layers like the flexors, but of much smaller size.

For a full account of the anatomy of the Crayfish, see Huxley, Medical Times and Gazette, Feb. 7, 1857, et seqq.

For figures of the various systems and organs of the animal, see Brandt, Medizinische Zoologie, Bd. ii., tab. xi., pp. 62-64.

For the stomatogastric system, see Brandt, Ann. Sci. Nat., Ser. ii., tom. v., 1 836, pl. iv., figs. I, 2, pp. 87-9I.

For the olfactory (auditory?) organ, as carried by the internal or superior pair of antennae, see Gerstaecker, Bd. v., p. 357, and La Valette, Leydig, and Fritz Müller, cit. in loc. See also Spence Bate, Sessile-Eyed Crustacea, vol. i., p. ix.

For the formation of the coecal sac opening into the commencement of the duodenum out of the yolk-sac, see Rathke, Entrvickelungsgeschichte der Flusskrebses, p. 64. For other coecal appendages to the digestive tract of Crustacea, see Milne Edwards, Hist. Nat. des Crustacés, 1834 , pp. 76, 77; and for the formation of the liver by a bilateral out-pouching of the yolksac, see Rathke, l.c.p.49, and Abhandlungen zur Buldungs-und Entwickelungsgeschichte, Theil. i., I 832 , p. I 5 ; Theil. ii., I 833 , p. 78 , in which latter memoir the relation of intestinal tract and yolk-sac is shown to be different in Oniscus and Astacus. 



\section{PLATE VIII.}

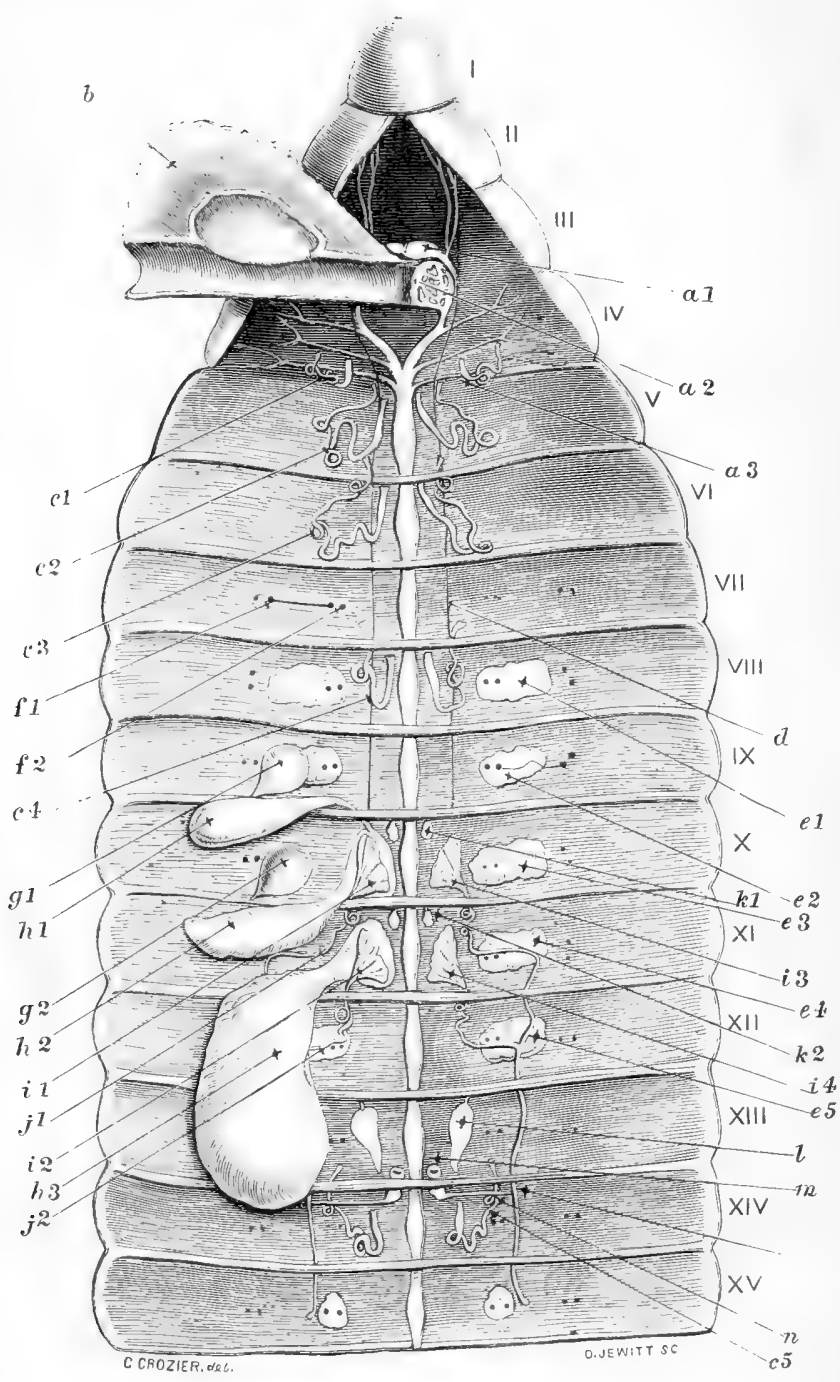

Earth Worm, Lumbricus Terrestris. 


\section{PLATE VIII.}

\section{EARTH Worm (Lumbricus Terrestris).}

The fifteen anterior segments of an Earth Worm (Lumbricus Terrestris), numbered from before backwards, the upper lip counting as the first segment.

THE integument has been divided, except in the first segment, down the middle dorsal line, and the greater part of the digestive tract has been removed, together with the pseud-haemal vessels, so as to show the nervous, muciparous, and reproductive organs.

a I. Bilobed supra-oesophageal ganglionic mass; giving off from either outer angle a nerve which bifurcates very soon after its origin, and passes to distribute itself in the tactile upper lip.

a 2. Visceral or stomatogastric system of the right side, consisting of a long ganglion lying upon the lateral wall of the pharynx, and running parallel with the cord of commissure between the supra-oesophageal and the sub-oesophageal ganglia, with which it communicates by several roots anteriorly, as it does posteriorly with a reticulate ganglionic plexus upon the posterior part of the pharynx. This plexus lies immediately externally to the mueous lining of the pharynx, and some of the glandular and muscular tissues of its outer walls must be cleared away in order to demonstrate it clearly. Figured roughly by Morren, l.c. Tabs. xix.-xxi., figs. I and $2 k . l_{.}$; and described more accurately by Quatrefages, Ann. Sei. Nat., Ser. iii., tom. viii., 1847 , p. $3^{6}$.

a 3 . Commencement of chain of ventral ganglia. The ventral chain consists here, as in Arthropoda, of fibrous elements 
placed superiorly, and vesicular placed inferiorly. The latter form a continuous stratum with aggregations at intervals corresponding to the middle of each segment, which are called ganglia, and give off two pairs of nerves on either side. The nerve-cord gives off in each segment anteriorly to the two pairs arising from the ganglioniform intumescence a single pair, which distributes itself along the line of the anterior dissepiment of each segment, and appears to correspond to the Nervi transversi of the Arthropoda. The four nerves given off in the middle of each segment are accompanied by branches from the pseud-haemal vessels which run on either side of the nerve-cord; the two nerves given off anteriorly to them are similarly accompanied by branches from the azygos pseud-haemal vessel which underlies the nerve-cord. These nervous and vascular branches are not given in this Plate.

b. Pharynx, turned aside to the left, the right half of the organ, except the small portion upon which the right stomatogastric plexus, $a 2$, is seen, having been removed. The walls of the pharynx are of great thickness superiorly, glandular tissue forming the exterior, and muscular the middle layers, whilst the mucous membrane forms the innermost, and attains a considerable thickness where it lines the saucer- or sucker-shaped cavity which opens from above into the cavity of the tube.

$c$ 1. First muciparous gland, or ' segmental organ,' opening externally in segment iv. Ordinarily the thickened muscular portion of the tube of the convolutions of which these glands are made, opens externally in the segment immediately posterior to that in which its internal funnelshaped opening is situated, this internal funnel-shaped opening being carried upon a short hollow stalk prolonged through the anterior muscular dissepiment of each posterior segment of the two with which each segmental organ is connected. But as segment iv. is not limited off from segment iii. by any such perfect or nearly perfect dissepiment as limits the segments after segment v. from the segments next in front of them, the anterior funnel-shaped termination is not seen so distinctly to be in a different 
segment from the one in which the mass of the coils of the gland are lodged.

$c$ 2. Segmental organ similarly modified to $c \mathbf{I}$.

$c_{3}, c_{4}, c_{5}$. Normal segmental organs, the opening on to the exterior being usually close to the inner row of setae, and in the anterior portion of each segment, though it may vary considerably, and even come to lie exteriorly and superiorly to the outer row of locomotor spines. The funnel-shaped internal opening is seen a short way from the outer edge of the nerve-cord, and near the ventral surface in the segment anterior to that in which the gland communicates with the exterior. The coils of the posterior, which is much the larger part of these organs, are connected by a mesentery-like lamina to each other and to the dissepiments of the segments.

d. Muscle passing up from one of the ventral muscles to attach itself to the capsule of the supra-oesophageal ganglia and the circumjacent parts, to which it stands in the relation of a powerful retractor.

$e_{1}, e_{2}, e_{3}, e_{4}, e_{5}$. ' Capsulogenous glands.' These bodies appear to be specially-modified and greatly-developed setiparous glands, which attain this prominence in the segments connected with the essential, and with the accessory organs of generation; amongst the latter of which the inner setae of many segments may be reckoned, besides those here lettered $e x$ to $e 5$. At $e 2$ we see a slip of muscle passing across the glandular mass, and connecting the inmer with the outer row of setae. Over the capsulogenous gland lettered $e 4$ is seen the vas deferens passing forward and through the dissepiment separating segment xi. from segment $\mathrm{x}$., to end in an infundibulum closely similar in form, relations, and connections to the more delicate tubular stalk carrying the funnelshaped ending of an ordinary segmental organ. On the capsulogenous gland labelled $e 5$ are seen the junction of the stem of a second vas deferens with the anterior one seen at $e 4$, and the commencement of the common duct.

$f 1$. Outer row of setae. Each seta is secreted by a separate gland, and has a separate insertion. The setae of the aquatic Oligochata are, on the contrary, 'fuscieulate' in their inser- 
tion. The outer row of setae is often ranting in the anterior segments; in the others it is usually connected with the inner row by a transverse muscular slip, such as that seen here, or at $e 2$. In the region of the clitellus the outer row of setae may be adapted to serve as accessory copulatory organs; elsewhere they are purely locomotor.

$f 2$. Inner row of setae. The spines are solitary in their insertion as in the outer row, but they are in many segments, as, for example, in the tenth and fifteenth, besides the segments constituting the clitellus, modified so as to serve as organs of adhesion.

$g$ I. Anterior receptaculum seminis of the left side, opening in the interval between the ninth and tenth segments, and between the lateral and dorsal muscles in the line of the outer row of setae.

g 2. Posterior receptaculum seminis, opening in the interval between the tenth and eleventh segments. These organs are very variable in size, and have had their existence overlooked and denied. Their outer opening is marked by a small elongated papilla; but their development is not always exactly correlated with that of the rest of the generative apparatus.

$h$ I. Anterior vesicula seminalis of the left side, attached to the posterior dissepiment of the ninth segment, and communicating, as does the middle vesicula seminalis $l 2$, with the anterior compartment of a sac with delicate walls which occupied a space in the tenth and eleventh segments corresponding to that underlaid by the azygos ventral muscle, and received the openings of the vesiculae of both sides.

$h$ 2. Middle vesicula seminalis of left side.

$h_{3}$. Posterior and largest vesicula seminalis, opening into the posterior compartment of the azygos central atrial sac just described.

$i$ r. Funnel-shaped orifice of vas deferens anterior of left side.

$i$. Similar orifice of vas deferens posterior of left side.

$i_{3}$. Similar orifice of vas deferens anterior of right side.

$i_{4}$. Similar orifice of vas deferens posterior of right side. Externally and interiorly to each of these infundibula there exists in each of these segments a segmental organ's 
posterior and larger portion; and posteriorly to each of these infundibula there exists also in each of these segments the funnel-shaped opening of the segmental organ of the segment next behind it. The coexistence therefore of the vasa deferentia with the very similarly constructed segmental organs would appear to be inconsistent with a view which should regard them as moditications of those glands. Still the great development and increase of mass observable in other organs in these segments may, as suggested by Mr. Lankester, induce us to hold that the typical number of segmental organs in any one segment is four, and that this number is attained to in those generative segments only on account of their superabundant nutrition. Upon this view the vasa deferentia, as also the oviducts $n$, would be serially homologous with the segmental organs.

$j \mathbf{r}$. Vas deferens from anterior spermatic infundibulum of left side.

j2. Vas deferens from posterior spermatic infundibulum of left side. The junction of the two vasa deferentia to form one common canal is well seen in the twelfth segment on the right side, and the ending of the common canal there formed is well shown on both sides in the fifteenth segment. The external opening of the common vas deferens has the shape of an oval slit, with its long axis transverse to that of the animal's body, guarded at the breeding season by prominent tumid lips.

$k \mathbf{I}$. Anterior testis of right side.

k 2. Posterior testis of right side.

$l$. The single ovary of the right side, occupying the same position relatively to the nerve-cord and the inner row of setae as the testes.

m. Infundibular ciliated mouth of oviduct, holding a similar position to that held by the infundibulum of the segmental organ $c 5$, which opens both internally and externally in the same segments.

n. Oviduct in the posterior of the two segments in which its various parts are found. After passing through the dissepiment separating the thirteenth from the fourteenth segment, the oviduct has a saccular dilatation, ordinarily found to 
contain ova, appended to it. It then passes outwards in relation with the dissepiment, to end by opening externally immediately externally to the internal row of setae. It is crossed just before its termination by a part of one of the tubular muciparous or segmental organs which is passing forwards to pierce the dissepiment, and end in its infundibulum in the segment next in front.

For the nerve system, see Lockhart Clarke, Royal Society's Proceedings, vol.viii., I 857, p. 343 ; see also Quatrefages, Ann. Sci. Nat., Ser. iii., tom. viii., I 847 , p. $3^{6}$; Morren, De Lumbrici Terrestris Historia Naturali necnon Anatomia Tractatus, I 829, tabs. xix.-xxi., figs. I and 2, k.l., p. I 19; and Leydig, Handbuch Vergleich. Anatomie, tab.iv., p. I68.

For the reproductive system, see Hering, Zeitschrift Wiss. Zool., vol. viii., 1857 ; Lankester, Quarterly Journal of Microscopical Society, vol. v., I865, p. 10.

For the segmental organs, see Gegenbaur, Zeitschrift Wiss. Zool., vol. iv., 1853 , p. $22 \mathrm{I}$; Hering, l.c., p. 401 ; Ehlers, Die Borstenwurmer, i., pp. 37-45, I864; Claparède, Introduction to work on Annelids of Bay of Naples, translated by W. S. Dallas, Ann. and Mag. Nat. Hist., Ser. iii., vol. xx., 1867, p. 355. 



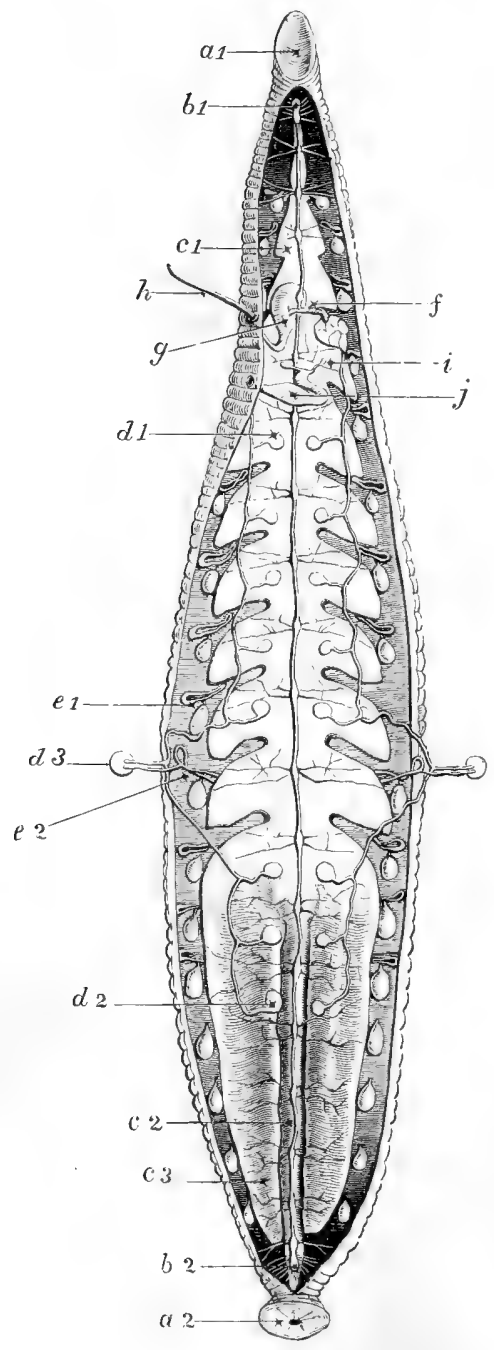

Medicinal Leech, Hirudo Medicinalis. 


\section{PLATE IX.}

\section{Figure of Medicinal Leech (Hirudo Medicinalis),}

Dissected so as to show its nervous, digestive, reproductive and segmental organs, as seen from below; slightly altered from Moquin Tandon's figure, pl. viii., fig. 10, Monographie des Hirudinées, 1846 .

THE integuments are drawn as divided down the middle ventral line, from the posterior border of the anterior sucker to the anterior border of the posterior sucker; two of the testes and two of the segmental organs have been displaced outwards in the segment, lettered $d_{3}, e_{2}$; the rest of the organs have been left undisturbed in situ, after the fastening out of the integuments on either side.

a 1. Anterior sucker, formed by the proboscidiform upper lip, which is made up of four incomplete annuli, representing however probably at least as many segments, and by the first complete annulus surrounding the mouth. The mouth opens in the middle of this sucker; six of the eyes are carried by the first, second, and third of the rays of the upper lip.

a 2. Posterior sucker, formed by the fusion of seven distinct annuli, to which seven distinct ganglia subsequently fused into the single posterior ganglion of the ventral chain, corresponded at one period of the animal's development. The stellate spot in the centre of the sucker must not be taken as representing the opening of the anus, which is situated anteriorly to the sucker in the line of constriction marking it off from the posterior annuli, which are not similarly modified. The anus does however open in the centre of the anal sucker in Acanthobdella, as also in the Polychaetous Annelid, Leucodore 
$b \mathbf{I}$. First and second pairs of sub-oesophageal ganglia, very closely apposed to each other. From the first sub-oesophageal ganglion, five pairs of nerves are given off; from the second only two, as from all the other twenty ganglia placed posteriorly to it, with the exception of the two last.

$b$ 2. Last ganglion, the twenty-second of the ventral chain. This ganglion gives off from five to nine pairs of nerves, which are distributed to the posterior sucker. The penultimate ganglion gives off only one pair of nerves. The supraoesophageal ganglion, with the three stomato-gastric ganglia connected with it and supplying the jaws, is not shown here; nor the azygos sympathetic nerves with a course above the ventral nerve-chain, and between it and the digestive tract upon which it forms gangliated plexuses, and sends branches along its lateral diverticula.

$c$ I. First lateral diverticulum of the portion of the digestive tract, which comes next after the pharynx, and which is called 'oesophageal' by Gratiolet, inasmuch as its functions are, according to him, merely those of a reservoir for the more solid parts of the animal's food, from which the watery part is squeezed out by the muscular contractions of the body-walls whilst it is contained there; and which, after remaining there thus condensed for several months, still retains the faculty of reddening, when exposed to the oxygen of the air.

c 2. 'Small intestine' of most authors, 'gastroiléal' portion of digestive tube of Gratiolet, in which the blood undergoes the alterations ordinarily effected in it by digestion. It ends posteriorly in a short ovoidal colon, which again ends in a short rectum, which turns slightly upwards to end at the anus. The small intestine is a little dilated at its commencement in the interval between the two terminal sacculi $c 3$; this dilatation representing the much larger bilobed dilatation, with which the homologous segment of the digestive tract commences in the Horse-leech (Aulostoma Gulo).

c 3. Eleventh lateral diverticulum of right side prolonged downwards on either side of the small intestine and colon, as far as the point where the rectum begins. The calibre of either 
of these terminal coeca is much larger than that of the segment of the digestive tube which lies between them, and which further differs from the homologous segment in the Horse-leech, in not possessing any lateral sacculations.

$d \mathrm{I}$. The most anteriorly placed of the nine testes of either side, communicating by a short transverse duct passing outwards, with a common vas deferens, which receives posteriorly the secretion of the eight posterior testes, and anteriorly leads into a convoluted epidymis-like vesicula seminalis, which is seen in this figure in the space bounded by the lines lettered $i$ and $f$.

d2. Last testis of right side. The segments between this one and the most anterior of the genital segments $f$, have their cutaneous glands greatly enlarged at the time of oviposition, and secrete the external chitinous shell of the 'cocoon' in which the eggs are lodged; whilst the glands of the female generative apparatus secrete the albuminous matter which fills the shell and surrounds the eggrs.

$d_{3}$. Sixth testis, displaced outwards so as to show its own connection with the vas deferens, and the relation of apposition with it, into which a coecal process from one of the segmental organs, $e$ 2, comes.

$e \mathrm{I}$. Segmental organs consisting of one portion, which is tubular and loop-shaped to the naked eye, but so mutually inter-communicating when examined with the microscope as to be really labyrinthiform; of a second portion, which is vesicular and opens on to the exterior; of a third, which, as a slender but resistent duct, connects the loop-shaped with the vesicular portions; and, in the eleven posterior segments, of a fourth portion, in the shape of a coecal process, which is prolonged inwards in the two most posterior up to the nerve-cord; in the ante-penultimate up to the vas deferens from the last testis; and in the eight others up to the eight anterior testes.

$e$ 2. Segmental organ, shown with all the four constituent portions just mentioned; the testis with which its coecal process comes into apposition, though not into any tubular continuity, having been displaced outwards. The vesicular part of the segmental organ lies in every case posteriorly 
to the looped portion, with the anterior element of which it is connected by the duct; and in the segmental organs, which are in the relation mentioned with the testes, the vesicular portions occupy the angle bounded by the vasa deferentia and the inner parts of the looped portions, and alternate in position with the testes. The coecal process constituting a fourth portion in the segmental organs in relation with the nine testes, is always brought into relation with the anterior one of the two testes, with which the segmental organ alternates, except in the case of the last testis, in which the coecal process appears only to reach the vas deferens of that last gland. In this figure four segmental organs are represented as existing posteriorly to the last testis; in nature there are only three, the most anteriorly placed one of which is connected with the male organs as just mentioned; whilst the two posterior ones have their coecal processes prolonged nearly up to the middle ventral line occupied by the nerve-cord. The seven segmental organs situated anteriorly to the most anterior testis, are represented in this figure by four. None of these seven possess the inwardly prolonged coecal process, but consist of a simple loop-shaped portion, the outer and larger end of which lies almost vertically in the natural condition, whilst the inner and smaller is prolonged inwards, and more or less horizontally, beneath the digestive tube, as in the other segmental organs, a duct and a vesicle open exteriorly. The coecal process when present may be taken to be homologous with the open infundibulum of the oviducts, and vasa deferentia of the Lumbricidae (see pl. viii., $i_{3}, i_{4}, m$ ). In some Hirudineae, the segmental organs may resemble those of other Annelids, in opening by ciliated infundibula into the general cavity of the body (Branchiobdella), or into the interior of one of the pseud-haemal canals (Clepsine), but they never are subordinated, as in those orders, to the function of conveying the generative products. In the middle regions of the body, the segmental organs are repeated at regular intervals, five annuli being interposed between the outlets of each pair; and the annulus immediately posterior to these outlets carries a nerve ganglion on 
its inferior and inner, and a pair of white spots on its superior outer surface. The colouration also, it may be observed, of some varieties of the true Medicinal Leech, as also and more markedly of Hirudo troctina, a distinct but closelyallied species, appears to indicate similarly that five smaller or secondary annuli enter into the composition of the primary segments, by the aggregation of which the middle body is made up. At the anterior part of the body the segmental organs are arranged with less regularity. The segmental organs of one family of marine Annelids, the Capitelleae, are said to resemble those of the Leech in having no inner orifice; and in a few Annelids they may be absent, or represented simply by apertures in the bodywalls.

f. Muscular ductus ejaculatorius of left side, leading from the convoluted vesicula seminalis into the base of the flaskshaped intromittent organ. It is by the secretion of the vesicula seminalis that the spermatozoa are agglutinated into a spermatophore.

g. Club-shaped end of intromittent apparatus, glandular at its coecal convex end, and tapering off into the muscular penis below.

h. Penis, surrounded where it passes out of the integument by a strong sphincter. This orifice is separated by an interval of five secondary annuli from that of the female organs.

$i$. Ovary of left side, carried upon one of the short oviducts. The ovary of the other side is seen on the farther side the nerve-cord, underneath which its oviduct passed.

$j$. Muscular vagina, in which after sexual congress the spermatophore is found. Between the vagina and the two oviducts, a common oviduct intervenes, which takes a tortnous course, and has its coils surrounded by a mass of loose tissue, composed of unicellular glands, which are probably the main agents in the secretion of the albumen which envelopes the eggs in the cocoon. The azygos character of the two generative outlets is especially noteworthy. In all other Annelids the generative glands discharge their products by dehiscence into the perivisceral cavity, whence they are taken up by the open mouths of infundibular ducts, as in Ganoid Fishes, 
and in the females of all higher Vertebrata; but in the Hirudineae the walls of the generative glands are continuous with the capsules of the generative glands; and, with the exceptions above stated, p. 220, the segmental organs have no opening internally. In the possession of accessory sexual organs, the Hirudineae and Oligochaeta resemble each other, and differ from the other Annelids.

For the general anatomy of the Leech, see Brandt, Medizinische Zoologie, Bd. ii., pp. 239-2.53; or Leuckart, Die Menschlichen Parasiten, Bd. i., pp. 634-720.

For the 'segmental' organs, see Gratiolet, Ann. Sci. Nat., Ser. iv., tom. xvii., I862, p. I92, pl. vii., fig. 4 .

For the nervous system, see Leydig, Vergleichende Anatomie, p. I62, ibique citata; and Taf. i., figs. 4 and 6; Taf. ii., figs. I, 2, 3, 5; Taf. iii., fig. I ; Taf. iv., fig. 1 ; and for the sensory organs called by him 'Becherformige Sinnesorgane,' see Archiv. für Anatomie und Physiologie, I86I, p.601. For the 'ganglions de renforcement' developed upon the inferior pair of nerves given off by each ganglia of the ventral chain, except the first and the two last, see, in addition to the references given at p. I 33 supra, G. R. Treviranus, Zeitschrift für Physiologie, Bd. iii., Hft. 2, I829, pp. I57-172; cited by Claparède, $l . c$., p. 356 .

For the development, see Leuckart, l. c., 686; and Rathke, Beiträge zur Entwickelungsgeschichte der Hirudineen (Nephelis, Clepsine), cit. in loco.

For the existence of blood-corpuscles in the psendhaemal system, see Quatrefages, Hist. Nat. Annalés, 1865, i., p. 63 , ii., p. 168, where Syllidea armata is stated to possess blood-corpuscles in those vessels; and the statement as to Glycera made in the Ann. Sci. Nat., 1850 , iii. 14, p. 288, appears to be withdrawn.

For a statement as to their presence in the 'pseudhaemal' system of some other Annelids, see Claparède, Ann. and Mag. Nat. Hist., Ser. iii., vol. xx., 1867, p. 350 , where Glycera is stated to be devoid of the vascular system in question. For the propriety, however, of elassing Phoronis as an Ammelid, as is done at p. I 38 supra, see Allman, Fresh-water Polyzoa, pp. 55-57, and Dyster, cit., p. I $3^{8}$. 

PLATE $\mathrm{X}$.

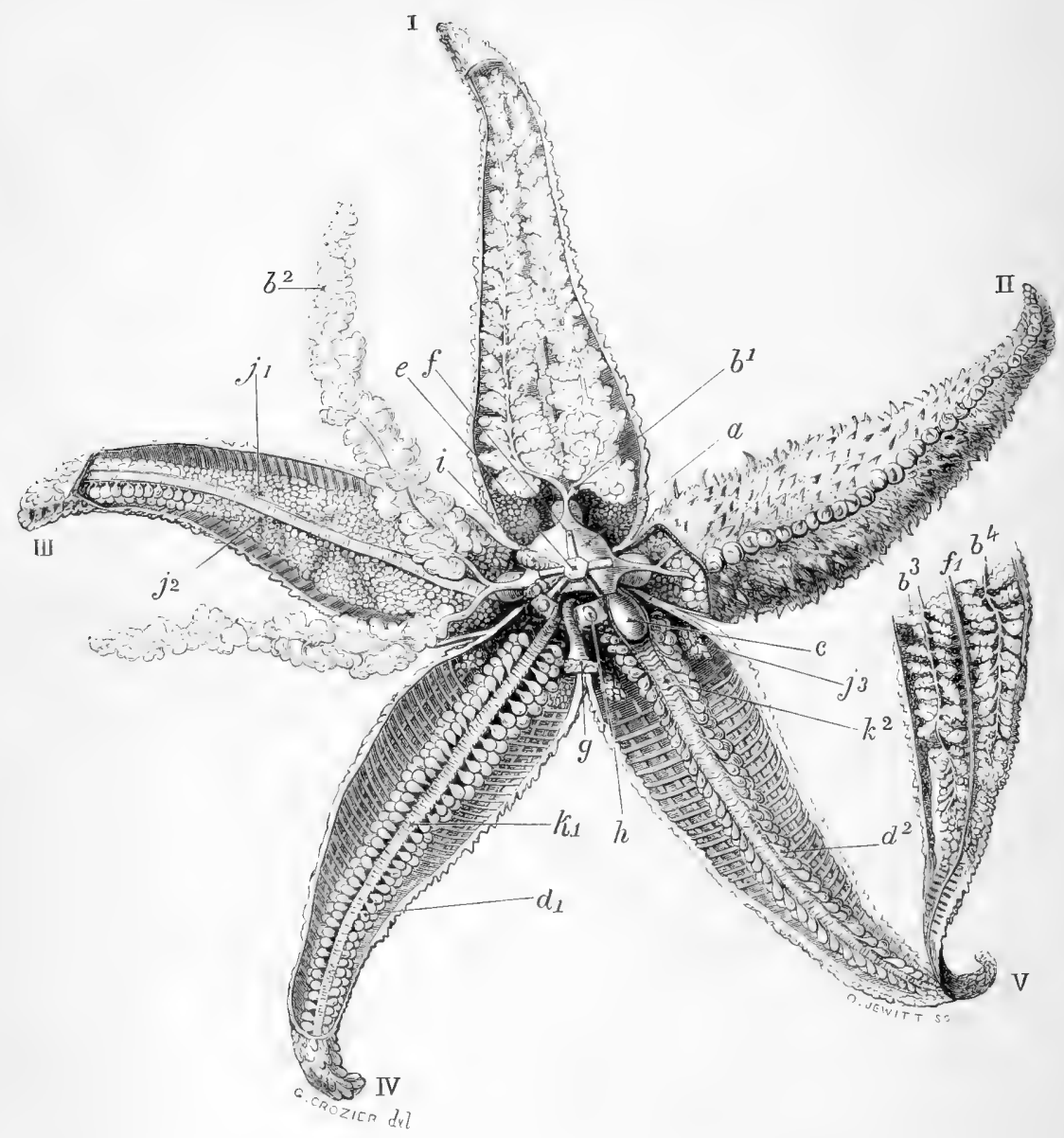

Common Star-Fish. Asterias Rubens. Linn. 


\section{PLATE X.}

\section{Common Starfish (Asterias Rubens), LiNN.,}

Dissected so as to show its motor, digestive, and reproductive systems.

The dorsal integument, with its multitudinous imbedded ossicles, has been removed from the central ray of the trivium, I; from its left ray; and from both rays of the anal bivium, a part of it being left attached to the right ray of the bivium at its apex, to show the attachment to it of the radial digestive coeca. The digestive and other viscera have been in great part removed from the interior of the two rays of the bivium and the ampullae $d 2$, and the ambulacral ossicles $k 2$ exposed $i$ situ. The digestive coeca have been displaced from their attachments in the left ray of the trivium; they have been left undisturbed in the central ray; and in the right ray all the organs, with the exception of a small part of the dorsal integument next to the eentral dise, have been left undisturbed.

The Roman numerals I, II, and III, denote the central and the right and left rays of the trivium, which is distinguishable from the bivium numbered IV and V, by the position of the madreporic tubercle $g$ and the anus .f, opposite to its central ray $I$, and to the interradial space between rays IV and V. In the irregularly-shaped Echinodermata, such as the Spatangidae, among the Echinoidea, and Cuvieria, the functions and structure of the bivium and trivium respectively may be very different, and may not only make it easy to demonstrate the existence of a bilateral symmetry, but may also constitute a ventral and dorsal surface respectively. But 
the regular Echinodermata, such as the Asteridae, Ophiuridae, and the regular Echinoidea, to the ambulacral regions in which all the five rays contribute equally, do not in adult life keep, when in locomotion, any one of these always pointing anteriorly; and it is by the relations of the anus in the proctuchous forms and of the madreporic tubercle when the anus is absent, that we are enabled to divide the five rays into two sets of them and two rays respectively. In the Ophiuridae, in which there is no anus, and in which the madreporic tubercle is not always visible externally, being fused with one of the interradially-placed circumoral plates, the adult animal may seem to be perfectly radiate, and we have to refer to the pluteiform larva for proof of its essentially bilateral character.

I. Central radius of trivium; a line drawn along the long axis of this ray to the madreporic tubercle $g$, would, in the undisturbed condition of the parts, have the anus a little on its left; and if prolonged, would pass down the interradial space of the bivium IV and $\mathrm{V}$.

II. Right radius of trivium, with the greater part of the tegument left in situ. The inward prolongation of the external ossiferous envelope is well seen in the interradial space between arm I and arm II ; and the generative gland of either ray is seen on either side of the septum thus constituted, with which it is connected by a single efferent duct with a cribriform opening on to the exterior. The dorsal integument contains a large number of ossicula imbedded in its substance, some of which carry small conical prickly spines, whilst others simply connect the spinigerous ossicles into a reticulation. Down the centre of each ray the spinigerous tubercles are in this species arranged with considerable regularity, so as to form a mesial series; in the other portions of the dorsal area, they are scattered irregularly. The intervals between the dorsal ossicula are perforated by respiratory pores, through which coecal processes of the perivisceral sac protrude, and are exposed to the circumambient aerating medium. Pedicellariae of considerable size are scattered over the interspinal areae, and smaller and inconspicuous ones surround many of the spines in a circle. They 
may be so numerous in this species as to give the surface a villous appearance.

III. Left radius of trivium. The two digestive coeca have been displaced from their normal connections within the cavity of the ray, and are displayed in the interradial space on either side. Towards the apex of the ray are seen the ambulacral ampullae belonging to one of the two biserial rows of locomotor feet, in the middle line are seen the ambulacral ossicles, and on either side the generative glands, $j 1, j 2$.

IV and V. Left and right rays of bivium. The greater part of the digestive and reproductive organs have been removed, and the ambulacral ampullae, $d_{2}$, forming four rows, corresponding to the two rows of sucker-like feet arranged on either side of the ventrally-placed ambulacral furrows, are seen on either side of the middle line occupied by the mesial articulations of the successive pairs of 'vertebral' or 'ambulacral' ossicles, $k \mathbf{I}, k 2$. Externally on either side to the rows of ampullae, are shown diagrammatically the more or less regularly quadrangular reticulations, formed by the ' interambulacral' ossicles. Of these interambulacral ossicles, there are in this species eight rows, interposed between the ambulacral ossicles and the less regularly disposed 'tergal' ossicles. Of the interambulacral rows, the first, third, and sixth carry spines on their ventral surfaces; the second, fourth, fifth, seventh and eighth are devoid of them, and act simply as commissural bars uniting the whole series into a quadrangularly reticulate skeleton. Of the tergal ossicles, some are spinigerous and some simply connective; the ambulacral never carry spines.

a. Intestinal cavity, communicating freely with the stomach proper, seen below at $c$, and giving off a stem which bifureates as it enters each ray.

$b_{1}$. One of the arborescent divisions into which the radial diverticulum of radius $I$ divides. It is only in the Asteriae that this digestive tract has this radial arrangement of digestive or 'hepatic' coeca. 
b 2. Arborescent coecum of radius III, displaced, as is its fellow, into the next interradial space.

$b_{3}$ and $b_{4}$. Terminations of coeca of radius $\mathrm{V}$ attached to the dorsal integumentary skeleton by a mesentery.

c. Stomach proper, bulging into the cavity of the several rays at a lower level than the coeca, $b$, but only for a short distance. Ligaments may be observed passing up on either side of $c$ from the ambulacral ossicles, by means of which the stomach can be retracted after being protruded, as it often is by the animal when feeding. To the right of $c$ is seen one of the interradial septa to which the ducts of the generative coeca on either side are attached.

$d$. Ampullae of ambulacral feet of radius IV; they are biserial on either side, in correspondence with the four sucker-like feet which communicate with them through conjugate foramina formed by the alternating apposition of emarginations of the ambulacral ossicles; for which see fig. 3, pl. i., Wright, British Fossil Echinodermata from the Oolite, 1862; Gaudry, Ann. Sci. Nat., Ser. iii., tom. xvi., pl. I3, fig. I.

d 2. Ampullae of radius $\mathrm{V}$.

$e$. Subcentrally-placed anus.

$f$. Origin of extensor muscle of radius I from inner surface of centre of dorsal integument. It is by the action of this muscle that the distal extremity of the rays and the compound eyes they carry, have their ordinary up-turned direction, as shown in this figure, given to them.

$f$. Distal termination of extensor muscle of radius $\mathrm{V}$.

g. Madreporic canal and plate displaced backwards into the interradial space of the bivium, opposite to which it is placed in the natural position of the parts. The madreporic plate being porous, and the madreporic tube, in spite of a somewhat complicated internal structure, being very readily permeable by fluid, it is easy to see how the sea-water can find its way into the water-vascular ambulacral system with which the madreporic canal is connected by its junction to circum-oral water-vascular ring. The 'heart' of the pseudhaemal system is inclosed in the same membranous sheath with the madreporic canal, and, like it, communicates with a circum-oral annular vessel, which lies inferiorly to the 


\section{Common Starfish.}

water-vascular ring, between it and the commissural ring, or rather commissural pentagon, formed by the nervous bands connecting the proximal ends of the gangliated radial cords.

$h$. 'Polian vesicles ;' muscular sacculi appended to the water-vascular circum-oral ring. There are in this species ten Polian vesicles, one corresponding to each biserial row of ampullae ; their functions, however, cannot be here of the importance which they may possess when of the proportions observed in the Holothurians (see Description of Preparation 47). Corresponding again to the Polian vesicles is to be found, on the internal aspect of the water-vascular ring, a series of glandular sacculi, the so-called 'racemose vesicles.' Of these there are nine in this species, one being aborted at the point of insertion of the madreporic canal isto the ring.

$j$ I and $j 2$. Reproductive glands of radius III, consisting of multiramified coeca appended to a single efferent duct, as in many but not all proctuchous Asteriae, and in Ctenodiscus amongst the aproctous. The efferent duct of each gland comes into relation with the corresponding interradial septum, and the small ova find their way into the sea-water through a cribriform external opening, which may be found on the corresponding side of the apex of each interradial angle on the dorsal surface of the body. See Müller and Troschel, Die Asteriden, pl. xii., fig. 2, p. 133.

j3. Point of attachment of efferent generative duct of right generative gland of radius $\mathrm{V}$ to interradial septum, which is formed by the prolongation inwards of the external envelope containing a number of small flat ossicles.

$k \mathrm{I}$ and $k 2$. Ambulacral ossicles forming by their mesial abutment the commissural ambulacral arches. There may be as many as 140 ambulacral arches in each ray, but as each arch is never in relation with more than a single pair of ampullae, and as the ampullae in Asteracanthion form two biserial rows, these rows are only half as numerous as the ambulacral arches. The apposition of the ambulacral arches forms inferiorly the ambulacral furrow, in the upper part of which is lodged the ambulacral water-vessel, and in the lower part of which, immediately beneath the integument, 
runs the gangliated nerve-cord. Each ambulacral ossicle abuts upon its fellow by a facet a little below the level to which the lines $k \mathrm{I}, k 2$, are drawn, the interval between this level and that of the articular facets being filled up by muscular fibres, which by contracting must act as divaricators of the ambulacral ossicles. Adductor muscular fibres, on the other hand, are found in the concavity of eash ambulacral arch, crossing from one ossicle to the other in the interval between the radial water-vessel and the nerve-cord. The structures in the Ophiuridae, which are homologous with the ambulacral ossicles of the Asteriae, are the tivo immoveably articulated halves of a vertebral ossicle, which, in the absence of any prolongations of the digestive or generative organs into the arms, occupies a much larger space relatively than the ambulacral ossicles of the Asteriae. The structures in the Echinoidea, which are homologous with the ambulacral ossicles of the Asteriae, are the socalled 'Auriculae' of Echinus, which in Echinanthus are repeated upon each ambulacral plate. The ambulacral plates, again, of the Echinoidea are not represented by any calcification in the Asteriae, being developed in the layer of perisoma which lies externally to the radial nerve-cords, and which remains free from induration in the order just named; though it carries four rows of scutes, one dorsal, two lateral, and one ventral, in the Ophiurae.

For the digestive system of the Asterias (Asteracanthion) mbens, see Müller and Troschel, System der Asteriden, Taf. xi., fig. I, p. I 32 .

For the reproductive system, see Müller and Troschel, ibid., pp. I 33,134 .

For the motor and skeletal system, see Professor Sharpey, Cyclopaedia of Anatomy and Physiology, article 'Echinodermata,' figs. 9 and 12, pp. 32, 34 ; Wilson, Linn. Soc. Trans., vol. xxiii., I 860 , p. 107, tab. I4, fig. 7 .

For the skeletal system, see Gaudry, Ann. Sci. Nat., Ser. iii., tom. xvi., I 85 I, pl. 3 , fig. 1 .

For the homology of the Auriculae of the Echinoidea and the calcareous ring of the Holothuroidea with the ambulacral ossicles 
of the Asteroidea as invalidating, pro tanto, Müller's dictum, that this latter class alone of Echinodermata possesses an internal skeleton, see Semper, Reisen in Archipel des Phillipiclen, Theil. ii., Hft. iv., p. 162 ; see also Wright, British Fossil Echinodermata of the Oolitic Formations, Palaeontographical Society's Memoirs, 1862, vol. ii., p. I4. For a comparison of the osseous skeleton of Asterias (Uraster) mbens with that of a fossil species from the Middle Lias, Uraster Gaveyi, Forbes, see Wright, l. c., p. 100, pl. i.

For an account of the Pedicellariae, see Sars cit. Wright, l. c., p. I9. The pedicellariae of the Asteriae and Echinoidea are not homologous with the avicularia of the Polyzoa, to which they bear a considerable resemblance. The pedicellariae are modified spines; the avicularia are specially modified or polymorphic individuals of the compound Polyzoan colony. The two sets of structures appear however to be analogous, being both alike prehensile organs. 


PLATE XI.

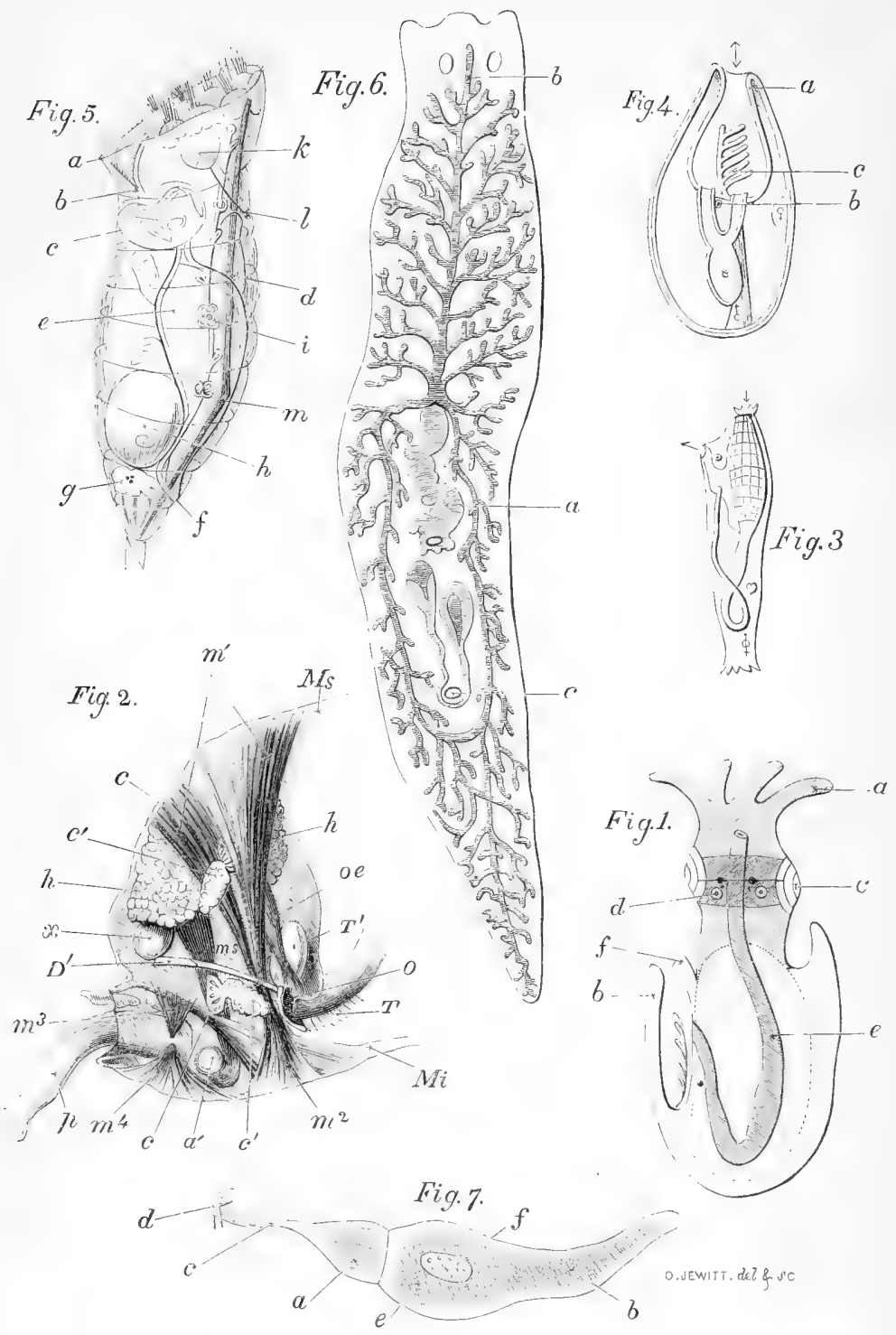

Fig. 1. Diagram of Cephalopod.

Fig. 2. BRachiopod. Rhynchonella Psittacea.

Fig. 3. Diagram of Ascidian.

Fig. 4. Diagram of Polyzoon.
Fig. 5. Rotrfer. Hydatina Senta.

Fig. 6. Turbellarian. Dendrocalum $N$ cusicar.

Fig. 7. Gregarine. Stylorhynchus Oligacanthus. 


\section{PLATE XI.}

\section{Figure i.}

Diagram of Cephalopod, from V. Carus' Icones Zootonicae, p. iii., fig. 30 .

THE following points, characteristic of the class, are embodied in this figure; the formation of 'arms,' $a$, by the division and elongation of the margins of the 'foot' proper; the formation of a funnel, $f$, by the coalescence of the epipodia; the relations of the mantle, $b$, to the funnel, branchiae, and anus ; the presence of a cephalic cartilage, of highly-developed eyes, and of a digestive canal which, though provided with accessory organs not shown here, is never, in this cläss, complexly convoluted.

a. The arms, which in the more highly organized Dibranchiate subdivision of the class are provided with suckers.

b. The mantle, which not only protects the branchiae, and brings them into relation with the aerating medium, but also whilst doing so, by its contracting and expelling the water from its cavity through the funnel $f$, enables the creature to swim backwards.

c. Eyes, sessile, as in the Dibranchiata.

d. Auditory vesicle, contained, together with the main nerve centres, in a cartilaginous capsule.

e. Intestinal tract, not forming complex convolutions.

$f$. Funnel formed by the coaleseence of the epipodia posteriorly to the 'foot' proper, which here takes the shape of 'arms' at $a$. Below the funnel are seen the gills, and between them and the rectum one of the inter-viscerally placed ganglia, which are so abundantly developed in this class.

For a figure giving full details of the anatomy of a Cephalopod, Octopns Tulgaris, see Milne Edwards, Ann. Sci. Nat., Ser. iii., tom. iii., pl. 13, p. 34I; or in Règne Animal; or in Victor Carus' Icones Zootomicae, tab. xxiii. 6.

For the nervous system in Cephalopoda, see Hancoek, Ann. and Mag. Nat. Hist., 1852 , Ser. ii., vol. i., pp. 1-1 + . 


\section{Figure 2.}

Lateral view of viscera of Brachiopod, Rhynchonella Psittacea, together with portions of the mantle, peduncle, and arms; after Huxley, Proc. Roy. Soc., I854.

The view here given shows that a section of the animal in the plane of the aperture of its two valves would not divide it into two symmetrical halves, as in the Lamellibranchiata, and that its valves consequently cannot be spoken of as right and left, as in those animals. The two valves of the shell, the posterior third only of the cavity of which was occupied by the body of the animal, have been removed, as have also the anterior two-thirds of the mantle lobes which were in relation with, though they did not, as in Terebratula, send coecal processes into them. The spirally coiled mass which the arms made up, and which filled up the greater part of the mantle cavity, has been removed; the arm of the right side has been cut away from its origin, and only a small part of the arm of the opposite side left on the other side of the mouth.

Ms. Lobe of mantle which was in relation with the valve ordinarily called 'dorsal.'

Mi. Lobe of mantle which was in relation with the so-called 'ventral' valve. Both valves in the Brachiopoda arise from the 'dorsal' or ' haemal' aspect of the animal, as they do in the Lamellibranchiata, but in the former class they are articulated across, whilst in the latter they are articulated along the dorsal ridge. It is the 'ventral' valve which, either by becoming adherent to some marine object, as in Thecidium and Crania, or, as in the species before us, by giving attachment on its inner surface to the peduncle $p$, furnishes the entire shell with a fixed point for its limited movements in the adult state. And Brachiopoda, whilst still free in certain stages of their development, have been observed to move from point to point by means of a pair of rigid spines, one of which was inserted on either side of the ventral pallial lobe. During the free stages of the life of such larvae the dorsal valve, as being the heavier, has been ordinarily observed to be inferior in position; it is so 
in the adult condition of the pedunculate, though, as it is always the free valve, it occupies the reverse position in the adnate Brachiopoda.

$x$. Heart, unilocular as in all Brachiopoda, and globular as in the articulate division of the class. Its position justifies the application of the term 'dorsal' to the valve in relation with it.

O. Mouth, immediately posteriorly to which the main nerve ganglia, three in number, one placed mesially and two laterally, were situated, forming the under side of an oesophageal collar, completed by commissural cords passing up to join on either side a ganglion of small size at the base of either arm.

Oe. Oesophagus; of considerable length, the mouth being so near the ventral valve.

$h$. Liver, surrounding the stomach, into the cardiac end of which it opens by four ducts. Immediately below the posterior lobe of the liver the intestine is seen passing downwards, and slightly tapering in its course towards the ventral valve. Having reached the valve it turns a little upwards and backwards, to end at $a^{\prime}$ in a coecal extremity, as in other articulate Brachiopoda.

$a^{\prime}$. Coecal extremity of digestive tube. The simple curve described by the digestive tube of the Rhynchonella has its concavity directed towards the ventral valve, just as the primary curve of the digestive tract of the inarticulate Lingula, which differs however from it by not ending coecally, and by having convolutions superadded to it, of which the intestine in the articulate species is destitute.

T. Tentacular cirrhi upon portion of left arm. The mouth, as in all Brachiopoda, is situated between the points of junction of the two arms to the visceral mass.

$T$. Sac, or ampulla, in connection with the great brachial canal; serving probably to increase the surface through which the fluids in the perivisceral cavity and in the brachial canals can act upon each other.

$7{ }^{\prime}$. Crural lamina, arising from hinge process of upper valve in Rhynchonella for the support of the right arm, which has 
been removed. The shell having been removed, the hinge process is figured as broken.

c. Laminated portions of oviducts, opening by an expanded orifice into the perivisceral cavity. In Rhynchonella there are four oviducts, one pair within the ventral, the other within the dorsal valve. The dorsal oviducts open into the perivisceral cavity by orifices looking forwards and upwards; the ventral by orifices looking backwards.

$c^{\prime}$. Tubular portions of oviducts, opening downwards. Those of the dorsal oviducts open above the mouth, those of the ventral below, into the mantle cavity.

p. Peduncle passing through a foramen, which is incomplete in young shells, to be attached by a pair of muscles within the umbo of the ventral valve.

$m^{\prime}$. Occlusor muscle.

m 2. Divaricator muscle, passing from ventral valve to cardinal process of dorsal.

m 3. Adjustor muscle, passing from linge process in the dorsal valve into the peduncle.

m 4. Adjustor muscle, passing from ventral valve into peduncle.

ms. Mesenterial lamina, connecting the two limbs of the bent tube made up by the digestive tract, and supporting the expanded inner segments of each of the four oviducts.

For a figure giving more details of the anatomy of Rhynchonella Psittacea, see Hancock, Phil. Trans., 1 858, pl. 1xi., fig. 2.

For figures of the nerve system, see Hancock, ibid., p. 845 , pl. lxii. For the various names which have been applied to each of the two valves, see Lacaze Duthiers, Ann. des Sciences Naturelles, Ser. iv., tom. xv., I86r, p. 266.

For the various views which may be taken as to the relationship of the class, see Lacaze Duthiers, Comptes Rendus, 1865, ii., p. 800 ; Haneock, l.c., p. 848 .

For the entire organization of the Brachiopoda, see Hancock, l.c., ibique citata, and Lacaze Duthiers, $l l$. citt.

For a description of a larval form of Brachiopod, see Fritz Müller, in Reichert and Du Bois Reymond's Archiv., т860, p. 72; Me Crady, Silliman's Journal, I860, xxx., p. 157. 


\section{Figure 3 .}

Plan of Ascidian ; from Bronn's ' Klassen und Ordnungen des Thierreichs,' pl. xvii., fig. 9, after Allman, 'Fresh-water Polyzoa,' p. 44, fig. 6.

Arrows mark the directions taken by the inhaled and exhaled currents, and a figure of a heart has been placed in a line with the ventral margin of the branchial sac, with which one end of the vasiform heart is very directly connected by means of a vessel in relation with the structure known as the 'endostyle,' and indicated in this figure by the thick vertical line passing down the left side of the branchial net-work. Functionally, the direction of the heart's action, and of the currents of blood it propels, are alternately reversed in the Ascidians, as shown by Milne Edwards (Mémoire sur les Ascidies Composées, Mém. de l'Institut, tom. xviii., I 842, p. 228); but homologically, this vasiform prolongation along the line of the endostyle is probably to be considered as representing the veins which in the Lamellibranchiata bring blood back to the heart from various parts of the mantle, as well as from the gills (see p. 60, supra). The concavity of the curve described by the first segment of the intestine, together with the stomach, looks in most Ascidians towards the line of the endostyle, and away from the single nerve ganglion seen in this figure between the inhalant and exhalant orifices. This disposition however of the parts is not constant in the Ascidians, not being, for example, maintained in Ascidia affinis, the species described under Preparation 22, p. 66 supra.

If this figure be so viewed as that the nerve ganglion shall occupy the same relative place as the branchial or parieto-splanchnic ganglion $l$, of the Lamellibranchiate figured on Plate V, and the arrow at the inhalant orifice occupy the same position as the line $a^{\prime}$, and the arrow at the exhalant the same position as the line $c^{\prime}$ in that figure, the theory here adopted as to the homologies of the several structures in the two classes of animals under comparison will be made plain. The single nerve ganglion of the Ascidian will then be seen to hold much the same relations to its exhalant and inhalant tubes as the parieto-splanchnic ganglia of the Lamellibranchiate do to the anal and branchial compartments of its mantle cavity; the branchial sac of the Ascidian will correspond with the inferior or 
ventral, and the atrial chamber with the superior or dorsal compartment of the mantle cavity of the bivalve. The generative duct is not figured in this diagram; it opens however ordinarily, together with the anus, into the free cloacal space which is seen between the anus and the nerve ganglion, and which corresponds very closely with the space called 'cloaca' in the description of Plate $\mathrm{V}$; differing indeed from it mainly in not being traversed by muscles such as the posterior adductor and retractor. The vessels passing in the non-cloacal portions of the atrial chamber from the pallial and visceral plexuses through the tubular ties described by Mr. Hancock to be distributed over the branchial net-work, would, possibly, correspond to the vascular system of the organ of Bojanus, which is interposed between the systemic and the branchial vessels. The absence of a foot, and with it of a pedal ganglion, and the asymmetry and less perfect evolution of the branchial sac in the Ascidians, must be borne in mind as being the main points which mask the fundamental unity of type existing between the two classes under comparison.

For views more or less in accordance with those adopted here, see Cuvier, Mémoires du Muséum, tom. ii., 181.5, pp. 13-34, or Mémoires pour servir à l'Histoire et à l'Anatomie des Mollusques, 18I7; V. Baer, Meckel's Archiv., 1830, p. 34I ; Hancock, Journal of Proceedings of Linnaean Society, June $20,1867$.

See also Allman, 'Freshwater Polyzoa,’ pp. 43-55; Quarterly Journal of Microscopical Science, Jan., 1869, p. 62; Nitsche, Dubois Reymond und Reichert's Archiv., 1868, Hft. iv., p. 518; Lacaze Duthiers, Ann. Sci. Nat., Ser. v., tom. iv., 1865; Sur un genre nouveau d'Ascidian Le Chenreulius Callensis, L.D.

For the view according to which the branchial sac of the Ascidian represents the dilated pharynx of a Lamellibranchiate Molluse, see Milne Edwards, Observations sur les Ascidies Composées, Mémoires de l'Institut, xviii., p. 274; Huxley, Phil. Trans., 1851 ; British Association Reports, 1852 ; Transact. Linn. Soc., 1860, xxiii., p. 202.

For the structure of the external test, see Huxley, Cyclopaedia of Anatomy and Physiology, article 'Tegumentary Organs;' F. E. Schultze, Zeitsehrift für Wiss. Zool., xii., p. I75, I863. 


\section{Figure 4.}

Plan of Polyzoon, from Bronn's 'Klassen und Ordnungen des Thierreichs,' iii. I, Taf. xviii., fig. I, after Allman, 'Fresh-water Polyzoa,' figs. I and 2, p. 7, fig. 8, p. 45 .

The animal is figured as it is seen when its lophophore, with the tentacles it supports, the lower segment and outlet of the intestine, and the single nerve ganglion which is situated between them, are retracted into a cavity $a$, formed for their reception by the invagination of the endocyst into the 'cell.' The double arrow above $a$ indicates that the cavity thus temporarily formed is common to both inhalant and anal orifices.

6. Nerve ganglion, situated between the two openings of the digestive canal.

c. Lophophore, representing in this figure only one-half of the horseshoe-shaped or ' hippocrepian' structure, distinguishing all fresh-water species, except Paludicellea and Urnatellea, and replaced in all marine species, except Rhabdopleura and Pedicellina, by a simple orbicular collar. The hippocrepian form of lophophore may be considered as constituted by the prolongation into two arms of the simple circlet of the marine species. The mouth opens between the two lips of the lophophore in all species, marine and fresh-water alike; and in all, except Pedicellina, both lips are beset with a row of ciliated tentacles. The two arms of the lophophore are attached to the polypide around its mouth, of which they appear to be a development, and they form thus the roof of its perivisceral space, with which their interior freely communicates. They are free in the rest of their length, and project from the oral over towards the neural and rectal aspect of the animal. Hence in this dingram the anal orifice occupies the right, and the oral the left side of the nerve ganglion. There is no gizzard in fresh-water Polyzoa, but the stomach has a large pylorie coeeum; from the lower end of this a cord is figured as passing to the bottom of the cell. This cord represents the eylindrical granular 'funiculus ;' in connection with which the testis of the Polyzoa, 
and also in the fresh-water species, certain non-sexual reproductive gemmae are developed. The ovary is figured on the oesophageal side of the cell, and towards its upper part. From the bottom of the cell, where in most cases a distinct septum separates the several polypides, retractor muscles are figured as passing upwards and attaching themselves to the sides and upper part of the oesophagus. As the nerve ganglion has been described as sending filaments to these muscles, as also to the evaginable endocyst, lophophore, tentacles, epistome, and digestive tract, it would appear to correspond not only to the cerebroid ganglia of higher molluses, but also to the parieto-splanchnic. A nerve collar has also been figured as passing round the oesophagus from the infra-oesophageal mass. The Polyzoa are devoid of a heart; and the blood contained in their perigastric cavities is aerated and kept in motion partly by the ciliary action of the inner surface of the endocyst; partly by its muscular contractions; and partly by the muscular movements retracting and protracting the entire polypide; which canse the contents of the perivisceral and of the tentacular cavities to be freely interchanged.

For a figure giving full details on a large scale of the lophophore, and its relations to the mouth, anus, nerve-ganglion, and epistome, see Allman's Monograph, 'Tresh-water Polyzoa,' published by the Ray Society, pl. ii., fig. 24; and passim for information as to the entire class, and especially as to the fresh-water representatives of it.

For an enlarged vier of the nerve-ganglion, drawn as surrounding the oesophagus with a collar, see Nitsche, Dubois Reymond, and Reichert, Archiv., 1868, Taf. xiii., fig. 23. See also Dumortier and Van Beneden, Mem. Acad. Bruxell., tom. xv., pl. iv., fig. 5, p. 85; Hyatt, Proceedings of Essex Institute, Salem, U. S. A., v. 4, Oct., I 867 , p. 107.

For a figure of a marine species, showing its orbicular lophophore, ovicell, and avicularia, see Bronn, Klassen und Ordnungen des Thierreichs, iii. 9, Taf. v., fig. 3 .

For the existence of a nerve-system common to an entire colony, see Fritz Müller, Archiv. fur Naturgeschichte, I860, p. 31 I. 


\section{Figure 5 .}

Figure of Rotifer (Hydatina Senta), Female, from Pritchard's Infusoria. Natural size, $\frac{1}{36}$ to $\frac{1}{48}$ of an inch.

The body is divided into nine zonular segments by eight annular muscles; its anterior extremity, which is much the larger of the two, carries the ciliated apparatus, from the appearance produced by the action of which the name of the class is taken, and its posterior end is a pincer-like foot.

a. Emargination of ciliated border of anterior extremity of body, leading into digestive tract.

b. Mouth, opening directly into a muscular pharynx or 'mastax' $c$, armed with chitinous teeth, which leads, by a short and narrow canal $d$, into

$e$. The stomach, a large sacculated and ciliated organ, with the upper end of which two large glandular organs are in relation, one only of which, that of the right side, is here figured.

$f$. Cloaea, into which open, not only the rectum and the oviduct, but also

g. The contractile vesicle, which receives the lateral terminations of the two water-vascular tubes.

h. Ovary.

$i$. Water-vascular tubes, convoluted at intervals, and giving off also certain pedunculate infundibula, which are richly ciliated, and open into the perigastric cavity, as do the segmental organs of the Annelids. There are never less than five of these ciliated infundibula in Rotifers.

$k$. Nerve ganglion, on the side of the body away from which the mouth opens.

l. Tentacular organ, consisting of a setigerous pit, situated on the dorsal surface of the body, and receiving filaments from the nerve ganglion. There are no eyes in the genus Hydatina. The surface upon which the tentacular organ is developed, and which corresponds in genera provided with a lorica, to its convex portion, is kept upwards by the animal in moving. 
$m$. Longitudinal muscles, the action of which, as also of the circular muscles, giving the body its annulated appearance, is counteracted by the elasticity of the chitinous integuments.

For a description of the Hydatina Senta, see Cohn, Zeitschrift für Wiss. Zool., I 855 ; or Huxley, Med. Times and Gazette, July 26,1856 .

For the anatomy and relationships of the Rotifera generally, see Huxley, Trans. Micros. Soc., 1853, I-19; Moxon, Linn. Soc. Trans., xxiv., I864, p. 459; Pritchard, 'Infusoria,' 4th ed., pp. 468,656 .

\section{Figure 6.}

Figure of Turbellarian Worm (Dendrocoelum Nausicaa), after O. Schmidt, Zeitschrift für Wissenschaftliche Zoologie, Bd. xi., Taf. ii., fig. I.

This figure is intended to show, firstly, the general external appearance of this Turbellarian, which bears a strong resemblance to that of the common Dendrocoelum lacteum, which is found abundantly in the streams and ditches of the south of England, especially in masses of the American weed (Anacharis Alsinastrum); and secondly, the peculiarities of the digestive system, whence the Dendrocoelous sub-order of Turbellarians takes its name. The cilia which cover the whole of the bodies of these worms, and from which the order takes its name, as also the nervous system, and the complicated organs of generation, with the exception of the intromittent organ with its capsule, and an organ of obscure function but of similar outer form to the male organ, have been omitted in this figure.

a. Muscular pharynx, communicating with the mouth, which lies a little posteriorly to the middle of the body. The pharynx is in this species so long as to require to be thrown into convolutions when retracted into its sheath, and it attains thus a deceptive similarity to the proboscis of the Nemertines or Rhynchocaelous Turbellarians. Probably in no true Turbellarian does the mouth open quite terminally at the cephalic extremity of the mouth, and the organ which 
is described as such in V. Carus' Icones Zootomicae, Taf. viii., fig. I6, in Prostomum lineare, is really homologous with the proboscis of the Nemertines, and probably also with a rudimentary structure which by careful focussing can be seen in the central lobe of the three into which the frontlet of many Dendrocoela is divided, as in this specimen. The Turbellarians never possess suckers, differing herein from the two other orders of Platyelminthes, the Trematodes and the Cestodes; and the structure which has been described in Prostomum lineare as being a sucker, has been shown by Claparède to communicate with its comparatively simple and aproctous digestive sac. See Claparède, Beobachtungen über Anatomie und Entwickelungsgeschichte Wirbellos. Thiere, ı 863 , pp. 16, ı7, Taf. iii., fig. 3 .

b. Anterior coecal end of intestine, passing uprards between the two eyes, and seen very clearly in the marine species allied to this one to be underlaid by a band of nervous tissue, passing across as a commissure between the two nerve-ganglia in relation with the eyes. Of the presence however of even the nerve-ganglia it is not always easy to convince oneself with the semi-transparent fresh-water species Dendrocoetum lacteum under the microscope, and it must be borne in mind that in comparative anatomy, as in development, the evolution of the organs of special sense may take precedence of the differentiation of central nerve-organs (see p. 157, supra). The digestive tract between the opening into it of the pharynx and this anterior coecal end gives off from eight to eleven lateral branches; two other branches pass back from the point of junction of the digestive tract with the pharynx, and surround the area in which that organ, as also the orifice of the bisexual generative glands, and the male intromittent and another organ of uncertain function, are seen to be situated. These two branches fuse posteriorly, and from the arch formed by their anastomosis numerous branches pass backwards and outwards. This arborescent form of intestine is always correlated with the absence of an anus in the Turbellarians; and in the Rhabdocoelous Prostomum and Vortex, where the digestive tract is aproctous, indications of a tendency to form lateral diverticula, 
as in the Dendrocoela, and less markedly in Rhynchocoela, are not wanting to careful inspection.

c. Orifice of female organs. The penis, and a pear-shaped organ which is of doubtful function, but which may be supposed to be concerned in the formation of the shell of the ova, have their openings distinet from, and placed posteriorly to, this orifice instead of within it, as in the genus Planaria, which is on this account separated from the genus Dendrocoelum. For detailed descriptions and for figures of the reproductive organs, see $O$. Schmidt, Zeitschrift für Wiss. Zoologie, x., 1859 , p. 24, Tafs. iii. and iv., xi., I86ı, p. I I, Tafs. i., ii., iii., iv.

The Turbellarian Worms show in various parts of their organisation points of affinity to several other orders of animals besides the Trematodes and Taeniadae, with which they have been here classed as Platyelminthes.

In some of the smaller aud almost microscopic forms of Rhabdocoelous Turbellarians the oesophagus opens into the general cavity of the body, no distinct intestinal wall being developed ; the resemblance of such forms to the larger Infusoria, and indeed also to the Coelenterata, is very close, so far as the digestive and tegumentary systems are concerned. Still even in a young Turbellarian, in which the digestive tract might not be distinguishable within, nor the generative organs differentiated from the general parenchyma of the body, the presence of such organs as the otolithic capsule would point to the real character of the animal. The presence of 'thread cells' in the integument is a point common to the Turbellarians, with the Coelenterata and many of the Holotrichous Infusoria (Parancuecium bursuria), but it has been noted also in certain Polychaetous Vermes, and in the Nudibranchiate Mollusea, which by their dendritic digestive tract present a real resemblance to the Dendrocoelous Turbellarians; as also to some extent by their complex reproductive organs. The singular aproctous parasitic Molluse Entoconche mirabilis, which appears to be nearly allied to the Nudilmranchiate Molluses, is, as figured and described by Baur, Nova Acta, I864, p. 35, by no means unlike, in the general relations of its various systems, to an aproctous Rhabdocoelous Turbellarian.

It is of more importance perhaps to note that the order Turbellarians comprises forms which, whilst inseparably connected with each other by connecting links, are yet so various as to present, at either end of the series they make up, close approximations both to the highest and to the lowest of the Vermes, to the unity and real compactness of which subkingdom they thereby appear to speak very distinctly. Dinophilus, for example, has 1 e $n$ ranked by Schmarda with the Naidina (see Nene Wir- 
bellose Thiere, i. 2, p. 9), whilst by most other authors, as Van Beneden, V. Carus, and O. Schmidt, it is ranked as a Turbellarian. Such a form as MIFacrostomum setosum (Schmarda, l. c., p. 7 , Taf. i. 15 and $\mathbf{I}_{5}$ a) is especially instructive as showing how direct the transition may be from the ciliated integument, whence the Turbellarians take their name, to the setigerous exterior of the Annelicls. The Nemertina s. Rhynchocoela, with which these minute worms are more or less closely allied, are by almost universal consent ranked as Turbellarians, and they by their possession of a perivisceral carity, which is wanting in the Rhabdocoelous and Dendrocoelous sub-orders, bring the entire order into still eloser relationship with the Annelids.

On the other hand, the kinship of the Turbellarians with the lowest of the Vermes, the Trematodes and Taeniadae, is even more obvious, and by virtue of it these three orders are ordinarily classed together; and it may be sufficient here to refer to the description of the class given in the Introrluction, some of the chief points of resemblance specified in which may be illustrated from Schmarda's work, pp. xi., xiii., Taf. ii. 22.

For the classification and for many points in the anatomy of the Turbellarians, sce Max Schultze, Archiv. für Naturgeschichte, 1849, p. 280; Archiv. für. Anatomie und Physiologie, i 853, p. 25I; O. Schmidt, Sitzungsbricht. Akad. Wiss. Wien, xxii., $1857, \mathrm{p} .347$.

For the anatomy of the Nemertina $s$. Turbellaria Rhynchocoela, see Keferstein, Zeitschrift für Wiss. Zool., xii., 1862, p. 66.

\section{Figure 7 .}

Gregarine (Ftylorhynchus Oligacanthus), a Parasite found in the intestinal tract of Callepteryx Virgo; after Stein, in V. Carus' Icones Zootomicae, tab. i., fig. 3 .

This animal consists of two nnequal parts, the smaller being the anterior, and armed with a coronet of spines; the larger being the posterior. It contains a large nucleus. The division between the two parts of the body is formed, according to Köliker, not by an involution of the integument, but by an induration of the hyaline cytoplasm or protoplasm, which, together with the nucleus and the fatty granules which in all but young specimens give a milky colour to these animals, make up its contents or parenchyma. Gregarinae, therefore, even when 'dicystideous,' as in this case, are really unicellular organisms. There are no sensory, circulatory, digestive, or other specialized organs in this animal. 
Its power of executing active movements is due to the contractility of its amorphous protoplasm or cytoplasm.

a. Anterior part of body or 'head.' The part upon which the line $a$ abuts is of dark colour, to denote the presence there of the opaque fatty granules which give the adult Gregarines their milk-white appearance.

b. Posterior half of body, the integument or cell-wall being slightly removed from the contained parenchyma, as it may be by imbibition of water, though in the normal condition of the parts it is not very sharply limited off from it.

c. Proboscis, into which it will be observed the granular opaque element of the parenchyma does not extend.

d. Apical expansion armed with excretions of the cell-membrane in the form of spines.

$e$. Should have pointed to the line of compartmental severance between the two halves of the body, and this diaphragm should, according to Kölliker, have been drawn as produced by the contained protoplasm, not by the enveloping cell-wall.

$f$. Nucleus containing a number of brightly refracting granules. It is not known to be directly concerned with the reproduction of these Protozoa, as is the 'nucleus' of Infusoria, or at least not more directly than by being involved in the general solution and rearrangement into small round masses, and ultimately into 'pseudonavicellae,' which the entire parenchyma undergoes after encystation, and which constitutes most of what we know of the developmental history of Gregarinae.

See, for a general account of the Gregarinae, Kölliker, Icones Histiologicae, i., p. 7. See also Lieberkuhn, Archiv. für Anatomie und Physiologie, 1865 , p. $5 \circ 8$; Lankester, Quarterly Journal of Microscopical Society, vol. vi., p. 23 ; Stein, Der Organismus der Infusionsthiere, ii., 1867, pp. 6-8, 19, 20.

For the possibility of a subsistence of a relationship between the organisms known as 'psorospermiae' and 'pseudentozoa' and the Gregarinae, see Leuckart, Die Menschlichen Parasiten, pp. I4I, 743: Beale, Third Report of Cattle Plague Commissioners, 1866, Appendix, pp. 14I-144; Cobbold, On the Nature of Pseudentozoa found in Diseased and Healthy Cattle, Entozoa, Supplement, I 869 , p. 4 ०. 


\section{,}

. 


\section{PLATE XII.}

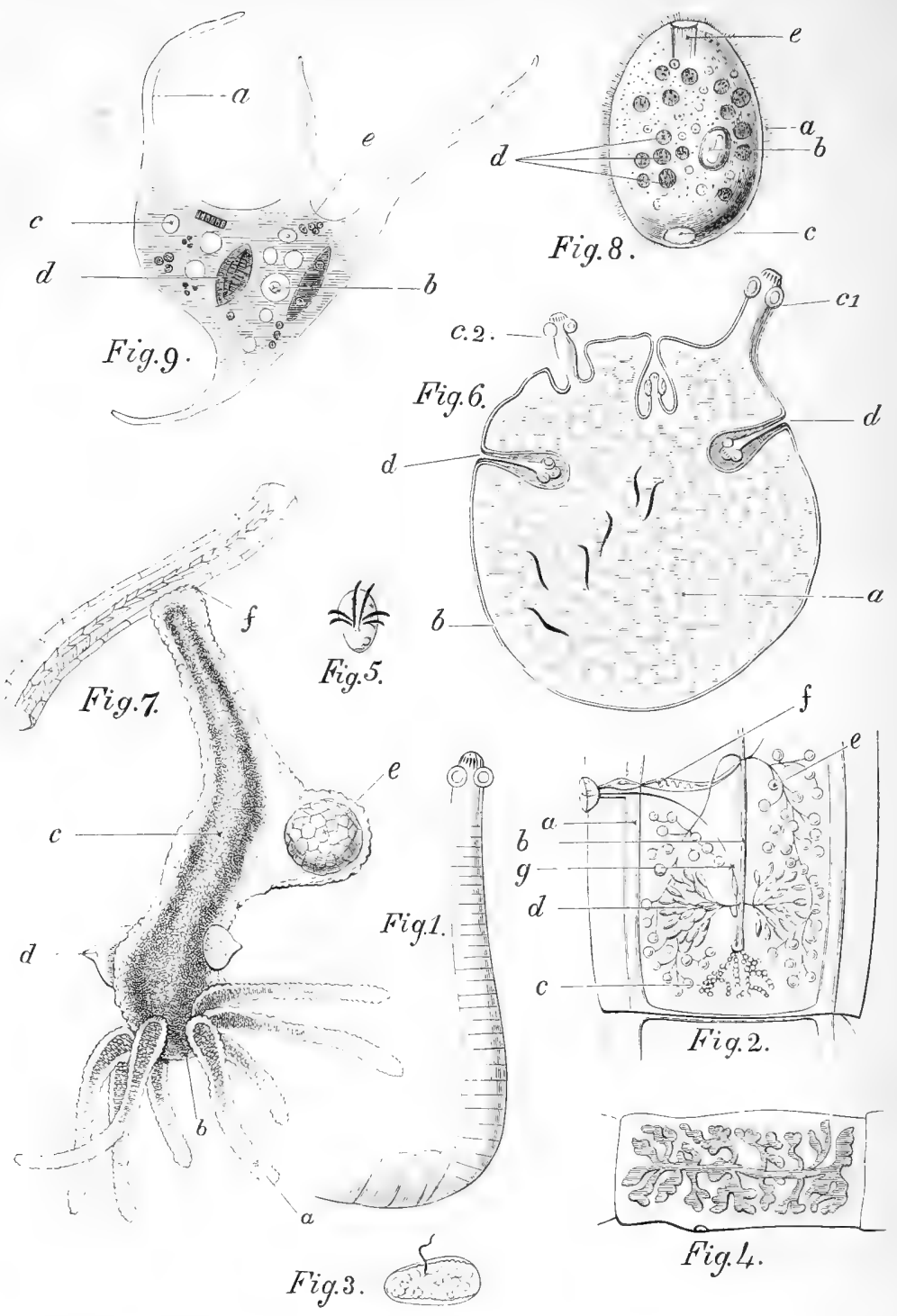

Fig. 1. Diagram of TAPEwory in Cestoid or Strobile Stage.

Fig. 2. Half of a young segment or Proglottis of TaPewora (Tania Canurus) magnified.

Fig. 3. Diagram of entire segment as detached when ripe or adult.

Fig. 4. Ripe segment, twice the natural size, of Trenia Solium.
Fig. 5. Embryo of Tapeworm without the shell.

Fig. 6. Diagram of Many-Headed Bladder Worm (Tania Canurus) in cystic stage.

Fig. 7. HYdRA Viridis.

Fig. 8. Infusonium. Prorodon Teres.

Fig. 9. RHizopod. Amoba Radiosa. 


\section{PLATE XII.}

The figures I to 5 are intended to show semi-diagrammatically the different stages of the metamorphosis or the 'alternation of generations' in the life of one of the typical Taenioid Flatworms or Platyelminthes. Figure I represents the perfect animal as it is found in the compound form, called 'strobile,' from the analogy of the cone of a fir, in the intestinal canal of ordinarily a carnivorous or omnivorous vertebrate 'host,' such as the dog, or the human subject. Figure 2 represents one of its segments, the so-called 'proglottides,' as it may be seen before the great development of the ova in the uterus has overwhelmed and caused the disappearance of the other sexual organs, female and male, which each segment after the sexless adherent 'head' or 'nurse' contains. Figures 3 and 4 represent ripe segments of the compound animal, so distended with ova as to have caused the ripe proglottides, which retain considerable locomotor powers, to be called 'ovaria ambulantia.' Figure 5 shows one of the microscopic embryos, the so-called 'proscolex,' as it appears when set free from its shell by the action of the digestive secretions of the intestinal tract, into which it is introduced; the entire ovum having been set free from the substance of the 'proglottis' by its spontaneous or other dehiscence, inside or outside of the digestive tract of the animal, which is to be its.host. Figure 6 shows the eystic stage into which such a proscolex as that shown in Figure 5 developes into, when it has belonged to Taenia caenurus, which differs from other Tapeworms except Taenia echinococcus, in having its proscolex proliferating as shown in the figure, instead of producing a solitary 'new head' or 'scolex.' This cystic stage is passed in the parenchyma of some solid organ, such as the liver or the muscles; and in the particular 
case of Taenia caenurus, in the brain of the sheep, most usually, though not rarely, in other parts of the body of this ruminant, as also of rodents. (See Description of Preparation 43, p. I $3^{6, \text { supra.) }}$

\section{Figure I.}

Tapeworm, as found in the intestinal canal of man or of a dog, semi-diagrammatic; after Van Beneden, Mémoire sur les Vers Intestinaux, Paris, 1858, pl. xxvi., fig. 25 .

The asexual ' head' or 'nurse' is armed with a double circlet of spines, as is the case with Taeniae which are harboured in the intestines of Birds and of carnivorous mammals; whilst the Taeniae of fish, batrachians, and herbivorous mammals are not possessed of this armature. Posteriorly to the circlets of spines is seen a circlet of four suckers. 'The definition of the segments begins to be evident a short way posteriorly to the head; the segments increase in size and ripeness from before backwards; the most posterior may be taken to have been such segments as are figured at 3 and 4 . 'The entire compound animal as seen in this figure is trimorphic, consisting of a sexless armed adhesive 'head' or 'scolex ;' of unripe 'proglottides' secondly; and of ripe proglottides thirdly.

\section{Figure 2.}

Half of an unripe segment of Taenia Caenurus, to show the generative organs, male and female; after Leuckart, Die Menschlichen Parasiten, p. I 79, fig. 30.

a. Water-vascular or excretory system. Two longitudinal vessels, one of which is often much larger than the other, and is not shown in this diagram, run along either side of each segment, parallel with and close to each other, and are connected with their fellows on the opposite side of each segment by a transverse annular anastomosis. This transverse connecting vessel takes in the last segment the shape of a median vesicle into which the lateral vesicles converge, and through which they open on to the exterior. In some cases similar openings have been observed in the anterior portions of the Tapeworm, posteriorly to the suckers, and 
communicating with the lateral trunks by short transverse anastomoses. These vessels are both contractile and ciliated. In their ramifications, besides other excretory matters which they may be supposed, from the analogy of other allied animals (guanin having been found in the water-vascular system of Trematodes) to contain, crystals of carbonate and phosphate of calcium are found, and sometimes, as in both the other classes of Platyelminthes, in great abundance. These calcareous corpuscles are found both in the central parenchyma and in the cortical layers of the Taenia, but in greatest abundance in the latter strata, into which a dense reticulation of capillary vessels, in which the corpuscles are lodged, may be observed to spread from the larger quadrilaterally arranged vessels which lie in the central parenchyma.

6. Uterus, in the unripe segment running as a straight tube from the posterior part of each segment to its anterior.

c. Ovary, or rather, as the yolk is furnished in these as in other Platyelminthes by a separate set of glands, the 'germigenous' gland. This organ occupies a place quite at the posterior end of each segment, and has a reticular arrangement.

d. Bilaterally symmetrical yolk-secreting gland or ' vitellarium,' lying anteriorly to the germigenous gland. The two stems carrying the digitate processes of either side unite into one common duct; this common vitelliferous duct joins the vagina just above the spot where it dilates into a receptaculum seminis. The common duct formed of these three factors carries its two kinds of contents into the dilated end of the uterus, just where it receives the duct from the germigenous gland, the products of which are thus brought at once into relation with the yolk and the spermatozoa. The granular layer of the cortical stratum which immediately underlies and secretes the chitinous 'cuticular' structure of the cortex, and overlies the muscles, has been sometimes mistaken for the true vitelligenous glands here described.

$e$. Testes appended in a racemose manner by very delicate ducts to the vasa deferentia. They were more abundant in the 
anterior half of the segment which is removed, than in this, the posterior.

$f$. Intromittent organ, essentially a specialization of the muscular ductus ejaculatorius. It is armed with spines, which favour its retention in the vagina, in the act of self-impregnation observable in these 'heautandrous' hermaphrodites. It is here figured as retracted and coiled up spirally; it is figured as protruded in Figure 3 .

g. Vagina dilating into an oval receptaculum seminis, before joining the duct of the two vitelligenous glands. The vagina opens externally in the posterior half of a saucer-like depression on one side of a segment; in the anterior half of each the male outlet is situated. The generative outlets are similarly arranged in the Taenia cucumerina, a tapeworm commonly found in the dog; and in the Taenia elliptica, a tapeworm which infests the cat; but the glandular organs being double, the outlets are double also, and exist on both lateral edges in each segment. In the Taenia mediocanellata of the human species, the common generative depression is situated some way behind the middle of the lateral border of each segment; in the Taenia solium it is nearer to the middle line, whilst in Bothriocephalus latus, which, like the two tapervorms, infests the human subject, both orifices are situated on one of the flat aspects of the segment they belong to. In other species, the male orifice may be situated on the edge, and the female on the flat aspect of each segment.

A segment with the generative organs in the condition here figured, would be found in either Taenia solium or Taenia mediocanellata, the two common human tapeworms, at about the 45 oth segment counting backwards from the head; and the segments would assume the appearance given in Figures 3 and 4, after about 200 more segments in Taenia solium, and 360 to 400 in Taenia mediocanellata. 


\section{Figure 3.}

Diagram of a ripe Proglottis, as cast free from the posterior end of the compound colony; one of the 'Vermes Cucurbitini' of the older authors.

Its edges are rounded off; the penis is figured as protruded from the orifice into which the generative ducts open; but the rest of the generative organs are overwhelmed by the abundant ova. But such a proglottis as this might retain, even when detached from the strobile, the power both of vegetative growth and of locomotion; and whilst moving freely in the contents of the digestive tract it was infesting, might grow to be as large as the entire strobile. Such proglottides have been mistaken for Trematodes, or for Taeniae without segments. By means of the three muscular layers of the cortex, the proglottis can move with considerable power and effect from place to place, when discharged from the intestinal canal of its host, so long as it is in an atmosphere saturated with watery vapour. Such proglottides have been aptly styled 'ovaria ambulantia.' The ova are ultimately set free by the spontaneous dehiscence of the cortical walls.

See Van Beneden, Mémoire sur les Vers Intestinaux, 1858, p. 249, and pl. xxvi., fig. 26, whence this figure is taken. For the muscular layers in the cortex of the Taeniadae and Trematodes, see Leuckart, Die Menschlichen Parasiten, Bd. i., p. 459.

\section{Figure 4.}

Segment of Taenia Solium, to show the dendritic outgrowing of the uterus, about twice the natural size; after Leuckart, l.c., p. I77, fig. 29.

This segment is not so far advanced towards maturity as the segment figured at 3 , its angles not being rounded off; but the uterus and its contents have increased and encroached so much upon the rest of the generative organs, as to have caused their disappearance. In Taenia solium, these dendritic ramifications would have a yellowish colour, and be found to be made up of aggregations of embryos, such as the one figured at 5 , enclosed in a hard resistent shell. It has been remarked that the proglottides 
of different species of Taeniae differ often very little or not at all from each other, even though their ova would give rise to as different a series of phaenomena as are presented by the histories of the Taenia caenurus and the Taenia serrata, the ova from the former of which would produce in a sheep such an organism as that figured at 6 ; whilst the ova of the latter would produce in a sheep no appreciable effect at all. The Medusae of different species of Polypes are similarly much alike; and in each case it is possible that the similar mode of life which the sexual zooid in each set of cases goes through, accounts for the loss at that particular stage of its specific and distinctive characteristics. The reverse is the case in the developmental history of the parasitic Crustacea, in which the larvae are alike, and the sexual animals very different in structure. See Van Beneden, l. c., pp. II3, I48; Polypes, Introd., p. 7 .

\section{Figure 5.}

Embryo or proscolex of an ordinary Trenia, armed, as is the case except in certain marine fish-infesting Taeniae (Tetrarhynchus) with six spines; after Van Beneden, l.c., pl. xxvi., fig. 27 .

Such an embryo as this would be of about three times the size of a human blood-corpuscle, $0.022-0.028 \mathrm{MIm}$, and when set free from the hard shell, which is not drawn in this figure, by the action of the digestive fluids of its host, it would bore and push its way from the mucous surface of the intestinal tract into the blood-vessels, and so pass along them into the liver, a very common place for the development of the cystic stage, or, subsequently, into other organs. The two spines of the central pair of the three are symmetrical, and, in piercing the portal radicles, they have an antero-posterior movement analogous to that executed by the oral stylet of certain parasitic Crustaceans. The two spines again on the extreme right and left of the series are symmetrical with each other, as are the two remaining ones, which, in numbering the whole series from left to right, would stand as 2 and 5. These two latter pairs move in the piercing of the tissues much as the fore limbs do in swimming. The wound made is, on account of the small size of the embryo, readily overlooked; and it has been incorrectly supposed that the embryos found their way into the liver by the way of the bile- 
ducts. The six spines are to be recognised again, though scattered and dislocated from their position as given here, in the more or less distended, cystic or cysticercoid vesicle, into which the proscolex expands when it reaches its place of lodgment in the tissues.

See fig. $6 b$ for Caenurus cerebralis, Van Beneden, l.c., pl. xxvi., fig. 34 ; for the six spines as seen in the cystic stage of Tuenia echinococcus, Leuckart, l. c., fig. 5I, Micrographic Dietionary, pl. 16, fig. 2; for the six spines in Taenia solium, Cysticercus cellulosae, see Cobbold, Entozoa, p. 225, fig. 48 ; for those in Cysticercus limacis, and Stein, for similar organisms from the perivisceral cavity of the larvae of Tenebrio molitor, which must be supposed to gain the cestoid form in the digestive tube of some insect-eating bird or mammal, Zeitschrift für Wissenschaftliche Zoologie, Bd. iv., 196, Taf. x., figs. 12, I3, 14, I6, and V. Carus' Icones Zootomicae, Taf. vii., fig. 20.

For a history of the migration of these embryos, see Van Beneden, l.c., p. ${ }_{2} 3^{8}$; Leuckart, l.c., p. $19^{8}$.

\section{Figure 6.}

Cystic stage in the derelopment of Many-headed BIadder-worm, Caenurus Cerebralis, after Van Beneden, $l$. c., pl. xxvi., fig. $3 \mathbf{r}$.

The embryonic hexacanth embryo, figured at 5 , has become greatly distended after coming to rest in the organ, ordinarily the brain of a sheep, into which it is carried by the blood after penetrating these vessels. The six hooks are observed to be senttered and dislocated over its surface at 6 , and a number of 'scolices,' the potential 'heads' or 'nurses' of a future tapeworm, are observed to be developed upon one of the poles of the enlarged vesicle. The way in which these heads are formed in the Tacniadae appears to be as follows. In the innermost submuscular cellular layer of the cyst, a proliferation of cells takes place, and forms a thickened dise. Into this a single depression in the monocephalous Taeniadac, and from 3 or 4 up to 300 or 400 in the Caenuri, make their way from the outside of the mother eyst inwards. On and out of the thus inverted external layer, the cuticular layer of the future scolex, with 
its spines and suckers, is developed; whilst out of the thickened disc the deeper layers of the cortex are formed. Each head thus at first points inwards towards the interior of the parent cyst; but by the contractions of the muscular layers of this cyst, as also by those of the intrinsic muscles of the cortex of each head, it may come to have its apex pointing in either direction, either outwards towards the circumambient tissues of its host, or inwards towards the interior of the maternal vesicle.

a. Wall of embryonic dilated cyst, containing, as do the homologous structures in the other Platyelminthes, calcareous corpuscles.

b. Hooks of embryonic vesicle scattered and dislocated by its distension.

$c$ I. Scolex fully protruded.

$c$ 2. Scolex half protruded.

d. Scolex as developed with its apex pointing inwards and its tubular body in communication therefore, not with the parent cyst, but with the cavity of the adventitious cyst thrown round the entire organism by the irritated tissues of its host. The central parenchymatous portion of none of these scolices is as yet developed, the sexual organs of which the central parenchyma is all but exclusively made up, not being developed except in the cestoid stage attained to in the intestine of the dog.

For history of Caenurus cerebralis, see Van Beneden, l. c., p. I46; Cobbold, Entozoa, p. 116 seqq. Gamgee, Report on the Parasitic Diseases of Quadrupeds used as Food (Med. Officers' Privy Council Office Report, v. 1862); Thudichen, ibid., vii., 1865 .

For other figures illustrating the various stages in the development of these Taeniadae, see Cobbold's Entozoa, p. 216, pl. xii., et passim. 


\section{Figure 7.}

Common Hydra (Hydra Viridis) showing the perfectly free communication or continuity with the body cavity which the digestive tract possesses; the continuity of the cavities of the tentacles with the digestive sac, and their contractility, as indicated by the annulation of their external surface as at $a$; and the reproductive organs in situ. After Greene; Manual of Coelenterata, I\$6I, p. 24.

The animal is drawn as attached by its 'hydrorhiza' to a piece of weed with the oral end downwards, as in the position very ordinarily assumed by it during life. It is much enlarged, its natural size being, at the greatest, little over three quarters of an inch in length. The Hydra differs from most other Hydrozoa, except the free forms of the class, in the three following particulars: firstly, in consisting of but a single polype, in which point only a few Corynidae resemble it; secondly, in being totally destitute of any external polypary; and, thirdly, in possessing the power of locomotion as well as that of fixation to one spot. It differs again from all Coelenterata, with the exception of Cordylophora lacustris, by its fresh-water habitat.

$a$. One of the tentacles, externally annulated, owing to the contraction of the external layer or ectoderm, which, in the terminal part of the tentacles, can be very well seen to be bounded internally by a structureless 'basement membrane'like layer, which again forms here the innermost layer, the cellular endoderm not being developed. The ectoderm is very richly bestudded with the thread cells, so characteristic of all Coelenterata (except Ctenophora?), but, besides a few pigment cells, it is said by Reichert to contain no other morphological element, its contractility depending upon a perfectly homogeneous and hyaline substance, as in Rhizopoda. The basement-like membrane is an excretion from the ectoderm, just as the chitinous external polypary is also in other Hydroid Zoophytes, but has been supposed to be muscular in character. As this figure shows that contractility resides in parts of the organism of the Hydra, where the purely cellular endoderm is absent, that layer of the body at all events may be supposed with some probability to be devoid of this faculty. 
b. Mouth, 'trompe buceale' of Van Beneden; a clear line marking the line of junction of endoderm and ectoderm.

c. Body-cavity, directly continuous with the digestive, and so, indirectly, with the tentacular cavities.

d. Conical testicular glands, which set free their spermatozoa by dehiscence outwards, and can be approximated by flexion of the animal's body to the inferiorly placed ovaria.

$e$. Large protuberance containing a single ovum, as seen in the autumn, proliferation taking place in the way of gemmation and separation of the buds during the summer months, just as agamogenesis prevails during the same period in the Daphnidae and Rotifera, but is replaced by the sexual impregnation of the 'winter ova' at the latter end of the year. In the Spongilla, and the fresh-water Polyzoa, on the other hand (see pp. 163 and 238 , supra), this history is reversed, agamogenesis by means of gemmules inclosed in a resistent capsule, taking place towards the close of the warmer months of the year, whilst a true sexual process takes place during the summer months. The ovum here is seen to be surrounded by a polygonally-shagreened capsule, which, however, is not spinous here as in Hydra vulgaris. The ovum is still enclosed within another capsule, furnished to it by the substance of the body-walls, in which, between the endoderm and ectoderm, the generative products are developed.

The Hydra is not always monoecious, as figured here; most ordinarily the Hydroid Zoophytes are dioecious; and as the Hydra possesses a certain power of movement from place to place, while the other Hydroids do not, we should, $\grave{a}$ priori, have expected to find the allocation of hermaphroditism to be the reverse of what it actually is. The history, however, of Cerianthus, one of the Anthozoa which possesses some slight power of locomotion, which is rare in the class it belongs to, and is at the same time hermaphrodite, which no other Anthozoon is known to be, is similarly surprising. The analogy of the language universally employed by us when speaking of animals in any one of the higher sub-kingdoms, would cause us to speak of the structures here lettered $d$ and $e$, as 'organs;' whilst the history of the development of the various Hydroid Zoophytes, or an observation of the uubroken chain of gradations which connects these 'organs,' through such fixed gonozooid forms as those of 
the sea-fir, Sertularia abietina (for which, see Description of Preparation 48, p. I60), with the free 'Medusae,' would induce us to speak of them as 'individuals.'

$f$. Hydrorhiza, forming the single point of attachment of the animal, and supposed by some to be perforated so as to give passage outwards to certain secretions from the body cavity, the mouth being undoubtedly the channel by which the refuse of the ingested alimentary matter is ejected. The external layer of integument covering the adhering disc, is made up of sub-cyliudrical cells, larger and more closely set than those on the rest of the polype-stem.

For the histology of the Hydridae, see Huxley, Müller's Archiv., I 85 I, p. 38 I ; Oceanic Hydrozon, I 859, p. I; Leydig, M:Iler's Archiv., 1854 , p. 276 ; Professor Reichert, Monatsbericht der Akademie der Wissensehaf en zu Berlin, July, 1866, translated in the Annals and Magazine of Natural History for January, 1867, p. 54. For the intermediate excretionary layer, see Claus, Zeitschrift für Wiss. Zoologie, x., I 860, p. 300. See also Kölliker, Icones Histiologicae, ii. Abtheilung, pp. 88, I ००, I 866 ; Leuckart, Archiv. für Naturgeschichte, 1854 , i. 369 ; Leydig, l.c. For the discussions as to the individuality of the various Zooids, see Claus, l.c., pp. 326-329; Gegenbaur, Vergleichende Anatomie, pp. 94-103, where, as also in V. Carus' Icones Zootomicae, p. ii., exceedingly instructive semidiagrammatic figures of those organisms in the Hydrozoa are given. See also Hincks, History of British Hydroid Zoophytes, pp. xxxv-xxxix; Leuckart, Polymorphismus der Individuen oder die Erscheinungen der Arbeitstheilung in der Natur., 185 I.

\section{Figure 8.}

Holotrichous Infusorium (Prorodon Teres), from Stein, in V. Carus' Icones Zootomicae, Taf. i., fig. 27.

We see its armed oral inlet at one pole of the body, its contractile vesicle at the other, the cilia which in the sub-order Holotricha elothe the entire surface with a uniform covering, the sexual organs, and the globular masses of nutriment, which having been ingested by the mouth have been distributed throughout the parenchyma of the body. 
a. Cilia, of uniform size all over the body. These organs are supposed to belong to the parenchyma of the body, and to be protruded through innumerable very fine orifices in the indurated integument. The integument in the ciliated Infusoria is sufficiently resistent to give their bodies the definite outline which distinguishes them from those of the other Protozoa; but it is not ordinarily demonstrable as distinct from the contained parenchyma without the use of reagents.

b. 'Nucleus' or ovary, with adherent 'nucleolus' or testis.

$c$. Contractile vesicle, probably representing rudimentarily a water-vascular or depuratory system, and opening on the exterior of the body. It is always situated in the cortical layers of the parenchyma, but does not appear to have definite walls of its own, as distinct from the contractile cytoplasm in which we find it. Tubular ramifications exist in connection with it in some genera.

d. Particles of alimentary matter, which, together with the structures lettered $b, c, e$, and with pigment granules, oil globules, and very fine cortically-placed granules, make up the morphological elements contained in the hyaline 'sarcode' or 'cytoplasm.'

$e$. Oral inlet placed in this species, though not ordinarily in others, at the apical pole of the body. It is prolonged into an oesophagus lined by a prolongation inwards of the cuticle, and strengthened by the development upon it of longitudinal teeth forming a circlet. The oesophagus opens directly into the central parenchyma of the body, which is less closely compacted together than the cortical layers, and in which the particles of food, together with such water as is swallowed with them, can freely circulate. The undigested refuse of the alimentary particles are ultimately extruded by the anus, which has a fixed position in all Infusoria except the aproctous Opalinae and Acinetinae, and which in this species is near the contractile vesicle $c$, at the aboral pole of the body. It is ordinarily visible only at the moment of the extrusion of the faeces, except in the few cases, of which Prorodon is not one, in which the cuticle is prolonged inwards at that, as it is at the oral orifice. The excess of 


\section{- Fresh-water Rhizopod.}

ingested water must be supposed to be got rid of by passing into the vessels in connection with the contractile vesicle, and by being thus expelled from the body.

For an account of the anatomy of the Protozoa, see Kölliker's Icones Histiologicae, Abtheil. i., pp. 9-24, 1864; Stein, Organismus der Infusionsthiere, Abtheil. ii., pp. 1-140, 1867; Claparède et Lachmann, Études sur les Infusoires et les Rhizopodes, vols. i. and ii., I858-1861 ; Extr. des tomes v. et vii. l'Institut Génévois; Leuckart, Die Menschlichen Parasiten, p. 135.

For an account of the genus Prorodon, see Claparède et Lachmann, l.c., vol. i., 3 I 8 .

\section{Figure 9.}

Amoeba Radiosa, a fresh-water Rhizopod; after Auerbach, Zeitschrift für Wiss.

Zoologie, viii., Taf. xxi.

Showing its pseudopodia, its contractile vacuoles, its nucleolated nucleus, and the algae and navicellae which it has enveloped in the substance of its parenchyma. The central portion of the body is very ordinarily of about the size of a human white blood-cell, and the pseudopodial processes may be as long as from twice the length of the diameter of the central mass up to as much as five times as long; but the size and shape both of body and of pseudopodia are very variable, and make the distinction of species a matter of much uncertainty.

a. One of the pseudopodia. The pseudopodia differ from those of most other Rhizopoda in not being branched at their apices; in not anastomosing with each other; and, as this figure shows, in not having the granular substance of the central parenchyma body circulating' within them. The 'sarcodic expansions,' as the pseudopodia have been called, are very usually more broadly lobate than those figured here; it is by their alternate protrusion and retraction, from which these animals take their names, that locomotion is effected.

b. Nucleus and nucleolus.

c. Contractile vacuole. The possession of vacuoles, as also of the 
nucleus and nucleolus, by the Amoebina and Actinophryna, differentiates them from the other Rhizopoda, and has caused them to be placed in a separate order, as 'Infusoria Rhizopoda,' or 'Rhizopoda Sphygmica.' The Actinophryna differ from the Amoebina in having their granular central parenchyma carried by circulation into the interior of their pseudopodia, which also are delicate and filamentous, and anastomose apically, like those of the Foraminifera and Radiolaria; but they resemble the shelless Rhizopod here figured, not only by possessing the structures $b$ and $c$, but also by enveloping alimentary substances within their parenchyma, as the Amoeba is seen to do at $d$ and $e$. At the same time, the circulation which takes place in the pseudopodia of the Actinophryna is to be borne in mind as favouring endosmosis, and thus, though it is much less energetically carried on in them than in the typical Rhizopoda, enabling them to extract nutriment from their prey by the same suctorial process which is the single method by which those animals absorb nutriment.

d. Navicula, one of the Diatomaceae, swallowed as food.

$e$. Spore of conferva enveloped as nutriment by the parenchyma of the body. It is only in the larger specimens that these vegetable remains are found; and it is rare in any Amoeba to find any traces of any other kind of nutriment. The action of digestion is shown by the decolorization of the chlorophyll, as well as by other changes effected in the ingesta. It does not seem possible to demonstrate the presence of an external enveloping membrane in the Amoebina, except in Amoeba bitimbosa, unless reagents be employed, which themselves probably cause the differentiation observable after their use. And there does not seem to be any positive reason for supposing that these animals possess a mouth which is only opened at the moment of swallowing, and has its lips so closely appressed at other times as to make the aperture invisible, as is the case in the Infusorial genus Amphileptus. The absence of mouth, anus, differentiated tegumentary envelope, and cilia, must be held to justify the separation of Amoebina from the Infusoria, with which however they are placed by Kölliker and V. Carus, 
on the groundthat they not only possess, as do the Actinophryna, a nucleolated nucleus and a contractile vesicle, but also differ, which the Actinophryna do not, from the other Rhizopoda in having no anastomoses between, and no circulation of granular sarcode within their pseudopodia.

For the anatomy and physiology of the Amoebae, see Auerbach, Zeitschrift für Wiss. Zoologie, vii., 1855, p. 365 ; Claparède et Lachmann, Études sur les Infusoires et les Rhizopodes, vol. i., p. 4I3.

For other figures of Amoeba radiosa, see Auerbach, l.c., Taf. xxi., and for descriptions, p. 400; Pritchard's Infusoria, pp. 204, 548 .

For the relationships of the Actinophryna to the Amoebean and the more typical Rhizopoda, see Claparède et Lachmann, $l_{\text {. }}$., p. 4 I 8 .

For the recent Foraminifera of Great Britain, see Professor Williamson's Monograph, published by the Ray Society, 1858 .

For the organization and classification of the Rhizopoda generally, see Carpenter's Introduction to the Study of the Foraminifera, (published by the Ray Society), I862, pp. 12-17; and for the Rhizopoda of the deep sea, see Carpenter, Royal Society's Proceedings, June, I 869, vol. xviii., p. I I 4 .

For the sareodie substance of the Rhizopoda, see Professor Häckel, Zeitschrift für Wiss. Zoologie, xv., 1 865, p. 342. 


\section{ADDITIONS AND ERRATA.}

Page 8, 5 lines from bottom of the page; in accordance with the language employed by Mr. William K. Parker, in his work on the 'Shoulder Girdle,' pp. I $45,209,210$, which was not in my hands when the first pages of this part of this book were printed off, for "There are two lateral episternal," read "There are two lateral omosternal;" and at 3 lines from bottom of page, for "there is no central episternum," read "The praesternum does not develope a pro-osteon, as in Helamys and Coelogenys."

Page 9, II lines from bottom of the page, add reference to Mr. Parker's work, "A Monograph on the Structure and Development of the Shoulder-Girdle and Sternum in the Vertebrata," by W. K. Parker, F.R.S., F.Z.S., London, published for the Ray Society by Robert Hardwicke, I92 Piccadilly, 1868.

Page 12, II lines from bottom of the page, add reference to Mr. Darwin's work, which, like Mr. Parker's, was not in my hands when these pages were struck off, "The Variations of Animals and Plants under Domestication," vol. i., pp. II 5-130, Osteological Characters of Rabbits.

Page 29, I5 lines from top of page, add reference to Professor Huxley's Paper "On the Alectoromorphae," Proceedings of the Zoological Society, May 14, 1868, p. 294.

Page 33, 16 lines from bottom of the page, for "The Ophidia differ," read "The Ophidia and the apodal Sauria differ." See V. Carus, Handbuch der Zuologie, i. Bd. p. $37^{2}$.

Page I38, note c, 7 lines from top of the page, dele "Gephyrei ;"-and 2 lines from bottom of page, erase words "Glycera and Phoronis hippocrepia," and substitute "Opheliae and Cirratulidae." See Claparède, Annélides Chétopodes du Golfe du Naples, p. 19, 1868.

Page 147, note e, for "an Echinus," read "an Echinoid."

Page I49, line I, for "with the masticatory apparatus," read "with the radial elements of the masticatory apparatus."

Page I52, note, $3_{2}$ lines from top of the page, after words "of the "nettle-cells," " add words, "See, however, p. cxliv supia, ibique citata."

Page I53, 4 lines from the bottom of the page, for " to the majority of Vermes," read " to many Vermes, such as Aphroditea, Glycerea, and Polycirrida." See Claparède l. c. supra, and Ann. and Mag. Nat. Hist., I867, vol. xx. p. 348 .

Page 177,8 lines from bottom of page, for "This latter branch is not," read "This latter branch, by which the blood from the posterior limbs can find its way directly back to the heart, is not." 


\section{N D E X.}

\section{Abranchiata.}

Abranchiata, xl.

Acanthobdella, I3I.

Acanthocephali, 155 .

Acanthopteri, lxxvili ; 40, 45 .

Accipitres, lii, liv.

Acherontia atropos, $73,78,79$.

Acranial Vertebrata, xxxiii, lxxxiv.

Actinia, 158 .

Air-bladder, lxxv ; 4I, 43.

Air sacs, 16.

Agassiz, xxiii.

Alae cordis, cv, exx; 101 .

Albuminiparous gland, 50, 190.

- Allantoid bladder, I83.

Allantoidea, xl, xli.

Allman, 70, 72 .

Ambulacral system, cxlvii ; I4I.

Amniota, xxxix, sl.

Amphibia, lxv-lxvii ; 18I-185.

Amphidiscs, 163.

Amphinomidae, accessory nerve system of, 123.

Amphirrhina, lxxviii.

Amphisbaenoidea, lvii.

Ampullae of feet in Echinodermata, I 4 I, I 44.

- Anallantoidea, xli.

Animals, characters of, as opposed to Vegetables, clxii.

Annelides, II9.

Annulata, cxxii, cxxvii ; 138 .

Annuloida, exxiii.

Anodon, 54-66.

Antedon rosaceus, $15 \%$.

Antennae, homologies of, 75 .

Antennules, 9I.

Anthozor, clviii ; 152 .

Anticlinal vertebra, 7 .

Aorta of Mammals, xlv; 168.

— of Birds, xlix; 176.

— of Reptiles, lix.
Botalli ductus.

Aorta of Fishes, lxxii.

Aphis, Io9-II3.

Aphrodite, I22.

Apteryx, liv, lv.

Apus, III.

Acarina, exviii.

Arachnida, cxvi ; IIO, II5.

Archaeopteryx, l.

Arion, I90.

Armadillo, xliv.

Arthropoda, civ; 73, II9.

Ascidia, c ; 66-7I.

Aspidochirotae, 147.

Astacus, 90-II9.

Asterias, I 4I-I 45, 223-229.

Asteriae, cliii.

Asteroidea, cliii ; I 41-145, 223-229.

Astropecten, I45.

Aulostoma gulo, I28, I30.

Auriculae of Echinoidea, homology of, clii.

Autolytus, 137 .

Autophagi, lv.

Aves, $x l-x$ lix, lix, lx; 175 .

Axolotl, xlii.

Azygos nerve, 132.

- vein, 2, I7I.

B.

Bacr, v, xxi ; 65,69 .

Barkow, I5.

Bastian, Dr. Charlton, xvii ; 157.

Bate, Mr. Spence, 94.

Beneden, Van, 7I, II9.

Bipinnaria asterigera, I 54 .

Bojanus, organ of, the renal organ of Mollusca, lxxxvi, xc, xciii, xciv, xcvii, xcix; $54,60-62,64,69$, 67.

Botalli ductus, 185 . 


\section{Brachiopoda.}

Brachiopoda, xcviii ; 232.

- Brachycephalus, lxii.

Bradypoda, xlv.

Branchellion, I35.

Branchiate Vertebrata, xli.

- Arthropoda, cv, cxviii.

- Vermes, exxviii.

Branchiae of Fishes, lxxiv.

- of Cephalopoda, xc.

- of Lamellibranchiata, xevi.

- of Crustacea, cxx.

- of Vermes, cxxix.

Branchiobdella, I38.

Branchipus, II I.

Brisinga, 145 .

Bronn, 48, 70 .

Brücke, 32.

Bruta, $x] \mathrm{v}$.

Bruzelius, II3.

Buccal mass in Mollusca, 48, I89.

Bugle Coralline, 73 .

Bulbus arteriosus, lxiii, lxxii ; 40, 99.

Bursa Entiana, lxxii.

Busk, 73.

\section{C.}

Carddis flies, 76 .

Caducibranchiate Amphibia, lxvi, lxvii.

Caeciliae, lxii, lxiii, lxvi.

Calciferous glands, I 25 .

Camelidae, xlv.

Campanularidae, I6I, I62.

Canalis temporalis, 8.

Capsulogenous glands, 125.

Carapace, $9 \mathrm{I}$.

Carcinus moenas, I Io.

Carinatae, lv.

Carnivora, xlvi ; 7, I69.

Carotid gland of frog, 184 .

Carpenter, Dr., 259.

Carpus, of Mammals, 9.

— of Birds, slix; i $7,23$.

Carus, C. G., 13, 16.

Carus, V., clxvi.

Casuarius, Iv.

Cauda equina, I.

Centetes, xlv, xlviii.

Cephalopoda, 49 ; Ixxxvii.

Cephalostegite, 96 .

Ceratophrys, lxii.

Ceratospongiae, $16_{4}$.

Cerianthidae, clviii ; I59.

Cestodes, cxl ; 136 .

Cetacea, xliv, xlv, xlvi ; 5 .

Chaetognatha, cxxxvii.

Chamaeleonoidea, lvii.

Chealiodes, 1xxviii.

Chauveau, xvii.

Chelonia, lvi-lviii, $1 x$, lxi.

Chiasma optic, lxxij.

\section{Cytoplasm.}

Chilopoda, cxiv, cxvi ; I08-II3.

Chimaerae, lxix-lsxi.

Chimpanzee, 9 .

Chiroptera, 9, I 70.

Chondrostei, Ixxxii.

Choroid gland, Ixxviii.

Cilia, absent in Arthropoda, cviii.

- present in a Sagitta, exxxvii.

Ciliated sac of Ascidian, 67 .

Cirrhostomi, lxxxiv.

Cirripedia, elxiii.

- Cladodactyle, I46.

Claparède, xviii ; 97, I57, 259.

Claus, clviii.

Clepsine, I35.

Clitellus of earthworm, II9.

Cloaca, in Mammals, xlv.

- in Birds, lii; $\mathbf{1} 75$.

- in Reptiles, lxi.

- in Fishes, lxxii.

- in Lamellibranchiata, xcvi ; 65, 197.

- in Tunicata, c; $67,236$.

Clymene, 138 .

Clypeastridae, clii.

Cockroach, common, 86, 199.

Cod, common, 45,46 .

Coeca of Birds, I 77 .

- hepatic, of Arthropoda, exx; 104.

- pyloric, of Fishes, xxxiv ; 40.

Coecum of rodent, 4,172 .

- azygos of Crustacea, 104.

Coelenterata, clvi-clx; 152, I $5^{8-163}$, 165.

Coenosare, 160.

Coenurus, 136.

Coleoptera, 75 .

Colleterial glands, cxi.

Columba livia, 12-25.

Copepoda, II 5 .

Corethra, 109.

Craspeda, 159

Cremaster, 76 .

Crinoidea, cliv ; I44.

Crocodilina, lvi; 176 .

Crop, I4.

Crustacea, cxviii ; 90-I19, 205-210.

Cryptobranchus, lxiv.

Cryptogamia, clx.

Ctenocyst, clviii.

Ctenodiscus, cliv; 145.

Ctenophorae, clvii, clviii.

Cuchia, lxxiv.

Cucumaria, I45.

Cuvier, $x x i$; 9, I4, I 5, 4I, 5I, 54 .

Cuvierian ducts, lxxiii.

- organs, 146 .

Cyclas, xcvii.

Cyclostomi, xxxv-xxxix ; 46 .

Cyprinoids, lxxii ; 45 .

Cystic stage of Tapeworm, 136 .

-Cytoplasm, cls. 


\section{Daphnidae.}

D.

Daphnidae, cxlvii.

Darwin, xxiv ; II4.

Dart sac, 50.

Decapodous Crustacea, 92.

Deciduate Vertebrata, xlviii.

Dendrochirotae, 147 .

Derotremata, lxvi.

Deuterozooids, 137 .

Development of Vertebrata, xxxviii.

- Amphioxus, lxxx, lxxxv.

- Amphibia, lxvi.

- Fishes, lxxix.

- Echinodermata, cxlvi.

- Cephalopoda, xci.

- Gasteropoda, xciii.

- as a basis of Classification, xxi.

Diaphragm, 2, 168, г 76 .

Dias longiremis, I I 5 .

Dibranchiate Cephalopoda, xci.

Dicystidea, clxviii.

Didelphia, xlviii.

Dinosauria, 1.

Dipnoi, lxviii, Ixxxi.

Diphyodont Mammals, xv.

Dominant systems, 35 .

Donders, sviii.

Dromaeus, lv.

Ductus Cuvieri, lxxiii.

Duodenum, 15 .

Duvernoy, 15, 32-66.

E.

Echinococcus, I36.

Echinodermata, cxliii ; I 4 I, 223.

Echinoidea, cl.

Ecker, 173, 185.

Edwards, Alphonse Milne, xxi ; II 9.

- Milne, xxi; 2, 16, 67, 70.

Ehlers, cxxxiii.

Elasmobranchii, lxvii, lxxxii.

Endoskeleton, lxviii.

Endostyle, 67 .

Entomostraca, IoI.

Ephemeridae, $8 \mathbf{9}$.

Epigastric vein, 36, 181, 183 .

Epipodites, 103, I04.

Esocidae, 45.

Eroskeleton, lxviii.

Eyes of Insects, 74 .

- of Crustacea, I I3.

- of Vermes, lxxx.

\section{F.}

Fat-body in Snakes, 32.

- in Frog, 18 .

- in Caterpillars, $73,79,81$.

- in perfect Insects, 86, 89 .
Guanin.

Fierasfer, xlii.

Fins, function of, 4.3 .

Flagella, distal elements of antennules in Crustacea, 92.

Flagellum, replacing eye-facets in a Crustacean, II 3 .

- secretes spermatophore in certain Molluses, 50.

Flustra, 7I.

Foramen Pannizzae, lvi.

Fowl, common, bones of, 25-29.

Frenulum bulbi in Amphibia, 184 .

Frog, 35-40, I8I-185.

G.

Gadus morrhua, 45, 46 .

Gall-bladder, 184 .

Gallus Gallinaceus, 25-29.

Gammarus pulex, II 2.

Ganglia of Tunicata, 67,68 .

- Gasteropoda, 48, 49, 52, 54 .

- Lamellibranchiata, 62-64.

- Mollusca and Molluscoidea, Ixxxvii, lxxxviii.

- Arthropoda, 83, I Io.

- accessory of Annulata, I 23, I 32, I33.

- of Lamellibranchiata, xevii.

- of Cephalopoda, xc.

Ganglia, stomatogastric, of Gasteropoda, 53 .

— of Arthropoda, 87, 103, 107.

- de renforcement, 132 .

Ganglion, frontali, 79,87 , I 2 .

Ganoidei, lxxiv, lxxxii.

Gasteropoda, xcii ; 48-54, I87-I9r.

Gaudry, I+3.

Gephyrea, cxxxi; $155,{ }_{5} 6$.

Gerstaecker, I I9.

Giraldés, organ of, xxxv.

Glands, antennary, 98 .

- carotid, I84.

- choroid, lxxviii.

- Harderian, 3, i 70.

- hermaphrodite, 50.

- hibernating, 3 , I 70 .

- salivary, $3,49,87$.

- silk, 75, 80.

- uropygial, 16 .

Glycera, I38.

Gnathostoma, 1xxxiii.

Goat moth, 79.

Gonophore, I60.

Gonozooid, 16o.

Gratiolet, I35.

Gregarinae, clxvii, clxviii.

Gromida, clxv.

Grube, cxlvi.

Guanin, 159 . 
Haeckel.

$\mathrm{H}$.

Haeckel, civ, clxii.

Haemal flexure, 68.

Haemapodous character of Vertebrates, I67.

Halisarca, I64.

Hancock, Mr. Albany, 69.

Harderian gland, 3 .

Heart of Vertebrata, xxxi.

- Mammalia, xlv.

- Birds, lii.

- Reptiles, lviii.

- Amphibia, 1xiii.

- Fishes, 1xxii.

- Arthropoda, cv.

- Insecta, cx.

- Crustacea, cxx; 98, I00, 101.

Hedriophthalmata, 92, 101 .

Helix, 47-54, 190.

Helmholtz, xvii; i r 8.

- Hepatic Cocca, cxx; 104.

Heptanchus, lxxiv.

Hering, 2 I 6.

Hermaphrodite gland, I9I.

Hessling, Von, 60, 65, 198.

Hexanchus, lxxiv.

Hibernating gland, 3, 169 .

Highly specialized as opposed to high types, 42 .

Hincks, British Hydroid Zoophytes, 162.

Hirudo, $122,127-136$.

Holostean Ganoids, cxxxii.

Holothurioidea, cslviii ; 145.

Homarus, 96.

Homologies, tables of, appendages and segments in Arthropoda, II6, I17.

- ganglia in Arthropoda, IIO.

Horse-leech, I35.

Huxley, Professor, 48, 49, 57, 69, 75, $90,96,162$.

Hyatt, 72 .

Hydrotheca, I60.

Hydrothiza, 160.

Hydrozoa, clix.

Hymenoptera, 75 .

Hyperoartii, lxxviii-1xxxiv.

Hyperotreti, lxxviii-lxxxiv.

I.

Ichthyobatrachia, lxvii.

Icthyopsida, lxvii.

Imago of Insects, 78 .

Impregnation of ova in Fishes, 1xxix.

- in Amphibia, lxv.

- in Lamellibranchiata, xcvii ; 65 .

- in Tunicata, c.

Infusoria, clxiv.

Insecta, cviii ; 73-90, 199-204.
Macdonnell, $D r$.

Insectivora, I 70 .

Intermaxillary bone, 6 .

Intermediary nerve in leech, 132.

Interparietal bone, 8 .

Isopoda, 92, 93, I IO, III.

\section{J.}

Jourdain, 177 .

Jugular, external jugular vein, 3 .

- left jugular vein, 185 .

K.

Keferstein, cxxxiii ; 156.

Kidney in Vertebrata, xxxv.

— in Mammals, xlvi ; 3,168 .

— in Birds, liii ; 16,177 .

- in Reptiles, lx.

- in Amphibia, lxiv ; 183.

- in Fishes, lxxv.

Kölliker, clxvi ; 46,163 .

Kowalewsky, ci.

Kupffer, ci.

L.

Lacaze Duthiers, cxxxiii ; I90.

Lacrymal gland, double, of rat, 3, I 70.

Lamellibranchiata, xev ; 54-66.

Languettes in Ascidians, 67 .

Lankester, Mr. E. Ray, I 20, I 26.

Lantern of Aristotle, cli.

Lateral ganglia in Annulata, r32, r 33.

- line, system of, in Fishes, lxii, lxviii, Ixxviii ; 4 .

Leydig, cxlix ; II I.

Leidy, 5I.

Lepidoptera, 74 .

Lepidosiren, lxv.

Leptocardia, cxxxiv.

Lepus cuniculus, Io.

Leuckart, 255, $25 \%$.

Leucodore, I 38 .

Libellulidae, 89 .

Ligamentum nuchae, I1, I69.

Limacidae, 50.

Limax, 187-I9I.

Lister, Professor, xviii.

Lithydrodea, clix.

Loricate Reptiles, 1vi.

Lubbock, Sir John, II7, 204.

Luidia, I45.

Lumbricus, II9-I 26.

Lungs of Mammals, xlvi.

— of Birds, liii.

- of Reptiles, 1x; 3 .

y

M.

Macdonald, Dr., yo.

Macdonnell, Dr., 42. 
Macleay, Mr.

Macleay, Mr., xxi, xxiv.

Madreporic tubercle, cxlvii ; $\mathbf{1} 4 \mathbf{I}$.

Malacopteri, 43.

Malacopterygii, lxxv.

Malpighian vessels, cx; 80-86.

Mammalia, xlii-xlix.

Marsipobranchii, $1 \times x-1 \times x x i i i$.

Marsupialia, slviii ; $\mathrm{I} 7 \mathrm{x}$.

Masticatory apparatus of Mammals, 6 .

Matuta victor, 93.

Medusae, clix ; 16 r.

Medusiform buds, I6o.

Membrana nictitans, lxviii.

Metagenesis, $x \times x$ viii, criii, cxxvi, cxlvi ; ${ }_{4} 4,153$.

Metamorphosis of Insects, cxiii ; 79.

- of Echinodermata, cxlvi.

- of Platyelminthes, cxlii.

- of Vermes, cxxvi.

- relation of fresh-water habitat to, cxlii ; 105.

- parasitism to, exxvii.

Mollusca, lxxxv ; 47-66, 187-I91, 231.

Molluscoidea, lxxxvii ; 60-73, 232-238.

Monitor, lvii.

Monodelphia, xlix.

Monophyodont Mammals, xlv.

Monorrhina, lxxviii, lexxiii.

Monotremata, slvii.

Morphology as opposed to teleology, xxii.

Morgagni, cyst of, xxxv.

Moth, death's-head, 73 .

Muffle, I 72.

Müiler, Fritz, 72, 97, II 4.

Müller, H., 55 .

Müller, J., cli.

- duct of, $x \times x \nabla$, Ixiv.

Mus decumanus, I, I 67 .

Muscidae, 84 , Io9.

Muscles of Birds, I3.

- of Ophidia, 30.

- compensatory relation of muscles of body-wall to internal muscles in Ophidia, 30.

- in Hirudineae, 129.

- of Helix, 48, 49-5x.

- of Anodon, 56, 193.

- of Insects, 85 .

- of Crustacea, 108.

- of Lumbricus terrestris, 123.

- of Cucumaria, 148.

- of Asterias rubens, 225.

Mustelus laevis, lxxv.

Mycetozoa, clxii.

Myrianida, 137.

Myriopoda, cxiv-cxri; 115.

Myriothela, 162.

Mysis, 115.

Myzinoids, Ixxriii-lxxxiii.
Os en charrue.

Myxogastres, clxii.

Myxomycetes, clxii.

$$
\text { N. }
$$

Nauplius, II4.

Nematelminthes, cxsxiii; I35.

Nematoids, I 38.

Nephelis, 135 .

Nereis, 132, 137 .

Nervi transversi, 106, I 22, I32.

Nervous system in Vertebrata, xxxi, xxxv.

- in Mammals, xlvi.

— in Birds, liii.

- in Reptiles, $1 x$.

- in Amphibia, lxv.

- in Fishes, lsxvi.

- in Mollusca, lxxxvii.

- in Molluscoidea, Ixxsviii.

- in Lamellibranchiata, scvii.

- in Brachiopoda, xcix.

- in Polyzoa, ciii.

- in Arthropoda, cvi ; I is, I16, NII 7 .

- in Vermes, cxxv; I21, 133 .

- in Cestodes, cxlii.

- in Nematelminthes, cxxxv.

- in Echinodermata, cxlv.

- in Rotifera, cxxxix.

- in Coelenterata, clvi.

- as a basis of classification, xxi.

- late development of, in Arthropoda, rog.

- development of, in Ascidians, ci.

Nervus recurrens, 79, 87 .

Neural flexure, $49,58$.

Neuropodous character of Invertebrata, xxii ; 168 .

Neuroptera, 75 .

'Nurses' in Platyelminthes, 136, 137.

- in Vermes generally, cxxvi.

\section{o.}

Occipital condyle in Birds, 25.

- in Mammals, xliii.

- in Amphibia, Ixii.

Odontophorous Mollusca, 1xxxvii ; 63 .

Oesophagus in Ophidia, 30.

- in Rodents, 2.

Oligochaeta, cxxviii ; 120, I 25.

Omentum, peculiar to Mammals, $4,168$.

Omostegite, 95 .

Oniscus murarius, $110,112$.

Ophidia, 29-35.

Ophiuridae, cxlv.

Orbit of Rodents, 7 .

Ornithodelphia, xlv.

Orthoptera, 86, II I.

Os en charrue of Birds, 21, 26. 
Otic vesicle.

Otic vesicle, I 90 .

Ovary, 88.

Oviscapt, 88 .

Owen, Professor, 13, 24, 35, 102.

P.

Pancreas, I 5 .

Parasitism in Vertebrata, "xlii.

- in Mollusca, Ixxxvi.

- in Nematelminthes, cxxxvi.

- in Gregarinae, clxi.

- entails morphological degradation, xi.

Parker, MIr. W. K., 39.

Parosteal bones, 36 .

Parovarium, $\mathrm{xxxv}$.

Patagia, 78.

- Paxillae, I42.

Pecten, liv, 1x; I9I.

Pectoral muscles, 13.

- muscle, second, in birds, homology of, 179 .

Pedicellariae, $\mathbf{I}_{4} \mathbf{2}$.

Pelodytes, cxxxv.

Pelvis in Birds, 28, 29.

- in Reptiles, lvii.

Peneus, 115.

Penguin, 1 .

Perca fluviatilis, 40-45.

Perennibranchiate Amphibia, lxvii.

Perichaetous Annelides, I 25, I 26.

Pexipatus, 156 .

Periplaneta orientalis, 86, II 2

Petromyzontidae, Ixxviii, 1xxxiii.

Phalaena, 109.

Pharyngobranchii, 1sxxiv.

Pharyngognathi, lxxv.

Pharynx, externally villous in earthworm, I 24.

- in leech, I29.

Phascolosoma, cxxxi; I53.

Phoronis, 138.

Phrenic nerve, I 7 I.

Phylactolaematous Polyzoa, ci.

Phyllopoda, is 2 .

Physoklisti, lxxxiii.

Physostomi, lxix, Ixxxiii ; 46.

Pipa, lxiii.

Pisces, lxviii, lxxxv.

Plagiostomi, lxix; 46.

Planaria, 154.

Planula, clx.

Platyelminthes, cxl; $138,154,240$.

Plectognathi, lxxv.

Polian vesicles, 149 .

Polychaeta, cxxviii.

Polymorphismus, I62.

Polypterus, 1xxiii.

Polyzoa, ci; $7 \mathrm{I}-73,237,23^{8}$.

\section{Reproduction.}

Pontobdella, 128.

Porifera, clxvi.

Portal system of Vertebrata, xxxiv.

- rudimentary, $1 \mathrm{xxxv}$.

Priapulacea, cxxxi.

Privet Hawk-Moth, 82.

Processus uncinati, li; 20, 26, 27.

Proglottis, I 36 .

Prolegs, 64 .

Proscolex, 136.

Proteus, lxiii.

Protisticum Regnum, clxiii.

Protoplasm, clx.

Protozoa, clx.

Protula, cxx.

Pseudhaemal vessels, cxxiv, cxlv; 122, $124,149$.

Psittacidae, li.

Psolus, ${ }_{4} 6$.

Pteropoda, xciii.

Pterylography, xlix.

Ptilocercus, xliv.

Pupa, 73, 76 .

Pyloric coeca in Fishes, 1xxii ; 40.

- in Orthoptera, 86.

- portion of stomach in Reptiles, Iviii.

Q.

Quadrate bone, $18,38,43$.

Quekett, 46.

R.

Rabbit's vertebrae, IO.

Radiolaria, clxii.

Rana, 35-46, 181-185.

Rasores, 20, 25, 29.

Rat, I-9, I67-I 73.

Ratitae, liii, liv.

Rathke, 106, 107.

Recurrent nerve, 133 .

Reichert, Professor, I63.

Regnum Protisticum, clxii.

Renal-portal system, lii, lix, lxiv; I77, $18 \mathrm{I}, 183$.

Renforcement, ganglions de, $\mathrm{I}_{32}$.

Reproduction in Fishes, lxxix.

- in Amphibia, Ixvi.

- in Mollusca, lxxxvi.

- in Arthropoda, cvi.

- in Vermes, cxxv.

- in Echinodermata, cxlv.

- in Coelenterata, clvii.

- in Protozoa, clxi.

Reproduction of lost organs in Coelen terata, clx.

- in Echinodermata, I43.

- in Amphibia, lxvii.

- in Arachnida and Crustacea, cxvii. 
Reproduction.

Reproduction in Reptiles, 1xi.

Reptiles, lv.

- relation of, to Birds, 175 .

Retia mirabilia, 6I, I 49 .

Rhabdocoelous Turbellaria, cxli.

Rhea, li.

Rhinocryptis, lxxiii.

Rhizopoda, clxv, clxvi.

Rhynchocoelous Turbellaria, cxli.

Rodentia, xlv.

Rotifera, cxxxviii-cxl.

Ruminantia, I69.

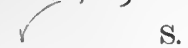

Saccobranchus, lxxiv.

Salicornaria, 73 .

Salivary glands, xlv, lii, lviii, lxxi.

Salmonidae, Ixxix ; 45.

Sarcode, clx.

Sars, I 45, 229.

Sauria, lvii.

Sauropsida, xlvii, lv.

Savigny, c.

Scaphirhynchus, Ixxxii.

Schmarda, 155 .

Schmidt, O., xxi.

Schneider, cxxxv.

Schultze, F. E., I 29.

Sciuri, 172.

Sclerotic, bony, I 8 .

Scolex, I36.

Scolopendridae, cxv.

Scorpionidae, cxi ; I09, II0, II 7 .

Scutigera, cxv.

Segmental organs in Annulata, cxxv; I 26.

- modified to serve as efferent generative ducts, cxxx; 215 .

Semper, xviii ; $154,229$.

Semper's organ, 53, 189.

Sensory organs in lateral line of Fish, lxxvii.

- on anterior segments in Leech, I28, 129.

Sepia, Ixxxix.

Serialaria, ciii.

Serpula, exxviii.

Serranus, lxxix.

Sertularia abietina, r6o.

Setae, I 22.

Setiparous glands, I 25.

Sharks, lxix.

Sharpey, Dr., $143,228$.

Shell in Mollusca, 47, 48, 54-57.

Siluroideae, lxxv.

Simiadae, xlv; 170 .

Siphonizantia, cxv.

Siphonostomum, cxxviii.

Sipunculidae, cxxxii ; 54 .

Slug, 187-191.

Solenobia, cxii.
Teeth of Rodents.

Spencer, Mr. Herbert, cxxii, clv.

Sphaerodorum, 157.

Sphaerularia, cxxxvi.

Sphingidae, 74 .

Sphyrocephalus, 155 .

Spicula, 163.

Spinneret, 75-80.

Spio, exxviii.

Spirachtha, abdominal appendages" of, cix.

Spiracle, 74.

Spirorbis, 161 .

Spirula, lxxxix.

Spleen, 3, 168, I 71, I84.

- absent in Marsipobranchii, lxxxiii.

Spondylus, xevii ; I9I.

Spongiadae, clxvi.

Spongilla, 163 .

Squalidae, lxxix.

Squamata, lvi.

Squillina, Ior.

Staurocephali, exxix.

Sternaspidea, cxxxii.

Sternum in Amphibia, lxiii.

- absent in Fishes, lxviii.

Stomatogastric nerves, absent in Anodontophorous Mollusca, xcvii.

- present in Odontophora, xc.

- in Arthropoda, crí.

- undergo little change in the metamorphosis in Insects, 79.

- peculiarities of in Crustacea, 107.

- in Oniscus, i I 2.

chtomias, lxxviii.

Strepsiptera, cxi.

Strobile in Taeniadae, I37.

Strombidae, xcii.

Strongylostoma, cxxvi.

Struthio, li.

Sturgeon, Ixix.

Suspensorium, lxii, lxx; 43.

Swimmeret, 90.

Sympathetic nerve-system in Vertebrata, xxxvii.

- in Fishes, lxxvii.

- absent in Marsipobranchii, lxxxiii.

- absent in Lamellibranchiata, xcvii.

Syllidea, cxxvi.

Synapta, lxxxvi, cxxviii.

Synaptidae, 147 .

T.

Tables of Classification, xxvii-xxx.

- of Homologies, 110, I16, I1 7 .

Taeniadae, 136-1 40 .

Tarsus of Birds, li ; $17,18$.

Teeth of Mammals, xliv.

- of Reptiles, lxviii.

- of Amphibia, lxiii.

- of Fishes, lxsi.

- of Rodents, 6 . 
Teeth, embryonic, in Birds.

Teeth, embryonic, in Birds, li.

Teléophores, I 60.

Teleostei, Ixxii, Ixxxiii.

Telson, as segment, 95 .

Testis, with a rudimentary ovary combined with it, lxv.

- superadded to an ovary in certain Fishes, Ixxix.

Thalestris, I I5.

Thread-cells, cxxviii ; 159.

Thymus of Frog, 185.

- homologue of, in Fish, 4I.

Thyroid of Frog, 185.

Toad, skeleton of, 39 .

Tomopteris, cxxviii.

Tongue, sheath of, in Ophidia, 30.

Tracheata Arthropoda, cr, cvi.

Transition piece in Hydroid Zoophytes, $16 \mathrm{x}$.

Trematodes, cxl ; 138.

Trilobites, I 12.

Tropidonotus natrix, 39 .

Tubicolar Annelides, I23, 157.

Tubulipora, 147 .

Tunicata, c.

- classed with Vermes by Gegenbaur, ci.

- supposed similarity of development into that of Vertebrata, ci.

- Turbellarian Vermes, cxl; I38, 155.

Torner, Professor, i.

U.

Umbilical vein, 182

Unsymmetrical viscera of Ophidia, 29.
Zooids.

Unionidae, 54-66, 192-I98.

Uterus, ' $169,172$.

V.

Vas deferens, I 77 .

Vegetables, distinction of, from Animals, clxii, clxiii.

Vena azygos, 2.

Vena cava, I69.

Vermes, cxxii ; 152, I53.

Vertebrae, lxix.

Vertebrata, xxxi ; 167.

Vesicular seminales, 125 .

Vibrios, xvii.

Vibrissae, 4.

Volvocineae, clxii.

Vorticlava, I62.

\section{W.}

Waterhouse, Mr., 4.

Water vascular system in Mollusca, Ixxxvi.

- in Vermes, cxxiv, cxxxiv,

- in Echinodermata, cxlv, cliv.

Wolffian body, lxv, lxxv; I 72 .

\section{$Z$.}

Zaddach, 75, 85-II3, II9,

Zenker, i 18 .

Zoea, larval form in developing Crustacea, II 5 .

Zooids, 164 .

- relation of, to organs, I62. 
if

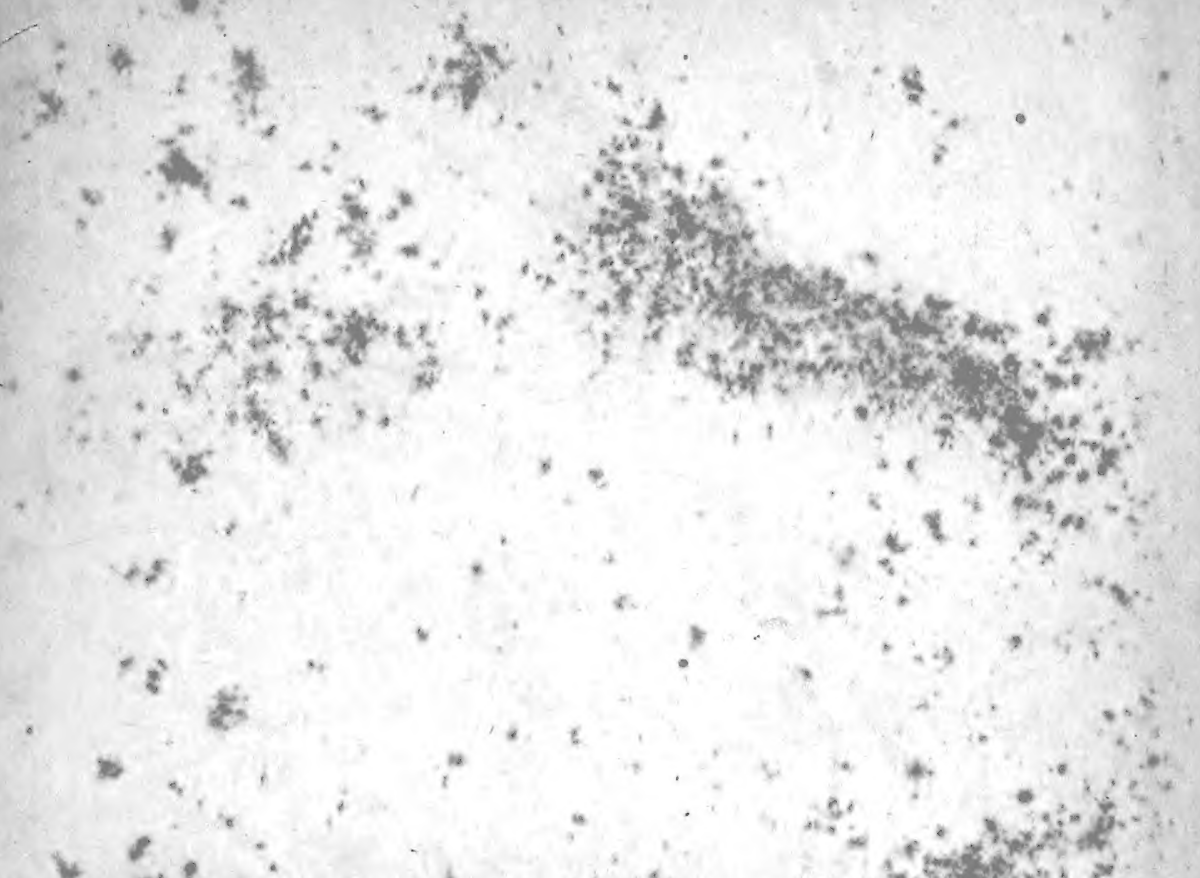

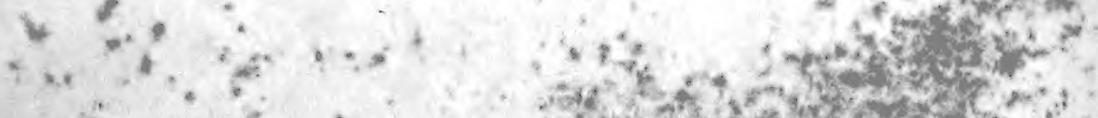

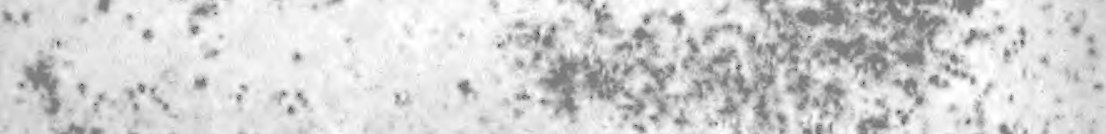

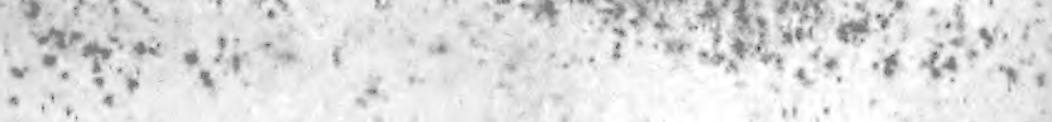

$x ; x$ $+2$

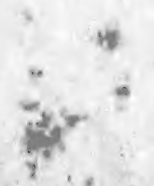

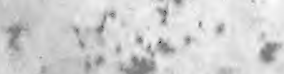

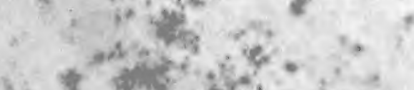

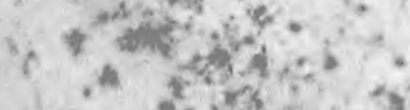

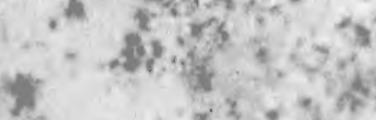

\%

$$
x^{3}+y^{2}, 4
$$

$$
\text { 1. B., }: 3
$$

$7 . x^{3}$ nis $2^{2}+2$
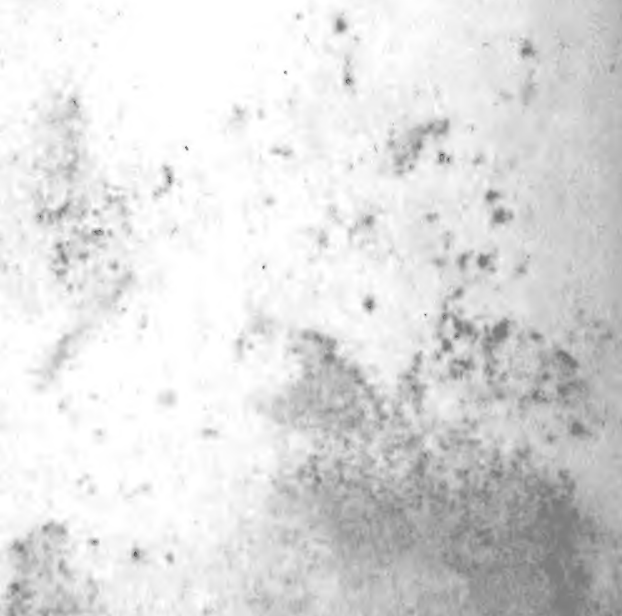


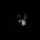




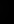




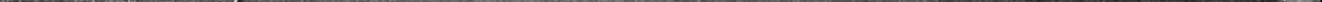

